\title{
ESTUDO TEÓRICO-EXPERIMENTAL DO COMPORTAMENTO DE NÓS DE PÓRTICO DE CONCRETO ARMADO SUBMETIDOS A AÇÕES CÍCLICAS
}

Gerson Moacyr Sisniegas Alva

Tese apresentada ao Departamento de Engenharia de Estruturas da Escola de Engenharia de São Carlos, como parte dos requisitos necessários à obtenção do título de Doutor em Engenharia de Estruturas.

ORIENTADORA: Prof. Dra. Ana Lúcia H. C. El Debs 
À minha esposa Ana Carolina, pelo constante apoio e carinho. 


\section{AGRADECIMENTOS}

Inicialmente, agradeço a Deus, o criador de todas as coisas, sem o qual não poderia começar nem terminar este trabalho.

À professora Ana Lúcia, pela amizade e pela orientação dispensada durante a elaboração deste trabalho.

À FAPESP pela bolsa de estudos concedida, a qual possibilitou a realização deste trabalho.

Aos funcionários da secretaria do Departamento de Estruturas: Nadir, Rosi e Eli, pela disponibilidade e atenção. Aos funcionários do Laboratório de Estruturas: Luis Vareda, Amauri, Mário, Valdir e Fabiano pelo bom trabalho durante os ensaios.

Aos amigos Yuri, Patrícia, Rodrigo, Rejane, Valentim, Marcelo, Carrazedo, Fernando e Josafá, pelo companheirismo destes anos em que convivemos juntos.

Aos meus pais Heli e Nora, pelo apoio e encorajamento que sempre me deram, e por quem tenho grande respeito.

À minha esposa Ana Carolina, pelo enorme carinho, incentivo e compreensão, durante a realização deste trabalho.

Enfim, deixo a minha gratidão a todos que participaram e contribuíram, direta ou indiretamente, na elaboração desta pesquisa. 


\section{SUMÁRIO}

\section{INTRODUÇÃO}

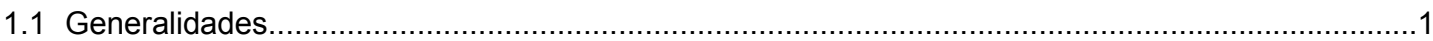

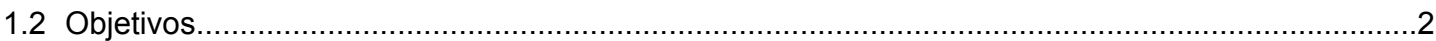

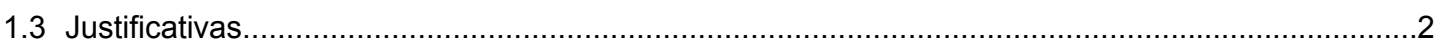

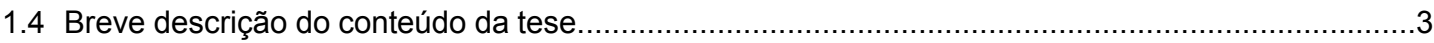

\section{NÓS DE PÓRTICO EM ESTRUTURAS DE CONCRETO ARMADO}

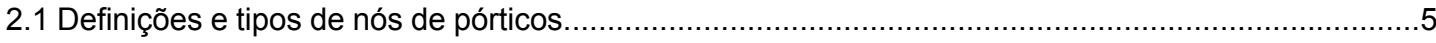

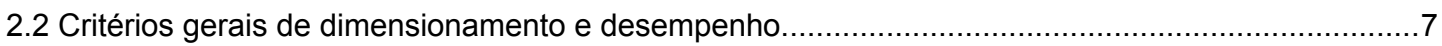

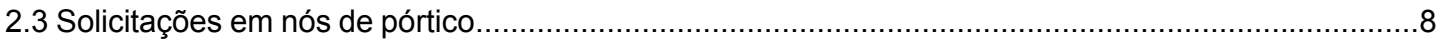

2.3.1 Forma usual de determinação dos esforços solicitantes............................................8

2.3.2 Ações Gravitacionais e Horizontais......................................................................

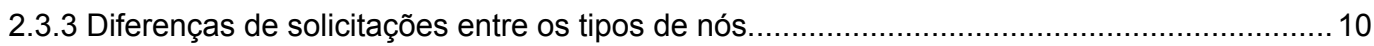

\section{DIMENSIONAMENTO E DETALHAMENTO DE NÓS DE PÓRTICOS}

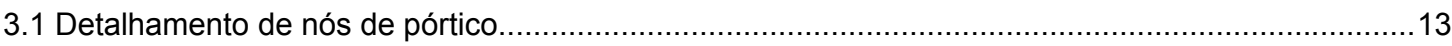

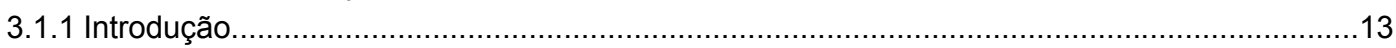

3.1.2 Detalhamento de ligações viga-pilar de extremidade: nós externos....................................14

3.1.3 Detalhamento de ligações viga-pilar intermediário: nós internos........................................18

3.2 Recomendações normativas para o dimensionamento................................................... 19

3.2.1 Classificação dos nós segundo as normas americanas: ACl 352 (1991) e ACl 318 (1995)....20

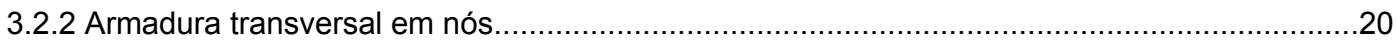

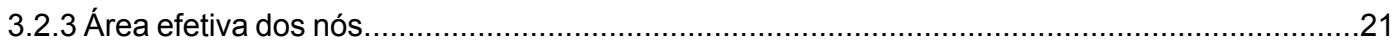

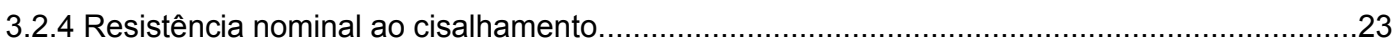

3.2.5 Ancoragem das barras longitudinais das vigas.........................................................24

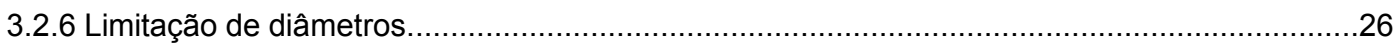

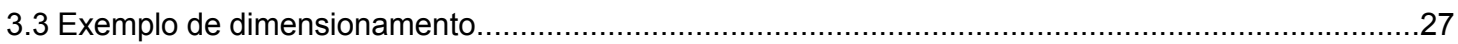

\section{EFEITO DAS AÇÕES CÍCLICAS SOBRE OS NÓS DE PÓRTICO}

4.1 Revisão sobre os estudos experimentais realizados............................................................. 31

4.2 Fatores que influenciam o comportamento da ligação............................................................3

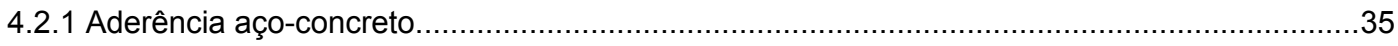

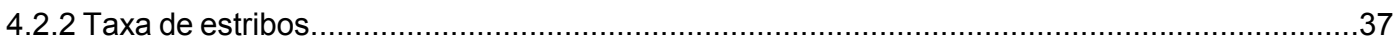

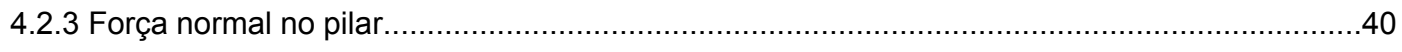

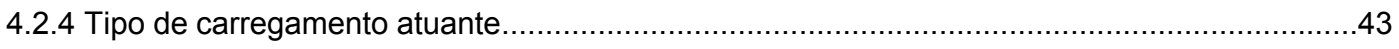

4.2.5 Resistência à compressão do concreto...................................................................4.

4.2.6 Dimensões do nó: relação entre as alturas das seções da viga e do pilar............................44

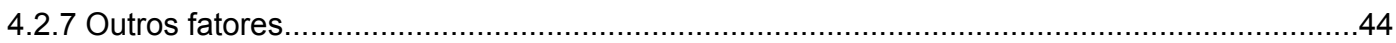

\section{MODELOS TEÓRICOS}

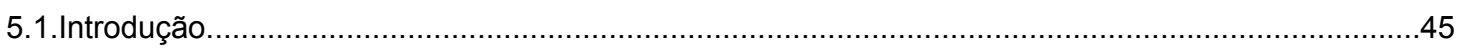

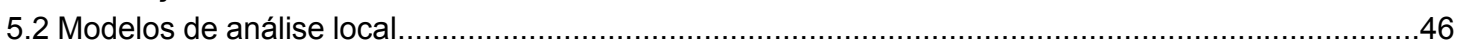

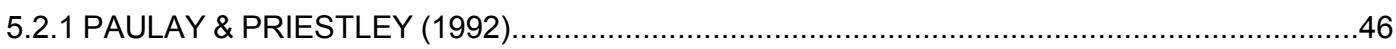

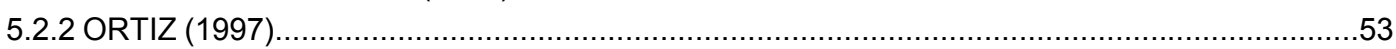

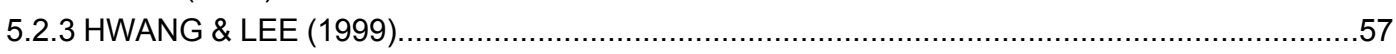


5.2.4 Comparação entre modelos de resistência ao cisalhamento............................................ 67

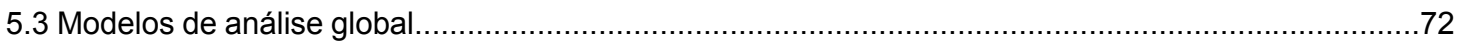

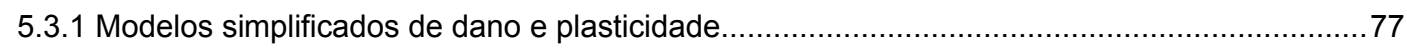

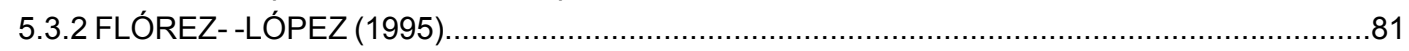

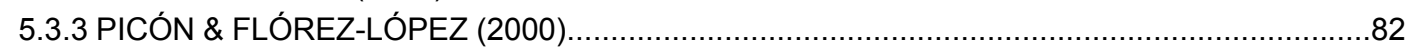

5.3.4 Simulações numéricas com os modelos de dano originais.................................................83

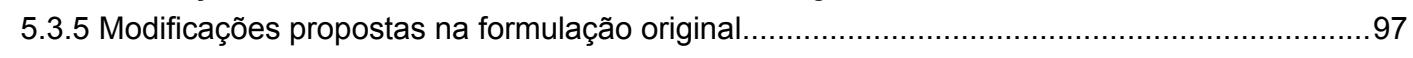

5.3.6 Simulações numéricas com os modelos de dano modificados........................................102

\section{PROGRAMA EXPERIMENTAL}

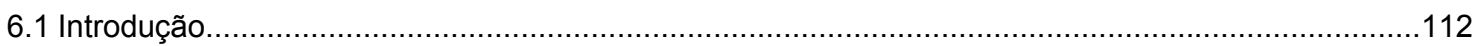

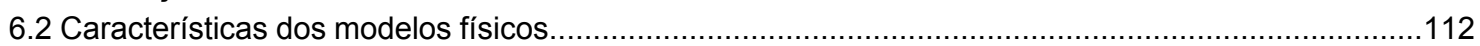

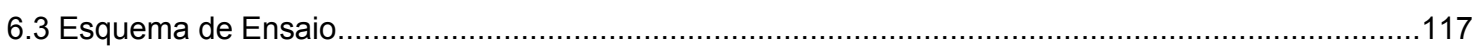

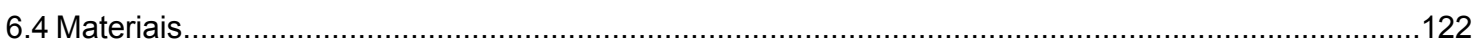

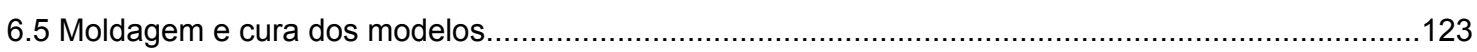

6.6 Instrumentação dos modelos e equipamentos utilizados..................................................125

6.7 Procedimentos de Ensaio e Resultados Obtidos............................................................... 131

\section{RESULTADOS E ANÁLISES}

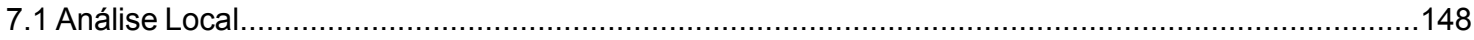

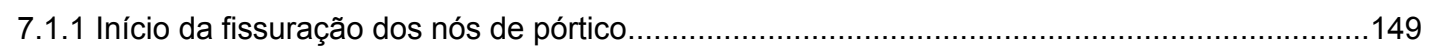

7.1.2 Comportamento mecânico dos nós frente às ações cíclicas.............................................. 154

7.1.3 Resistência ao cisalhamento dos nós de pórtico......................................................172

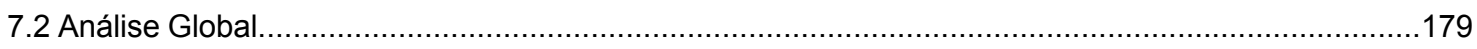

7.2.1 Emprego de modelos simplificados de dano e plasticidade.................................................179

7.2.2 Comparações adicionais entre os modelos físicos ensaiados.........................................202

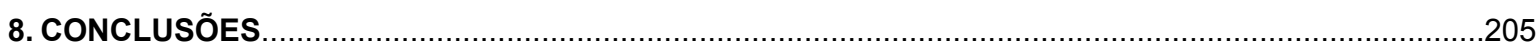

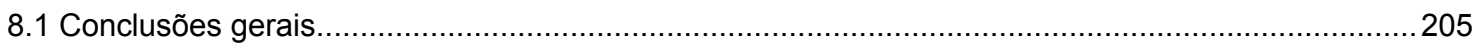

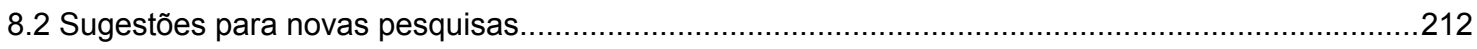

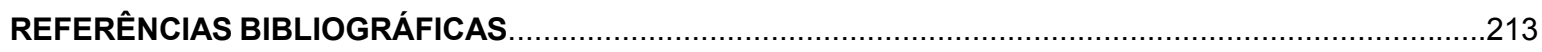

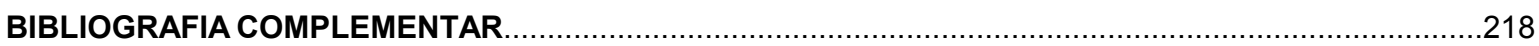




\section{RESUMO}

ALVA, G.M.S. (2004). Estudo teórico-experimental do comportamento de nós de pórtico de concreto armado submetidos a ações cíclicas. São Carlos, 2004. 218p. Tese (Doutorado) - Escola de Engenharia de São Carlos, Universidade de São Paulo.

Este trabalho consiste em um estudo do comportamento de nós de pórtico de ligações viga-pilar de concreto armado submetidos a ações cíclicas. O trabalho é composto por duas etapas: uma de investigação experimental e outra de cunho teórico.

A etapa experimental teve como base os ensaios realizados em cinco modelos físicos de ligações viga-pilar. Os resultados desses ensaios permitiram a observação de diversos aspectos do comportamento estrutural dos nós de pórtico frente às ações cíclicas e a avaliação da influência de algumas variáveis. Neste trabalho, as variáveis escolhidas foram a variação do carregamento aplicado e o detalhamento da armadura transversal na região do nó.

Os principais efeitos das ações cíclicas sobre as cinco ligações ensaiadas foram: aumento generalizado dos deslocamentos globais, perda de resistência e de rigidez dos elementos estruturais, propagação e aumento da abertura das fissuras inicialmente formadas, tendência de uniformização das deformações dos estribos do nó ao longo dos ciclos e maior deterioração do nó de pórtico em relação aos elementos viga e pilar.

$\mathrm{Na}$ etapa teórica, foram empregados essencialmente dois tipos de modelos: i) modelos derivados da idealizações dos modelos clássicos de biela e tirante. ii) modelos simplificados que empregam conceitos da Mecânica do Dano e da Fratura, para a avaliação dos efeitos de perda de rigidez (dano) e das deformações permanentes (plasticidade) na resposta global da ligação viga-pilar.

Por fim, foram feitas comparações entre os resultados experimentais e teóricos, chegando-se a importantes conclusões sobre o comportamento mecânico do nó frente às cargas cíclicas e sobre a eficiência dos modelos teóricos em simular a resposta do nó de pórtico e da ligação como um todo. As comparações mostraram que, dentro de certos limites, os modelos teóricos fornecem resultados satisfatórios frente aos resultados experimentais.

Palavras-chave: concreto armado, ações cíclicas, ligações viga-pilar, nós de pórtico, dano 


\begin{abstract}
ALVA, G.M.S. (2004). Theoretical and Experimental Study of Reinforced Concrete Frame Joints Behavior under Cyclic Load. São Carlos, 2004. 218p. Doctoral Thesis - School of Engineering at São Carlos. The University of São Paulo.
\end{abstract}

The present thesis studies the behavior of frame joints in reinforced concrete beamcolumn joints subjected to cyclic loads. The thesis is divided into two parts: an experimental study and a theoretical-based study.

The experimental study is based on laboratory tests on five physical models of beam-column joints. The results of this experimental study permitted the observation of various aspects of the structural behavior of frame joint subjected to cyclic load and estimating the influence of certain variables the affect the behavior of such joints. In the present thesis, the variables studied are the applied load and reinforcement detailing at the joint location.

The effects of cyclic loads on the tested joints were: an increase in the overall deformation, loss of strength and stiffness of structural elements, crack propagation and increase in crack width of previously formed cracks, a tendency towards a uniform strain distribution in the transverse reinforcement at the joint section and a more rapid deterioration of frame joints compared to beam/column joints.

At the theoretical level, two types of models were used to study the behavior of the joint: i) a model derived from the idealization of the classical strut-tie model, and ii) a simplified damage and fracture mechanics-based model for estimating the effects of the loss of stiffness (damage) and permanent strains (plasticity) on the overall response of the beamcolumn joint.

To reach any conclusion on the mechanical behavior and the efficiency of existing theoretical models employed in the design of reinforced beam-column joints and other joints subjected to cyclic loading, a comparative study between the theoretical and experimental results was carried out. The results show that within certain limits, the theoretical models employed are in good agreement with experimental results.

Keywords: cyclic load, beam-column joint, frame joint, damage mechanic. 
INTRODUÇÃo

\subsection{GENERALIDADES}

As ações cíclicas ou dinâmicas atuantes nas estruturas podem ter diversas origens, dependendo da finalidade e das condições a que essas estruturas são expostas. Entre as diversas origens das solicitações cíclicas, encontra-se a ação de cargas móveis, de pontes rolantes, de ondas marítimas, de pressões hidrostáticas variáveis, de sismos, de vento, de variações de temperatura e de umidade, impacto e de máquinas sujeitas à vibração.

As cargas cíclicas são caracterizadas pela variação de amplitude de um determinado parâmetro, tal como a tensão, podendo haver também a inversão de sinal (direção). As cargas cíclicas podem ser vistas sob dois aspectos:

- Sob o número de ciclos: Os elementos estruturais podem estar submetidos a um número baixo de ciclos, porém com uma grande variação da intensidade do carregamento, como é o caso das ações decorrentes de terremotos ou de vento, tendo maior relevância nos estados limites últimos. Para um número elevado de ciclos, com intensidade de carregamento ao nível de serviço, as ações provocam a fadiga desses elementos.

- Sob o tipo de tensão aplicada: O carregamento cíclico pode ser repetido (ou unidirecional) ou alternado. No repetido ou unidirecional, as tensões produzidas pelo carregamento cíclico não apresentam inversão de sinal. É o caso típico de carregamento de fadiga. No alternado, as tensões sofrem inversão de sinal. Este é o caso típico de ações sísmicas.

Um dos principais efeitos das ações cíclicas nas estruturas em pórtico de concreto armado é a deterioração mecânica nos nós formados a partir das ligações entre viga e pilar. Essa degradação ocorre progressivamente sobre as propriedades dos materiais aço e concreto ao longo da história de carregamento (ou deslocamento). Evidentemente, em função da intensidade dessas ações, pode-se ter, em menor ou maior grau, a ocorrência de fenômenos tais como: perda de aderência das armaduras, escoamento das barras, fissuração diagonal e distorções por cisalhamento do nó. Tais fenômenos afetam o comportamento da estrutura tanto em termos de deslocamentos como em termos de resistência.

Até três décadas atrás, relata-se na bibliografia especializada que pouca importância era dispensada ao projeto dos nós de pórtico. Pelo visto, os engenheiros estruturais mantinham o foco apenas no dimensionamento das vigas e dos pilares. Entretanto, nessas últimas três 
décadas, iniciaram-se pesquisas sobre comportamento dos nós de pórtico sujeitos a cargas cíclicas, motivadas em grande parte por observações reais da ocorrência de ruína dos nós quando submetidos a ações cíclicas de origem sísmica, em diversas edificações de concreto armado. $\mathrm{O}$ assunto entretanto é complexo e envolve um grande número de variáveis a serem analisadas.

A contribuição deste trabalho de Doutorado reside num estudo específico acerca dos nós de pórticos, cujas respostas experimentais frente ao carregamento cíclico permitiram um entendimento mais apurado dos fenômenos envolvidos nesse tipo de carregamento e da influência dos parâmetros selecionados como variáveis sobre o comportamento dos nós. Os resultados experimentais deram suporte à avaliação da eficiência dos modelos teóricos utilizados neste trabalho, a saber: i) modelos baseados na Mecânica do Dano e na Teoria da Plasticidade para simular o comportamento global da ligação viga-pilar; ii) modelos de biela e tirante para representar os nós de pórtico do ponto de vista local da ligação.

\subsection{OBJETIVOS}

O objetivo desta pesquisa reside na análise, por meio de investigação experimental e análise teórica, do comportamento estrutural de nós de pórticos formados nas ligações vigapilar de concreto armado, quando submetidos a carregamentos cíclicos.

Por meio da investigação experimental, verificaram-se propriedades que influenciam o comportamento das ligações viga-pilar mediante as ações cíclicas, em especial o detalhamento da armadura na região do nó e a variação do carregamento aplicado. Ou seja, procurou-se analisar como tais variáveis podem afetar o nó de pórtico e a ligação quanto à resistência, à ductilidade, à fissuração e à perda de rigidez.

A análise teórica foi apoiada por modelos numéricos de Dano e Plasticidade e por modelos de biela e tirante aprimorados, os quais foram propostos recentemente por outros pesquisadores. Algumas desses modelos sofreram alguns ajustes, sendo modificados em função de necessidades associadas à qualidade dos resultados.

Inclui-se ainda a comparação dos resultados da análise numérica com os resultados experimentais, a partir da qual foi possível chegar a diversas conclusões. Adicionalmente, são feitas algumas sugestões a respeito do dimensionamento de nós de pórtico de concreto.

\subsection{JUSTIFICATIVAS}

Os nós de pórticos, definidos pela ligação entre vigas e pilares, caracterizam-se por serem regiões diferenciadas nas estruturas de concreto armado, devido a uma série de fatores, a saber:

- As ligações entre vigas e pilares formam pórticos que conferem estabilidade lateral à estrutura frente às ações horizontais (vento);

- São regiões de forças cortantes e momentos fletores de grande intensidade;

- A mudança de direção dos esforços internos que ocorrem nos nós provoca uma alteração na distribuição de tensões;

- A limitação das dimensões dos elementos estruturais e a necessidade de se atender aos critérios de ancoragem podem ocasionar o congestionamento das armaduras que concorrem no nó; 
- Em virtude da concentração de armadura nos nós, estas regiões oferecem condições mais difíceis de concretagem.

Como conseqüência desses fatores, verifica-se a complexidade do comportamento estrutural dos nós viga-pilar.

Diversas pesquisas foram realizadas a respeito do comportamento dos nós de pórtico, incluindo diversos tipos de detalhes de armadura e a aplicação de materiais de resistência maior, como o concreto de alta resistência (CAR). Entretanto, devido ao grande número de variáveis envolvidas e que afetam o comportamento mecânico do nó, o assunto ainda não está completamente esclarecido e, por isso, vem sendo objeto de estudos constantes.

Ainda com relação à resposta dos nós de pórticos em presença de carregamento cíclico, existe a necessidade de se considerarem os fenômenos responsáveis pela não linearidade física do material. Dessa forma, surge a preocupação em se modelar os processos que geram a degradação estrutural do concreto. Nesse contexto, dentro de certos limites, os modelos de danificação e plastificação são adequados em análises numéricas, pois:

- os modelos que se baseiam na Mecânica do Dano permitem simular as perdas progressivas de rigidez e de resistência do material concreto;

- os modelos provenientes da Teoria da Plasticidade permitem avaliar a irreversibilidade da resposta do material nas situações de carga e descarga.

Por outro lado, na representação do nó propriamente dito, os conhecidos modelos de biela e tirante são adequados, pois:

- os modelos de biela e tirante são bem compreendidos no cálculo de estruturas de concreto armado;

- os modelos de biela e tirante são úteis no dimensionamento e podem prever, com segurança, a capacidade resistente dos nós frente aos esforços cisalhantes.

\subsection{BREVE DESCRIÇÃO DO CONTEÚDO DA TESE}

Neste capítulo 1, apresentam-se brevemente a origem e os tipos de cargas cíclicas, acenando para os efeitos dessas ações sobre os nós de pórticos, regiões especiais do sistema estrutural formadas nas ligações viga-pilar. Apresentam-se os objetivos principais deste trabalho e as motivações que deram origem ao mesmo.

No capítulo 2, apresentam-se a definição e os tipos de nós de pórticos em estruturas correntes de concreto armado, incluindo os critérios de dimensionamento e de desempenho usualmente adotados em nível de projeto. Comentam-se também as diferentes formas de solicitações nos nós em função da natureza das ações.

O capítulo 3 é voltado para o dimensionamento e detalhamento dos nós de pórtico de acordo com as recomendações das principais normas que tratam do assunto e segundo sugestões de alguns pesquisadores. Adicionalmente, desenvolve-se um exemplo numérico referente ao dimensionamento.

No capítulo 4, apresenta-se uma revisão bibliográfica sobre os principais trabalhos experimentais acerca do comportamento de nós de pórtico submetidos a ações cíclicas, desenvolvidos nas últimas três décadas. Com base nas conclusões dessas pesquisas 
anteriores e com a experiência obtida nos ensaios do programa experimental, comenta-se sobre os principais fatores que influenciam o comportamento estrutural dos nós.

No capítulo 5, são abordados os modelos teóricos utilizados para representar a resposta dos nós de pórtico e das ligações viga-pilar. Os modelos são divididos em dois grupos:

- Modelos de análise local, ou seja, os que se propõem a modelar a região do nó propriamente dita, cujas grandezas principais são forças, tensões e deformações. Empregam os conceitos utilizados nos modelos de biela e tirante.

- Modelos de análise global, os quais se fundamentam na Mecânica do Dano e na Teoria da Plasticidade. Avaliam os efeitos globais (deslocamentos ou rotações) na ligação, como conseqüência da deterioração mecânica das extremidades dos elementos viga/pilar e, indiretamente, como conseqüência dos fenômenos ocorridos no nó de pórtico.

O capítulo 6 é inteiramente voltado para a etapa experimental da pesquisa. Nesse capítulo, aborda-se sobre o planejamento e montagem da estrutura de reação, o esquema adotado para ensaiar as ligações, materiais utilizados, instrumentação e as observações experimentais dos ensaios das cinco ligações envolvidas. As variáveis escolhidas foram o detalhamento da armadura transversal na região do nó e a forma de aplicação do carregamento.

No capítulo 7 apresentam-se os resultados experimentais obtidos dos ensaios, no formato de figuras, tabelas e gráficos, desenvolvendo-se as respectivas análises e conclusões pertinentes. Nesse capítulo são confrontados os resultados experimentais com os obtidos por meio dos modelos teóricos, procurando-se avaliar as vantagens e as limitações de tais modelos na simulação da resposta dos nós e das ligações viga-pilar.

Por fim, no capítulo 8, apresentam-se as principais conclusões tiradas durante toda a pesquisa. 


\section{NÓS DE PÓRTICO EM ESTRUTURAS DE CONCRETO ARMADO}

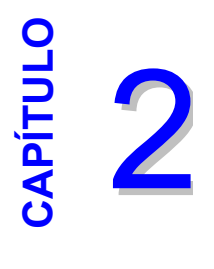

\subsection{DEFINIÇÕES E TIPOS DE NÓS DE PÓRTICOS}

Nós de pórticos são definidos a partir das ligações entre vigas e pilares. São regiões (volumes) gerados pela interseção da viga com o pilar, tal como ilustra a figura 2.1. Na realidade, o nó de pórtico é uma porção do pilar de altura igual à da seção da viga.

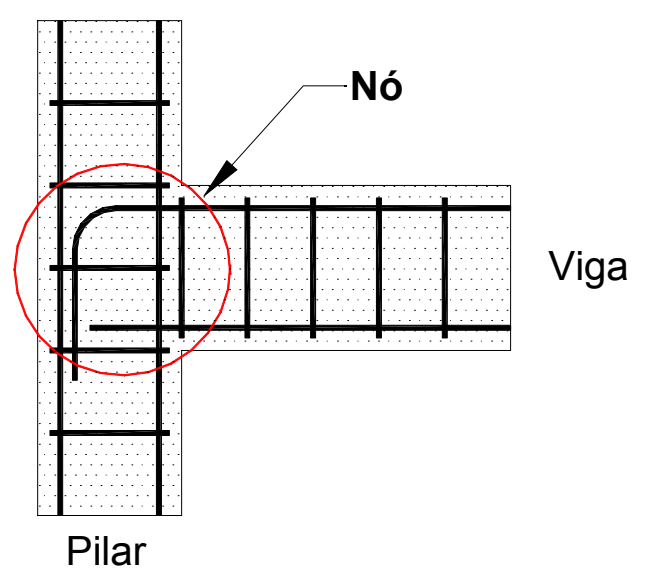

Figura 2.1: Definição de nó de pórtico.

Usualmente, o termo nó de pórtico é utilizado para se referir à ligação viga-pilar como um todo. A rigor, a ligação é formada pelo nó e pelos elementos estruturais pilar, viga e laje.

Os nós podem ser distinguidos em termos da configuração geométrica das ligações e do comportamento estrutural. A figura 2.2 apresenta as configurações mais usuais para nós de estruturas em pórticos retangulares planos e espaciais.

Segundo PAULAY \& PRIESTLEY (1992), a classificação dos nós pode ser feita levando-se em conta as diferenças observadas nos mecanismos de ancoragem da armadura da viga, dividindo os nós em dois grupos: externos - figura 2.2(a) à (f); internos - figura 2.2(g) à (j). Nessa figura, as lajes não são desenhadas a fim de facilitar a visualização. 


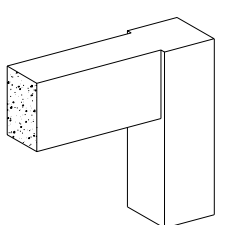

a)

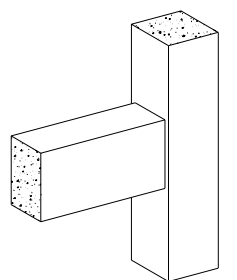

d)

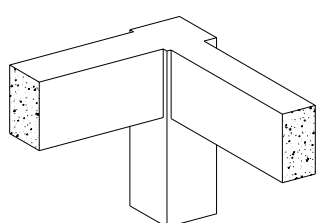

b)

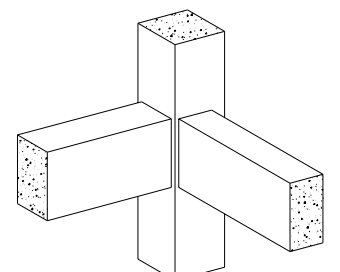

e)

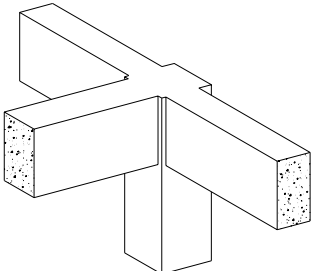

c)

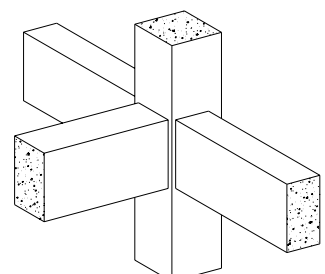

f)

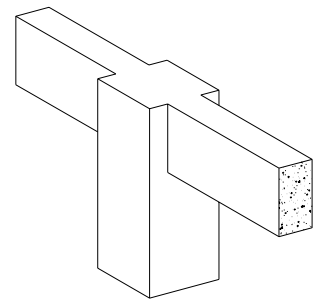

g)

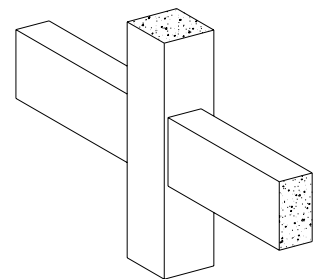

i)

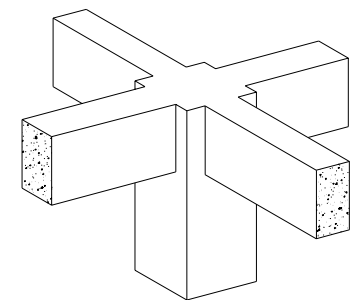

h)

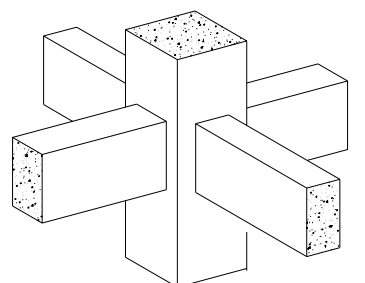

j)

Figura 2.2: Geometrias usuais de nós - Adaptado de PAULAY \& PRIESTLEY (1992).

Neste trabalho, o termo nó externo refere-se ao nó definido pelas ligações viga-pilar de extremidade, enquanto que o termo nó interno refere-se ao nó definido pelas ligações viga-pilar interno (figura 2.3). Estes são os dois tipos de nós mais enfatizados nesta pesquisa. 


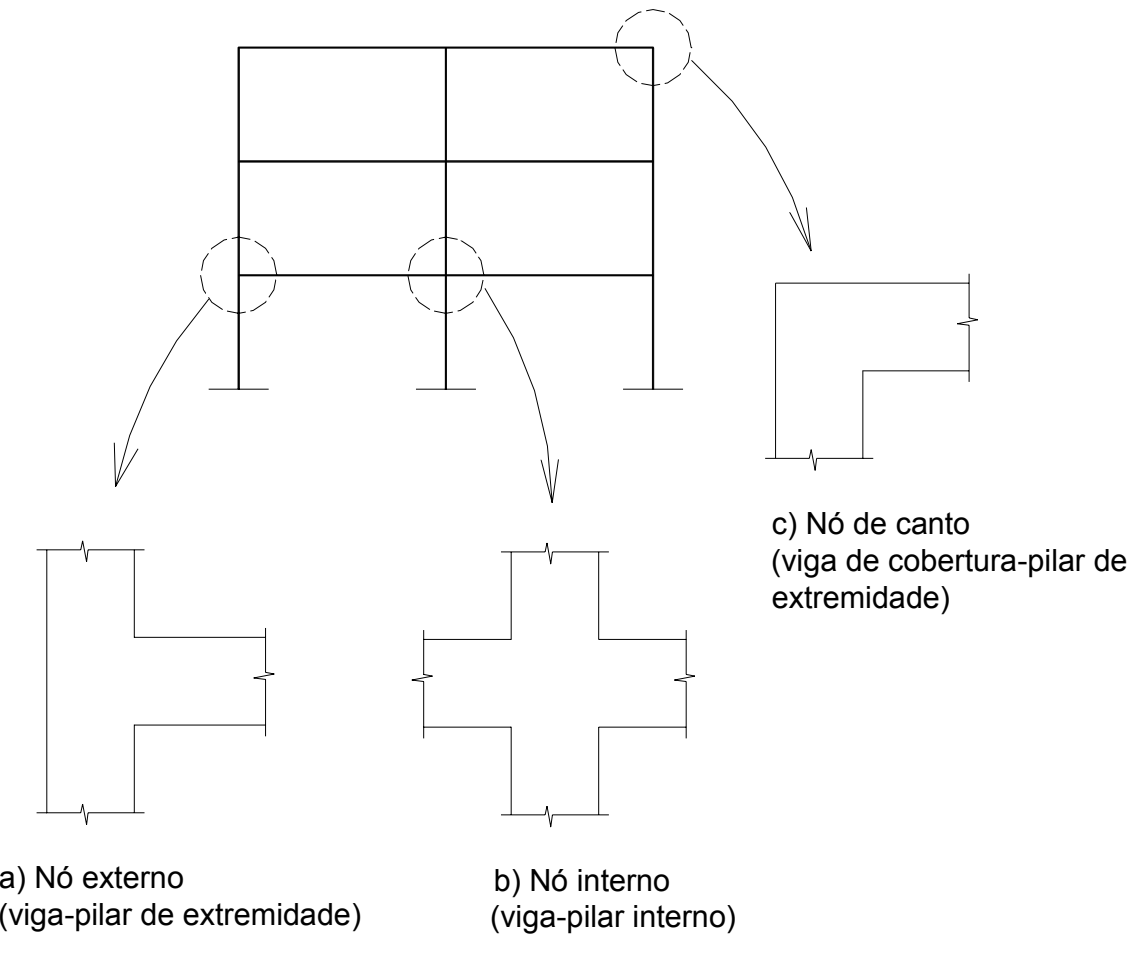

Figura 2.3: Nomenclatura utilizada para a classificação dos nós de pórtico

\subsection{CRITÉRIOS GERAIS DE DIMENSIONAMENTO E DESEMPENHO}

Nas últimas três décadas, pode-se dizer que houve uma maior preocupação com o comportamento mecânico dos nós de pórtico, fato confirmado pelo crescimento das pesquisas envolvendo tal região do sistema estrutural. Antes disso, em nível de projeto, admitia-se que as condições nos nós de pórtico não eram críticas. Ou seja, admitia-se que a resistência da ligação era igual à do elemento estrutural menos resistente. Entretanto, pode-se dizer que os nós de pórtico são, com freqüência, regiões mais críticas do sistema estrutural como um todo, devido a uma série de fatores, entre os quais se incluem a mudança de direção de esforços e tensões, as elevadas tensões cisalhantes que ali surgem, além dos aspectos construtivos associados à ancoragem das armaduras.

A fim de apresentar um desempenho estrutural satisfatório, as ligações viga-pilar devem preencher alguns requisitos (PARK \& PAULAY (1975)):

- O comportamento da ligação em serviço deve ser, em termos qualitativos, igual ao dos elementos que serão conectados;

- A ligação deve possuir resistência suficiente para suportar as combinações de carregamentos mais desfavoráveis aos elementos estruturais a serem conectados;

- A ligação não deve governar a capacidade resistente da estrutura, nem deve impossibilitar o desenvolvimento de toda a capacidade resistente dos elementos estruturais adjacentes;

- O arranjo das armaduras na ligação não deve dificultar a sua colocação nem a compactação do concreto durante a execução. 
O comportamento estrutural das ligações viga-pilar de concreto é significativamente afetado pelo tipo de carregamento atuante. No caso de estruturas em pórtico de concreto armado, submetidas exclusivamente às ações gravitacionais, o procedimento de cálculo usualmente empregado restringe-se à verificação da resistência do nó para o caso de carregamento monotônico.

No entanto, em se tratando de solicitações cíclicas, em especial quando há inversão de sinal, a resistência e a ductilidade governam o cálculo da ligação, requerendo-se maiores quantidades de armaduras na região nodal. Dessa forma, o projetista estrutural deve preocupar-se com o problema do congestionamento das armaduras nos nós de pórticos. Em muitos casos de projeto, inclusive, as dimensões dos pilares acabam sendo definidas pelos critérios de dimensionamento e detalhamento das ligações adotados pelas normas.

\subsection{SOLICITAÇÕES EM NÓS DE PÓRTICO}

\subsubsection{Forma usual de determinação dos esforços solicitantes}

Os nós de pórticos, em função da geometria das ligações e em função da posição das armaduras longitudinais da viga, estão submetidos, essencialmente, a esforços de cisalhamento.

Usualmente, o nó de pórtico é encarado como um painel submetido a um estado plano de tensões. A força cortante solicitante é obtida simplesmente por equilíbrio de forças no painel. Assim, em um nó externo, por exemplo, a força cortante horizontal atuante é expressa por (vide figura 2.4):

$\mathrm{V}_{\mathrm{jh}}=\mathrm{T}_{\mathrm{v}}-\mathrm{V}_{\mathrm{p}}$

onde

$\mathrm{T}_{\mathrm{v}}$ é a resultante na armadura tracionada da viga;

$V_{p}$ é a força cortante no pilar.
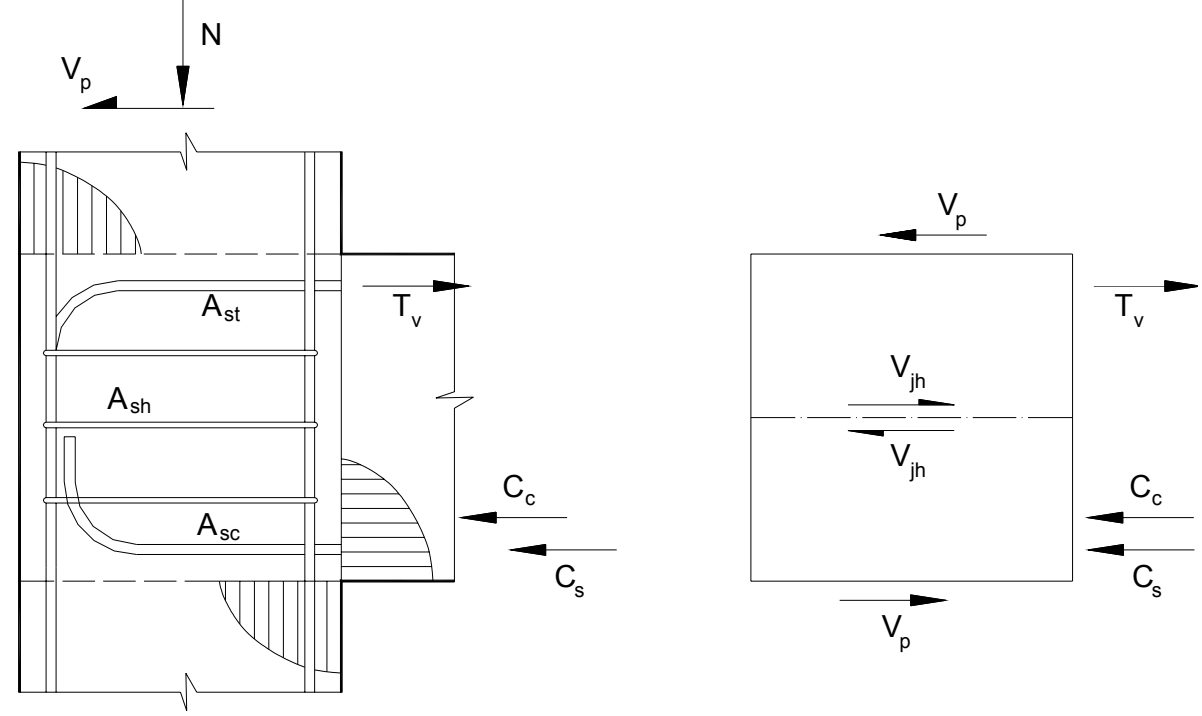

Figura 2.4: Forças solicitantes em nós externos 
Analogamente, podem ser obtidas as forças cortantes nos nós internos. Entretanto, a forma como as forças cortantes atuam nesses tipos de nós depende do tipo de ação atuante, neste caso, se as ações são gravitacionais (verticais) ou se as ações são horizontais (laterais).

\subsubsection{Ações Gravitacionais e Horizontais}

Embora a função primária das estruturas em edifícios seja a de resistir às ações gravitacionais, tais estruturas podem estar também submetidas a ações laterais de caráter cíclico, tais como as ações do vento, ou até mesmo às ações sísmicas. A forma como essas ações solicitam os nós pode ser entendida a partir de uma simples análise estática, ilustrada na figura 2.5. As solicitações impostas aos nós de pórtico, ao produzirem momentos que tracionam fibras opostas nos elementos estruturais, geram nesses nós forças cortantes cuja magnitude pode superar em várias vezes as atuantes nas vigas e pilares adjacentes.

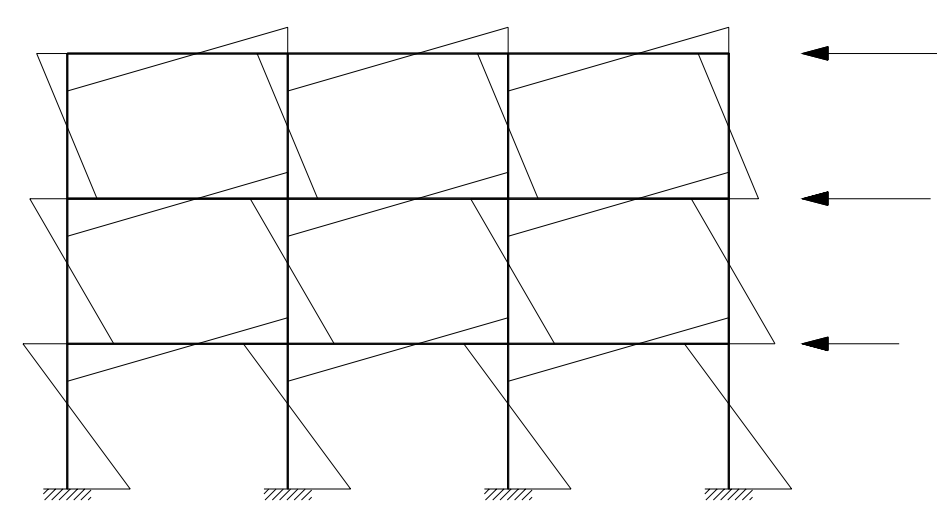

a)

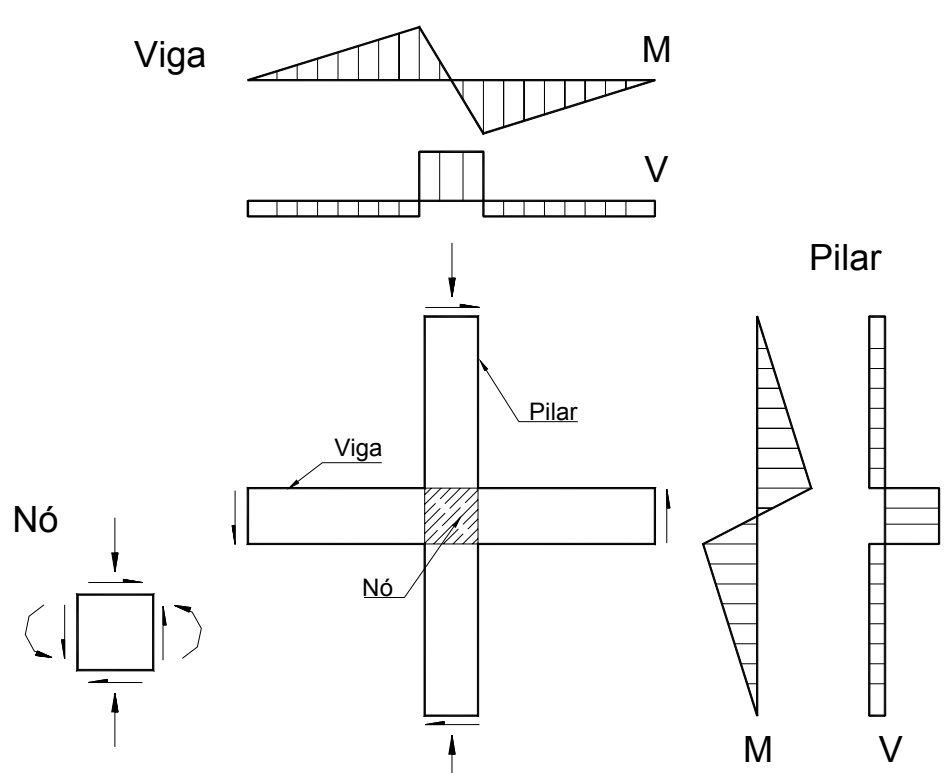

b)

Figura 2.5: Pórtico submetido a ações laterais: a) Momentos fletores nos elementos estruturais: b) Variação dos esforços solicitantes em um nó. 
Analisando-se o caso dos nós internos, percebe-se que as solicitações produzidas pelas ações gravitacionais são diferentes das produzidas pelas ações horizontais, conforme ilustrado na figura 2.6. Evidentemente, os dois tipos de solicitação podem ocorrer simultaneamente, somando-se os efeitos.

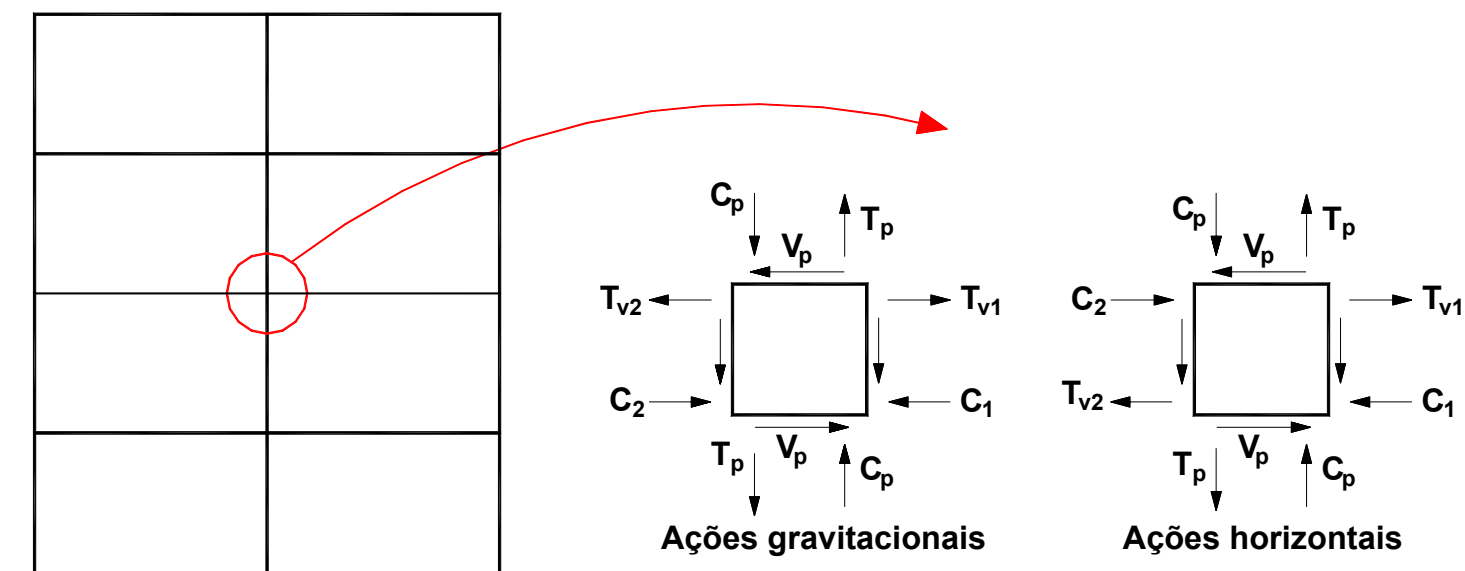

Figura 2.6: Solicitações em nós internos - Ações gravitacionais e Ações Horizontais

\subsubsection{Diferenças de solicitações entre os tipos de nós}

Nos nós internos, quando as ações horizontais predominam sobre as gravitacionais, a resultante de compressão no concreto de um lado do nó soma-se com a resultante de tração na armadura do outro lado. A força cortante solicitante pode ser expressa então por:

$\mathrm{V}_{\mathrm{jh}}=\mathrm{T}_{\mathrm{v} 1}+\mathrm{C}_{2}-\mathrm{V}_{\mathrm{p}}$

Com base na comparação entre as expressões (2.1) e (2.2), pode-se afirmar que, de forma geral, os nós internos são mais solicitados que os nós externos, devido ao acréscimo da parcela $\mathrm{C}_{2}$ de compressão no concreto. Tal fato implica em condições de aderência mais desfavoráveis para as barras longitudinais da viga nos nós internos, justificando a limitação dos diâmetros recomendada pelas principais normas de dimensionamento.

A fim de promover um entendimento inicial do comportamento dos nós externos e internos, serão apresentadas algumas análises feitas por PARK \& PAULAY (1975) na situação de carregamentos cíclicos de elevada intensidade.

\section{Nós externos:}

A partir da posição das resultantes das tensões na viga e no pilar (figura 2.7), nota-se a atuação de tensões diagonais de tração e de compressão $\left(\sigma_{\mathrm{c}}\right.$ e $\left.\sigma_{\mathrm{t}}\right)$. Quando os elementos conectados desenvolvem a sua capacidade resistente última, a considerável intensidade dessas tensões de tração pode levar à fissuração excessiva do nó na direção diagonal. 


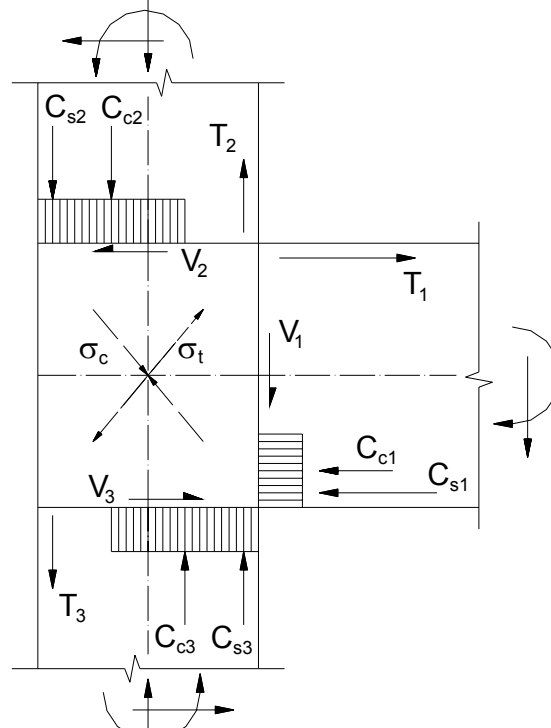

a)

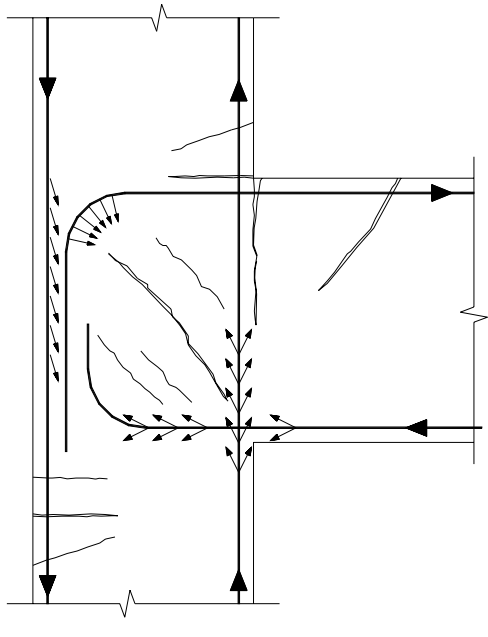

b)

Figura 2.7: Nós de pórtico externos: a) tensões e forças resultantes. b) configuração das fissuras e forças de aderência.

A intensidade das tensões diagonais de tração é influenciada pela taxa de armadura de flexão da viga e pela magnitude da força normal de compressão no pilar.

PARK \& PAULAY (1975) fazem uma análise das condições de aderência para as barras da armadura superior e inferior da viga e para as barras da armadura longitudinal do pilar localizadas na face externa mais afastada da viga. Essa análise é descrita a seguir.

Devido às condições mais desfavoráveis de aderência para as barras na face superior da viga, aparecem, em níveis de solicitação relativamente baixos, fissuras por fendilhamento ao longo dessas barras. O efeito da solicitação cíclica agrava ainda mais a situação, podendo ocorrer uma total perda da aderência até o início da dobra da barra.

As barras da face inferior da viga, submetidas à compressão, são alojadas no nó em uma zona mais favorável de aderência. Entretanto, uma considerável perda de aderência também é possível, devido ao efeito da solicitação cíclica e eventual escoamento da armadura.

As barras da armadura longitudinal do pilar encontram-se em condições mais desfavoráveis de aderência, devido à superposição das forças de tração e de compressão da armadura do pilar. A força que deve ser transmitida por aderência, portanto é igual a $C_{s 2}+T_{3}$, conforme a figura 2.7 .

Pela configuração das fissuras, percebe-se que a biela diagonal transmite boa parte das tensões de cisalhamento e de compressão. Na realidade, após alguns ciclos de carregamento, nota-se a existência de diversas bielas separadas pelas fissuras diagonais, conforme a figura $2.7 \mathrm{~b}$, sendo importante então a presença de estribos para a formação de um mecanismo de treliça.

\section{Nós internos:}

PARK \& PAULAY (1975) descrevem dois mecanismos de transmissão dos esforços em nós internos. No primeiro mecanismo, uma única biela diagonal comprimida é responsável pelo 
equilíbrio das forças atuantes no nó, conforme a figura 2.8b. Este mecanismo se desenvolve nos estágios iniciais de carregamento, antes da ocorrência do escoamento das armaduras de flexão e da formação de fissuras ao longo de toda a altura do nó. As forças cortantes, desse modo, são introduzidas no nó pelas zonas comprimidas da viga e do pilar.

Após a ocorrência de alguns ciclos no campo inelástico, seguidos pela perda da aderência, as forças cortantes no nó são equilibradas por bielas comprimidas de pequena largura, formadas entre as fissuras diagonais, e pelas forças de tração nas armaduras horizontais e verticais, definindo assim um mecanismo de treliça. Este modelo é adotado pelo CEB (1985) e também pela norma neozelandesa NZS-3101 (1995).

Alguns pesquisadores alertam sobre a necessidade de avaliar a efetiva contribuição do concreto na resistência do nó, após vários ciclos de carregamento alternado no campo inelástico, especialmente quando as forças normais de compressão no pilar são baixas.

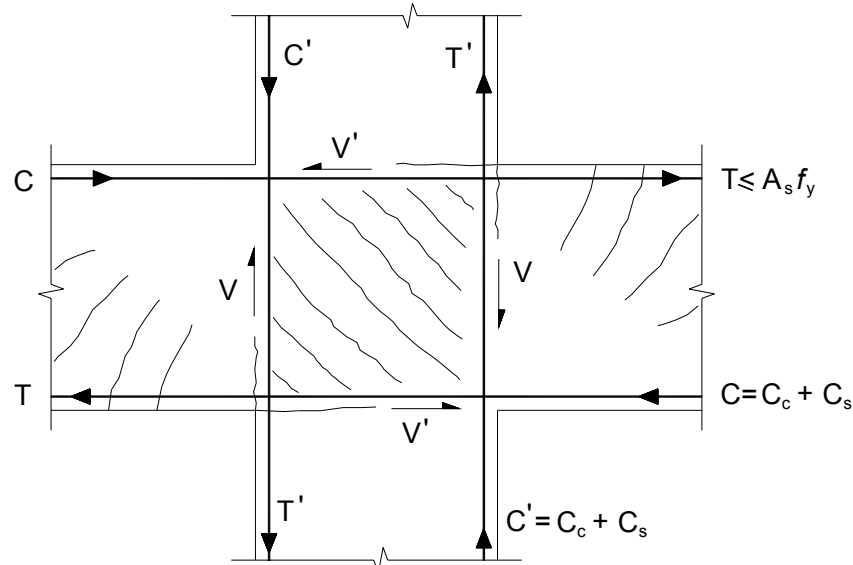

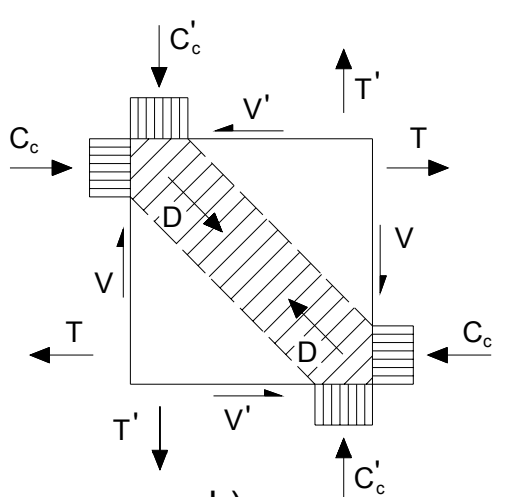

b)

a)

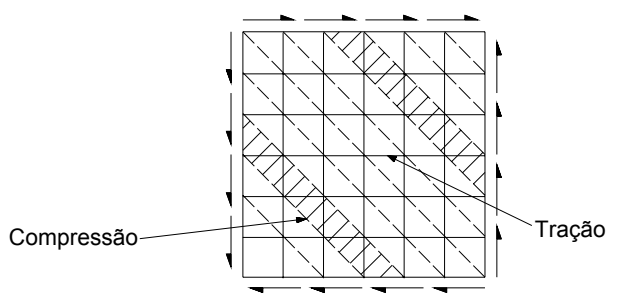

c)

Figura 2.8: Nós de pórtico internos: a) Forças internas e configuração das fissuras. b) Equilíbrio por biela comprimida. c) Equilíbrio por mecanismo de treliça.

Ao contrário do que ocorre em nós externos, onde as barras longitudinais da viga são normalmente dobradas para dentro do nó formando ganchos em suas extremidades, em nós internos as forças requeridas para a ancoragem da armadura das vigas devem ser inteiramente mobilizadas por aderência. Quando calculadas, estas tensões de aderência facilmente assumem valores acima dos recomendados pelas principais normas. Portanto, com respeito à questão da aderência, as condições são mais críticas em nós internos que em nós externos. 


\section{DIMENSIONAMENTO E DETALHAMENTO DE NÓS DE PÓRTICO}

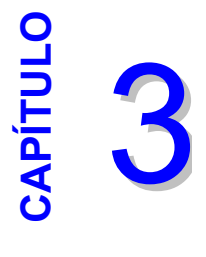

\subsection{DETALHAMENTO DE NÓS DE PÓRTICO}

\subsubsection{Introdução}

Neste item são apresentados os tipos de detalhamento empregados em nós de pórticos de concreto armado e as principais recomendações normativas envolvendo o dimensionamento dos nós.

A escolha do tipo de detalhamento em nós de pórtico está diretamente ligada ao tipo de modelo teórico escolhido para o dimensionamento. A escolha do tipo de detalhamento também depende da forma como os nós são solicitados - sentido, intensidade e reversibilidade das solicitações - além de características de ductilidade que possam ser requeridas para a ligação.

Com respeito ao dimensionamento dos nós, os modelos de biela e tirante são amplamente utilizados em virtude da facilidade de aplicação e por serem de fácil entendimento. Os modelos de resistência ao cisalhamento horizontal de nós externos, como os abordados no capítulo 5, baseiam-se em conceitos empregados nos modelos de biela e tirante. Uma abordagem ampla sobre a aplicação dos modelos de biela e tirante em estruturas de concreto armado pode ser encontrada em SILVA \& GIONGO (2000).

O projeto das ligações deve ser conduzido de modo a evitar possíveis tipos de ruína, dentre os quais estão incluídos a ruína por esmagamento das bielas comprimidas do nó, por ancoragem inadequada das armaduras, por deformações excessivas causadas pelo escoamento das armaduras principais e pelas tensões de tração diagonais que surgem devido à mudança de direção dos esforços internos.

Neste trabalho, a ênfase esteve voltada ao estudo dos nós externos e internos, de forma que são abordados apenas esses dois tipos de nó neste texto. Informações sobre o comportamento estrutural e o detalhamento de outros tipos de nós, como os nós de canto e os nós definidos por ligações viga de cobertura-pilar intermediário são encontrados em MAYFIELD et al. (1971), NILSSON (1973), PARK \& PAULAY (1975), NILSSON \& LOSBERG (1976), LEONHARDT \& MÖNNIG (1978), SKETTRUP et al. (1984), LUO et al. (1994). 


\subsubsection{Detalhamento de ligações viga-pilar de extremidade: nós externos}

Diversos arranjos de armadura foram analisados por pesquisadores em ensaios de ligações viga-pilar de extremidade, deixando sugestões com respeito ao detalhamento na região nodal.

LEONHARDT e MÖNNIG (1978) discutem diversas disposições de armadura para nós externos, dentre as quais duas são ilustradas na figura 3.1. Na figura 3.1a, as barras tracionadas da viga são dobradas em forma circular para o interior do nó, com um diâmetro interno $d_{B}$. A figura $3.1 \mathrm{~b}$ é uma variante para a ancoragem das barras da viga. Ambos os arranjos abordados apresentam barras inclinadas suplementares.

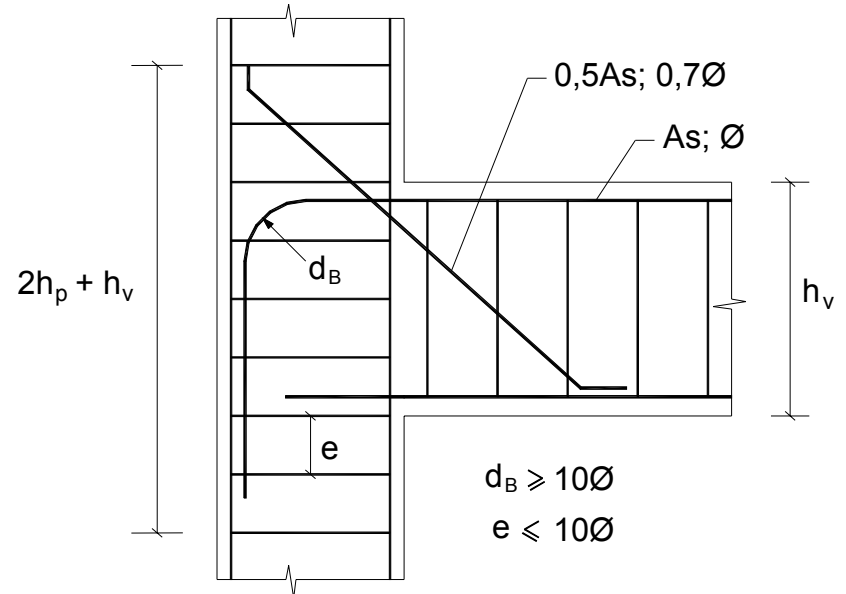

a)

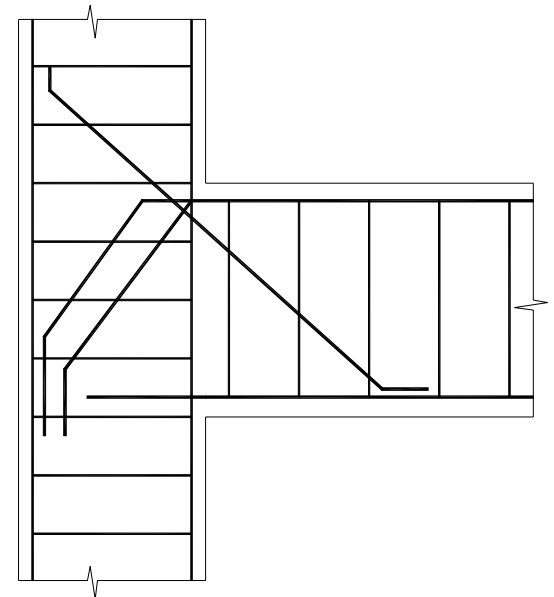

b)

Figura 3.1: Discussão sobre o detalhamento de armaduras de nós externos - LEONHARDT \& MÖNNIG (1978)

De acordo com LEONHARDT \& MÖNNIG (1978), os estribos do pilar na região do nó devem ter o espaçamento reduzido para no máximo $10 \mathrm{~cm}$, em um trecho de comprimento igual a $2 h_{p}+h_{v}$, onde $h_{p}$ é a altura do pilar e $h_{v}$ é a altura da viga. A armadura inclinada deve possuir uma área igual à metade da área da armadura longitudinal da viga que será ancorada $\mathrm{e}$ um diâmetro de aproximadamente $70 \%$ do diâmetro das barras da viga.

No entanto, LEONHARDT \& MÖNNIG (1978) lembram que nos diversos ensaios realizados com diferentes arranjos de armadura, inclusive com barras inclinadas, observou-se que a capacidade resistente teórica da ligação não era alcançada integralmente. Com a disposição de armadura indicada na figura 3.1a, por exemplo, atingiu-se a capacidade integral da ligação (eficiência de 100\%) para taxas de armadura da viga inferiores a 0,6\%. Para taxas maiores que $0,6 \%$, a máxima eficiência atingida foi da ordem de $80 \%$.

Entende-se que, para o bom desempenho da ligação, as armaduras adicionais nas ligações devam envolver a região do nó por completo, e não atravessá-lo. Dessa forma, no detalhamento de ligações, recomenda-se que o arranjo da figura $3.1 \mathrm{~b}$ ) seja totalmente descartado. 
A partir de resultados experimentais em nós externos submetidos a ações monotônicas, ORTIZ (1997) faz importantes observações com relação ao detalhamento da região do nó. A autora sugere que, além dos estribos calculados com o modelo de biela e tirante proposto em seu trabalho (colocados entre as barras tracionadas da viga e a zona comprimida da mesma), devam ser colocados pelo menos mais dois estribos iguais logo acima do nó (figura 3.2), para garantir o não alargamento da fissura que normalmente tende a se propagar para aquela região.

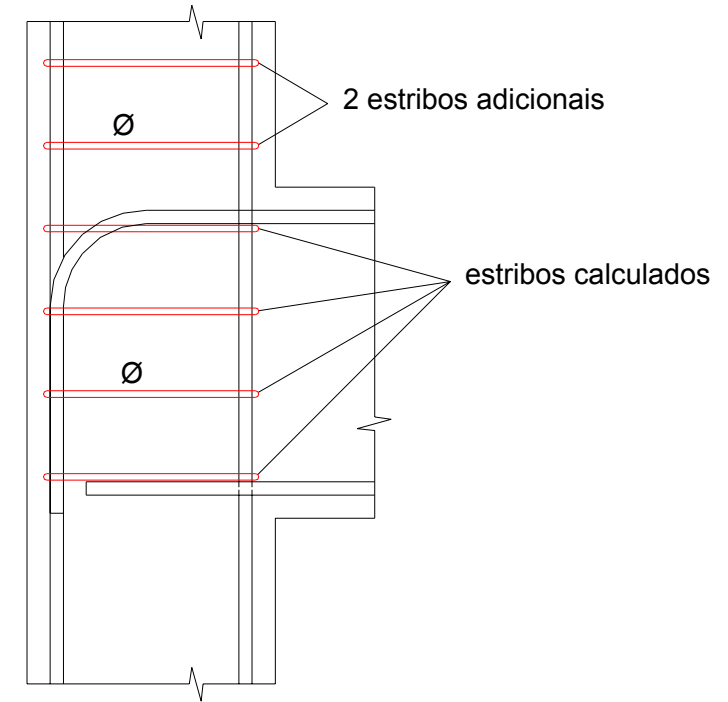

Figura 3.2: Colocação de estribos adicionais acima do nó - ORTIZ (1997).

MURTY et al. (1998) fizeram um estudo experimental sobre ligações viga-pilar de extremidade (caso monotônico) cuja principal variável era a forma de ancoragem das barras da viga. Três tipos de detalhamento foram ensaiados, conforme ilustra a figura 3.3 , sendo as ligações identificadas por:

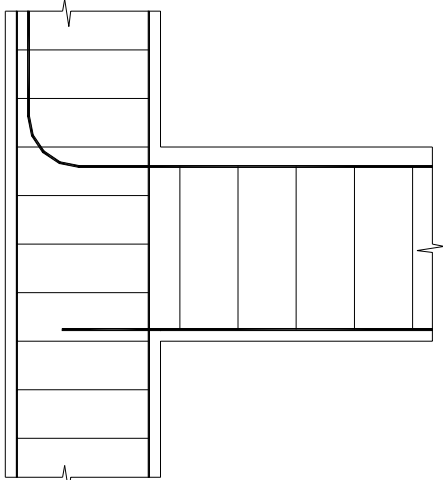

a)

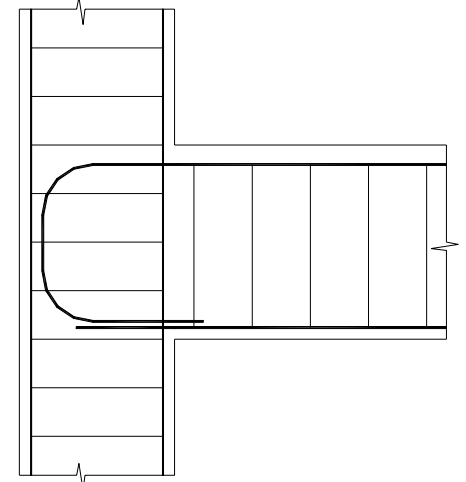

b)

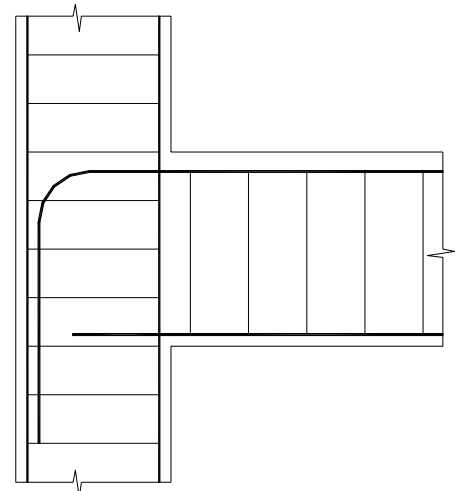

c)

Figura 3.3: Arranjos para a ancoragem das barras das vigas analisados por MURTY et al. 
BDT: Barras principais superiores da viga dobradas no pilar em 90 graus para fora do nó, acima do nível da face superior da viga (figura 3.3a);

BDW: Barras principais superiores da viga dobradas em 90 graus no interior do nó e dobradas novamente em direção da viga, terminando na face inferior da mesma (figura 3.3b);

BDB: Barras principais superiores da viga dobradas em 90 graus para o interior do nó, terminando abaixo do nível da face inferior da viga (figura 3.3c).

Os resultados dos ensaios mostraram que os modelos de ligações BDB suportaram um momento último maior que os demais. Os modelos BDB também apresentaram uma resistência maior à formação da primeira fissura diagonal do nó. É importante notar que, no modelo BDB, as armaduras da viga são dobradas para a face externa do pilar em uma região tracionada, aliviando as tensões nas barras longitudinais do pilar e diminuindo a variação dessas tensões entre as seções superior e inferior do elemento. Por sua vez, no modelo BDW, as armaduras da viga, retornam para uma região comprimida, a qual não requer armaduras adicionais.

Comparando os modelos BDW e BDT, o primeiro apresentou, do ponto de vista da fissuração, um comportamento mais aceitável.

Ainda sobre as três formas de ancoragem das barras da viga, ilustradas na figura 3.3, algumas observações merecem ser citadas. SCOTT (1996), com base em resultados experimentais, conclui que em qualquer caso, os tipos de detalhamento b) e c) apresentam melhor desempenho estrutural que o tipo a). Se a ductilidade é um parâmetro requerido, o detalhamento do tipo c), com as barras superiores dobradas a 90 graus para o interior do nó, torna-se mais adequado que o tipo de detalhamento b). Além disso, segundo BAKIR \& BODUROGLU (2002), pode-se ter uma perda de até $15 \%$ da resistência ao cisalhamento do nó, sob ações monotônicas, caso o nó seja detalhado com o tipo b) ao invés de ser detalhamento com o tipo $\mathrm{c}$ ).

Em se tratando de estruturas que devam resistir a ações cíclicas no campo inelástico, PARK \& PAULAY (1975) fazem algumas sugestões para o dimensionamento e detalhamento da região nodal. Em nós externos, os autores recomendam que apenas os estribos horizontais posicionados em uma altura igual a dois terços da altura útil da viga, medido a partir do eixo da armadura tracionada, devam ser considerados efetivos (figura 3.4a).

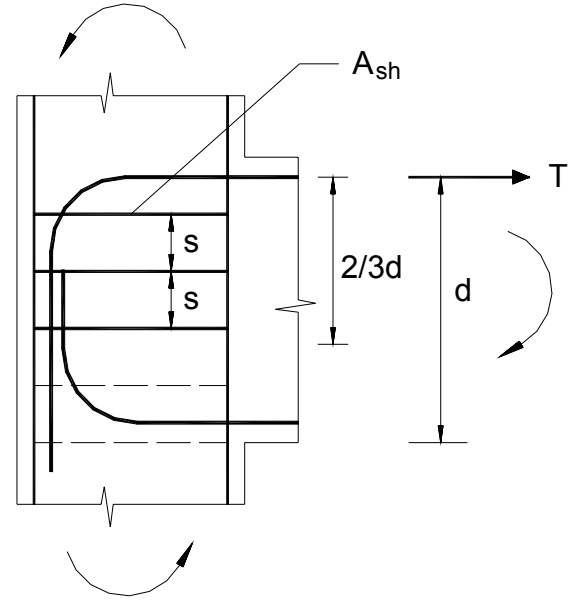

a)

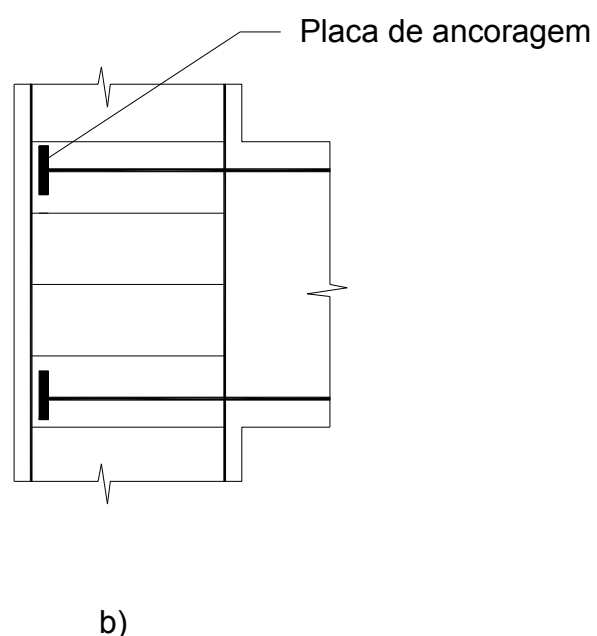

b)

Figura 3.4: Detalhamento proposto para nós externos - PARK \& PAULAY (1975) 
A partir dessa proposição, chega-se a área de estribos horizontais necessária, por camada, à altura efetiva:

$A_{s h}=\frac{3}{2} \frac{V_{s h}}{f_{y h}} \frac{s}{d}$

onde

$\mathrm{V}_{\mathrm{sh}}$ é a força cortante resistente devido aos estribos, calculada com $\mathrm{V}_{\mathrm{sh}}=\mathrm{T}-\mathrm{C}_{\mathrm{c}}$, sendo $\mathrm{T}$ a resultante de tração e $\mathrm{C}_{\mathrm{c}}$ a resultante de compressão do concreto da viga;

$f_{y h}$ é a resistência ao escoamento do aço dos estribos horizontais;

$s$ é o espaçamento entre os estribos na região do nó;

d é a altura útil da viga.

PARK \& PAULAY (1975) admitem, entretanto, que a expressão (3.1) representa uma condição muito severa, especialmente quando a relação entre a altura da seção da viga e a altura da seção do pilar é menor que 1,5. Além do motivo dado pelos autores, vale observar que, neste caso, a aderência das barras da viga está sendo totalmente desprezada, diferente, por exemplo, do que propuseram posteriormente PAULAY \& PRIESTLEY (1992), cujo modelo teórico de transferência de esforços é abordado no capítulo 5 .

Vale ressaltar, no que se refere a área de estribos efetiva, que a tendência geral no projeto é considerar como totalmente efetivas as áreas dos estribos próximos à metade da altura do nó e apenas $50 \%$ como efetivas as áreas dos estribos mais afastados da região central.

Em ligações cujos pilares possuem grande altura de seção, ou quando for preferível a ancoragem reta das barras da viga, a ancoragem mecânica com placas de aço pode ser vantajosa, segundo PARK \& PAULAY (1975). Neste caso, as barras longitudinais da viga atravessam os furos da placa de ancoragem, sendo soldadas a esta (figura 3.4b).

$\mathrm{Na}$ figura 3.5 estão resumidas algumas recomendações de PAULAY \& PRIESTLEY (1992) sobre o detalhamento de nós externos sob ações cíclicas intensas. No caso de barras dobradas à 90 graus, tais recomendações consistem em:

i) Desconsiderar, no cômputo do comprimento de ancoragem reto necessário $I_{\text {bh }}$, um trecho inicial medido a partir da face interna do pilar, e que corresponde ao menor valor entre a metade da altura da seção do pilar e dez vezes o diâmetro da barra.

ii) Adotar para a ponta vertical reta - trecho final da barra após a dobra em 90 graus - um comprimento maior ou igual à 12 vezes o diâmetro da barra.

Por fim, percebe-se que o detalhamento com as barras da viga dobradas em 90 graus no interior do nó com ponta vertical reta é o mais recomendado e mais usado para nós de pórtico externos, inclusive pelas principais normas que tratam do assunto. 


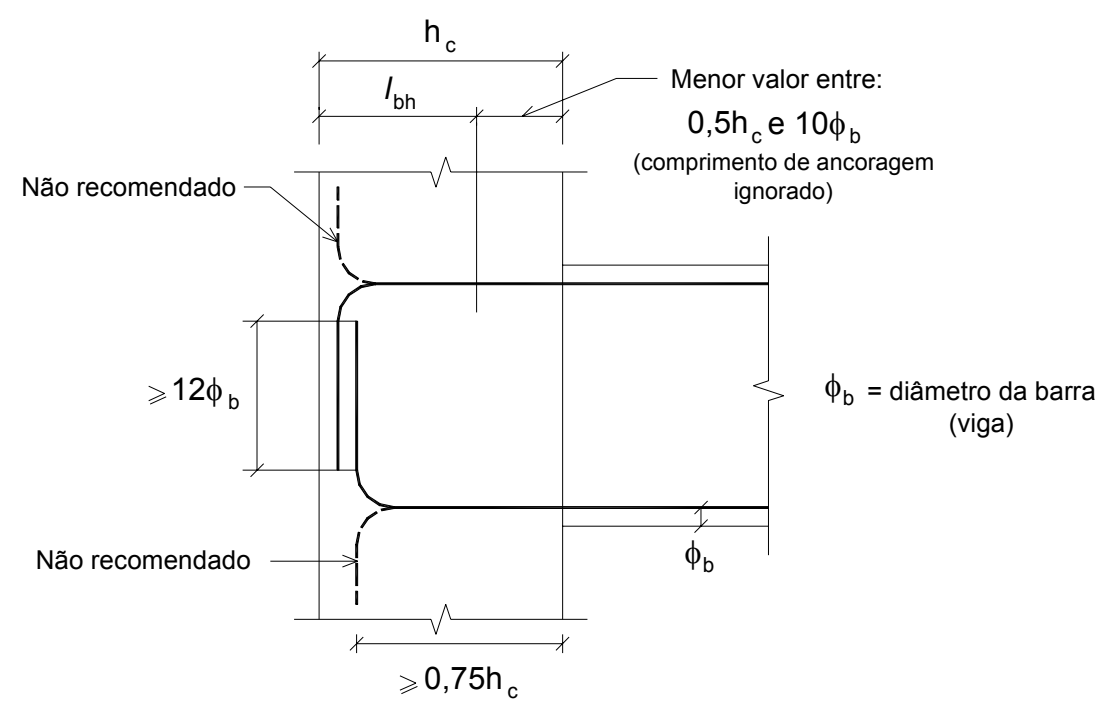

Figura 3.5: Sugestão de detalhamento das armaduras longitudinais da viga em nós externos PAULAY \& PRIESTLEY (1992).

\subsubsection{Detalhamento de ligações viga-pilar intermediário: nós internos}

Nesses tipos de ligações, as armaduras principais dos elementos são normalmente mantidas retas. Algumas formas de detalhamento são apresentadas em SCHLAICH \& SCHAFER (1989) conforme a figura 3.6.

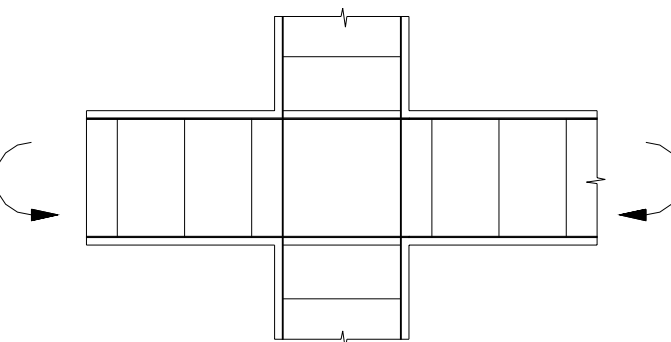

a)

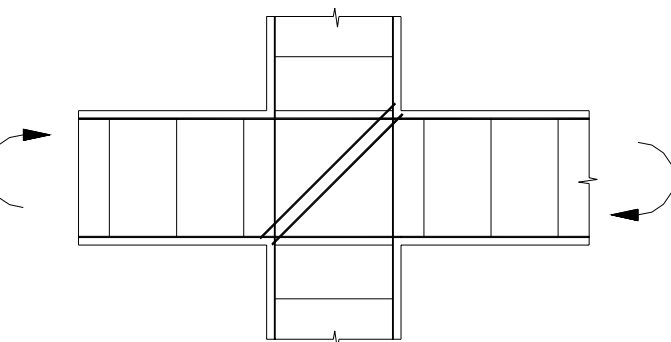

b)

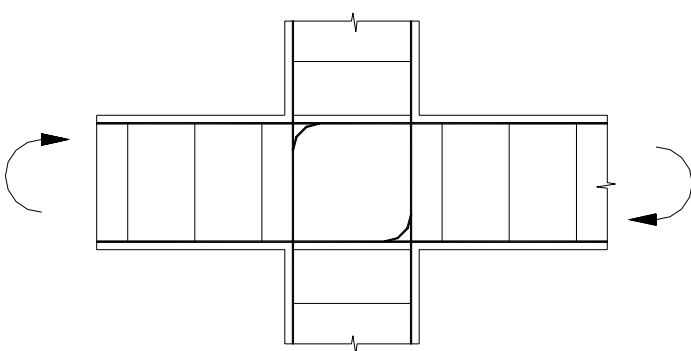

c)

Figura 3.6: Detalhamento proposto para os nós internos - SCHLAICH \& SCHAFER (1989)

O detalhamento sugerido na figura 3.6a aplica-se quando as ações gravitacionais são predominantes, situação em que a armadura inferior da viga se encontra comprimida. As 
formas de detalhamento das figuras 3.6b e 3.6c aplicam-se quando as ações laterais na estrutura são preponderantes.

Uma das sugestões de PAULAY \& PRIESTLEY (1992) para nós internos submetidos a ações cíclicas de sismos é ilustrada na figura 3.7, onde uma parte da armadura longitudinal das vigas é dobrada na direção diagonal do nó interno. Alertam, entretanto, que esse tipo de detalhamento deve ser cuidadosamente projetado.

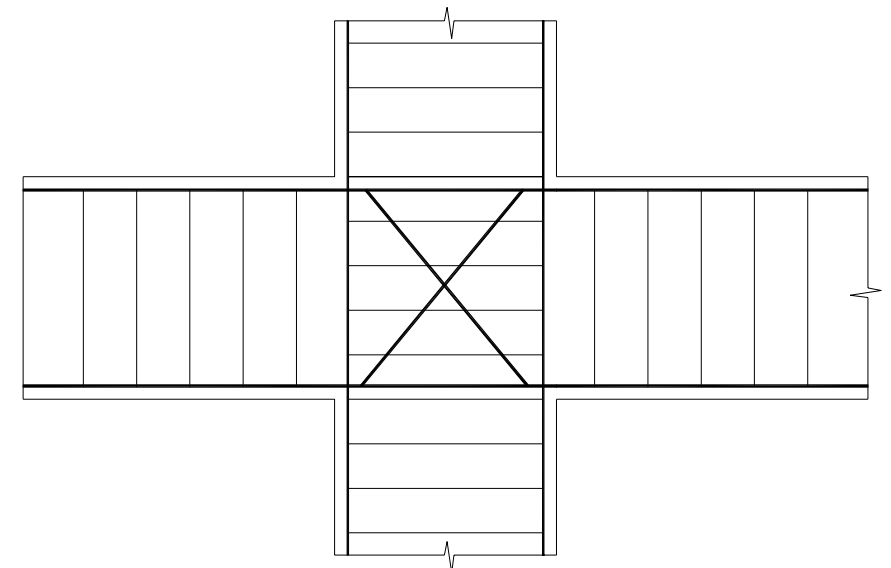

Figura 3.7: Alternativa de detalhamento proposto para os nós internos - PAULAY \& PRIESTLEY (1992)

Uma questão importante em nós internos, na situação em que as ações laterais predominam em relação às gravitacionais, é a limitação do diâmetro da barras longitudinais da viga em relação à altura da seção transversal do pilar. Entretanto, percebe-se que existe uma certa discordância entre os diversos pesquisadores sobre o quanto devem estar limitados esses diâmetros. Na verdade, tal limitação depende de uma série de parâmetros, tal como o nível das tensões atingidas, as taxas de armaduras existentes, o efeito do confinamento sobre a aderência, entre outros fatores.

\subsection{RECOMENDAÇÕES NORMATIVAS PARA O DIMENSIONAMENTO}

Entre as principais normas encontradas na literatura que tratam do dimensionamento de nós de pórtico de concreto, tanto para o caso de carregamento cíclico quanto para o caso monotônico, estão as normas americanas ACl-352 (1991) e ACl-318 (1995), a norma japonesa AlJ (1991) e a norma neozelandesa NZS-3101 (1995).

Observa-se que as normas apresentam entre si algumas diferenças no dimensionamento das ligações, em especial sobre os mecanismos resistentes do nó frente ao cisalhamento imposto pelos elementos conectados.

No modelo de cálculo adotado pelo ACl-318 (1995), assume-se que as forças cortantes são resistidas primariamente pelo núcleo de concreto (nó) e pela armadura longitudinal do pilar, sendo a integridade da ligação assegurada pela presença de estribos horizontais colocados na região do nó, os quais servem também para confinar o concreto. Com esse modelo, percebe-se que o nó é tratado como uma parte do pilar. Além disso, ignoram-se as tensões de cisalhamento verticais quando a armadura longitudinal do pilar é uniformemente distribuída ao longo do perímetro do nó. De qualquer modo, as tensões de cisalhamento verticais podem ser 
obtidas utilizando-se o mesmo raciocínio empregado na determinação da força cortante horizontal. Outra particularidade da norma americana é a consideração do efeito benéfico da presença de vigas transversais sobre o confinamento.

No modelo adotado pelas normas NZS-3101 (1995) e pelo CEB (1985), as tensões cisalhantes horizontais e verticais são consideradas no dimensionamento. As tensões internas do nó são obtidas por meio do equilíbrio de forças, de forma idêntica à apresentada no capítulo 2, no item 2.3. Segundo alguns pesquisadores, o modelo proposto pela norma neozelandesa conduz a uma grande quantidade de estribos horizontais e verticais na região do nó, fato atribuído ao próprio emprego do modelo de treliça.

A norma brasileira NBR 6118:2003 trata os nós de pórtico como regiões especiais, não valendo nessas regiões a hipótese da permanência das seções planas. Prescreve que, em decorrência da mudança de direção dos elementos estruturais, a resistência do conjunto depende da resistência à tração do concreto e da disposição da armadura, as quais devem ser consideradas no dimensionamento. Entretanto, não apresenta modelos de cálculo para o dimensionamento dos nós.

\subsubsection{Classificação dos nós segundo as normas americanas: ACI 352 (1991) e ACI 318} (1995)

Uma vez que o dimensionamento das ligações depende das condições de carregamento e deformabilidade de seus elementos, as normas americanas classificam os nós em duas categorias:

Tipo 1: Quando os nós de pórtico pertencem a elementos projetados sem provisões especiais de ductilidade. Os nós em estruturas de pórtico dimensionadas para resistir apenas às ações gravitacionais e às ações de vento usuais enquadram-se nesta categoria.

Tipo 2: Quando os nós são formados por elementos dos quais se requer dissipação de energia quando submetidos a ações cíclicas. Os nós em estruturas de pórticos dimensionadas para resistir aos efeitos de sismos, ações de ventos severos e efeitos de explosões enquadram-se nesta categoria.

\subsubsection{Armadura transversal em nós}

ACI 352 (1991) e ACI 318 (1995):

Em nós do tipo 1, recomenda-se a utilização de pelo menos duas camadas de estribos entre a armadura longitudinal superior e inferior da viga. A distância entre os estribos horizontais no nó não deve exceder $150 \mathrm{~mm}$, a fim de conferir certo grau de confinamento.

Em nós do tipo 2, quando forem utilizados estribos retangulares, a área de estribos horizontais do nó deve ser calculada por:

$A_{s h}=0,3 \operatorname{sh}_{c} \frac{f_{c}}{f_{y h}}\left(\frac{A_{g}}{A_{c h}}-1\right) \quad$ porém não menor que $0,09 \operatorname{sh}_{c} \frac{f_{c}}{f_{y h}}$

onde 
s é o espaçamento entre os estribos;

$\mathrm{h}_{\mathrm{c}}$ é a altura do núcleo de concreto, medida entre os eixos dos estribos;

$\mathrm{f}_{\mathrm{c}}$ é a resistência à compressão do concreto;

$\mathrm{f}_{\mathrm{yh}}$ é a resistência ao escoamento do aço dos estribos;

$A_{g}$ é a área bruta da seção transversal do pilar;

$A_{c h}$ é a área do núcleo de concreto, considerando as faces externas dos estribos.

As normas americanas recomendam que o espaçamento entre os estribos para nós do tipo 2 seja de, no máximo, igual ao menor dos seguintes valores: 1/4 da menor dimensão do pilar, 6 vezes o diâmetro das barras longitudinais do pilar e $150 \mathrm{~mm}$.

NZS 3101 (1995):

A norma neozelandesa adota o mesmo modelo resistente proposto por PAULAY \& PRIESTLEY (1992), o qual admite a contribuição do concreto (bielas diagonais comprimidas) e do aço (armadura transversal do nó). Essa norma considera as tensões cisalhantes tanto na direção horizontal quanto na vertical. Para o cálculo da armadura transversal necessária na resistência ao cisalhamento horizontal, pode-se empregar o equacionamento apresentado no capítulo 5, no item 5.2 .

\subsection{3 Área efetiva dos nós}

Nas verificações associadas ao nó, é usual expressar as forças cortantes em termos de tensões cisalhantes, calculadas simplesmente por:

$\tau_{\mathrm{n}}=\frac{\mathrm{V}_{\mathrm{jh}}}{\mathrm{A}_{\mathrm{j}}}$

onde $A_{j}$ é entendido como a área do nó de pórtico que efetivamente participa na resistência ao cisalhamento. Tal área ainda pode ser escrita como:

$$
A_{j}=b_{j} h_{j}
$$

onde $b_{j}$ e $h_{j}$ são a largura efetiva e a altura efetiva do nó, respectivamente (figura 3.8). 


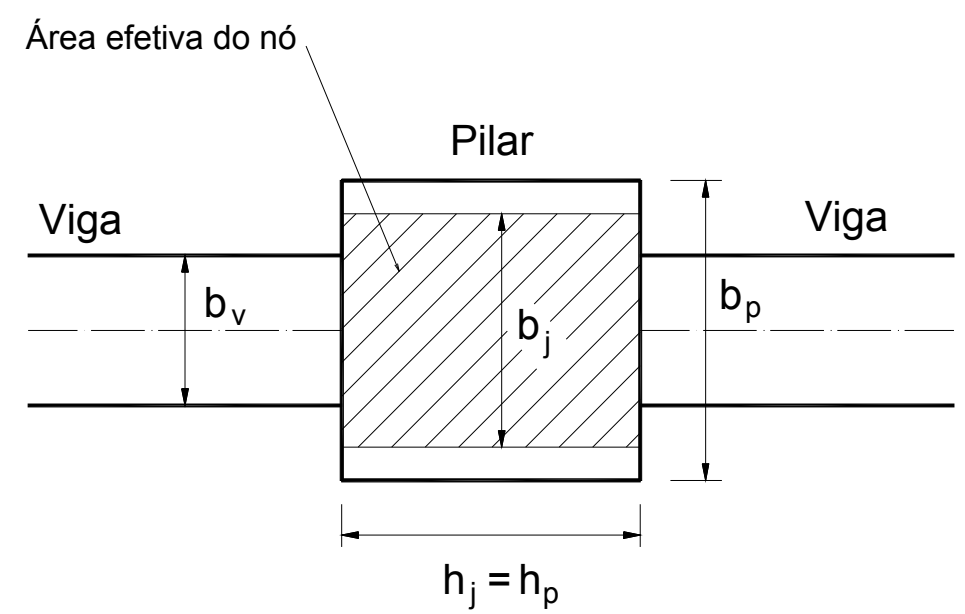

Figura 3.8: Área efetiva de nós de pórtico

Normalmente, adota-se para a altura efetiva $h_{j}$ o valor da altura da seção transversal do pilar na direção em que o cisalhamento é introduzido ao nó.

Por outro lado, a obtenção da largura efetiva está ligada às diferenças de largura e de posicionamento entre as seções dos pilares e das vigas. É evidente que áreas de concreto muito afastadas das faces verticais das vigas não participam eficientemente na resistência às tensões cisalhantes introduzidos ao nó de pórtico. Por esse motivo, algumas normas fornecem recomendações simples para o cálculo de uma largura efetiva para o nó.

Largura efetiva do nó

ACI 352 (1991) e ACI 318 (1995):

A largura efetiva do nó $b_{j}$, empregada no dimensionamento, é obtida com o menor dos seguintes valores:

$\frac{b_{v}+b_{p}}{2} ;$

$b_{p}$

$b_{v}$ acrescido de $0,5 h_{p}$ em cada lado da viga em que a face do pilar se estende além da face da viga.

onde

$b_{v}$ é a largura da seção da viga;

$b_{p}$ é a largura da seção do pilar;

$h_{p}$ é a altura da seção pilar na direção em que o cisalhamento está sendo considerado.

NZS-3101 (1995):

A largura efetiva $b_{j}$ é definida pelo menor dos seguintes valores: 
$b_{j}=b_{p} \quad$ ou $\quad b_{j}=b_{v}+0,5 h_{p} \quad$ quando $b_{p} \geq b_{v}$

$b_{j}=b_{v} \quad$ ou $\quad b_{j}=b_{p}+0,5 h_{p} \quad$ quando $b_{p}<b_{v}$

\subsubsection{Resistência nominal ao cisalhamento}

ACI 352 (1991) e ACI 318 (1995):

A resistência nominal ao cisalhamento de um nó de pórtico é calculada pela seguinte expressão:

$\tau_{\mathrm{n}}=\frac{\mathrm{V}_{\mathrm{n}}}{\mathrm{A}_{\mathrm{j}}}=0,083 \gamma \sqrt{\mathrm{f}_{\mathrm{c}}}$

onde

$\gamma$ é uma constante que depende da classificação do nó;

$\mathrm{f}_{\mathrm{c}}$ é a resistência à compressão do concreto em $\mathrm{MPa}$;

$A_{j}$ é a área efetiva do nó, com $A_{j}=b_{j} h_{p}$;

$b_{j}$ é a largura efetiva do nó;

$h_{p}$ é a altura da seção transversal do pilar na direção analisada.

A constante $\gamma$ é obtida a partir da tabela 3.1:

Tabela 3.1: Valores de $\gamma$ em ligações viga-pilar - ACl 352 (1991) e ACI 318 (1995)

\begin{tabular}{|c|c|c|c|}
\hline $\begin{array}{c}\text { Categoria } \\
\text { (Tipo) }\end{array}$ & $\begin{array}{c}\text { Nós confinados por 4 } \\
\text { faces verticais (nós } \\
\text { internos) }\end{array}$ & $\begin{array}{c}\text { Nós confinados por três faces } \\
\text { verticais ou por 2 faces opostas } \\
\text { (nós externos) }\end{array}$ & $\begin{array}{c}\text { Outros casos } \\
\text { (nós de canto) }\end{array}$ \\
\hline 1 & 24 & 20 & 15 \\
\hline 2 & 20 & 15 & 12 \\
\hline
\end{tabular}

NZS-3101 (1995) e AIJ (1991):

Segundo as normas neozelandesa e a japonesa, a resistência nominal ao cisalhamento $\tau_{\mathrm{n}}$ assume o seguinte valor:

$\tau_{\mathrm{n}}=\mathrm{kf}_{\mathrm{c}}$

onde

$\mathrm{k}=0,2$ para todos os tipos de nó, segundo a NZS-3101 (1995);

$\mathrm{k}=0,3$ para nós internos e $\mathrm{k}=0,18$ para nós externos, segundo a AIJ (1991).

A figura 3.9 contém uma comparação da tensão nominal resistente em função da resistência à compressão do concreto, segundo as três normas aqui mencionadas. 


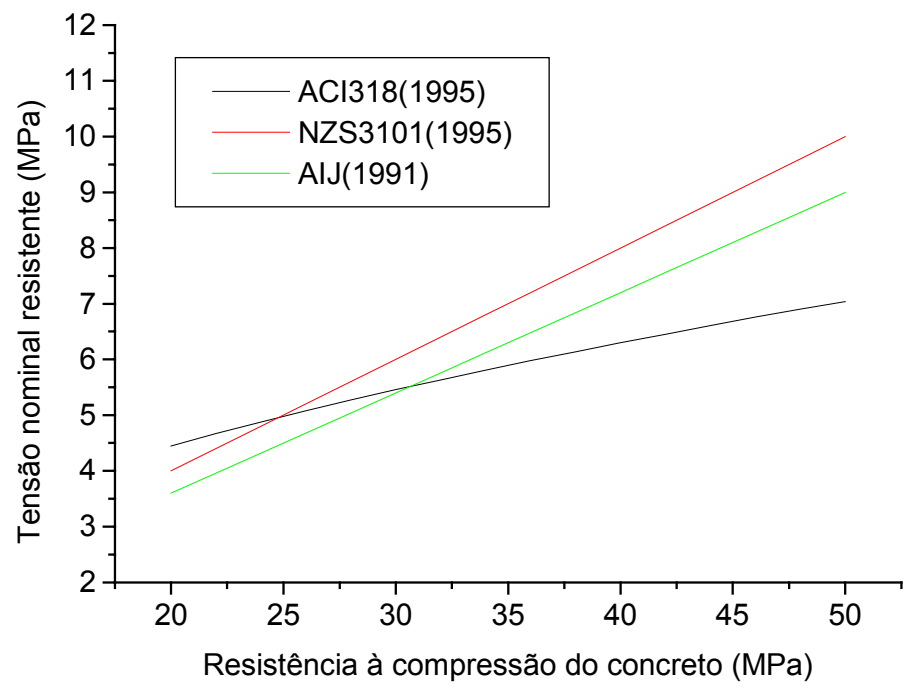

Figura 3.9: Resistência ao cisalhamento em função da resistência à compressão

\subsubsection{Ancoragem das barras longitudinais das vigas}

No caso em que as barras das vigas são dobradas para o interior do nó, em 90 graus, as normas fazem algumas recomendações de detalhamento, entre as quais estão incluídas o comprimento de ancoragem reto necessário $\ell_{\mathrm{bh}}$, a ponta reta vertical $\ell_{\mathrm{t}}$ após a curvatura da barra e o raio interno de dobra $\mathrm{R}$ (figura 3.10 ).

Em nós externos, as normas do ACl 352 (1991) e do ACI 318 (1995) preconizam que, quando as barras longitudinais são dobradas a 90 graus, o comprimento de ancoragem reto, medido a partir da face interna do pilar, seja obtido com a expressão:

$\ell_{\mathrm{bh}}=\frac{\mathrm{f}_{\mathrm{y}} \phi_{\mathrm{b}}}{4,2 \sqrt{\mathrm{f}_{\mathrm{c}}^{\prime}}} \quad$ tipo $1 \quad \ell_{\mathrm{bh}}=\frac{\alpha \mathrm{f}_{\mathrm{y}} \phi_{\mathrm{b}}}{6,2 \sqrt{\mathrm{f}_{\mathrm{c}}^{\prime}}} \quad$ tipo $2, \operatorname{com} \alpha=1,25$

porém sempre maior que $8 \phi_{b}$ ou $150 \mathrm{~mm}$. Na expressão (3.7), $f_{c}$ e $f_{y}$ são fornecidos em MPa.

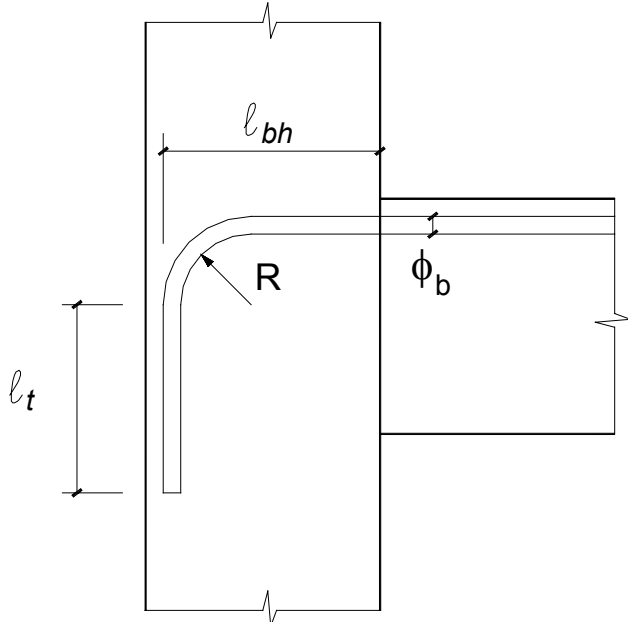

Figura 3.10: Ancoragem das barras da viga em nós externos 
Para os nós do tipo 2, as normas americanas recomendam que o comprimento $\ell_{\mathrm{bh}}$ seja medido a partir da superfície externa dos estribos do pilar, ou seja, desconsiderando o cobrimento do pilar. Esta recomendação baseia-se em resultados experimentais de carregamentos reversíveis, onde se observou que o cobrimento da região nodal, devido à sua deterioração, é ineficiente na transferência de esforços.

Por sua vez, a norma brasileira NBR 6118:2003 recomenda que o comprimento de ancoragem necessário das armaduras tracionadas com ganchos, medido a partir da face interna do pilar, seja determinado por:

$$
\ell_{\mathrm{bh}}=0,7 \ell_{\mathrm{b}} \frac{\mathrm{A}_{\mathrm{s}, \mathrm{cal}}}{\mathrm{A}_{\mathrm{s}, \mathrm{ef}}} \geq \ell_{\mathrm{b}, \mathrm{min}}
$$

onde

$\ell_{\mathrm{b}}$ é o comprimento de ancoragem básico, calculado por $\frac{\phi_{\mathrm{b}}}{4} \times \frac{f_{\mathrm{yd}}}{\mathrm{f}_{\mathrm{bd}}}$

$f_{y d}$ é a resistência ao escoamento de cálculo e $f_{b d}$ a resistência à aderência de cálculo ( $\left.M P a\right)$;

$A_{s, c a l}$ é a área de armadura calculada para resistir ao esforço solicitante e $A_{s, e f}$ a área de armadura existente;

$\ell_{\mathrm{b}, \min }$ é o maior valor entre $0,3 \ell_{\mathrm{b}}, 10 \phi_{\mathrm{b}}$ e $100 \mathrm{~mm}$.

Assumindo que $\frac{A_{s, \text { cal }}}{A_{s, e f}}=1,0$ e adotando demais expressões recomendadas pela NBR 6118 (2003):

$f_{b d}=\eta_{1} \eta_{2} \eta_{3} \frac{0,21 f_{c k}{ }^{2 / 3}}{\gamma_{c}} \quad f_{y d}=\frac{f_{y}}{\gamma_{s}}$

pode-se deduzir a seguinte expressão para o comprimento de ancoragem das armaduras com ganchos, em apoios externos:

$\ell_{\mathrm{bh}}=\frac{1}{1,2 \eta_{1} \eta_{2} \eta_{3}} \frac{\mathrm{f}_{\mathrm{yk}} / \gamma_{\mathrm{s}}}{\mathrm{f}_{\mathrm{ck}}^{2 / 3} / \gamma_{\mathrm{c}}} \phi_{\mathrm{b}}$

onde

$\mathrm{f}_{\mathrm{yk}}$ e $\mathrm{f}_{\mathrm{ck}}$ são os valores característicos da resistência ao escoamento do aço e da resistência à compressão do concreto, respectivamente;

$\eta_{1}$ é igual a 2,25 para barras nervuradas, 1,4 para barras dentadas e 1,0 para barras lisas;

$\eta_{2}$ é igual a 1,0 para situações de boa aderência e 0,7 para situações de má aderência;

$\eta_{3}$ é igual a 1,0 quando $\phi_{\mathrm{b}}<32 \mathrm{~mm}$ e igual a $\frac{132-\phi_{\mathrm{b}}}{100}$ para $\phi_{\mathrm{b}}>32 \mathrm{~mm}$, com $\phi_{\mathrm{b}}$ em mm;

$\gamma_{c}$ e $\gamma_{s}$ são os coeficientes de ponderação da resistência do concreto e do aço, respectivamente. 
Em relação à curvatura das barras dobradas, o raio interno mínimo $\mathrm{R}$ em nós de pórtico não deve ser inferior a $7,5 \phi_{\mathrm{b}}$. A ponta reta vertical $\ell_{\mathrm{t}}$ não deve ser inferior a $8 \phi_{\mathrm{b}}$.

A norma neozelandesa NZS 3101 (1995), por sua vez, recomenda que o comprimento $\ell_{\mathrm{t}}$ não seja inferior a $12 \phi_{\mathrm{b}}$.

\subsubsection{Limitação de diâmetros}

Em virtude das condições mais críticas, em termos de solicitação, encontradas para os nós internos, as principais normas limitam o valor dos diâmetros barras das vigas (tabela 3.2). O objetivo dessas limitações inclui também evitar o deslizamento excessivo das armaduras no interior dos nós. Uma demonstração mais detalhada da necessidade de limitação dos diâmetros é apresentada no item 5.2.1

Tabela 3.2: Diâmetros máximos das barras longitudinais das vigas em nós internos

\begin{tabular}{|c|c|c|}
\hline ACI 352 (1991) / ACI 318 (1995) & NZS 3101 (1995) & AIJ (1991) \\
\hline$\frac{\phi_{b}}{h_{p}} \leq \frac{1}{20}$ & $\frac{\phi_{b}}{h_{p}} \leq \frac{3,3 \alpha_{f} \sqrt{f_{c}}}{\alpha_{0} f_{y}}$ & $\frac{\phi_{b}}{h_{p}} \leq \frac{2,78(1+v) \frac{f_{c}}{f_{u}}}{1+\beta}$ \\
\hline
\end{tabular}

Na tabela 3.2,

$h_{p}$ é a altura da seção do pilar;

$f_{c}$ e $f_{y}$ são fornecidos em MPa;

$\mathrm{f}_{\mathrm{u}}$ é a resistência à ruptura do aço, em $\mathrm{MPa}$;

$\beta$ é a relação entre a área de armadura de compressão e a área de armadura de tração da viga;

$v$ é a força adimensional do pilar, igual a $N / A_{c} f_{c}$;

$\mathrm{N}$ é a força normal do pilar;

$A_{c}$ é área da seção transversal do pilar;

$\alpha_{f}$ é igual a 0,85 quando as barras da viga atravessam o nó em duas direções (pórticos em duas direções) e igual a 1,0 quando atravessam em uma única direção;

$\alpha_{0}$ é igual a 1,25 quando se espera a formação de rótulas plásticas nas vigas próximas as faces dos pilares. Caso contrário, igual a 1,0.

Por uma simples verificação das expressões apresentadas na tabela 3.2, pode-se perceber que os valores das limitações variam consideravelmente de norma para norma. $O$ gráfico da figura 3.11 ilustra bem essa situação. A relação entre o diâmetro da barra e a altura da seção do pilar é representada por uma razão genérica $1 / K$, com os valores de $K$ no eixo das ordenadas. 


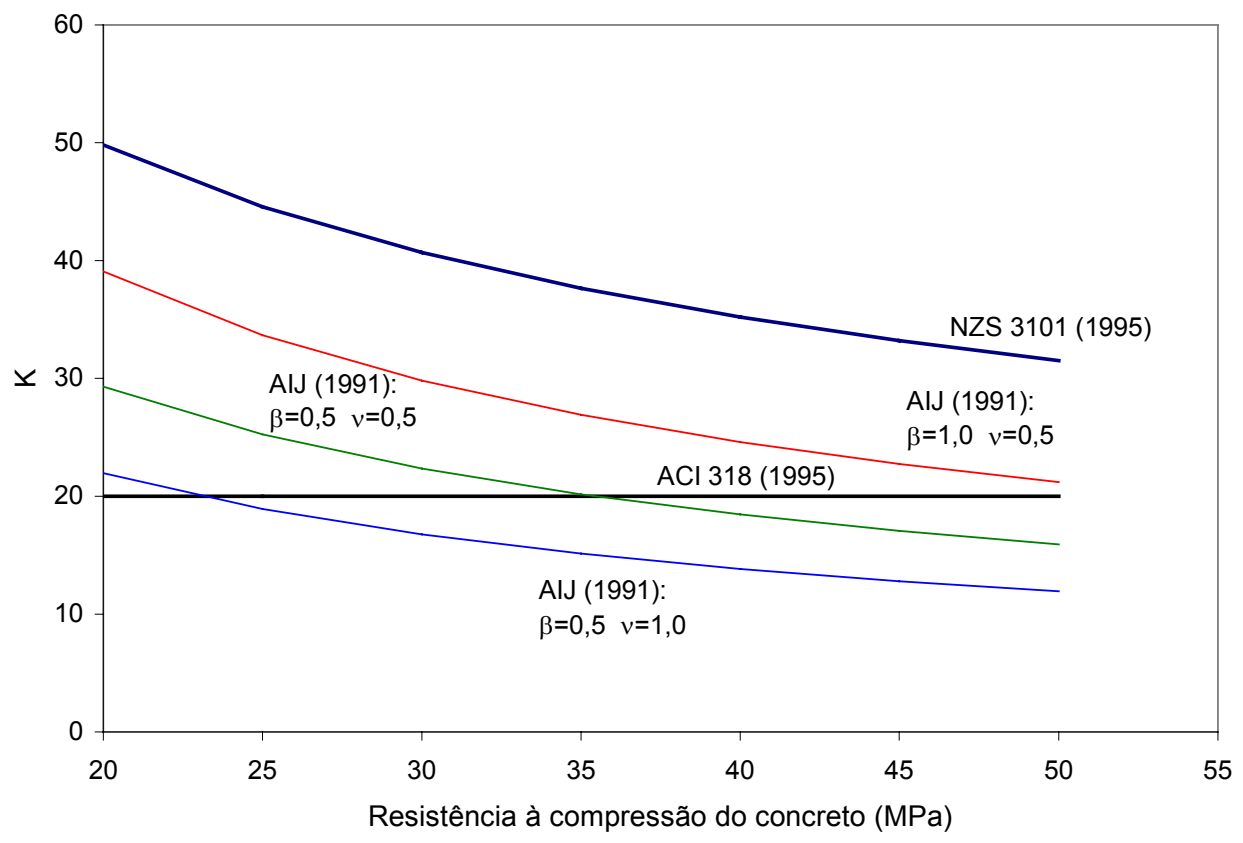

Figura 3.11: Limitação do diâmetro das barras principais da viga em nós internos comparação entre recomendações de normas

Na figura 3.11, admitiu-se $\alpha_{f}$ igual a 0,85 e $\alpha_{0}$ igual a 1,25, imaginando-se um nó com vigas transversais formando pórticos em duas direções, com a possibilidade de formação de rótula plástica na viga. Pelo gráfico da mesma figura, percebe-se também o efeito da normal no pilar e da armadura negativa das vigas sobre as condições de aderência de nós internos, considerada pela norma japonesa AIJ (1991).

\subsection{EXEMPLO DE DIMENSIONAMENTO}

\section{Nó externo: ligação viga-pilar de extremidade}

Neste item, desenvolveu-se um exemplo de cálculo associado ao dimensionamento de nós de pórtico externos, dando maior destaque às recomendações do $\mathrm{ACl}-352 / \mathrm{ACl} 318$.

Os procedimentos de cálculo deste exemplo consistem na determinação da força cortante solicitante, na verificação da resistência ao cisalhamento, no dimensionamento dos estribos horizontais do nó e na verificação do comprimento de ancoragem das barras longitudinais da viga.

\begin{tabular}{|l|l|l|}
\hline \multicolumn{1}{|c|}{ Materiais: } & \multicolumn{1}{|c|}{ Armaduras da viga } & \multicolumn{1}{c|}{ Armaduras do pilar } \\
\hline Concreto: $\mathrm{f}_{\mathrm{c}}=30 \mathrm{MPa}$ & Longitudinal: $4 \phi 16 ; 4 \phi 10$ & Longitudinal: $8 \phi 16$ \\
Aço: $\mathrm{f}_{\mathrm{y}}=\mathrm{f}_{\mathrm{yh}}=500 \mathrm{MPa}$ & Transversal: $\phi 8 \mathrm{c} / 15 \mathrm{~cm}$ & Transversal: $\phi 6,3 \mathrm{c} / 15 \mathrm{~cm}$ \\
\hline
\end{tabular}



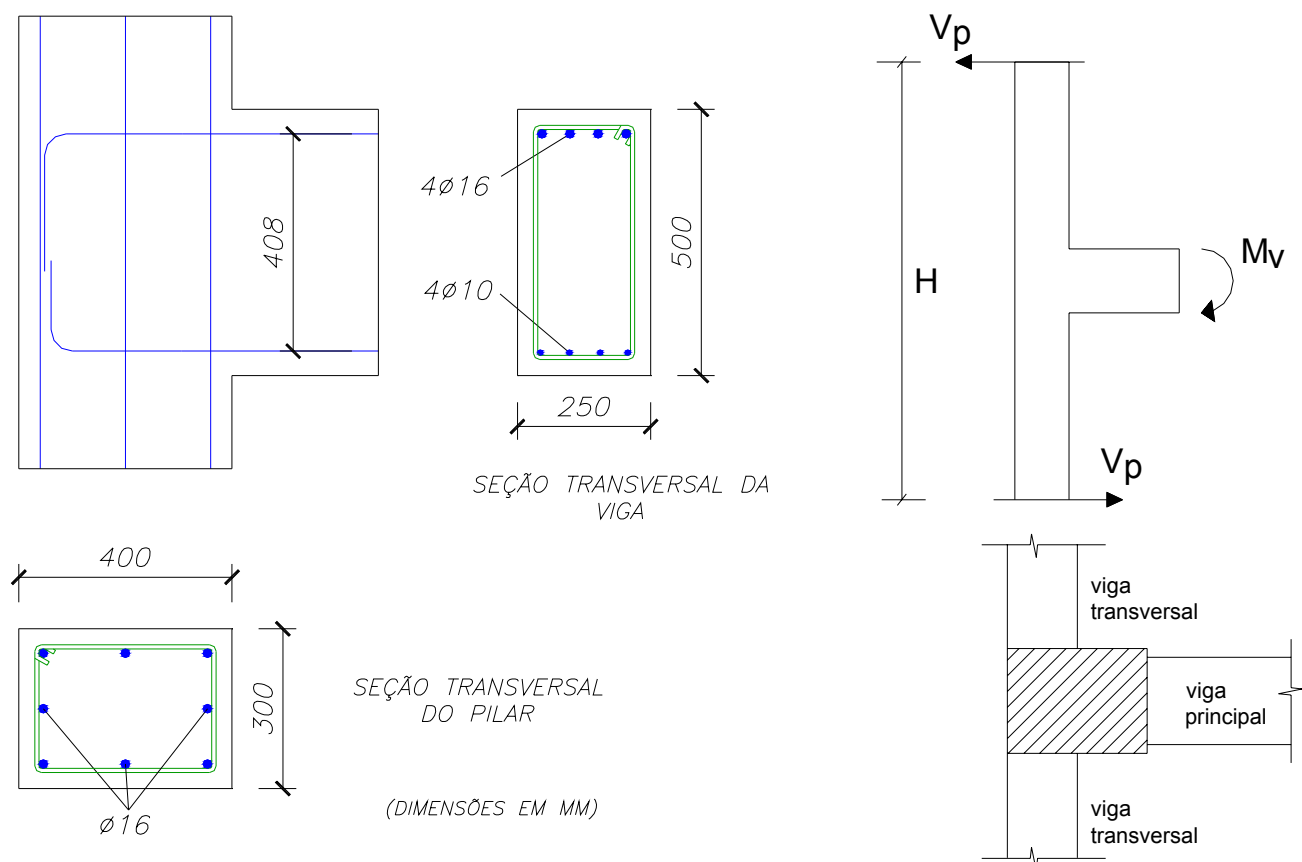

Figura 3.12: Ligação viga-pilar de extremidade do exemplo numérico

\section{Determinação dos esforços solicitantes no nó de pórtico:}

Com base no critério de que o nó de pórtico não deve impedir o desenvolvimento de toda a resistência dos elementos conectados, obtém-se a solicitação por força cortante no mesmo, admitindo que a viga atinja o momento último. Para calculá-lo, empregou-se as hipóteses usuais assumidas no estado limite último de seções armadas. Os esforços inicialmente calculados referem-se a valores nominais, devendo-se aplicar os devidos coeficientes de minoração das resistências dos materiais aço e concreto, conforme a norma em questão.

$$
\begin{array}{ll}
M_{v}=M_{u}=17.000 \mathrm{kN} . c m & \text { (para nós do tipo 1, com } \alpha=1,0) \\
M_{v}=M_{u}=21.100 \mathrm{kN} . \mathrm{cm} & \text { (para nós do tipo 2, com } \alpha=1,25)
\end{array}
$$

No cálculo do momento último, $\alpha$ é um coeficiente que deve ser multiplicado à resistência ao escoamento das barras tracionadas da viga. $O$ valor de $\alpha=1,0$ adotado, pela norma americana para os nós do tipo 1, é justificado pelo fato de a ligação não ser projetada para atingir grandes deformações plásticas. $O$ valor de $\alpha=1,25$ para os nós do tipo 2 leva em conta a possibilidade de ocorrência de grandes deformações plásticas com encruamento do aço, mediante solicitações cíclicas reversíveis.

Portanto, a resultante de tração na viga é igual a:

$$
\begin{array}{ll}
T_{v}=A_{s t} \alpha f_{y}=8,0 \times 1,0 \times 50=400 \mathrm{kN} & \text { (para nós do tipo 1) } \\
T_{v}=A_{s t} \alpha f_{y}=8,0 \times 1,25 \times 50=500 k N & (\text { para nós do tipo 2) }
\end{array}
$$


Assumindo uma altura $\mathrm{H}=300 \mathrm{~cm}$ para a distância entre os pontos de momento nulo no pilar, a força cortante $V_{p}$ é determinada por:

$V_{p}=\frac{M_{v}}{H}=\frac{17.000}{300}=56,67 \mathrm{kN} \quad($ Tipo 1)

$V_{p}=\frac{M_{v}}{H}=\frac{21.100}{300}=70,33 \quad$ (Tipo 2)

Finalmente, a força cortante solicitante horizontal nó externo é igual a :

$\mathrm{V}_{\mathrm{jh}}=\mathrm{T}_{\mathrm{v}}-\mathrm{V}_{\mathrm{p}}=400-56,67=343,33 \mathrm{kN} \quad$ (Tipo 1)

$\mathrm{V}_{\mathrm{jh}}=\mathrm{T}_{\mathrm{v}}-\mathrm{V}_{\mathrm{p}}=500-70,33=429,67 \mathrm{kN} \quad$ (Tipo 2)

\section{Verificação da resistência ao cisalhamento:}

De acordo com a expressão (3.5), calcula-se a forca cortante resistente nominal, tanto para os nós tipo 1 quanto para os nós tipo 2:

$V_{n}=0,083 \gamma A_{j} \sqrt{f_{c}}$

onde

$\gamma=20$ para nó externo tipo 1

$\gamma=15$ para nó externo tipo 2

Largura efetiva do nó: $b_{j}=\frac{b_{v}+b_{p}}{2}=\frac{25+30}{2}=27,5 \mathrm{~cm}$

Área efetiva do nó: $A_{j}=b_{j} h_{p}=27,5 \times 40=1100 \mathrm{~cm}^{2}$

Portanto,

$\mathrm{V}_{\mathrm{n}}=0,083 \times 20 \times 1100 \times \sqrt{25} \times 0,1=913 \mathrm{kN} \quad$ (tipo 1)

$\mathrm{V}_{\mathrm{n}}=0,083 \times 15 \times 1100 \times \sqrt{25} \times 0,1=685 \mathrm{kN} \quad$ (tipo 2)

A norma americana considera um coeficiente de minoração de resistência igual a $\phi=0,85$. Logo, a força cortante solicitante não deve ultrapassar os valores da resistência de cálculo:

$$
\begin{array}{lll}
\phi \bigvee_{\mathrm{n}}=0,85 \times 913=776 \mathrm{kN}>\bigvee_{\mathrm{jh}}=343,3 \mathrm{kN} & (\mathrm{OK}) & \text { (Tipo 1) } \\
\phi \bigvee_{\mathrm{n}}=0,85 \times 685=582 \mathrm{kN}>\bigvee_{\mathrm{jh}}=429,7 \mathrm{kN} & \text { (OK) } & \text { (Tipo 2) }
\end{array}
$$

\section{Armadura transversal na região do nó:}

Para nós do tipo 1, a norma americana recomenda a utilização de pelo menos duas camadas de estribos, com espaçamento de, no máximo, de 150mm. Com base na figura 3.12, 
é possível adotar 3 estribos de $\phi 6,3$, mantendo o espaçamento de $150 \mathrm{~mm}$. Tais estribos devem ser posicionados entre os níveis das armaduras longitudinal superior e inferior da viga.

Para os nós do tipo 2, a área de estribos na direção do cisalhamento é calculada utilizando a expressão (3.2). O espaçamento máximo entre os estribos é obtido com o menor valor entre $1 / 4$ da menor dimensão do pilar, 6 vezes o diâmetro das barras longitudinais do pilar e $150 \mathrm{~mm}$. Isso resulta em um espaçamento igual a $\mathrm{s}=1 / 4 .(30 \mathrm{~cm})=7,5 \mathrm{~cm}$. Portanto,

$$
A_{s h}=0,3 \operatorname{sh}_{c} \frac{f_{c}}{f_{y h}}\left(\frac{A_{g}}{A_{c h}}-1\right)=0,3 \times 7,5 \times 33,4 \times \frac{25}{500} \times\left(\frac{1200}{816}-1\right)=1,77 \mathrm{~cm}^{2} \quad(3 \phi 6,3)
$$

porém não menor que

$$
A_{s h} \geq 0,09 \mathrm{sh}_{\mathrm{c}} \frac{\mathrm{f}_{\mathrm{c}}}{\mathrm{f}_{\mathrm{yh}}}=0,09 \times 7,5 \times \frac{25}{500}=1,12 \mathrm{~cm}^{2} \quad(\mathrm{OK})
$$

Tomando o espaçamento máximo entre os estribos de $7,5 \mathrm{~cm}$, chega-se a uma armadura transversal composta por 6 estribos de $6,3 \mathrm{~mm}$, posicionados entre os níveis das barras superiores e inferiores da viga.

\section{Verificação da ancoragem das barras longitudinais da viga}

Escolhendo a ancoragem das barras da viga em ganchos de 90 graus, calcula-se o comprimento de ancoragem necessário no pilar (expressão 3.7):

$$
\begin{aligned}
& \ell_{\mathrm{bh}}=\frac{\mathrm{f}_{\mathrm{y}} \phi_{\mathrm{b}}}{4,2 \sqrt{\mathrm{f}_{\mathrm{c}}}}=\frac{500 \times 1,6}{4,2 \times \sqrt{25}}=37,8 \mathrm{~cm} \quad \text { (tipo 1) } \\
& \ell_{\mathrm{bh}}=\frac{\alpha \mathrm{f}_{\mathrm{y}} \phi_{\mathrm{b}}}{6,2 \sqrt{\mathrm{f}_{\mathrm{c}}}}=\frac{1,25 \times 500 \times 1,6}{6,2 \times \sqrt{25}}=32,3 \mathrm{~cm} \quad(\text { tipo } 2)
\end{aligned}
$$

Os comprimentos de ancoragem disponíveis são:

Tipo 1: $\ell_{\mathrm{bh}}=40-3,0-0,63=36,4 \mathrm{~cm} \quad(-3,7 \%) \quad(\mathrm{OK})$

Tipo 2: $\ell_{\mathrm{bh}}=40-3,0-0,63-3,0=33,4 \mathrm{~cm} \quad(\mathrm{OK})$

\section{Comentário:}

Como era de se esperar, as condições dos nós submetidos a ações cíclicas no campo inelástico (tipo 2) são menos favoráveis que a dos nós submetidos a ações predominantemente gravitacionais (tipo 1). No breve exemplo desenvolvido, a verificação da resistência ao cisalhamento mostrou-se ser mais crítica para os nós do tipo 2. Quanto à armadura transversal no nó, foi necessária uma taxa maior de estribos para esse tipo de nó, a fim de promover maior confinamento do mesmo durante as solicitações por cargas cíclicas reversíveis. No capítulo 4 são discutidas com mais detalhes os efeitos das ações cíclicas sobre o comportamento estrutural do nó e sobre a ligação como um todo. 


\section{EFEITOS DAS AÇÕES CÍCLICAS SOBRE OS NÓS DE PÓRTICO}

\subsection{REVISÃO SOBRE OS ESTUDOS EXPERIMENTAIS REALIZADOS}

Os primeiros trabalhos que visaram o estudo de ligações viga-pilar sob a influência de ações cíclicas surgiram no final da década de 60 e início da década de 70. Tais estudos experimentais foram motivados pela preocupação com as ações sísmicas, as quais são enquadradas como ações cíclicas de elevada intensidade e com inversão de sinal. Poucos estudos, entretanto, foram realizados com carregamento cíclico não reversível.

Grande parte dos resultados experimentais já obtidos provém de ensaios com controle de deslocamento, o que é usual em simulações de carregamento cíclico (figura 4.1). Os modelos físicos utilizados na maioria dos casos constituem-se de ligações isoladas (sem a presença de laje e sem a presença de paredes estruturais).
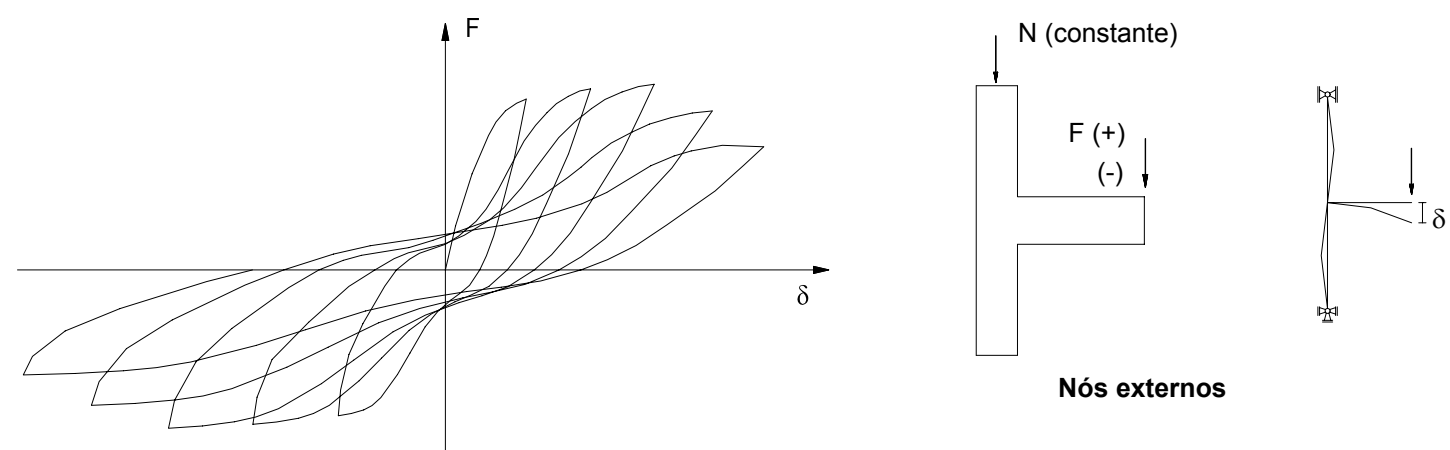

Nós externos

a) Diagrama força-deslocamento típico

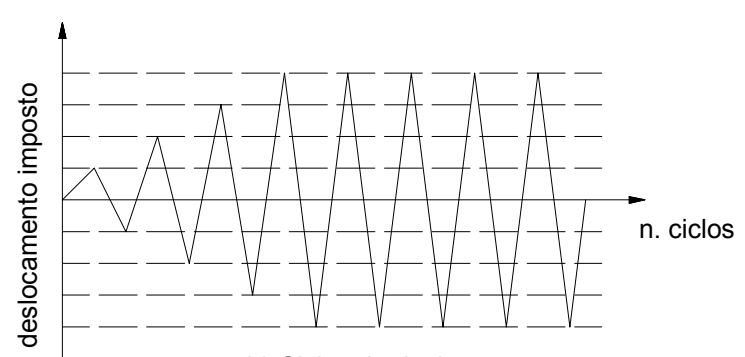

b) Ciclos de deslocamento

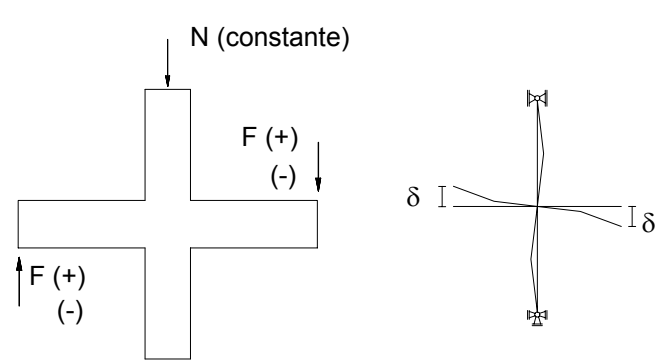

Nós internos

Figura 4.1: Ensaios usuais em ligações viga-pilar isoladas sob ações cíclicas. 
Os resultados típicos desses ensaios são apresentados por meio de diagramas forçadeslocamento no ponto de aplicação da força ou por meio de diagramas momento-rotação. A resposta global da ligação permite avaliar outros aspectos do comportamento da ligação, tais como perda de rigidez, ductilidade e dissipação de energia. A observação da configuração de fissuras na ligação e as medidas de deformações em armaduras estão contidas entre os principais resultados.

Praticamente não foram encontrados estudos experimentais sobre nós de canto submetidos a ações cíclicas, existindo mais trabalhos envolvendo o caso de carregamento monotônico.

A tabela 4.1 contém uma visão geral dos principais trabalhos, relacionados com análises experimentais de ligações viga-pilar de concreto, colocados em ordem cronológica ao longo das últimas décadas.

Tabela 4.1: Principais estudos experimentais em ligações viga-pilar sob ações cíclicas

\begin{tabular}{|c|c|}
\hline PESQUISADORES & CONTRIBUIÇÃO \\
\hline $\begin{array}{l}\text { HANSON \& CONNOR } \\
(1967) \\
\text { Estados Unidos }\end{array}$ & $\begin{array}{l}\text { Um dos primeiros trabalhos abordando as ligações viga-pilar sob ações } \\
\text { cíclicas. Observaram a influência benéfica da armadura transversal disposta } \\
\text { na região do nó quando submetida a ações cíclicas reversas. Mostraram } \\
\text { também que a presença de vigas transversais (elementos perpendiculares } \\
\text { ao plano definido por pilar e viga principais) melhora o desempenho da } \\
\text { ligação, devido à contenção lateral que oferecem. }\end{array}$ \\
\hline $\begin{array}{l}\text { RENTON (1972), } \\
\text { MEGGET (1971), SMITH } \\
\text { (1972) e PARK \& } \\
\text { PAULAY (1973) } \\
\text { Nova Zelândia }\end{array}$ & $\begin{array}{l}\text { Com base em ensaios em ligações viga-pilar de extremidade (nós externos) } \\
\text { submetidas a ações cíclicas alternadas, fizeram algumas constatações } \\
\text { importantes, a saber: } \\
\text { i) A ruína do nó ocorre mesmo em ligações que apresentam taxas de } \\
\text { armadura transversal igual ou superior às fornecidas pela analogia de } \\
\text { treliça clássica, com bielas comprimidas inclinadas à } 45^{\circ} \text {. Segundo os } \\
\text { autores, esse fato aponta para algumas limitações do modelo tradicional de } \\
\text { treliça quando aplicado a esta situação. } \\
\text { ii) A consideração da contribuição de outros mecanismos complementares } \\
\text { na resistência ao cisalhamento não é realista, sugerindo, dessa maneira, } \\
\text { considerar apenas a contribuição da armadura transversal; } \\
\text { iii) A geometria do nó exerce uma grande influência no comportamento da } \\
\text { ligação. Em geral, o desempenho da ligação é inferior quando se têm vigas } \\
\text { de grande altura conectadas a pilares de pequena altura; } \\
\text { iv) As dimensões absolutas do nó também são fatores de influência. } \\
\text { Condições ideais de aderência e ancoragem são mais difíceis de serem } \\
\text { alcançadas em nós de pequenas dimensões; } \\
\text { v) Existe uma influência benéfica da força normal de compressão do pilar } \\
\text { sobre o comportamento da ligação. }\end{array}$ \\
\hline $\begin{array}{l}\text { LEE et al. (1977) } \\
\text { Estados Unidos }\end{array}$ & $\begin{array}{l}\text { Fizeram uma investigação do comportamento de nós de pórtico externos, } \\
\text { cujos resultados serviram para a sugestão de novas recomendações de } \\
\text { projeto para a norma americana em vigor na época. Uma de suas principais } \\
\text { conclusões indicam que a analogia clássica de treliça não é um método } \\
\text { confiável para determinar a contribuição da armadura transversal na } \\
\text { resistência ao cisalhamento de um nó. }\end{array}$ \\
\hline $\begin{array}{l}\text { EHSANI \& WIGHT } \\
(1985) \\
\text { Estados Unidos }\end{array}$ & $\begin{array}{l}\text { Fizeram um estudo experimental sobre ligações viga-pilar de extremidade } \\
\text { submetidas a ações sísmicas. Entre as variáveis estudadas, estavam a taxa } \\
\text { de armadura transversal do nó e a intensidade das tensões de }\end{array}$ \\
\hline
\end{tabular}




\begin{tabular}{|c|c|}
\hline & $\begin{array}{l}\text { cisalhamento no nó, apresentada em função da resistência à compressão } \\
\text { do concreto. Segundo os autores, a perda de rigidez observada nas curvas } \\
\text { do tipo força-deslocamento das ligações ensaiadas é atribuída à } \\
\text { deterioração do concreto na região do nó, ao deslizamento das barras } \\
\text { longitudinais do pilar e ao deslizamento excessivo das barras longitudinais } \\
\text { da viga. }\end{array}$ \\
\hline $\begin{array}{l}\text { PAULTRE et al. (1989) } \\
\text { Canadá }\end{array}$ & $\begin{array}{l}\text { Investigaram o comportamento de ligações viga-pilar com a presença de } \\
\text { laje, submetidas a carregamentos cíclicos alternados. Os resultados dos } \\
\text { ensaios mostraram a importância de considerar a contribuição da armadura } \\
\text { da laje no cálculo da capacidade resistente da viga, bem como a } \\
\text { importância de se dimensionar criteriosamente a região do nó para resistir } \\
\text { aos esforços cisalhantes. }\end{array}$ \\
\hline $\begin{array}{l}\text { LEON (1990) } \\
\text { Estados Unidos }\end{array}$ & $\begin{array}{l}\text { Realizou um estudo que procurou estabelecer uma relação clara entre as } \\
\text { tensões cisalhantes de um nó de pórtico interno com o comprimento de } \\
\text { ancoragem das vigas. A principal variável portanto foi a altura do pilar, o } \\
\text { que possibilitou o emprego de diversos comprimentos de ancoragens. }\end{array}$ \\
\hline $\begin{array}{l}\text { ALAMEDDINE \& } \\
\text { EHSANI (1991) } \\
\text { Estados Unidos }\end{array}$ & $\begin{array}{l}\text { Realizaram um estudo experimental acerca de ligações viga-pilar (nós } \\
\text { externos) empregando concreto de alta resistência. Os parâmetros } \\
\text { variáveis investigados foram a resistência à compressão do concreto, as } \\
\text { tensões de cisalhamento atuantes no nó e a quantidade de armadura } \\
\text { transversal na região do nó. Esse estudo forneceu importantes conclusões } \\
\text { com relação à ductilidade e à resistência ao cisalhamento em ligações de } \\
\text { concreto armado com concreto de alta resistência. }\end{array}$ \\
\hline $\begin{array}{l}\text { JIURU et al. (1992) } \\
\text { China }\end{array}$ & $\begin{array}{l}\text { Descrevem os resultados experimentais em } 12 \text { modelos de ligações viga- } \\
\text { pilar (nós externos e internos) empregando concreto reforçado com fibras. } \\
\text { Os resultados indicaram que a adição de fibras de aço melhora o } \\
\text { desempenho das ligações no que diz respeito à resistência ao cisalhamento } \\
\text { do nó, bem como a ductilidade e a capacidade de dissipação de energia. }\end{array}$ \\
\hline $\begin{array}{l}\text { PANTAZOPOULOU \& } \\
\text { BONACCI (1993) } \\
\text { Canadá }\end{array}$ & $\begin{array}{l}\text { Realizaram uma compilação de dados experimentais provenientes de } \\
\text { ensaios realizados em } 86 \text { modelos físicos de ligações viga-pilar interno (nós } \\
\text { internos) e } 57 \text { modelos de ligações viga-pilar de extremidade (nós } \\
\text { externos). A compilação desses resultados permitiu uma ampla } \\
\text { investigação paramétrica sobre comportamento das ligações. Também } \\
\text { deixaram diversas sugestões aplicáveis ao dimensionamento de nós de } \\
\text { pórtico. }\end{array}$ \\
\hline $\begin{array}{l}\text { RAFFAELLLE \& WIGHT } \\
\text { (1995) } \\
\text { Estados Unidos }\end{array}$ & $\begin{array}{l}\text { O trabalho experimental consistiu em ensaios de ligações viga-pilar } \\
\text { excêntricos, onde o eixo do pilar e o eixo da viga, paralelos entre si, não } \\
\text { pertencem no mesmo plano. Os parâmetros variáveis investigados foram a } \\
\text { geometria da viga e a taxa de armadura longitudinal da viga. Avaliaram } \\
\text { também o efeito da excentricidade sobre a resistência da ligação. }\end{array}$ \\
\hline $\begin{array}{l}\text { SCOTT (1996) } \\
\text { Inglaterra }\end{array}$ & $\begin{array}{l}\text { Investigou a influência da altura da viga, da taxa de armadura de tração da } \\
\text { viga e da força normal do pilar em ligações viga-pilar de extremidade. A } \\
\text { influência desses parâmetros sobre o comportamento da ligação foi } \\
\text { avaliada através de deformações medidas ao longo das barras da armadura } \\
\text { da viga e do pilar. }\end{array}$ \\
\hline $\begin{array}{l}\text { MURTHY et al. (1998) } \\
\text { Índia }\end{array}$ & $\begin{array}{l}\text { Realizaram um estudo experimental sobre a resistência e a ductilidade de } \\
\text { nós viga-pilar submetidos a cargas verticais cíclicas, com dois tipos de aços } \\
\text { de características mecânicas diferentes. A partir desses ensaios, fizeram } \\
\text { também uma avaliação da ductilidade das barras da armadura, as quais } \\
\text { estiveram submetidas à repetição e à inversão de sinal das deformações. }\end{array}$ \\
\hline SCOTT et al. (1999) & Fizeram uma comparação entre os resultados experimentais de ensaios \\
\hline
\end{tabular}




\begin{tabular}{|l|l|}
\hline Inglaterra & $\begin{array}{l}\text { com ligações viga-pilar de extremidade, utilizando concreto de alta } \\
\text { resistência e concreto de resistência usual. A principal variável analisada foi } \\
\text { o número de estribos na região do nó. Entre as principais conclusões está o } \\
\text { fato de que o uso de concreto de alta resistência aumenta a resistência ao } \\
\text { cisalhamento do nó, permitindo o desenvolvimento de maiores deformações } \\
\text { nos estribos posicionados no nó. }\end{array}$ \\
\hline $\begin{array}{l}\text { REAVELEY et al. (2000) } \\
\text { Estados Unidos }\end{array}$ & $\begin{array}{l}\text { Por meio de ensaios em ligações viga-pilar de extremidade, verificaram que } \\
\text { da força normal de compressão no pilar produz um acréscimo na } \\
\text { resistência ao cisalhamento da ligação. Por outro lado, notaram que a } \\
\text { resistência do pilar à força normal de compressão é reduzida à medida que } \\
\text { o nó sofre uma deterioração em sua resistência. }\end{array}$ \\
\hline $\begin{array}{l}\text { ZAID et al. (2000) } \\
\text { Japão }\end{array}$ & $\begin{array}{l}\text { Realizaram um estudo experimental em ligações viga-pilar interno, cuja } \\
\text { principal variável era o detalhamento da armadura. Propuseram um novo } \\
\text { tipo de detalhamento que possibilita à ligação absorver maiores forças } \\
\text { cisalhantes, reduzir as deformações no nó e aumentar a capacidade de } \\
\text { dissipação de energia. }\end{array}$ \\
\hline $\begin{array}{l}\text { KARAYANNIS \& } \\
\text { CHALIORIS (2000) } \\
\text { Grécia }\end{array}$ & $\begin{array}{l}\text { Através de ensaios em 20 ligaçães viga-pilar de extremidade, analisaram a } \\
\text { influência da ação de carregamentos cíclicos sobre a capacidade resistente } \\
\text { das ligações e sobre a degradação de rigidez nas mesmas em função da } \\
\text { idade do concreto. }\end{array}$ \\
\hline
\end{tabular}

Merecem ser citados outros trabalhos importantes que não envolveram ações cíclicas, mas cujos resultados experimentais contribuíram de alguma forma para a compreensão do comportamento mecânico do nó. Entre esses, estão o trabalho de ORTIZ (1993), ORTIZ (1997), MURTHY et al. (1998), entre outros.

\subsection{FATORES QUE INFLUENCIAM O COMPORTAMENTO DA LIGAÇÃO}

A principal dificuldade encontrada na mecânica da ligação consiste na existência de um elevado gradiente de forças que ocorre em uma região de área e geometria relativamente pequena. Além disso, o comportamento da ligação é influenciado por diversas variáveis, as quais podem estar relacionadas com a geometria da ligação, com a intensidade das tensões cisalhantes no nó de pórtico, com a resistência dos materiais constituintes (em particular do concreto), com o confinamento do nó e com o próprio tipo de carregamento atuante na ligação. Além disso, deve-se reconhecer que, por causa das limitações de recursos e de tempo disponível para realização de um grande número de ensaios, muitos pesquisadores se confrontaram com a dificuldade de isolar as variáveis envolvidas.

Portanto, embora se encontrem muitas pesquisas acerca das ligações viga-pilar de concreto armado na bibliografia, nota-se que os avanços têm sido alcançados de forma mais lenta.

Motivados por essas dificuldades, PANTAZOPOULOU \& BONACCI (1993) fizeram uma compilação de resultados experimentais realizados durante o período de quase três décadas, identificando os principais parâmetros que influenciam a resposta estrutural das ligações vigapilar de concreto, tanto em nós internos quanto externos, sem a presença de laje. A maioria dos resultados foi obtida de ensaios realizados nos Estados Unidos, Canadá, Japão e Nova Zelândia. Notaram que a maioria dos ensaios evidenciou a dependência da resistência ao cisalhamento do nó com um certo número de variáveis. Os principais parâmetros variáveis considerados foram: 
- O grau de confinamento no nó;

- A intensidade da força normal no pilar;

- A intensidade das tensões cisalhantes no nó;

- A resistência à compressão do concreto;

- A magnitude das forças de aderência mobilizadas ao longo da armadura da viga que atravessa o interior do nó;

- A presença de vigas transversais.

Os ensaios das ligações da etapa experimental deste trabalho revelaram uma significativa influência da resistência à compressão do concreto sobre a capacidade do nó de pórtico. Os ensaios mostraram também que a taxa de estribos no nó de pórtico, em se tratando de carregamentos cíclicos de elevada intensidade, influência a capacidade resistente e o comportamento global da ligação, em termos de deslocamentos e rotações.

\subsubsection{Aderência aço-concreto}

A transferência das forças da armadura para o concreto é um fenômeno complexo e é altamente influenciado pelo histórico do carregamento. Os fenômenos associados à aderência exercem influência notável sobre o comportamento de um nó de pórtico.

$\mathrm{Na}$ análise estrutural convencional, as ligações viga-pilar são admitidas como rígidas, não havendo separação entre as interfaces dos elementos viga e pilar. Essa hipótese implica em não haver rotação relativa entre viga e pilar.

Entretanto, no campo inelástico, especialmente sob a atuação de carregamentos cíclicos, as hipóteses de ligação rígida e aderência perfeita entre aço e concreto não são mais realistas. BERTERO \& POPOV (1977) mostraram que a hipótese de perfeita aderência entre aço e concreto aproxima-se do comportamento real somente antes do escoamento da armadura.

O caráter cíclico do carregamento induz à progressiva degradação da aderência entre as barras da armadura e o concreto. Além disso, as deformações da armadura atingem valores significativos no escoamento, induzindo a formação de fissuras tanto na viga quanto no nó. Essas fissuras provocam uma rotação relativa excessiva entre viga e pilar, caracterizando a formação de rótula plástica. Logo, a perda da aderência afeta o comportamento global da ligação.

Quando a aderência no nó de pórtico não é adequada para suportar as solicitações dos elementos estruturais que ali concorrem, a ocorrência da ruína do nó propriamente dita será menos provável durante a atuação do carregamento cíclico. Na verdade, todo o mecanismo de transmissão de esforços ao nó de pórtico depende da resistência de aderência. A perda da aderência pode significar o impedimento do total desenvolvimento da capacidade da ligação.

Com relação à questão da aderência sob o efeito de ações cíclicas, tanto unidirecionais (repetidas) quanto alternadas, diversas pesquisas são encontradas na literatura. Entre os trabalhos publicados, podem ser citados os de LARANJEIRAS (1976), TASSIOS (1979), HAWKINS et al. (1982), ELIGEHAUSEN et al. (1983), POPOV (1984), BALÁZS (1991), KOCH \& BALÁZS (1993) e VALLE (1994). Uma ampla descrição do comportamento da aderência sob ações monotônicas e repetidas, incluindo os principais trabalhos relacionados com o assunto, encontram-se em FERNANDES (2000) e CASTRO (2002). 
Merecem destaque os ensaios descritos por POPOV (1984), relacionados com estudos experimentais realizados na Universidade de Berkeley, os quais permitiram investigar a deterioração da aderência em pórticos rígidos e a influência do efeito de diversos parâmetros sobre o comportamento local da curva tensão de aderência-deslizamento. Entre eles, estão a forma de aplicação do carregamento (monotônico e cíclico), a resistência do concreto, o diâmetro e o espaçamento entre as barras e o efeito da força normal do pilar.

Uma breve demonstração da resposta da aderência em nós viga-pilar com o decorrer dos ciclos de carregamento pode ser feita a partir do diagrama tensão de aderência versus deslizamento da figura 4.3, obtido dos ensaios descritos por POPOV (1984) em modelos indicados na figura 4.2. Nesse tipo de ensaio, com carregamento cíclico alternado de elevada intensidade, nota-se claramente a significativa deterioração da aderência nos primeiros ciclos de inversão de carregamento. $O$ dano associado à aderência aumenta gradativamente conforme o número de ciclos aplicados, observando-se nos estágios finais grandes deslizamentos para baixas tensões de aderência.
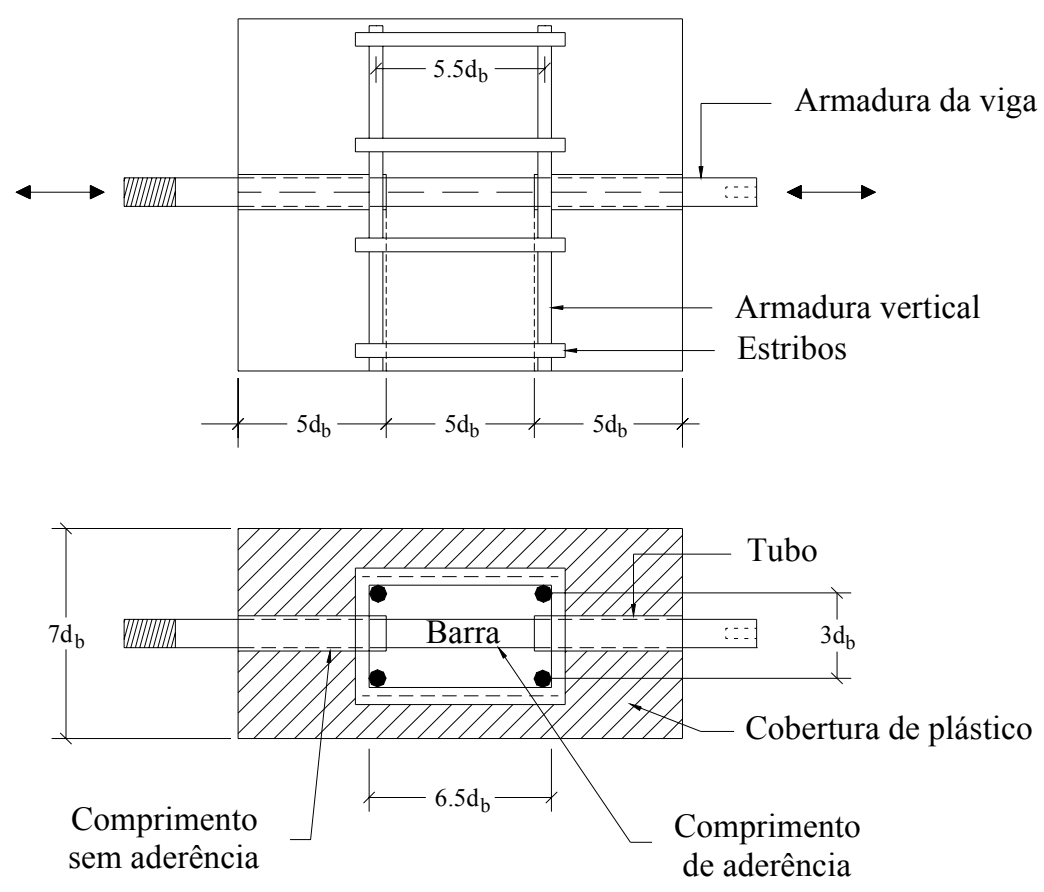

Figura 4.2: Modelo de ensaio para a obtenção da curva tensão de aderência-deslizamento em concreto confinado - POPOV (1984) 


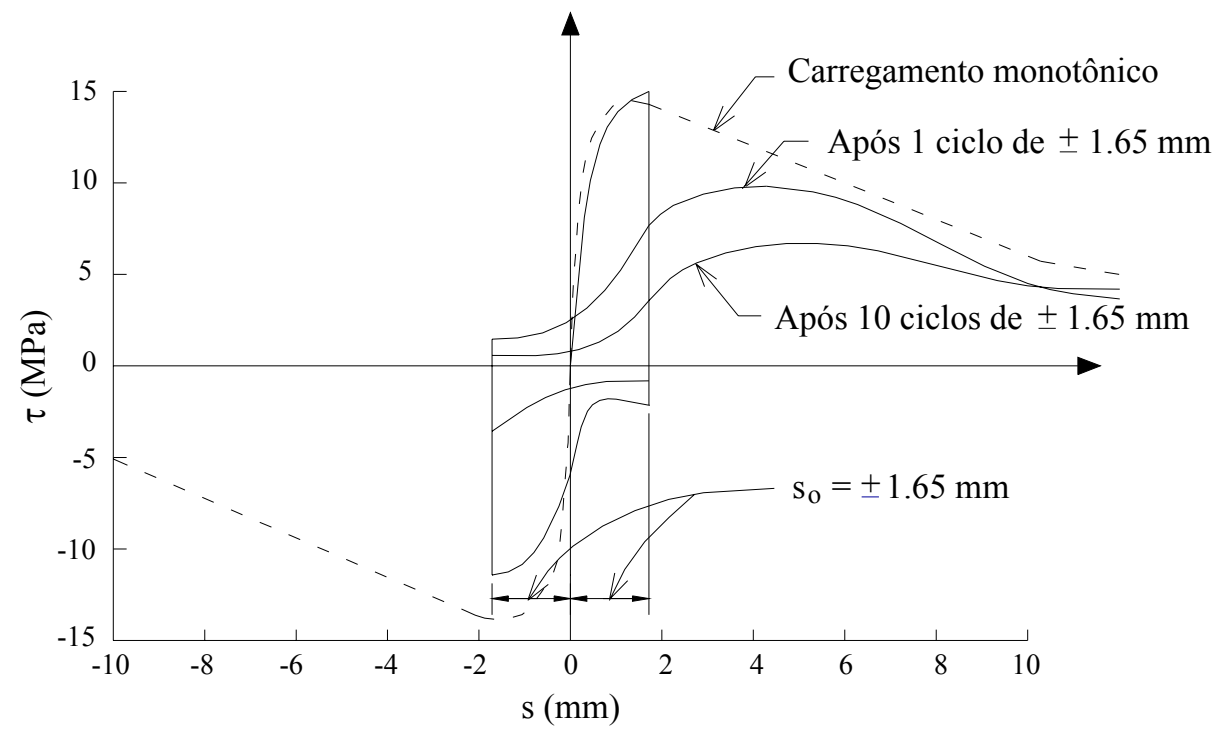

Figura 4.3: Curva experimental tensão de aderência-deslizamento para ação cíclica alternada em barra de $8 \mathrm{~mm}$ - POPOV(1984).

\subsubsection{Taxa de estribos}

A armadura transversal em um nó de pórtico possui dois papéis essenciais: primeiro, de participar diretamente da resistência ao cisalhamento do nó; segundo, de conferir um certo grau de confinamento ao nó, aumentando a resistência do pilar e promovendo uma maior participação do mecanismo de biela diagonal.

Naturalmente, espera-se que um aumento da taxa de estribos possa aumentar a resistência mecânica do nó de pórtico. Entretanto, buscando uma compreensão mais exata a respeito da influência da taxa de estribos, realizou-se uma análise comparativa baseada em resultados experimentais de ligações submetidas a ações cíclicas e monotônicas, encontradas na bibliografia. Os dados experimentais envolvidos nesta análise referem-se a ligações vigapilar de extremidade isoladas, sem a presença de laje, com as armaduras longitudinais superiores das vigas dobradas a 90 graus para o interior do nó.

Para avaliar o efeito dos estribos horizontais em nós sujeitos a ações cíclicas, foram analisados os dados experimentais de 43 ligações, apresentados em PANTAZOPOULOU \& BONACCI (1994) e referentes aos ensaios conduzidos por HANSON \& CONNOR (1967), HANSON (1971), LEE et al. (1977), EHSANI \& WIGHT (1985), ALAMEDDINE \& EHSANI (1991), KAKU \& ASAKUSA (1991) e FUJII \& MORITA (1991). Os dados situam-se em uma faixa de resistência ao escoamento dos estribos entre $250 \mathrm{MPa}$ e $510 \mathrm{MPa}$ e em uma de faixa de resistência à compressão do concreto entre $22 \mathrm{MPa}$ e $93 \mathrm{MPa}$.

No caso de ligações submetidas a carregamentos monotônicos, foram analisados os dados experimentais de 27 ligações, apresentados em VOLLUM \& NEWMAN (1999) e referentes aos ensaios conduzidos por ORTIZ (1997), KORDINA (1984), TAYLOR (1974), SCOTT (1996), SCOTT \& HAMIL (1998) e WILSON (1998).

Usualmente, assume-se que a resistência do nó seja dada pela contribuição da biela diagonal e pela parcela resistente da armadura transversal, admitindo-se o escoamento dos estribos. Tal procedimento é adotado, por exemplo, nos mecanismos de resistência propostos 
por PAULAY \& PRIESTLEY (1992) e ORTIZ (1997). Portanto, força cortante resistente do nó é expressa da seguinte maneira:

$$
\mathrm{V}_{\mathrm{jh}}=\mathrm{V}_{\mathrm{ch}}+\mathrm{A}_{\mathrm{sh}} \mathrm{f}_{\mathrm{yh}}
$$

$\mathrm{Na}$ bibliografia especializada, é usual quantificar a capacidade ao cisalhamento por meio de um coeficiente $\gamma$, levando em conta, inclusive, as dimensões do nó e a resistência à compressão do concreto:

$$
\gamma=\frac{\mathrm{V}_{\mathrm{jh}}}{\mathrm{A}_{\mathrm{j}} \sqrt{\mathrm{f}_{\mathrm{c}}}}
$$

onde

$\mathrm{V}_{\mathrm{jh}}$ é a máxima força cortante horizontal atingida em todo o ensaio;

$A_{j}$ é a área efetiva do nó, determinada, nesta análise, com as recomendações do $\mathrm{ACl} 318$ (1995);

$\mathrm{f}_{\mathrm{c}}$ é a resistência à compressão do concreto em corpos cilíndricos, em MPa.

Para quantificar a máxima contribuição possível da armadura transversal à resistência do nó, utiliza-se o coeficiente SI, conhecido na literatura como stirrup index:

$$
S I=\frac{A_{s h} f_{y h}}{A_{j} \sqrt{f_{c}}}
$$

Dividindo ambas as parcelas da expressão (4.1) por $A_{j} \sqrt{f_{c}}$ tem-se:

$$
\frac{V_{j h}}{A_{j} \sqrt{f_{c}}}=\frac{V_{c h}}{A_{j} \sqrt{f_{c}}}+\frac{A_{s h} f_{y h}}{A_{j} \sqrt{f_{c}}}
$$

podendo ser reescrita, com base nas expressões (4.2) e (4.3) por:

$$
\gamma=\mathrm{k}+\mathrm{SI}
$$

sendo k uma constante que pode ser entendida como a parcela resistente do nó sem estribos.

A expressão (4.4), proveniente da hipótese de cálculo indicada pela expressão (4.1), denota que o acréscimo de resistência ao cisalhamento é igual ao acréscimo da resistência à tração promovida pelos estribos, indicando, aparentemente, uma relação linear entre as duas variáveis.

Para avaliar a influência dos estribos sobre a resistência do nó, agora com base em resultados experimentais, monta-se um gráfico $\mathrm{SI} \times \gamma$, conforme a figura 4.4 referente aos ensaios com carregamentos cíclicos: 


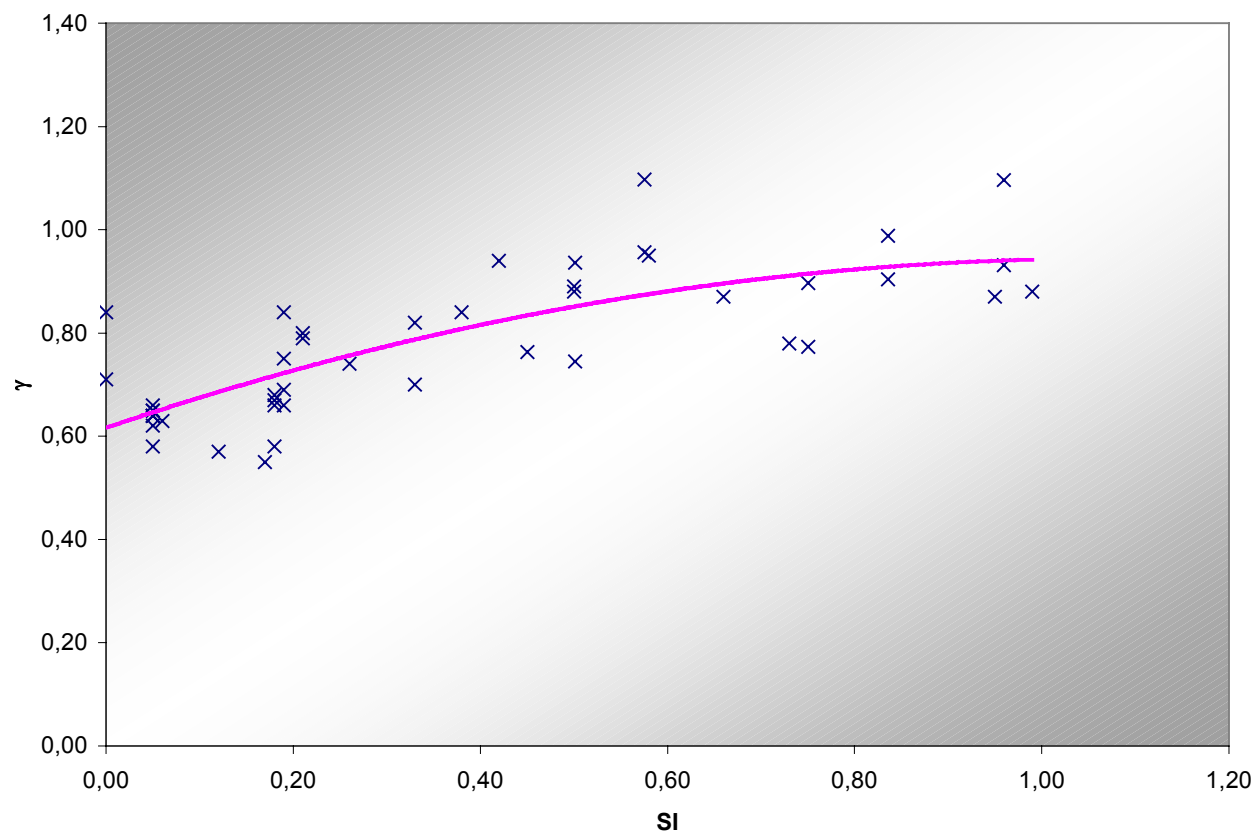

Figura 4.4: Influência dos estribos horizontais sobre a resistência do nó - Ações cíclicas

Pela figura 4.4, percebe-se que a resistência do nó realmente cresce com o aumento da força resistente promovida pelos estribos, porém de forma não-linear e menos acentuada que a esperada com a aplicação da expressão (4.1).

A figura 4.5 contém o gráfico $\mathrm{SI} \times \gamma$ para as ligações ensaiadas com carregamento monotônico:

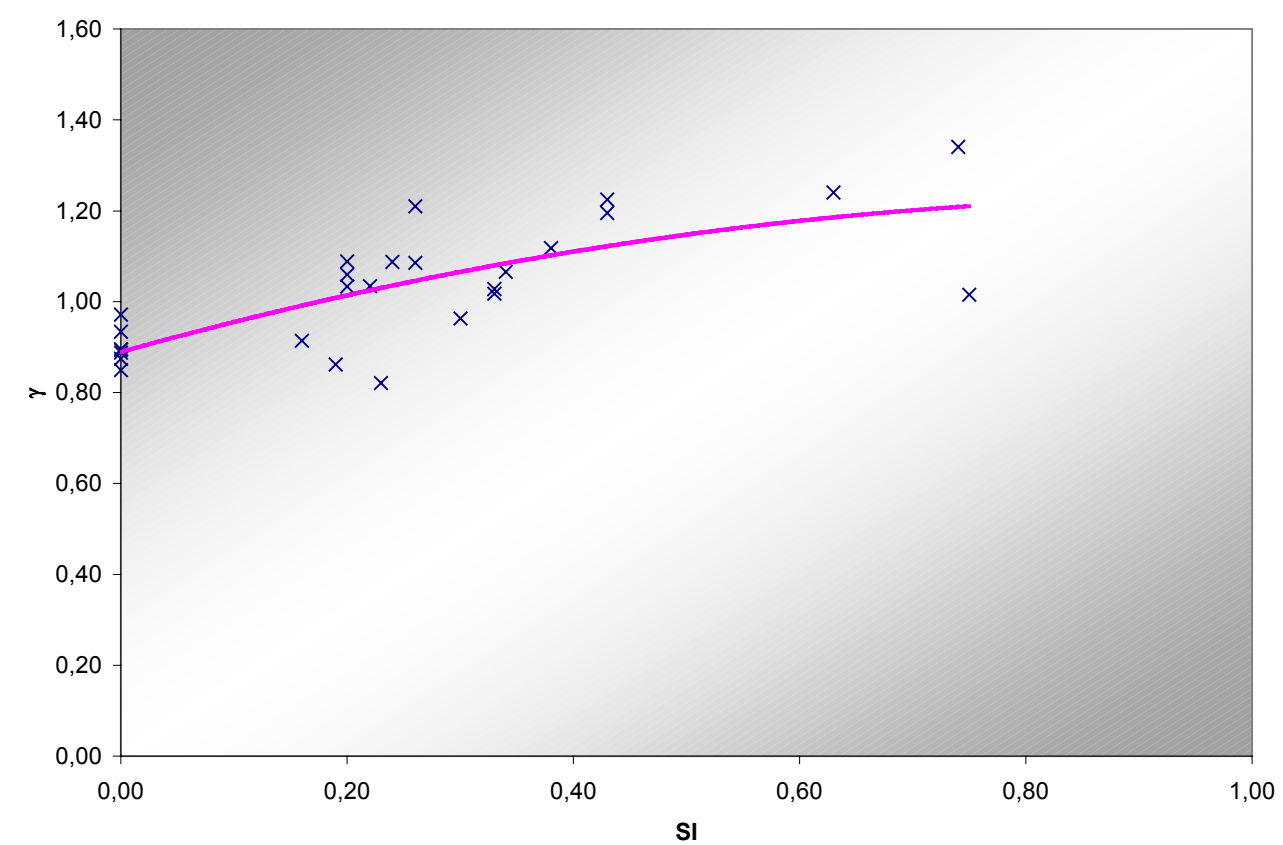

Figura 4.5: Influência dos estribos horizontais sobre a resistência do nó - Ações monotônicas 
Pela tendência observada na figura 4.5 , percebe-se novamente o crescimento da resistência do nó com o acréscimo de estribos, embora tal acréscimo não seja diretamente proporcional ao acréscimo força resistente nos estribos $A_{s h} f_{y h}$.

Nos ensaios realizados neste trabalho de doutorado, confirmou-se a tendência de que o aumento da área de estribos promove o aumento da resistência do nó de pórtico. Além disso, observou-se que a área de estribos influencia o panorama de fissuração e os deslocamentos globais da ligação, especialmente para intensidades elevadas de solicitação.

\subsubsection{Força normal no pilar}

Segundo a formulação algébrica dos mecanismos propostos pelo modelo de PAULAY \& PRIESTLEY (1992), abordado no item 5.2.1, a força normal no pilar exerce um efeito benéfico, tanto aos nós externos quanto aos internos, frente à força cortante horizontal. No modelo de HWANG \& LEE (1999), abordado no item 5.2.3, a força normal também exerce influência na resistência do nó. Na realidade, o que ocorre é o seguinte: com o aumento da intensidade da força normal, a altura da zona comprimida do pilar aumenta e, conseqüentemente, a área da biela diagonal, a qual constitui um dos parâmetros de entrada desse modelo. Esse fato também se aplica ao modelo de PAULAY \& PRIESTLEY (1992).

Entretanto, observou-se, ao analisar a bibliografia especializada, que o efeito da força normal na resistência ao cisalhamento e em outros aspectos do comportamento mecânico do nó é ainda um ponto pouco esclarecido entre os pesquisadores.

$\mathrm{Na}$ tentativa de perceber a real a influência da força normal, foram analisados resultados experimentais de 48 ligações viga-pilar de extremidade, no caso de ações cíclicas, referentes aos ensaios de HANSON \& CONNOR (1967), HANSON (1971), LEE et al. (1977), EHSANI \& WIGHT (1985), ALAMEDDINE \& EHSANI (1991), KAKU \& ASAKUSA (1991) e FUJII \& MORITA (1991). No caso de ações monotônicas, foram analisados os resultados de 28 ligações viga-pilar de extremidade ensaiadas por ORTIZ (1997), KORDINA (1984), TAYLOR (1974), SCOTT (1996), SCOTT \& HAMIL (1998) e WILSON (1998).

Em princípio, um gráfico que permitiria avaliar a influência da força normal seria a curva $\gamma$ versus $v$, sendo $v$ a força adimensional no pilar. Entretanto, conforme já apresentado, a resistência do nó também depende do potencial resistente dos estribos, representado pelo índice SI. Dessa forma, a fim de minimizar a possível interação entre os parâmetros, decidiu-se construir uma curva com o eixo das abscissas contendo os valores de $v$ e com o eixo das ordenadas contendo os valores de um coeficiente $\beta$, definido por:

$\beta=\frac{\gamma}{(b+m S I)}=\frac{V_{j h}}{A_{j} \sqrt{f_{c}}(b+m S I)}$

admitindo que o coeficiente $\gamma$ possa ser representado, de forma simplificada, por uma reta $\gamma=b+m S I$, cujos termos $b$ e $m$ são obtidos por regressão linear com o método dos mínimos quadrados. A figura 4.6 contém o gráfico $\beta$ versus $v$ dos resultados experimentais com ações cíclicas. 


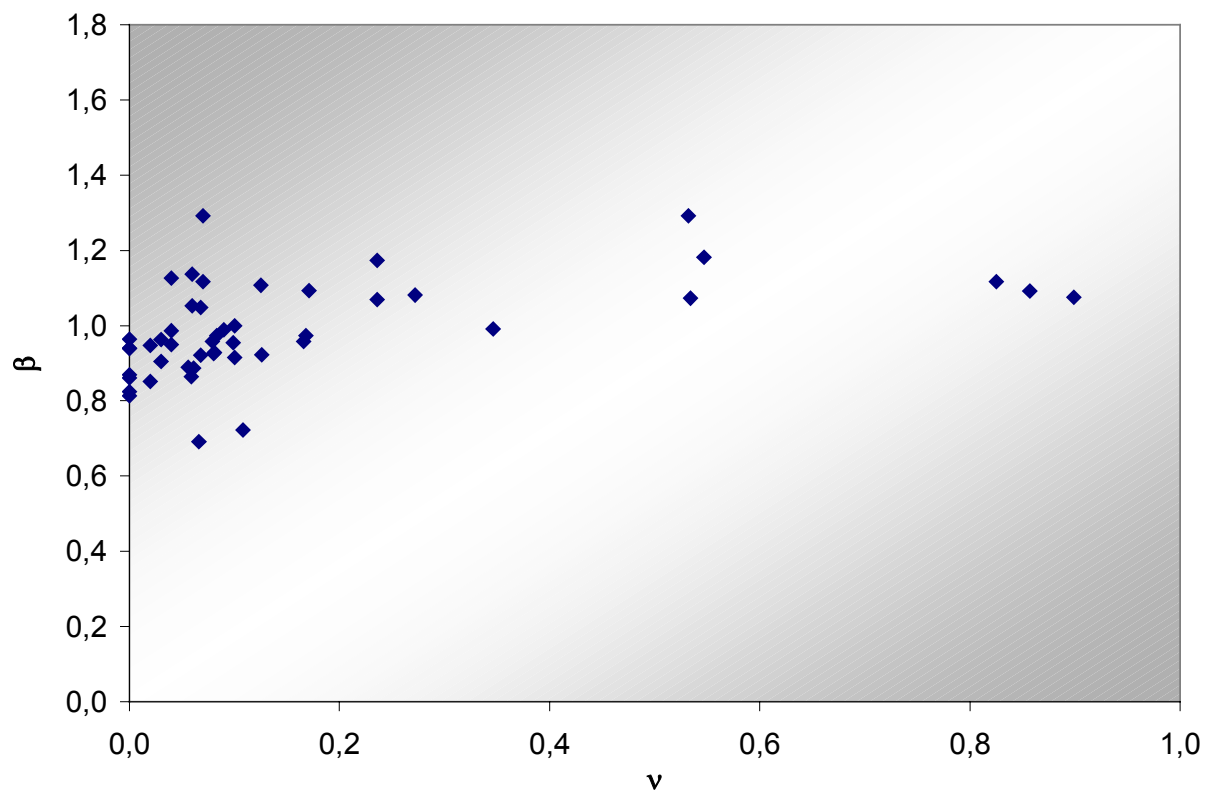

Figura 4.6: Influência da força normal sobre a resistência ao cisalhamento do nó - ações cíclicas

Da mesma forma, construiu-se o gráfico da figura $4.7 \mathrm{com}$ os dados experimentais das ligações submetidas a ações monotônicas.

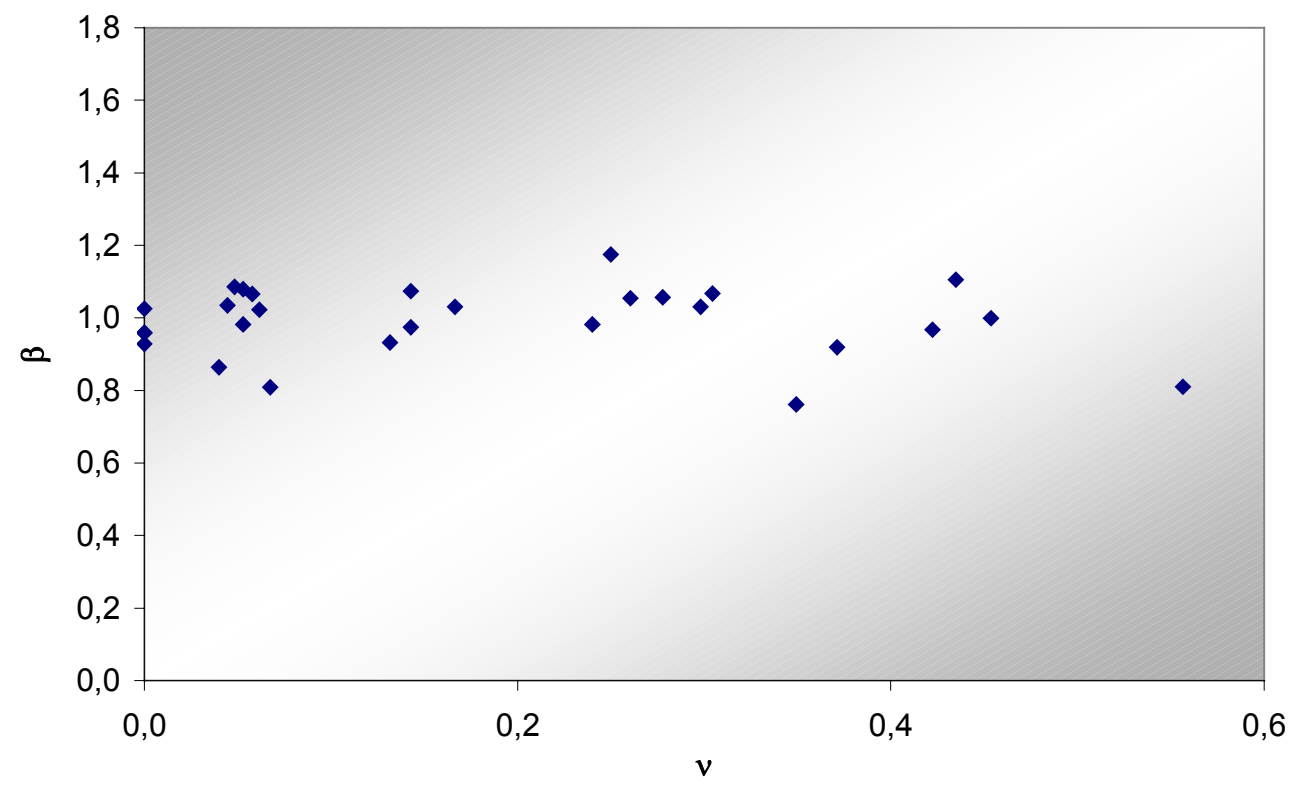

Figura 4.7: Influência da força normal sobre a resistência ao cisalhamento do nó - ações monotônicas

Analisando-se os gráficos das figuras 4.6 e 4.7, percebe-se grande dispersão dos dados, não existindo uma evidente correlação entre a força normal e a resistência cisalhante do 
nó, tanto no caso de ações cíclicas quanto monotônicas. Nos nós internos, percebe-se a mesma falta de correlação entre as duas variáveis.

Com relação a não-unanimidade da influência da força normal, são destacadas, a seguir, observações feitas por alguns pesquisadores.

- No caso de nós externos sob ações monotônicas, VOLUMN \& NEWMAN (1999) citam que a resistência ao cisalhamento pode ser considerada praticamente independente da força normal, exceto quando ocorre a formação de rótula no pilar superior. BAKIR \& BODUROGLU (2002) chegam a uma conclusão similar, citando, entretanto, que a intensidade da força normal pode interferir no modo de colapso da ligação.

- No caso de nós internos com ações cíclicas, KITAYAMA et al. (1991) afirmam que a força normal, embora não pareça exercer influência na resistência ao cisalhamento, pode acelerar o colapso da biela diagonal de concreto para elevadas forças normais, após o escoamento das armaduras longitudinais das vigas. PANTAZOPOULOU \& BONACCI (1994) citam que, provavelmente, a força normal tenha mais influência sobre a deformabilidade da ligação do que sobre a resistência do nó.

- Por outro lado, REAVELEY et al. (2000) concluíram, baseados em ensaio de ligações viga-pilar de extremidade submetidas a ações cíclicas, que o coeficiente $\gamma$ (indicativo da resistência do nó) cresce com o aumento da força normal adimensional v. A faixa de valores de $v$ analisada esteve compreendida entre 0,10 e 0,25.

- PARK (1997) considera o efeito da normal em nós de pórtico sem armadura transversal por meio de um coeficiente $\mathrm{k}$, conforme a seguinte expressão proposta para a determinação da força cortante resistente:

$$
V=k \sqrt{f_{c}} \sqrt{1+\frac{N}{A_{p} k \sqrt{f_{c}}}} b_{j} h_{p}
$$

onde $A_{p}$ é a área da seção do pilar e $k$ igual a 0,4 em nós externos com barras longitudinais da viga terminadas em ganchos.

Vale lembrar que as normas que abordam o dimensionamento de nós de pórtico não incluem o efeito da força normal no cálculo da resistência ao cisalhamento.

Logo, entende-se que esta variável deva ser melhor investigada futuramente a fim de obter informações mais conclusivas.

\section{Observações acerca da análise paramétrica}

Deve-se reconhecer a existência de uma razoável dispersão dos dados experimentais observada nos gráficos das figuras 4.4 à 4.7. Tal dispersão pode ser atribuída ao seguinte fato: a resistência ao cisalhamento depende de um grande número de variáveis. Assim, embora as variáveis escolhidas tenham sido analisadas isoladamente, a resposta do nó é suscetível a interferência de outras variáveis.

Ainda que as conclusões obtidas com esta análise não possam ser encaradas como definitivas, acredita-se que tais serviram para aprimorar o entendimento acerca do complexo comportamento dos nós de pórtico.

\subsubsection{Tipo de carregamento atuante}


Com relação ao tipo de carregamento atuante, os nós estão sujeitos a ações que podem variar segundo o sentido, intensidade e reversibilidade. Este último aspecto é de interesse especial para o trabalho, devido à ênfase nas ações de natureza cíclica.

Sabe-se de antemão que, em se tratando de carregamentos cíclicos, tanto o repetido quanto o alternado, a evolução da danificação é evidenciada pela crescente microfissuração na estrutura. Os principais efeitos associados à aplicação de cargas cíclicas no concreto são a perda da rigidez do material e o aparecimento de deformações permanentes, decorrentes da evolução de microfissuras. De fato, o concreto, quando submetido a solicitações cíclicas, exibe um comportamento mais complexo quando comparado ao caso de carregamento monotônico.

O comportamento do aço sob carregamentos cíclicos interessa sob o ponto de vista da fadiga das armaduras, e depende de uma série de fatores, tais como a presença ou não de nervuras, diâmetro das barras, existência de dobramento nas barras e emendas por traspasse.

Os resultados obtidos na etapa experimental nesta pesquisa de doutorado revelaram que o aumento do número de ciclos de carregamento, para uma mesma amplitude de força, produz uma aumento das deformações nos estribos (maior participação da armadura transversal) e um aumento dos deslocamentos globais na ligação, como conseqüência da deterioração mecânica gradativa do concreto.

\subsubsection{Resistência à compressão do concreto}

A resistência do nó frente a força cortante cresce com o aumento da resistência à compressão do concreto. A maioria dos pesquisadores e algumas das principais normas de cálculo assumem que esse crescimento seja proporcional à raiz quadrada da resistência à compressão. Outras normas porém consideram a resistência ao cisalhamento simplesmente proporcional à resistência do concreto à compressão.

As análises feitas nesta pesquisa, com base nos modelos teóricos que representam nós externos e com base nos resultados obtidos na etapa experimental, permitem afirmar que a resistência do nó de pórtico é muito afetada pela resistência à compressão do concreto, sendo esta, em muitos casos, mais determinante que a influência dos estribos.

\subsubsection{Dimensões do nó: relação entre as alturas das seções da viga e do pilar}

A relação entre as alturas da seção do pilar e da viga exerce uma influência direta no comportamento do nó de pórtico. Nós de pórtico com alturas de viga significativamente maiores que as alturas do pilar possuem um comportamento menos favorável frente a ações cíclicas, em particular frente às de origem sísmica. Se fosse este o caso, sob uma ação cíclica intensa, rótulas plásticas provavelmente se desenvolveriam nos pilares antes que nas vigas, comportamento indesejável na filosofia usual de projeto. Por esse motivo, a norma americana ACI 318 (1995) estabelece que a soma dos momentos resistentes nominais das seções dos pilares, localizadas imediatamente acima e abaixo da viga, seja maior que 6/5 da soma dos momentos resistentes nominais das seções da viga que chegam no pilar. Evidentemente, tal recomendação está ligada à altura dos elementos estruturais. 


\subsubsection{Outros fatores}

Além dos fatores já mencionados, outras variáveis podem influenciar o comportamento dos nós de pórtico, tais como a presença da laje, de vigas transversais e questões referentes ao detalhamento das armaduras, como a forma de ancoragem das barras da viga, o raio de dobra dessas barras e o diâmetro das barras longitudinais que atravessam o nó.

Uma análise da presença da laje nos ensaios com ligações submetidas a ações cíclicas pode ser encontrada em PAULTRE et al. (1989). A influência das demais variáveis citadas neste item podem ser identificadas nas análises paramétricas de PANTAZOPOULOU \& BONACCI (1994) e BAKIR \& BODUROGLU (2002), os quais se basearam em resultados experimentais da bibliografia, tanto sobre carregamentos cíclicos quanto monotônicos. 


\subsection{INTRODUÇÃO}

Com relação aos modelos teóricos que representam o comportamento dos nós e das ligações viga-pilar de concreto armado, alguns trabalhos foram encontrados na literatura, embora em número menor se comparados com as investigações experimentais.

Os modelos teóricos empregados para as ligações são distinguidos não apenas conceitualmente, mas também pelos objetivos a que se destinam.

Os modelos que procuram analisar a distribuição de forças e de tensões na região nodal são postulados por observações experimentais ou de idealizações do fluxo de tensões, tais como os modelos de biela e tirante, ou ainda por meio de elementos bidimensionais que consideram as propriedades do nó, utilizando relações constitutivas para os materiais e variáveis cinemáticas apropriadas. Por conveniência de distinção, estes modelos são denominados neste trabalho de modelos de análise local.

Os modelos de biela e tirante são modelos bem conhecidos na representação do campo de tensões nos elementos estruturais de concreto, em regiões descontínuas, como o caso dos nós de pórticos. Entretanto, poucas aplicações desses modelos foram encontradas na literatura para representar os nós, principalmente no caso de carregamento cíclico. As aplicações desses modelos restringem-se a auxiliar o detalhamento das armaduras e a determinar a capacidade resistente dos nós.

A complexidade da mecânica da ligação, em princípio, pode motivar a utilização de modelos numéricos mais sofisticados e com maior número de discretização, tais como modelos que utilizam elementos bidimensionais ou como os que se propõem a avaliar separadamente os efeitos não-lineares e inelásticos envolvidos na ligação. No entanto, o considerável trabalho computacional envolvido na análise e a dificuldade de empregá-los em estruturas inteiras de pórtico ainda tornam a aplicação desses modelos pouco prática. Na realidade, tais modelos tornam-se menos interessantes quando o objetivo das análises limita-se ao comportamento global.

Por outro lado, podem-se citar os modelos unidimensionais para pórticos planos, os quais se caracterizam pela idealização relativamente simples da estrutura e pelo número reduzido de graus de liberdade globais. Tais modelos procuram avaliar os efeitos não-lineares ocorridos na ligação sobre a resposta global da estrutura, por meio de rotações inelásticas na interface viga-pilar ou extremidades dos elementos. Na literatura, são conhecidos como modelos de plasticidade concentrada, os quais fazem parte de um grupo de modelos denominados simplificados. Esses tipos de modelos são denominados, neste texto, de modelos de análise global. 


\subsection{MODELOS DE ANÁLISE LOCAL}

Neste item serão apresentados os modelos resistentes de nós de pórtico propostos por PAULAY \& PRIESTLEY (1992), ORTIZ (1997) e HWANG \& LEE (1999). Os três modelos permitem o dimensionamento de armaduras na região do nó, porém diferem entre si pelas hipóteses adotadas e pela formulação empregada nos cálculos.

\subsubsection{PAULAY \& PRIESTLEY (1992)}

PAULAY \& PRIESTLEY (1992) propõem que a resistência ao cisalhamento do nó seja composta pela contribuição de duas parcelas: uma parcela relativa ao concreto, promovida pela biela diagonal comprimida, e a outra relativa à armadura transversal. Assumem algumas hipóteses de cálculo com relação à transferência de esforços, as quais permitem determinar a área de estribos horizontais na região nodal.

Embora a preocupação estivesse voltada para as ações cíclicas reversíveis, a formulação proposta pelos autores para o cálculo da armadura transversal em nós de pórtico pode nortear o dimensionamento sob ações monotônicas, como no caso dos nós externos.

Algumas expressões apresentadas originalmente pelos autores foram novamente deduzidas e reescritas, ficando isentas de simplificações adicionais que não são comentadas neste trabalho.

\section{Nós externos:}

Segue-se a nomenclatura utilizada no equacionamento deste item:

T e T' são as resultantes da armadura longitudinal de tração das vigas;

$\mathrm{C}_{\mathrm{s}}$ e $\mathrm{C}_{\mathrm{s}}^{\prime}$ são as resultantes da armadura longitudinal de compressão das vigas;

$\mathrm{C}_{\mathrm{c}}$ e $\mathrm{C}_{\mathrm{c}}$ são as resultantes das tensões de compressão no concreto nas seções das vigas;

$V_{p}$ é a força cortante atuante no pilar;

$\mathrm{N}$ é a força normal de compressão no pilar;

$A_{c p}$ é a área bruta da seção do pilar;

$A_{s t}$ é a área da armadura longitudinal de tração da viga;

$A_{s c}$ e $A_{s c}^{\prime}$ são as áreas da armadura longitudinal de compressão das vigas;

$A_{s h}$ é a área total de estribos horizontais necessários no nó;

$x_{p}$ é a altura da zona comprimida do pilar;

$h_{p}$ é a altura da seção do pilar;

$\mathrm{u}_{0}$ é o fluxo de cisalhamento produzido pela transmissão das forças de compressão da armadura da viga ao interior do nó por aderência;

$\mathrm{f}_{\mathrm{c}}$ é a resistência à compressão do concreto;

$f_{y}$ é a resistência ao escoamento do aço para as armaduras principais de vigas e pilares; 
$f_{y h}$ é a resistência ao escoamento do aço para os estribos horizontais do nó.
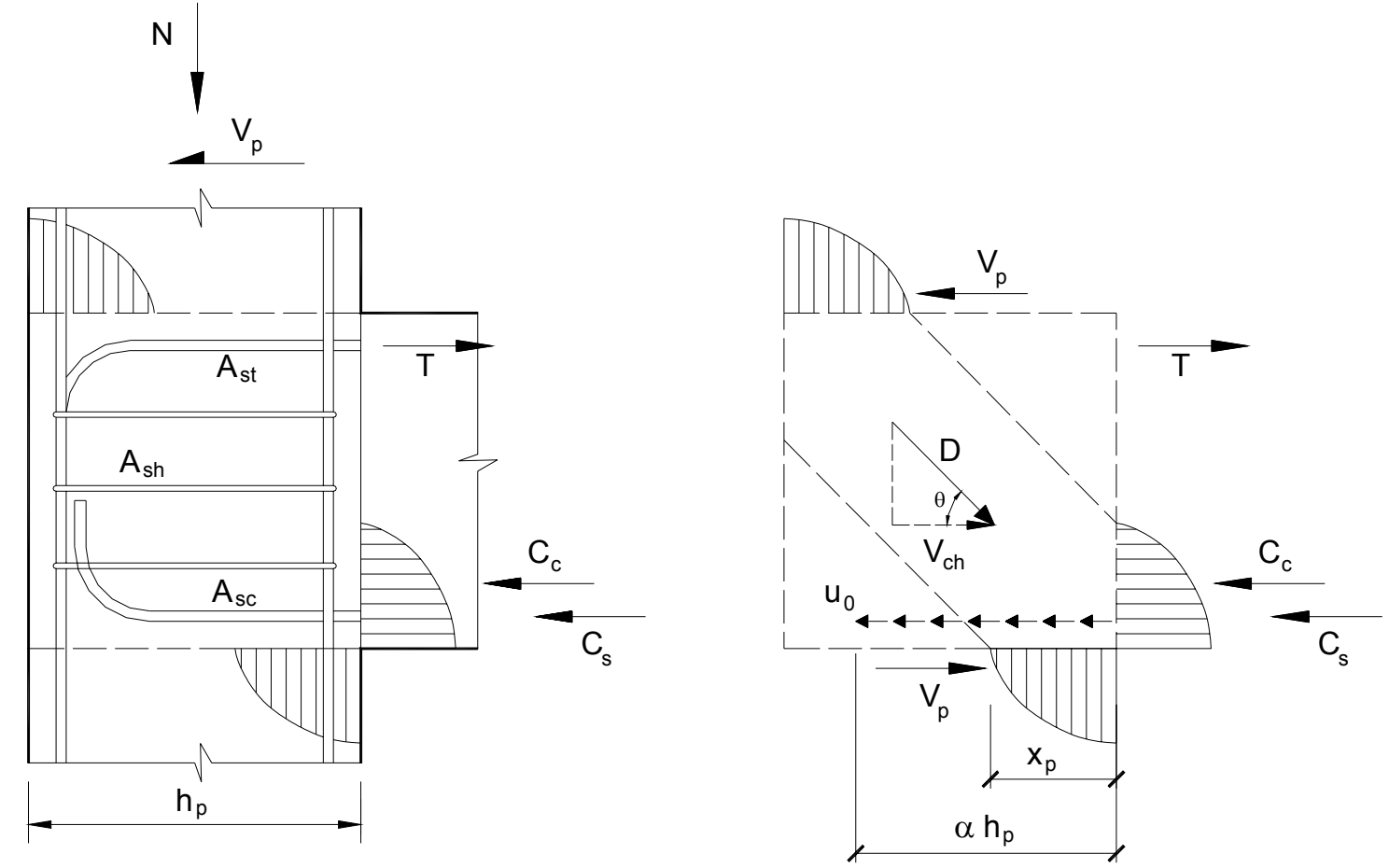

Figura 5.1: Ações em nós de pórtico externos

Com base no esquema de tensões internas e respectivas resultantes em nós de pórtico externos, ilustrado na figura 5.1, obtém-se, por equilíbrio de forças, a seguinte expressão para calcular a força cortante horizontal atuante no nó:

$\mathrm{V}_{\mathrm{jh}}=\mathrm{T}-\mathrm{V}_{\mathrm{p}}$

$O$ valor desta força cortante é a soma da contribuição do concreto $V_{c h}$ e da contribuição da armadura (estribos horizontais) $\mathrm{V}_{\mathrm{sh}}$ :

$\mathrm{V}_{\mathrm{jh}}=\mathrm{V}_{\mathrm{ch}}+\mathrm{V}_{\mathrm{sh}}$

A contribuição de resistência do concreto pode ser deduzida por meio do equilíbrio de forças no volume de concreto definido pela interseção da biela comprimida com as zonas de compressão da viga e do pilar (figura 5.2):

$\mathrm{V}_{\mathrm{ch}}=\mathrm{C}_{\mathrm{c}}+\Delta \mathrm{T}_{\mathrm{c}}-\mathrm{V}_{\mathrm{p}}$

onde $\Delta \mathrm{T}_{\mathrm{c}}$ é a parcela da resultante da armadura comprimida $\mathrm{C}_{\mathrm{s}}$ a ser transmitida à biela comprimida, com $\Delta \mathrm{T}_{\mathrm{c}}<\mathrm{C}_{\mathrm{s}}$. Esta hipótese justifica-se pelo fato de os ganchos da armadura comprimida não serem totalmente eficientes na transmissão das resultantes de compressão 
para o interior do nó ou da biela. Em outras palavras, $\Delta T_{c}$ representa a força que pode ser efetivamente transmitida à biela diagonal, por aderência, na zona comprimida do pilar $x_{p}$.

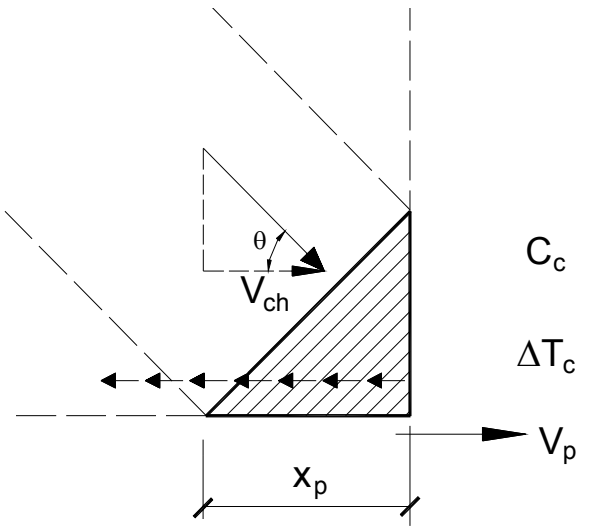

Figura 5.2: Equilíbrio de forças para o cálculo de $\bigvee_{c h}$

O fluxo de cisalhamento, ou a força total a ser ancorada no nó, por unidade de comprimento, é dada por:

$\mathrm{u}_{0}=\frac{\mathrm{C}_{\mathrm{s}}}{\alpha \mathrm{h}_{\mathrm{p}}}$

onde

$\alpha h_{p}$ é o comprimento de ancoragem efetivo, com $\alpha<1$ em virtude da presença dos ganchos.

Os autores propõem o valor de $\alpha$ igual à 0,7 .

Admite-se que a transferência das forças de aderência à biela comprimida ocorre efetivamente em apenas $80 \%$ da zona comprimida $x_{p}$ do pilar. Dessa forma,

$\Delta \mathrm{T}_{\mathrm{c}}=\mathrm{u}_{0}\left(0,8 \mathrm{x}_{\mathrm{p}}\right)$

Com a expressão (5.4), obtém-se $\Delta \mathrm{T}_{\mathrm{c}}$ por:

$\Delta T_{c}=\frac{C_{s}}{\alpha h_{p}} 0,8 x_{p}$

Calcula-se a parcela de resistência à força cortante relativa ao concreto $V_{c h}$ :

$V_{c h}=C_{c}+\frac{C_{s}}{\alpha h_{p}} 0,8 x_{p}-V_{p}$

De acordo com as expressões (5.2) e (5.7), tem-se que: 
$V_{s h}=V_{j h}-V_{c h}=T-V_{p}-\left(C_{c}+\frac{C_{s}}{\alpha h_{p}} 0,8 x_{p}-V_{p}\right)=T-C_{c}-\frac{C_{s}}{\alpha h_{p}} 0,8 x_{p}$

Sabendo que em vigas $C_{s}=T-C_{c}$ e substituindo este valor em (5.8), pode-se escrever que:

$\mathrm{V}_{\mathrm{sh}}=\mathrm{C}_{\mathrm{s}}\left(1-\frac{0,8 \mathrm{x}_{\mathrm{p}}}{\alpha \mathrm{h}_{\mathrm{p}}}\right)$

Finalmente, a área de estribos horizontais necessários é determinada por:

$A_{s h}=\frac{V_{s h}}{f_{y h}}=\frac{C_{s}}{f_{y h}}\left(1-\frac{0,8 x_{p}}{\alpha h_{p}}\right)$

As expressões (5.9) e (5.10) podem ser reescritas considerando-se que a altura da zona comprimida do pilar é razoavelmente estimada por meio da seguinte aproximação:

$x_{p}=\left(0,25+\frac{0,85 N}{f_{c} A_{c p}}\right) \times h_{p} \quad$ válida para $\frac{N}{f_{c} A_{c p}}>0,1$

Substituindo o valor de $x_{p}$ nas expressões (5.9) e (5.10) e adotando o valor sugerido de $\alpha=0,7$, obtém-se que:

$V_{s h}=C_{s}\left(0,7-\frac{N}{f_{c} A_{c p}}\right)$

$A_{s h}=\frac{V_{s h}}{f_{y h}}=\frac{C_{s}}{f_{y h}}\left(0,7-\frac{N}{f_{c} A_{c p}}\right)$

De acordo com o modelo de PAULAY \& PRIESTLEY (1992), tanto na expressão (5.10) quanto na expressão (5.13), percebe-se que a força normal do pilar influencia o comportamento do nó, uma vez que o aumento da intensidade da normal reduz a quantidade de estribos necessários ao nó de pórtico.

\section{Nós internos:}

A formulação é análoga à apresentada para os nós externos. De acordo com a figura 5.3, a força cortante horizontal atuante no nó interno pode ser expressa por: 

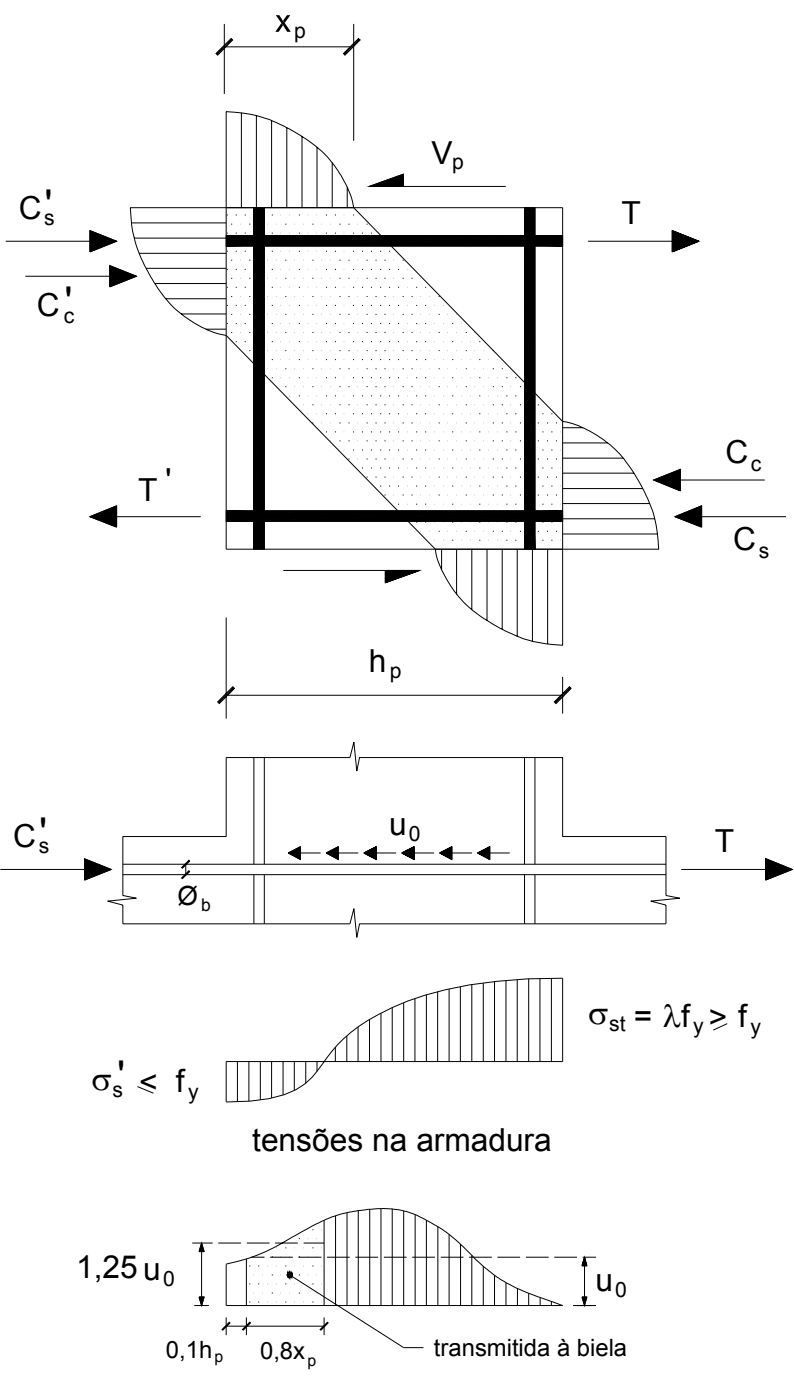

forças de aderência (por unid. comp.)

Figura 5.3: Ações em nós de pórtico internos.

$\mathrm{V}_{\mathrm{jh}}=\mathrm{T}+\mathrm{C}_{\mathrm{c}}^{\prime}+\mathrm{C}_{\mathrm{s}}^{\prime}-\mathrm{V}_{\mathrm{p}}$

Em vigas, pode-se escrever que $\mathrm{T}^{\prime}=\mathrm{C}_{\mathrm{c}}^{\prime}+\mathrm{C}_{\mathrm{s}}$. Logo:

$\mathrm{V}_{\mathrm{jh}}=\mathrm{T}^{\prime}+\mathrm{T}^{\prime}-\mathrm{V}_{\mathrm{p}}$

Novamente, considerando as contribuições do concreto e da armadura transversal,

$\mathrm{V}_{\mathrm{jh}}=\mathrm{V}_{\mathrm{ch}}+\mathrm{V}_{\mathrm{sh}}$

De maneira similar à expressão (5.3), a parcela de resistência associada ao concreto pode ser expressa por: 
$\mathrm{V}_{\mathrm{ch}}=\mathrm{C}_{\mathrm{c}}^{\prime}+\Delta \mathrm{T}_{\mathrm{c}}^{\prime}-\mathrm{V}_{\mathrm{p}}$

A força $\Delta \mathrm{T}_{\mathrm{c}}^{\prime}$ consiste na parcela da resultante $\mathrm{C}_{\mathrm{s}}^{\prime}$ da armadura comprimida da viga que é transmitida à biela, podendo ser escrita em função do fluxo de cisalhamento $\mathrm{u}_{0}$. Conforme a distribuição de esforços ilustrada na figura 5.3, tem-se que:

$\mathrm{u}_{0}=\frac{\mathrm{T}+\mathrm{C}_{\mathrm{s}}}{\mathrm{h}_{\mathrm{p}}}$

Quando as ações cíclicas são de elevada intensidade, os autores propõem as condições de ancoragem no interior do nó indicada na figura 5.3. Nessas condições, admite-se que a armadura de tração da viga possa alcançar o encruamento, havendo degradação de aderência e deslizamento das barras. Outras duas hipóteses adicionais são estabelecidas, a saber:

a) Assume-se que as tensões de aderência não se desenvolvem em uma distância (ou em um cobrimento) correspondente à $0,1 \mathrm{~h}_{\mathrm{p}}$;

b) O valor do fluxo de cisalhamento - ou forças de aderência por unidade de comprimento - na porção comprimida do pilar corresponde a 1,25 vezes o valor médio $u_{0}$. Admitese que a distância efetiva para a transmissão dessas forças à biela diagonal seja igual a $0,8 x_{p}$.

Com essas hipóteses assumidas,

$\Delta \mathrm{T}_{\mathrm{c}}^{\prime}=\left(1,25 \mathrm{u}_{0}\right)\left(0,8 \mathrm{x}_{\mathrm{p}}\right)=\mathrm{u}_{0} \mathrm{x}_{\mathrm{p}}=\left(\frac{\mathrm{T}+\mathrm{C}_{\mathrm{s}}^{\prime}}{\mathrm{h}_{\mathrm{p}}}\right) \mathrm{x}_{\mathrm{p}}$

Da expressão (5.16),

$V_{c h}=C_{c}^{\prime}+\left(\frac{T+C_{s}^{\prime}}{h_{p}}\right) x_{p}-V_{p}$

A partir das expressões (5.15) e (5.18), determina-se a contribuição dos estribos $V_{\text {sh }}$ :

$$
\begin{aligned}
& T+T^{\prime}-V_{p}=C_{c}^{\prime}+\left(\frac{T+C_{s}^{\prime}}{h_{p}}\right) x_{p}-V_{p}+V_{s h} \\
& V_{s h}=T+T^{\prime}-C_{c}^{\prime}-\left(\frac{T+C_{s}^{\prime}}{h_{p}}\right) x_{p}
\end{aligned}
$$

Como $T^{\prime}-C_{c}^{\prime}=C_{s}^{\prime}$ em vigas, então: 
$V_{s h}=T+C_{s}^{\prime}-\left(\frac{T+C_{s}^{\prime}}{h_{p}}\right) x_{p}$

ou

$V_{s h}=\left(C_{s}^{\prime}+T\right)\left(1-\frac{x_{p}}{h_{p}}\right)$

A área de estribos horizontais necessária ao nó é calculada por:

$A_{s h}=\frac{V_{s h}}{f_{y h}}=\frac{C_{s}^{\prime}+T}{f_{y h}}\left(1-\frac{x_{p}}{h_{p}}\right)$

A aproximação da expressão (5.11) para a obtenção de $x_{p}$ também pode ser aplicada. Neste caso, $V_{s h}$ e $A_{\text {sh }}$ ficam determinadas por:

$V_{s h}=\left(C_{s}^{\prime}+T\right)\left(0,75-\frac{0,85 N}{f_{c} A_{c p}}\right)$

$A_{s h}=\frac{C_{s}^{\prime}+T}{f_{y h}}\left(0,75-\frac{0,85 N}{f_{c} A_{c p}}\right)$

A expressão (5.23) demonstra, assim como já observado para os nós externos, a influência da força normal do pilar sobre área de estribos requerida.

\section{Limitação do diâmetro das barras longitudinais da viga em nós internos}

A comparação entre as forças de aderência que surgem nos dois tipos de nós de pórtico abordados indica que as condições são mais críticas nos nós internos, pois além de estarem submetidos à transmissão de forças de aderência de maior intensidade, em nós internos dificilmente se dispõem de ganchos para a ancoragem das barras das vigas, ao contrário do que ocorre em nós externos.

Para entender o motivo da limitação do diâmetro $\phi_{\mathrm{b}}$ das barras em nós internos, segue-se uma simples dedução da formulação envolvida. Com base na transmissão de forças ilustrada na figura 5.3, calcula-se a tensão média de aderência $\tau$, assumindo que 0 comprimento efetivo de ancoragem seja igual a $h_{p}$ :

$\tau=\frac{\mathrm{C}_{\mathrm{s}}^{\prime}+\mathrm{T}}{\pi \phi_{\mathrm{b}} \mathrm{h}_{\mathrm{p}}} \leq \bar{\tau}$

Essa tensão média atuante, evidentemente, deve ser limitada a um valor $\bar{\tau}$, associado com própria resistência à aderência entre o aço e o concreto. Supondo-se agora que: 
$\mathrm{C}_{\mathrm{s}}^{\prime}<\mathrm{T}$

$\mathrm{C}_{\mathrm{s}}^{\prime}=\mathrm{A}_{\mathrm{sc}}^{\prime} \beta \mathrm{f}_{\mathrm{y}} \quad$ com $\quad \beta \leq 1$

$\mathrm{T}=\mathrm{A}_{\mathrm{st}} \lambda \mathrm{f}_{\mathrm{y}} \quad$ com $\quad \lambda \geq 1$

Substituindo na expressão (5.24),

$\tau=\frac{f_{y}\left(\beta A_{s c}^{\prime}+\lambda A_{s t}\right)}{\pi \phi_{b} h_{p}} \leq \bar{\tau}$

Multiplicando numerador e denominador por $\phi / 4$,

$\tau=\frac{\frac{f_{y} \phi_{b}}{4}\left(\beta A_{s c}^{\prime}+\lambda A_{s t}\right)}{\frac{\pi\left(\phi_{b}\right)^{2} h_{p}}{4}}=\frac{\frac{f_{y} \phi_{b}}{4}\left(\beta A_{s c}^{\prime}+\lambda A_{s t}\right)}{A_{s c}^{\prime} h_{p}} \leq \bar{\tau}$

Manipulando-se os termos da expressão (5.26), encontra-se a seguinte relação:

$\frac{\phi_{\mathrm{b}}}{\mathrm{h}_{\mathrm{p}}} \leq \frac{4 \bar{\tau}}{\mathrm{f}_{\mathrm{y}}}\left(\frac{\mathrm{A}_{\mathrm{sc}}^{\prime}}{\beta \mathrm{A}_{\mathrm{sc}}^{\prime}+\lambda \mathrm{A}_{\mathrm{st}}}\right)=$ constante

Conclui-se pela expressão (5.27) que a relação entre o diâmetro das barras principais da viga e a altura da seção do pilar dever ser limitada a um valor constante. É o que recomendam, por exemplo, a norma americana ACI 318 (1995) e a norma neozelandesa NZS 3101 (1995).

Na maioria das vezes, de posse do valor da altura da seção do pilar, limita-se o diâmetro das barras longitudinais da viga. Essa limitação não é usualmente aplicável aos nós externos, não significando, contudo, que o diâmetro das barras da viga não influencie o comportamento estrutural destes nós quando submetidos a ações cíclicas.

\subsubsection{ORTIZ (1997)}

Com base nos resultados experimentais de ligações viga-pilar de extremidade (submetidas a ações monotônicas) e no desenvolvimento de um modelo de biela e tirante, ORTIZ (1997) propõe um procedimento de cálculo para determinar a quantidade de estribos horizontais no nó que garante a sua máxima resistência.

Segundo o modelo, a força de compressão na biela diagonal do nó é resultado da contribuição de duas parcelas: a primeira parcela está relacionada ao efeito de ancoragem em curva da armadura longitudinal tracionada da viga; a segunda parcela está relacionada ao trabalho dos estribos que são tracionados em conseqüência da abertura das fissuras do concreto.

O modelo admite que, quando o nó não possui estribos, a largura da biela assume o valor a, conforme a figura 5.4. No entanto, a presença de estribos horizontais - por aumentar a capacidade resistente do nó à força cortante - promove um acréscimo da largura da biela para 
um valor $w$. Assim, o principal ponto do modelo consiste na idéia de que os estribos propiciam um alargamento da biela diagonal. Na verdade, o que ocorre de fato é o efeito benéfico do confinamento, que aumenta a capacidade resistente do nó.

Segue-se a nomenclatura utilizada neste item:

w é a largura de biela necessária;

$\mathrm{w}_{\mathrm{s}}$ é a largura de biela devido aos estribos;

a é a largura de biela devido ao concreto (sem estribos);

$b_{j}$ é a largura do nó;

$h_{p}$ é a altura da seção do pilar;

$x_{p}$ é a altura da zona comprimida do pilar;

$V_{p}$ é a força cortante do pilar;

$V_{\text {sh }}$ é a força cortante horizontal resistente devido aos estribos;

$\mathrm{V}_{\mathrm{jh}}$ é a força cortante horizontal solicitante no nó;

$V_{j v}$ é a força cortante vertical solicitante no nó;

$f_{y h}$ é a resistência ao escoamento do aço dos estribos horizontais;

$h_{v}$ é a altura da seção da viga;

$T_{v}$ é a resultante da armadura tracionada da viga;

$x_{v}$ é a altura da zona comprimida da viga;

$A_{s h}$ é a área de estribos horizontais;

$V_{c h}$ é a força cortante horizontal resistente devido ao concreto (sem estribos);

$V_{\mathrm{sh}}$ é a força cortante horizontal resistente devido ao trabalho dos estribos;

$\mathrm{N}$ é a força normal no pilar;

$\theta$ é a inclinação da biela em relação à horizontal;

$\mathrm{w}_{\max }$ é a máxima largura disponível para a biela;

$\sigma_{c, \text { máx }}$ é a máxima tensão admitida para a biela, segundo a tensão última adotada;

D é a resultante diagonal de compressão na biela. 

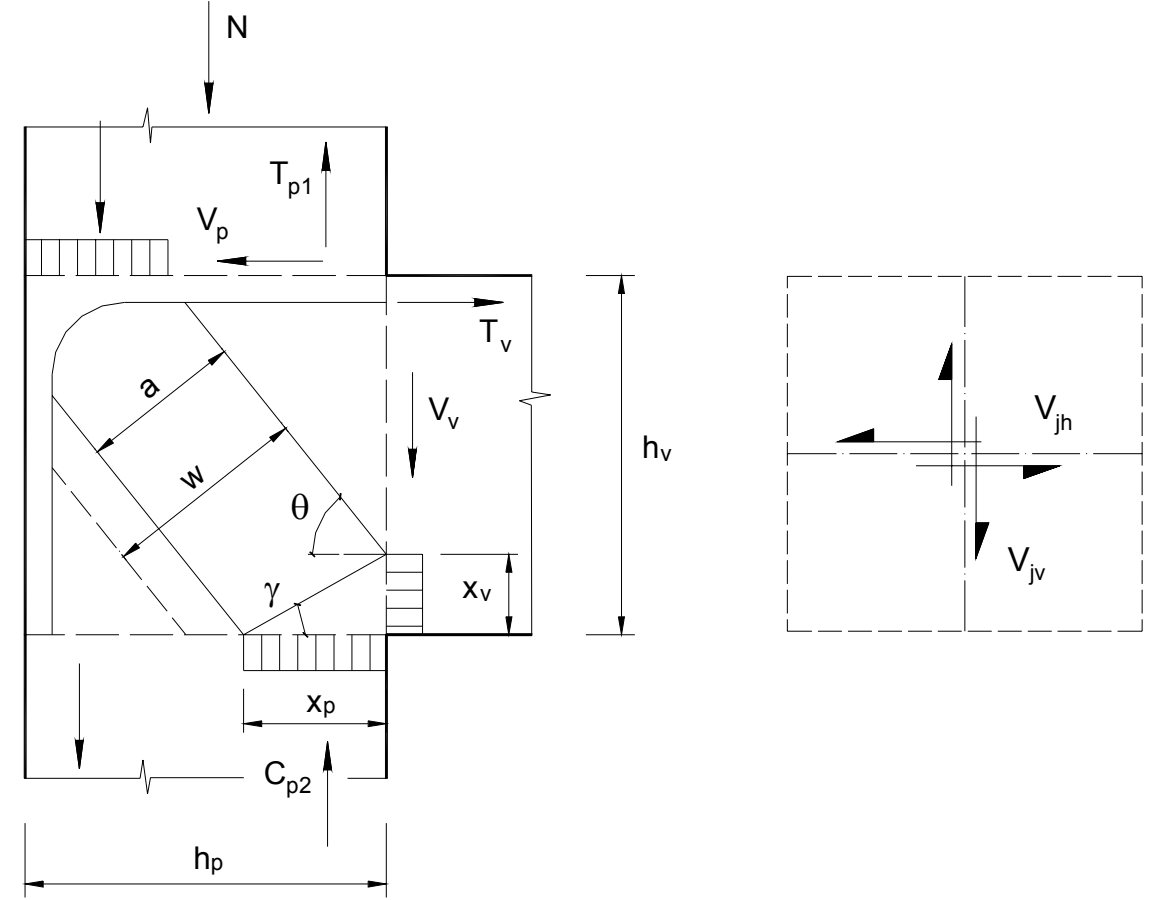

Figura 5.4: Forças atuantes em nó externo. Largura da biela comprimida

O ângulo de inclinação da biela $\theta$ é calculado por:

$\theta=\operatorname{arctg}\left(\frac{\mathrm{V}_{\mathrm{jv}}}{\mathrm{V}_{\mathrm{jh}}}\right)$

Por equilíbrio de forças, a cortante horizontal atuante no nó é obtida por:

$\mathrm{V}_{\mathrm{jh}}=\mathrm{T}_{\mathrm{v}}-\mathrm{V}_{\mathrm{p}}$

A relação entre a força diagonal na biela e a força cortante horizontal é dada pela expressão:

$\mathrm{D} \cos \theta=\mathrm{V}_{\mathrm{jh}}$

A largura $w$ da biela deve ser tal que as tensões do concreto não ultrapassem as tensões últimas. Dessa forma,

$\mathrm{D}=\mathrm{wb}_{\mathrm{j}} \sigma_{\mathrm{c} \text {,máx }}$

$\mathrm{w}=\frac{\mathrm{D}}{\mathrm{b}_{\mathrm{j}} \sigma_{\mathrm{c}, \text { máx }}}=\frac{\mathrm{D}_{1}+\mathrm{D}_{2}}{\mathrm{~b}_{\mathrm{j}} \sigma_{\mathrm{c}, \text { máx }}}=\frac{\mathrm{V}_{\mathrm{jh}}}{\mathrm{b}_{\mathrm{j}} \sigma_{\mathrm{c}, \text { máx }} \cos \theta}$

onde a resultante $D_{1}$ é decorrente apenas à contribuição do concreto sem estribos e a resultante $D_{2}$ é o acréscimo de resistência decorrente da presença dos estribos. Entendendo 
que esse acréscimo de resistência corresponde à resistência dos estribos horizontais, tem-se que:

$\mathrm{V}_{\mathrm{sh}}=\mathrm{A}_{\mathrm{sh}} \mathrm{f}_{\mathrm{yh}}=\mathrm{D}_{2} \cos \theta$

A largura da biela $w$ é a soma das contribuições do concreto (sem estribos) e dos estribos horizontais:

$\mathrm{w}=\mathrm{w}_{\mathrm{c}}+\mathrm{w}_{\mathrm{s}}=\frac{\mathrm{D}_{1}}{\mathrm{~b}_{\mathrm{j}} \sigma_{\mathrm{c}, \text { máx }}}+\frac{\mathrm{D}_{2}}{\mathrm{~b}_{\mathrm{j}} \sigma_{\mathrm{c}, \text { máx }}}=\frac{\mathrm{V}_{\mathrm{ch}}}{\mathrm{b}_{\mathrm{j}} \sigma_{\mathrm{c}, \text { máx }} \cos \theta}+\frac{\mathrm{V}_{\mathrm{sh}}}{\mathrm{b}_{\mathrm{j}} \sigma_{\mathrm{c}, \text { máx }} \cos \theta}$

onde a largura de biela associada à contribuição dos estribos é calculada por:

$\mathrm{w}_{\mathrm{s}}=\frac{\mathrm{V}_{\mathrm{sh}}}{\mathrm{b}_{\mathrm{j}} \sigma_{\mathrm{c}, \text { máx }} \cos \theta}=\frac{\mathrm{A}_{\mathrm{sh}} \mathrm{f}_{\mathrm{yh}}}{\mathrm{b}_{\mathrm{j}} \sigma_{\mathrm{c}, \text { máx }} \cos \theta}$

ORTIZ (1997) ressalva que o excesso de estribos não pode alargar a biela além da área de concreto existente - o que depende das dimensões do nó, em especial da altura da seção do pilar. Assim, a largura máxima disponível é calculada pela expressão (5.36), podendo ser deduzida a partir da figura 5.5:

$\mathrm{w}_{\text {máx }}=\mathrm{h}_{\mathrm{p}} \operatorname{sen} \theta+\mathrm{x}_{\mathrm{v}} \cos \theta$

Entretanto, deve-se alertar que, do ponto de vista técnico, não é possível que a biela alcance a largura $W_{\text {máx }}$ uma vez as dimensões do nó estão limitadas pelas armaduras do pilar, não chegando às faces externas do mesmo.

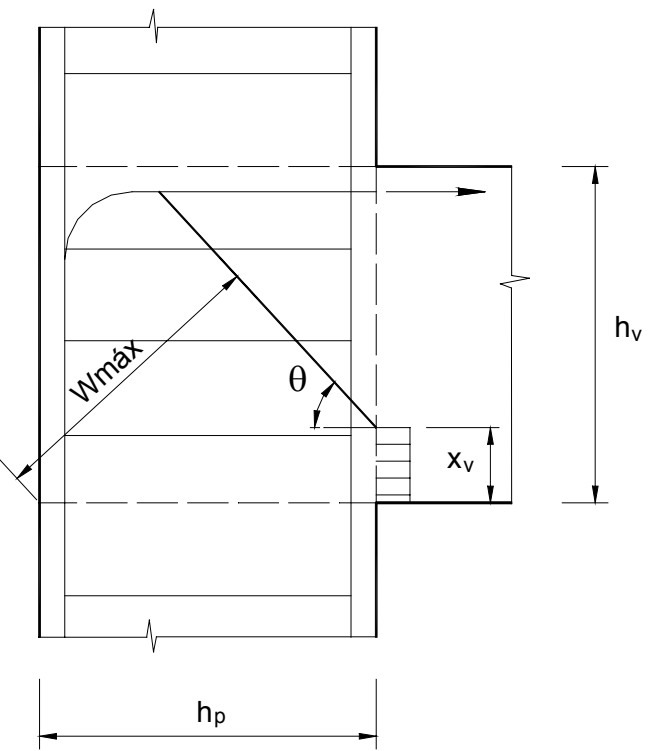

Figura 5.5: Largura máxima disponível para a biela - ORTIZ (1997) 
As observações experimentais mostraram que o nó de pórtico, sem estribos, resiste a uma força cortante correspondente a uma largura de biela igual à $45 \%$ da largura máxima $\mathrm{w}_{\text {máx. }}$. Portanto, os estribos devem ser responsáveis por 0,55 w máx. Partindo dessa observação, ORTIZ (1997) apresenta uma expressão para calcular a máxima área de estribos úteis, a qual garante a máxima resistência do nó:

$A_{s h} f_{y} \leq \frac{b_{j} \sigma_{c, m a ́ x} 0,55\left(h_{p} \operatorname{sen} \theta+x_{v} \cos \theta\right) \cos \theta}{f_{y h}}$

Áreas de estribos maiores que as calculadas pela expressão (5.37) não produzem efeito benéfico algum na resistência do nó.

Notou-se que o emprego da expressão proposta por ORTIZ ao dimensionamento de nós de pórticos pode conduzir a uma elevada quantidade de estribos. Em particular, quando as dimensões do pilar forem maiores - o que permite a formação de bielas mais largas - não existe a necessidade de o nó desenvolver toda a sua capacidade resistente, podendo-se dispor de uma quantidade de estribos menor que a calculada pela expressão (5.37).

\subsubsection{HWANG \& LEE (1999)}

Neste item aborda-se o modelo analítico proposto por HWANG \& LEE (1999) para a avaliação da força cortante resistente em nós externos. Consideram-se importantes os procedimentos de avaliação da resistência ao cisalhamento dos nós de pórticos, pois são úteis ao dimensionamento e podem auxiliar na previsão da forma de colapso da ligação, uma vez que é possível existir situações em que o nó de pórtico represente a região menos resistente da ligação.

A figura 5.6 ilustra a classificação dos modos típicos de colapso em modelos físicos de ligações viga-pilar extremidade, apresentada por HWANG \& LEE (1999).

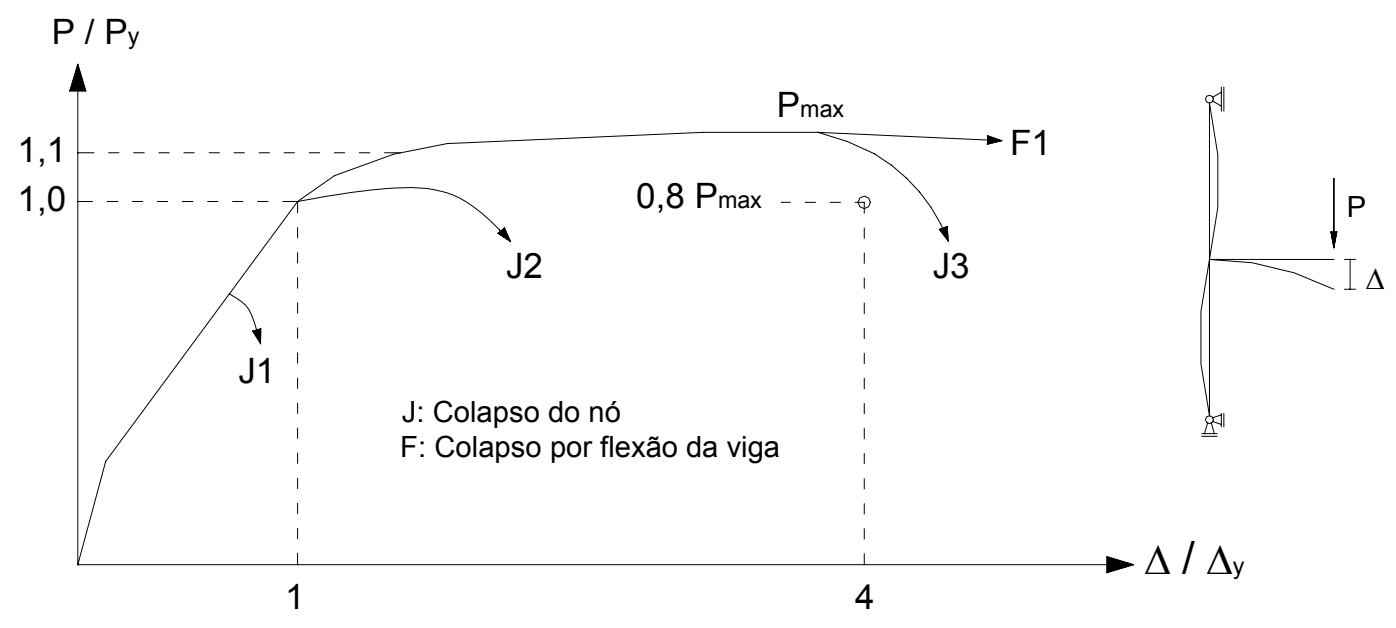

Figura 5.6: Formas possíveis de colapso em nós externos - Adaptado de HWANG \& LEE 
Pelo gráfico da figura 5.6, nota-se que a máxima força atingida na extremidade da viga e, conseqüentemente, a máxima força cortante atuante no nó, estão limitadas por uma das quatro possíveis formas de colapso da ligação:

J1: Colapso por cisalhamento do nó antes de que se atinja a força de plastificação $P_{y}$;

J2: Colapso por cisalhamento do nó após a força de plastificação: $P / P_{y}>1,0$;

J3: Colapso por cisalhamento do nó para $\mathrm{P} / \mathrm{P}_{\mathrm{y}}>1,1$ e $\Delta_{(0,8 \mathrm{Pmax})}>4 \Delta_{\mathrm{y}}$, onde $\Delta_{\mathrm{y}}$ é o deslocamento na plastificação;

F1: Colapso por flexão da viga.

O modelo proposto pelos autores deriva dos modelos de biela e tirante; no entanto, além de satisfazer apenas as condições de equilíbrio, também considera a compatibilidade de deformações e as leis constitutivas do material concreto. Um modelo analítico similar, aplicável aos nós internos, é apresentado em HWANG \& LEE (2000).

Os resultados do modelo proposto por HWANG \& LEE (1999) apresentam uma correlação satisfatória com resultados experimentais obtidos por diversos pesquisadores. $O$ modelo permite, inclusive, avaliar as tensões médias atuantes no concreto e nos estribos, prevendo a forma de colapso do nó de pórtico.

A seguir apresenta-se as hipóteses e a formulação matemática do referido modelo:

O modelo é composto por três mecanismos. A resistência do nó se deve a participação da biela diagonal comprimida, dos estribos horizontais e das barras intermediárias do pilar (estribos verticais). O mecanismo promovido pela biela comprimida denomina-se mecanismo diagonal e os mecanismos promovidos pelos estribos horizontais e verticais, mecanismo horizontal e mecanismo vertical. A transferência de forças nesses mecanismos é ilustrada na figura 5.7 .

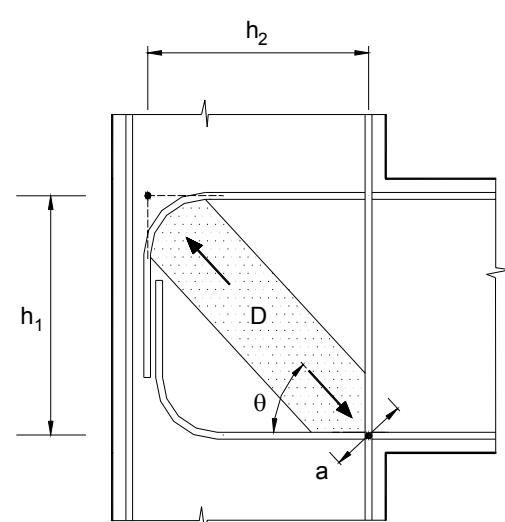

a) Mecanismo Diagonal

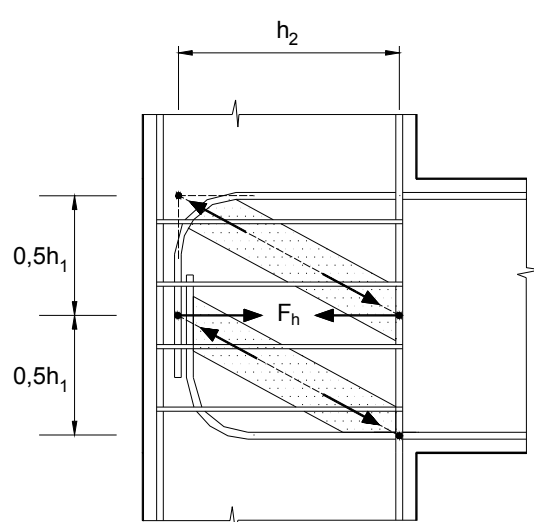

b) Mecanismo Horizontal

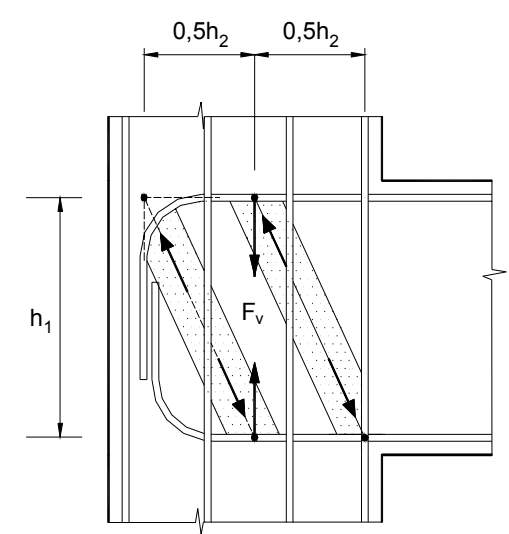

c) Mecanismo Vertical

Figura 5.7: Mecanismos de resistência ao cisalhamento. a) Mecanismo Diagonal. b) Mecanismo Horizontal. c) Mecanismo Vertical 
O mecanismo diagonal é composto pela biela de compressão principal, cujo ângulo de inclinação é definido a partir da seguinte expressão:

$\theta=\arctan \left(\frac{\mathrm{h}_{1}}{\mathrm{~h}_{2}}\right)$

onde

$\mathrm{h}_{1}$ é a distância vertical entre o eixos das armaduras superior e inferior da viga;

$\mathrm{h}_{2}$ é a distância horizontal entre o eixo da armadura longitudinal mais próxima da face interna do pilar e o eixo da armadura da viga dobrada a 90 graus no nó, conforme a figura 5.7.

Outro parâmetro referente ao mecanismo diagonal é a área efetiva da biela, definida por:

$A_{b}=a \times b_{j}$

onde

a é a largura da biela;

$b_{j}$ é a largura efetiva do nó.

A largura da biela é definida a partir das zonas comprimidas da viga e do pilar. HWANG \& LEE (1999) sugerem que essa largura seja estimada, com razoável precisão, a partir da expressão proposta por PAULAY \& PRIESTLEY (1992):

$a=x_{p}=\left(0,25+\frac{0,85 N}{A_{p} f_{c}}\right) h_{p} \quad \quad \operatorname{com} \frac{N}{A_{p} f_{c}}>0,1$

onde

$x_{p}$ é a altura da zona comprimida do pilar;

$\mathrm{N}$ é a força normal no pilar;

$A_{p}$ é a área da seção transversal do pilar;

$\mathrm{f}_{\mathrm{c}}$ é a resistência à compressão do concreto em corpos de prova cilíndricos;

$h_{p}$ é a altura da seção do pilar.

Um procedimento mais exato para obter a largura da biela é proposto neste trabalho pela seguinte expressão:

$a=\sqrt{x_{v}{ }^{2}+x_{p}{ }^{2}} \operatorname{sen}\left(\theta+\operatorname{arctg}\left(\frac{x_{v}}{x_{p}}\right)\right)$

onde

$\mathrm{X}_{\mathrm{v}}$ é a altura da zona comprimida na seção da viga. 
A largura efetiva do nó $b_{j}$ pode ser obtida com as recomendações das principais normas que tratam do assunto. Em suas análises, HWANG \& LEE (1999) utilizaram a largura efetiva definida pelo ACl-318 (1995).

O mecanismo horizontal consiste em um tirante (representando os estribos horizontais) e em duas bielas secundárias, mais abatidas que a biela principal. É importante citar que os diversos estudos experimentais realizados em nós de pórtico indicam que os estribos horizontais mais solicitados são os que se encontram mais próximos à metade da altura do nó, enquanto que os demais são menos solicitados. Por esse motivo, HWANG \& LEE (1999) sugerem que os estribos centrais sejam considerados totalmente efetivos no cômputo da área da seção do tirante, devendo-se considerar, para os demais estribos, uma contribuição de apenas $50 \%$ da área.

O mecanismo vertical é composto por um tirante vertical e duas bielas secundárias mais íngremes que a biela principal. O tirante vertical representa as barras longitudinais intermediárias do pilar. A forma de avaliar a área do tirante vertical é similar à indicada para o mecanismo horizontal. Evidentemente, quando o pilar não possui barras intermediárias, ou seja, quando contém apenas barras longitudinais próximas às faces externas do mesmo, o mecanismo vertical inexiste.

A figura 5.8 ilustra o modelo de biela e tirante empregado por HWANG \& LEE (1999).

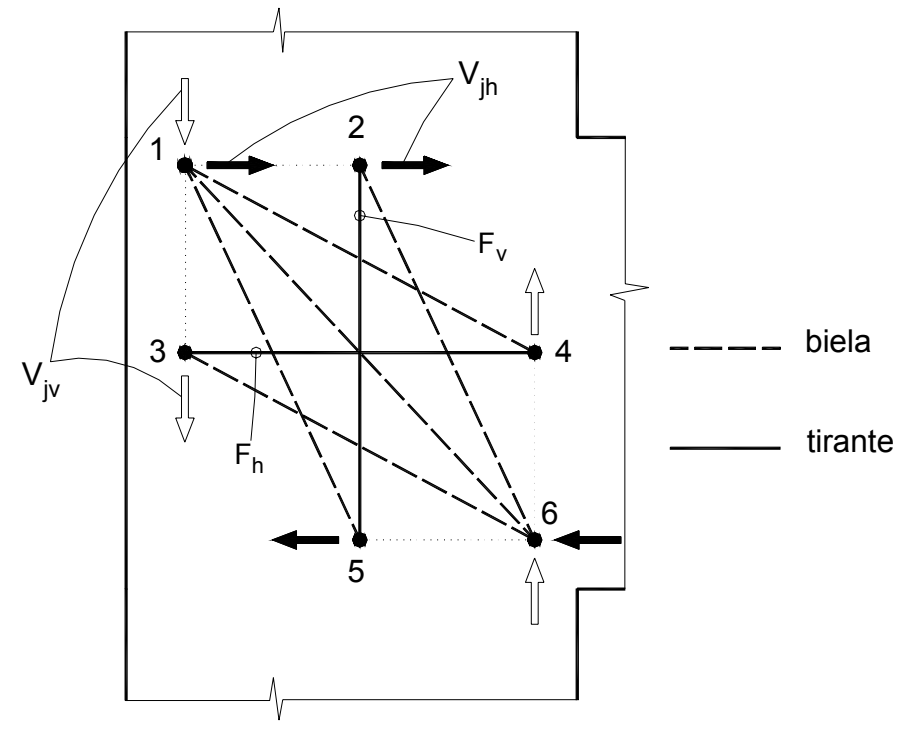

Figura 5.8: Modelo de biela e tirante utilizado por HWANG \& LEE (1999)

Segundo o modelo de HWANG \& LEE (1999), o escoamento dos estribos não necessariamente interrompe o desenvolvimento da resistência ao cisalhamento do nó, pois a biela diagonal é capaz de transmitir esforços de cisalhamento sozinha. Portanto, a máxima resistência do nó é alcançada quando a tensão de compressão na biela atinge a capacidade resistente do concreto. 


\section{Equilíbrio de forças}

Com base no modelo de biela e tirante da figura 5.8, por equilíbrio de forças, determina-se a força cortante horizontal a ser resistida pelo nó:

$V_{\mathrm{jh}}=\mathrm{D} \cos \theta+\mathrm{F}_{\mathrm{h}}+\mathrm{F}_{\mathrm{v}} \operatorname{cotg} \theta$

onde

$D$ é a força resultante de compressão na biela;

$F_{h}$ é a força resultante de tração no tirante horizontal;

$F_{v}$ é a força resultante de tração no tirante vertical.

De forma similar, a força cortante vertical é expressa por:

$V_{j v}=D \operatorname{sen} \theta+F_{h} \operatorname{tg} \theta+F_{v}$

A relação entre a força cortante vertical e a força cortante horizontal é dada por:

$\frac{V_{j v}}{V_{j h}}=\operatorname{tg} \theta$

A parcela de força cortante horizontal e vertical resistidas pelos estribos são obtidas conforme sugerido por JENNEWEIN \& SCHÄFER (1992):

$F_{h}=\gamma_{h} V_{j h} \quad$ onde $\quad \gamma_{h}=\frac{2 \operatorname{tg} \theta-1}{3}$ para $0 \leq \gamma_{h} \leq 1$

O fator $\gamma_{h}$ representa a fração de força cortante horizontal transmitida pelo tirante horizontal sem a presença do tirante vertical. Da mesma maneira,

$F_{v}=\gamma_{v} V_{j v} \quad$ onde $\quad \gamma_{v}=\frac{2 \operatorname{cotg} \theta-1}{3}$ para $0 \leq \gamma_{v} \leq 1$

onde o fator $\gamma_{v}$ representa a fração de força cortante transmitida pelo tirante vertical sem a presença do tirante horizontal.

Com base nas expressões (5.42), (5.45) e (5.46), as forças envolvidas nos três mecanismos $\left(D, F_{h}\right.$ e $\left.F_{v}\right)$ podem ser convenientemente expressas em função da força cortante horizontal: 
$D=\frac{1}{\cos \theta}\left(\frac{R_{d}}{R_{d}+R_{h}+R_{v}}\right) V_{j h}$

$F_{h}=\left(\frac{R_{h}}{R_{d}+R_{h}+R_{v}}\right) V_{j h}$

$F_{v}=\frac{1}{\operatorname{cotg} \theta}\left(\frac{R_{v}}{R_{d}+R_{h}+R_{v}}\right) V_{\text {jh }}$

onde $R_{d}, R_{h}$ e $R_{v}$ são termos adimensionais que indicam a parcela de força cortante horizontal resistida pelo mecanismo diagonal, horizontal e vertical, respectivamente. $O$ valor desses termos são determinados por:

$$
\begin{aligned}
& \mathbf{R}_{d}=\frac{\left(1-\gamma_{h}\right)\left(1-\gamma_{v}\right)}{1-\gamma_{v} \gamma_{h}} \\
& R_{h}=\frac{\gamma_{h}\left(1-\gamma_{v}\right)}{1-\gamma_{v} \gamma_{h}} \\
& R_{v}=\frac{\gamma_{v}\left(1-\gamma_{h}\right)}{1-\gamma_{v} \gamma_{h}}
\end{aligned}
$$

Naturalmente, a soma dessas três parcelas adimensionais deve ser igual à unidade. Quando não houver barras longitudinais intermediárias no pilar, não há formação do mecanismo vertical, ou seja, $\gamma_{v}$ é igual a 0 . A figura 5.9 indica como ocorre a distribuição das forças em nós de pórtico externos em função do ângulo de inclinação da biela.

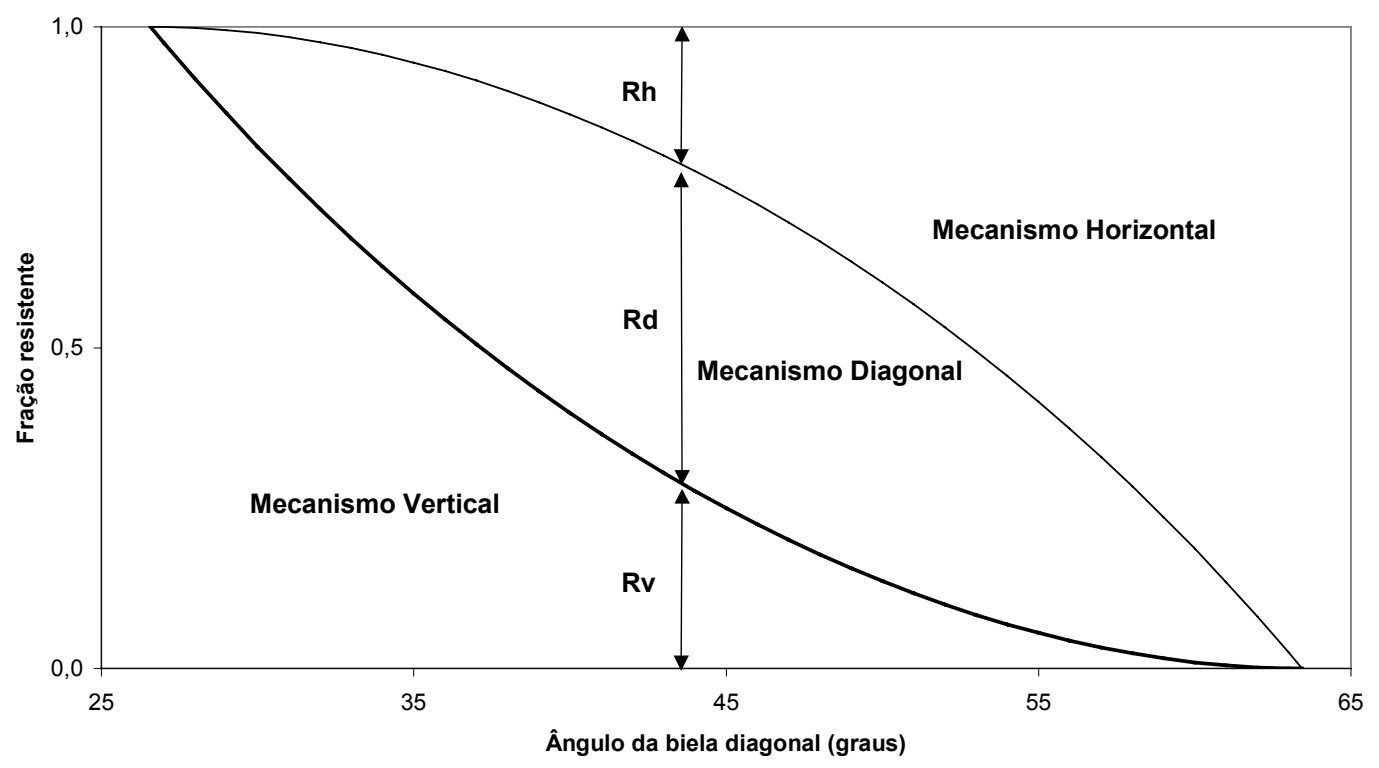

Figura 5.9: Distribuição da força cortante horizontal entre os três mecanismos

Para ângulos de inclinação da biela iguais a 45 graus, o mecanismo diagonal é o que mais participa da resistência ao cisalhamento. Nesta situação, $R_{d}$ assume valor igual a 0,5 . A 
figura 5.9 também indica que a participação dos estribos horizontais na resistência à força cortante é maior à medida que a inclinação da biela aumenta. Assim, em nós de pórtico formados por vigas de grande altura em relação à altura da seção do pilar, a presença de estribos horizontais é mais relevante.

Para verificar se a resistência do nó foi alcançada, as tensões de compressão da região nodal (nó 6 da figura 5.8) devem ser verificadas. Com algum esforço algébrico, determina-se a máxima tensão normal de compressão na região nodal, atuante na direção principal $d$, por:

$$
\sigma_{\mathrm{d}, \max }=\frac{1}{\mathrm{~A}_{\mathrm{b}}}\left[\mathrm{D}+\frac{\cos \left(\theta-\operatorname{arctg}\left(\frac{\mathrm{h}_{1}}{2 \mathrm{~h}_{2}}\right)\right)}{\cos \left(\operatorname{arctg}\left(\frac{\mathrm{h}_{1}}{2 \mathrm{~h}_{2}}\right)\right)} \times \mathrm{F}_{\mathrm{h}}+\frac{\cos \left(\operatorname{arctg}\left(\frac{2 \mathrm{~h}_{1}}{\mathrm{~h}_{2}}\right)-\theta\right)}{\operatorname{sen}\left(\operatorname{arctg}\left(\frac{2 \mathrm{~h}_{1}}{\mathrm{~h}_{2}}\right)\right)} \times \mathrm{F}_{\mathrm{v}}\right]
$$

Segundo HWANG \& LEE (1999), é possível demonstrar que a direção principal $d$ coincide com a direção da biela diagonal.

\section{$\underline{\text { Leis constitutivas }}$}

Sabe-se que o concreto em zonas fissuradas apresenta resistência e rigidez menores que o concreto submetido apenas à compressão uniaxial, em virtude dos efeitos de tração da armadura que o atravessa. Um exemplo típico deste comportamento é o caso das bielas comprimidas em nós de pórtico.

Uma vez que as atenções estão voltadas para a resistência, representa-se apenas o ramo ascendente da curva tensão-deformação do concreto fissurado (figura 5.10) por:

$$
\begin{aligned}
& \sigma_{d}=\zeta f_{c}=\left[2\left(\frac{\varepsilon_{d}}{\zeta \varepsilon_{0}}\right)-\left(\frac{\varepsilon_{d}}{\zeta \varepsilon_{0}}\right)^{2}\right] \text { para } \frac{\varepsilon_{d}}{\zeta \varepsilon_{0}} \leq 1 \\
& \zeta=\frac{5,8}{\sqrt{f_{c}}} \frac{1}{\sqrt{1+400 \varepsilon_{r}}} \leq \frac{0,9}{\sqrt{1+400 \varepsilon_{r}}}
\end{aligned}
$$

onde

$\sigma_{d}$ é a tensão principal de compressão na direção $d$.

$\zeta$ é o coeficiente adimensional de redução da resistência;

$\varepsilon_{\mathrm{d}}$ e $\varepsilon_{\mathrm{r}}$ são as deformações principais médias na direção $d$ e $r$

$\varepsilon_{0}$ é a deformação correspondente à tensão de resistência à compressão (corpo de prova cilíndrico), a qual pode ser estimada por:

$$
\varepsilon_{0}=-0,002-0,001\left(\frac{f_{c}-20}{100}\right) \quad \text { para } \quad 20 \mathrm{MPa} \leq \mathrm{f}_{\mathrm{c}} \leq 100 \mathrm{MPa}
$$




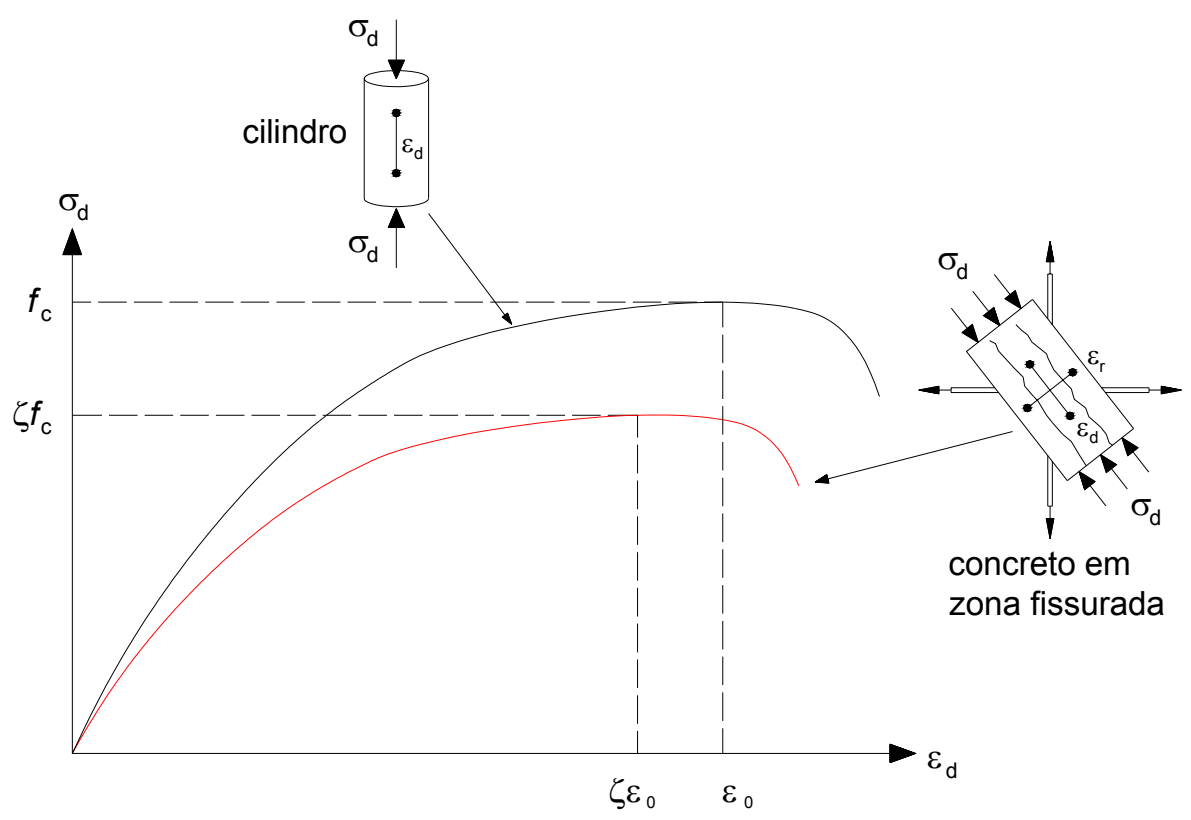

Figura 5.10: Comportamento do concreto armado em zonas fissuradas em decorrência de deformações transversais

A máxima resistência ao cisalhamento é alcançada sempre que a tensão de compressão e a deformação na biela diagonal atingirem os valores máximos, ou seja:

$\sigma_{\mathrm{d}}=\zeta \mathrm{f}_{\mathrm{c}}$

$\varepsilon_{\mathrm{d}}=\zeta \varepsilon_{0}$

Para o aço, adota-se o modelo elasto-plástico perfeito. Assim, as relações entre as forças resultantes nas armaduras transversais e as respectivas deformações de tração podem se escritas da seguinte forma:

$\begin{array}{llllll}\mathrm{F}_{\mathrm{h}}=\mathrm{A}_{\mathrm{sh}} \mathrm{E}_{\mathrm{s}} \varepsilon_{\mathrm{h}} & \text { se } & \varepsilon_{\mathrm{h}}<\varepsilon_{\mathrm{yh}} & \mathrm{F}_{\mathrm{h}}=\mathrm{F}_{\mathrm{yh}}=\mathrm{A}_{\mathrm{sh}} \mathrm{f}_{\mathrm{yh}} & \text { se } & \varepsilon_{\mathrm{h}} \geq \varepsilon_{\mathrm{yh}} \\ \mathrm{F}_{\mathrm{v}}=\mathrm{A}_{\mathrm{sv}} \mathrm{E}_{\mathrm{s}} \varepsilon_{\mathrm{v}} & \text { se } & \varepsilon_{\mathrm{v}}<\varepsilon_{\mathrm{yv}} & \mathrm{F}_{\mathrm{v}}=\mathrm{F}_{\mathrm{yv}}=\mathrm{A}_{\mathrm{sv}} \mathrm{f}_{\mathrm{yv}} & \text { se } & \varepsilon_{\mathrm{v}} \geq \varepsilon_{\mathrm{yv}}\end{array}$

onde

$A_{s h}$ e $A_{s v}$ são as áreas de estribos horizontais e verticais, respectivamente;

$E_{s}$ é o módulo de elasticidade do aço;

$\varepsilon_{\mathrm{h}}$ e $\varepsilon_{\mathrm{v}}$ são as deformações nos estribos horizontais e verticais;

$\varepsilon_{y h}$ e $\varepsilon_{y v}$ são as deformações nos estribos horizontais e verticais correspondentes ao início do escoamento;

$f_{y h}$ e $f_{y v}$ são as tensões de escoamento do aço dos estribos horizontais e verticais. 


\section{Compatibilidade}

São duas as equações de compatibilidade que relacionam as deformações médias nos diferentes sistemas de coordenadas. Uma vez conhecida a direção principal das tensões de compressão, a deformação principal de tração $\varepsilon_{r}$ pode ser relacionada com a deformação horizontal $\varepsilon_{h}$, a deformação vertical $\varepsilon_{v}$ e a deformação principal de compressão $\varepsilon_{d}$ da seguinte maneira:

$\varepsilon_{\mathrm{r}}=\varepsilon_{\mathrm{h}}+\left(\varepsilon_{\mathrm{h}}-\varepsilon_{\mathrm{d}}\right) \operatorname{cotg}^{2} \theta$

$\varepsilon_{\mathrm{r}}=\varepsilon_{\mathrm{v}}+\left(\varepsilon_{\mathrm{v}}-\varepsilon_{\mathrm{d}}\right) \operatorname{tg}^{2} \theta$

\section{Procedimentos de resolução}

O algoritmo para a resolução do problema inicia-se com a adoção de um valor inicial para a resistência ao cisalhamento do nó $V_{\mathrm{jh}}$, seguida de três etapas:

1) Empregam-se as equações de equilíbrio para encontrar a tensão máxima de compressão $\sigma_{\mathrm{d}, \max }$ que atua na região nodal (expressão 5.53). Assumindo-se que a resistência da biela tenha sido alcançada, obtém-se o valor do coeficiente $\zeta$ por meio de $\zeta=\frac{\sigma_{\mathrm{d}, \max }}{\mathrm{f}_{\mathrm{c}}}$

2) Utilizam-se as leis constitutivas dos materiais para determinar as deformações na biela e nos tirantes;

3) Aplicando-se as equações de compatibilidade, obtém-se um novo valor para $\zeta$. Se este valor estiver suficientemente próximo do valor calculado na etapa 1 , então o valor atual de $V_{\mathrm{jh}}$ é a resistência ao cisalhamento do nó; caso contrário, continua-se o procedimento iterativo.

O algoritmo de resolução é encontrado detalhadamente em HWANG \& LEE (1999).

Vale notar que o modelo contêm 10 variáveis que devem ser determinadas, a saber:

Quatro variáveis de forças: $V_{\mathrm{jh}}, \mathrm{D}, \mathrm{F}_{\mathrm{h}}, \mathrm{F}_{\mathrm{v}}$;

Uma variável de tensão: $\sigma_{\mathrm{d}, \max }$;

Uma variável associada ao material: $\zeta$;

Quatro variáveis de deformações: $\varepsilon_{\mathrm{d}}, \varepsilon_{\mathrm{h}}, \varepsilon_{\mathrm{v}}, \varepsilon_{\mathrm{r}}$

Em função do número de variáveis envolvendo os tirantes, cinco situações de cálculo são possíveis na determinação de $V_{\mathrm{jh}}$ :

Situação E: A biela de compressão atinge a resistência máxima enquanto que os tirantes horizontais e verticais permanecem no regime elástico; 
Situação YH: Primeiramente, ocorre o escoamento do tirante horizontal. A força cortante restante é resistida apenas pelo mecanismo diagonal e vertical, até a biela de compressão atingir sua resistência máxima, permanecendo o estribo vertical em regime elástico;

Situação YV: O escoamento do tirante vertical ocorre primeiro. Analogamente à situação $\mathrm{YH}, \mathrm{O}$ acréscimo de força cortante deve ser redistribuído apenas para o mecanismo horizontal e diagonal, até que a biela atinja a resistência máxima, permanecendo o tirante horizontal em regime elástico;

Situação YHV: O tirante horizontal atinge o escoamento, seguido do escoamento do tirante vertical após a redistribuição de forças. Após o escoamento dos tirantes, a biela atinge a resistência máxima;

Situação YVH: Análoga a situação YHV, porém com o tirante vertical atingindo primeiro o escoamento.

\section{$\underline{\text { Confronto }} \underline{\text { com resultados }} \underline{\text { experimentais: }} \underline{\text { acões cíclicas }}$}

HWANG \& LEE (1999) fizeram uma comparação entre os resultados fornecidos pelo modelo analítico proposto e os resultados experimentais de 63 modelos de ligações viga-pilar de extremidade encontrados na literatura, provenientes de trabalhos realizados nos Estados Unidos, na Nova Zelândia, no Japão e em Taiwan.

Foram analisadas apenas ligações viga-pilar isoladas, sem a presença de laje e sem a presença de vigas transversais. Quanto à ancoragem, foram selecionadas apenas as ligações em que as barras das vigas são dobradas a 90 graus para o interior do nó. Entretanto, o conjunto de dados das ligações selecionadas abrange uma ampla variação nas propriedades dos materiais, intensidade de carregamento, seqüência de carregamento e detalhamento das armaduras.

A comparação dos resultados mostrou que o modelo proposto fornece resultados satisfatórios na previsão da resistência à força cortante horizontal do nó (figura 5.11).

Observou-se também que o modelo fornece melhores resultados em ligações onde o colapso ocorre no nó, com um dos tirantes (ou estribos horizontais ou verticais) mantendo-se capaz de oferecer restrição ao avanço das fissuras. Em ligações onde o colapso ocorre por flexão da viga, o nó não desenvolve toda a sua capacidade ao cisalhamento, obtendo-se resultados menos precisos com a utilização do modelo analítico. 


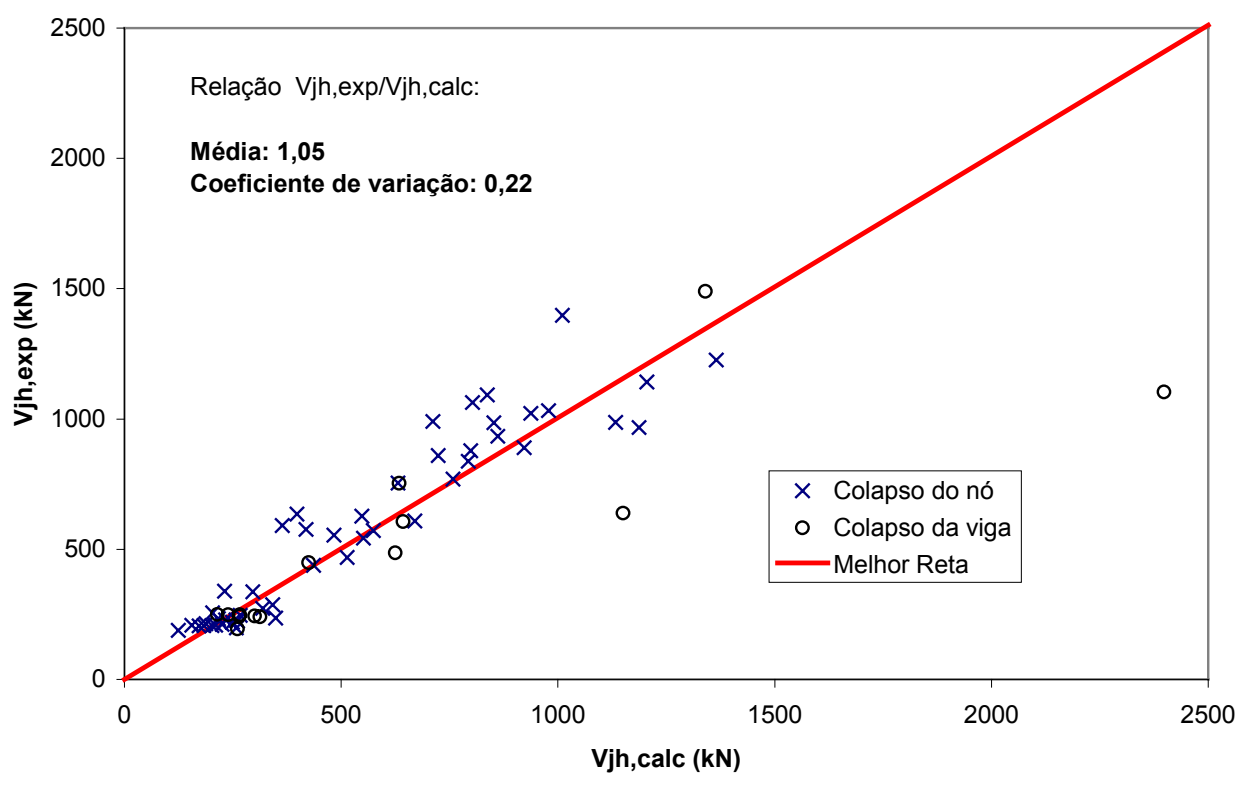

Figura 5.11: Correlação entre os resultados experimentais e os previstos pelo modelo de HWANG \& LEE (1999): ações cíclicas

Nas ligações escolhidas para a análise, a variação quanto à resistência do concreto, à força normal aplicada no pilar, ao ângulo de inclinação da biela e à força cortante atuante no nó abrangeram as seguintes faixas:

$22<\mathrm{f}_{\mathrm{c}}<93(\mathrm{MPa}) \quad-0,04 \leq \frac{\mathrm{N}}{\mathrm{A}_{\mathrm{p}} \mathrm{f}_{\mathrm{c}}} \leq 0,35 \quad 42^{\circ} \leq \theta \leq 68^{\circ} \quad 180<\mathrm{V}_{\mathrm{jh}, \mathrm{exp}}<1500(\mathrm{kN})$

incluindo a presença ou não de estribos horizontais e de barras longitudinais intermediárias no pilar.

Os valores das forças cortantes experimentais no gráfico da figura 5.11 foram obtidos ou pela citação dos pesquisadores que conduziram os ensaios ou foram calculados com base no máximo valor da força de tração na armadura da viga durante o ensaio.

\subsubsection{Comparação entre modelos de resistência de cisalhamento}

Neste item realiza-se uma comparação de resultados fornecidos pelos modelos de HWANG \& LEE (1999) e PAULAY \& PRIESTLEY (1992). Com base na análise dos resultados, são feitas algumas observações e comentários.

Para as comparações, escolheu-se um nó de pórtico externo, com geometria e materiais indicados na tabela 5.1. A geometria da viga e do pilar foram mantidas, variando-se apenas a área de estribos horizontais no nó. 
Tabela 5.1: Dados relativos à geometria da ligação e aos materiais adotados

\begin{tabular}{|l|l|l|l|}
\hline \multicolumn{1}{|c|}{ Materiais } & \multicolumn{1}{|c|}{ Viga } & \multicolumn{1}{c|}{ Pilar } & \multicolumn{1}{c|}{ Nó de pórtico } \\
\hline $\mathrm{f}_{\mathrm{c}}=30 \mathrm{MPa}$ & $\mathrm{b}_{\mathrm{v}}=20 \mathrm{~cm} \quad \mathrm{~A}_{\mathrm{st}}=8,04 \mathrm{~cm}^{2}$ & $\mathrm{~b}_{\mathrm{p}}=20 \mathrm{~cm} \mathrm{~N} \quad \mathrm{~N}=360 \mathrm{kN}$ & $\mathrm{A}_{\mathrm{b}}=278 \mathrm{~cm}^{2}$ \\
$\varepsilon_{\mathrm{o}}=-0,002$ & $\mathrm{~h}_{\mathrm{v}}=40 \mathrm{~cm} \quad A_{\mathrm{sc}}=8,04 \mathrm{~cm}^{2}$ & $\mathrm{~h}_{\mathrm{p}}=30 \mathrm{~cm}$ & $\mathrm{~A}_{\mathrm{j}}=600 \mathrm{~cm}^{2}$ \\
$\mathrm{f}_{\mathrm{yh}}=500 \mathrm{MPa}$ & $\mathrm{h}_{1}=32,8 \mathrm{~cm}$ & $\mathrm{~h}_{2}=22,8 \mathrm{~cm}$ & $\theta=55,2^{\circ}$ \\
$\mathrm{E}_{\mathrm{s}}=210.000 \mathrm{MPa}$ & & & \\
\hline
\end{tabular}

Com os dados da tabela 5.1, calcula-se a resistência ao cisalhamento do nó, ou seja, a máxima força cortante possível, em função da área de estribos. Além disso, são calculadas as parcelas de contribuição da biela e dos estribos na resistência do nó.

Foram adotados os seguintes critérios adicionais para os cálculos:

- A altura da zona comprimida do pilar $x_{p}$ nos dois modelos foi avaliada com a expressão (5.40);

- Nos cálculos envolvendo o modelo de PAULAY \& PRIESTLEY (1992), adotou-se, para a obtenção da resistência ao cisalhamento do nó, a expressão da norma neozelandesa NZS 3101 (1995), a qual emprega o mesmo mecanismo resistente proposto por PAULAY \& PRIESTLEY. Assim, a máxima força cortante possível foi de $V_{j h}=0,2 f_{c} A_{j}$.

- O algoritmo de resolução empregado nos cálculos do modelo de PAULAY \& PRIESTLEY é descrito a seguir:

1) Assumir $\sigma_{\mathrm{sh}}=\mathrm{f}_{\mathrm{yh}}$

2) Calcular $V_{s h}=A_{s h} f_{y h}$

3) Calcular $C_{s}=\frac{V_{s h}}{1-\frac{0,8 x_{p}}{0,7 h_{p}}}$

4) Com as equações de equilíbrio e compatibilidade na seção, calcular T e o momento na viga $\mathrm{M}_{\text {viga }}$

5) Calcular para o pilar: o momento $M_{\text {pilar }}=\frac{M_{\text {viga }}}{2}$ e a força cortante $V_{p}=\frac{M_{\text {pilar }}}{H / 2} \quad(H$ : altura total do pilar)

6) Calcular $V_{j h}=T-V_{p}$

7) Se $V_{j h} \leq 0,2 f_{c} A_{j}$

então ok! (escoamento dos estribos)

senão $V_{j h}=0,2 f_{c} A_{j}$ (esmagamento da biela diagonal do nó)

i) A partir de $V_{j h}$, recalcular $T, V_{p}$ e $C_{s}$ com equações de equilíbrio (na seção e na ligação) e de compatibilidade (seção)

ii) Calcular $\mathrm{V}_{\mathrm{sh}}=\mathrm{C}_{\mathrm{s}}\left(1-\frac{0,8 \mathrm{x}_{\mathrm{p}}}{0,7 \mathrm{~h}_{\mathrm{p}}}\right)$

iii) Calcular $\sigma_{\mathrm{sh}}=\frac{\mathrm{V}_{\mathrm{sh}}}{\mathrm{A}_{\mathrm{sh}}}$ 
A tabela 5.2 contém uma comparação de resultados fornecidos pelos dois modelos de resistência para os nós de pórtico. Os resultados da tabela 5.2 são reproduzidos graficamente nas figuras 5.12 à 5.14 .

Tabela 5.2: Comparação de resultados: modelos de HWANG \& LEE (1999) e PAULAY \& PRIESTLEY (1992)

\begin{tabular}{|c|c|c|c|c|c|c|c|c|}
\hline & (1) & (2) & (1) & (2) & (1) & (2) & (1) & (2) \\
\hline$A_{\text {sh }}$ & $\begin{array}{l}\mathbf{V}_{\mathrm{jh}} \\
(\mathrm{kN})\end{array}$ & $\begin{array}{l}\mathbf{V}_{\mathrm{jh}} \\
(\mathrm{kN})\end{array}$ & $\begin{array}{c}\sigma_{d} \\
\left(k N / \mathrm{cm}^{2}\right)\end{array}$ & $\begin{array}{c}\sigma_{d} \\
\left(k N / \mathrm{cm}^{2}\right)\end{array}$ & $\begin{array}{c}\sigma_{\mathrm{sh}} \\
\left(\mathrm{kN} / \mathrm{cm}^{2}\right)\end{array}$ & $\begin{array}{c}\sigma_{\mathrm{sh}} \\
\left(\mathrm{kN} / \mathrm{cm}^{2}\right)\end{array}$ & Colapso & Colapso \\
\hline $1 \phi 8\left(1,0 \mathrm{~cm}^{2}\right)$ & 281,2 & 332,3 & 1,46 & 1,78 & 50,00 & 50,00 & $\mathrm{E}$ & $E$ \\
\hline $2 \phi 8\left(2,0 \mathrm{~cm}^{2}\right)$ & 298,0 & 355,0 & 1,25 & 1,61 & 50,00 & 50,00 & $\mathrm{E}$ & $\mathrm{E}$ \\
\hline $3 \phi 8\left(3,0 \mathrm{~cm}^{2}\right)$ & 314,9 & 360,0 & 1,04 & 1,63 & 50,00 & 33,98 & $\mathrm{E}$ & $B$ \\
\hline $4 \phi 8\left(4,0 \mathrm{~cm}^{2}\right)$ & 331,7 & 360,0 & 0,83 & 1,63 & 50,00 & 25,49 & $\mathrm{E}$ & B \\
\hline $6 \phi 8\left(6,0 \mathrm{~cm}^{2}\right)$ & 359,0 & 360,0 & 0,85 & 1,63 & 37,44 & 16,99 & B & B \\
\hline $8 \phi 8\left(8,0 \mathrm{~cm}^{2}\right)$ & 376,9 & 360,0 & 0,89 & 1,63 & 29,48 & 12,74 & B & B \\
\hline & IWAN & LE & $2-n$ & o de F & AY 8 & STLEY & & \\
\hline E: escoamentc & dos & ibos 1 & rizontais; & B: esn & mento & jiela diag & & \\
\hline
\end{tabular}

Na tabela 5.2:

$\sigma_{d}$ é a tensão de compressão na biela diagonal, calculada por $\sigma_{d}=\frac{D}{A_{b}}$ $\sigma_{\text {sh }}$ é a tensão média de tração nos estribos, calculada por $\sigma_{\mathrm{sh}}=\frac{V_{\mathrm{sh}}}{\mathrm{A}_{\mathrm{sh}}}$

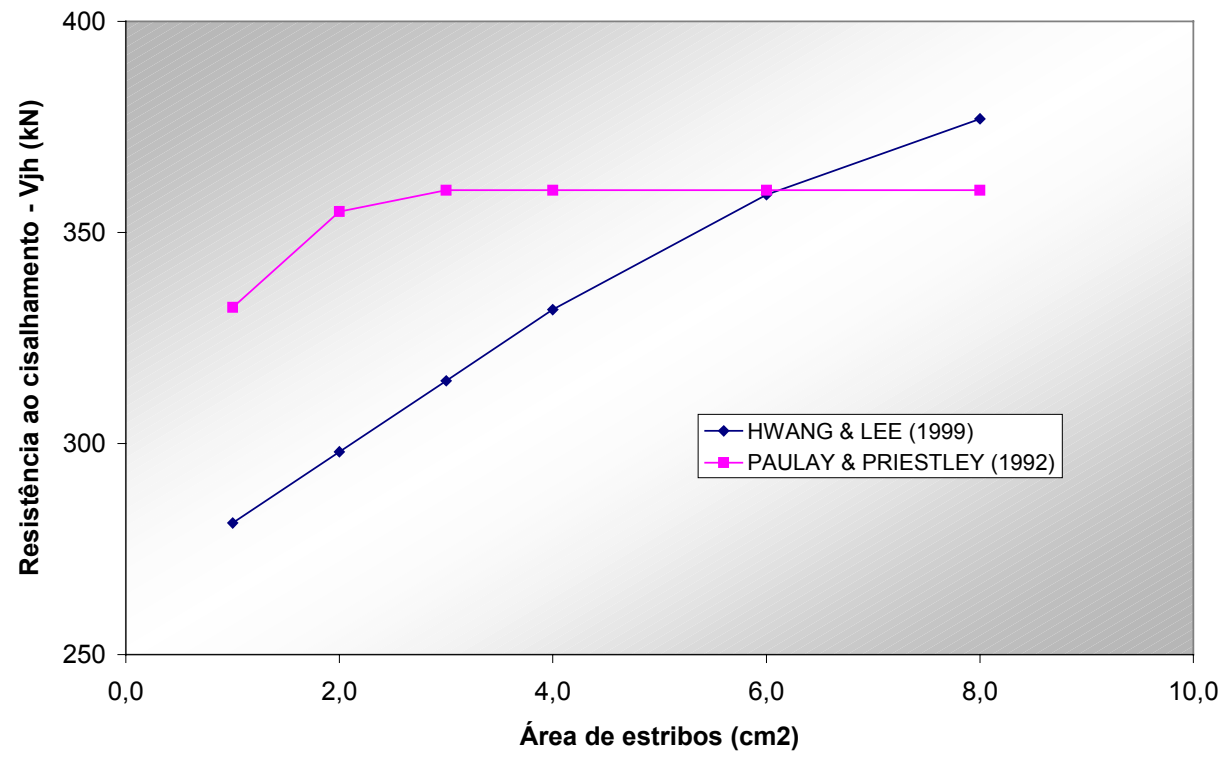

Figura 5.12: Resistência ao cisalhamento: HWANG \& LEE (1999) e PAULAY \& PRIESTLEY (1992) 


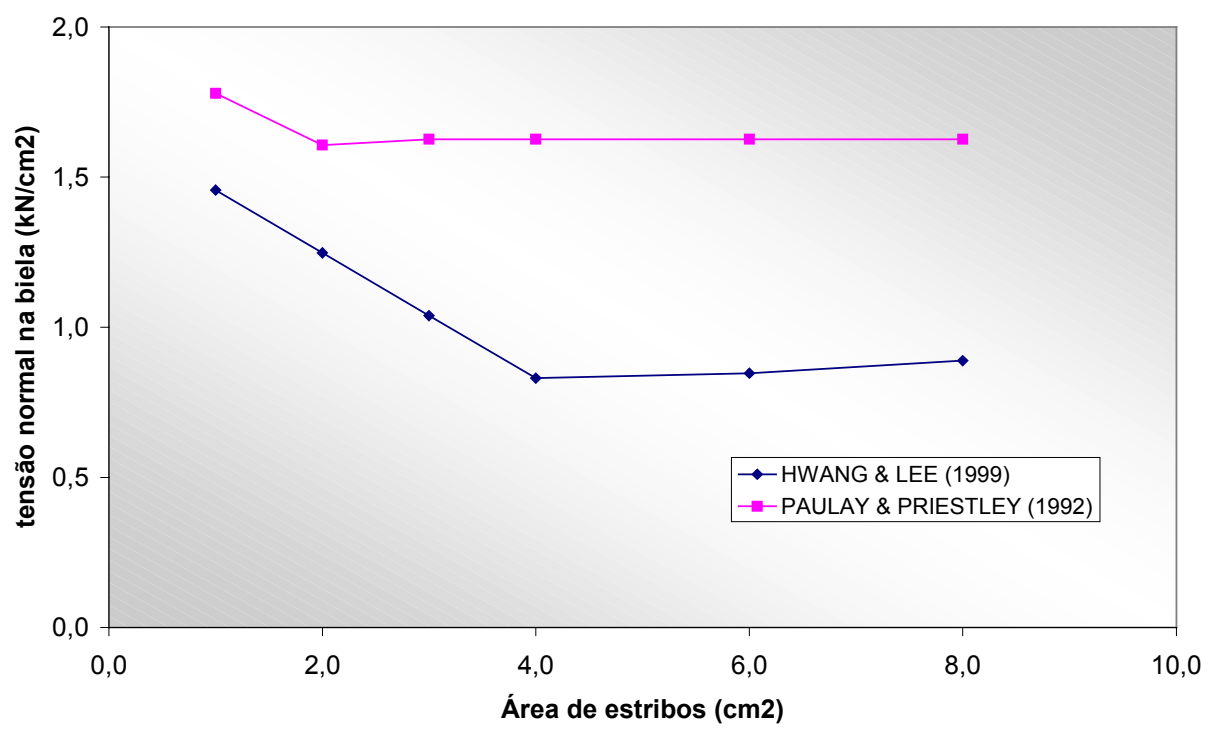

Figura 5.13: Tensão normal na biela: HWANG \& LEE (1999) e PAULAY \& PRIESTLEY (1992)

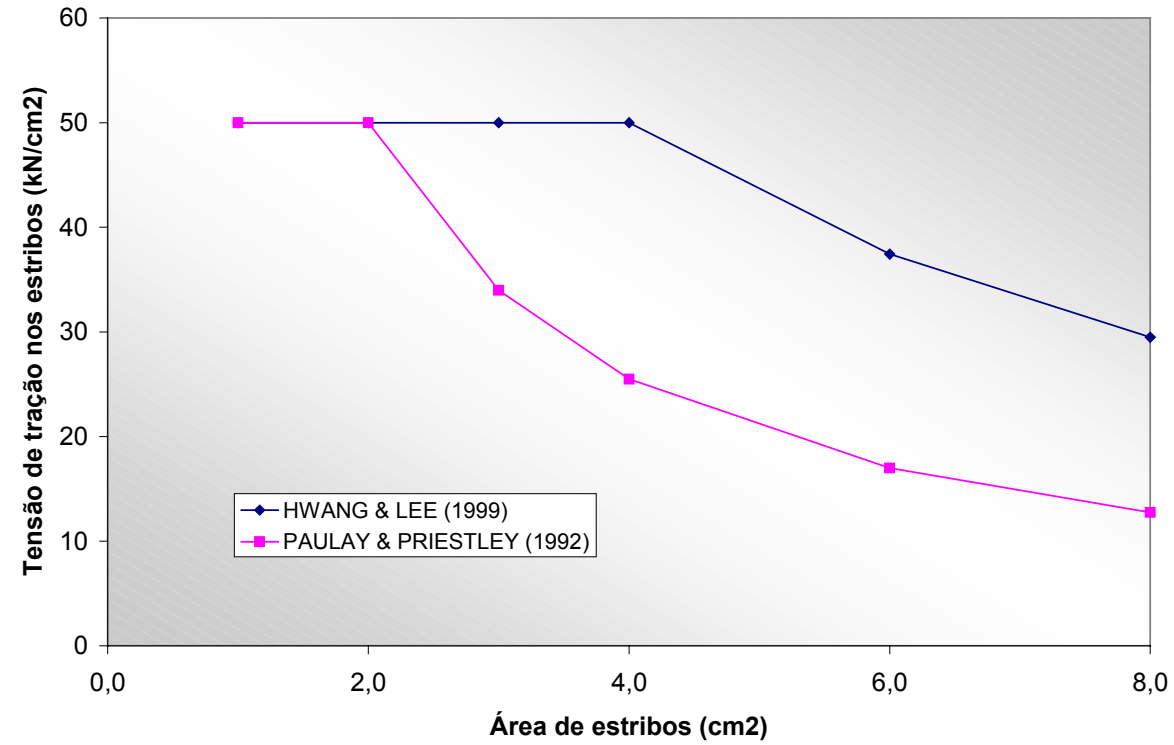

Figura 5.14: Tensão de tração nos estribos: HWANG \& LEE (1999) e PAULAY \& PRIESTLEY (1992)

A partir dos resultados obtidos, são feitas as seguintes observações comuns aos dois modelos:

- Para taxas de estribos pequenas, a resistência ao cisalhamento do nó é governada pelo escoamento dos estribos. Para taxas de estribos maiores, a resistência do nó acaba sendo governada pela resistência da biela comprimida, podendo os estribos trabalhar no regime elástico.

- A resistência ao cisalhamento cresce linearmente com a área de estribos enquanto estes permanecem em regime de escoamento. Quando os estribos começam a trabalhar no regime elástico, observa-se um crescimento não-linear da resistência com a área de armadura transversal. 
- A tensão normal na biela decresce linearmente com o aumento da área de estribos, enquanto estes ainda atingem o escoamento. Quando os estribos horizontais começam a trabalhar no regime elástico, a tensão normal da biela apresenta uma taxa de crescimento modesta, até que o nó não seja mais capaz de suportar o carregamento imposto.

- No exemplo de nó de pórtico em questão, a resistência do nó é alcançada antes que ocorra o momento último previsto para a viga. $\mathrm{Na}$ realidade, o contrário é mais desejável em termos de comportamento estrutural.

As seguintes diferenças entre os dois modelos foram identificadas:

- Em situação de projeto, o modelo de PAULAY \& PRIESTLEY é mais prático que o modelo de HWANG \& LEE, pois com uma única expressão - que depende apenas da resultante de compressão da armadura da viga, da altura da zona comprimida do pilar e altura da seção do mesmo - é possível dimensionar ou verificar o nó de pórtico. $O$ modelo de HWANG \& LEE apresenta uma formulação mais sofisticada e utiliza um processo iterativo de resolução, sendo mais conveniente empregá-lo com o auxílio de computador.

- O modelo de PAULAY \& PRIESTLEY faz uso apenas de equações de equilíbrio de forças em sua formulação. O modelo de HWANG \& LEE, além de utilizar equações de equilíbrio de forças, também faz uso de equações de compatibilidade de deformações e de leis constitutivas dos materiais, apresentando, em princípio, mais consistência em termos mecânicos.

- Para as taxas de estribos não muito elevadas, o modelo de PAULAY \& PRIESTLEY fornece uma resistência ao cisalhamento maior que o modelo de HWANG \& LEE.

- O modelo de PAULAY \& PRIESTLEY fornece maiores valores de tensão normal na biela quando comparada ao modelo de HWANG \& LEE, ou seja, a contribuição da biela diagonal na resistência ao cisalhamento é maior no primeiro modelo.

- A determinação da resistência do nó empregando o modelo de PAULAY \& PRIESTLEY depende das taxas de armaduras principais da viga e do emprego das equações de compatibilidade e equilíbrio na seção da mesma. Por sua vez, o modelo de HWANG \& LEE não requer os valores das resultantes das armaduras longitudinais da viga, pois a área da seção da biela pode ser estimada apenas com o valor da força normal do pilar (expressões 5.39 e 5.40 ).

- O modelo de PAULAY \& PRIESTLEY não é aplicável aos casos em que não existe armadura negativa na viga. Este fato decorre em virtude da força cortante $V_{\text {sh }}$ resistida pelos estribos depender da resultante de compressão $\mathrm{C}_{\mathrm{s}}$. $\mathrm{O}$ mesmo não ocorre com o modelo de HWANG \& LEE.

- O modelo de PAULAY \& PRIESTLEY também não é aplicável na ausência de estribos no nó. Neste caso, o modelo de HWANG \& LEE deve ser utilizado, assumindo-se que a deformação $\varepsilon_{h}$ na expressão (5.61) seja igual à deformação das barras longitudinais de tração da viga. 


\subsection{MODELOS DE ANÁLISE GLOBAL}

Neste item são abordados os modelos numéricos para a análise global da ligação vigapilar, conforme mencionado no início deste capítulo. Estes modelos, em sua maioria, empregam exclusivamente elementos finitos unidimensionais e simulam a resposta forçadeslocamento ou momento-rotação da estrutura em análise. Outros modelos utilizam elementos unidimensionais (para simular a viga e o pilar) juntamente com elementos bidimensionais (para simular o painel nó de pórtico).

Alguns trabalhos mais recentes envolvendo a simulação numérica de ligações vigapilar com modelos de análise global serão mencionados brevemente. Em seguida, serão abordados exclusivamente os modelos escolhidos para as análises numéricas desta pesquisa, envolvendo os modelos globais.

LA BORDERIE (1991), em sua pesquisa sobre a resposta dos elementos estruturais de concreto armado submetidos a ações cíclicas, desenvolveu um modelo constitutivo para o concreto baseado na Mecânica do Dano Contínuo. Esse modelo considera os principais fenômenos ocorridos no concreto sob carregamento cíclico, como a perda de rigidez decorrente da fissuração, o aparecimento de deformações permanentes decorrentes da evolução do dano e a recuperação da rigidez durante a inversão do sentido do carregamento, quando as fissuras iniciam seu fechamento (figura 5.15).

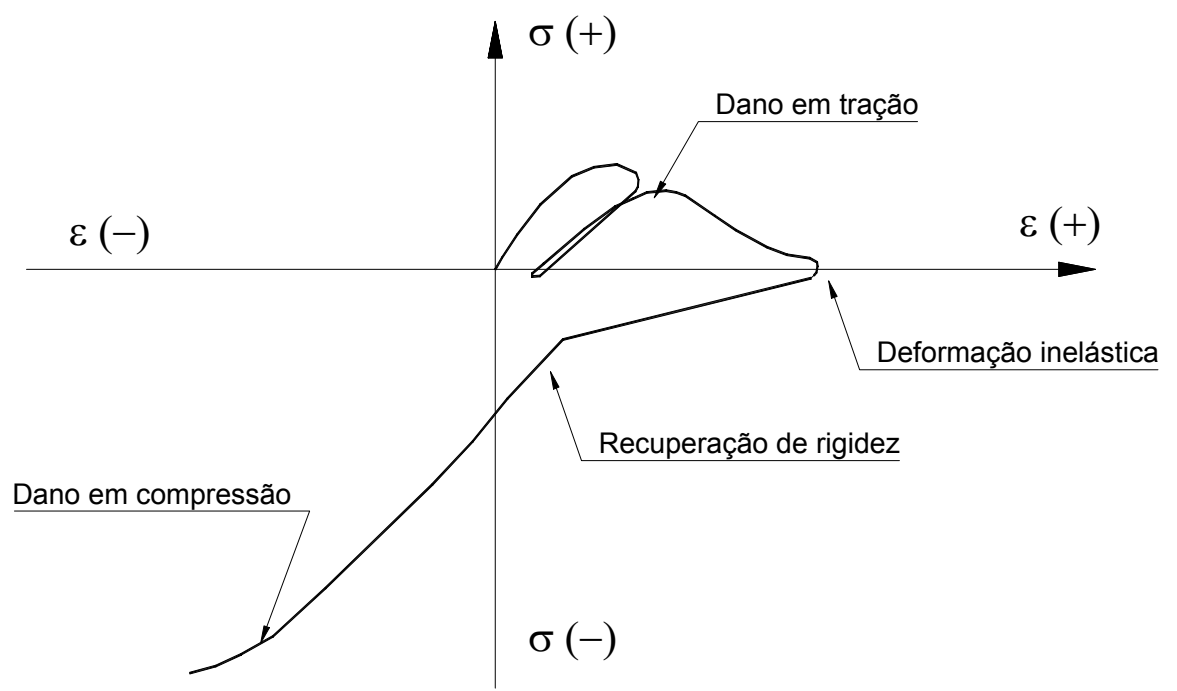

Figura 5.15: Comportamento unilateral do concreto submetido a carregamento cíclico LA BORDERIE (1991).

A fim de avaliar o desempenho do modelo proposto, LA BORDERIE et al. (1991) apresentaram uma simulação numérica de uma ligação viga-pilar interno, implementando o modelo constitutivo proposto para o caso unidimensional. A comparação com resultados experimentais (figura 5.16) mostrou que o modelo apresenta resultados satisfatórios, uma vez que as ligações foram admitidas como perfeitamente rígidas. Entretanto, esta hipótese pode não ser razoável quando as distorções do nó por cisalhamento e/ou os deslizamentos das armaduras da viga forem significativos. Outra ressalva à aplicação do modelo em ligações é o fato deste não considerar eventuais rotações plásticas entre viga e pilar, fato que afeta os deslocamentos globais da ligação. 

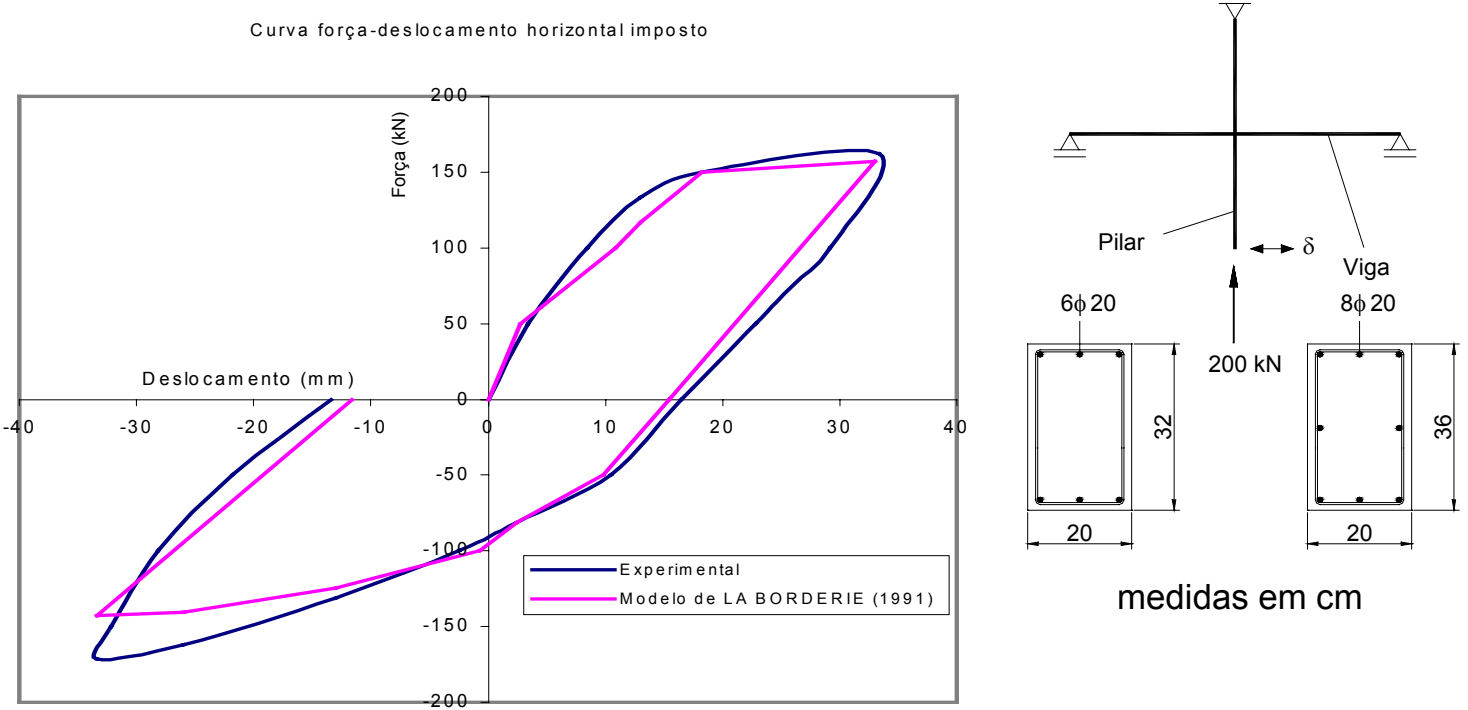

Figura 5.16: Resposta global da ligação viga-pilar empregando o modelo de LA BORDERIE (1991).

VASSILEV et al. (1994) apresentam um modelo que considera a semi-rigidez das ligações viga-pilar por meio de molas rotacionais não-lineares. O modelo é capaz de quantificar a degradação de rigidez e de resistência observadas nos ciclos de histerese de curvas do tipo força-deslocamento. No modelo proposto pelos autores, essa quantificação depende da máxima amplitude do carregamento e do número de ciclos.

O modelo proposto utiliza curvas bi-lineares de momento-rotação ou forçadeslocamento, conforme indicado na figura 5.17. Introduz-se uma variável escalar positiva $D$ para quantificar a danificação:

$D(\beta)=\frac{\left(e^{n \beta}-1\right)}{\left(e^{n}-1\right)} \quad(0 \leq D \leq 1)$

onde

$\beta=\mathrm{C} \sum_{\mathrm{i}} \frac{\delta_{\mathrm{i}}}{\delta_{\mathrm{F}}} \quad(\mathrm{i}=1 . . \mathrm{N})$

$\delta_{\mathrm{i}}$ é o deslocamento máximo no i-ésimo ciclo;

$\delta_{\mathrm{F}}$ é o deslocamento último (ruptura) do carregamento monotônico;

$C$ é uma constante a ser calibrada com os dados experimentais;

$n$ é outra constante que deve ser determinada a partir de resultados experimentais. 


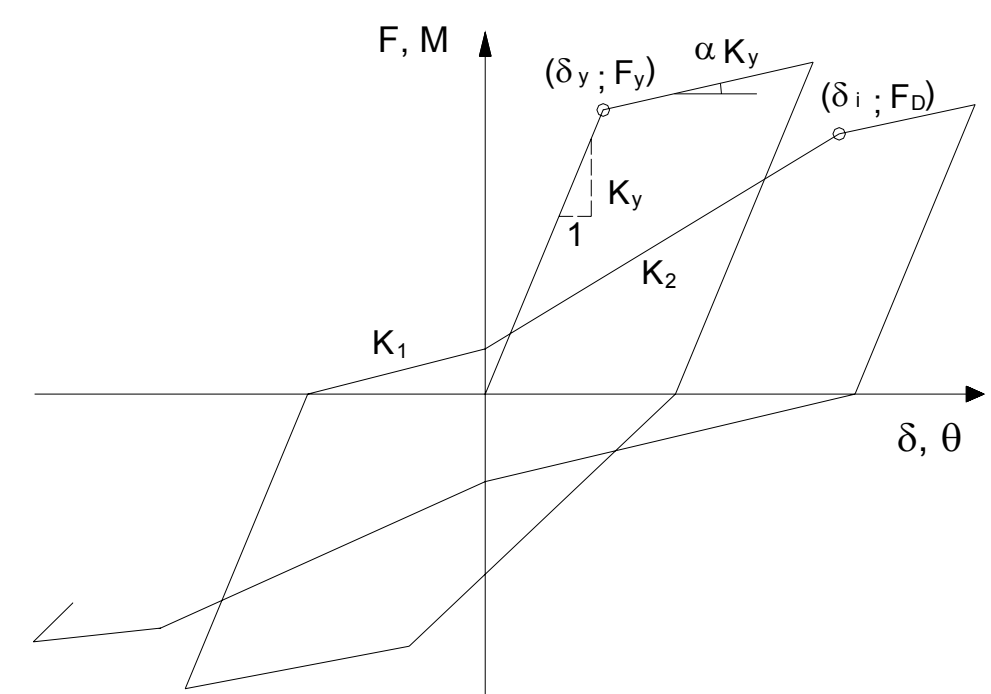

Figura 5.17: Curva força-deslocamento/momento-rotação - VASSILEV et al. (1994).

A partir da figura 5.17, nota-se que o módulo de rigidez $\mathrm{K}$ da curva força-deslocamento é reduzido à medida que a danificação cresce. Os autores sugerem que o módulo de rigidez $\mathrm{K}$ seja dividido em dois, a fim de levar em conta o fenômeno conhecido como efeito pinching ou efeito constritivo (figura 5.18):

- $\quad \mathrm{K}_{1}$, válido a partir do ponto de interseção da curva com o eixo $\mathrm{F}$, e calculado por $\mathrm{K}_{1}=\mathrm{K}(1-\mathrm{D})$;

- $\quad K_{2}$, que é obtido a partir do ponto $\left(\delta_{i} ; F_{D}\right)$ referente ao i-ésimo ciclo. $F_{D}$ é a força/momento correspondente à plastificação.

O modelo proposto foi implementado em programa computacional, simulando o comportamento de ligações viga-pilar de concreto armado. As simulações numéricas com carregamento cíclico alternado mostraram uma boa aproximação com resultados experimentais.

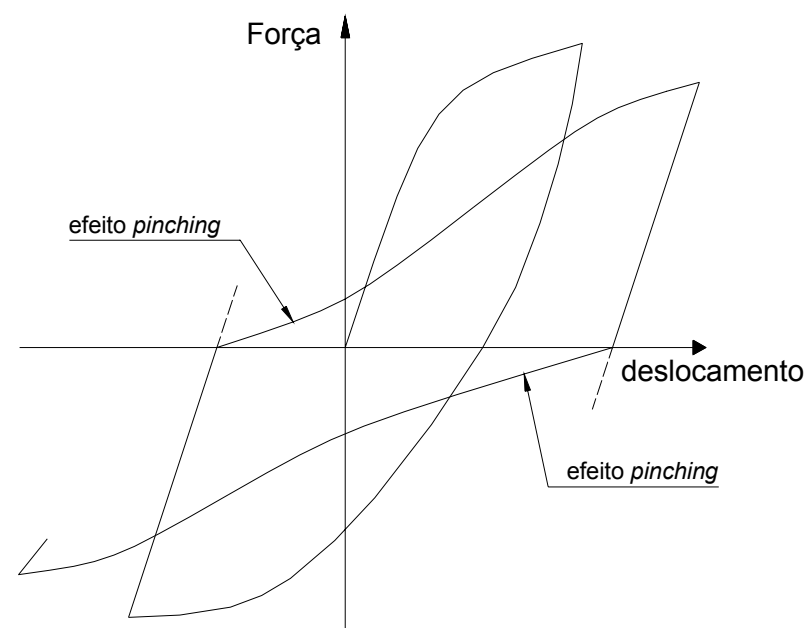

Figura 5.18: Efeito pinching ou constritivo observado nos ciclos de histerese de curvas forçadeslocamento. 
FLEURY et al. (2000) propuseram um modelo para representar os nós de pórticos de concreto armado, com a possibilidade de reuni-los a elementos unidimensionais, tais como vigas e pilares. O modelo é composto por diversos elementos:

- um elemento bidimensional com quatro nós, empregado para simular os efeitos de distorção por cisalhamento do nó;

- uma série de elementos unidimensionais que representam as barras de aço e a respectiva aderência com o concreto ao longo da ligação;

- Dois elementos de transição, formados por um elemento unidimensional de viga de concreto sem armadura, de modo que a aderência aço-concreto possa ser modelada separadamente;

- Elementos de treliça que representam a armadura longitudinal dos pilares.

Deve-se fazer uma compatibilidade entre os deslocamentos dos diversos elementos que compõem o modelo, impondo-se relações entre os graus de liberdade. A figura 5.19 contém um esquema geral do modelo proposto por FLEURY et al. (2000).

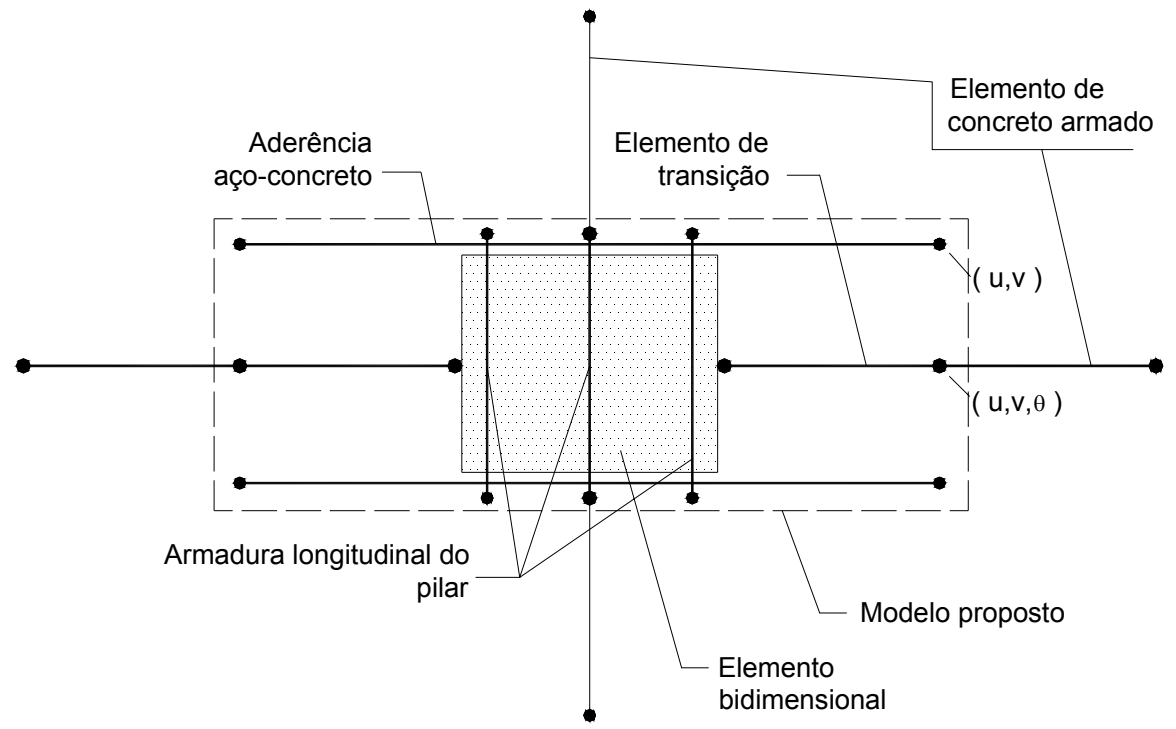

Figura 5.19: Modelo global proposto FLEURY et al. (2000).

O modelo constitutivo utilizado para representar o comportamento biaxial do concreto admite um estado plano de tensões, considerando que as fissuras surgem em direção perpendicular às tensões principais de tração. Assim, o concreto foi modelado como um material ortótropo, cujas direções de ortotropia são normais e paralelas às fissuras. Para o aço, utilizou-se um modelo elasto-plástico bi-linear com encruamento isótropo, sem considerar o efeito Bauschinger. Para a aderência aço-concreto, empregou-se o modelo uniaxial de aderência-deslizamento proposto por ELIGEHAUSEN et al. (1983). A partir de comparações feitas com dados experimentais de nós internos submetidos a carregamentos cíclicos alternados, notou-se que os resultados numéricos do modelo proposto por FLEURY et al. (2000) foram satisfatórios. 
Entre os modelos mais complexos, pode-se citar o trabalho de ZIYAEIFAR \& NOGUCHI (2000), os quais propuseram um modelo sofisticado para a simulação do comportamento de nós viga-pilar, cuja formulação baseia-se no método dos elementos finitos e permite a consideração da não-linearidade dos materiais e grandes deformações associadas ao regime de ruptura.

Por fim, conforme já mencionados, estão os modelos de plasticidade concentrada, aplicados aos pórticos de concreto armado, os quais admitem que as deformações inelásticas concentram-se nas extremidades dos elementos estruturais, regiões onde os momentos fletores são máximos no caso de ações laterais atuantes. Estes modelos apresentam algumas características e facilidades, sendo comentadas no item 5.3.1.

\section{Aderência aço-concreto:}

Embora existam diversos trabalhos no campo experimental sobre a aderência mediante os efeitos das solicitações cíclicas, o mesmo não se pode dizer com relação aos modelos numéricos que possam representá-la. Na tentativa de reproduzir a aderência aço-concreto, alguns modelos analíticos foram propostos, podendo estes ser encontrados em NGO \& SCORDELIS (1967), NILSON (1971), DEGROOT et al. (1981), FILIPPOU et al. (1983), POPOV (1984), YANKELEVSKY (1985) e KEUSER \& MEHLHORN (1987). Estes trabalhos são brevemente comentados em MONTI et al. (1997).

Nos últimos anos, no campo da modelagem numérica da aderência, alguns trabalhos indicaram avanços nessa área:

MONTI et al. (1997) propuseram um modelo de elemento finito para barras de armaduras ancoradas em concreto, utilizando funções interpoladoras para as tensões de aderência. Nesse estudo, as análises associadas ao comportamento cíclico basearam-se no modelo proposto por ELIGEHAUSEN et al. (1983) para a relação tensão de aderência versus deslizamento. Por meio de comparações feitas com dados obtidos experimentalmente, provenientes inclusive de ensaios em nós externos, notou-se que o modelo proposto pelos autores apresentou resultados razoáveis na simulação de perda de aderência no caso de ações cíclicas.

ELMORSI et al. (2000) propuseram um modelo de elemento finito aplicável a ligações viga-pilar de concreto armado, seguindo a mesma linha do modelo proposto por FLEURY et al. (2000), dando uma ênfase maior na modelagem da aderência-deslizamento. O modelo proposto leva em consideração os efeitos do deslizamento da armadura e das distorções por cisalhamento, sendo incorporados a um modelo global de ligação viga-pilar (figura 5.20). $\mathrm{O}$ modelo apresentou resultados satisfatórios quando comparados com dados experimentais. 


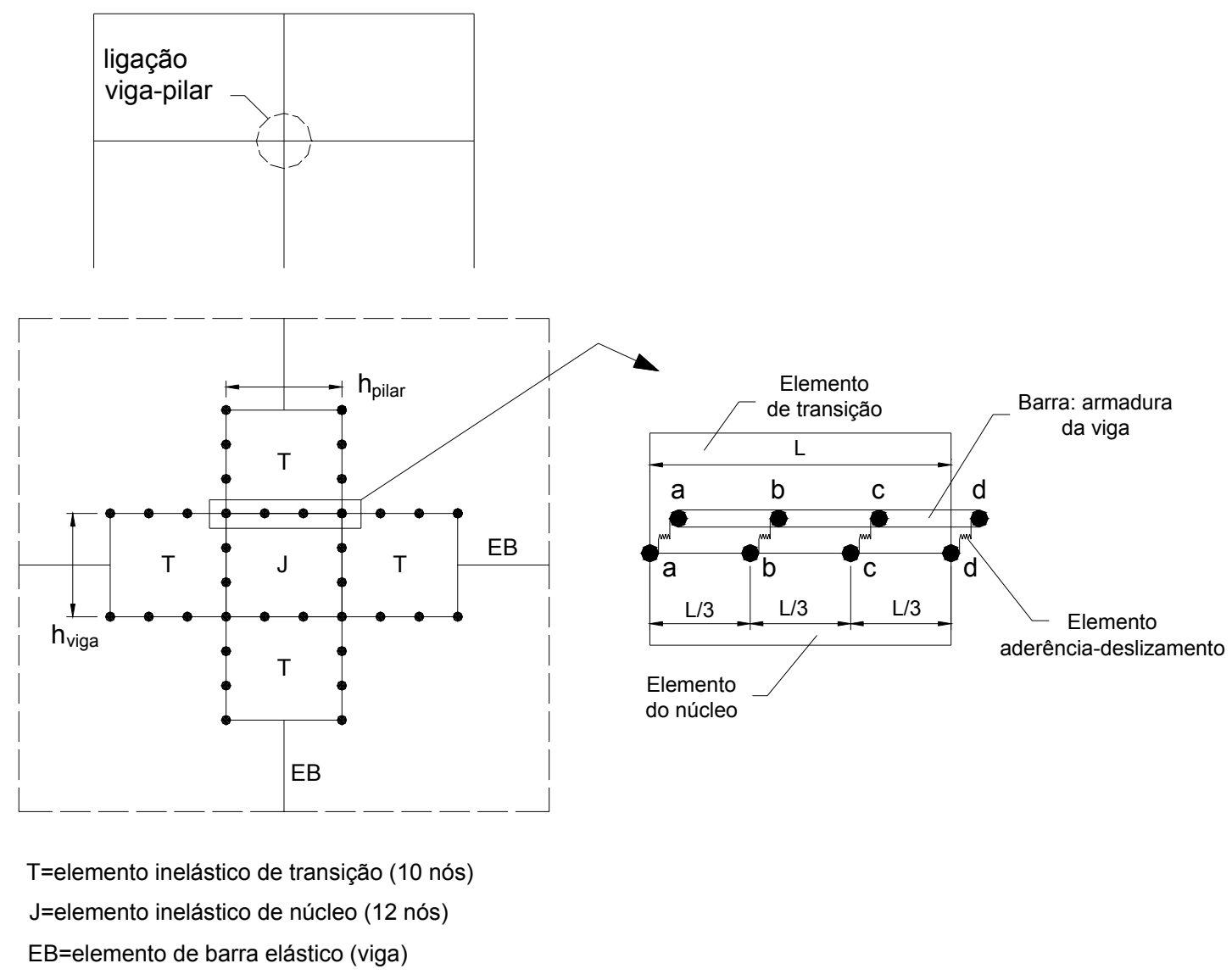

Figura 5.20: Modelo global proposto por ELMORSI et al. (2000) para ligações viga-pilar.

\subsubsection{Modelos simplificados de dano e plasticidade}

Os modelos ditos simplificados procuram simular a resposta global de estruturas em pórticos, considerando os efeitos da evolução da deterioração mecânica das mesmas. Estes modelos se caracterizam por apresentar uma formulação simples com aplicações em estudos unidimensionais. Outra vantagem prática da utilização de modelos simplificados é o fato de que a maioria dos resultados experimentais disponíveis na literatura especializada referentes ao comportamento das ligações encontra-se na forma de curvas do tipo força-deslocamento ou equivalentes.

Dessa forma é possível avaliar a influência de fenômenos tais como a fissuração do concreto, o escoamento do aço e o deslizamento das armaduras sobre a resposta global das ligações (figura 5.21). Em se tratando de ações cíclicas reversíveis, a perda de rigidez e de resistência no decorrer dos ciclos de carregamento e a dissipação de energia são pontos adicionais a serem analisados. 


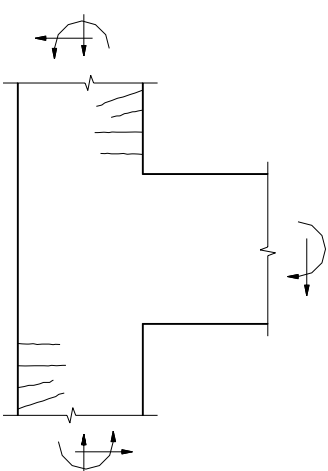

a) Fissuração do pilar

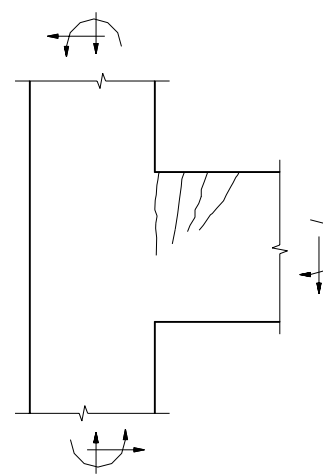

b) Fissuração da viga

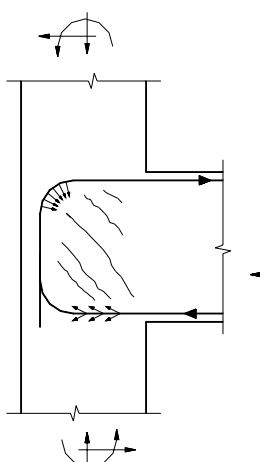

c) Fissuração do nó

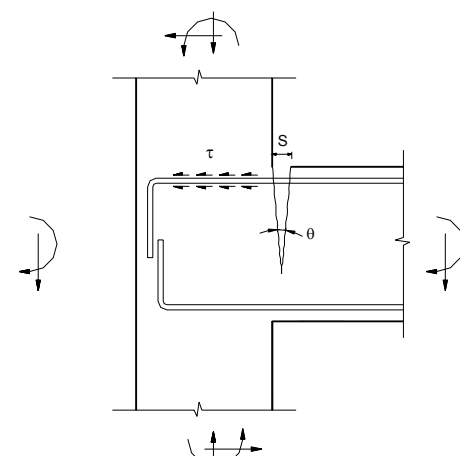

d) Deslizamento das armaduras

Figura 5.21: Fenômenos associados à deterioração mecânica de ligações viga-pilar de extremidade.

Existem modelos unidimensionais para pórticos planos que procuram avaliar os efeitos não-lineares e inelásticos ocorridos na ligação sobre a resposta global da estrutura, por meio de índices que quantificam a degradação da rigidez dos elementos e por meio de rotações inelásticas nas extremidades dos elementos. Entre os modelos unidimensionais empregados para representar pórticos de concreto armado, incluindo o comportamento histerético mediante ações reversíveis, podem-se citar os de TAKEDA et al. (1970), OTANI (1974), MEYER \& ROUFAIEL (1983), KUNNATH et al. (1990), MULAS \& FILIPPOU (1990), MIRAMONTES et al. (1996), D`AMBRISI \& FILIPPOU (1999), entre outros. Em virtude da idealização simples da estrutura e do número reduzido de graus de liberdade globais, os modelos unidimensionais são atrativos na simulação do comportamento dinâmico não-linear de estruturas de pórticos inteiras.

Para a presente pesquisa, foi de particular interesse o emprego de modelos que acoplam fenômenos de plasticidade e de dano, possibilitando a obtenção de deformações permanentes e de índices que meçam o quanto a estrutura está degradada, decorrentes da aplicação do carregamento cíclico.

Com o objetivo de representar a resposta global das ligações submetidas a solicitações cíclicas, utilizou-se o modelo de dano proposto por PICON \& FLÓREZ-LÓPEZ (2000), o qual foi precedido por relevantes trabalhos relacionados com a consideração dos efeitos da degradação do material e das deformações permanentes de estruturas em pórtico de concreto: CIPOLLINA \& FLÓREZ-LÓPEZ (1995), CIPOLLINA et al. (1995) e FLÓREZ-LÓPEZ (1995). Nesses modelos, assume-se que os processos dissipativos do elemento ocorrem em rótulas dispostas nas suas extremidades, mantendo o comportamento elástico no restante da barra (figura 5.22). 


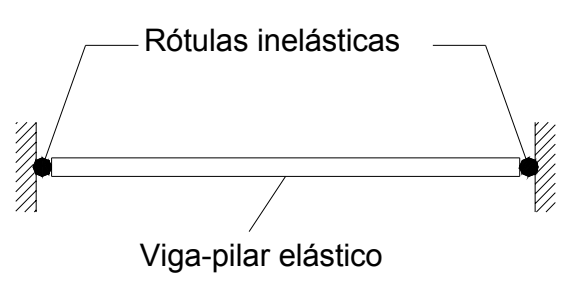

a) Elemento finito

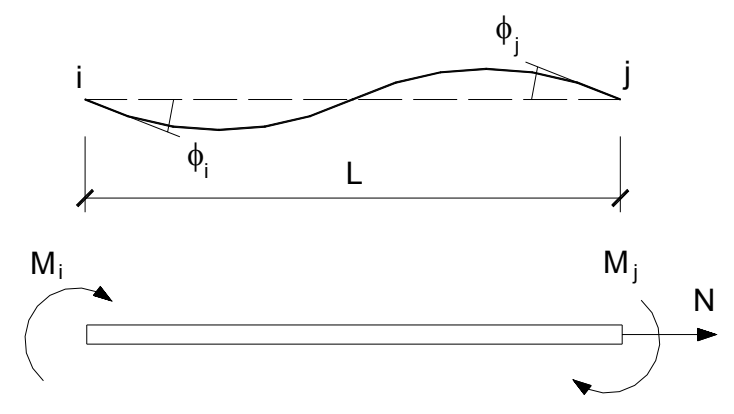

b) Deformações e esforços no elemento

Figura 5.22: Elemento de barra dos modelos simplificados de dano e plasticidade

O modelo simplificado apresentado por CIPOLLINA \& FLÓREZ-LÓPEZ (1995) serviu como referência para os demais modelos simplificados que surgiram posteriormente. Este modelo é aplicável a pórticos planos constituídos por elementos de concreto armado, admitindo, como simplificação, que os processos dissipativos concentram-se nas extremidades, simulando os efeitos de perda de rigidez e o aparecimento de deformações plásticas frente a ações monotônicas ou ações repetidas (sem inversão de sinal).

No referido modelo, a relação tensão-deformação generalizada de um elemento de barra com dano é definida por:

$$
\{M\}=\left[S^{e d}\right]\left\{\phi-\phi^{p}\right\}
$$

onde

$\{M\}$ é o vetor das tensões generalizadas (esforços) do elemento;

$\left[S^{e d}\right]$ é a matriz de rigidez do elemento, considerando-se as variáveis de dano pertinentes;

$\{\phi\}$ é o vetor de deformações generalizadas (deslocamentos) do elemento;

$\left\{\phi^{p}\right\}$ é o vetor de deformações plásticas do elemento.

A matriz de rigidez de uma barra com momento de inércia igual a $I$, de área $A$ e de comprimento $L$, considerando-se pequenos deslocamentos, é dada por:

$$
\left[S^{\text {ed }}\right]=\left[\begin{array}{ccc}
\frac{\left(1-d_{i}\right)\left(4-d_{j}\right)}{4-d_{i} d_{j}} 4 E I / L & \frac{4\left(1-d_{i}\right)\left(1-d_{j}\right)}{4-d_{i} d_{j}} 2 E I / L & 0 \\
S I M . & \frac{\left(1-d_{j}\right)\left(4-d_{i}\right)}{4-d_{i} d_{j}} 4 E I / L & 0 \\
& & \left(1-d_{n}\right) E A / L
\end{array}\right]
$$

onde

$d_{i}$ e $d_{j}$ são os parâmetros que medem o dano correspondente à rotação das rótulas;

$d_{n}$ é o valor de dano devido ao esforço axial na barra. 
Os valores de $d_{i}, d_{j}$ e $d_{n}$ variam entre 0 e 1 . Vale observar que, quando os três índices de dano são iguais a zero, obtém-se a matriz de rigidez para uma barra com comportamento elástico. Para $d_{i}$ e $d_{j}$ iguais à unidade, obtém-se a matriz de rigidez de uma barra de treliça.

A partir de resultados experimentais, as seguintes funções limites foram propostas para o controle do dano e da plastificação:

$f=\left|M-\left(\frac{1-d}{4-d}\right) c \phi^{p}\right|-4\left(\frac{1-d}{4-d}\right) M_{y} \quad$ (plasticidade)

$g=G-\left(G_{c r}+q \frac{\ln (1-d)}{(1-d)}\right) \quad($ dano $)$

onde

M é o momento fletor na extremidade do elemento;

d é o valor do dano na extremidade;

$\phi^{\mathrm{p}}$ é a rotação plástica na extremidade;

$\mathrm{G}=\frac{1}{2 \mathrm{~S}_{11}}\left(\frac{\mathrm{M}}{1-\mathrm{d}}\right)^{2} ; \mathrm{G}_{\mathrm{cr}}=\frac{\mathrm{M}_{\mathrm{cr}}{ }^{2}}{2 \mathrm{~S}_{11}} ; \mathrm{S}_{11}=4 \mathrm{EI} / \mathrm{L}$

c, $M_{y}$, q e $G_{c r}$ são constantes que caracterizam o elemento.

O pequeno número de parâmetros requeridos para a determinação das constantes é uma das principais vantagens do modelo de dano em questão. São esses parâmetros: o momento de fissuração $M_{c r}$, o momento de plastificação $M_{p}$, o momento último $M_{u}$ e a rotação plástica última $\phi_{\mathrm{pu}}$ do elemento, todos possuindo um significado físico bem claro para o engenheiro estrutural, e podem ser obtidos experimentalmente ou pelo cálculo tradicional de seções de concreto armado. A determinação das demais constantes, calculadas a partir dos quatro parâmetros referidos, é apresentada em ÁLVARES (1999) e abordada brevemente no ANEXO A.

Com a finalidade de considerar as diferentes deformabilidades sobre a rotação plástica $\phi^{p}$, de modo que possam ser aplicadas em modelos de plasticidade concentrada, PARK \& ANG ${ }^{1}$ apud CEB (1994) Bulletin d'Information n.220 propuseram um modelo semi-empírico para avaliar essas rotações plásticas em termos dos parâmetros geométricos e mecânicos dos elementos. A rotação $\phi^{p}$ pode então ser expressa pela contribuição de três parcelas:

$\phi^{\mathrm{p}}=\phi_{\text {flex }}+\phi_{\text {slip }}+\phi_{\text {shear }}$

onde

$\phi_{\text {flex }}$ é a contribuição das deformações por flexão;

$\phi_{\text {slip }}$ é a contribuição do deslizamento das armaduras;

$\phi_{\text {shear }}$ é contribuição das deformações por cisalhamento.

\footnotetext{
${ }^{1}$ PARK, Y.J.; ANG, A.M. (1985). Mechanistic seismic damage model of reinforced concrete. Journal of Struct. Engrg. ASCE, v.111, ST4, p.722-39; COMITEE EURO-INTERNATIONAL DU BETON - CEB (1994). Behavior and analysis of reinforced concrete structures under alternate actions inducing inelastic response. Bulletin d'Information, n.220.
} 
O CEB (1994) Bulletin d'Information n.220 apresenta com mais detalhes a formulação para a cálculo dos valores dessas três parcelas. Vale lembrar que nas ligações viga-pilar, o efeito do deslizamento das barras contribui significativamente para a rotação total dos elementos.

A perspectiva de obter resultados satisfatórios empregando os já mencionados modelos de dano e plasticidade na resposta global da ligação surgiu das contribuições do trabalho de ÁLVARES (1999), em pesquisa desenvolvida no Departamento de Estruturas da Escola de Engenharia de São Carlos, relacionada ao estudo de modelos simplificados aplicáveis a estruturas de barras em concreto armado.

\subsubsection{FLÓREZ-LÓPEZ (1995)}

Dando continuidade aos modelos simplificados de dano e plasticidade, deve-se citar o trabalho de FLÓREZ-LÓPEZ (1995), que apresentou um modelo de dano mais amplo, utilizando uma formulação similar ao modelo de CIPOLLINA \& FLÓREZ-LÓPEZ (1995), porém aplicável às ações cíclicas reversíveis. Neste modelo foi possível a consideração de dois aspectos importantes quando se trata de ações reversíveis:

- Permitiu a análise numérica de seções não-simétricas quanto à armadura principal, o que não era possível com os outros modelos anteriores;

- Possibilitou a representação do comportamento unilateral. Nos elementos de concreto armado, este tipo de comportamento ocorre devido ao fechamento das fissuras na inversão do sinal do carregamento. O termo unilateral está associado ao fato de o dano provocado pelas ações positivas não exercer influência sobre o dano produzido pelas ações negativas.

FLÓREZ-LÓPEZ (1995) utiliza dois conjuntos de variáveis independentes de dano: uma associada a ações ditas positivas e outra associada a ações de sentido contrário às primeiras, ditas negativas. As novas funções limites do modelo apresentam a seguinte forma:

\section{Ações positivas}

$$
\begin{aligned}
& \mathrm{f}^{+}=M-\alpha^{+} \frac{1-\mathrm{d}^{+}}{4-\mathrm{d}^{+}} c^{+} \phi^{p}-\frac{1-\mathrm{d}^{+}}{4-\mathrm{d}^{+}}\left[\left(1-\alpha^{+}\right) c^{+} p+4 \mathrm{M}_{\mathrm{y}}^{+}\right] \\
& \mathrm{g}^{+}=\mathrm{G}^{+}-\mathrm{G}_{\mathrm{cr}}^{+}-\mathrm{q}^{+} \frac{\ln \left(1-\mathrm{d}^{+}\right)}{1-\mathrm{d}^{+}}
\end{aligned}
$$

\section{Ações negativas}

$$
\begin{aligned}
& \mathrm{f}^{-}=-\mathrm{M}+\alpha^{-} \frac{1-\mathrm{d}^{-}}{4-\mathrm{d}^{-}} \mathrm{c}^{-} \phi^{\mathrm{p}}-\frac{1-\mathrm{d}^{-}}{4-\mathrm{d}^{-}}\left[\left(1-\alpha^{-}\right) \mathrm{c}^{-} \mathrm{p}+4 \mathrm{M}_{\mathrm{y}}{ }^{-}\right] \\
& \mathrm{g}^{-}=\mathrm{G}^{-}-\mathrm{G}_{\mathrm{cr}}{ }^{-}-\mathrm{q}^{-} \frac{\ln \left(1-\mathrm{d}^{-}\right)}{1-\mathrm{d}^{-}}
\end{aligned}
$$

As novas constantes introduzidas ao modelo de dano de FLÓREZ-LÓPEZ (1995) são identificadas no ANEXO A. 
A figura 5.23 ilustra qualitativamente os resultados típicos obtidos com o emprego do modelo.

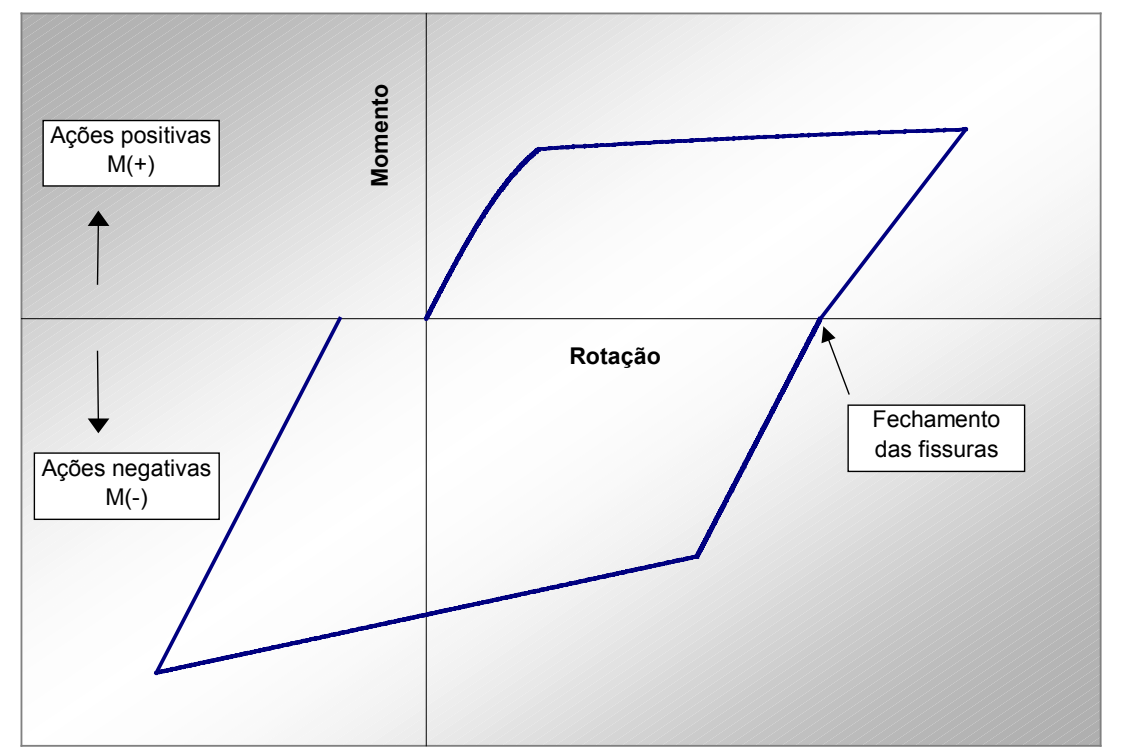

Figura 5.23: Resultados fornecidos pelo modelo unilateral de FLÓREZ-LÓPEZ (1995)

Neste modelo, o valor do dano é função da máxima amplitude de deformação atingida pelo elemento durante o carregamento cíclico, não dependendo do número de ciclos, o que impossibilita a consideração do efeito de fadiga. Assim, o modelo de dano proposto por FLÓREZ-LÓPEZ (1995) ainda não era capaz de considerar o acréscimo de dano em função do número de ciclos.

\subsubsection{PICÓN \& FLÓREZ-LÓPEZ (2000)}

Posteriormente, desenvolveram-se modelos simplificados de dano que incluíram o efeito de fadiga, ou seja, o efeito do aumento da degradação do material como conseqüência do número de ciclos de carga. Nessa linha de desenvolvimento, podem-se citar os trabalhos de BENDITO et al. (1997), THOMSON et al. (1998), PICÓN \& FLÓREZ-LÓPEZ (2000) e PERERA et al. (2000).

BENDITO et al. (1997) e THOMSON et al. (1998) apresentam uma formulação similar à proposta por FLÓREZ-LÓPEZ (1995), porém incluem um parâmetro adicional na lei de evolução de dano por fadiga, a qual possui a seguinte forma genérica:

$$
\begin{aligned}
& \dot{d}=\frac{G^{\alpha}}{R^{\alpha} \frac{\partial R}{\partial d}}<\dot{G}>\quad \text { se } \quad G \geq G_{c r} \\
& \dot{d}=0 \text { se } \quad G<G_{c r}
\end{aligned}
$$

onde $G$ são as forças termodinâmicas associadas ao dano e $R$ entendidas como a resistência à fissuração. $G_{c r}$ corresponde ao valor de $G$ para d igual à 0 . 
O parâmetro $\alpha$, que controla o incremento de dano por fadiga, é mantido constante em toda a análise numérica, e seu valor deve ser estimado a partir de resultados experimentais. Os autores recomendam, como simplificação, adotar um valor de $\alpha$ em torno de 2.0. Entretanto, as simulações numéricas, confrontadas com resultados experimentais, levaram os autores a reconhecer que manter o parâmetro $\alpha$ constante consistia em uma hipótese muito simplificadora.

PICÓN \& FLÓREZ-LÓPEZ (2000), por sua vez, propõem que o parâmetro $\alpha$ seja substituído por um parâmetro $z$, variável no decorrer da análise numérica e dependente das características da estrutura. Segundo os autores, o parâmetro z é decrescente com o dano, sendo representado por um polinômio do segundo grau definido a partir de três condições: i) para $d=0, z=30$; ii) para $d=1, z=0$; iii) para $d=d_{u}, z=2.5$. A partir dessas condições, chega-se a expressão proposta pelos autores para determinar $z$ :

$\mathrm{z}=\mathrm{Ad} \mathrm{d}^{2}+\mathrm{Bd}+30$

onde $A=\frac{2,5+30\left(d_{u}-1\right)}{d_{u}\left(d_{u}-1\right)}, \quad B=-A-30$ e $d_{u}$ é o dano correspondente ao momento último.

As simulações numéricas de vigas em balanço e de pórticos de concreto armado realizadas por PICÓN \& FLÓREZ-LÓPEZ (2000) mostraram um desempenho satisfatório em representar o fenômeno da fadiga. A formulação algébrica desse modelo é abordada no ANEXO A.

Tendo em vista o potencial do modelo de PICÓN \& FLÓREZ-LÓPEZ (2000), foram realizadas análises numéricas em ligações viga-pilar de extremidade empregando-se o referido modelo, cujos resultados e conclusões são descritos no item 5.3.4.

\subsubsection{Simulações numéricas com os modelos de dano originais}

O modelo de dano e plasticidade concentrada foi implementado em um programa computacional aplicável à resolução de pórticos planos, acrescentado-se os critérios de danificação e plastificação propostos por PICON \& FLÓREZ-LÓPEZ (2000), os quais incluem o efeito da fadiga. Foram feitas simulações numéricas que possibilitaram a comparação entre os resultados teóricos e os resultados experimentais de ensaios em ligações viga-pilar de concreto armado.

\section{Exemplo Teórico 1:}

Este exemplo refere-se a uma ligação viga-pilar de extremidade submetida a uma força normal constante no topo do pilar e uma força vertical variável na extremidade da viga. As seções do pilar e da viga são simétricas quanto à armadura principal. O deslocamento vertical é restrito na base do pilar e os deslocamentos horizontais restritos nas extremidades do mesmo. A seguir, resumem-se os valores utilizados nas propriedades físicas dos materiais e os valores dos parâmetros do modelo. 


\begin{tabular}{|c|c|c|c|c|}
\hline Materiais & \multicolumn{4}{|c|}{ Parâmetros do modelo simplificado } \\
\hline $\begin{array}{l}\text { Aço } \\
f_{y}=500 \mathrm{MPa}\end{array}$ & \multicolumn{2}{|c|}{$\underline{\text { Viga }}$} & \multicolumn{2}{|c|}{$\underline{\text { Pilar }}$} \\
\hline$f_{u}=1,2 f_{y}$ & $M_{c r}=1612 \mathrm{kN} \cdot \mathrm{cm}$ & $q=-43,655 \mathrm{kN} . \mathrm{cm}$ & $M_{c r}=2912 \mathrm{kN} \cdot \mathrm{cm}$ & $q=-29,184 \mathrm{kN} \cdot \mathrm{cm}$ \\
\hline $\mathrm{E}_{\mathrm{s}}=210000 \mathrm{MPa}$ & $M_{p}=13493 \mathrm{kN} \cdot \mathrm{cm}$ & $\mathrm{M}_{\mathrm{y}}=17590 \mathrm{kN} \cdot \mathrm{cm}$ & $M_{p}=11039 \mathrm{kN} . \mathrm{cm}$ & $M_{y}=17560 \mathrm{kN} \cdot \mathrm{cm}$ \\
\hline Concreto & $M_{u}=16587 \mathrm{kN} \cdot \mathrm{cm}$ & $\mathrm{c}=2877323 \mathrm{kN} . \mathrm{cm}$ & $M_{u}=11667 \mathrm{kN} \cdot \mathrm{cm}$ & $\mathrm{c}=7678543 \mathrm{kN} . \mathrm{cm}$ \\
\hline $\begin{array}{l}\mathrm{f}_{\mathrm{c}}=30 \mathrm{MPa} \\
\mathrm{E}_{\mathrm{c}}=26070 \mathrm{MPa}\end{array}$ & $\begin{array}{l}\phi_{p u}=0,0282 \mathrm{rad} \\
\alpha=0,8\end{array}$ & $d_{u}=0,631163$ & $\begin{array}{l}\phi_{p u}=0,0046 \mathrm{rad} \\
\alpha=0,8\end{array}$ & $\mathrm{du}=0,625699$ \\
\hline
\end{tabular}

Os valores dos parâmetros referem-se tanto às ações positivas quanto negativas, devido à simetria das seções.

A figura 5.24 contém a curva força-deslocamento na extremidade da viga aplicando-se um ciclo de carga (com inversão de sinal). A figura 5.25 contém a curva força-deslocamento para 20 ciclos de carregamento com amplitude de deslocamentos constante.

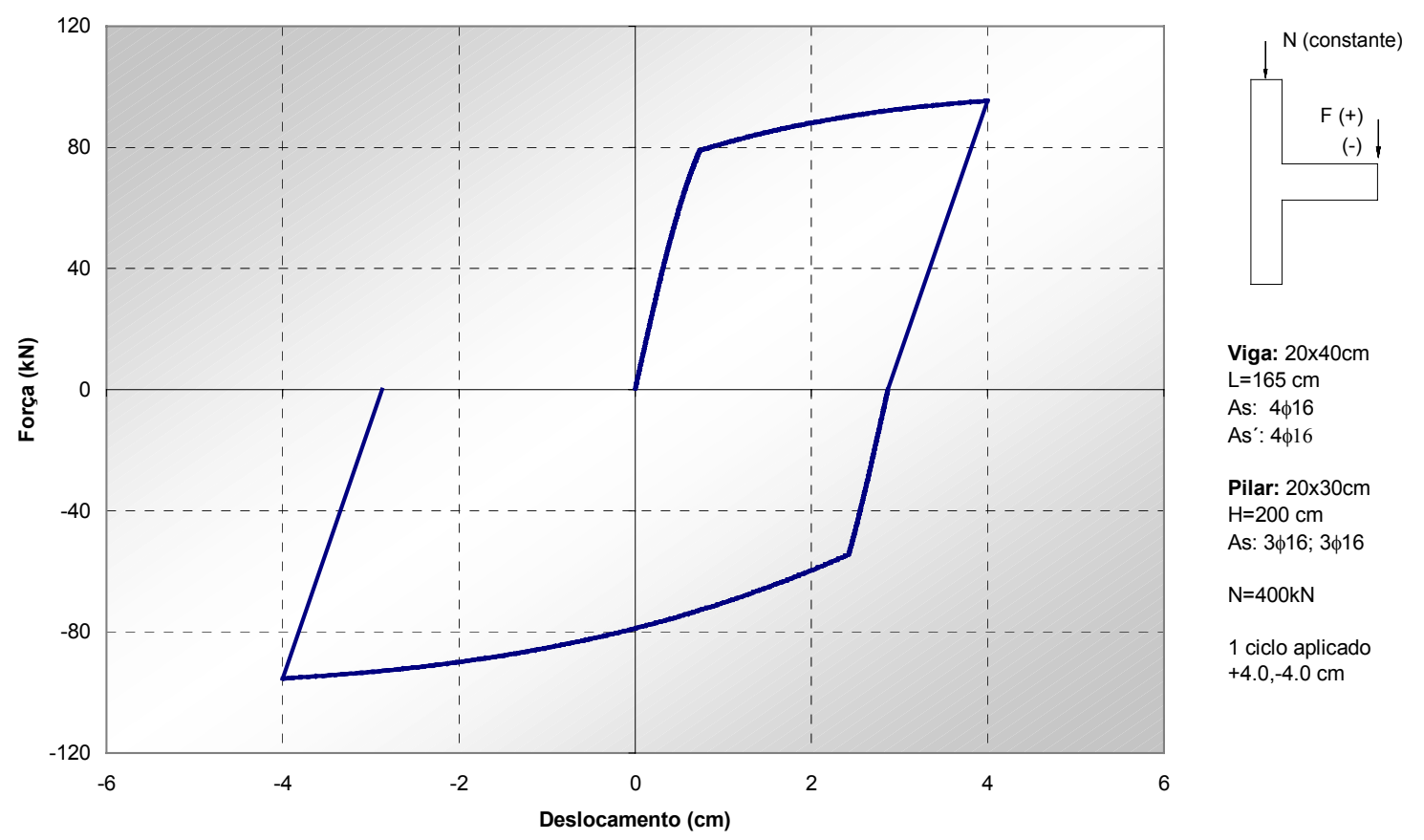

Figura 5.24: Curva força-deslocamento na extremidade da viga - 1 ciclo de carregamento

Pela figura 5.24, nota-se que o modelo simplificado consegue capturar as deformações permanentes na inversão de sinal. Observa-se que o descarregamento ocorre com uma inclinação da curva força-deslocamento menor que a do início do carregamento, fato que se deve à danificação atingida no ciclo. 


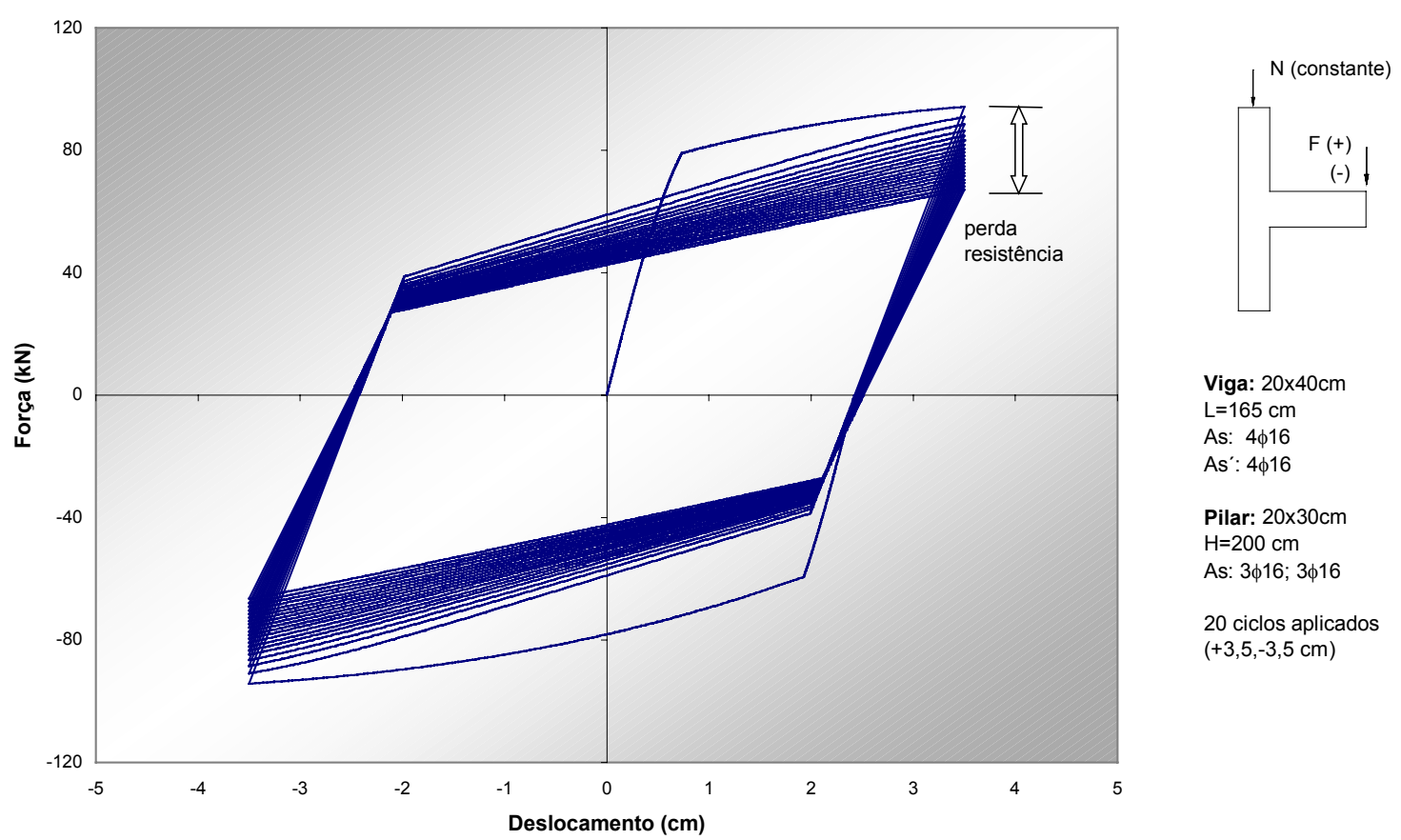

Figura 5.25: Curva força-deslocamento na extremidade da viga - 20 ciclos aplicados

Pela figura 5.25, percebe-se que o modelo simplificado considera também a evolução do dano em função do número de ciclos aplicados, e não somente em função do deslocamento atingido nos ciclos.

As figuras 5.26 e 5.27 ilustram o decréscimo de rigidez dos elementos estruturais da ligação com os ciclos de carregamento.

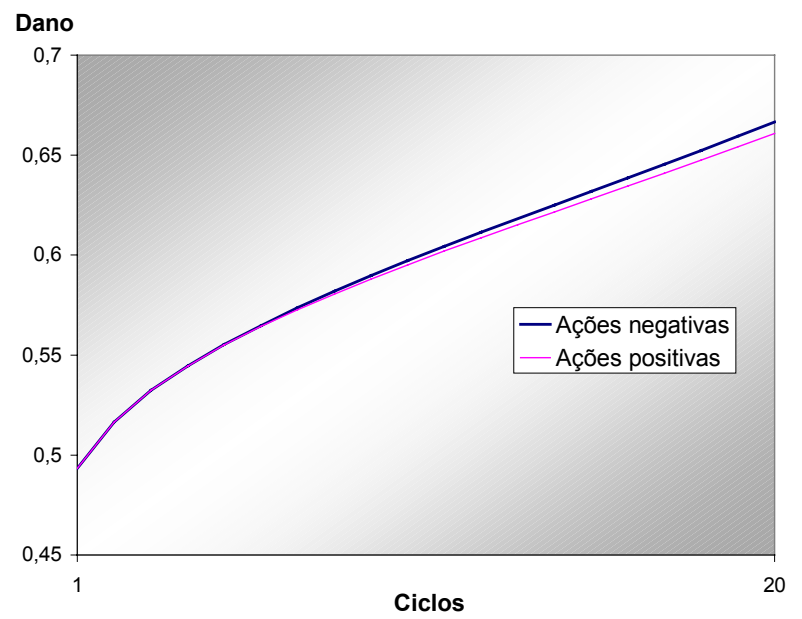

Figura 5.26: Evolução do dano em função dos ciclos - viga 


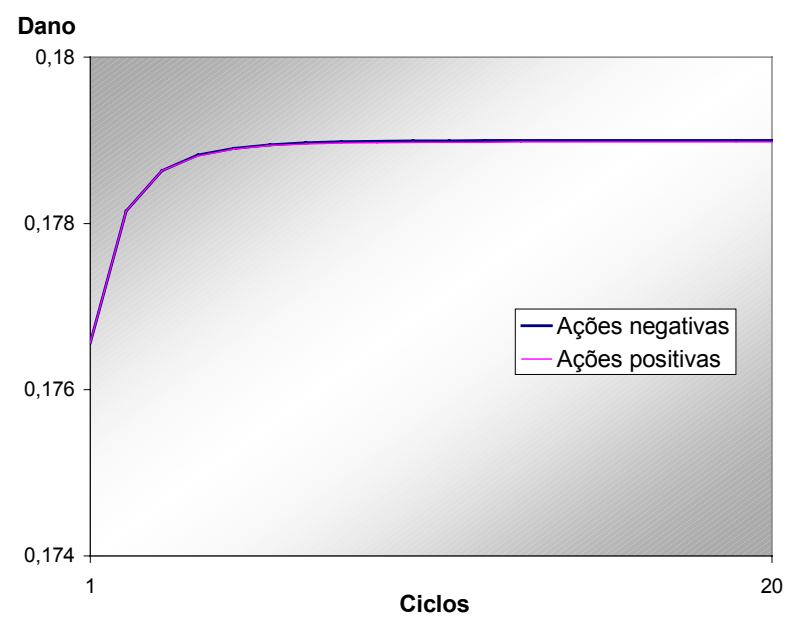

Figura 5.27: Evolução do dano em função dos ciclos - pilar

Nota-se neste exemplo que a evolução do dano na viga é maior que a do pilar, em virtude das diferentes intensidades de solicitação entre os elementos. Quanto maior o momento fletor alcançado no ciclo, mantendo-se constante a amplitude de deslocamentos, maior o decréscimo de rigidez por fadiga, especialmente para solicitações próximas à plastificação.

A partir da figura 5.28 constata-se que as rotações plásticas desenvolvidas na extremidade da viga durante os ciclos de carregamento também aumentam, em conseqüência do acréscimo do nível de dano ao longo dos ciclos.
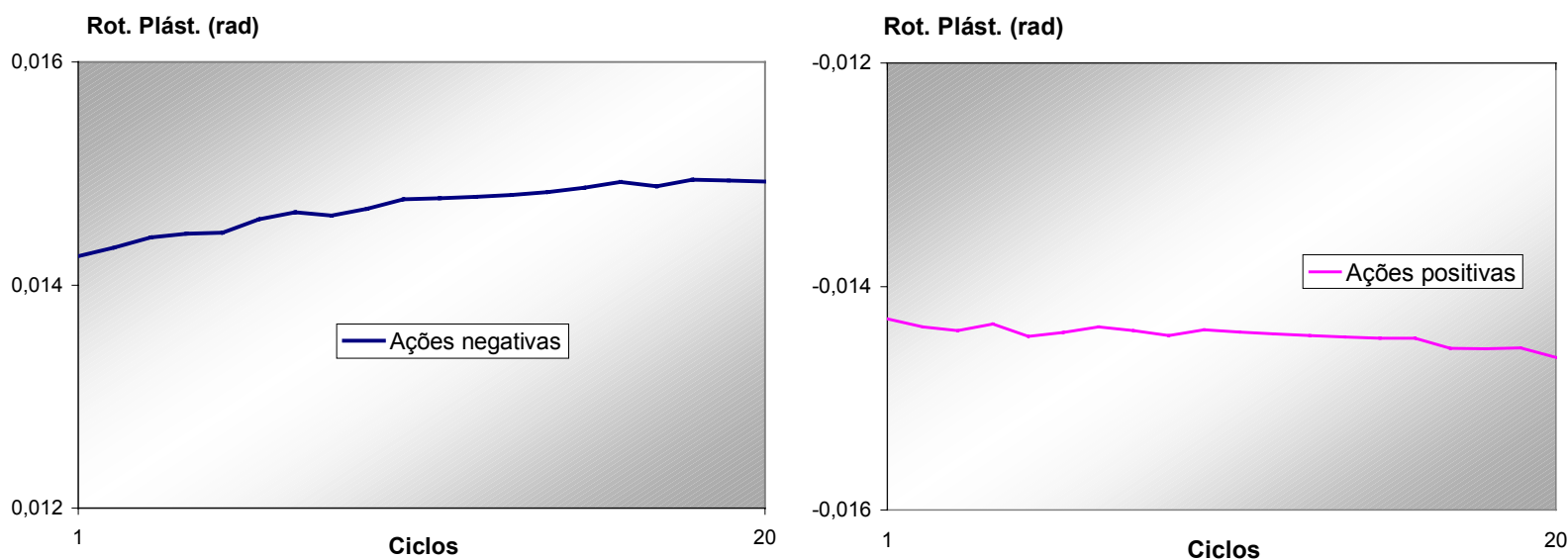

Figura 5.28: Rotações plásticas na extremidade da viga ao longo dos ciclos

Embora o modelo simplificado em questão não apresente um índice específico de dano devido à força normal, esta acaba sendo considerada na determinação dos parâmetros necessários ao modelo $\left(M_{c r}, M_{p}, M_{u}\right.$ e $\left.\phi_{p u}\right)$, influenciando, de certa forma, o comportamento global da ligação viga-pilar. A título de comparação, a tabela 5.3 apresenta os valores do nível de dano nas extremidades do pilar próximas à viga, utilizando valores diferentes para a força axial no pilar. 
Tabela 5.3: Nível de dano no pilar após 20 ciclos

\begin{tabular}{|c|c|}
\hline Força normal no pilar & Dano no pilar: ações negativas \\
\hline $400 \mathrm{kN}$ & 0,178997 \\
\hline $250 \mathrm{kN}$ & 0,256559 \\
\hline $150 \mathrm{kN}$ & 0,357585 \\
\hline
\end{tabular}

\section{Resultados experimentais de EHSANI \& WIGHT (1985)}

EHSANI \& WIGHT (1985) conduziram um estudo experimental com base no ensaio de seis ligações viga-pilar de extremidade submetidas a ações cíclicas reversíveis. Escolheu-se para a simulação numérica o modelo cuja a geometria e detalhamento estão indicados na figura 5.29. A tabela 5.4 apresenta as principais características dos materiais aço e concreto utilizados nos elementos estruturais.

Tabela 5.4: Características mecânicas dos materiais - EHSANI \& WIGHT (1985)

\begin{tabular}{|c|c|}
\hline Elemento & \multicolumn{1}{|c|}{ Propriedades resistentes dos materiais } \\
\hline Viga & Concreto $\mathrm{f}_{\mathrm{c}}=35 \mathrm{MPa} ;$ Armadura longitudinal $: \mathrm{f}_{\mathrm{y} 1}=331 \mathrm{MPa} ; \mathrm{f}_{\mathrm{y} 2}=345 \mathrm{MPa}$ \\
\hline Pilar & Concreto $\mathrm{f}_{\mathrm{c}}=35 \mathrm{MPa}$; Armadura longitudinal $: \mathrm{f}_{\mathrm{y} 1}=331 \mathrm{MPa} ; \mathrm{f}_{\mathrm{y} 2}=345 \mathrm{MPa}$ \\
\hline
\end{tabular}

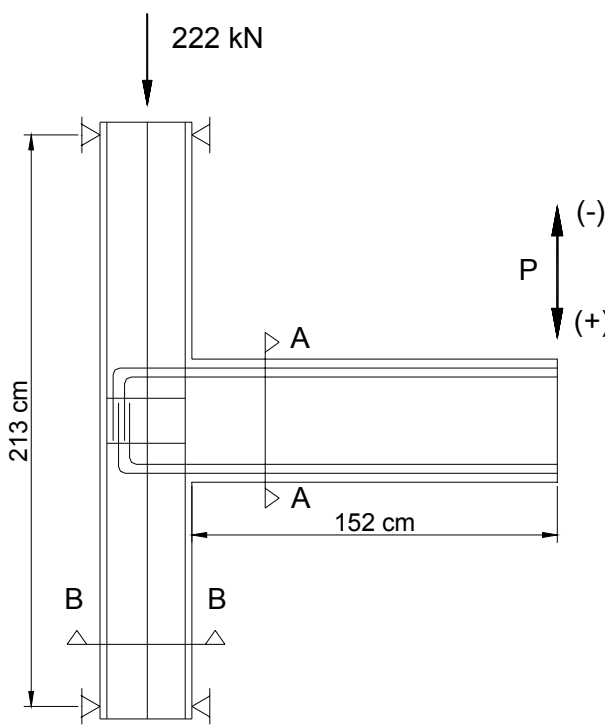

(Medidas em cm)
Viga:

Seção AA

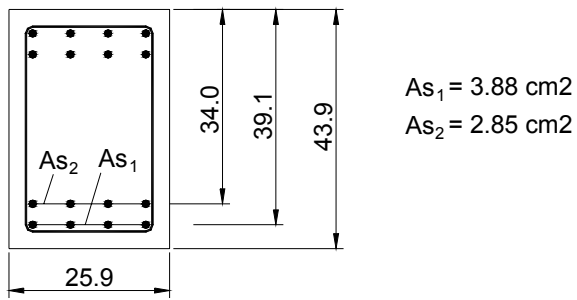

$\begin{array}{lll}A s_{1} & A s_{2} & A s_{1}\end{array}$

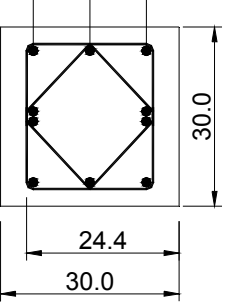

$A s_{1}=11.40 \mathrm{~cm} 2$

$\mathrm{As}_{2}=5.70 \mathrm{~cm} 2$

Pilar:

Seção BB

Figura 5.29: Geometria da ligação ensaiada por EHSANI \& WIGHT (1985).

O procedimento de ensaio pode ser resumido da seguinte maneira: inicialmente a aplicação de uma força normal constante no topo do pilar, com posterior aplicação de uma força vertical concentrada na extremidade da viga, controlando-se os deslocamentos. A figura 5.30 contém a história de deslocamentos aplicados à extremidade da viga. 
Os parâmetros do modelo foram obtidos por meio dos resultados experimentais. A determinação paramétrica também pode ser realizada ou auxiliada por meio do cálculo usual de seções de concreto armado.

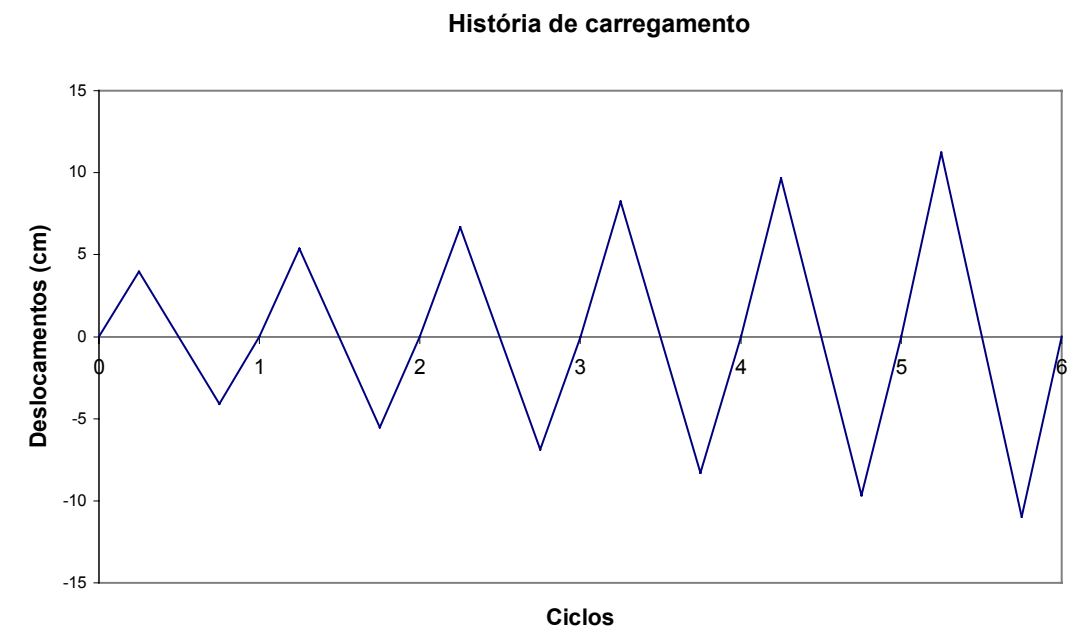

Figura 5.30: História de deslocamentos impostos à extremidade da viga.

As figuras 5.31 e 5.32 contêm as curvas força-deslocamento na extremidade da viga obtidas experimentalmente e pela simulação numérica utilizando o modelo simplificado de dano. 


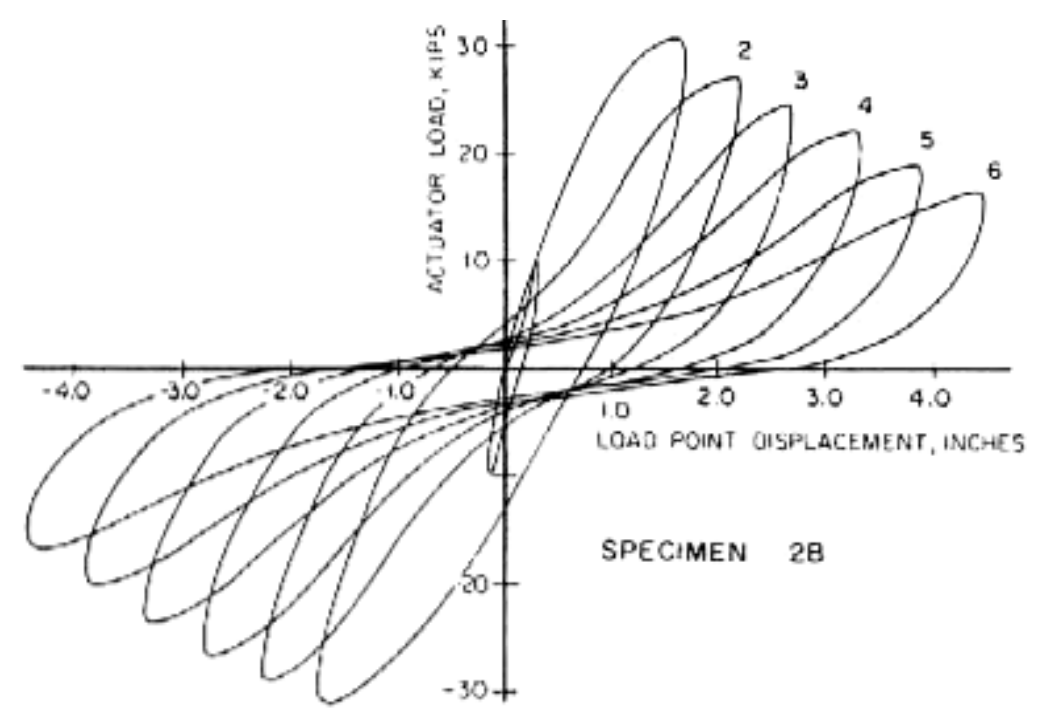

Figura 5.31: Curva força-deslocamento experimental - EHSANI \& WIGHT (1985)

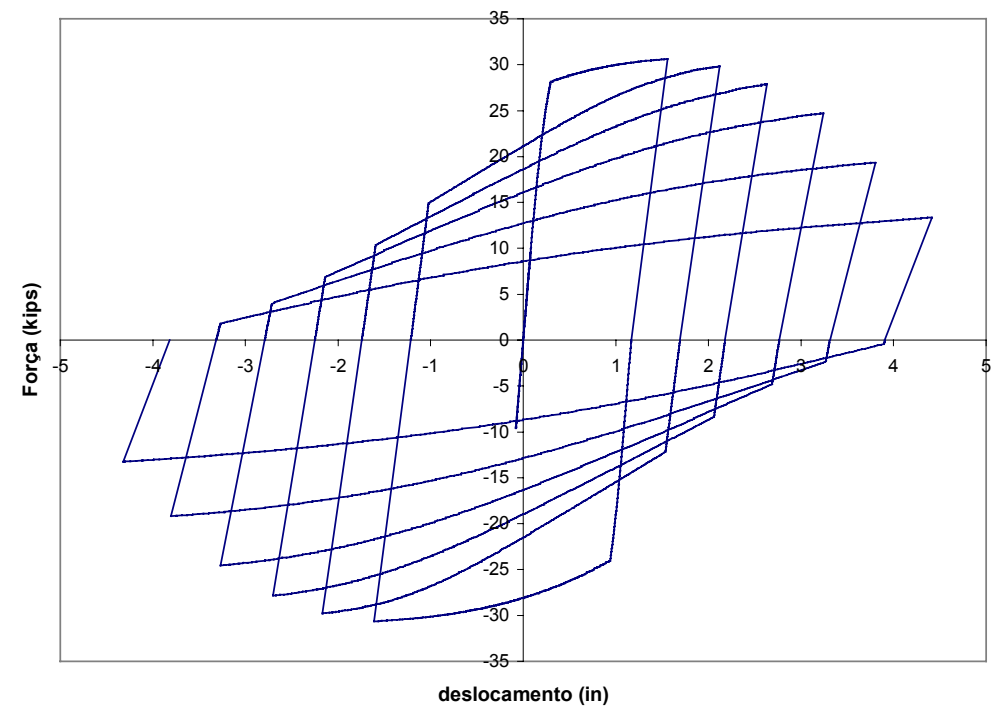

Figura 5.32: Curva força-deslocamento: modelo de PICÓN \& FLÓREZ-LÓPEZ (2000)

A comparação entre as figuras 5.31 e 5.32 indica que o modelo proposto por PICÓN \& FLÓREZ-LÓPEZ (2000) apresentou um bom desempenho em representar o comportamento global (histerético) da ligação, incluindo os fenômenos de perda de rigidez e de resistência e o aparecimento de deformações permanentes.

Uma das limitações do modelo, entretanto, é o fato de não considerar o efeito de estrangulamento, conhecido na literatura como efeito pinching, observado na curva forçadeslocamento para forças próximas de zero, entre uma fase descarregamento e o subseqüente recarregamento no sentido inverso. É um efeito típico que decorre da presença de elevadas forças cortantes.

As figuras 5.33 e 5.34 permitem visualizar o decréscimo da máxima força resistida pela ligação no decorrer dos ciclos. Pelas curvas das figuras mencionadas, pôde-se concluir que o modelo simplificado de dano fornece bons resultados no fenômeno de perda de resistência e de rigidez da ligação. 


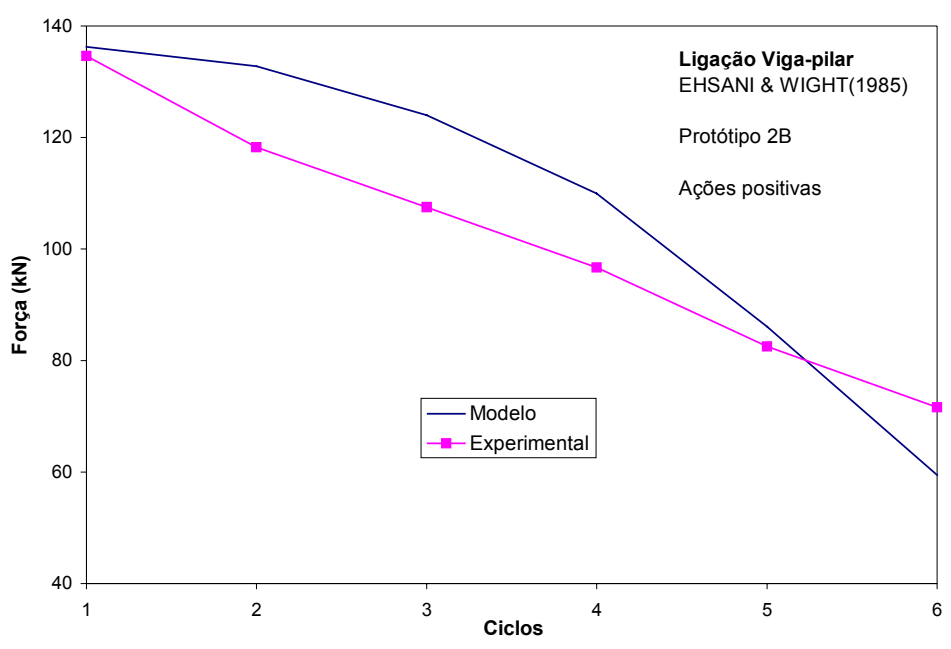

Figura 5.33: Força máxima alcançada ao longo dos ciclos: ações positivas

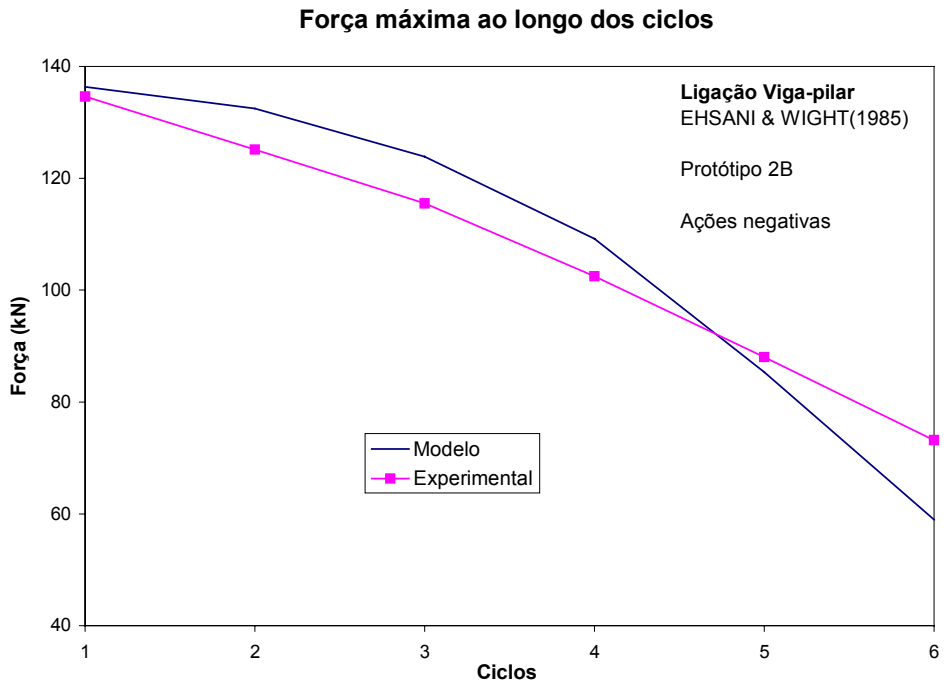

Figura 5.34: Força máxima alcançada ao longo dos ciclos: ações negativas

\section{$\underline{\text { Resultados experimentais de JIURU et al. (1992) }}$}

JIURU et al. (1992) realizaram um estudo experimental visando investigar o efeito da adição de fibras de aço sobre o comportamento estrutural de ligações viga-pilar frente às ações sísmicas. Os pesquisadores ensaiaram 12 modelos físicos representativos de nós externos (5) e de nós internos (7), dentre os quais estão inclusos modelos sem a adição de fibras. Escolheu-se, para a simulação numérica, o modelo físico identificado como $R C 4$ no trabalho de JIURU et al (1992), que consiste em uma ligação viga-pilar de extremidade sem fibras. A geometria da ligação está indicada na figura 5.35. Os valores da resistência à compressão do concreto e da resistência ao escoamento do aço empregados nos elementos estruturais estão contidos na tabela 5.5 . 
Tabela 5.5: Resistência à compressão do concreto e resistência ao escoamento das barras

\begin{tabular}{|c|c|}
\hline Elemento & Propriedades resistentes \\
\hline Viga & $\mathrm{f}_{\mathrm{c}}=21,3 \mathrm{MPa} ; \mathrm{f}_{\mathrm{y}}=450 \mathrm{MPa}$ \\
\hline Pilar & $\mathrm{f}_{\mathrm{c}}=31,9 \mathrm{MPa} ; \mathrm{f}_{\mathrm{y}}=450 \mathrm{MPa}$ \\
\hline
\end{tabular}
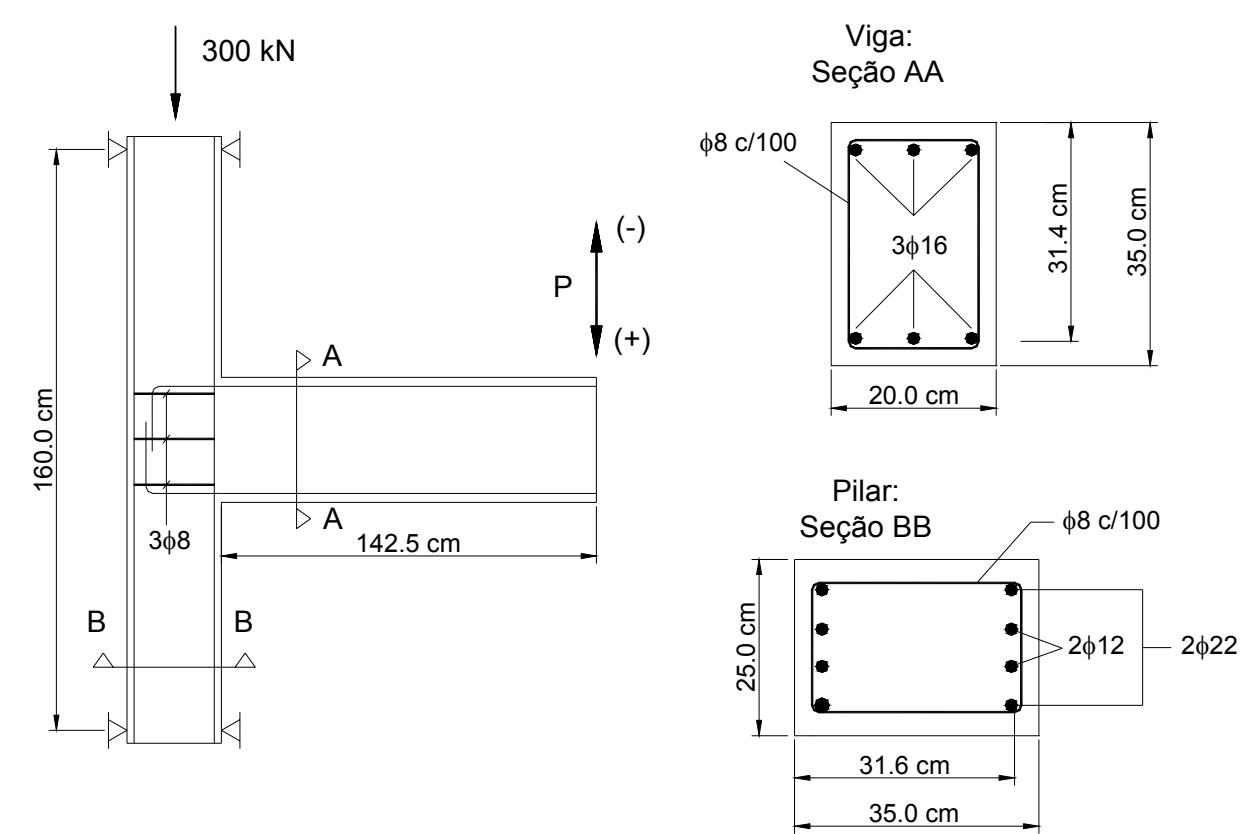

Figura 5.35: Geometria da ligação ensaiada por JIURU et al. (1992).

Com relação ao carregamento aplicado, o pilar foi submetido a uma força axial constante e igual à $300 \mathrm{kN}$ em todo o ensaio. Em seguida, a viga foi submetida a 5 ciclos de carregamento em sua extremidade, com controle de força (figuras 5.36), sendo posteriormente submetida aos deslocamentos impostos conforme a figura 5.37 .

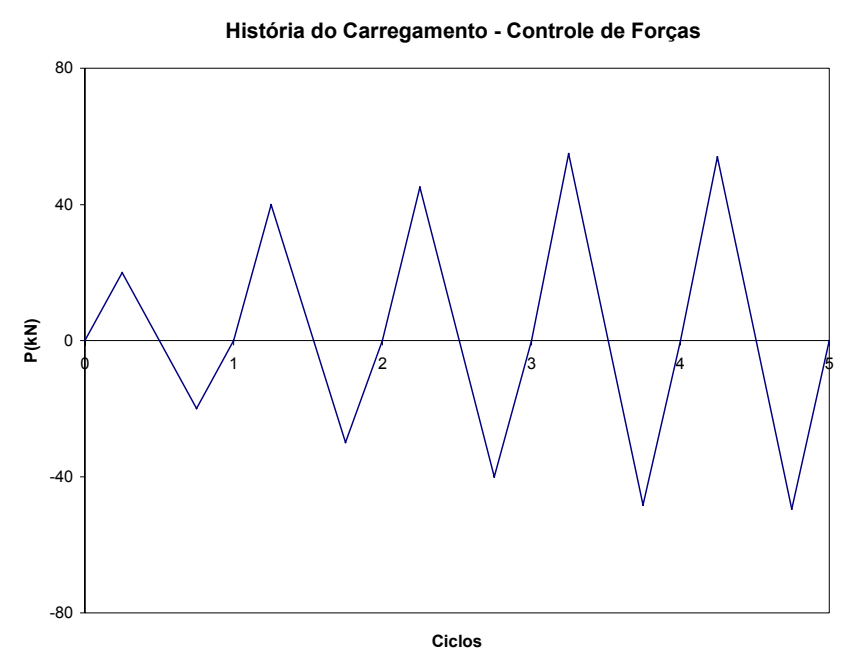

Figura 5.36: Carregamento aplicado - JIURU et al. (1992) 


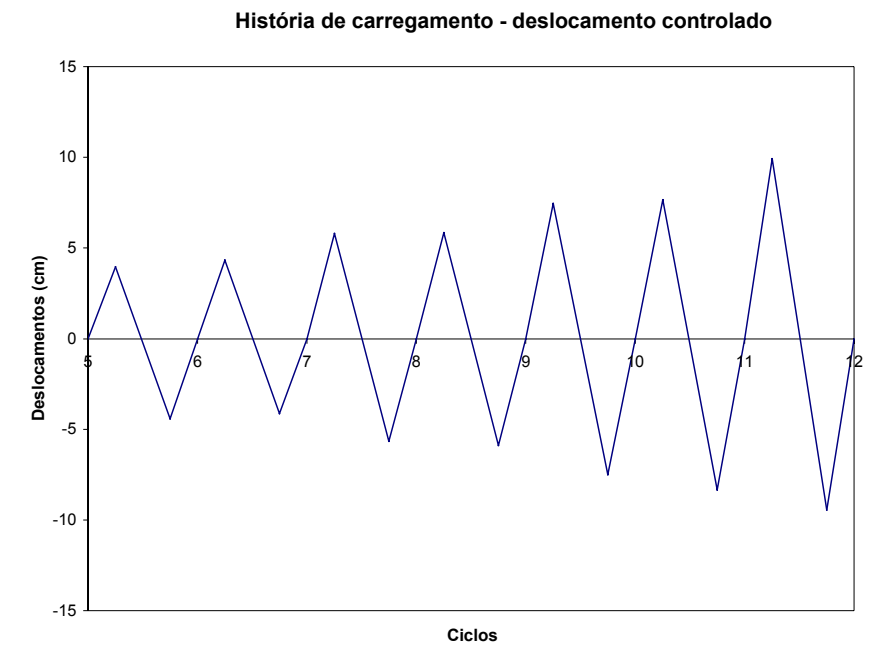

Figura 5.37: Deslocamento imposto - JIURU et al. (1992)

A comparação entre as curvas força-deslocamento na extremidade da viga - fornecida pelo ensaio e pelo modelo simplificado de dano - pode ser visualizada nas figuras 5.38 e 5.39. 


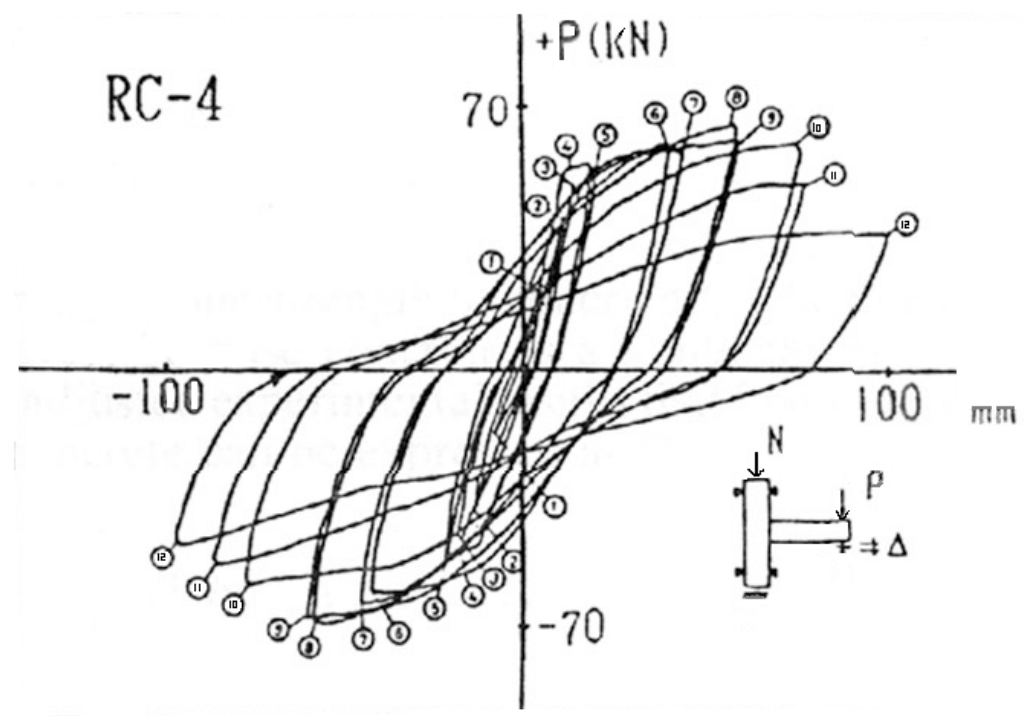

Figura 5.38: Curva experimental força-deslocamento - JIURU et al. (1992).

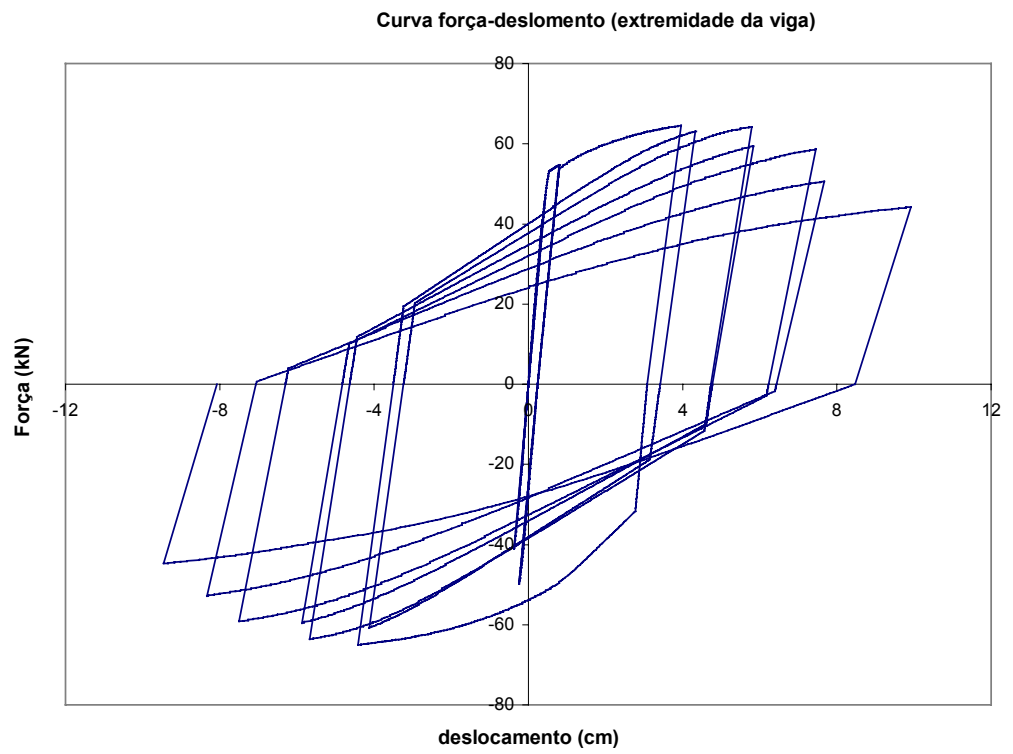

Figura 5.39: Curva força-deslocamento: modelo de PICÓN \& FLÓREZ-LÓPEZ (2000)

As figuras 5.40 e 5.41 contêm os gráficos da força máxima atingida em cada ciclo, referente à etapa de controle de deslocamentos, ilustrando o fenômeno da perda de resistência da ligação associada ao carregamento cíclico.

A comparação dos resultados mostra novamente o bom desempenho do modelo de dano e plasticidade concentrados na representação da resposta global da ligação e da fadiga devido ao caráter cíclico das ações aplicadas. 


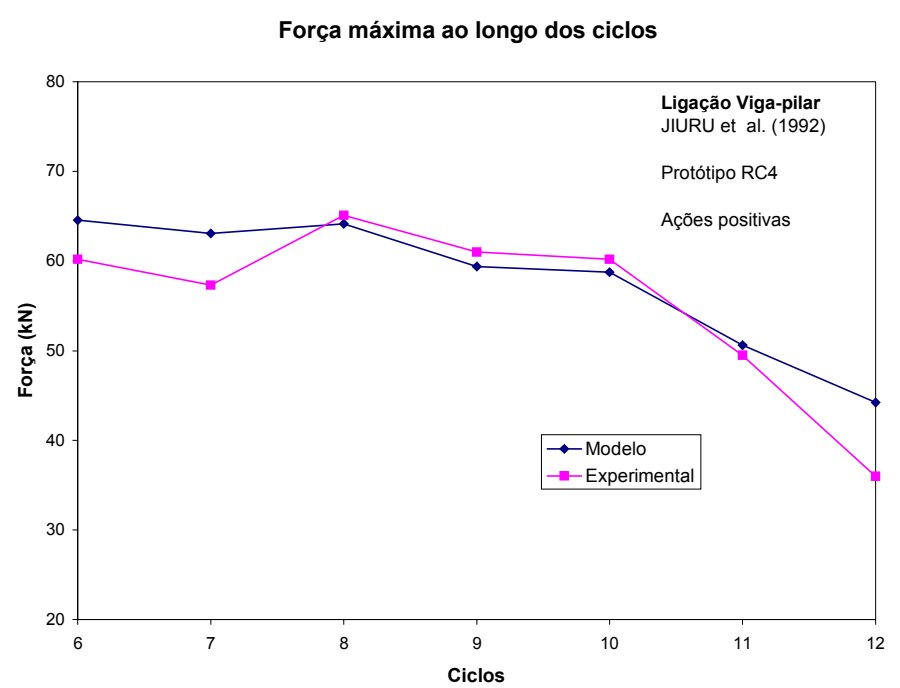

Figura 5.40: Força máxima alcançada ao longo dos ciclos: ações positivas

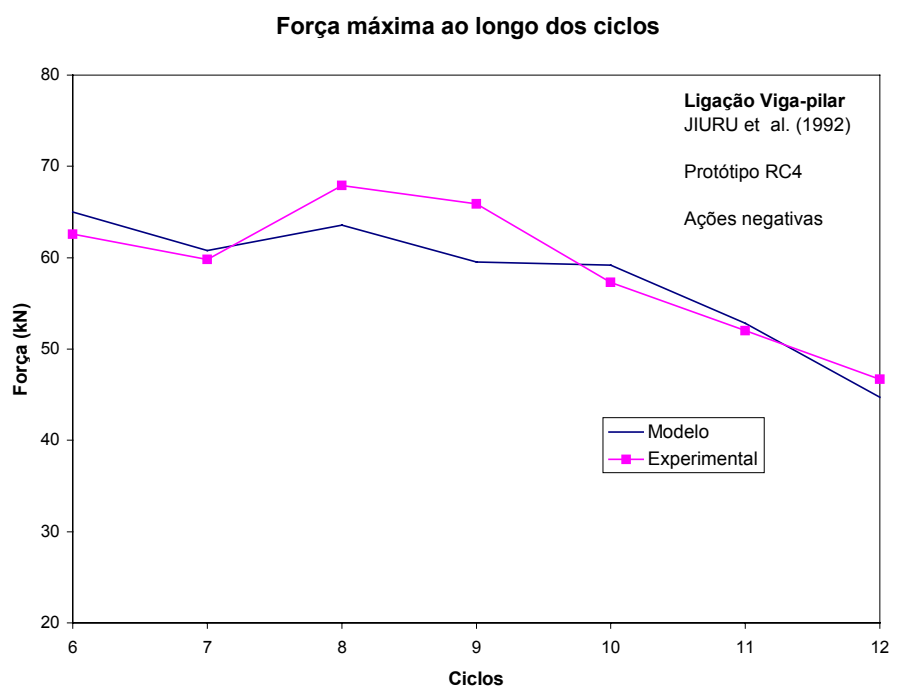

Figura 5.41: Força máxima alcançada ao longo dos ciclos: ações negativas

\section{Comentários a respeito das simulações numéricas}

As ligações viga-pilar escolhidas para as simulações numéricas foram analisadas experimentalmente pelos pesquisadores citados com o objetivo de aprimorar o entendimento sobre a resposta estrutural dessas ligações frente às ações sísmicas.

Em se tratando do dimensionamento em situação de sismos, a filosofia de cálculo das principais normas de projeto recomenda que as rótulas plásticas se formem nas vigas, evitando, por outro lado, a formação de rótulas plásticas nos pilares. Seguindo essas recomendações normativas, as dimensões e o detalhamento empregados nos elementos estruturais das ligações mencionadas resultaram em pilares mais resistentes e robustos que as vigas.

Por conseqüência, observou-se experimentalmente que os processos de deterioração mecânica foram mais concentrados na viga. Do mesmo modo, nas simulações numéricas, os 
pilares das ligações não atingiram as rotações plásticas, embora alcançassem um certo nível de dano.

Uma das questões que merece ser averiguada é saber se o modelo simplificado de dano pode apresentar bons resultados quando se dispõe de uma baixa taxa de estribos no interior do nó para resistir aos esforços cortantes dessa região. Sabe-se que os estribos horizontais dispostos na região dos nós contribuem na resistência frente às elevadas forças cortantes que surgem nessas regiões, além de propiciarem certo nível de confinamento ao nó, melhorando a resposta da ligação sob as ações cíclicas reversíveis.

As duas simulações numéricas realizadas envolveram ligações viga-pilar de extremidade. Entretanto, da mesma maneira, poderiam ser feitas simulações com outros tipos de ligações bastante estudadas, como as ligações viga-pilar interno e as ligações viga de cobertura-pilar de extremidade.

Observações a respeito da avaliação dos parâmetros do modelo simplificado

A fim de conseguir uma boa eficiência com o modelo simplificado de dano e plasticidade, convém que os seus respectivos parâmetros sejam determinados experimentalmente. No entanto, na ausência de resultados experimentais, tais parâmetros podem ser estimados pelo cálculo clássico de seções de concreto armado. Algumas observações entretanto merecem ser comentadas.

Os parâmetros $M_{c r}, M_{p}$ e $M_{u}$ podem ser estimados com boa precisão pelo cálculo convencional, utilizando-se as equações de equilíbrio e de compatibilidade da seção transversal. $O$ cálculo do momento de fissuração $M_{c r}$ depende primariamente das propriedades da seção bruta de concreto (não fissurada) e da resistência à tração do concreto, a qual pode ser facilmente avaliada através de expressões apresentadas pelas diversas normas de cálculo. Por sua vez, o momento de plastificação $M_{p}$ pode ser definido por uma das seguintes situações: o início do escoamento das armaduras ou o término da fase elástica do concreto comprimido. Usualmente, assume-se a plastificação das armaduras no cálculo de $M_{p}$, considerando, como simplificação, uma distribuição linear das tensões de compressão do concreto. $\mathrm{O}$ momento último $\mathrm{M}_{\mathrm{u}}$ corresponde ao máximo momento resistente da seção, obtido a partir das hipóteses usuais de cálculo no estado limite último. Como opção, a fim de obter um valor mais próximo do comportamento real do elemento, considera-se um acréscimo de resistência das armaduras a fim de levar em conta o encruamento do aço, normalmente compreendido entre 10 e 25 por cento sobre a resistência ao escoamento.

Entretanto, na determinação da rotação plástica última $\phi_{\mathrm{pu}}$, o cálculo clássico usual pode fornecer resultados muito conservadores, especialmente para as vigas, subestimando a ductilidade do elemento e, conseqüentemente, da ligação. Esse fato decorre do emprego de diagramas momento-curvatura idealizados para a seção, nos quais se adotam as mesmas hipóteses básicas utilizadas para o cálculo da resistência à flexão, como a permanência de seções planas após as deformações e a perfeita solidariedade dos materiais aço e concreto. Assim, acabam por não considerar o efeito de outros fenômenos importantes, como o deslizamento das barras da armadura, cuja parcela na rotação total do elemento é significativa no caso de ligações viga-pilar (ver figura 5.42). 


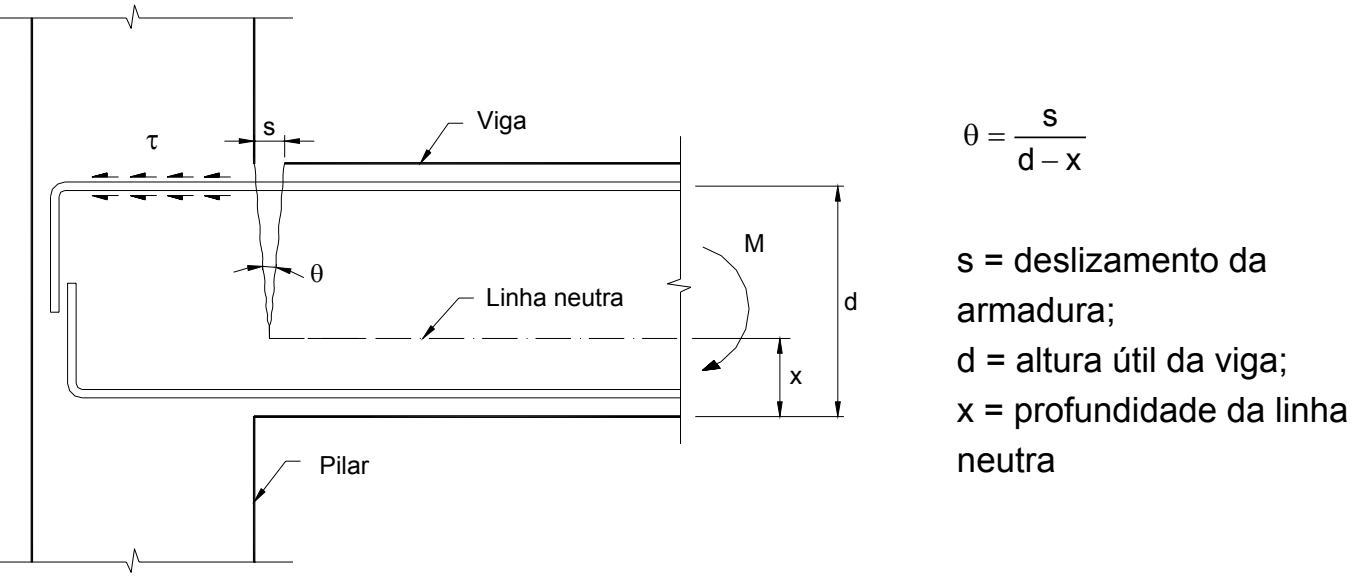

Figura 5.42: Efeito do deslizamento das barras da armadura sobre a rotação total da viga.

$\mathrm{Na}$ tentativa de obter um valor mais realista da rotação plástica última, em particular da viga, alguns modelos simples são propostos por pesquisadores para considerar os efeitos do deslizamento das barras da viga ancoradas no nó.

PAULTRE et al. (1989) apresentam a seguinte expressão analítica para estimar a contribuição do deslizamento na rotação da viga:

$\theta_{\text {slip }}=\frac{1}{8} \frac{\phi_{\mathrm{b}}}{\mathrm{d}-\mathrm{x}_{\mathrm{u}}} \frac{\mathrm{f}_{\mathrm{y}}}{\tau_{\mathrm{b}}}\left[\left(\frac{\mathrm{f}_{\mathrm{u}}}{\mathrm{f}_{\mathrm{y}}}-1\right)\left(\varepsilon_{\mathrm{u}}+\varepsilon_{\text {sh }}\right)+\varepsilon_{\mathrm{y}}\right]$

onde:

Diagrama tensão-deformação do aço

$\mathrm{f}_{\mathrm{y}}$ é a resistência ao escoamento;

$\varepsilon_{y}$ é a deformação de início do escoamento do aço;

$\varepsilon_{\text {sh }}$ é a deformação de início do encruamento do aço;

$\varepsilon_{\mathrm{u}}$ é a deformação última do aço;

$\phi_{\mathrm{b}}$ é o diâmetro das barras da armadura longitudinal;

$\tau_{b}$ é a tensão máxima de aderência, igual a 4,3

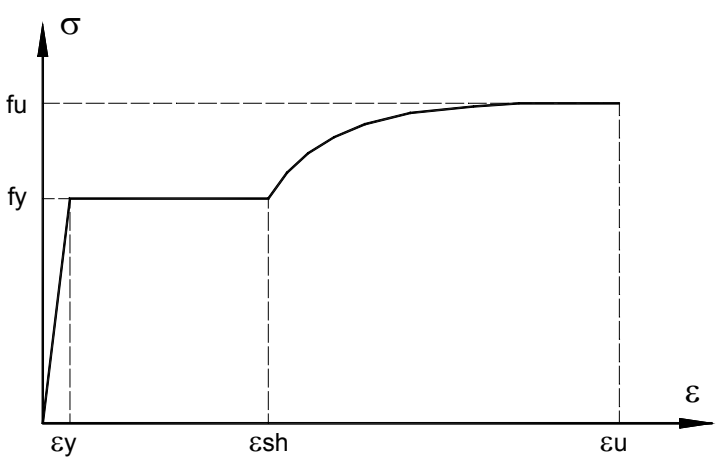

$\mathrm{MPa}$;

d é a altura útil da viga;

$\mathrm{x}_{\mathrm{u}}$ é a profundidade da linha neutra

correspondente ao momento último.

PARK \& ANG (1985), com base nos resultados de ensaios em vigas e pilares submetidos a ações monotônicas e cíclicas, propõem um modelo semi-empírico para a obtenção das rotações plásticas em elementos de concreto armado. Desse modelo são formuladas expressões analíticas para o cálculo da parcela de rotação associada ao deslizamento da armadura, reescritas pelo CEB (1994) Bulletin d'Information n.220 da seguinte forma: 
$\theta_{\text {slip }}=7 \times 10^{-5} \frac{\phi_{\mathrm{b}}}{\mathrm{z}}\left(\frac{\sigma_{\mathrm{s}}}{\sqrt{\tau_{\mathrm{b}}}}\right)^{3 / 2}$

onde

$\phi_{\mathrm{b}}$ é o diâmetro das barras da armadura longitudinal;

z é a distância entre a resultante de tração e a resultante de compressão na seção;

$\sigma_{\mathrm{s}}$ é a tensão de tração na armadura longitudinal, em MPa;

$\tau_{b}$ é a tensão máxima de aderência, igual a 10,3 MPa em zona de boa aderência e 6,2 MPa em zona de má aderência.

Alternativamente, o CEB (1994) recomenda o valor de $2 \sqrt{f_{c}}$ e $\sqrt{f_{c}}$ para zonas de boa e má aderência, respectivamente.

\subsubsection{Modificações propostas na formulação original}

Embora simulem a perda de rigidez e o surgimento das deformações permanentes, as simulações numéricas realizadas nesta pesquisa com ligações viga-pilar isoladas e as realizadas em outros trabalhos, como em ÁLVARES (1999), indicaram que os modelos de dano e plasticidade mencionados conduzem a uma resposta global mais rígida que a experimental, verificada a partir das curvas do tipo força-deslocamento. Tal fato torna-se mais relevante em simulações envolvendo ações monotônicas.

As figuras 5.43 à 5.45 ilustram o confronto entre os resultados experimentais e os resultados fornecidos pelo modelo simplificado de dano original em três tipos de estruturas de concreto armado: ligação viga-pilar com força vertical aplicada na extremidade da viga, pórtico de dois pavimentos submetido a força horizontal no topo de um dos pilares e viga simplesmente apoiada submetida a forças verticais concentradas nos terços dos vãos. $O$ comportamento mais rígido fornecido pelo modelo simplificado torna-se evidente nas três figuras, em especial antes do ponto de plastificação, a partir do qual ocorre uma queda mais brusca da inclinação da curva força-deslocamento.

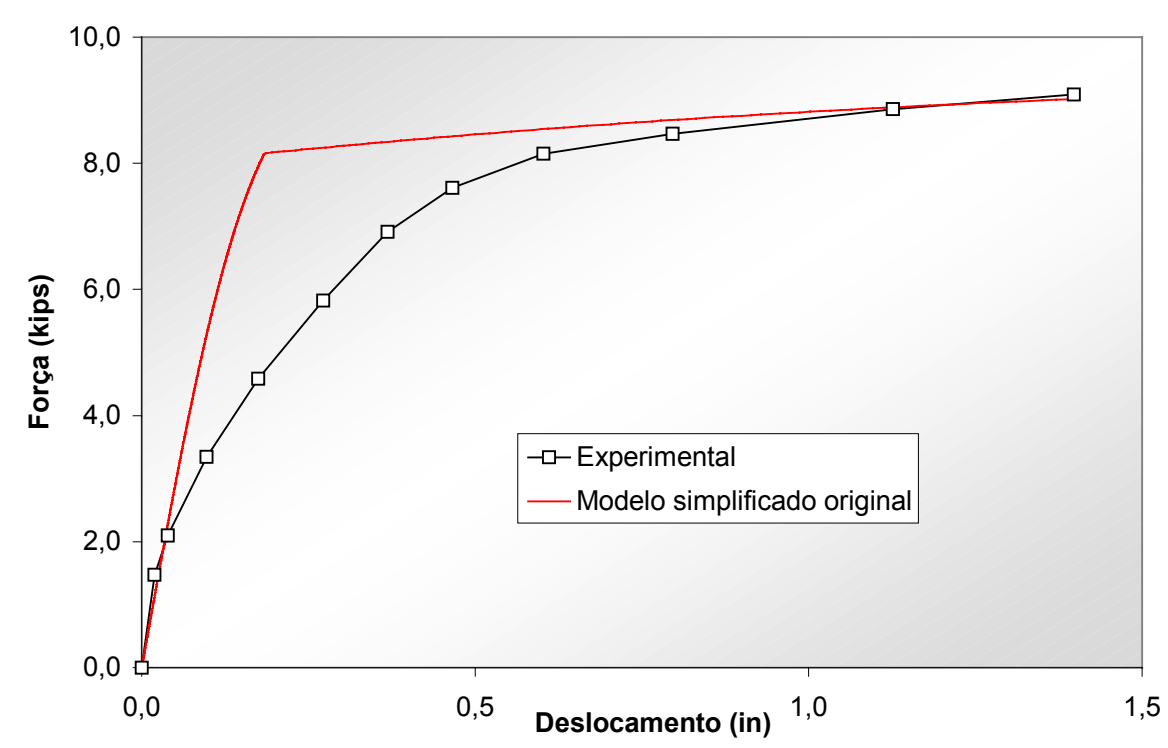

Figura 5.43: Ligação viga-pilar de extremidade - LEE et al. (1977) 


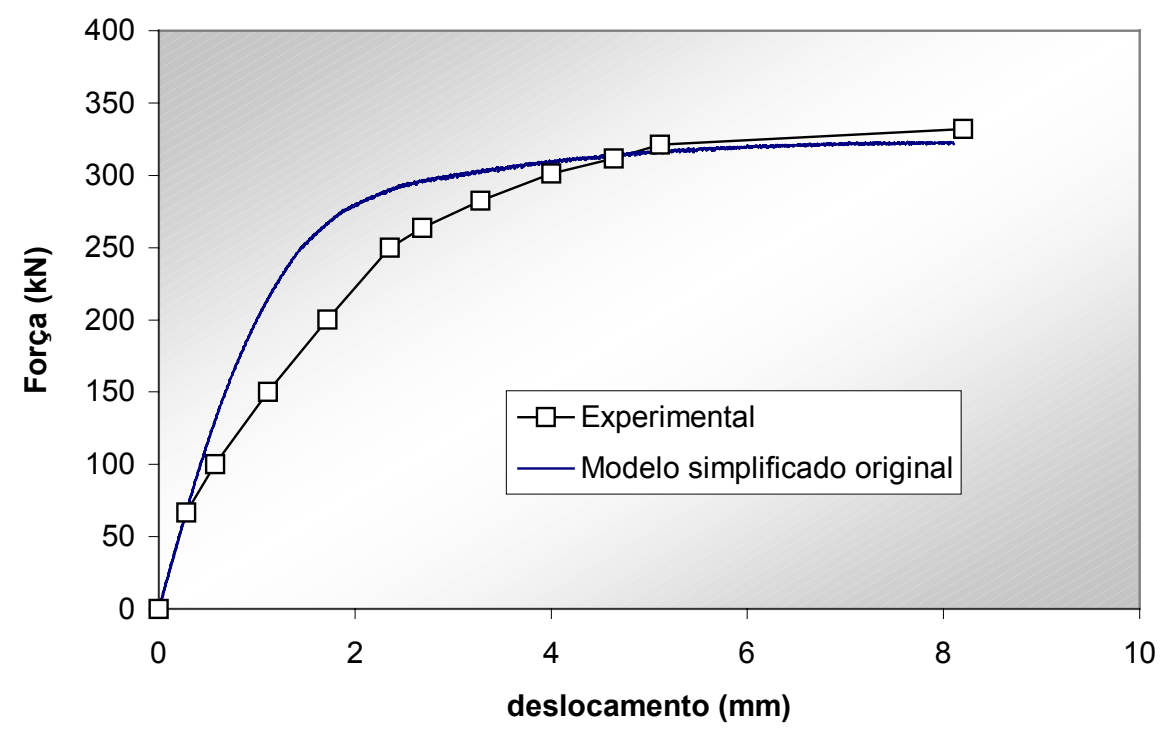

Figura 5.44: Pórtico de concreto armado - VECCHIO \& EMARA (1992)

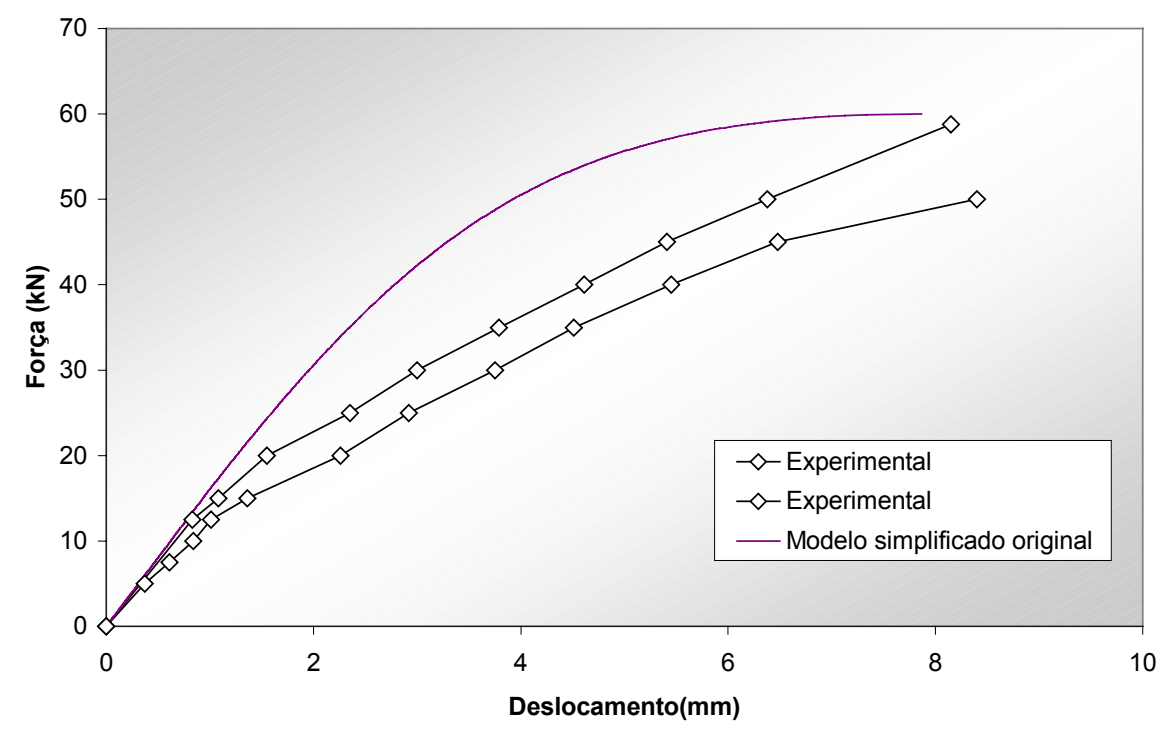

Figura 5.45: Viga simplesmente apoiada - ÁLVARES (1993)

Em estudos realizados com modelos simplificados em estruturas de barras de concreto armado, ÁLVARES (1999) aponta para a necessidade de se definir novas funções limites de dano e de plasticidade em peças estruturais que não apresentam características semelhantes às utilizadas para a identificação das funções originais propostas por CIPOLLINA \& FLÓREZLÓPEZ (1995). Essas novas funções devem ser verificadas por meio de resultados experimentais.

Em vista disso, sugerem-se algumas modificações nas funções limites de dano originalmente propostas, de modo que possam ser aplicadas às ligações viga-pilar de extremidade, mantendo-se a mesma função limite para as deformações plásticas. Embora seja interessante testar as modificações sugeridas em diversos elementos estruturais, não se têm a pretensão de generalizá-las a todos os tipos estruturais de pórtico de concreto armado. 
As modificações sugeridas foram também aplicadas às ligações do programa experimental desta pesquisa de doutorado. $\mathrm{O}$ confronto dos resultados numéricos com os resultados experimentais é apresentado no capítulo 7.

\section{Formulação sugerida: ajuste da função original de dano}

O modelo de dano originalmente proposto nos trabalhos de CIPOLLINA \& FLÓREZLÓPEZ (1995) e FLÓREZ-LÓPEZ (1995) admite a seguinte função limite para o controle da evolução da variável de dano:

$$
g=G-R \quad \text { sendo } \quad R=G_{c r}-q \frac{\ln (1-d)}{(1-d)}
$$

Embora não tenha realizado estudos experimentais específicos, ÁLVARES (1999) apresentou simulações numéricas em vigas simplesmente apoiadas e pórticos de concreto armado, sob ações monotônicas, utilizando a seguinte função limite de dano:

$g=G-R \quad$ sendo $\quad R=G_{c r}-q \frac{[\ln (1-d)]^{2}}{(1-d)}$

obtendo melhores resultados que os fornecidos pela função original. Nessas simulações, manteve-se a função original associada à evolução das rotações plásticas.

Como parte preliminar deste estudo, foram feitas simulações numéricas em ligações viga-pilar de extremidade empregando a função utilizada por ÁLVARES (1999). Entretanto, notou-se que tal função não forneceu bons resultados, conduzindo a curvas forçadeslocamento ainda significativamente mais rígidas que as observadas em diversas curvas experimentais.

Com o intuito de melhorar o desempenho do modelo, em particular em relação ao processo de evolução da variável de dano, sugere-se a seguinte modificação na função limite que controla a danificação:

$g=G-R \quad$ sendo $\quad R=G_{c r}-f \cdot q \frac{\ln (1-d)}{(1-d)}$

onde f é uma função utilizada para modificar o termo $R$ e que depende do valor do dano. Obteve-se $f$ após diversos testes com diferentes funções, buscando simular uma maior evolução inicial da variável de dano em relação à fornecida pela função limite original. A função f escolhida é dada por:

$f=e^{-\gamma(1-d)}$

onde

$\gamma$ é um novo parâmetro a ser introduzido ao modelo simplificado. Supõe-se que o valor de $\gamma$ dependa das características do elemento estrutural a ser analisado. 
Deve-se notar que, para $\gamma$ igual a zero, retorna-se ao modelo original proposto. Por meio das curvas da figura 5.46, observa-se que, quanto maior o valor de $\gamma$, maior a evolução do dano. Partindo deste ponto, o valor de $\gamma$ pode ser escolhido de modo a representar com mais eficácia a resposta experimental observada no elemento estrutural.

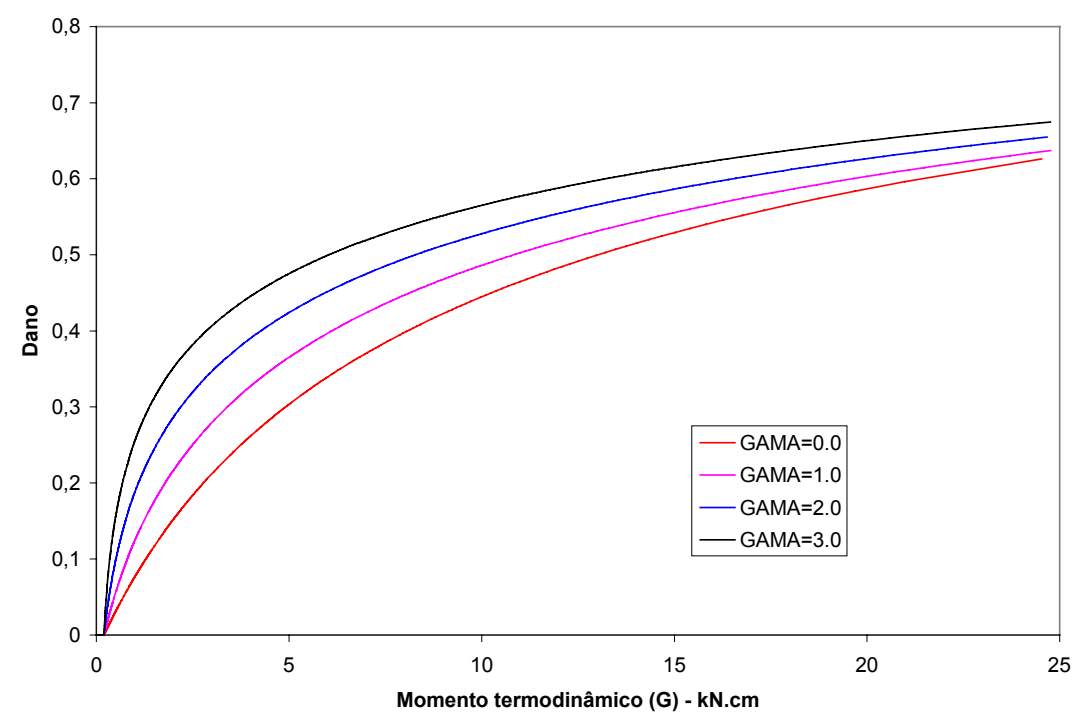

Figura 5.46: Evolução do dano em função do momento termodinâmico para diferentes valores de $\gamma$

\section{Determinação dos parâmetros do modelo a partir da função limite sugerida}

A determinação dos parâmetros, utilizando para a variável de dano a função sugerida na expressão (5.79), é feita por meio da resolução do seguinte sistema de equações nãolineares:

$$
\begin{aligned}
& M=M_{c r} \quad \Rightarrow \quad d=0 \quad \text { e } \quad g=0 \\
& M_{c r} \text { é o momento de fissuração; } \\
& M=M_{p} \quad \Rightarrow \quad \phi^{p}=0 ; \quad g=0 \quad \text { e } \quad f=0 \\
& M_{p} \text { é o momento de plastificação; } \\
& M=M_{u} \Rightarrow d M=0 \quad \text { e } \quad g=0 \\
& M_{u} \text { é o momento último ; } \\
& M=M_{u} \Rightarrow \phi^{p}=\phi_{u}{ }^{p} ; \quad g=0 \quad \text { e } \quad f=0 \\
& \phi_{\mathrm{u}}{ }^{\mathrm{p}} \text { é a rotação plástica última; }
\end{aligned}
$$

Partindo da condição g=0, tem-se:

$$
\begin{aligned}
& G=G_{c r}+f \frac{q \ln (1-d)}{1-d} \\
& \frac{M^{2}}{2 S(1-d)^{2}}=G_{c r}+f \frac{q \ln (1-d)}{1-d}
\end{aligned}
$$

para $\mathrm{M}=\mathrm{M}_{\mathrm{u}}, \mathrm{d}=\mathrm{d}_{\mathrm{u}}$ : 
$\frac{M_{u}{ }^{2}}{2 S\left(1-d_{u}\right)^{2}}=G_{c r}+f_{u} \frac{q \ln \left(1-d_{u}\right)}{1-d_{u}} \quad$ com $\quad f_{u}=e^{-\gamma\left(1-d_{u}\right)}$

Assumindo que o momento máximo ocorre para $M=M_{u}$ e $d=d_{u}$, obtém-se por meio de $\frac{d M^{2}}{d d}=0$ :

$-2\left(1-d_{u}\right) G_{c r}-f_{u} q\left[h_{u} \ln \left(1-d_{u}\right)+1\right]=0 \quad$ onde $\quad h_{u}=1+\gamma d_{u}-\gamma$

Com a resolução do sistema formado pelas equações (5.83) e (5.84), determinam-se os parâmetros $q$ e $d_{u}$

No início da plastificação, $M=M_{p}, d=d_{p}$ e $\phi_{p}=0$, valendo as seguintes condições:

Para $g=0$, determina-se $d_{p}$ com:

$\frac{M_{p}^{2}}{2 S\left(1-d_{p}\right)^{2}}=G_{c r}+f_{p} \frac{q \ln \left(1-d_{p}\right)}{1-d_{p}} \quad$ onde $\quad f_{p}=e^{-\gamma\left(1-d_{p}\right)}$

Para $\mathrm{f}=0$, determina-se $M_{y}$ com:

$M_{p}-\frac{4\left(1-d_{p}\right)}{\left(4-d_{p}\right)} M_{y}=0$

Finalmente, com a condição $\mathrm{f}=0$ para $\mathrm{M}=\mathrm{M}_{\mathrm{u}}, \mathrm{d}=\mathrm{d}_{\mathrm{u}}$ e $\phi_{\mathrm{p}}=\phi_{\mathrm{pu}}$, calcula-se o valor de $c$ :

$M_{u}-\frac{\left(1-d_{u}\right)}{\left(4-d_{u}\right)} c \phi_{p u}-\frac{4\left(1-d_{u}\right)}{\left(4-d_{u}\right)} M_{y}=0$

\section{Consideração do efeito de fadiga (low-cycle fatigue)}

Conforme já mencionado, o modelo de PICÓN \& FLÓREZ-LÓPEZ (2000) utiliza uma variável z para levar em conta a fadiga de baixos ciclos, determinada a partir do polinômio de $2^{\circ}$ grau da expressão (5.74). Partindo-se de uma análise de sinais dessa função, nota-se que a variável $z$ assume valores negativos em um determinado intervalo entre $0<d<1,0$.

Além disso, nas simulações feitas neste estudo com ligações viga-pilar de extremidade, empregando a expressão (5.74) para calcular o parâmetro z, as forças máximas ao fim de cada ciclo foram notavelmente menores que as experimentais, especialmente para valores de $z$ negativos, quando o acréscimo da variável de dano é bem significativo.

Desse modo, a fim de melhorar a resposta do modelo ao simular o efeito de fadiga, ajustou-se o parâmetro $z$ conforme a seguinte expressão:

$z=30(1-d)^{2}$ 
Notar que a expressão (5.88) foi mantida como um polinômio de segundo grau, assumindo valores positivos no intervalo $[0,1]$. Além disso, respeitou-se duas das três condições originais: para $d=0, z=30$ e para $d=1, z=0$.

A figura 5.47 contêm os gráficos da variável $z$ em função do dano. Em princípio, sugere-se ajuste indicado na expressão (5.88) apenas para o tipo de ligação analisada nas simulações numéricas, ou seja, para as ligações viga-pilar de extremidade isoladas.

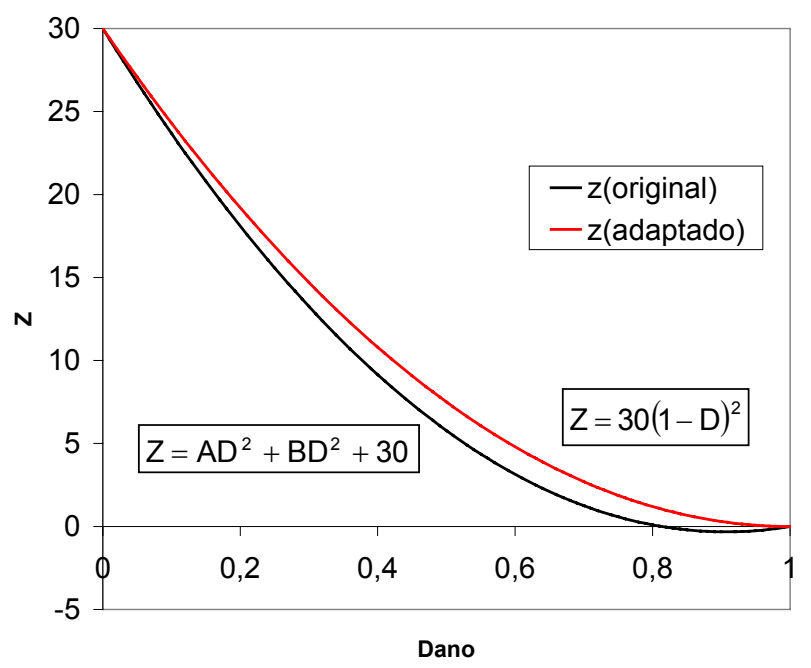

Figura 5.47: Variação do parâmetro z em função do dano

Nas simulações numéricas apresentadas a seguir, especificamente as que envolveram ações cíclicas de alta intensidade, utilizou-se a expressão adaptada (5.88) para a variável z.

\subsubsection{Simulações numéricas com os modelos de dano modificados}

\section{$\underline{\text { Resultados em ligações viga-pilar de extremidade: ações monotônicas }}$}

O objetivo da análise numérica a seguir foi verificar o desempenho da função limite de dano sugerida na representação da reposta global de ligações viga-pilar de extremidade sujeitas a ações monotônicas.

Neste item são apresentados os resultados de simulações numéricas de ligações investigadas experimentalmente por MURTHY (1998), referente às ligações $B D W$ e $B D B$, e por LEE et al. (1977), referentes às ligações specimen 2 e specimen 5.

A figura 5.48 ilustra as dimensões dos modelos físicos e as características geométricas gerais das ligações a serem analisadas. A tabela 5.6 contém os valores das características geométricas das ligações analisadas sob ações monotônicas. 

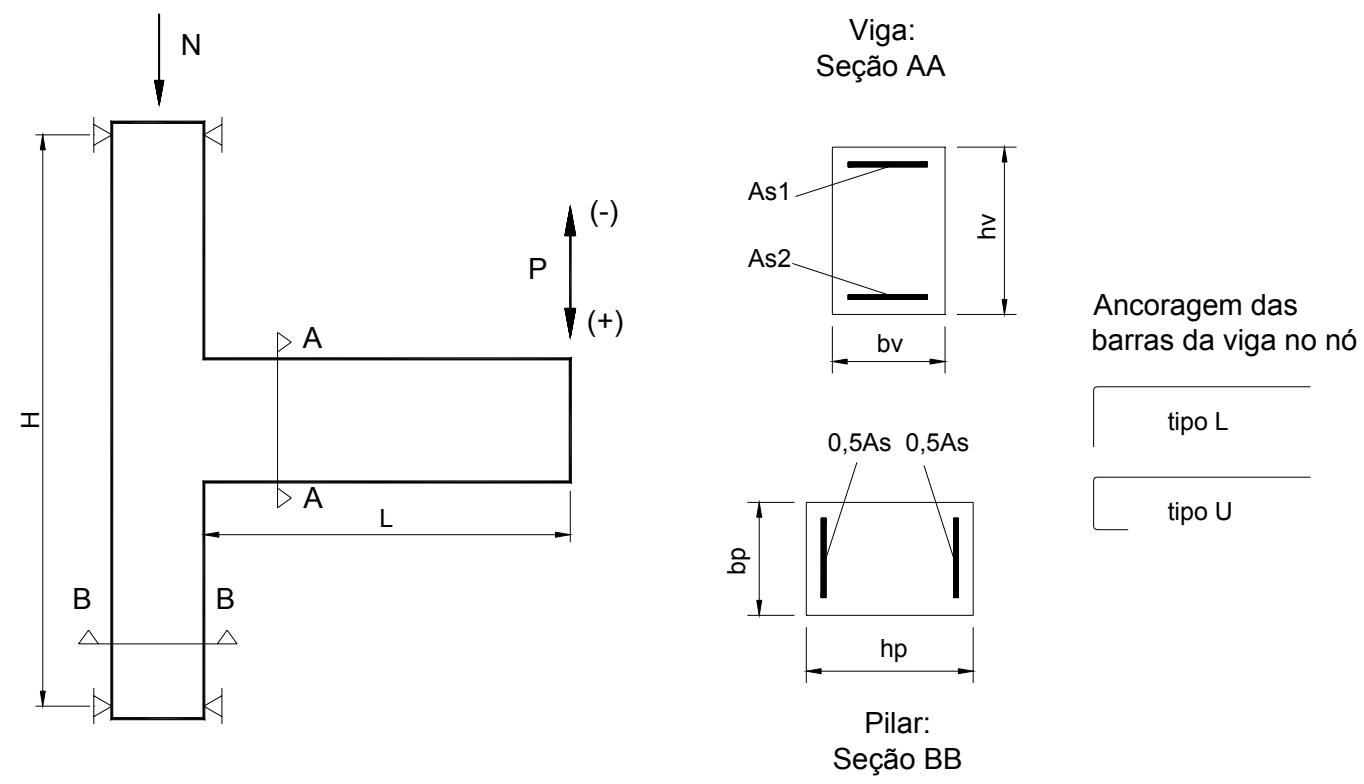

Figura 5.48: Geometria das ligações a serem analisadas

Tabela 5.6: Dimensões do modelo e características geométricas: ações monotônicas

\begin{tabular}{|c|c|c|c|c|c|c|c|c|c|c|}
\hline Ligação & $\mathbf{L}$ & H & $\mathbf{h}_{\mathrm{v}}$ & $\mathbf{b}_{\mathrm{v}}$ & $\mathbf{h}_{\mathrm{p}}$ & $b_{p}$ & $\mathbf{A}_{\mathbf{s 1}}$ & $\mathbf{A}_{\mathbf{s} 2}$ & $\mathbf{A}_{\mathbf{s}}$ & $\begin{array}{c}\text { Ancor } \\
\text { viqa }\end{array}$ \\
\hline & $(\mathrm{cm})$ & $(\mathrm{cm})$ & (cm) & $(\mathrm{cm})$ & $(\mathrm{cm})$ & (cm) & $\left(\mathrm{cm}^{2}\right)$ & $\left(\mathrm{cm}^{2}\right)$ & $\left(\mathrm{cm}^{2}\right)$ & \\
\hline Specimen 2 & 118,1 & 165,1 & 25,4 & 20,3 & 27,9 & 20,3 & 5,70 & 3,96 & 11,40 & $\mathrm{~L}$ \\
\hline Specimen 5 & 104,8 & 165,1 & 25,4 & 20,3 & 27,9 & 20,3 & 5,70 & 3,96 & 11,40 & $L$ \\
\hline BDB & 104 & 150 & 30 & 23 & 23 & 23 & 4,02 & 0,57 & 12,57 & $L$ \\
\hline BDW & 104 & 150 & 30 & 23 & 23 & 23 & 4,02 & 0,57 & 12,57 & U \\
\hline
\end{tabular}

Os parâmetros necessários ao modelo simplificado foram estimados experimentalmente, com o auxílio das curvas força-deslocamento e a partir das propriedades dos materiais, como a resistência à compressão e à tração do concreto e a resistência ao escoamento do aço.

As figuras 5.49 à 5.52 contêm as curvas força-deslocamento na extremidade da viga das ligações abordadas na tabela 5.6. 


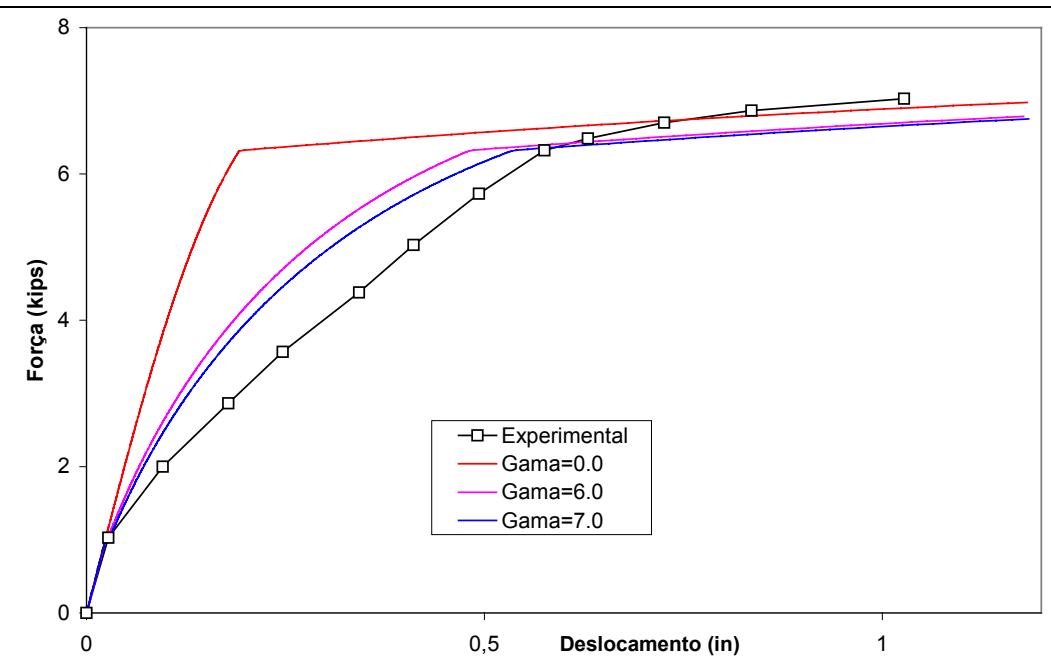

Parâmetros:

Viga:

$\mathrm{M}_{\mathrm{cr}}=6,00 \mathrm{kN} \cdot \mathrm{m}$

$\mathrm{M}_{\mathrm{p}}=31,75 \mathrm{kN} \cdot \mathrm{m}$

$\mathrm{M}_{\mathrm{u}}=43,55 \mathrm{kN} \cdot \mathrm{m}$

$\phi_{\mathrm{pu}}=0,06 \mathrm{rad}$

Pilar:

$\mathrm{M}_{\mathrm{cr}}=16,14 \mathrm{kN} \cdot \mathrm{m}$

$\mathrm{M}_{\mathrm{p}}=75,09 \mathrm{kN} \cdot \mathrm{m}$

$\mathrm{M}_{\mathrm{u}}=76,32 \mathrm{kN} \cdot \mathrm{m}$

$\phi_{\mathrm{pu}}=0,006 \mathrm{rad}$

Figura 5.49: Curva força-deslocamento (Specimen 2): LEE et al. (1977)

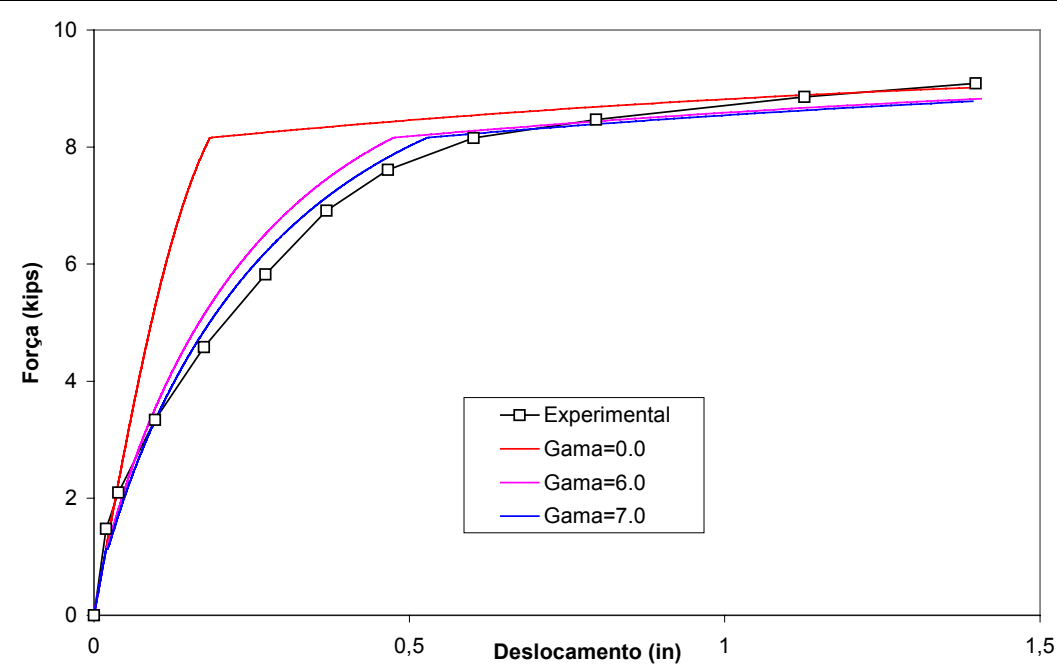

Parâmetros:

Viga:

$\mathrm{M}_{\mathrm{cr}}=6,00 \mathrm{kN} \cdot \mathrm{m}$

$\mathrm{M}_{\mathrm{p}}=43,10 \mathrm{kN} \cdot \mathrm{m}$

$\mathrm{M}_{\mathrm{u}}=49,28 \mathrm{kN} \cdot \mathrm{m}$

$\phi_{\mathrm{pu}}=0,06 \mathrm{rad}$

\section{Pilar:}

$\mathrm{M}_{\mathrm{cr}}=7,00 \mathrm{kN} \cdot \mathrm{m}$

$\mathrm{M}_{\mathrm{p}}=59,50 \mathrm{kN} \cdot \mathrm{m}$

$\mathrm{M}_{\mathrm{u}}=60,25 \mathrm{kN} \cdot \mathrm{m}$

$\phi_{\mathrm{pu}}=0,007 \mathrm{rad}$

Figura 5.50: Curva força-deslocamento (Specimen 5): LEE et al. (1977)

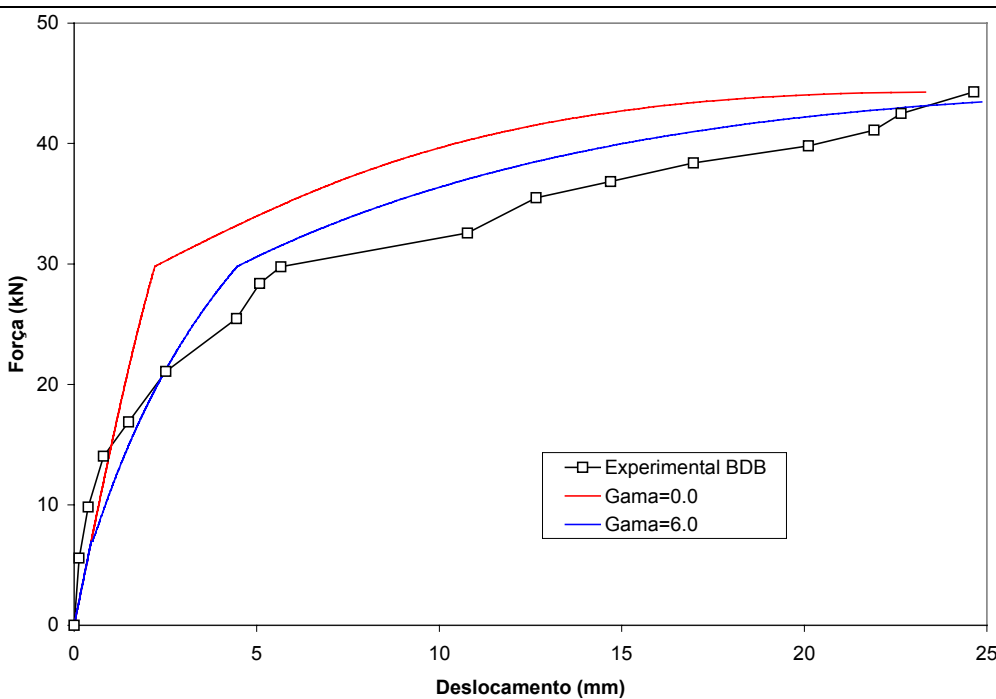

\section{Parâmetros:}

\section{Viga:}

$\mathrm{M}_{\mathrm{cr}}=8,05 \mathrm{kN} \cdot \mathrm{m}$

$\mathrm{M}_{\mathrm{p}}=34,42 \mathrm{kN} \cdot \mathrm{m}$

$\mathrm{M}_{\mathrm{u}}=51,15 \mathrm{kN} \cdot \mathrm{m}$

$\phi_{\text {pu }}=0,016 \mathrm{rad}$

\section{Pilar:}

$\mathrm{M}_{\mathrm{cr}}=4,26 \mathrm{kN} \cdot \mathrm{m}$

$\mathrm{M}_{\mathrm{p}}=42,43 \mathrm{kN} \cdot \mathrm{m}$

$\mathrm{M}_{\mathrm{u}}=56,90 \mathrm{kN} \cdot \mathrm{m}$

$\phi_{\mathrm{pu}}=0,008 \mathrm{rad}$

Figura 5.51: Curva força-deslocamento (modelo BDB): MURTHY et al.

(1998) 


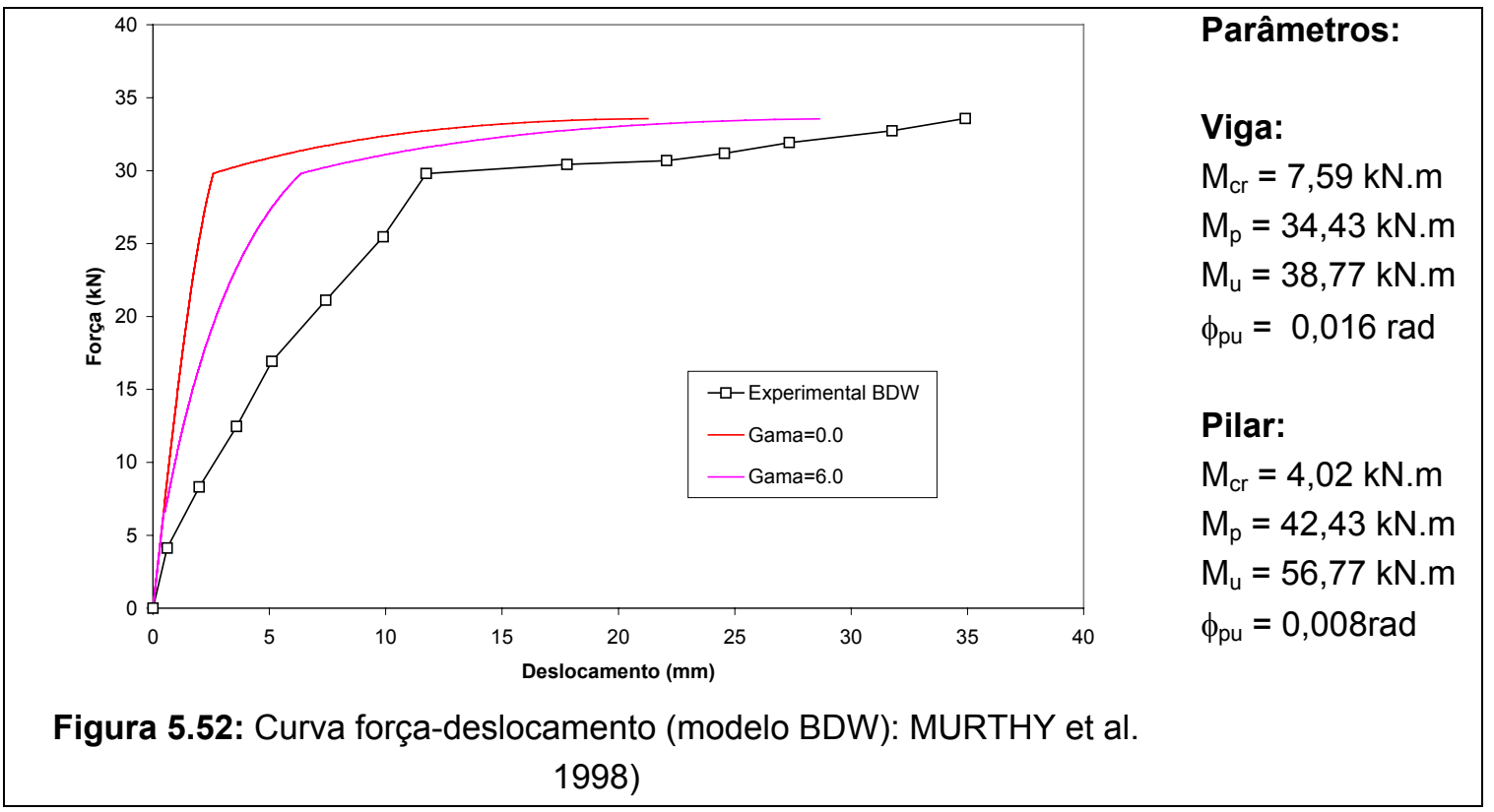

Assim como observado nos resultados das simulações apresentados nas figuras 5.43 à 5.45 , nota-se que o modelo original de dano $(\gamma=0)$ fornece uma curva força-deslocamento mais rígida até a força de plastificação da viga (figuras 5.49 e 5.50). Observa-se, entretanto, uma melhora na resposta global para valores de $\gamma$ próximos de 6,0 e 7,0 nas ligações Specimen 2 e Specimen 5. Os resultados numéricos também se ajustam bem para valores de $\gamma$ próximos de 6,0, conforme demonstrado na figura 5.51 referente à ligação $B D B$. Nas três ligações, as barras longitudinais superiores da viga são dobradas à 90 graus para o interior do nó de pórtico (tipo L). Nas ligações ensaiadas na etapa experimental deste trabalho de doutoramento, os valores de $\gamma$ para as vigas situaram-se entre 6,0 e 7,0.

Entretanto, observando a figura 5.52, nota-se que o valor de $\gamma$ igual a 6,0 não fornece resultados satisfatórios para a ligação $\mathrm{BDW}$, onde as barras principais superiores da viga são dobradas a 90 graus para o interior do nó, terminando no nível da face inferior da viga (tipo $U$ ). Isso pode indicar que o detalhamento empregado na ancoragem das armaduras de tração da viga também influencia o comportamento global da ligação e o desempenho do modelo de dano. De fato, ligações com o tipo $L$ de detalhamento apresentam um melhor desempenho estrutural quando comparados com ligações que empregam o tipo $\mathrm{U}$, conforme comentam SCOTT (1996) e MURTHY et al. (1998).

Nas simulações numéricas apresentadas neste item, manteve-se $\gamma$ igual a zero para as barras do pilar. Tal procedimento não pareceu prejudicar as conclusões destas análises, pois observou-se nas simulações numéricas que os resultados praticamente não sofrem alterações ao adotar para as barras do pilar valores de $\gamma$ maiores que zero. Além disso, nos ensaios experimentais das ligações em questão, os pilares sofreram uma deterioração mecânica bem menor que a sofrida pela viga, sem o aparecimento de rotações plásticas.

Entretanto, vale comentar que, nos ensaios da etapa experimental desta pesquisa, os valores de $\gamma$ situaram-se em torno de 3,0, em decorrência da grande deterioração do painel nó de pórtico como parte da ligação. 


\section{$\underline{\text { Resultados em ligações viga-pilar de extremidade: ações cíclicas }}$}

Na simulação de ligações submetidas à ações cíclicas de elevada intensidade, é de interesse maior avaliar a perda de resistência e de rigidez da ligação, incluindo a evolução dos deslocamentos inelásticos no decorrer dos ciclos.

As ligações escolhidas para as simulações numéricas provêm das investigações experimentais feitas por EHSANI \& WIGHT (1985), JIURU et al. (1992), LEE et al. (1977) e SCRIBNER \& WIGHT (1978), todas apresentando ancoragem das barras da viga do tipo L. A tabela 5.7 contém os valores das dimensões dessas ligações e suas principais características geométricas. Os resultados das simulações das duas primeiras ligações, empregando a formulação original, foram apresentados no item 5.3.4

Aplicam-se agora as modificações sugeridas tanto para a função limite de dano quanto para o parâmetro $z$ associado à fadiga. Os parâmetros que definem o modelo foram estimados a partir dos resultados experimentais. A escolha do parâmetro $\gamma$ visou o melhor ajuste da resposta numérica com a experimental.

Todas as análises numéricas foram conduzidas com controle de deslocamentos. As curvas força-deslocamento são referentes à extremidade da viga.

Tabela 5.7: Dimensões do modelo e características geométricas: ações cíclicas

\begin{tabular}{|c|c|c|c|c|c|c|c|c|c|}
\hline Ligação & $\mathbf{L}$ & $\mathbf{H}$ & $\mathbf{h}_{\mathbf{v}}$ & $\mathbf{b}_{\mathbf{v}}$ & $\mathbf{h}_{\mathbf{p}}$ & $\mathbf{b}_{\mathbf{p}}$ & $\mathbf{A}_{\mathbf{s 1}}$ & $\mathbf{A}_{\mathbf{s 2}}$ & $\mathbf{A}_{\mathbf{s}}$ \\
\cline { 2 - 8 } & $(\mathrm{cm})$ & $(\mathrm{cm})$ & $(\mathrm{cm})$ & $(\mathrm{cm})$ & $(\mathrm{cm})$ & $(\mathrm{cm})$ & $\left(\mathrm{cm}^{2}\right)$ & $\left(\mathrm{cm}^{2}\right)$ & $\left(\mathrm{cm}^{2}\right)$ \\
\hline $\begin{array}{c}\text { EHSANI \& WIGHT (1985) } \\
\text { Specimen 2B }\end{array}$ & 152,4 & 213,4 & 43,9 & 25,9 & 30,0 & 30,0 & 20,13 & 20,13 & 22,71 \\
\hline $\begin{array}{c}\text { SCRIBNER \& WIGHT } \\
\text { (1978) }\end{array}$ & 127,0 & 120,0 & 25,4 & 20,0 & 30,5 & 20,0 & 5,70 & 4,00 & 11,35 \\
\hline $\begin{array}{c}\text { JIURU et al. (1992) } \\
\text { RC4 }\end{array}$ & 142,5 & 160,0 & 35,0 & 20,0 & 35,0 & 25,0 & 6,03 & 6,03 & 19,73 \\
\hline $\begin{array}{c}\text { LEE et al. (1977) } \\
\text { Specimen 2 }\end{array}$ & 118,1 & 165,1 & 25,4 & 20,3 & 27,9 & 20,3 & 5,70 & 4,00 & 11,35 \\
\hline
\end{tabular}

As figuras 5.53 à 5.56 mostram o confronto entre resultados experimentais e numéricos. 


\begin{tabular}{|llll|}
\hline Parâmetros utilizados no modelo: Viga & \multicolumn{2}{l|}{ Parâmetros utilizados no modelo: Pilar } \\
$\mathrm{M}_{\mathrm{cr}}^{(+)}=28,1 \mathrm{kN} \cdot \mathrm{m}$ & $\mathrm{M}_{\mathrm{cr}}^{(-)}=28,1 \mathrm{kN} \cdot \mathrm{m}$ & $\mathrm{M}_{\mathrm{cr}}^{(+)}=26,5 \mathrm{kN} \cdot \mathrm{m}$ & $\mathrm{M}_{\mathrm{cr}}^{(-)}=26,5 \mathrm{kN} \cdot \mathrm{m}$ \\
$\mathrm{M}_{\mathrm{p}}^{(+)}=210,6 \mathrm{kN} \cdot \mathrm{m}$ & $\mathrm{M}_{\mathrm{p}}^{(-)}=210,6 \mathrm{kN} \cdot \mathrm{m}$ & $\mathrm{M}_{\mathrm{p}}^{(+)}=151,5 \mathrm{kN} \cdot \mathrm{m}$ & $\mathrm{M}_{\mathrm{p}}^{(-)}=151,6 \mathrm{kN} \cdot \mathrm{m}$ \\
$\mathrm{M}_{\mathrm{u}}^{(+)}=230,0 \mathrm{kN} \cdot \mathrm{m}$ & $\mathrm{M}_{\mathrm{u}}^{(-)}=230,0 \mathrm{kN} \cdot \mathrm{m}$ & $\mathrm{M}_{\mathrm{u}}^{(+)}=176,8 \mathrm{kN} \cdot \mathrm{m}$ & $\mathrm{M}_{\mathrm{u}}^{(-)}=176,8 \mathrm{kN} \cdot \mathrm{m}$ \\
$\phi_{\mathrm{pu}}^{(+)}=0,025 \mathrm{rad}$ & $\phi_{\mathrm{pu}}{ }^{(-)}=0,025 \mathrm{rad}$ & $\phi_{\mathrm{pu}}{ }^{(+)}=0,005 \mathrm{rad}$ & $\phi_{\mathrm{pu}}{ }^{(-)}=0,005 \mathrm{rad}$ \\
$\gamma^{(+)}=2,00$ & $\gamma^{(-)}=2,00$ & $\gamma^{(+)}=0,00$ & $\gamma^{(-)}=0,00$ \\
\hline
\end{tabular}

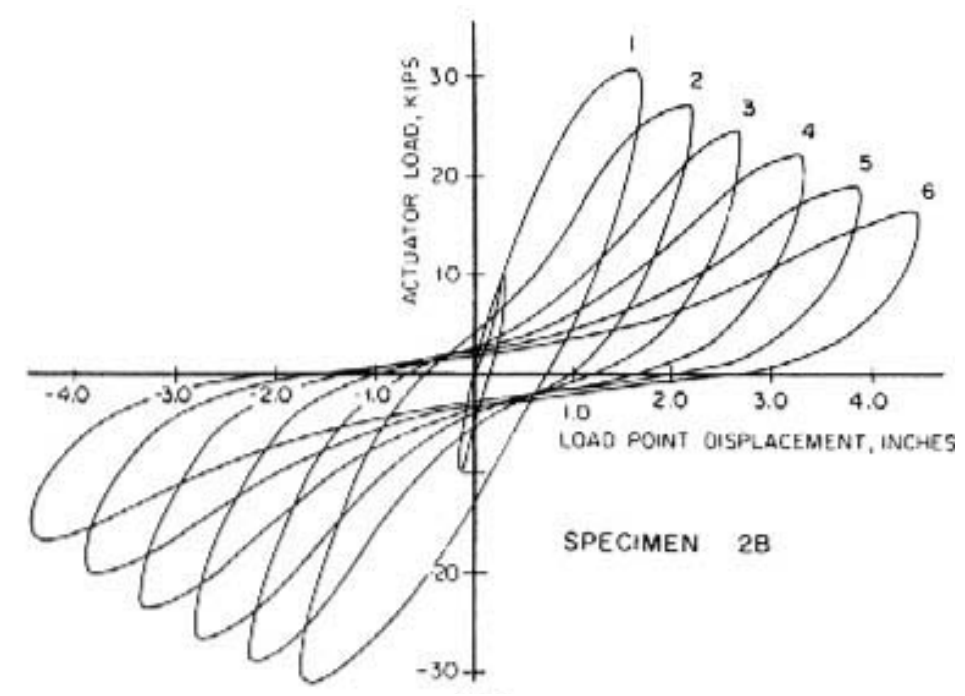

Experimental

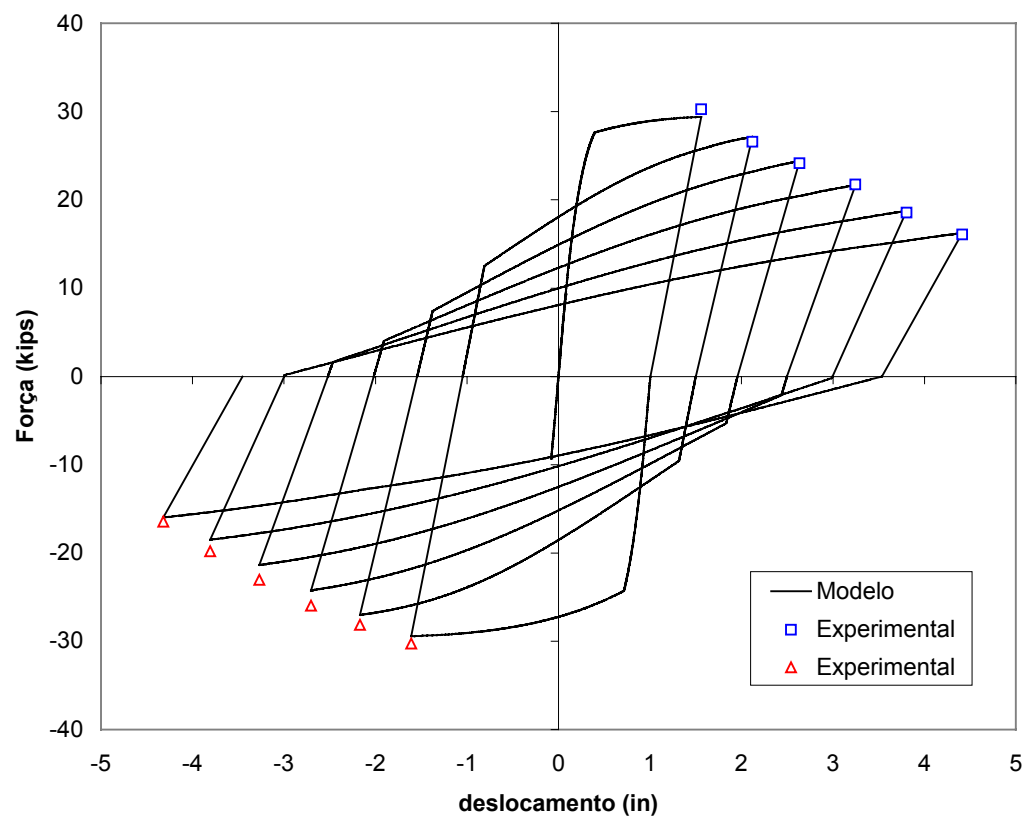

Figura 5.53: Confronto entre resultados experimentais e numéricos - EHSANI \& WIGHT (1985) 


\begin{tabular}{|llll|}
\hline \multicolumn{2}{|l|}{ Parâmetros utilizados no modelo: Viga } & \multicolumn{2}{l|}{ Parâmetros utilizados no modelo: Pilar } \\
$\mathrm{M}_{\mathrm{cr}}^{(+)}=9,88 \mathrm{kN} \cdot \mathrm{m}$ & $\mathrm{M}_{\mathrm{cr}}^{(-)}=9,88 \mathrm{kN} \cdot \mathrm{m}$ & $\mathrm{M}_{\mathrm{cr}}^{(+)}=33,67 \mathrm{kN} \cdot \mathrm{m}$ & $\mathrm{M}_{\mathrm{cr}}^{(-)}=33,67 \mathrm{kN} \cdot \mathrm{m}$ \\
$\mathrm{M}_{\mathrm{p}}^{(+)}=85,15 \mathrm{kN} \cdot \mathrm{m}$ & $\mathrm{M}_{\mathrm{p}}^{(-)}=85,15 \mathrm{kN} \cdot \mathrm{m}$ & $\mathrm{M}_{\mathrm{p}}^{(+)}=160,00 \mathrm{kN} \cdot \mathrm{m}$ & $\mathrm{M}_{\mathrm{p}}^{(-)}=160,00 \mathrm{kN} \cdot \mathrm{m}$ \\
$\mathrm{M}_{\mathrm{u}}^{(+)}=106,00 \mathrm{kN} \cdot \mathrm{m}$ & $\mathrm{M}_{\mathrm{u}}^{(-)}=106,00 \mathrm{kN} \cdot \mathrm{m}$ & $\mathrm{M}_{\mathrm{u}}{ }^{(+)}=169,00 \mathrm{kN} \cdot \mathrm{m}$ & $\mathrm{M}_{\mathrm{u}}^{(-)}=169,00 \mathrm{kN} \cdot \mathrm{m}$ \\
$\phi_{\mathrm{pu}}^{(+)}=0,033 \mathrm{rad}$ & $\phi_{\mathrm{pu}}{ }^{(-)}=0,033 \mathrm{rad}$ & $\phi_{\mathrm{pu}}{ }^{(+)}=0,010 \mathrm{rad}$ & $\phi_{\mathrm{pu}}{ }^{(-)}=0,010 \mathrm{rad}$ \\
$\gamma^{(+)}=0,80$ & $\gamma^{(-)}=0,80$ & $\gamma^{(+)}=0,00$ & $\gamma^{(-)}=0,00$ \\
\hline
\end{tabular}
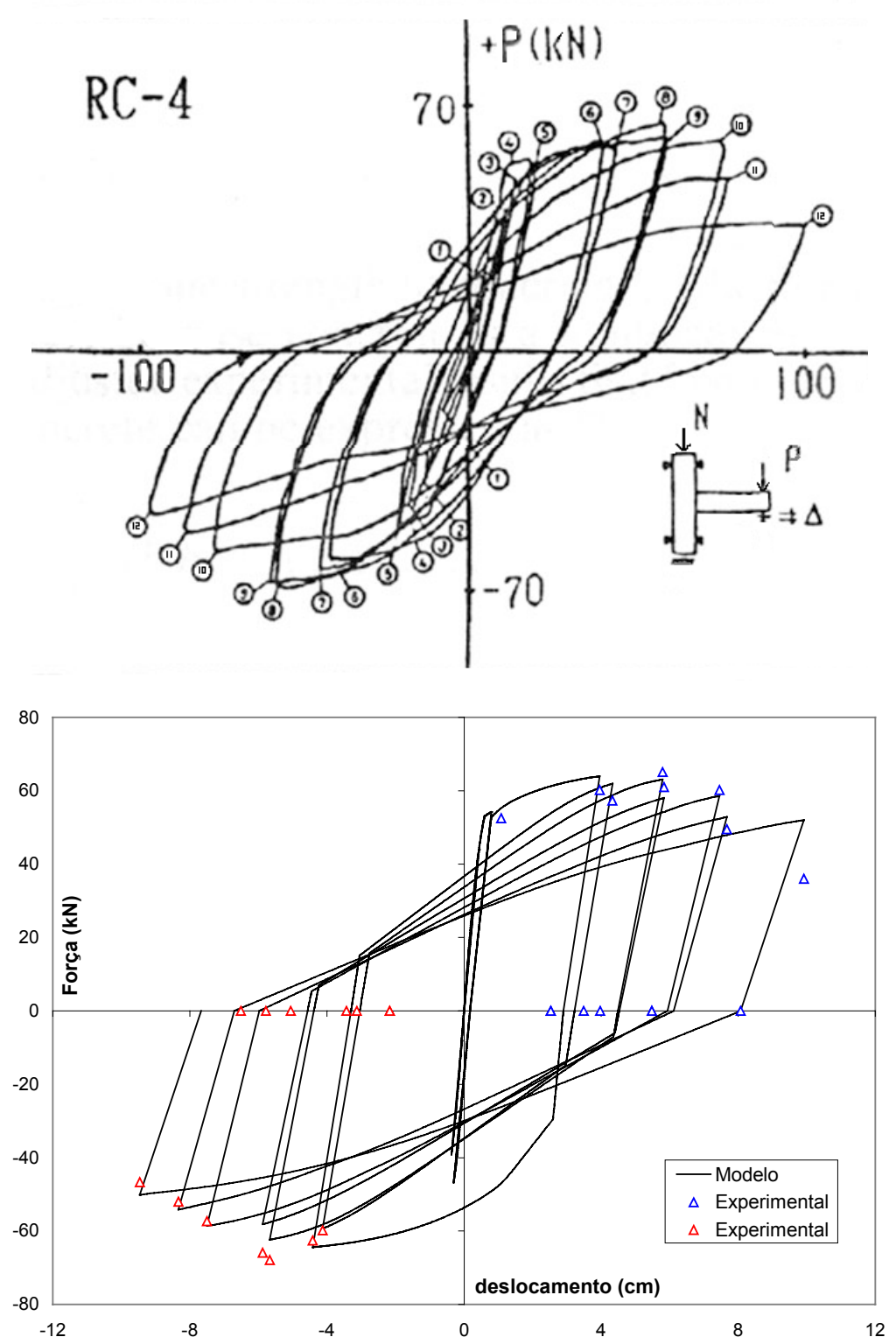

Figura 5.54: Confronto entre resultados experimentais e numéricos - JIURU et al. (1992) 


\begin{tabular}{|llll|}
\hline \multicolumn{2}{|l|}{ Parâmetros utilizados no modelo: Viga } & \multicolumn{2}{c|}{ Parâmetros utilizados no modelo: Pilar } \\
$\mathrm{M}_{\mathrm{cr}}^{(+)}=6,00 \mathrm{kN} \cdot \mathrm{m}$ & $\mathrm{M}_{\mathrm{cr}}^{(-)}=7,50 \mathrm{kN} \cdot \mathrm{m}$ & $\mathrm{M}_{\mathrm{cr}}^{(+)}=16,10 \mathrm{kN} \cdot \mathrm{m}$ & $\mathrm{M}_{\mathrm{cr}}^{(-)}=16,10 \mathrm{kN} \cdot \mathrm{m}$ \\
$\mathrm{M}_{\mathrm{p}}^{(+)}=37,15 \mathrm{kN} \cdot \mathrm{m}$ & $\mathrm{M}_{\mathrm{p}}^{(-)}=29,80 \mathrm{kN} \cdot \mathrm{m}$ & $\mathrm{M}_{\mathrm{p}}^{(+)}=75,10 \mathrm{kN} \cdot \mathrm{m}$ & $\mathrm{M}_{\mathrm{p}}^{(-)}=75,10 \mathrm{kN} \cdot \mathrm{m}$ \\
$\mathrm{M}_{\mathrm{u}}^{(+)}=43,55 \mathrm{kN} \cdot \mathrm{m}$ & $\mathrm{M}_{\mathrm{u}}^{(-)}=32,30 \mathrm{kN} \cdot \mathrm{m}$ & $\mathrm{M}_{\mathrm{u}}^{(+)}=76,30 \mathrm{kN} \cdot \mathrm{m}$ & $\mathrm{M}_{\mathrm{u}}^{(-)}=76,30 \mathrm{kN} \cdot \mathrm{m}$ \\
$\phi_{\mathrm{pu}}^{(+)}=0,060 \mathrm{rad}$ & $\phi_{\mathrm{pu}}^{(-)}=0,070 \mathrm{rad}$ & $\phi_{\mathrm{pu}}{ }^{(+)}=0,006 \mathrm{rad}$ & $\phi_{\mathrm{pu}}^{(-)}=0,006 \mathrm{rad}$ \\
$\gamma^{(+)}=0,00$ & $\gamma^{(-)}=0,00$ & $\gamma^{(+)}=0,00$ & $\gamma^{(-)}=0,00$ \\
\hline
\end{tabular}
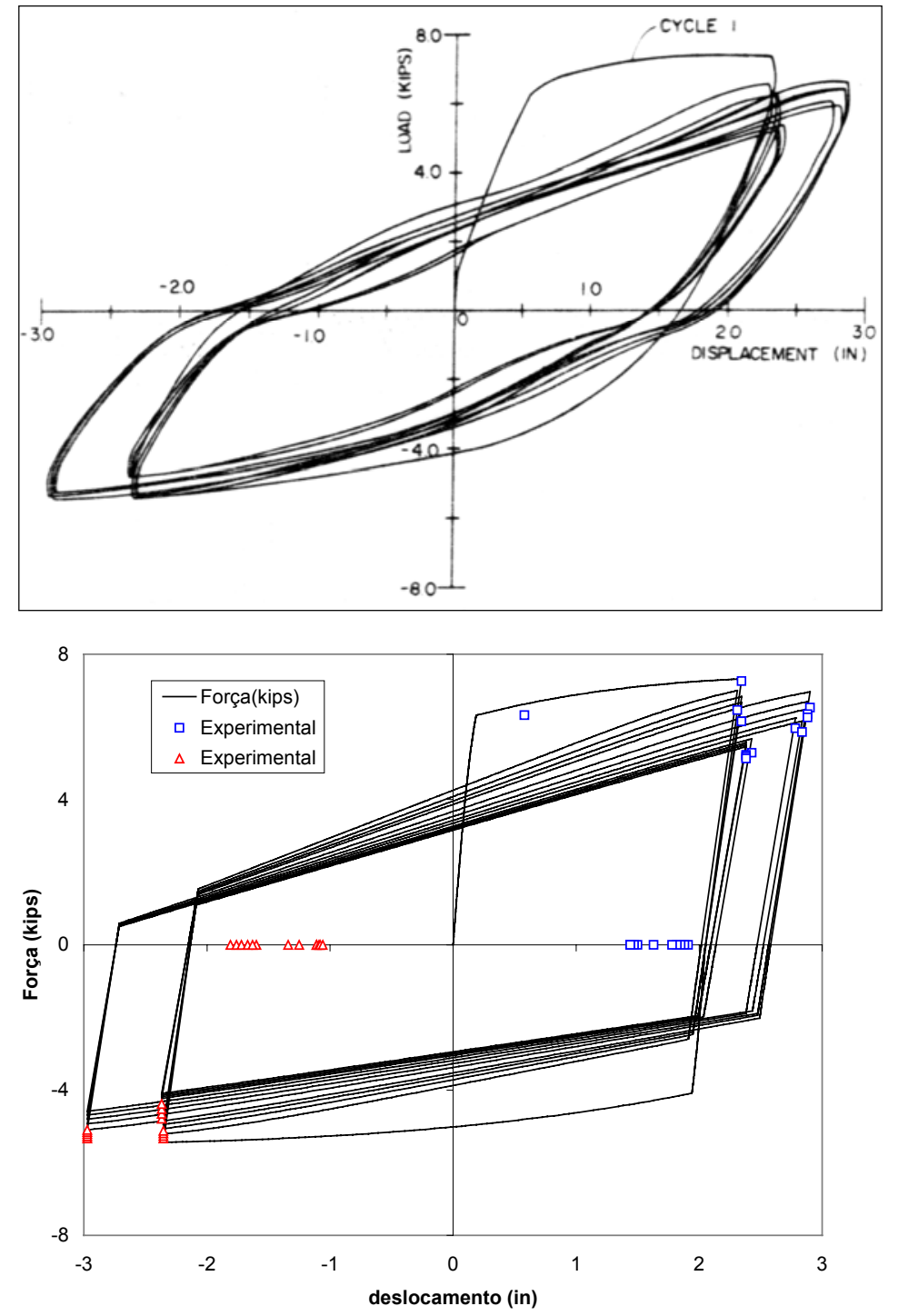

Figura 5.55: Confronto entre resultados experimentais e numéricos - LEE et al. (1977) 


\begin{tabular}{|llll|}
\hline \multicolumn{2}{|l|}{ Parâmetros utilizados no modelo: Viga } & \multicolumn{3}{l|}{ Parâmetros utilizados no modelo: Pilar } \\
$\mathrm{M}_{\mathrm{cr}}^{(+)}=7,50 \mathrm{kN} \cdot \mathrm{m}$ & $\mathrm{M}_{\mathrm{cr}}^{(-)}=7,50 \mathrm{kN} \cdot \mathrm{m}$ & $\mathrm{M}_{\mathrm{cr}}^{(+)}=12,00 \mathrm{kN} \cdot \mathrm{m}$ & $\mathrm{M}_{\mathrm{cr}}^{(-)}=12,00 \mathrm{kN} \cdot \mathrm{m}$ \\
$\mathrm{M}_{\mathrm{p}}^{(+)}=75,78 \mathrm{kN} \cdot \mathrm{m}$ & $\mathrm{M}_{\mathrm{p}}^{(-)}=63,02 \mathrm{kN} \cdot \mathrm{m}$ & $\mathrm{M}_{\mathrm{p}}^{(+)}=69,40 \mathrm{kN} \cdot \mathrm{m}$ & $\mathrm{M}_{\mathrm{p}}^{(-)}=69,40 \mathrm{kN} \cdot \mathrm{m}$ \\
$\mathrm{M}_{\mathrm{u}}^{(+)}=97,12 \mathrm{kN} \cdot \mathrm{m}$ & $\mathrm{M}_{\mathrm{u}}^{(-)}=76,54 \mathrm{kN} \cdot \mathrm{m}$ & $\mathrm{M}_{\mathrm{u}}^{(+)}=71,70 \mathrm{kN} \cdot \mathrm{m}$ & $\mathrm{M}_{\mathrm{u}}^{(-)}=71,70 \mathrm{kN} \cdot \mathrm{m}$ \\
$\phi_{\mathrm{pu}}^{(+)}=0,032 \mathrm{rad}$ & $\phi_{\mathrm{pu}}{ }^{(-)}=0,032 \mathrm{rad}$ & $\phi_{\mathrm{pu}}{ }^{(+)}=0,014 \mathrm{rad}$ & $\phi_{\mathrm{pu}}{ }^{(-)}=0,014 \mathrm{rad}$ \\
$\gamma^{(+)}=1,00$ & $\gamma^{(-)}=1,00$ & $\gamma^{(+)}=0,00$ & $\gamma^{(-)}=0,00$ \\
\hline
\end{tabular}

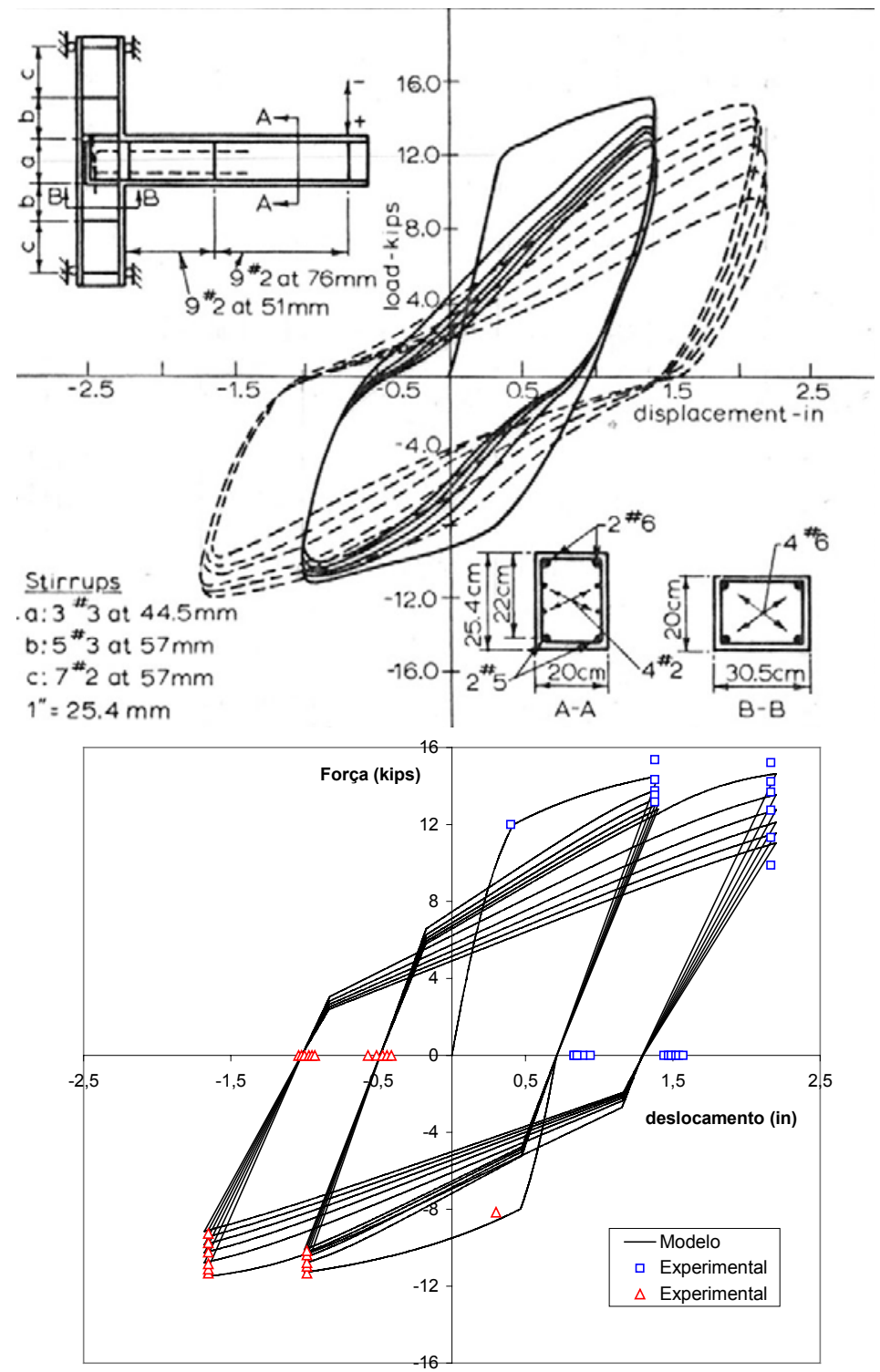

Figura 5.56: Confronto entre resultados experimentais e numéricos - SCRIBNER \& WIGHT

(1978)

Uma observação que deve ser comentada diz respeito ao estrangulamento observado nas curvas força-deslocamento para forças próximas de zero, durante a inversão do carregamento. Tal fenômeno, o efeito pinching, torna-se mais pronunciado com a redução da relação $L / d$, onde $L$ é o vão livre da viga e d é a altura útil da seção da viga. Ou seja, trata-se de um fenômeno decorrente da presença de elevadas forças cortantes, conforme já 
mencionado anteriormente. Novamente, vale frisar que os modelos simplificados de dano e plasticidade propostos por FLÓREZ-LÓPEZ (1995) e PICÓN \& FLÓREZ-LÓPEZ (2000) não simulam o efeito pinching.

$\mathrm{Na}$ ligação ensaiada por LEE et al. (1977), nota-se que o efeito pinching é menos pronunciado que nas ligações ensaiadas por JIURU et al. (1992) e SCRIBNER \& WIGHT (1978). Por outro lado, na ligação de EHSANI \& WIGHT (1985), o efeito pinching é bastante pronunciado. Nas simulações feitas nesta pesquisa e em outras similares, notou-se que o valor do coeficiente $\gamma$ que melhor se ajusta aos resultados experimentais - com relação à captura da máxima força alcançada durante os ciclos - cresce à medida que o efeito pinching é mais significativo.

A tabela 5.8 contém a relação entre as variáveis mencionadas, com respeito às ligações utilizadas nas simulações numéricas.

Tabela 5.8: Relação entre L/d e o coeficiente $\gamma$

\begin{tabular}{|c|c|c|}
\hline Ligação & L/d & $\gamma$ \\
\cline { 2 - 3 } & & \\
\hline $\begin{array}{c}\text { EHSANI \& WIGHT (1985) } \\
\text { Specimen 2B }\end{array}$ & 3,90 & $2,0(+)$ \\
\hline JIURU et al. (1992) & 4,54 & $0,8(+)$ \\
RC4 & & $0,8(+)$ \\
\hline LEE et al. (1977) & 5,81 & $0,0(+)$ \\
Specimen 2 & & $0,0(+)$ \\
\hline $\begin{array}{c}\text { SCRIBNER \& WIGHT } \\
\text { (1978) }\end{array}$ & 5,77 & $1,0(+)$ \\
& & $1,0(-)$ \\
\hline
\end{tabular}

Deve-se ressaltar, no entanto, que a resposta global da ligação pode sofrer a influencia de outras variáveis, como a taxa volumétrica de estribos, a taxa de armadura longitudinal da viga, a força normal adimensional no pilar, entre outras. Por isso, sugerem-se futuras investigações sobre a inclusão dessas variáveis nos parâmetros do modelo simplificado.

Deve-se deixar claro também que a modificação da função de limite de dano e da variação do parâmetro que controla a fadiga foram sugeridas especificamente para as ligações viga-pilar de extremidade, buscando obter melhores resultados na simulação do comportamento global. A extensão dessas modificações a outros tipos de estrutura requer maiores investigações experimentais do comportamento de cada um dos elementos estruturais analisados. 


\subsection{INTRODUÇÃO}

No programa experimental, foram realizados ensaios em 5 modelos físicos, os quais procuraram simular uma situação real de ligação entre uma viga e um pilar de extremidade em edifício de múltiplos andares.

As variáveis analisadas na etapa experimental foram o número de estribos no nó de pórtico e a forma de carregamento aplicado. As dimensões dos modelos, as armaduras longitudinais e as armaduras transversais dos elementos foram mantidas fixas, exceto 0 número de estribos na região do nó de pórtico.

Foram objetivos específicos da etapa experimental os seguintes pontos:

Análise da influência das variáveis escolhidas sobre o comportamento da ligação: Entender como a variável relativa à taxa de estribos do nó afeta o comportamento da ligação no que diz respeito à resistência, ductilidade, perda de rigidez e fissuração, sob a aplicação do carregamento cíclico.

Análise da eficiência dos modelos de dano e plasticidade - análise global: Inferir sobre o desempenho do modelo de dano originalmente proposto CIPOLLINA \& FLÓREZ-LÓPEZ (1995) e PICÓN \& FLÓREZ-LÓPEZ (2000) e do modelo modificado proposto no capítulo 5, com base nos resultados experimentais do tipo força-deslocamento e momento-rotação.

Comparação com os mecanismos de resistência ao cisalhamento - análise local: Avaliar a eficiência dos modelos de HWANG \& LEE (1999) e PAULAY \& PRIESTLEY (1992) na previsão da resistência ao cisalhamento do nó e da parcela de contribuição dos estribos, por meio dos resultados experimentais de deformações nas armaduras longitudinais e nos estribos do nó.

\subsection{CARACTERÍSTICAS DOS MODELOS FÍSICOS}

Todas as ligações foram constituídas por pilares de seção retangular com dimensões de $20 \mathrm{~cm} \times 30 \mathrm{~cm}$ e por vigas com $20 \mathrm{~cm}$ de largura e $40 \mathrm{~cm}$ de altura, sem a presença de laje. As vigas e os pilares foram dimensionados segundo os critérios da norma brasileira NBR 6118:2003 referentes ao estado limite último. 
A tabela 6.1 contém as principais informações sobre as armaduras utilizadas nos modelos. As figuras de 6.1 à 6.6 contêm o detalhamento da geometria e das armaduras das ligações.

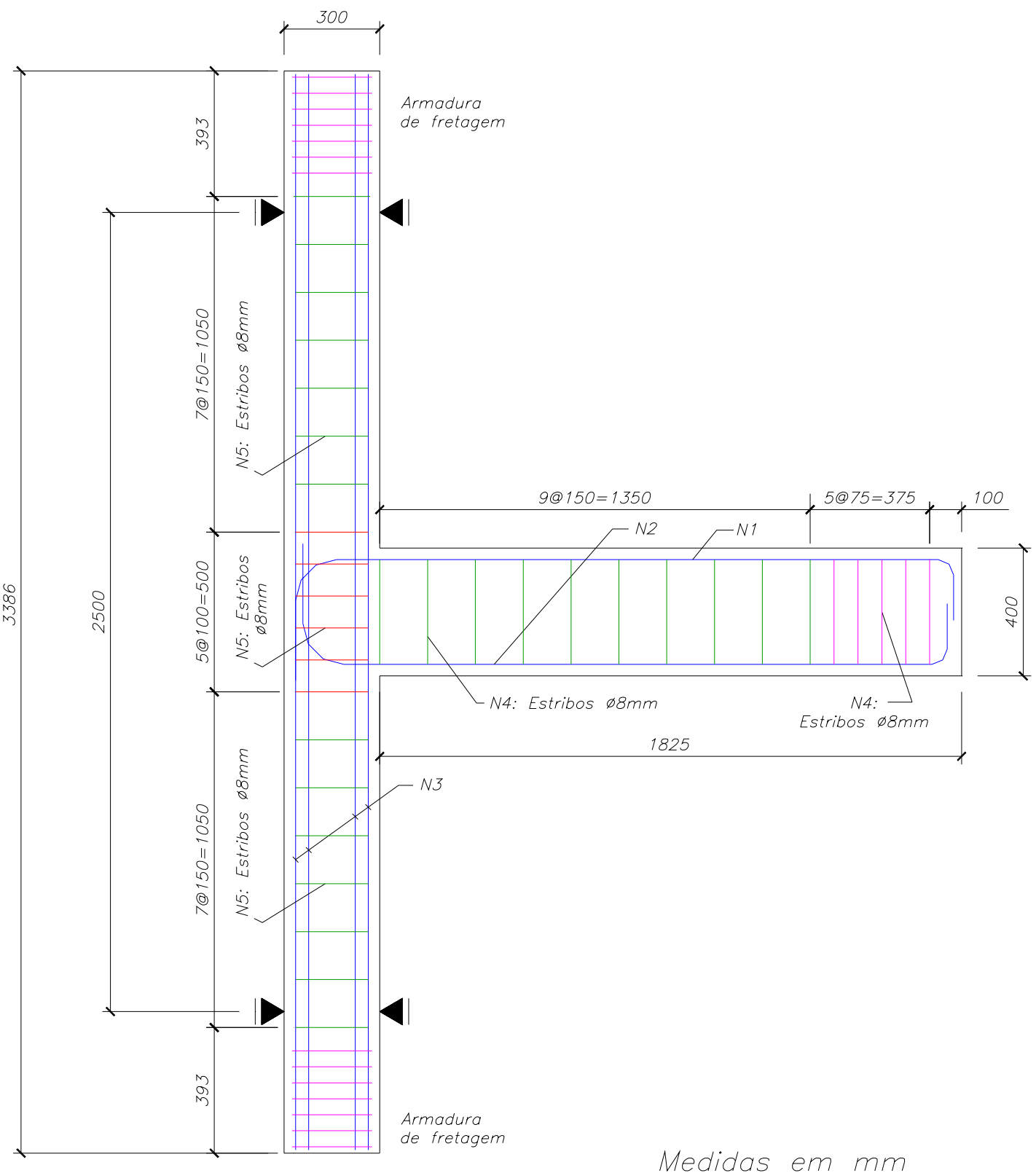

Figura 6.1: Detalhamento da ligação LVP1 


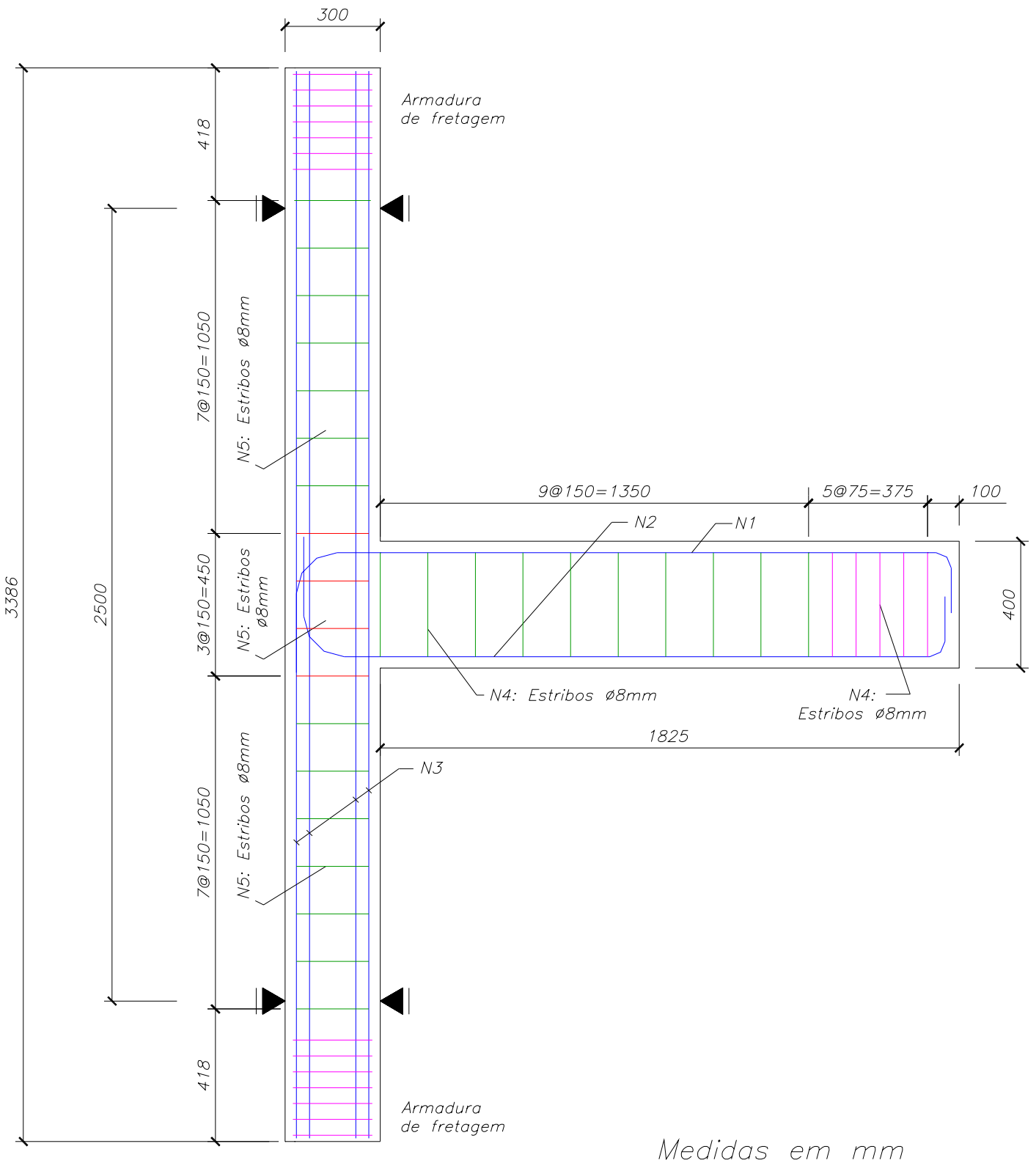

Figura 6.2: Detalhamento das ligações LVP2 e LVP4 


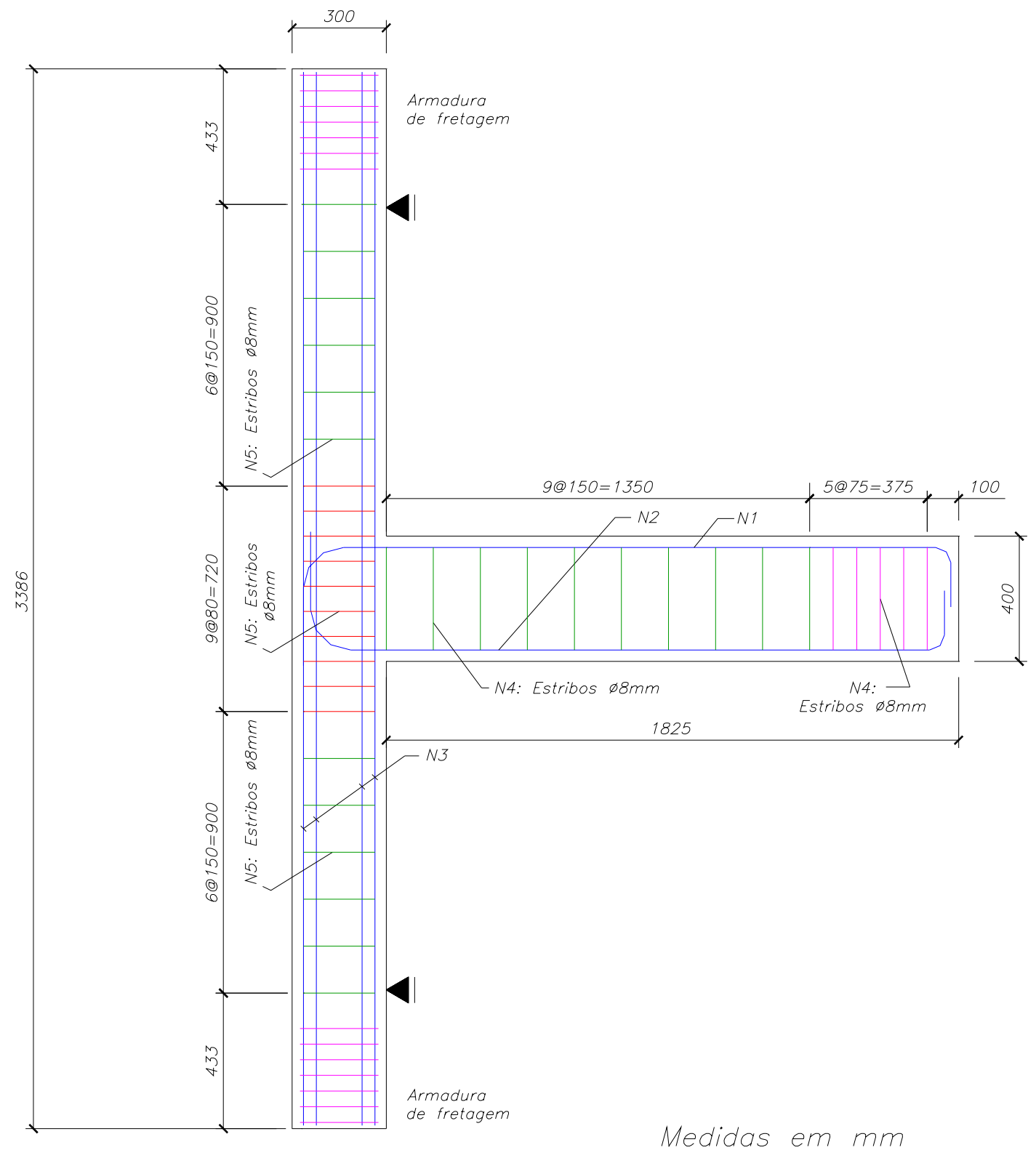

Figura 6.3: Detalhamento das ligações LVP3 e LVP5 

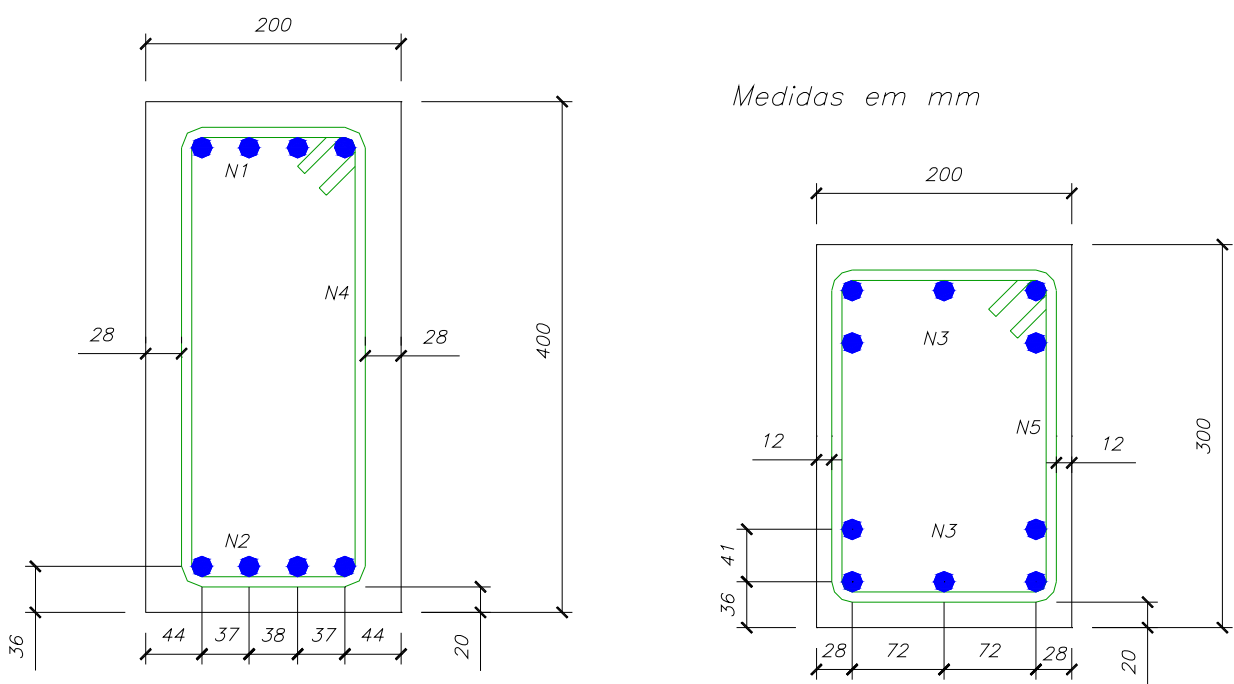

SEÇAO TRANSVERSAL DA VIGA

SECÁO TRANSVERSAL DO PILAR

Figura 6.4: Detalhe das seções transversais dos elementos viga e pilar

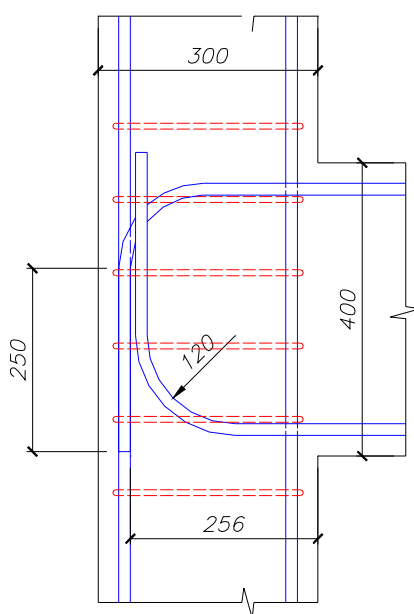

a) Modelo LVP1

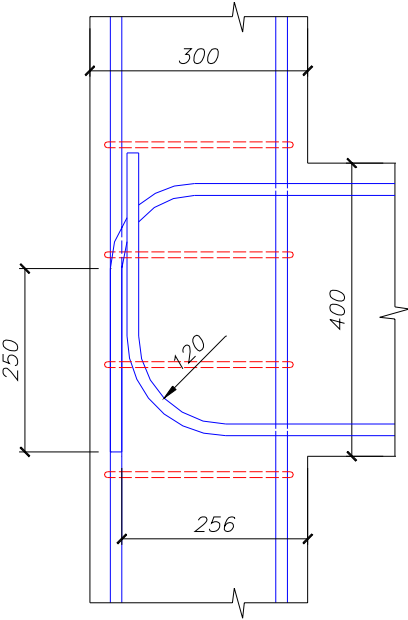

b) Modelo LVP2 e LVP4

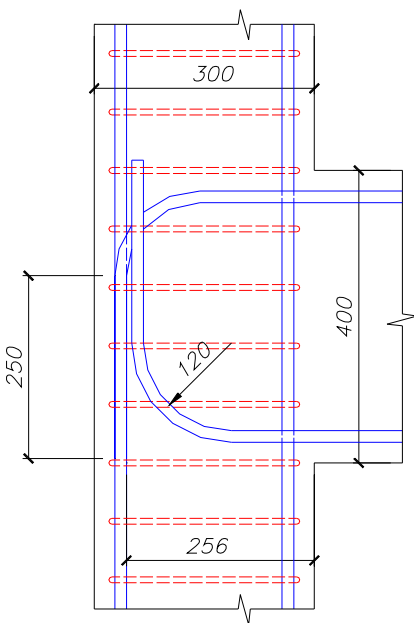

c) Modelo LVP3 e LVP5

Figura 6.5: Detalhe dos nós de pórtico das ligações ensaiadas

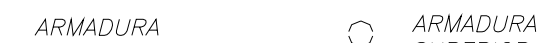

INFERIOR DA VIGA SUPERIOR DA VICA

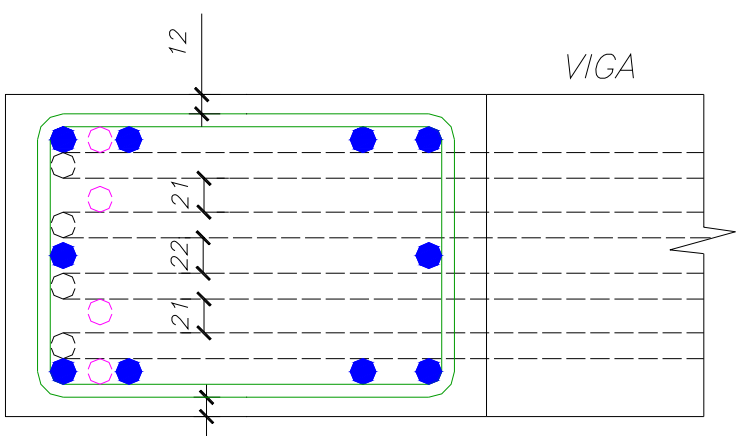

Figura 6.6: Detalhe das armaduras principais da viga e do pilar no interior do nó 
Tabela 6.1: Armaduras dispostas nas ligações

\begin{tabular}{|c|c|c|c|c|c|c|}
\hline \multirow{2}{*}{ Modelo } & \multicolumn{2}{|c|}{ Viga } & \multicolumn{2}{c|}{ Pilar } & Nó de Pórtico \\
\cline { 2 - 7 } & $\begin{array}{c}\text { Armadura } \\
\text { longitudinal }\end{array}$ & $\begin{array}{c}\text { Armadura } \\
\text { transversal }\end{array}$ & $\begin{array}{c}\text { Armadura } \\
\text { longitudinal }\end{array}$ & $\begin{array}{c}\text { Armadura } \\
\text { transversal }\end{array}$ & $\begin{array}{c}\text { Estribos } \\
\text { horizontais }\end{array}$ & $\begin{array}{c}\text { Estribos } \\
\text { Verticais* }\end{array}$ \\
\hline LVP1 & $4 \phi 16 ; 4 \phi 16$ & $\phi 8 c / 150$ & $6 \phi 16+4 \phi 16$ & $\phi 8 c / 150$ & $4 \phi 8$ & $4 \phi 16$ \\
\hline LVP2 & $4 \phi 16 ; 4 \phi 16$ & $\phi 8 c / 150$ & $6 \phi 16+4 \phi 16$ & $\phi 8 c / 150$ & $2 \phi 8$ & $4 \phi 16$ \\
\hline LVP3 & $4 \phi 16 ; 4 \phi 16$ & $\phi 8 c / 150$ & $6 \phi 16+4 \phi 16$ & $\phi 8 c / 150$ & $4 \phi 8$ & $4 \phi 16$ \\
\hline LVP4 & $4 \phi 16 ; 4 \phi 16$ & $\phi 8 c / 150$ & $6 \phi 16+4 \phi 16$ & $\phi 8 c / 150$ & $2 \phi 8$ & $4 \phi 16$ \\
\hline LVP5 & $4 \phi 16 ; 4 \phi 16$ & $\phi 8 c / 150$ & $6 \phi 16+4 \phi 16$ & $\phi 8 c / 150$ & $4 \phi 8$ & $4 \phi 16$ \\
\hline \multicolumn{7}{|c|}{$\left({ }^{*}\right):$ Barras longitudinais intermediárias do pilar } \\
\hline
\end{tabular}

$\mathrm{Na}$ tabela 6.1, as barras intermediárias referem-se as barras longitudinais da segunda camada de cada face do pilar. Essa distinção foi apresentada para levar em conta a contribuição de tais barras na resistência aos esforços cortantes no nó de pórtico.

$O$ raio interno de dobra das barras longitudinais da viga foi de $120 \mathrm{~mm}$ (figura 6.5), o que corresponde ao mínimo recomendado pela norma brasileira NBR 6118:2003, igual a 7,5 $\phi$. A ponta reta vertical, após a dobra da barra, foi especificada em $250 \mathrm{~mm}$. Vale ressaltar que o comprimento mínimo especificado pela norma brasileira é de $8 \phi$, neste caso, igual a $128 \mathrm{~mm}$. Por sua vez, em se tratando de ações cíclicas, PAULAY \& PRIESTLEY (1992) recomendam um comprimento de reto de $12 \phi$, ou seja, $192 \mathrm{~mm}$.

\subsection{ESQUEMA DE ENSAIO}

Inicialmente, pretendia-se ensaiar a ligação na posição vertical, como ilustrado na figura 6.7. Nesta posição, a ligação seria suportada por um pórtico de reação metálico, com o deslocamento vertical impedido pela laje de reação e os deslocamentos horizontais restritos nas extremidades do pilar.

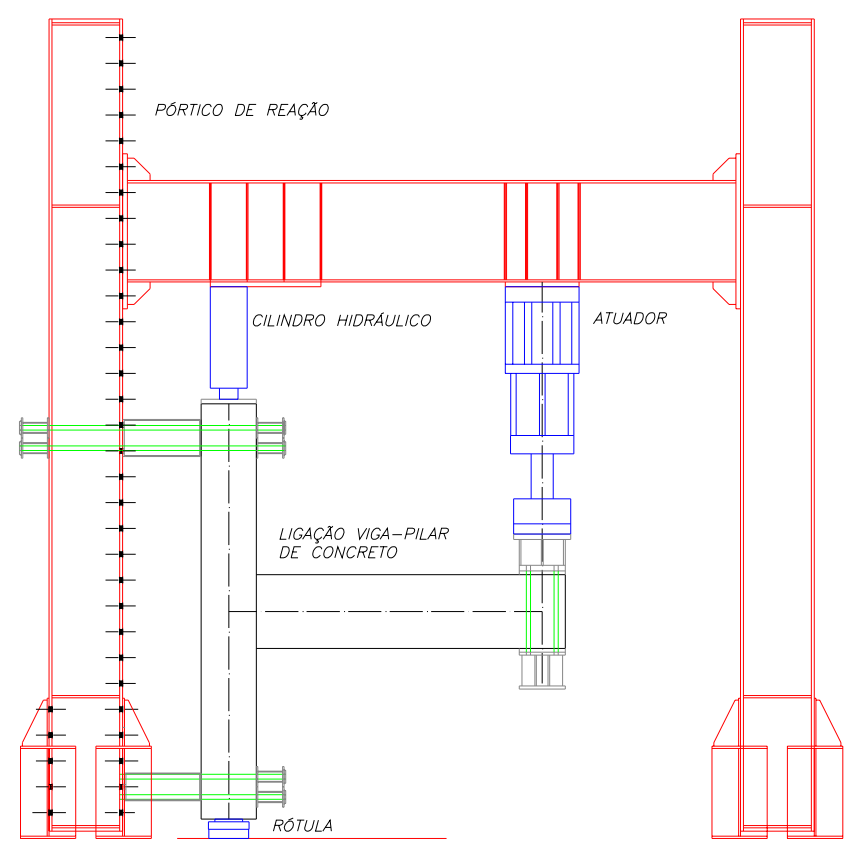

Figura 6.7: Ligação viga-pilar na posição vertical: opção inicial 
Entretanto, as investigações realizadas no laboratório indicaram que o ensaio na posição horizontal apresentaria mais vantagens, em especial na montagem e no monitoramento do ensaio.

Na posição horizontal, o cilindro hidráulico e o atuador servo-controlado, responsáveis pela aplicação da força normal no pilar e da força concentrada na extremidade da viga, foram suportados por pilares metálicos, aos quais foram conectados a barras inclinadas de travamento para reduzir os deslocamentos laterais. Os pilares metálicos e as barras de travamento foram fixados na laje de reação, em canaletas dispostas a cada 1,25 m.

A força aplicada na extremidade da viga produz um binário nas duas extremidades do pilar, que garante o equilíbrio global da ligação. As forças de reação correspondentes ao binário são paralelas aos eixos das canaletas (ver figura 6.8).

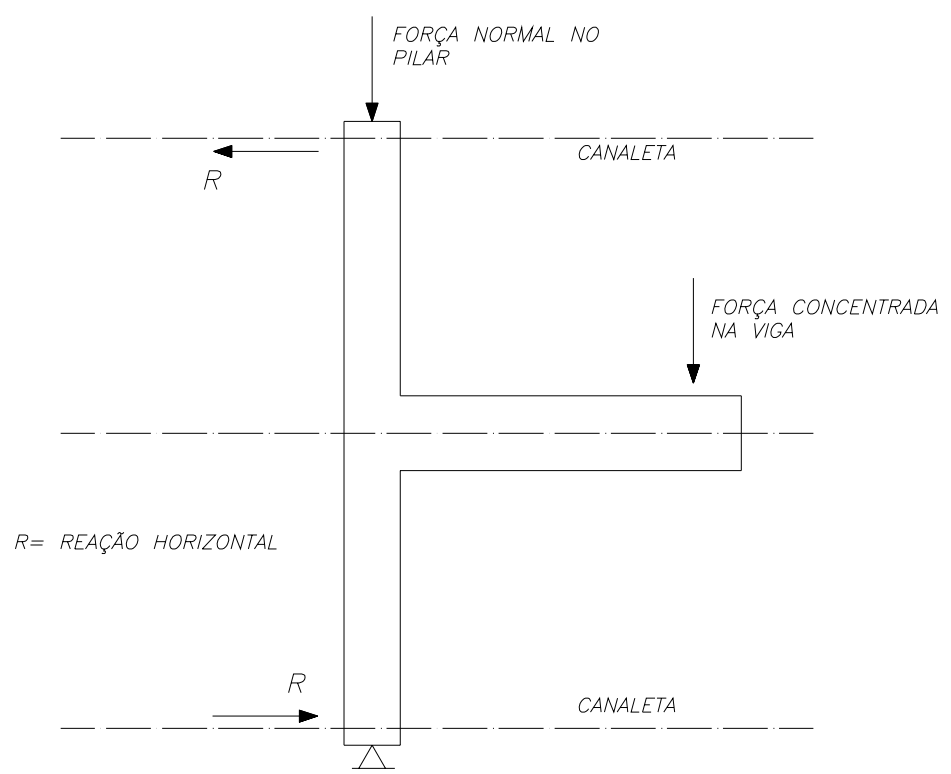

Figura 6.8: Equilíbrio estático da ligação viga-pilar de extremidade

Entretanto, por razões do próprio sistema de fixação dos elementos estruturais na laje de reação, não havia restrição aos deslocamentos na direção das canaletas. Por esse motivo, projetou-se um quadro horizontal auto-equilibrado para impedir os deslocamentos ao longo dessas canaletas. As figuras 6.9 à 6.12 ilustram o posicionamento detalhado da ligação vigapilar em relação aos diversos dispositivos e equipamentos. 


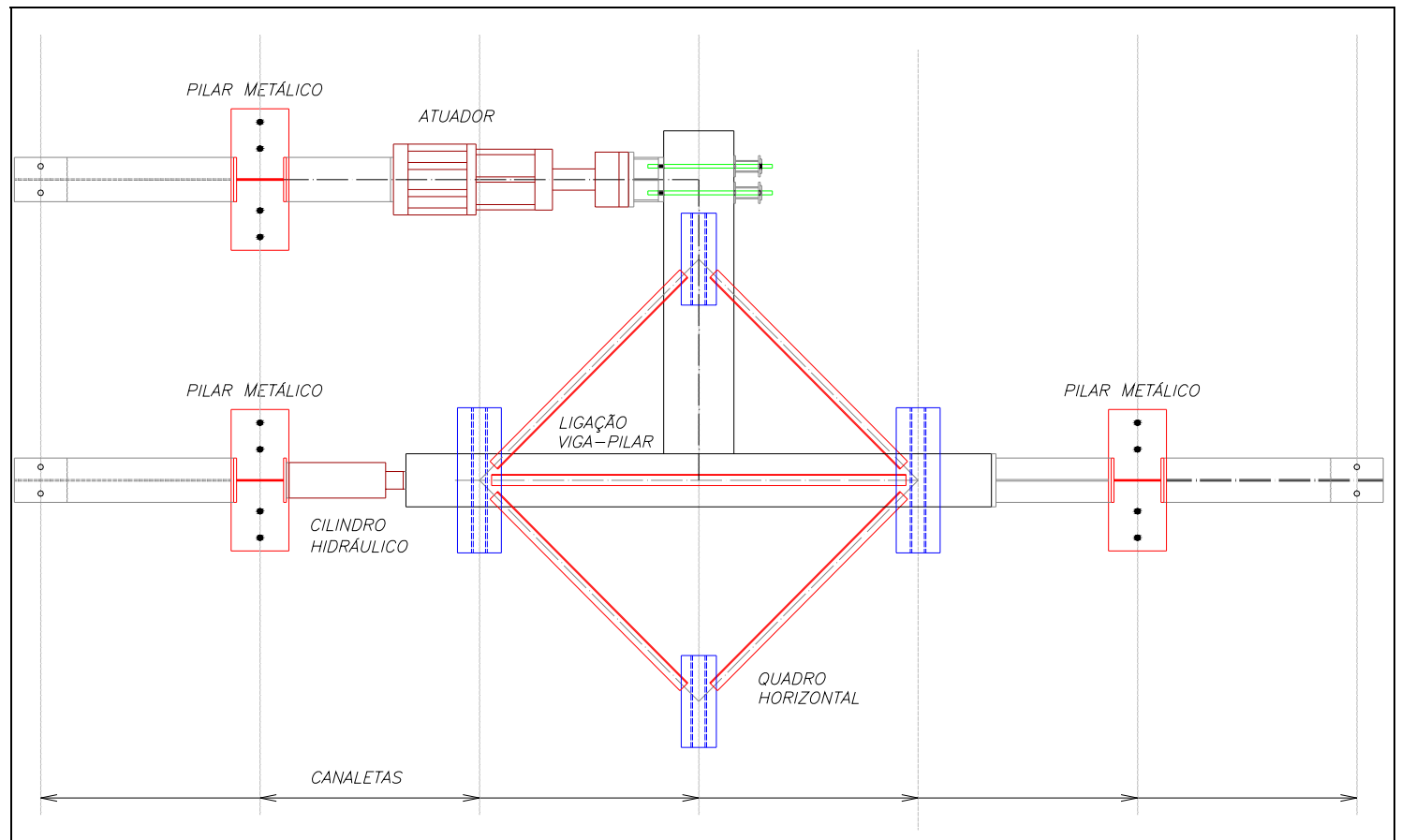

Figura 6.9: Posicionamento da ligação e dos dispositivos de ensaio: Vista superior

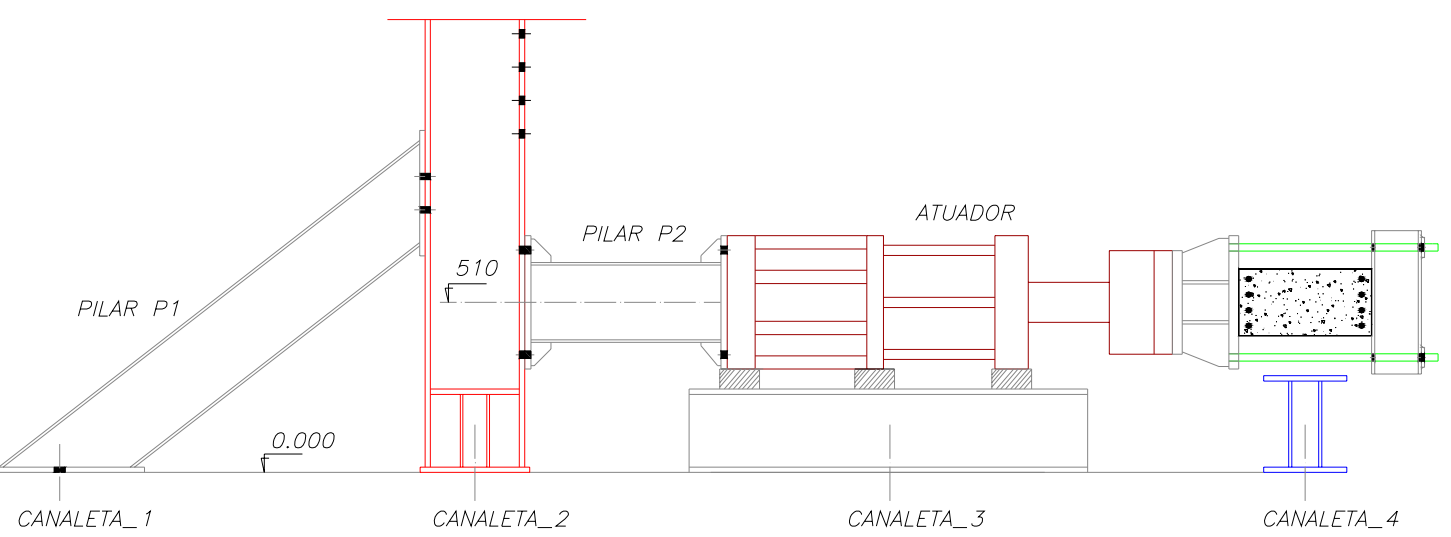

Figura 6.10: Posicionamento da ligação e dos dispositivos de ensaio: Eixo do atuador

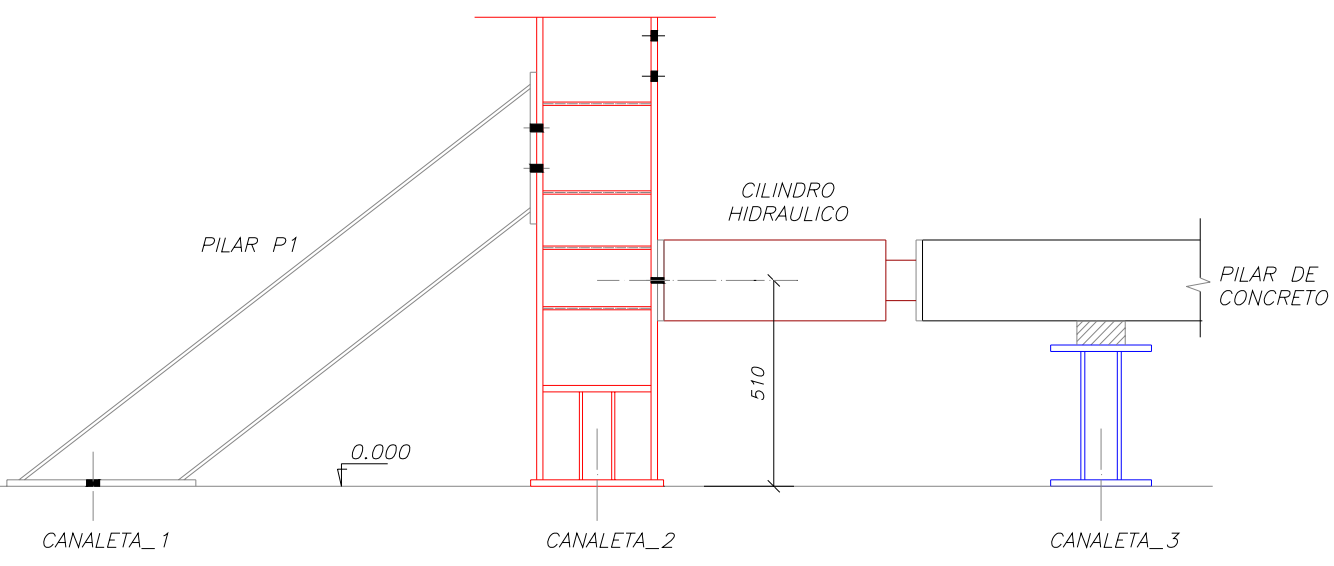

Figura 6.11: Posicionamento da ligação e dos dispositivos de ensaio: Eixo do cilindro hidráulico (topo do pilar) 


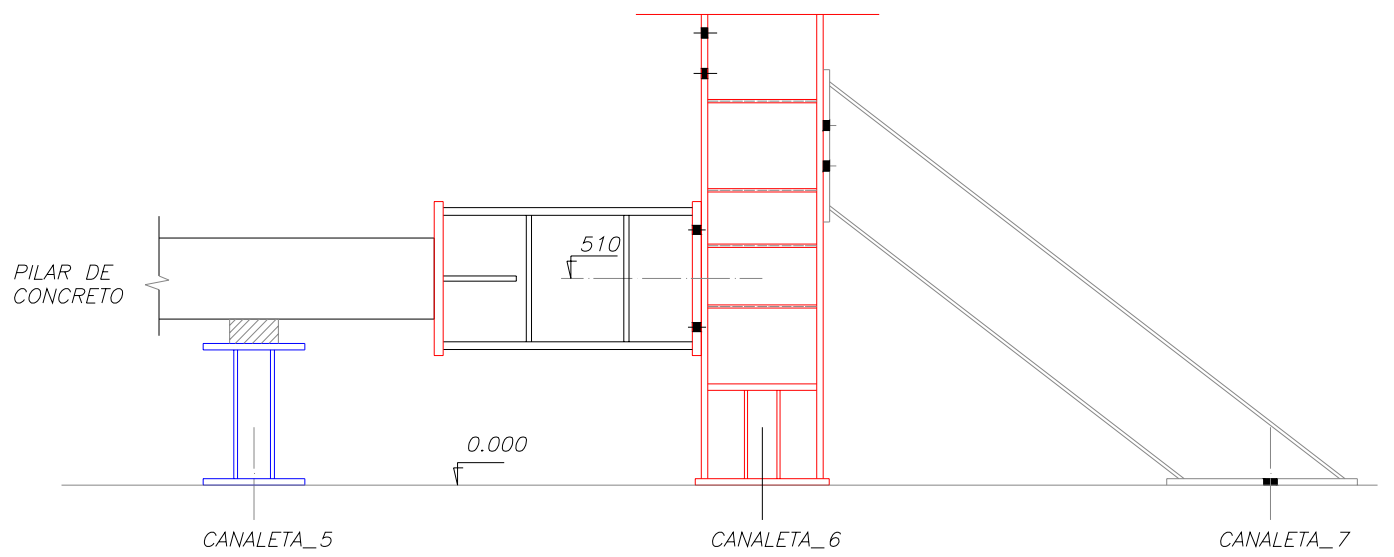

Figura 6.12: Posicionamento da ligação e dos dispositivos de ensaio: Eixo do cilindro hidráulico (base do pilar)

A figura 6.13 ilustra o quadro horizontal auto-equilibrado, o qual possibilitou que a ligação pudesse ser posicionada e ensaiada em um plano paralelo à laje de reação.

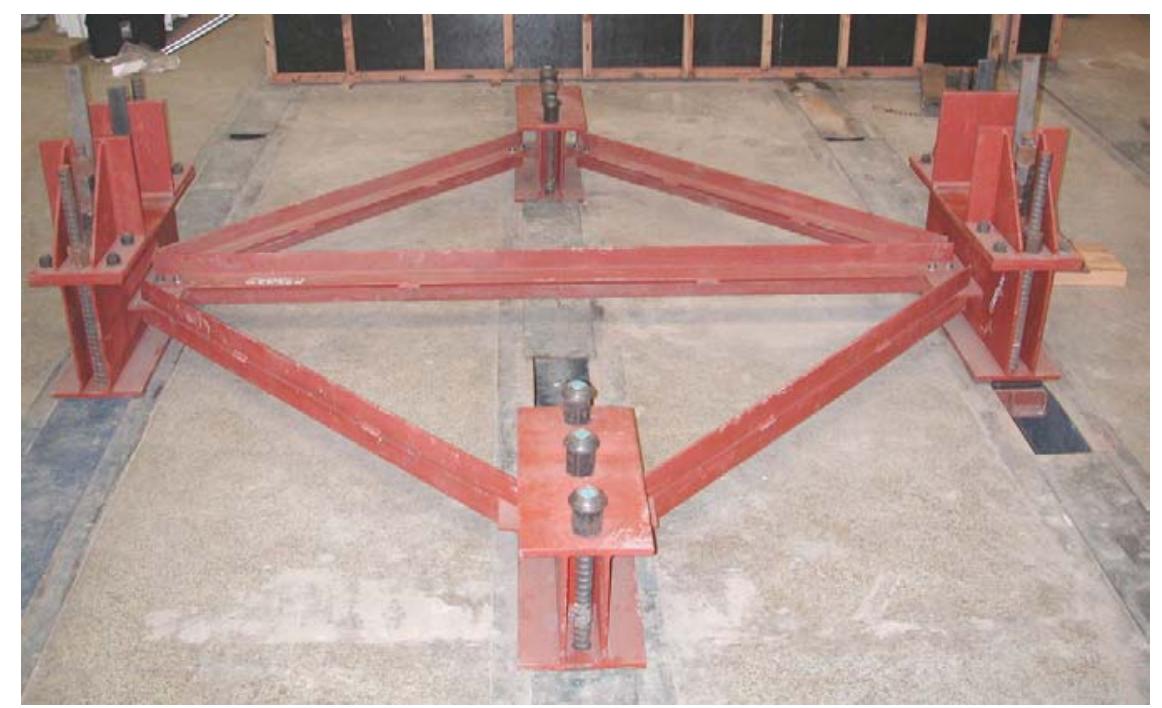

Figura 6.13: Quadro horizontal auto-equilibrado

O apoio lateral dos pilares em suas extremidades foram garantidos por um dispositivo metálico, semelhante a um pára-choque (figura 6.14). 


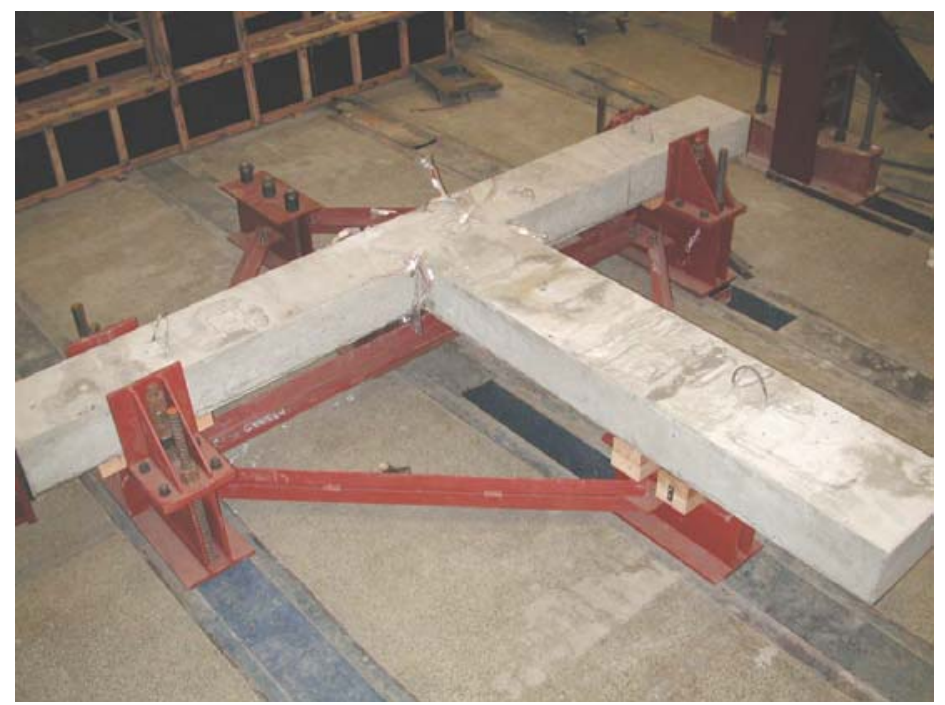

Figura 6.14: Ligação viga-pilar posicionada sobre o quadro horizontal

Os equipamentos de aplicação de forças, como o atuador servo-controlado e o macaco hidráulico foram fixados em pilares metálicos. Barras inclinadas foram conectadas a esses pilares para o travamento na direção de aplicação da força (figura 6.15).

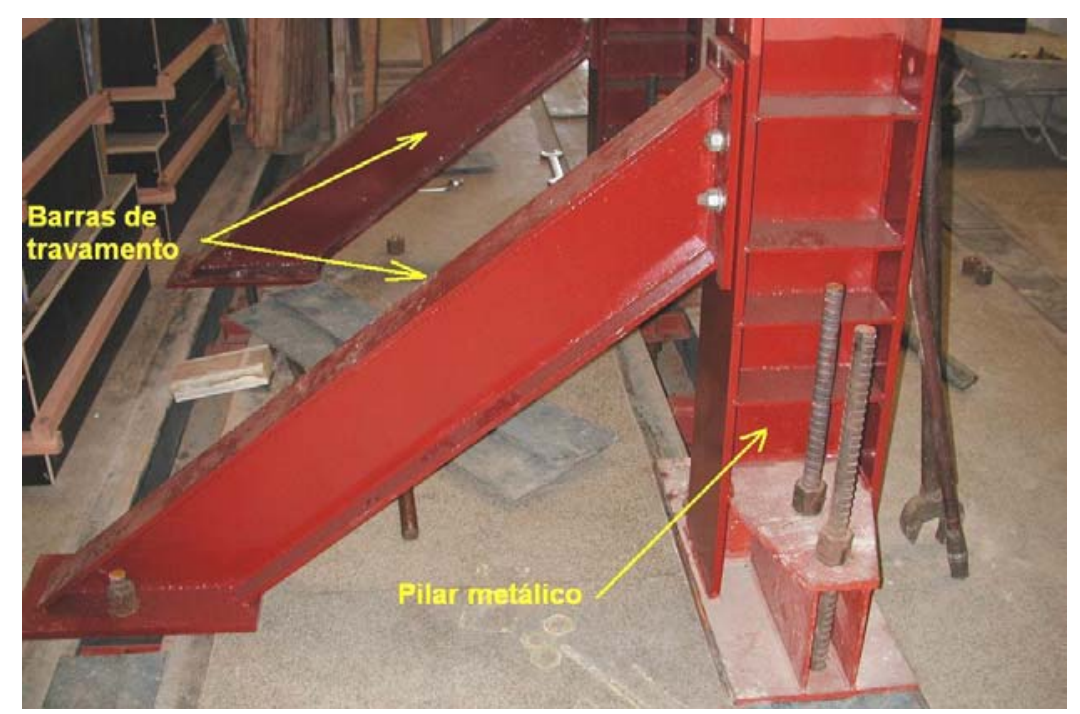

Figura 6.15: Pilar metálico para fixação do equipamento e as barras inclinadas de travamento

As figuras 6.16 e 6.17 ilustram a posição dos equipamentos em relação aos pilares metálicos. 


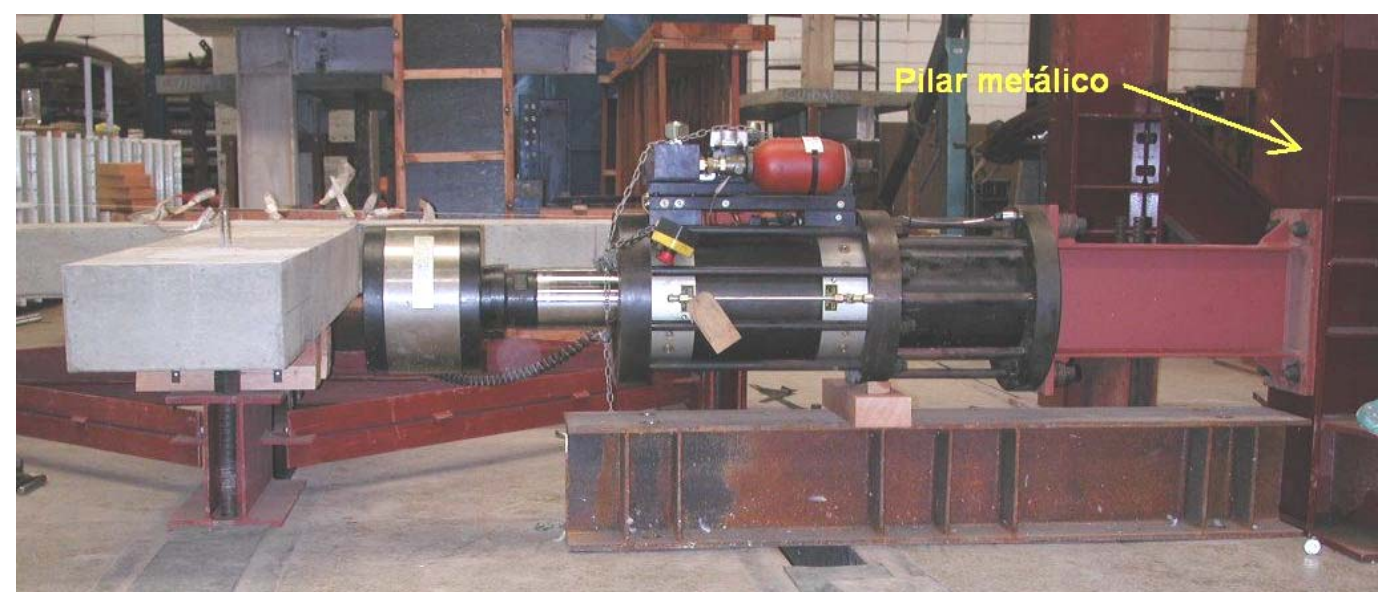

Figura 6.16: Atuador Servo-Controlado

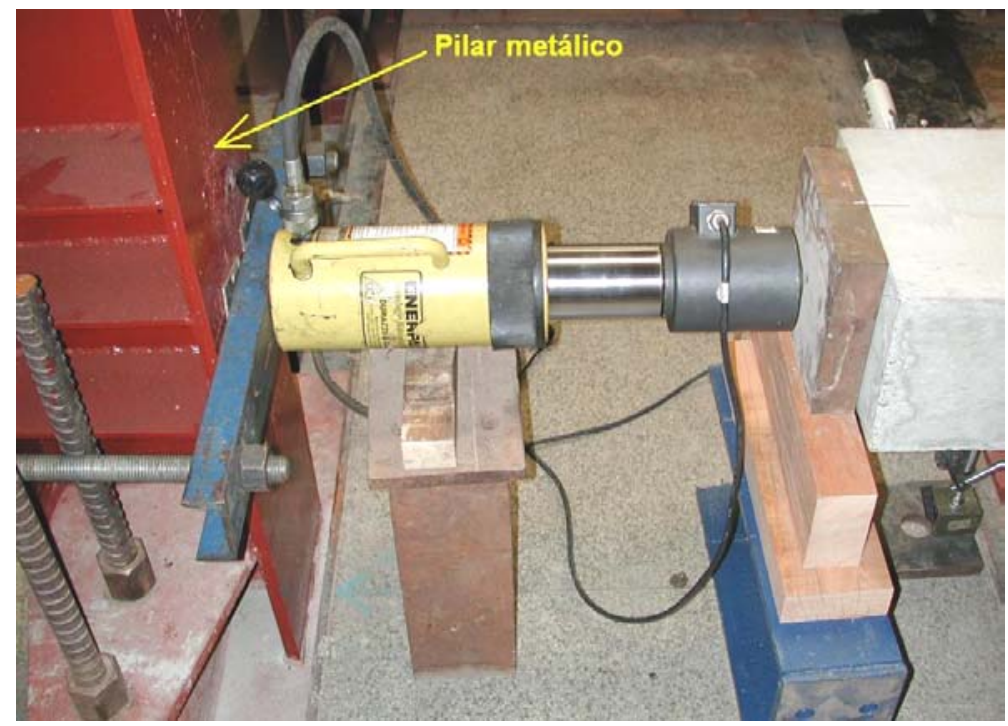

Figura 6.17: Macaco Hidráulico

\subsection{MATERIAIS}

\subsubsection{Concreto}

As ligações LVP1 e LVP2 foram moldadas com concreto produzido no laboratório. A dosagem empregada nesses modelos foi determinada a partir de um estudo preliminar de dosagem. Utilizou-se cimento de alta resistência inicial CP V-ARI-PLUS CIMINAS. Os agregados eram da região de São Carlos (Rio Mogi). A tabela 6.2 indica o consumo de materiais e o traço do concreto.

Tabela 6.2: Materiais constituintes do concreto: Modelos LVP1 e LVP2

\begin{tabular}{|c|c|c|c|c|}
\hline \multicolumn{4}{|c|}{ Consumo $\left(\mathbf{k g} / \mathbf{m}^{3}\right.$ ) } & \multirow{2}{*}{$\begin{array}{c}\text { Traço } \\
\text { (em peso) }\end{array}$} \\
\cline { 1 - 3 } $\begin{array}{c}\text { Cimento ARI V } \\
\text { Plus - CIMINAS }\end{array}$ & Areia & $\begin{array}{c}\text { Pedra } \\
\text { Britada } \mathbf{n}^{\circ} \mathbf{1}\end{array}$ & Água & \\
\hline 352 & 760 & 1112 & 218 & $1: 2,16: 3,16: 0,62$ \\
\hline
\end{tabular}


O valor do abatimento do tronco de cone foi de $15,0 \mathrm{~cm}$ para a ligação LVP1 e de 10,0 cm para a ligação LVP2.

Com o intuito de reduzir o tempo gasto com as atividades de concretagem, optou-se por utilizar concreto usinado nas demais ligações restantes (LVP3, LVP4 e LVP5), solicitando um concreto com resistência característica à compressão de $30 \mathrm{MPa}$, abatimento de tronco de cone igual a $10,0 \mathrm{~cm}$ e pedra britada ${ }^{\circ} 1$ como agregado graúdo.

No dia do ensaio de cada ligação, foram realizados os ensaios de caracterização do concreto, a saber, o ensaio de compressão axial - que permitiu determinar a resistência à compressão $f_{c}$, o módulo de deformação secante e tangente $\left(E_{c s}\right.$ e $\left.E_{c t}\right)$ - e o ensaio de compressão diametral, que possibilitou a determinação da resistência à tração. As propriedades mecânicas obtidas com os ensaios de caracterização do concreto estão resumidas na tabela 6.3 .

Tabela 6.3: Propriedades mecânicas do concreto obtidas nos ensaios

\begin{tabular}{|c|c|c|c|c|}
\hline Modelo & $\begin{array}{c}\mathbf{f}_{\mathbf{c}} \\
(\mathrm{MPa})\end{array}$ & $\begin{array}{c}\mathbf{E}_{\mathrm{cs}} \\
(\mathrm{MPa})\end{array}$ & $\begin{array}{c}\mathbf{E}_{\mathrm{ct}} \\
(\mathrm{MPa})\end{array}$ & $\begin{array}{c}\mathbf{f}_{\mathrm{t}, \text { diam }} \\
(\mathrm{MPa})\end{array}$ \\
\hline LVP1 & 40,43 & 27.902 & 31.712 & 2,87 \\
\hline LVP2 & 44,18 & 29.579 & 33.603 & 3,30 \\
\hline LVP3 & 23,89 & 25.093 & 28.315 & 1,95 \\
\hline LVP4 & 24,62 & 25.235 & 28.467 & 2,08 \\
\hline LVP5 & 25,91 & 25.487 & 28.736 & 2,20 \\
\hline
\end{tabular}

\subsubsection{Aço}

Para a caracterização do aço das armaduras, foram realizados ensaios de tração simples em duas amostras para cada diâmetro. As barras foram pesadas em balança e sua área efetiva foi calculada tomando-se a massa específica do aço como $7,85 \mathrm{~g} / \mathrm{cm}^{3}$. As armaduras foram adquiridas em duas compras, portanto decidiu-se realizar um ensaio para cada lote. A tabela 6.4 contém os valores médios das principais propriedades mecânicas do aço.

Tabela 6.4: Propriedades mecânicas do aço das armaduras

\begin{tabular}{|c|c|c|c|c|}
\hline Modelo & $\begin{array}{c}\text { Diâmetro da barra } \\
(\mathrm{mm})\end{array}$ & $\begin{array}{c}\mathbf{E}_{\mathbf{s}} \\
(\mathrm{MPa})\end{array}$ & $\begin{array}{c}\mathbf{f}_{\mathbf{y}} \\
(\mathrm{MPa})\end{array}$ & $\begin{array}{c}\mathbf{f}_{\mathbf{u}} \\
(\mathrm{MPa})\end{array}$ \\
\hline \multirow{2}{*}{ LVP1 } & 8 & 211.000 & 610 & 727 \\
\hline \multirow{2}{*}{ LVP2 à LVP5 } & 16 & 181.700 & 630 & 738 \\
\cline { 2 - 5 } & 8 & 212.400 & 602 & 692 \\
\hline
\end{tabular}

\subsection{MOLDAGEM E CURA DOS MODELOS}

As figuras 6.18 à 6.21 contêm o registro fotográfico das etapas de concretagem, controle do abatimento, adensamento do concreto e do método de cura. Para a cura do concreto, empregaram-se espumas umedecidas posicionadas sobre a face superior da ligação, durante um período de 3 dias. 


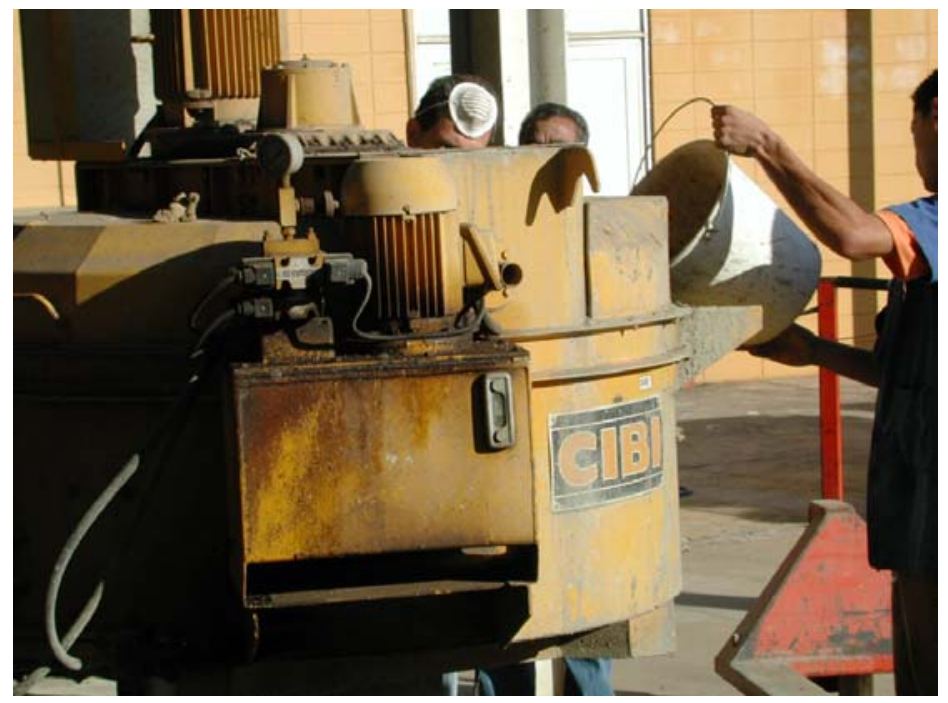

Figura 6.18: Lançamento dos materiais na betoneira: (Modelos LVP1 e LVP2)

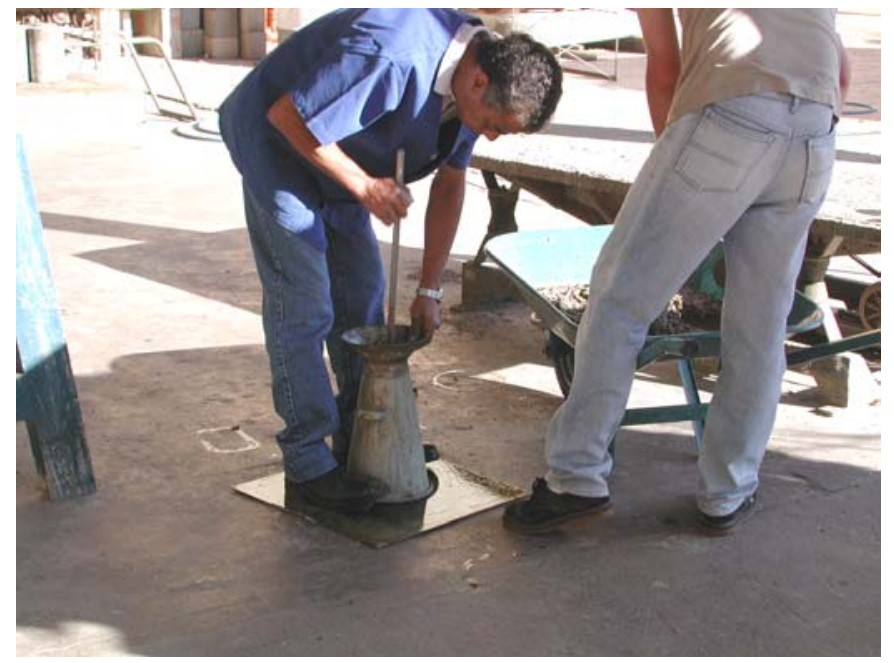

Figura 6.19: Controle do abatimento do tronco de cone

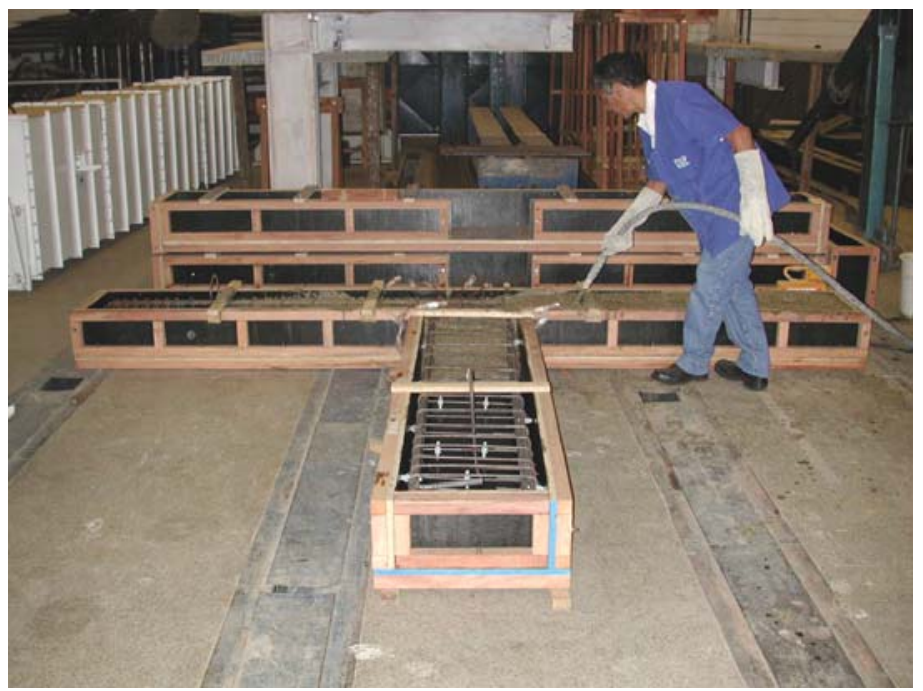

Figura 6.20: Adensamento do concreto na fôrma 


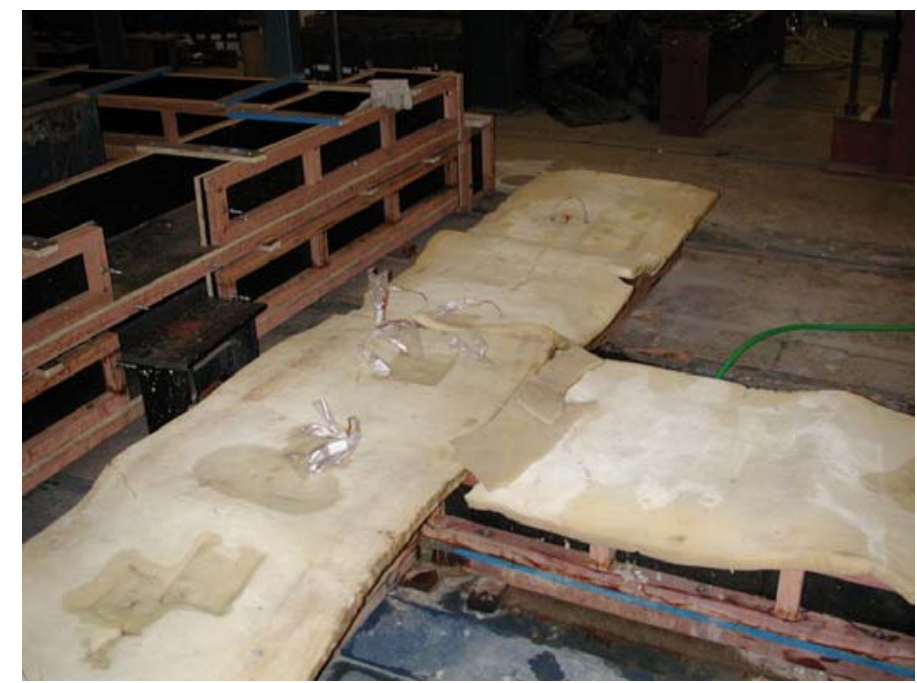

Figura 6.21: Cura com espuma umedecida.

\subsection{INSTRUMENTAÇÃO DOS MODELOS E EQUIPAMENTOS UTILIZADOS}

A figura 6.22 ilustra o posicionamento e a numeração dos transdutores de deslocamentos nas ligações viga-pilar.

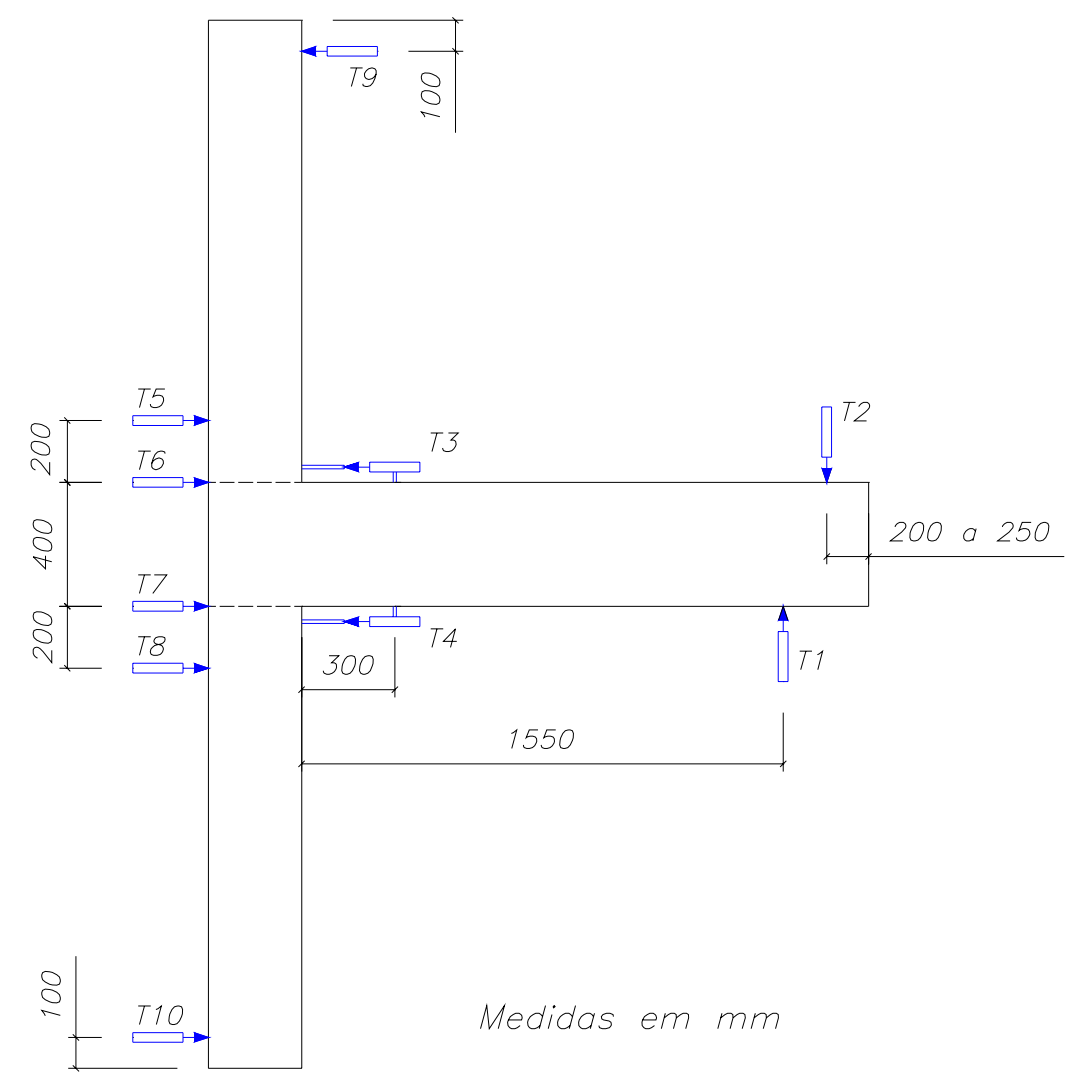

Figura 6.22: Posição dos instrumentos de medição de deslocamentos 
Além dos transdutores da figura 6.22 posicionados na ligação viga-pilar, foram empregados os transdutores T11 à T15 para o monitoramento da estrutura de reação (figura 6.23).

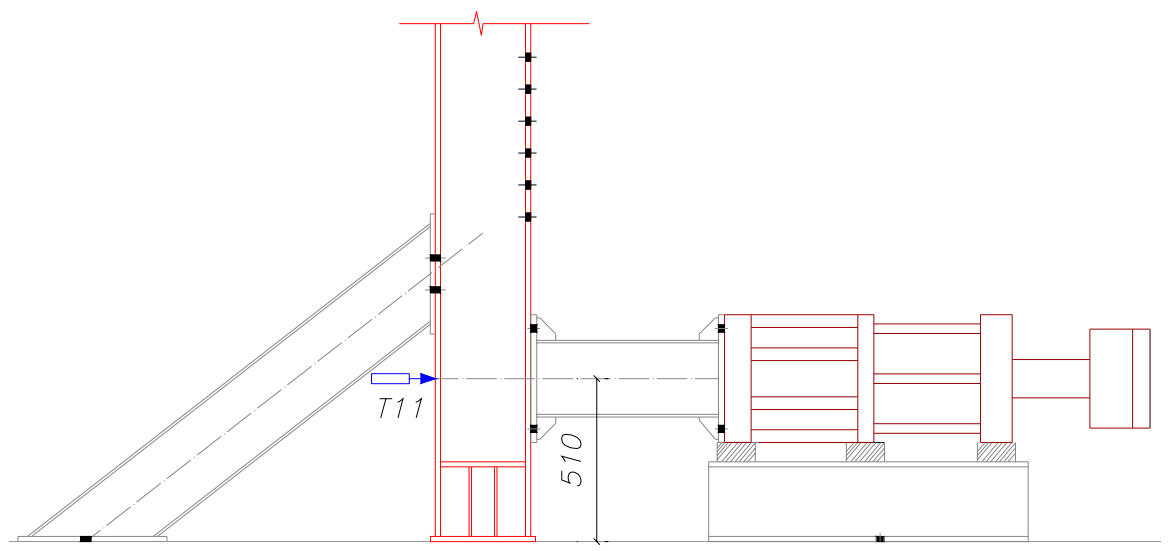

a)

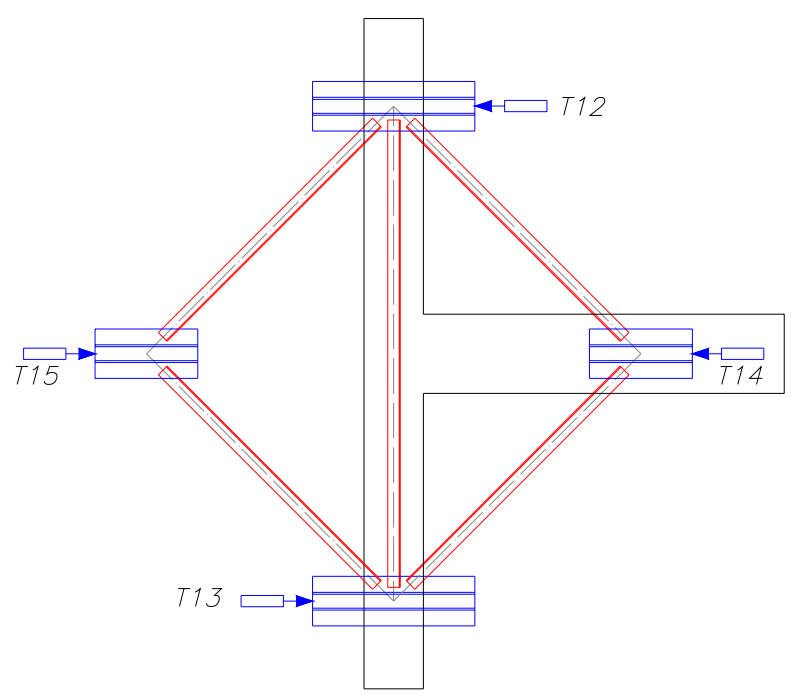

b)

Figura 6.23: Transdutores posicionados na estrutura de reação: a) no pilar do eixo do atuador. b) no quadro horizontal

O transdutor T1 teve a função de medir os deslocamentos na extremidade da viga no eixo de aplicação da força pelo atuador. $\mathrm{O}$ transdutor T2 funcionou como reserva, em caso de falha do transdutor T1. Os transdutores T3 e T4, colocados na face superior e inferior da viga, distantes $30 \mathrm{~cm}$ da face do pilar, foram utilizados para a obtenção das rotações relativas entre viga e pilar (figura 6.24).

Os transdutores T5 à T8 foram empregados para avaliar a rotação do pilar próximo a interseção com a viga (figura 6.25). Os transdutores T9 e T10 tiveram a função de monitoramento dos deslocamentos laterais no topo e na base do pilar. 


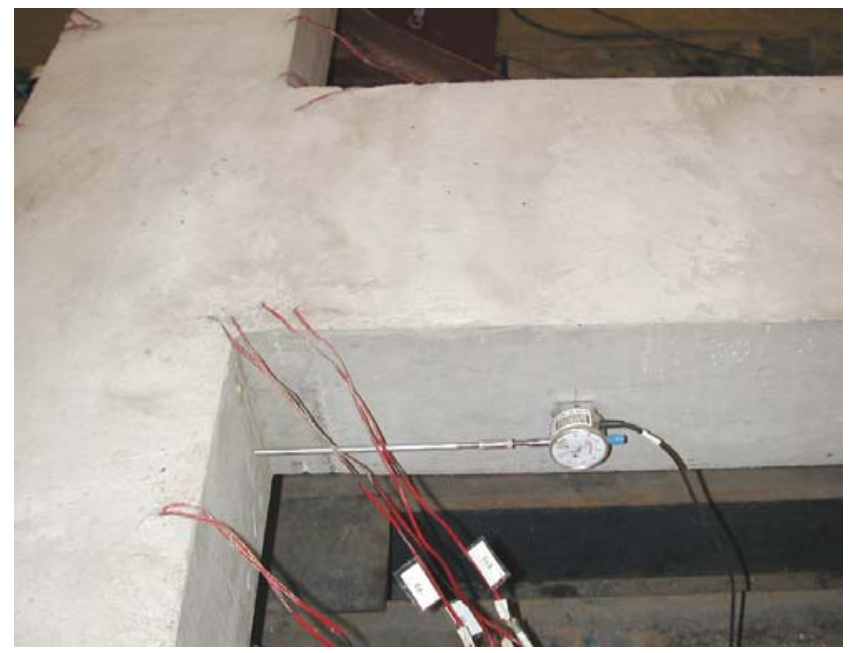

Figura 6.24: Relógio utilizado para medir a rotação relativa viga-pilar (T3 e T4)

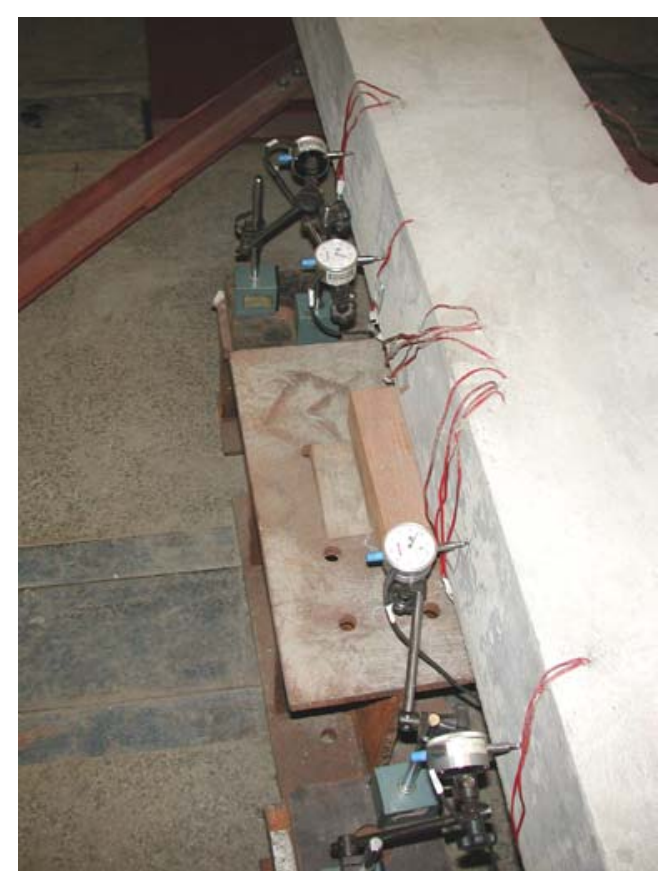

Figura 6.25: Relógios utilizados para medir as rotações do pilar

Para medir as deformações nas barras das armaduras da ligação, utilizaram-se extensômetros elétricos de resistência uniaxiais. Com relação às armaduras principais da viga e do pilar, instrumentou-se uma barra por camada. Assim, a viga teve duas barras instrumentadas (uma na face superior e outra na face inferior). De mesmo modo, foram colados extensômetros em duas barras do pilar (face interna e externa em relação à viga). A locação dos extensômetros nas barras longitudinais das vigas e dos pilares é indicada na figura 6.26. 


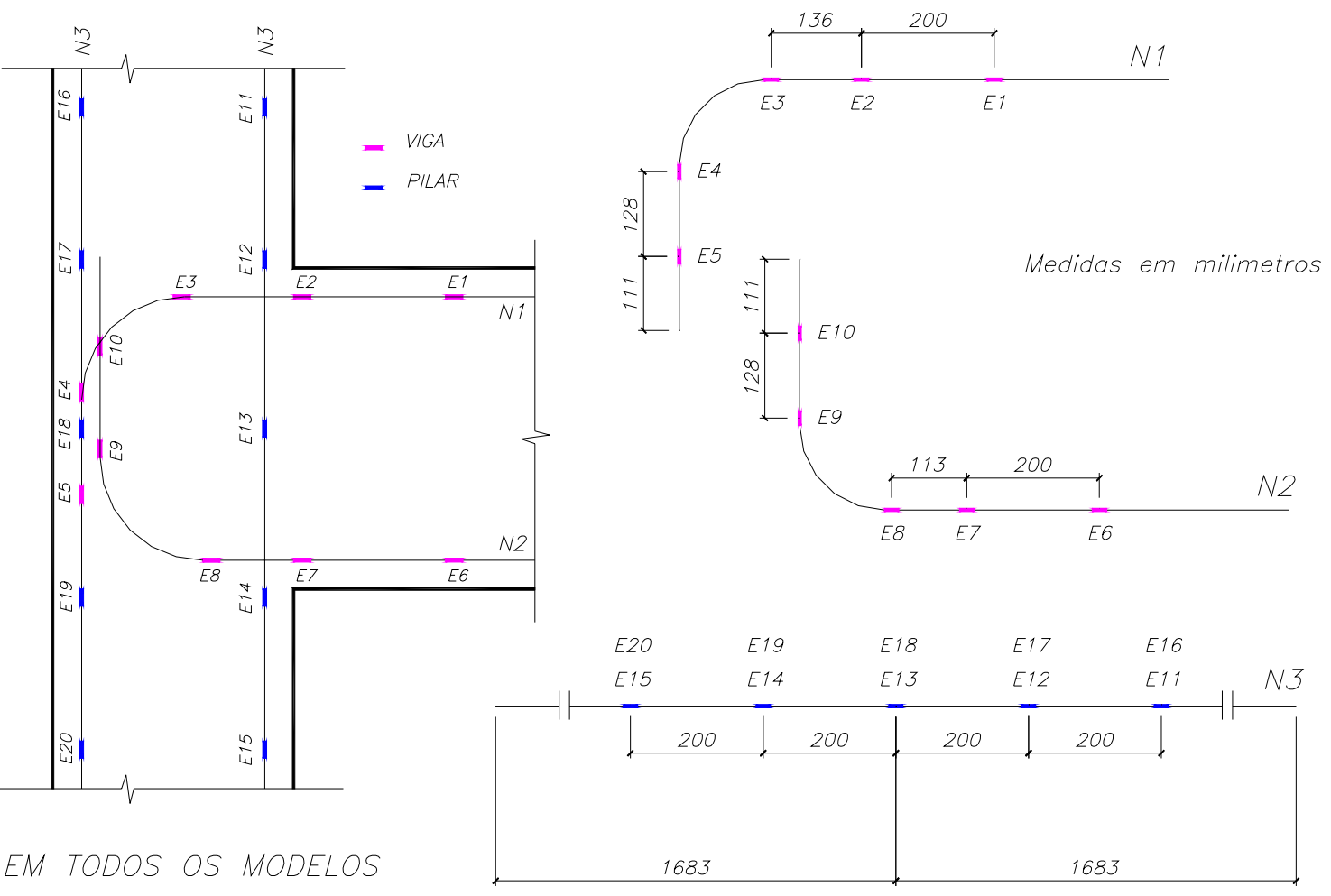

Figura 6.26: Posição dos extensômetros nas armaduras longitudinais da viga e do pilar

A locação dos extensômetros nos estribos do nó de pórtico é indicada na figura 6.27.
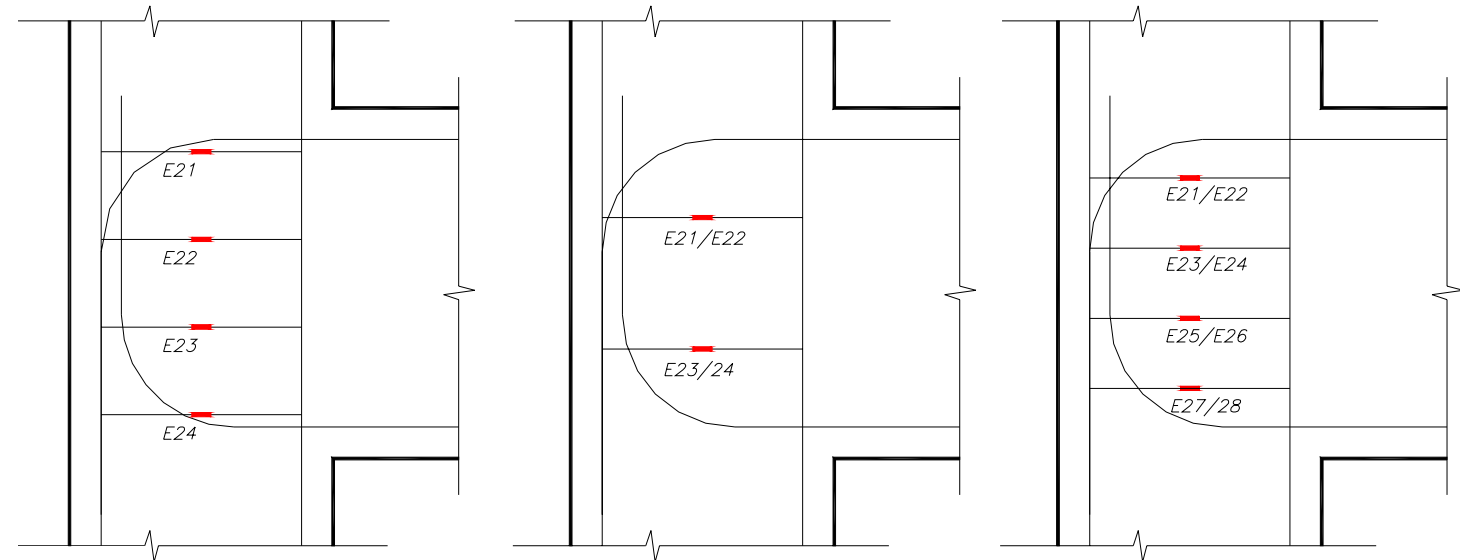

Figura 6.27: Posição dos extensômetros nos estribos do nó.

A partir da segunda ligação ensaiada (LVP2 à LVP5), decidiu-se colar dois extensômetros por estribo do nó, como precaução contra eventuais danificações. Pelo mesmo motivo, nas ligações LVP3, LVP4 e LVP5, foram colados alguns extensômetros reservas nas barras longitudinais das vigas.

As figuras 6.28 à 6.30 ilustram o posicionamento das armaduras nas fôrmas e a instrumentação na região do nó de pórtico. 


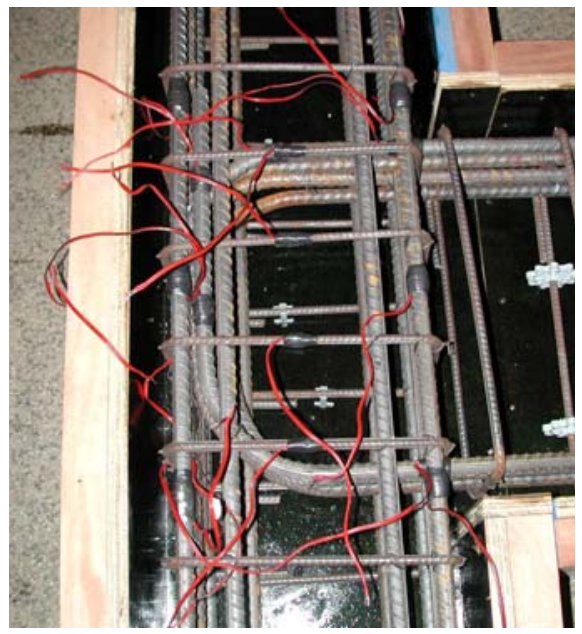

Figura 6.28: Detalhe das armaduras na região nodal: Modelo LVP1

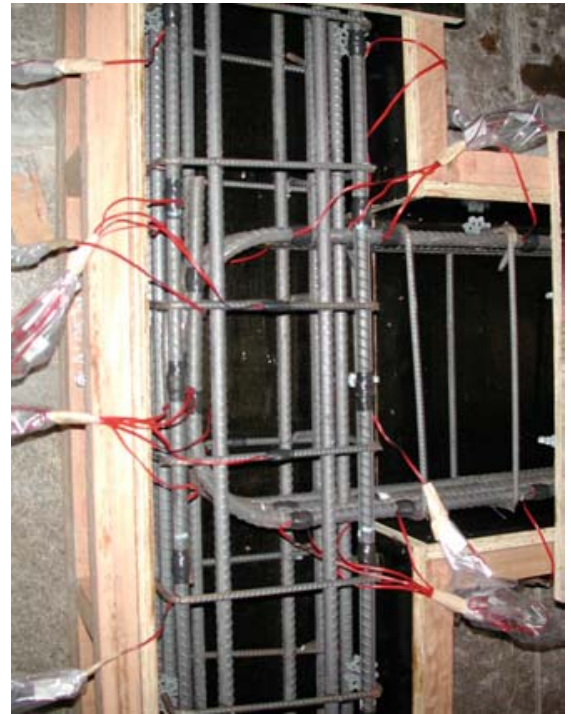

Figura 6.29: Detalhe das armaduras na região nodal: Modelos LVP2 e LVP4

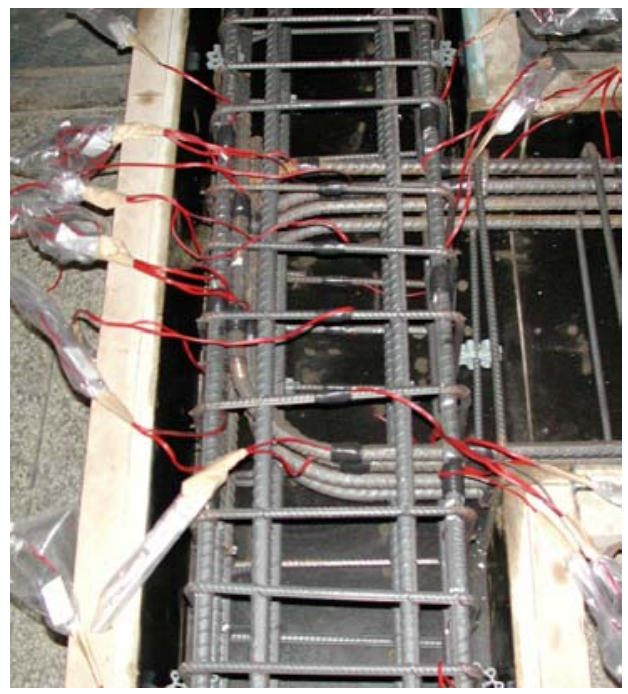

Figura 6.30: Detalhe das armaduras na região nodal: Modelos LVP3 e LVP5 
As especificações dos equipamentos e instrumentos de medição encontram-se na tabela 6.5 .

Tabela 6.5: Relação dos instrumentos de medição de deslocamentos e deformações

\begin{tabular}{|c|c|c|}
\hline Instrumento & Marca/Modelo/Sensibilidade & Posição \\
\hline $\begin{array}{c}\text { Relógio: } \\
\text { Curso de 10mm }\end{array}$ & $\begin{array}{c}\text { KYOWA/DT-10D } \\
\text { Sensibilidade: 0,003mm }\end{array}$ & T3 à T8 \\
\hline $\begin{array}{c}\text { Transdutor: } \\
\text { Curso de 10mm }\end{array}$ & $\begin{array}{c}\text { KYOWA/DTH-A10 } \\
\text { Sensibilidade: 0,001mm }\end{array}$ & T12, T13 e T14 \\
\hline $\begin{array}{c}\text { Transdutor: } \\
\text { Curso de 20mm }\end{array}$ & $\begin{array}{c}\text { KYOWA/DT-20D } \\
\text { Sensibilidade: 0,005mm }\end{array}$ & T15 \\
\hline $\begin{array}{c}\text { Transdutor: } \\
\text { Curso de 50mm }\end{array}$ & $\begin{array}{c}\text { KYOWA/DT50-A } \\
\text { Sensibilidade: 0,02mm }\end{array}$ & T9, T10 e T11 \\
\hline Transdutor: & KYOWA/DT50-A & T1 e T2 \\
Curso de 100mm & Sensibilidade: 0,03mm & Todas as armaduras \\
\hline Extensômetros & KYOWA/KFG-5-120-C1-11 & \\
\hline elétricos & Sensibilidade: $1 \mu \varepsilon$ & \\
\hline
\end{tabular}




\subsection{PROCEDIMENTOS DE ENSAIO E RESULTADOS OBTIDOS}

O procedimento geral de carregamento na ligação consistiu na aplicação de uma força normal constante, para simular as ações gravitacionais, e de uma força variável na extremidade da viga, visando simular ações laterais cíclicas em edifícios de múltiplos andares. A convenção de sinal dessa força é indicada na figura 6.31.

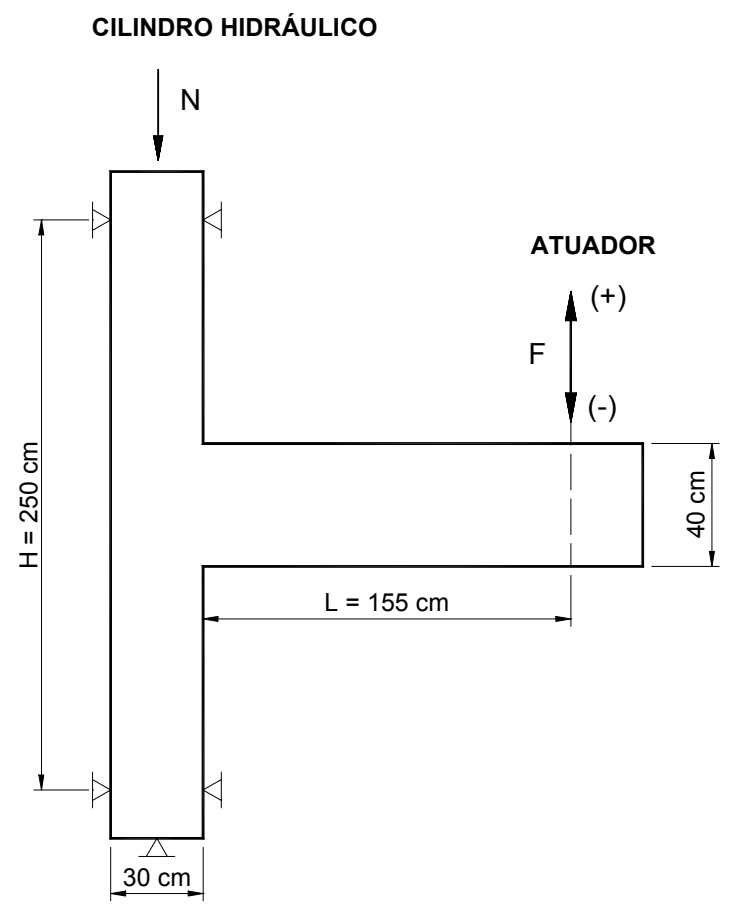

Figura 6.31: Esquema de aplicação do carregamento na ligação

Os procedimentos relacionados com o carregamento da estrutura iniciaram-se com o escorvamento do modelo, aplicando-se uma força na extremidade da viga em torno de $70 \%$ da força correspondente ao momento de fissuração: $-8 \mathrm{kN}$; $+8 \mathrm{kN}$ para as ligações LVP1 e LVP2 e $-5 \mathrm{kN} ;+5 \mathrm{kN}$ para as ligações LVP3 à LVP5.

Após o escorvamento, aplicou-se a força axial de compressão no pilar utilizando o macaco hidráulico posicionado no topo do pilar. Para simular uma ligação de pavimento situado em nível intermediário, estabeleceu-se uma força normal adimensional no pilar em torno de 0,15. Portanto, nas ligações LVP1 e LVP2, a normal aplicada foi de $360 \mathrm{kN}$. Nas demais ligações, constituídas de concreto de menor resistência à compressão, aplicou-se uma força axial de compressão de $240 \mathrm{kN}$.

Em seguida, iniciou-se a etapa 1 do ensaio, comum a todas as cinco ligações. Esta etapa consistiu na aplicação de carregamentos crescentes e inversíveis na extremidade da viga, com máximos/mínimos de $\pm 10 \mathrm{kN} ; \pm 20 \mathrm{kN} ; \pm 30 \mathrm{kN} ; \pm 40 \mathrm{kN} ; \pm 50 \mathrm{kN}$ e $\pm 60 \mathrm{kN}$, totalizando seis ciclos (figura 6.32). A velocidade de aplicação do carregamento pelo atuador foi de 0,05 $\mathrm{mm} / \mathrm{s}$. 


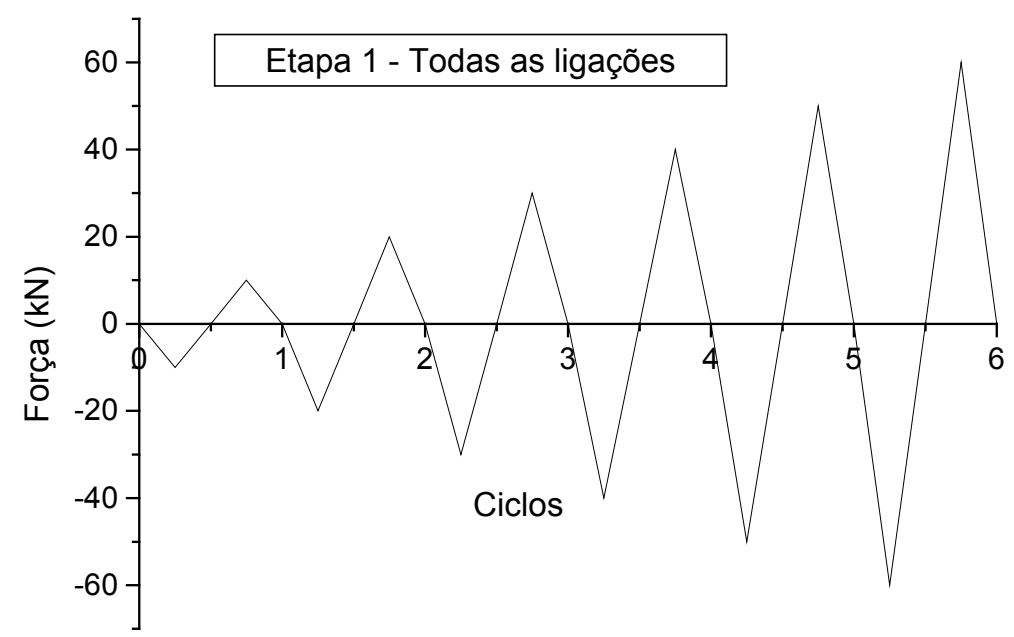

Figura 6.32: Carregamento aplicado na etapa 1: todas as ligações

As demais etapas de carregamento são descritas a seguir, para cada modelo de ligação:

\section{LIGAÇÃO LVP1:}

\section{Etapa 2:}

No modelo LVP1, a etapa 2 consistiu na aplicação de 20 ciclos com amplitude de força de $\pm 60 \mathrm{kN}$ e velocidade de carregamento de $0,5 \mathrm{~mm} / \mathrm{s}$. Como até aquele instante a automatização do processo cíclico por meio de programação do equipamento ainda não havia sido completamente estudada, decidiu-se estabelecer esta segunda etapa para avaliar a velocidade de aplicação dos ciclos, fazendo-se o controle manual do equipamento. A principal razão dessa avaliação foi a necessidade se ter uma idéia do número máximo de ciclos possíveis de serem aplicados, dentro de um tempo limite de operação, caso houvesse a necessidade utilizar o controle manual nas demais ligações.

\section{Etapa 3:}

Nesta etapa, a ligação viga-pilar foi submetida a ações cíclicas reversíveis de maior amplitude de forças, procurando-se simular uma ação sísmica de intensidade moderada. A simulação da ação sísmica foi realizada por meio de uma seqüência de carregamentos estáticos aplicados à extremidade da viga, com controle de deslocamentos, mantendo-se a força axial de compressão constante no pilar. A amplitude dos deslocamentos impostos previstos à extremidade da viga e o número de ciclos para cada amplitude são indicados no gráfico da figura 6.33. A escolha inicial do carregamento aplicado nesta etapa partiu de trabalhos encontrados na literatura especializada sobre ações de natureza sísmica em estruturas de concreto, como o de LEE et al. (1977). 


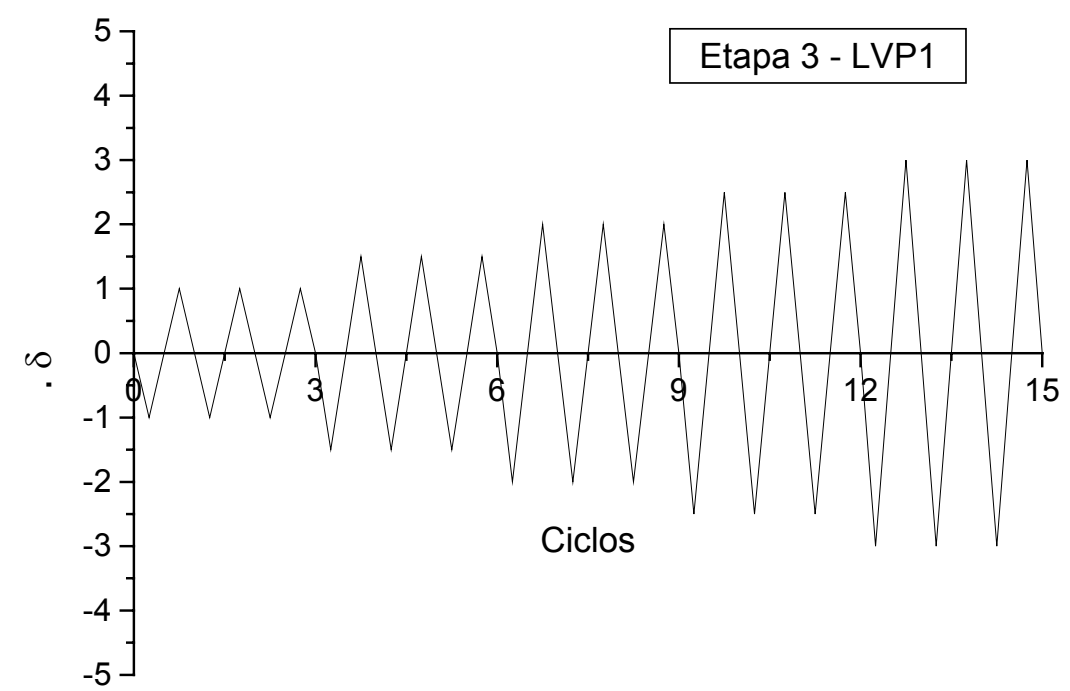

Figura 6.33: Imposição de deslocamentos previstos na etapa 3: modelo LVP1

O carregamento foi aplicado até o instante em que o alongamento nas barras da armadura principal da viga atingiu o valor de 0,003 . Para esta deformação, o deslocamento do atuador $\delta$ assumiu o valor de $27 \mathrm{~mm}$. No ensaio, utilizou-se esse valor para definir o início da plastificação da ligação. Assim, os deslocamentos impostos à extremidade da viga seriam múltiplos desse valor: $\pm 1,0 \delta ; \pm 1,5 \delta ; \pm 2,0 \delta ; \pm 2,5 \delta$, sendo três ciclos para cada amplitude de deslocamento (figura 6.33).

O carregamento foi conduzido de acordo com o previsto até o ciclo 5 , no sentido das forças negativas, quando a força no atuador começou a cair rapidamente (indicando perda de resistência da ligação) antes de atingir o deslocamento pré-estabelecido de $-1,5 \delta$. Nesse instante, notou-se a formação de uma grande fissura diagonal que se estendeu para fora dos limites no nó de pórtico, concluindo-se que se havia atingido a ruína do mesmo. Imediatamente, decidiu-se inverter a força para o sentido oposto, ou seja, para o sentido das forças positivas.

Nos ciclos 6, 7 e 8, no sentido das forças negativas, também ocorreram rápidas quedas de resistência da ligação antes de se atingir o deslocamento estipulado, procedendo-se à inversão do carregamento no instante em que isso acontecia.

No sentido das forças positivas, embora houvesse uma perda de resistência entre ciclos consecutivos de mesma amplitude de deslocamentos (fadiga de poucos ciclos), os deslocamentos pré-estabelecidos foram alcançados sem que antes ocorresse uma queda brusca de resistência.

Nos últimos ciclos de carregamento, observou-se o desprendimento do cobrimento do nó e uma intensa fissuração cruzada (nas direções das duas diagonais do nó).

O ensaio foi finalizado no ciclo 8 . Ao fim do ensaio, o nó de pórtico apresentou um aumento de volume visível, sugerindo a ocorrência do escoamento dos estribos horizontais.

A figura 6.34 contém fotografias dos estágios de fissuração da região nodal, tiradas durante o ensaio da ligação LVP1. 


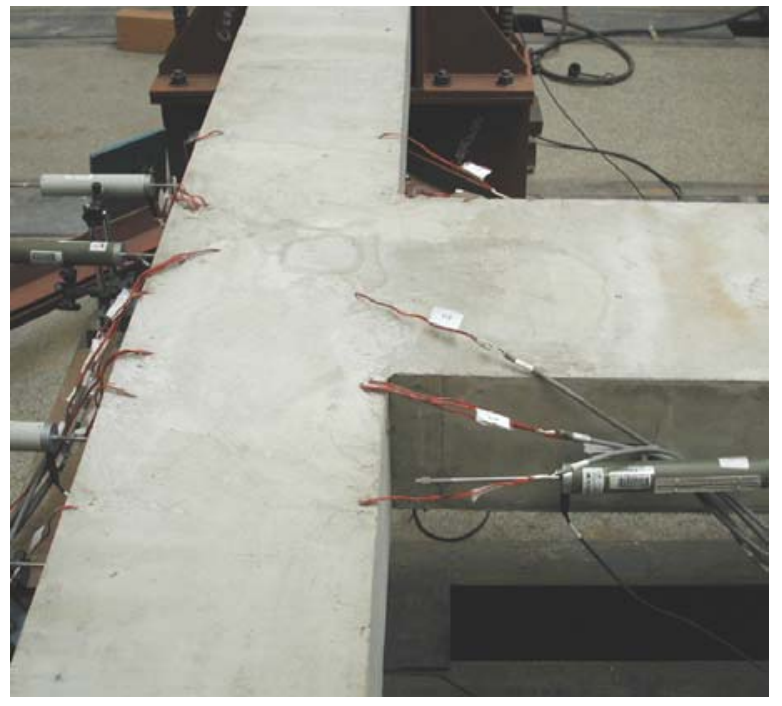

No início do ensaio

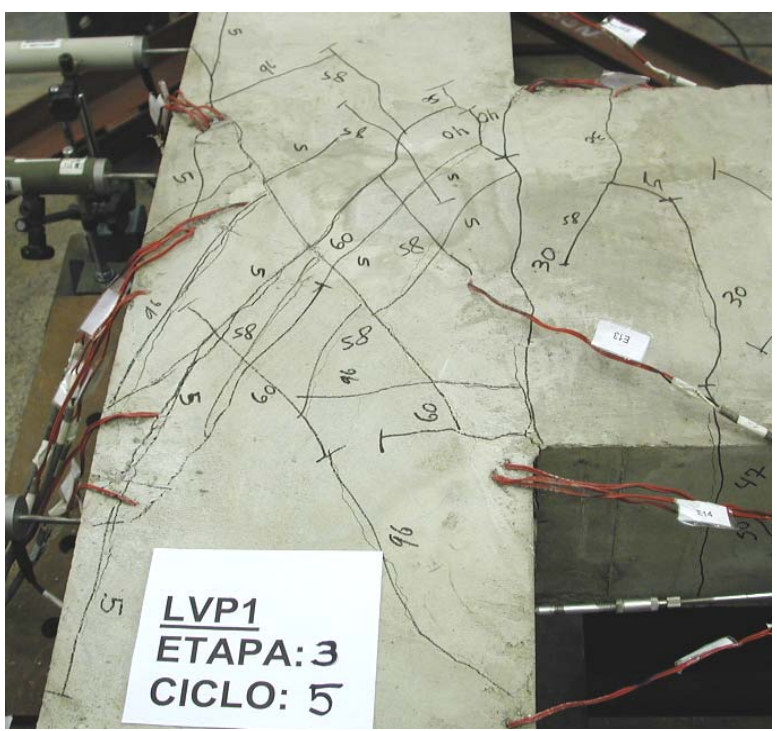

Etapa 3 - Ciclo 5: Primeira queda de resistência

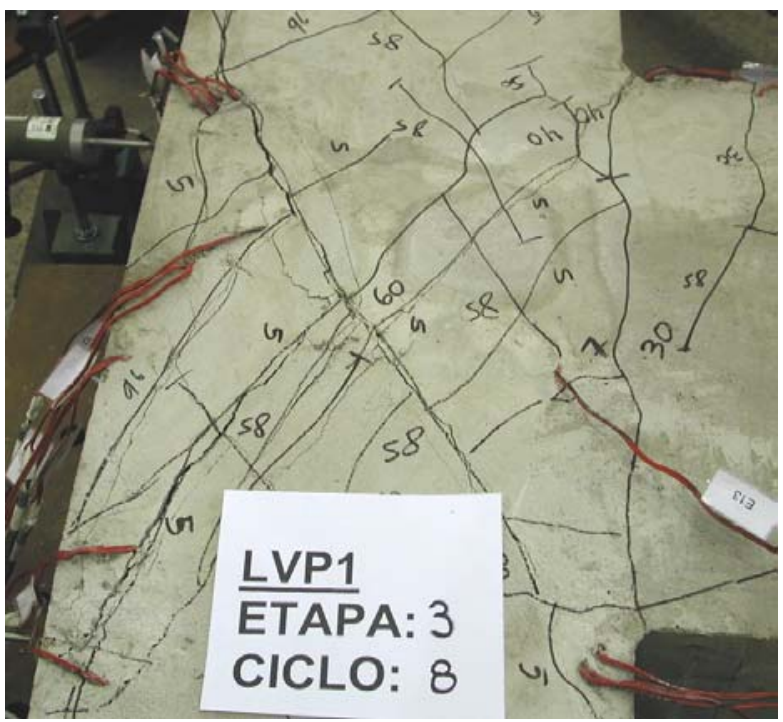

Etapa 3 - Ciclo 8: Final do ensaio

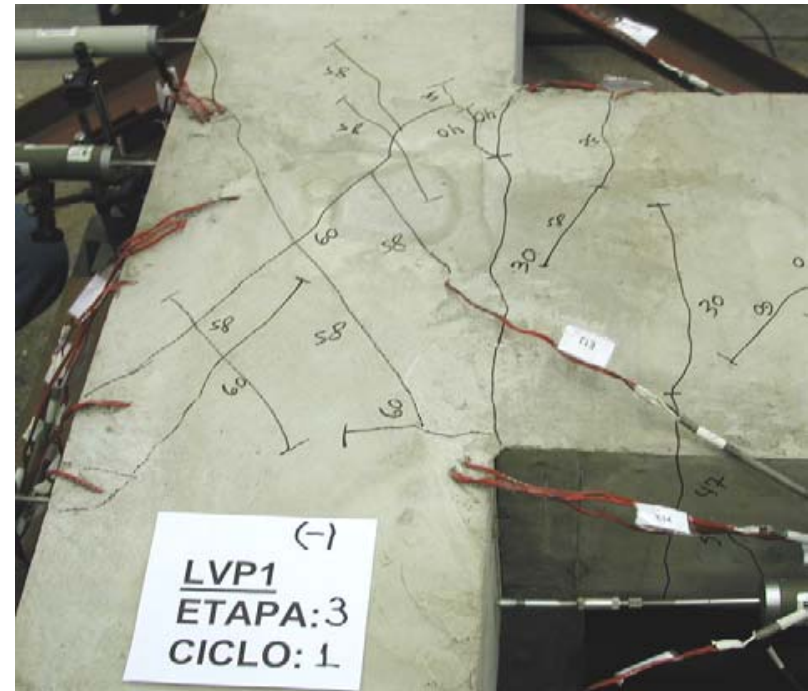

Etapa 3: Ciclo 1 das ações negativas

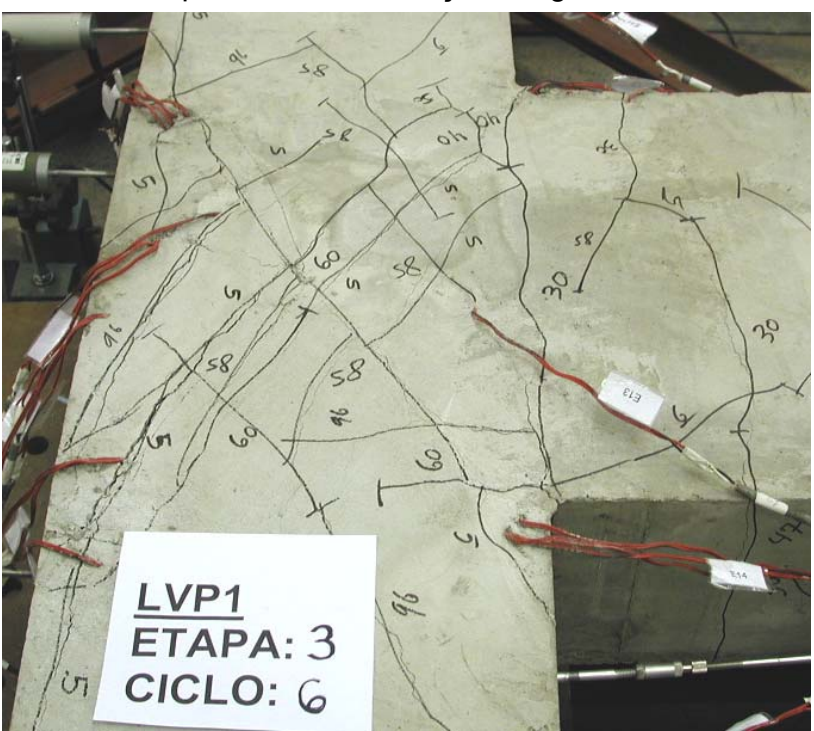

Etapa 3 - Ciclo 6

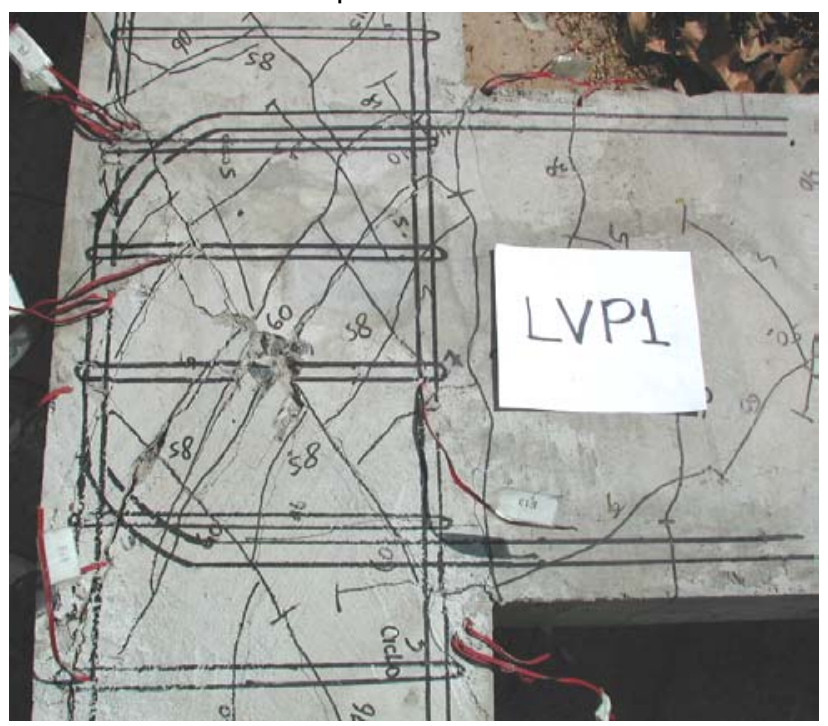

Fissuração em relação às armaduras

Figura 6.34: Fissuração na região do nó de pórtico ao longo do ensaio - Ligação LVP1 


\section{LIGAÇÃO LVP2:}

\section{Etapa 2:}

A segunda etapa consistiu na aplicação de 1000 ciclos com amplitude de força de \pm 60 $\mathrm{kN}$ na extremidade da viga, sendo possível utilizar um procedimento automatizado para a aplicação do carregamento cíclico por meio de programação do sistema de aplicação da força. O carregamento aplicado pelo atuador consistiu em uma onda triangular periódica, com freqüência de $0,1 \mathrm{~Hz}$ para os 200 primeiros ciclos e com freqüência de $0,14 \mathrm{HZ}$ para os ciclos restantes.

O objetivo desta etapa foi avaliar o comportamento da ligação sob carregamentos cíclicos reversíveis em regime de serviço. Entre os que foram objeto de análise, citam-se os seguintes:

- Quantificação do acréscimo dos deslocamentos na viga ao longo do carregamento cíclico;

- Observação do panorama de fissuração da região nodal ao longo dos ciclos;

- Análise do comportamento das deformações nos estribos ao longo dos ciclos;

- Avaliação da viabilidade de calibração do parâmetro de fadiga do modelo simplificado de dano com as modificações propostas na formulação original.

Não foram aplicados mais ciclos por causa das limitações de tempo operacional. Além disso, não seria possível trabalhar com freqüências muito maiores que as adotadas no ensaio, pois os deslocamentos na viga eram significados (da ordem de $10 \mathrm{~mm}$ ), e o atuador já estava trabalhando com uma velocidade de deslocamentos elevada (da ordem de $5 \mathrm{~mm} / \mathrm{s}$ ).

Com relação às principais observações experimentais desta etapa, podem citar-se:

- Acréscimo de deslocamentos na viga no decorrer dos ciclos, notado pelo transdutor T1;

- Propagação das fissuras da viga e da região do nó formadas na etapa 1;

- Propagação das fissuras diagonais do nó para o interior do pilar, com o aumento visível da abertura das mesmas.

\section{Etapa 3:}

Nesta etapa foram aplicados carregamentos crescentes e reversíveis na extremidade da viga (similares à etapa 1), até a constatação da ruína da ligação pelo nó de pórtico, identificada pela queda rápida de resistência e pela formação de grandes fissuras na região nodal . A etapa 3 teve um total de 5 ciclos, com máximos/mínimos de $\pm 70 \mathrm{kN} ; \pm 80 \mathrm{kN}, \pm 90 \mathrm{kN}$, $\pm 100 \mathrm{kN},-131,14 \mathrm{kN}$ e $+95,15 \mathrm{kN}$ (figura 6.35). A velocidade de carregamento nesta etapa foi de $0,4 \mathrm{~mm} / \mathrm{s}$.

A ruína da ligação ocorreu visualmente pelo esmagamento da biela comprimida do nó. As fissuras diagonais apresentaram aberturas significativas: em torno de $3,0 \mathrm{~mm}$ para a maior fissura diagonal produzida pelas forças de sentido positivo e em torno de 1,5 $\mathrm{mm}$ para a maior fissura diagonal produzida pelas forças no sentido negativo. 
Próximo da ruína, nos dois sentidos de força, pôde-se notar a formação de uma extensa fissura, que se originou da fissura diagonal do nó e se estendeu até a face externa do pilar (figuras 6.36 à 6.38)

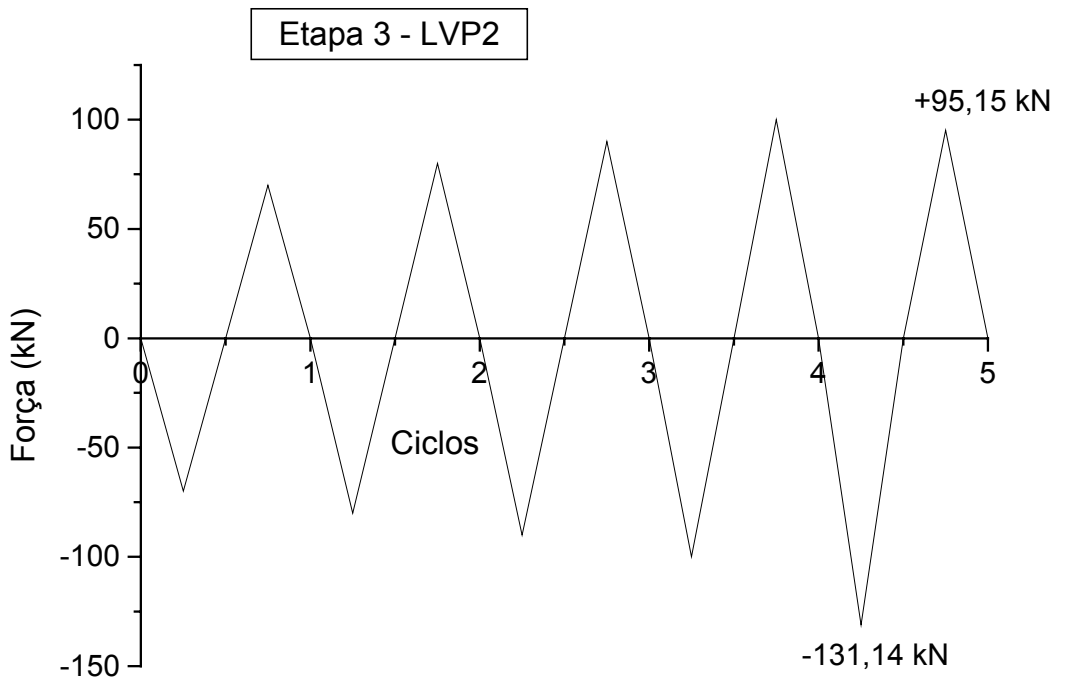

Figura 6.35: Carregamento aplicado na etapa 3 - modelo LVP2 

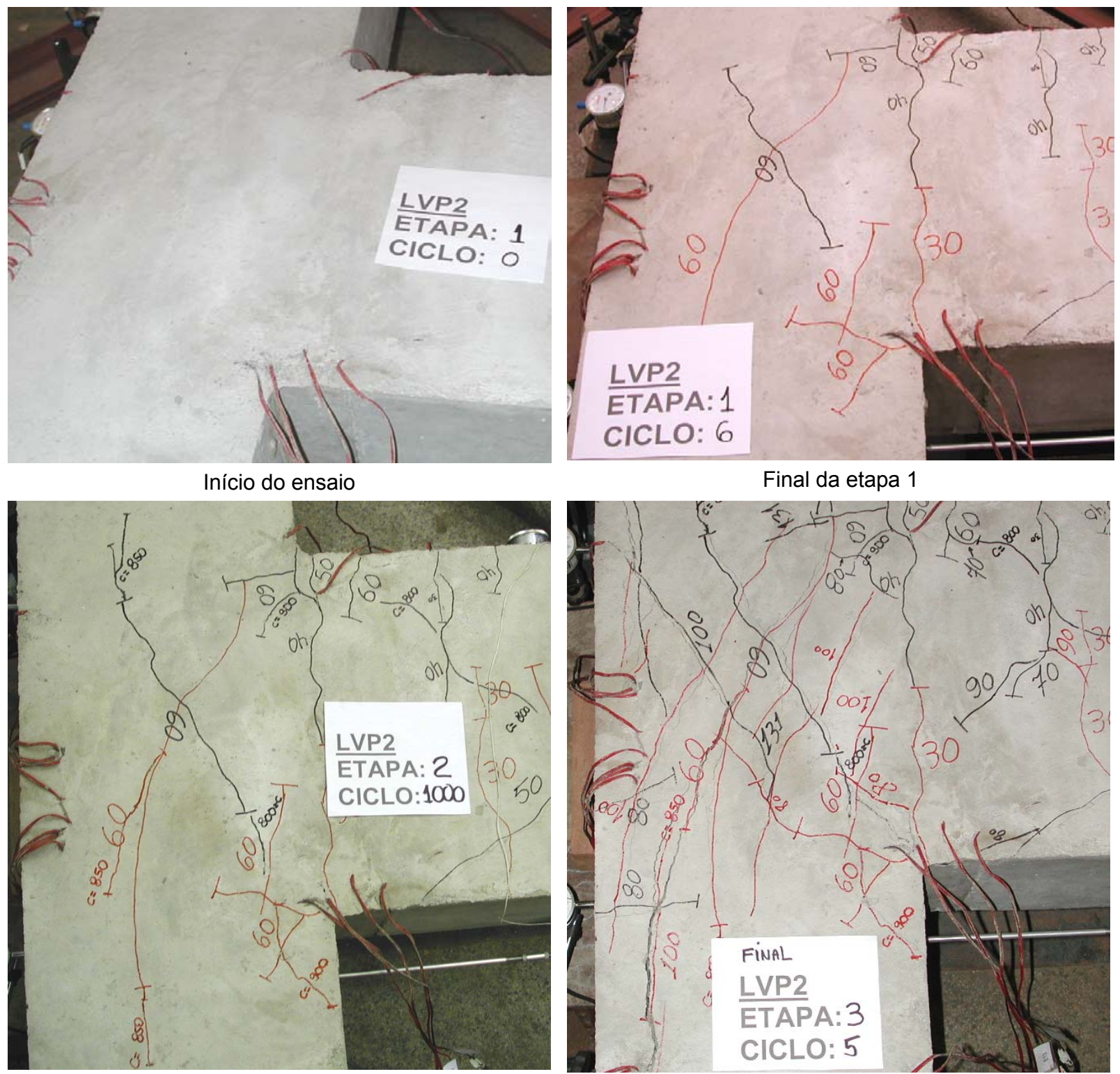

Final da etapa 2 após os 1000 ciclos
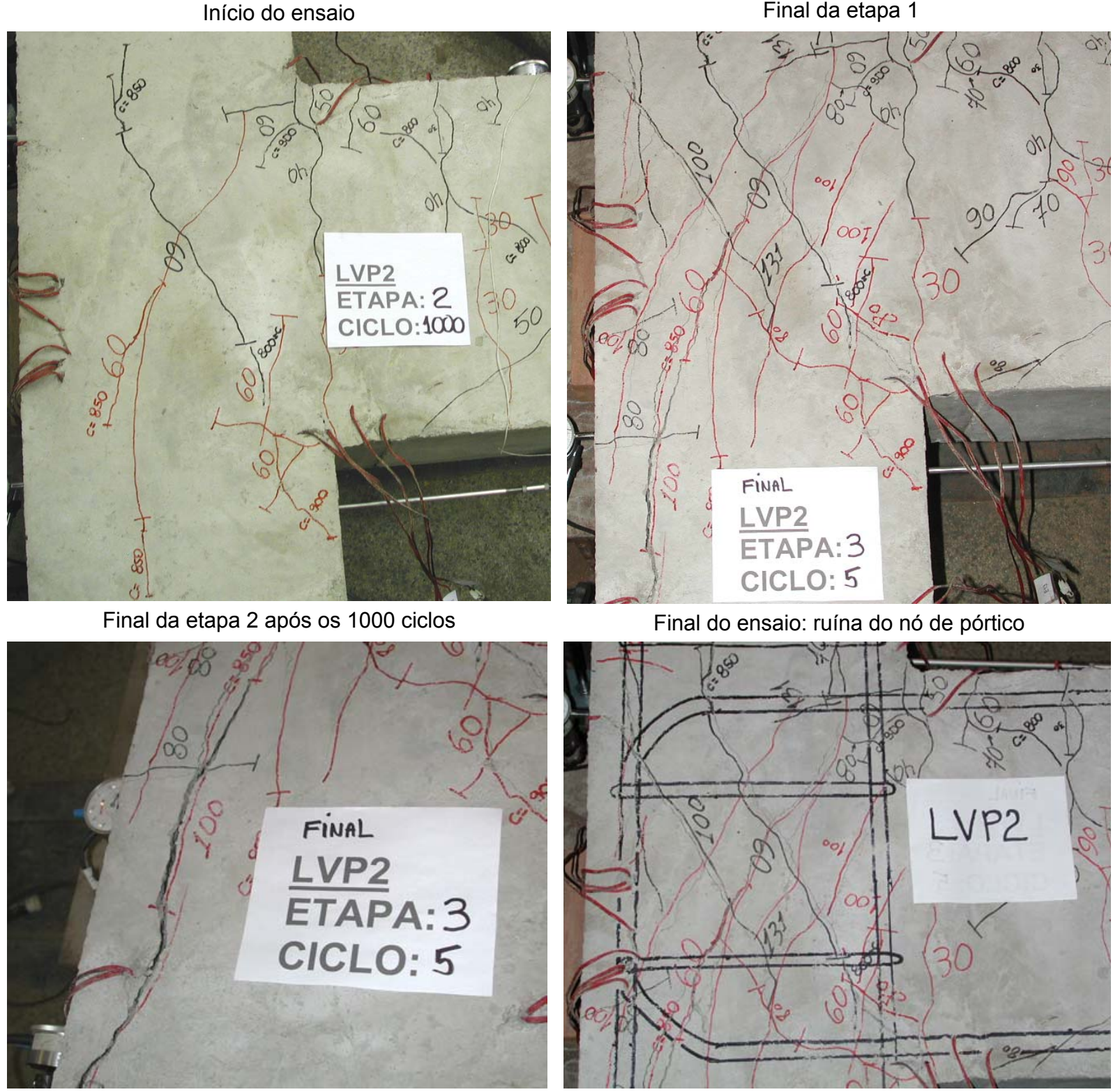

Detalhe da fissura propagada para fora do nó na ruína

Final do ensaio: ruína do nó de pórtico

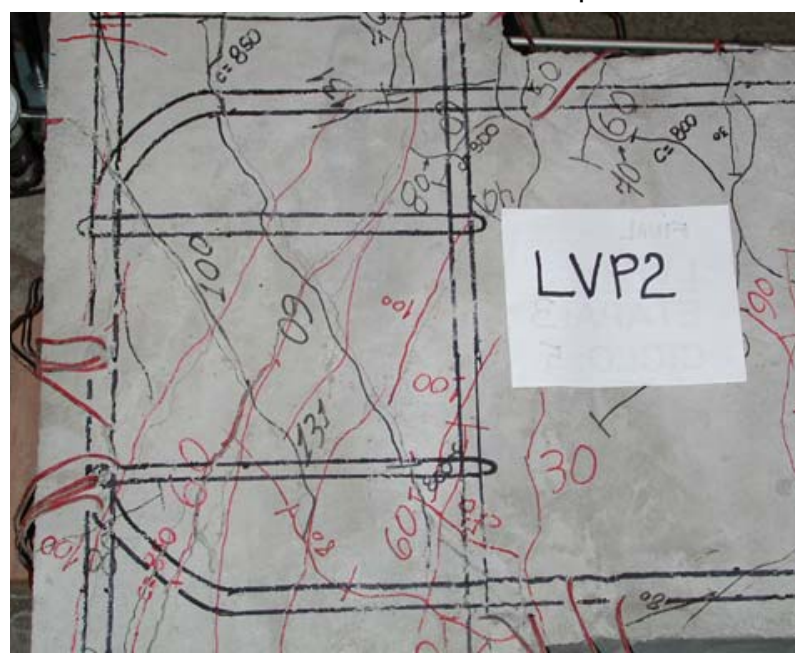

Fissuração em relação às armaduras

Figura 6.36: Fissuração na região do nó de pórtico ao longo do ensaio - Ligação LVP2 


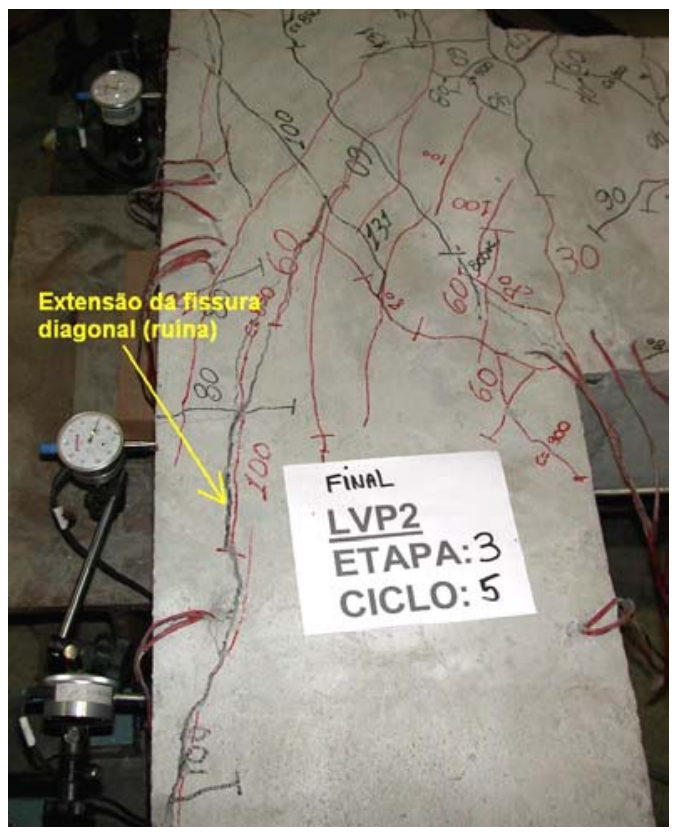

Figura 6.37: Propagação da fissura diagonal do nó na ruína: Forças de sentido positivo

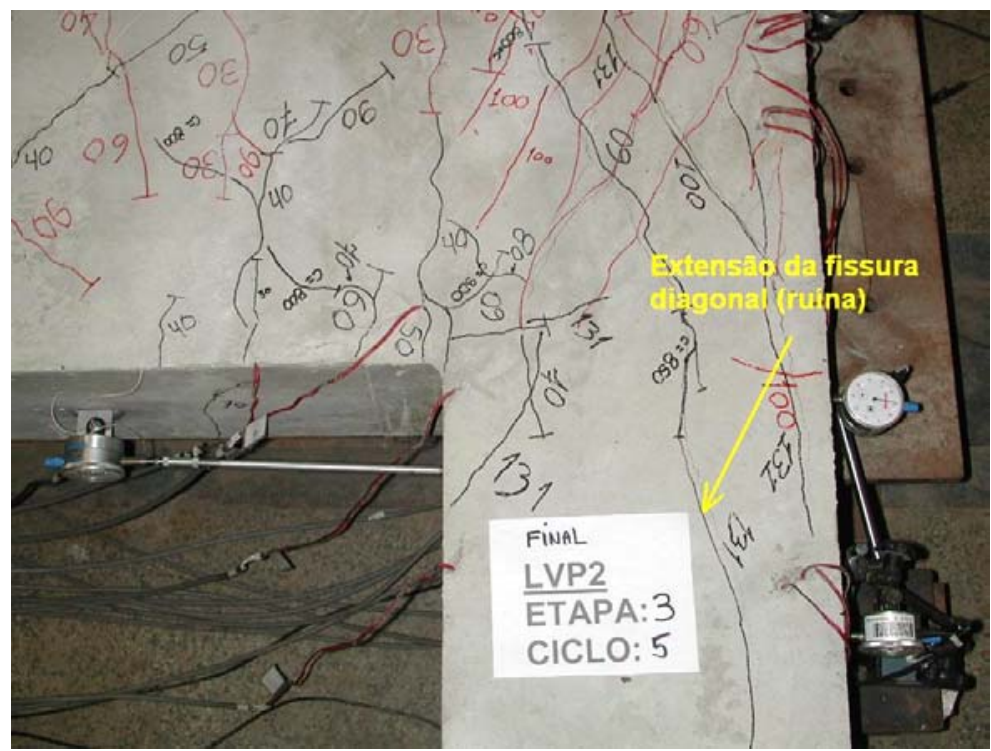

Figura 6.38: Propagação da fissura diagonal do nó na ruína: Forças de sentido negativo 


\section{LIGAÇÃO LVP3}

\section{Etapa 2:}

Estipulou-se para a segunda etapa a aplicação de carregamentos inversíveis, com 3 ciclos de amplitude $\pm 70 \mathrm{kN}, 3$ ciclos de amplitude $\pm 80 \mathrm{kN}, 3$ ciclos de $\pm 90 \mathrm{kN}$, assim por diante (figura 6.39), até que ocorresse a ruína da ligação ou queda rápida da resistência da ligação. Este procedimento de carregamento também foi adotado para a ligação LVP4.

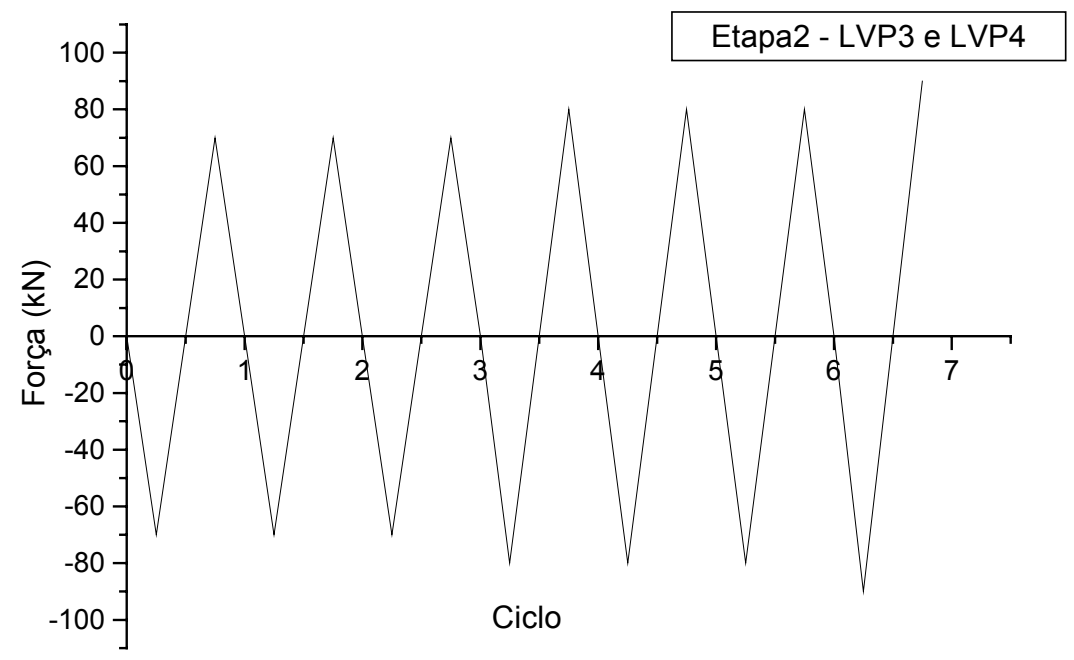

Figura 6.39: Carregamento previsto para a etapa 2: modelos LVP3 e LVP4

O carregamento foi conduzido conforme o previsto até o ciclo 7 . No ciclo 8 , no sentido das forças negativas, antes de se atingir $90 \mathrm{kN}$, houve uma rápida queda da força do atuador, indicando perda de resistência da ligação. A partir daí, inverteu-se a força para o sentido oposto.

Nos demais ciclos, as quedas rápidas de resistências continuaram a acontecer no sentido negativo. No sentido positivo, força máxima aplicada foi limitada pelo fim do curso do atuador. A tabela 6.6 resume as forças máximas dos ciclos da etapa 2. 
Tabela 6.6: Forças máximas nos ciclos - Etapa 2 da ligação LVP3

\begin{tabular}{|c|c|c|}
\hline Ciclo & $\begin{array}{c}\mathbf{F}(\mathbf{k N}): \\
\text { Sentido negativo }\end{array}$ & $\begin{array}{c}\mathbf{F}(\mathbf{k N}): \\
\text { Sentido positivo }\end{array}$ \\
\hline 1 & $-70,0$ & $+70,0$ \\
\hline 2 & $-70,0$ & $+70,0$ \\
\hline 3 & $-70,0$ & $+70,0$ \\
\hline 4 & $-80,0$ & $+80,0$ \\
\hline 5 & $-80,0$ & $+80,0$ \\
\hline 6 & $-80,0$ & $+80,0$ \\
\hline 7 & $-90,0$ & $+90,0$ \\
\hline 8 & $-60,8$ & $+90,0$ \\
\hline 9 & $-26,8$ & $+86,6\left(^{*}\right)$ \\
\hline 10 & $-9,2$ & $+78,4\left(^{*}\right)$ \\
\hline 11 & $-7,8$ & $+69,0\left(^{*}\right)$ \\
\hline 12 & $-8,2$ & $+64,5\left(^{*}\right)$ \\
\hline \multicolumn{2}{|c|}{} \\
\hline \multicolumn{2}{|c|}{ ( ) fim do curso do atuador }
\end{tabular}

Esta etapa foi caracterizada por uma intensa deterioração mecânica do nó, comprovada pela fissuração diagonal (cruzada) observada nas fotos da figura 6.40, mesmo não se tendo alcançado a plastificação das barras principais da viga. A partir do ciclo 8 , houve um grande desprendimento do cobrimento do concreto na região do nó e crescimento significativo das aberturas das fissuras diagonais. Notou-se também que o deslocamento na extremidade da viga aumentou acentuadamente com a degradação mecânica do nó de pórtico, mesmo nos ciclos com mesma amplitude de força. O ensaio foi finalizado no ciclo 12.

Em simulações envolvendo forças cíclicas de maior intensidade, como no caso da simulação de sismos, usualmente a aplicação do carregamento é feita por imposição de deslocamentos múltiplos do deslocamento de plastificação da viga, ou em termos da ductilidade. A escolha de fixar a amplitude de forças ao invés da amplitude de deslocamentos foi determinada pelo seguinte fato: com a resistência à compressão apresentada pelo concreto usinado, a previsão indicou a ruína do nó de pórtico por esmagamento da biela antes da plastificação das barras longitudinais da viga.

Vale destacar que o concreto fornecido pela empresa de concretagem apresentou uma resistência à compressão abaixo da esperada (esperava-se no mínimo $30 \mathrm{MPa}$ na data do ensaio, levando-se em conta o crescimento da resistência em função da idade e o fato de o concreto ter a sua resistência majorada para atender a resistência de dosagem). 

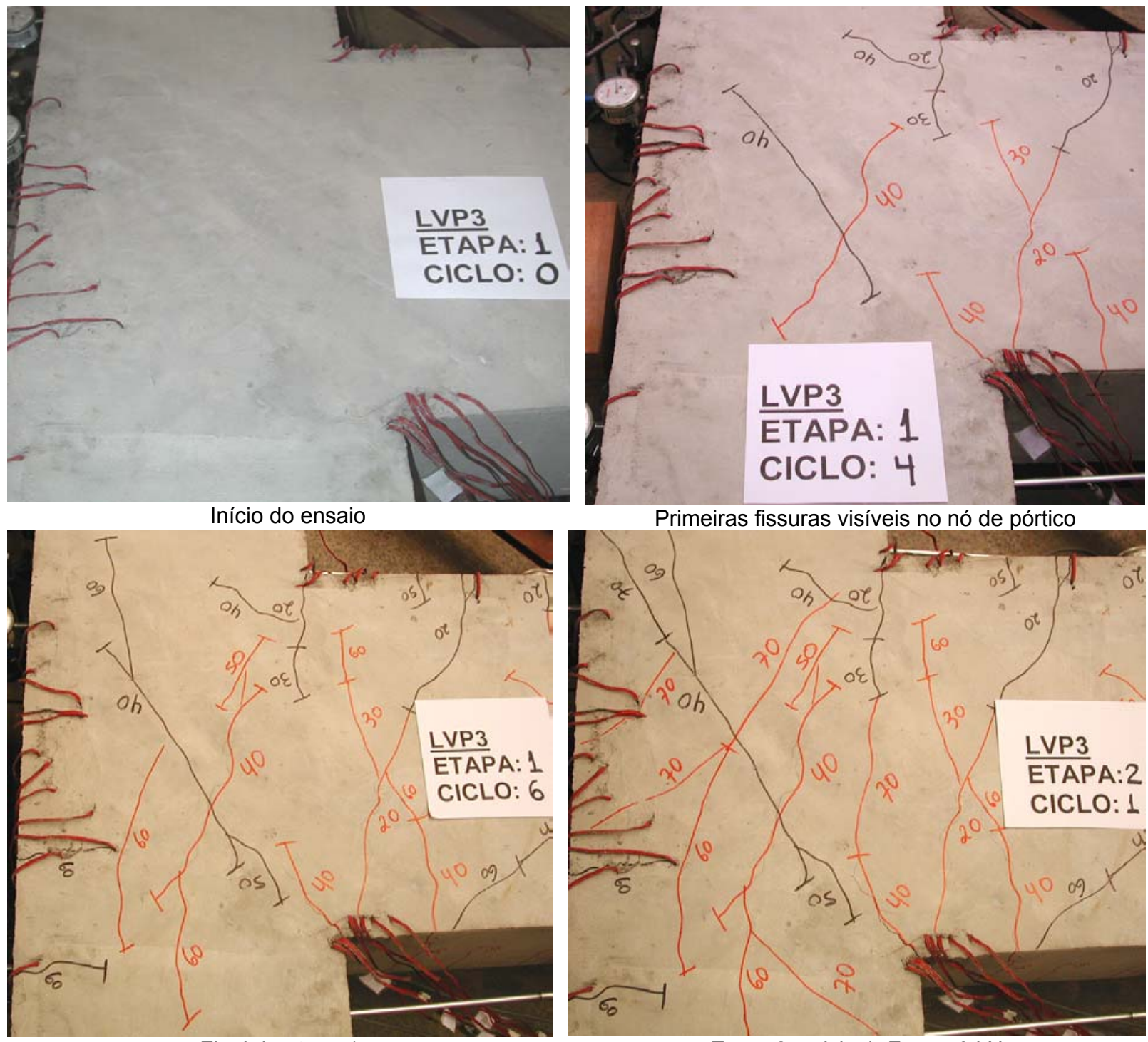

Final da etapa 1

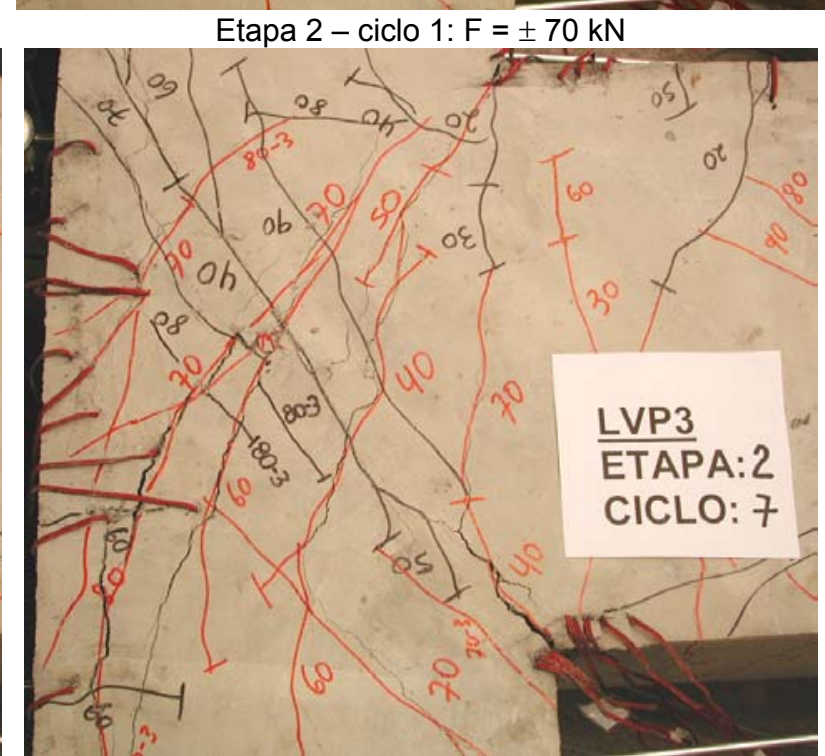

Etapa 2 - ciclo 4: $\mathrm{F}= \pm 80 \mathrm{kN}$

Etapa 2 - ciclo 7: $\mathrm{F}= \pm 90 \mathrm{kN}$

Figura 6.40: Fissuração na região do nó de pórtico ao longo do ensaio - Ligação LVP3 


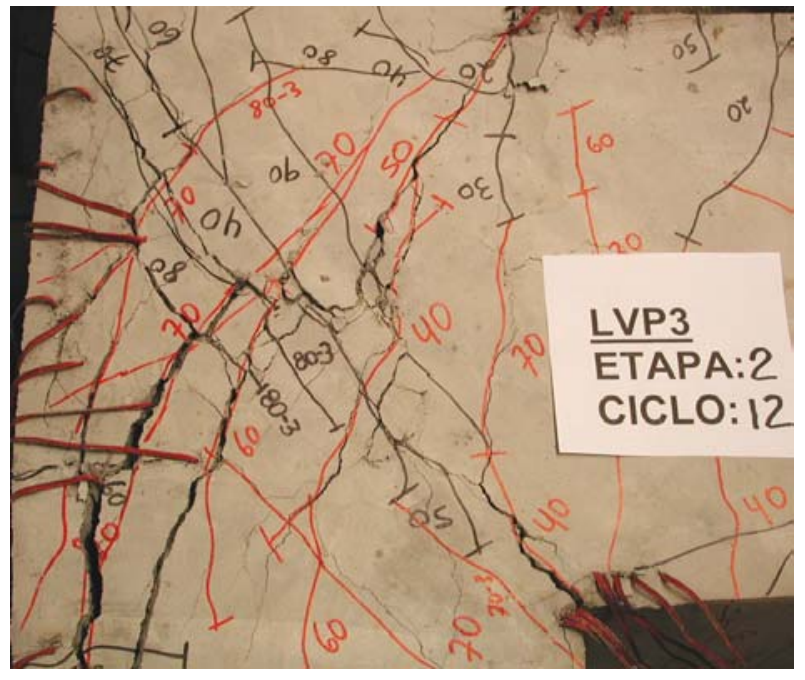

Final do ensaio: detalhe da ruína do nó

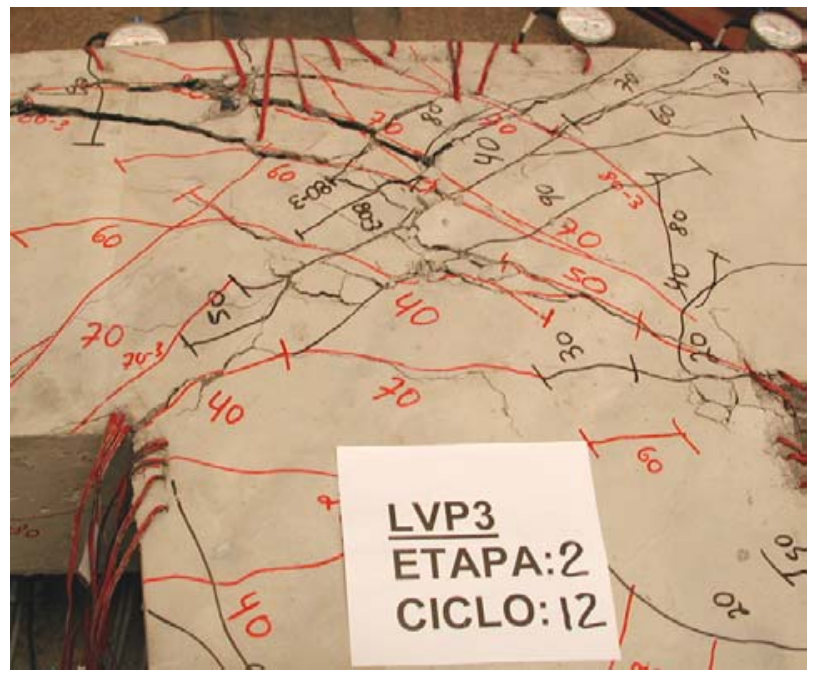

Final do ensaio: detalhe da ruína do nó

Figura 6.40 (Cont.): Fissuração na região do nó de pórtico ao longo do ensaio - Ligação LVP3 


\section{LIGAÇÃO LVP4}

\section{Etapa 2:}

Adotou-se o mesmo tipo de carregamento da etapa 2 do modelo LVP3, aplicando-se carregamentos inversíveis com 3 ciclos de amplitude de força $\pm 70 \mathrm{kN}, 3$ ciclos de amplitude \pm $80 \mathrm{kN}$, e assim sucessivamente, até que ocorresse a ruína da ligação ou queda rápida da resistência da ligação.

Entre o ciclo 1 e o ciclo $3(F= \pm 70 \mathrm{kN})$, houve aumento da fissuração na região nodal, com propagação e aumento das aberturas das fissuras formadas no ciclo 1. Os transdutores na viga também indicaram acréscimos de deslocamento em relação ao primeiro ciclo desta etapa. Este mesmo comportamento foi detectado nos ciclos 4 e $5(F= \pm 80 \mathrm{kN})$.

No ciclo 5 , os valores das deformações nos extensômetros indicaram o escoamento dos estribos dos nós.

No ciclo 6 , no sentido negativo, não foi possível atingir a força de $80 \mathrm{kN}$, ocorrendo uma rápida perda de resistência da ligação após o atuador atingir cerca de $58 \mathrm{kN}$. Detectada a queda rápida de força aplicada, procedeu-se a inversão da força para o sentido contrário. Nos ciclos 7, 8 e 9, o mesmo procedimento foi tomado.

No sentido das forças positivas, não foram notadas quedas rápidas de resistência durante a fase de carregamento. No ciclo 7 , a inversão da força se deu um pouco antes da força de $90 \mathrm{kN}$ prevista. No ciclo 9, a força foi limitada pelo fim do curso do atuador. De fato, assim como observado na ligação LVP3, os deslocamentos na extremidade da viga assumiram valores significativos, sendo mais pronunciados nos últimos ciclos no sentido positivo.

O ensaio foi finalizado no ciclo 9. A tabela 6.7 contém o valores das máximas forças atingidas durante os ciclos da etapa 2 .

Tabela 6.7: Forças máximas nos ciclos - Etapa 2 da ligação LVP4

\begin{tabular}{|c|c|c|}
\hline Ciclo & $\begin{array}{c}\mathbf{F}(\mathbf{k N}): \\
\text { Sentido negativo }\end{array}$ & $\begin{array}{c}\mathbf{F}(\mathbf{k N}): \\
\text { Sentido positivo }\end{array}$ \\
\hline 1 & $-70,0$ & $+70,0$ \\
\hline 2 & $-70,0$ & $+70,0$ \\
\hline 3 & $-70,0$ & $+70,0$ \\
\hline 4 & $-80,0$ & $+80,0$ \\
\hline 5 & $-80,0$ & $+80,0$ \\
\hline 6 & $-57,8$ & $+80,0$ \\
\hline 7 & $-32,1$ & $+73,3$ \\
\hline 8 & $-25,0$ & $+81,0$ \\
\hline 9 & $-6,7$ & $+68,5\left(^{*}\right)$ \\
\hline$\left(^{*}\right)$ fim do curso do atuador \\
\hline
\end{tabular}

A figura 6.41 contém fotos dos estágios de fissuração durante o ensaio da ligação LVP4. A comparação com o panorama de fissuração da ligação LVP3 indica maior deterioração mecânica da ligação LVP4. 

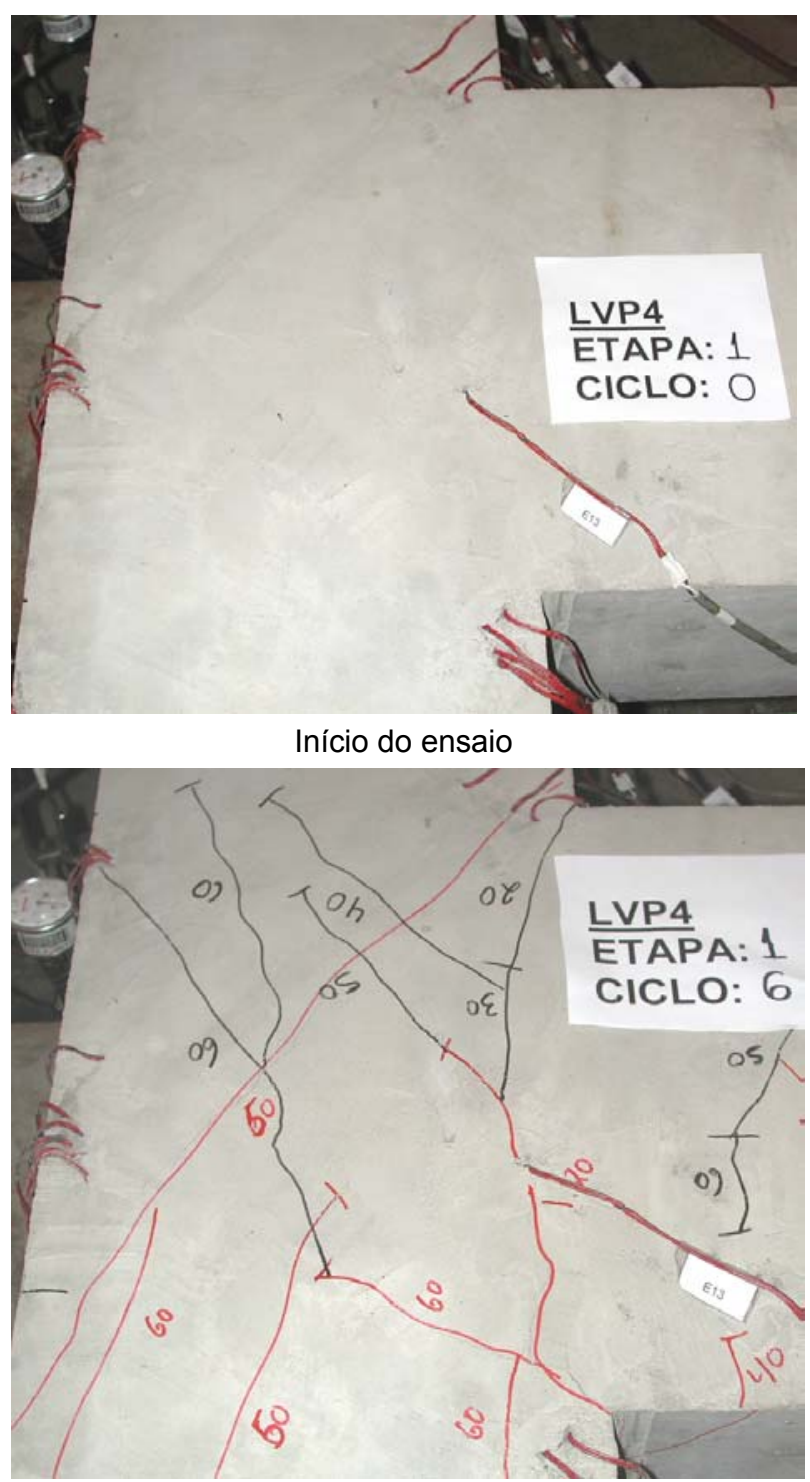

Final da etapa 1

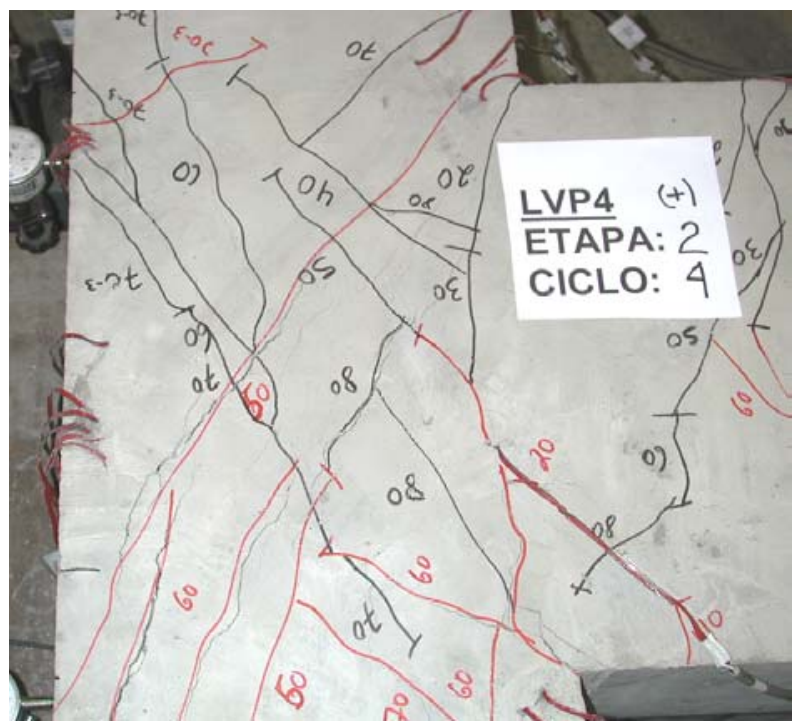

Etapa 2 - ciclo 4: $\mathrm{F}= \pm 80 \mathrm{kN}$

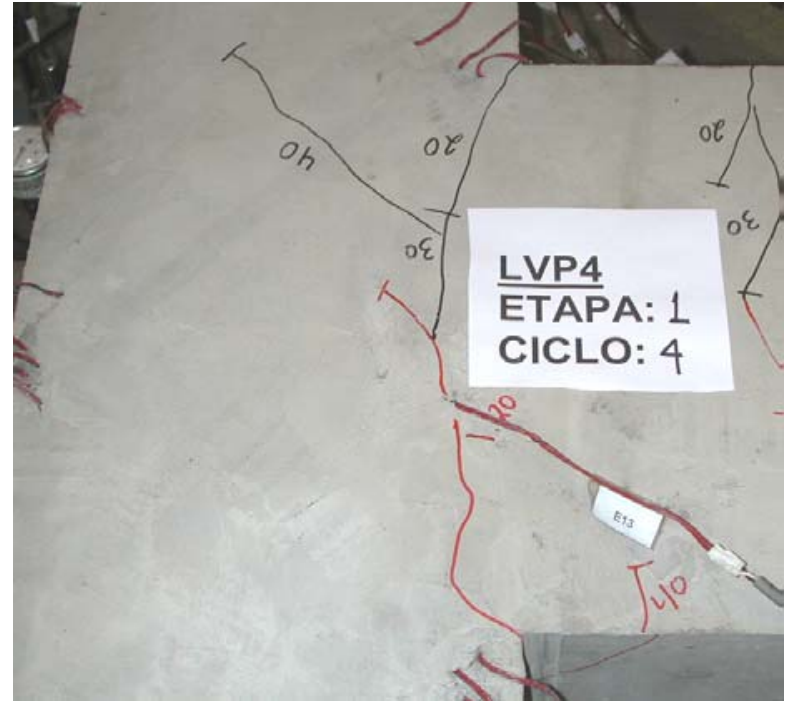

Primeiras fissuras visíveis no nó de pórtico

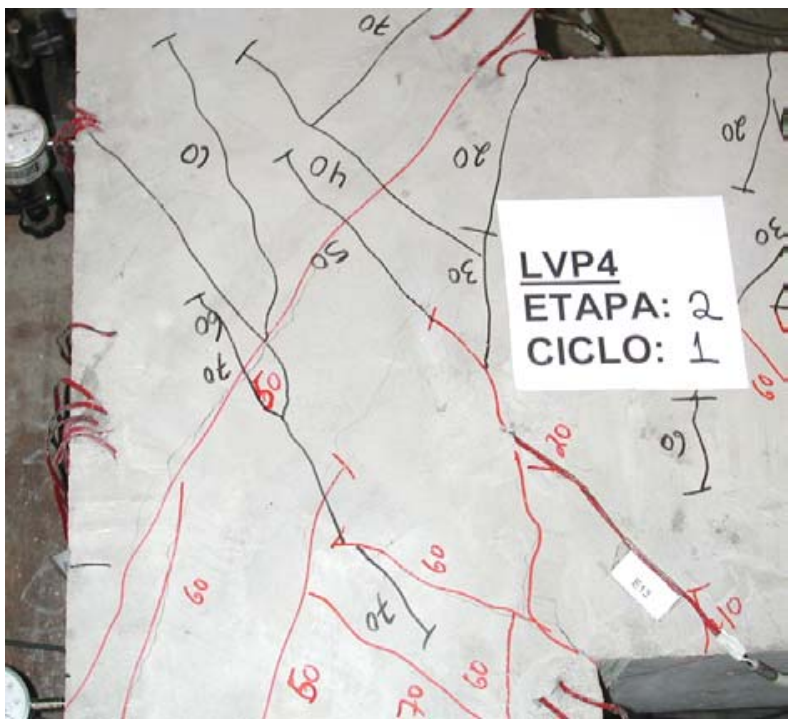

Etapa 2 - ciclo $1: \mathrm{F}= \pm 70 \mathrm{kN}$

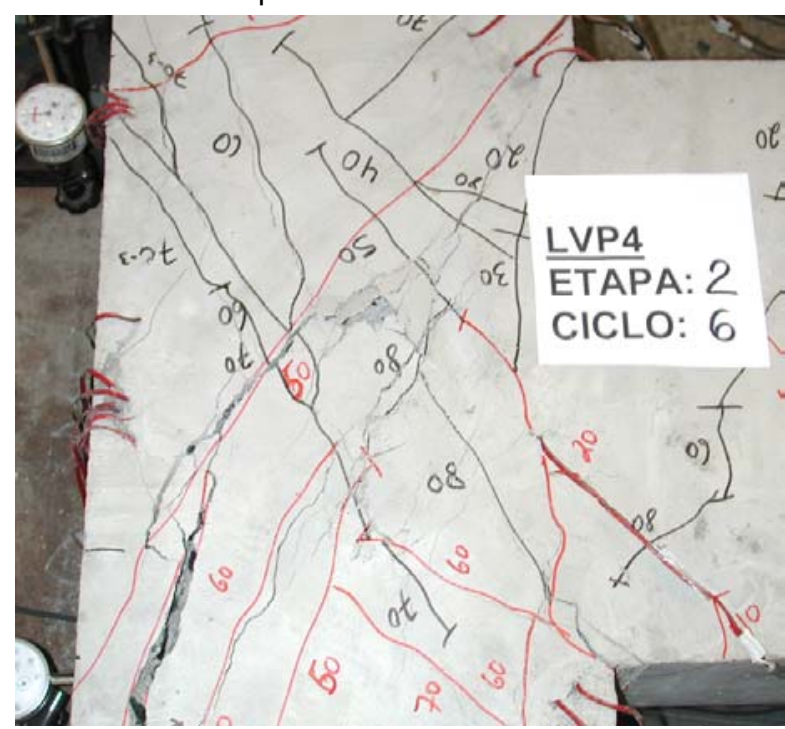

Etapa 2 - ciclo 6: Queda de resistência do nó

Figura 6.41: Fissuração na região do nó de pórtico ao longo do ensaio - Ligação LVP4 


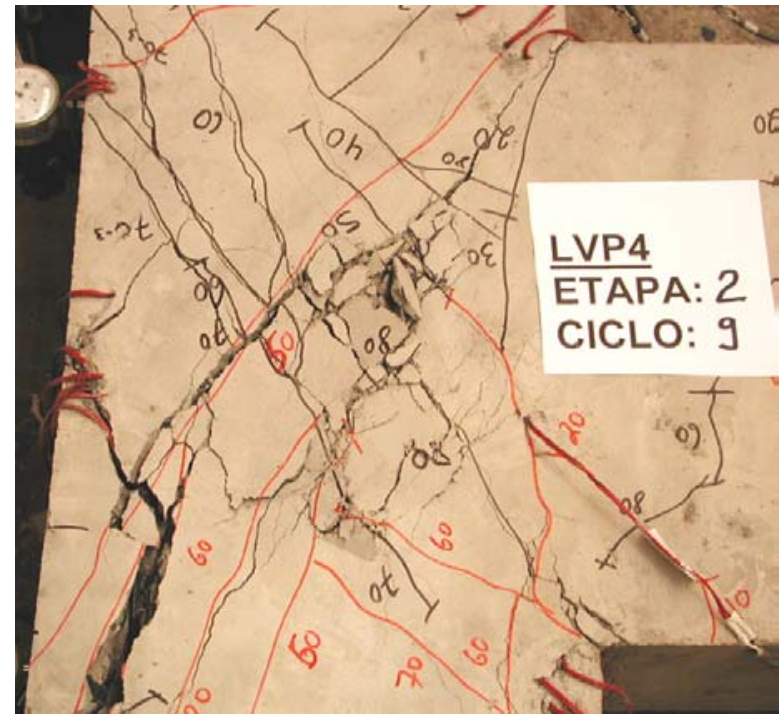

Final do ensaio: detalhe da ruína do nó

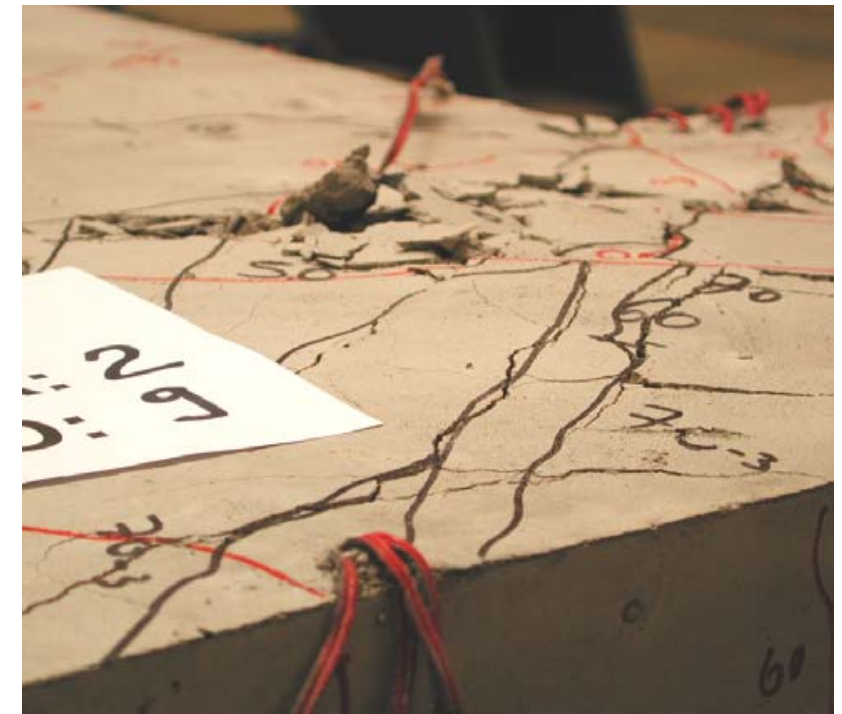

Final do ensaio: detalhe da dilatação do nó

Figura 6.41 (Cont.): Fissuração na região do nó de pórtico ao longo do ensaio - Ligação LVP4 


\section{LIGAÇÃO LVP5}

\section{Etapa 2:}

Nesta etapa, a aplicação do carregamento foi idêntica à da ligação LVP2. A força aplicada à extremidade da viga consistiu em onda triangular periódica, com freqüência de 0,14 $\mathrm{Hz}$ para todos os ciclos, com forças máximas e mínimas de $\pm 60 \mathrm{kN}$. Os objetivos desta etapa foram os mesmos pretendidos para a ligação LVP2.

Quando comparada à ligação LVP2, houve uma fissuração mais acentuada na região do nó da ligação LVP5. À primeira vista, esse fato pode ser explicado pela menor resistência à compressão do concreto da ligação LVP5 (cerca de $40 \%$ menor) em relação à LVP2, embora a ligação LVP5 tivesse o dobro do número de estribos no nó de pórtico.

Próximo ao ciclo 400 , já era perceptível uma propagação significativa das fissuras formadas na etapa 1 , notando-se, inclusive, aumento da abertura das mesmas (figura 6.43). Os deslocamentos na extremidade da viga, conforme se esperava, tiveram também um acréscimo em relação à etapa 1. Dessa forma, decidiu-se encerrar esta etapa após a aplicação de 437 ciclos.

\section{Etapa 3.}

Em virtude da intensidade da fissuração atingida na etapa 2, decidiu-se aplicar apenas um ciclo de carregamento à ligação (figura 6.42), com as forças máxima e mínima definas a partir da ocorrência da ruína do nó em cada sentido da força.

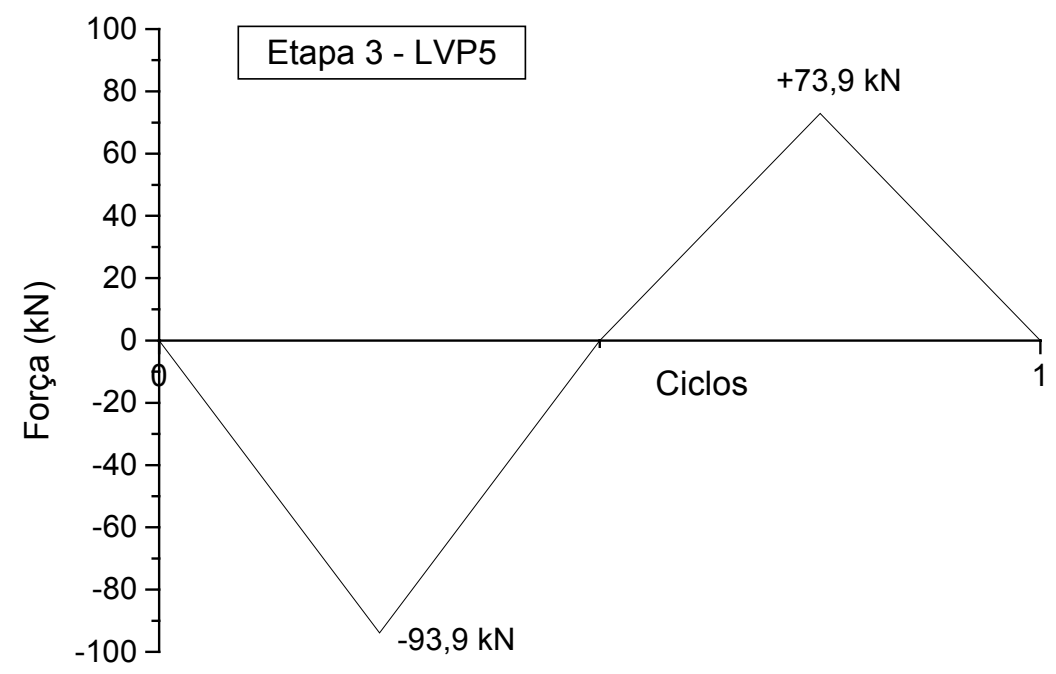

Figura 6.42: Etapa 3 de carregamento da ligação LVP5

A figura 6.43 mostra a configuração de ruína da ligação, que ocorreu pelo esmagamento das bielas diagonais do nó. Pela figura, observa-se inclusive a extensão das fissuras diagonais do nó em direção à face externa do pilar. 

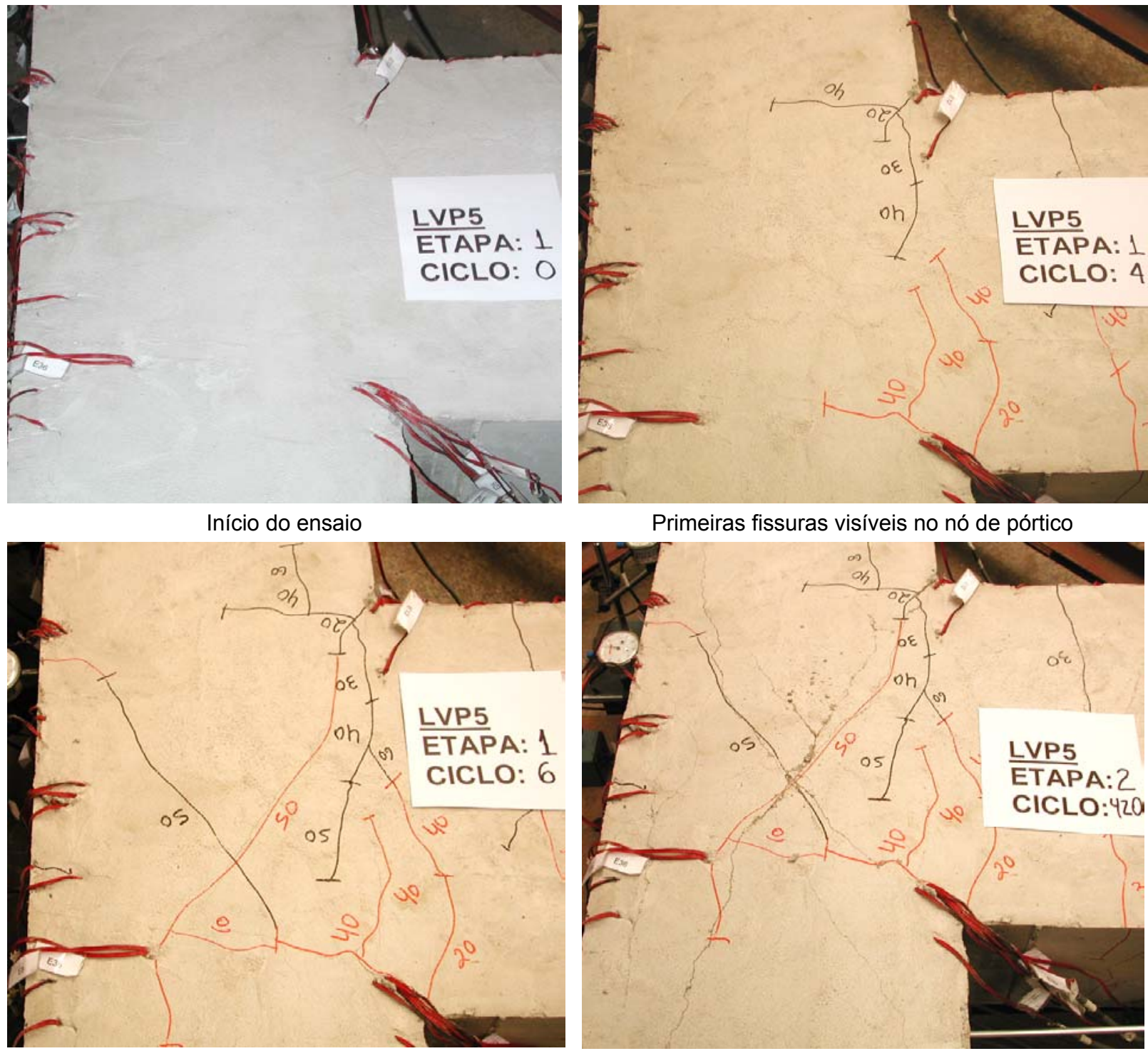

Final da etapa 1

Etapa 2 - ciclo 420

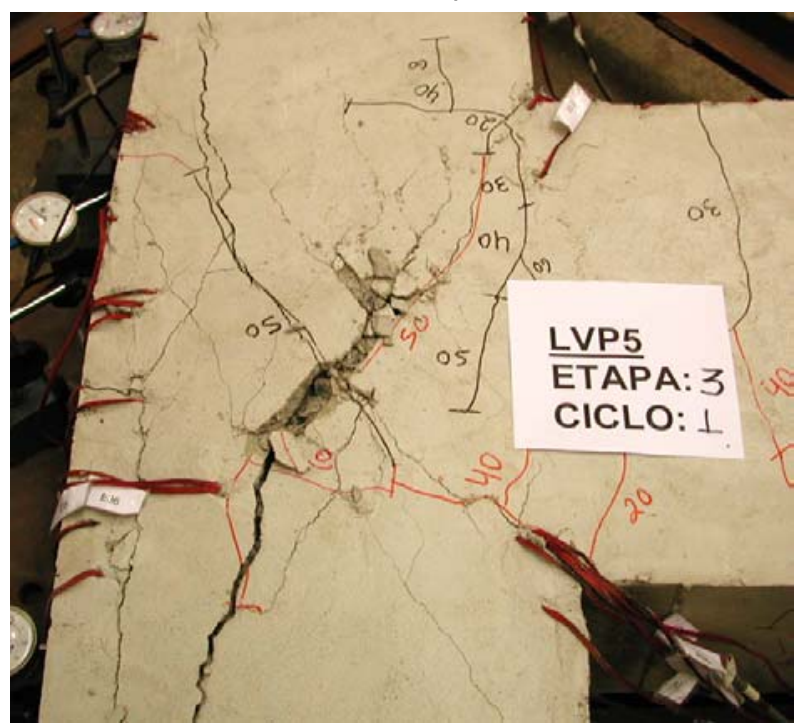

Final do ensaio: Detalhe da ruína do nó de pórtico

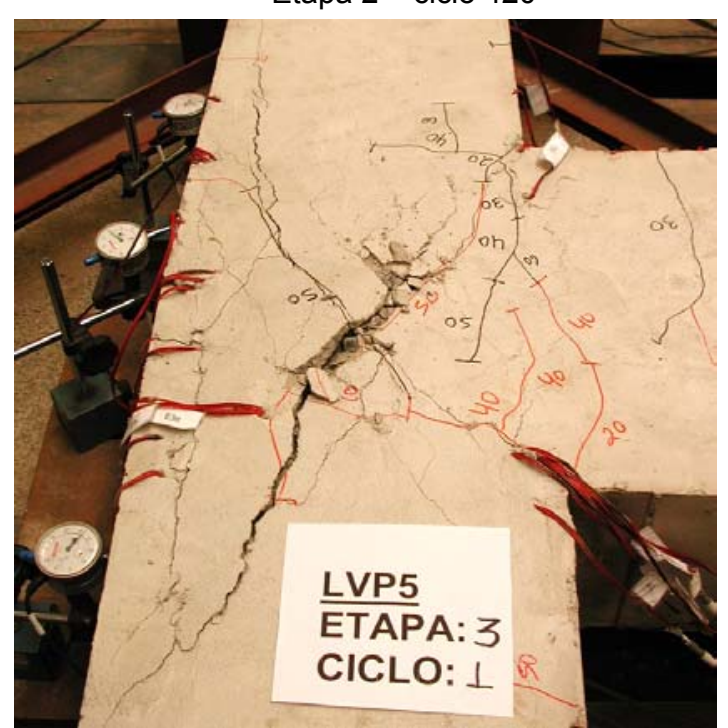

Final do ensaio: Detalhe da ruína do nó de pórtico

Figura 6.43: Fissuração na região do nó de pórtico ao longo do ensaio - Ligação LVP5 


\section{RESULTADOS E ANÁLISES}

Neste capítulo são feitas as análises dos resultados obtidos nos ensaios das cinco ligações viga-pilar de extremidade. Em princípio, as análises foram conduzidas segundo duas frentes: uma análise de caráter local - onde as atenções foram focalizadas no comportamento do nó de pórtico - e outra de caráter global, analisando-se o comportamento forçadeslocamento da ligação como um todo.

\subsection{ANÁLISE LOCAL}

Neste item, as análises referentes ao comportamento mecânico da região nodal foram realizadas segundo três pontos: o início da fissuração do nó de pórtico, o comportamento cíclico do nó (a partir da observação das deformações nos estribos) e a comparação entre os valores previstos e os valores experimentais da resistência ao cisalhamento.

Para efeito de identificação, adotou-se a seguinte numeração para os estribos, em função da posição dos mesmos na altura do nó, conforme a figura 7.1.

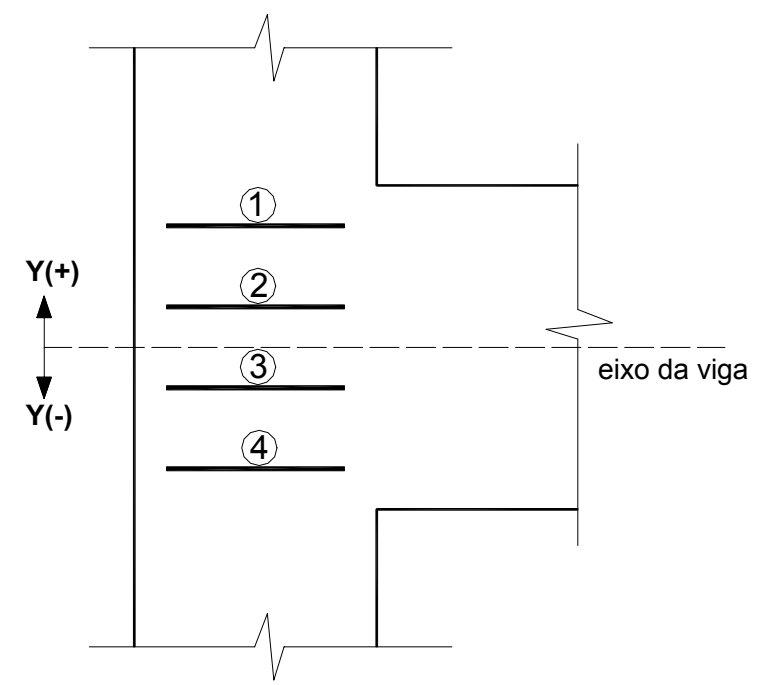

Figura 7.1: Numeração e posição dos estribos ao longo da altura do nó

Nas ligações LVP1, LVP3 e LVP5, os quatro estribos estão definidos. Nas ligações LVP2 e LVP4, com dois estribos apenas, estão definidos apenas os estribos centrais, ou seja, os estribos 2 e 3. 


\subsubsection{Início da fissuração dos nós de pórtico}

Antes do início da fissuração do concreto, as deformações nos estribos eram pouco significativas, sendo o concreto responsável por resistir praticamente a toda força cortante introduzida ao nó. Os estribos começaram a ser solicitados de fato a partir do surgimento da primeira fissura diagonal do nó, fato que ocorre quando a resistência à tração do concreto é alcançada.

Neste trabalho, a importância em se conhecer a força cortante de fissuração do nó reside na necessidade de se saber o nível de tensões aplicadas durante o carregamento cíclico, em especial nas etapas de menor intensidade. De fato, seria inútil aplicar à ligação um nível de solicitação cíclica abaixo do correspondente ao início de fissuração do nó de pórtico.

As figuras 7.2 a 7.7 permitem identificar a força no atuador que corresponde ao início da fissuração dos nós. Identifica-se esta força a partir de um crescimento significativo das deformações nos estribos. A força de fissuração pode ser obtida graficamente traçando-se as tangentes das curvas antes e depois desse crescimento das deformações.

Para as ligações LVP1, LVP3 e LVP5 escolheu-se o estribo 3 (um dos estribos centrais) para identificar a força de fissuração. Para as ligações LVP2 e LVP4 escolheu-se o estribo central 2. 


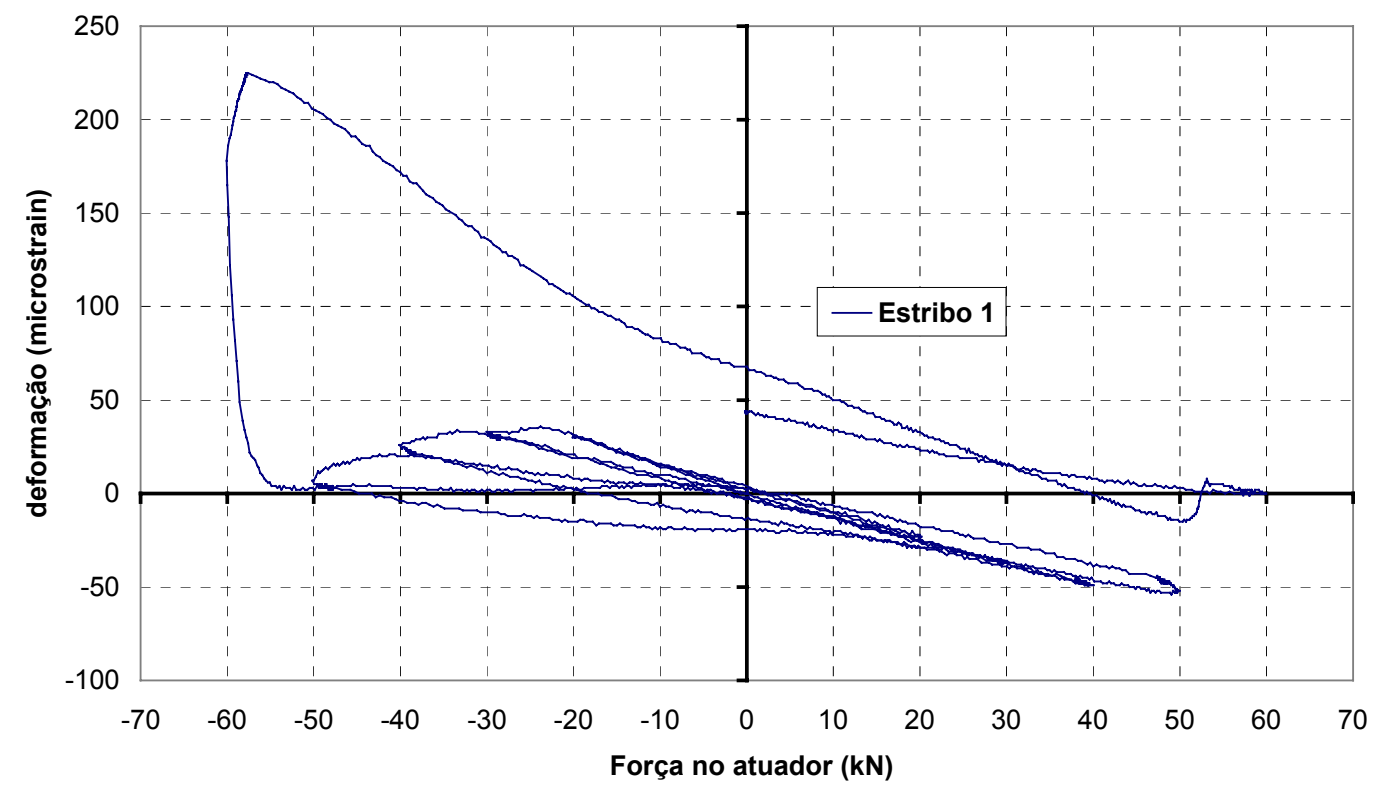

Figura 7.2: Deformações no estribo 1 da ligação LVP1 - etapa 1

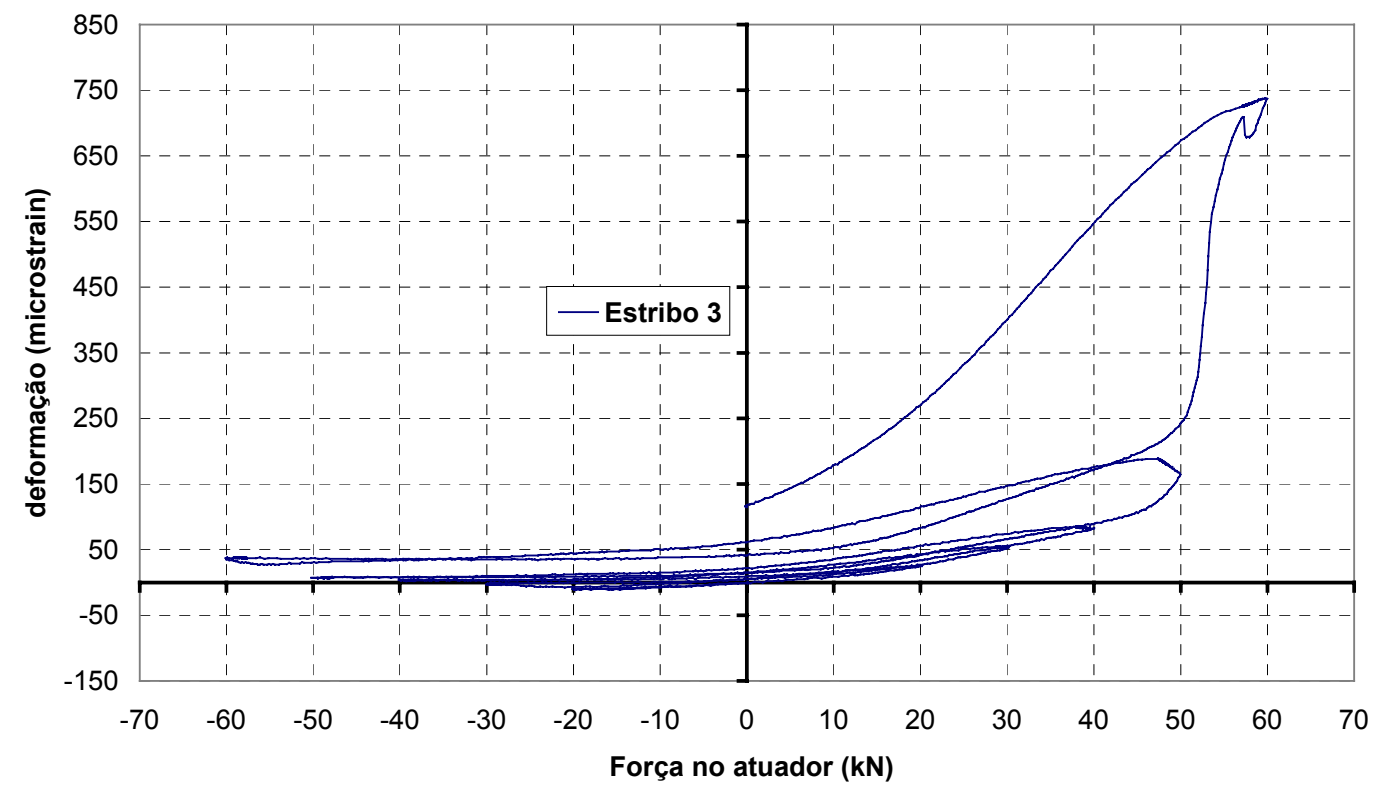

Figura 7.3: Deformações no estribo 3 da ligação LVP1: Etapa 1 


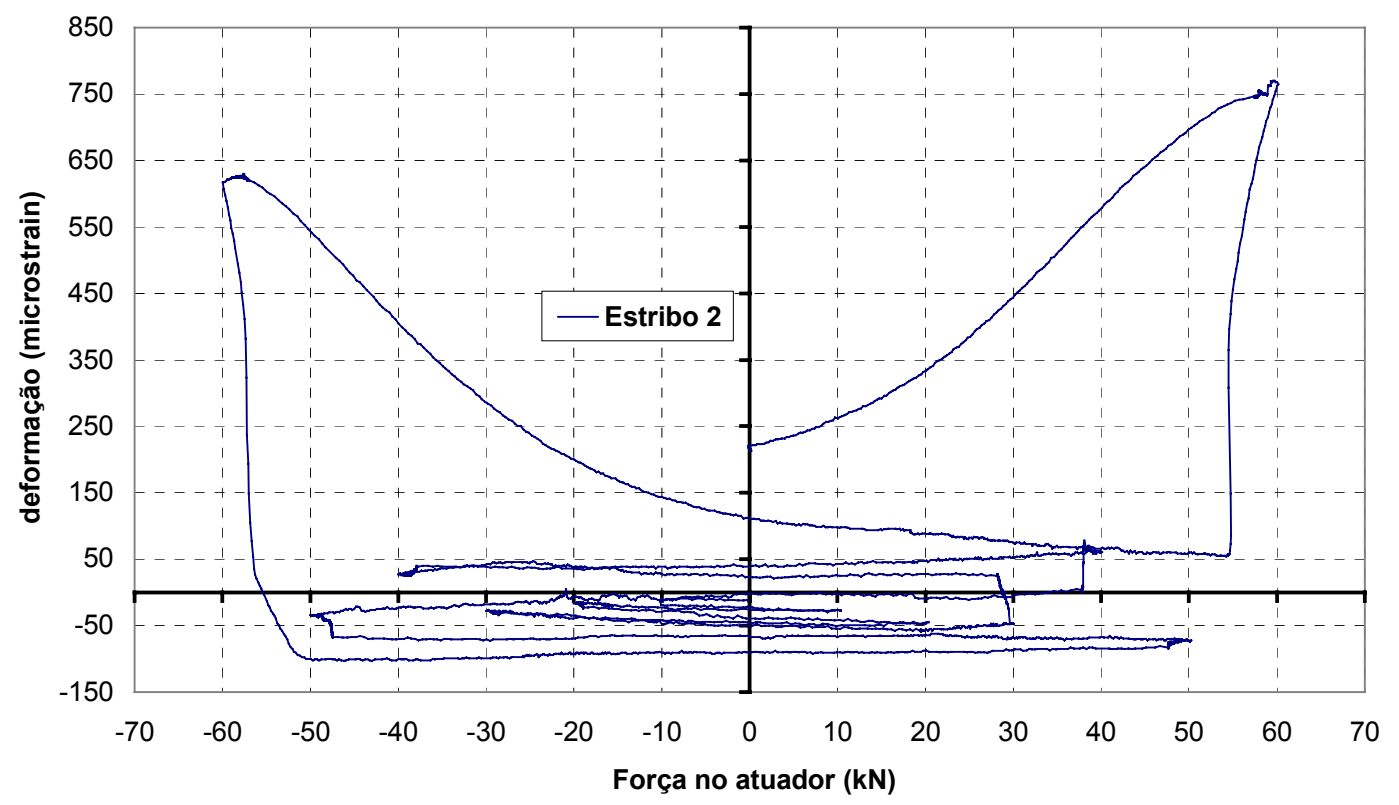

Figura 7.4: Deformações no estribo 2 da ligação LVP2: Etapa 1

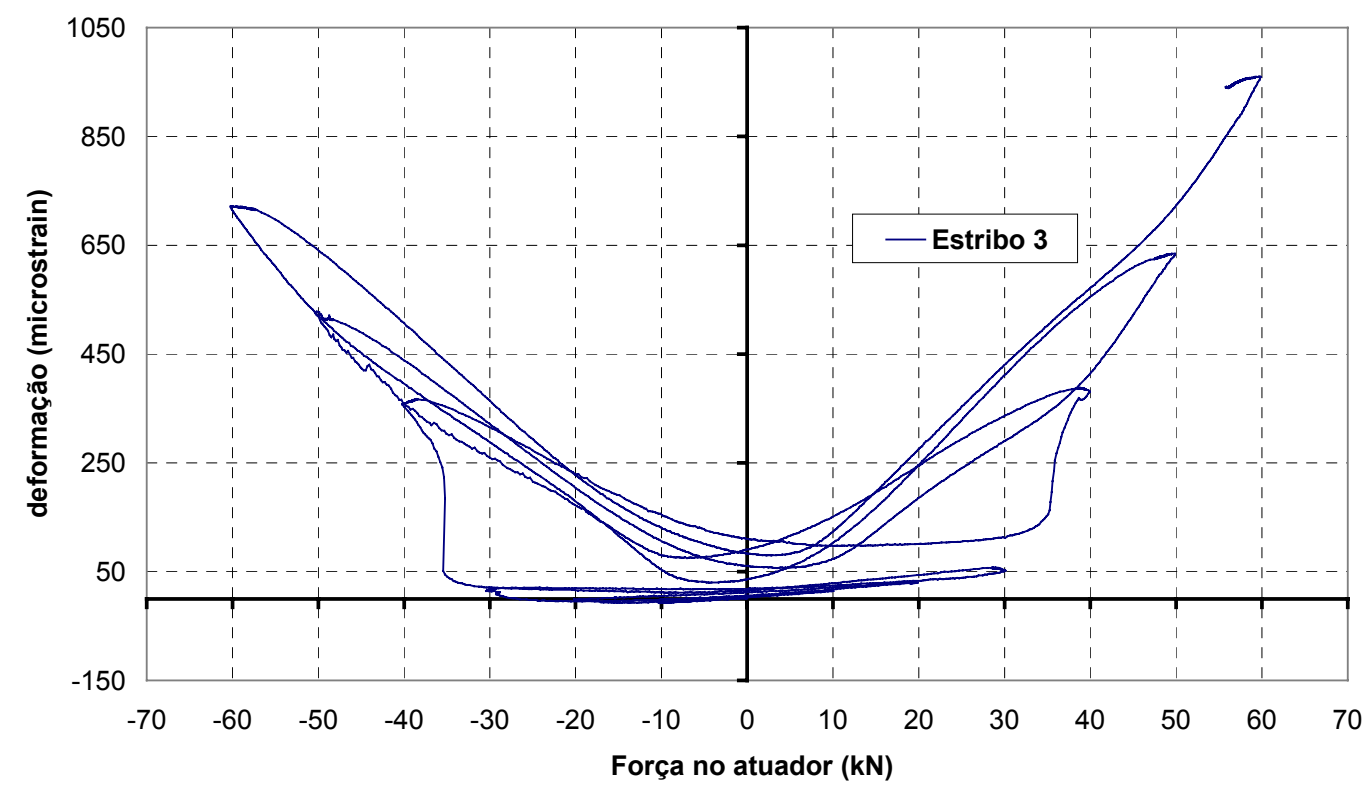

Figura 7.5: Deformações no estribo 3 da ligação LVP3: Etapa 1 


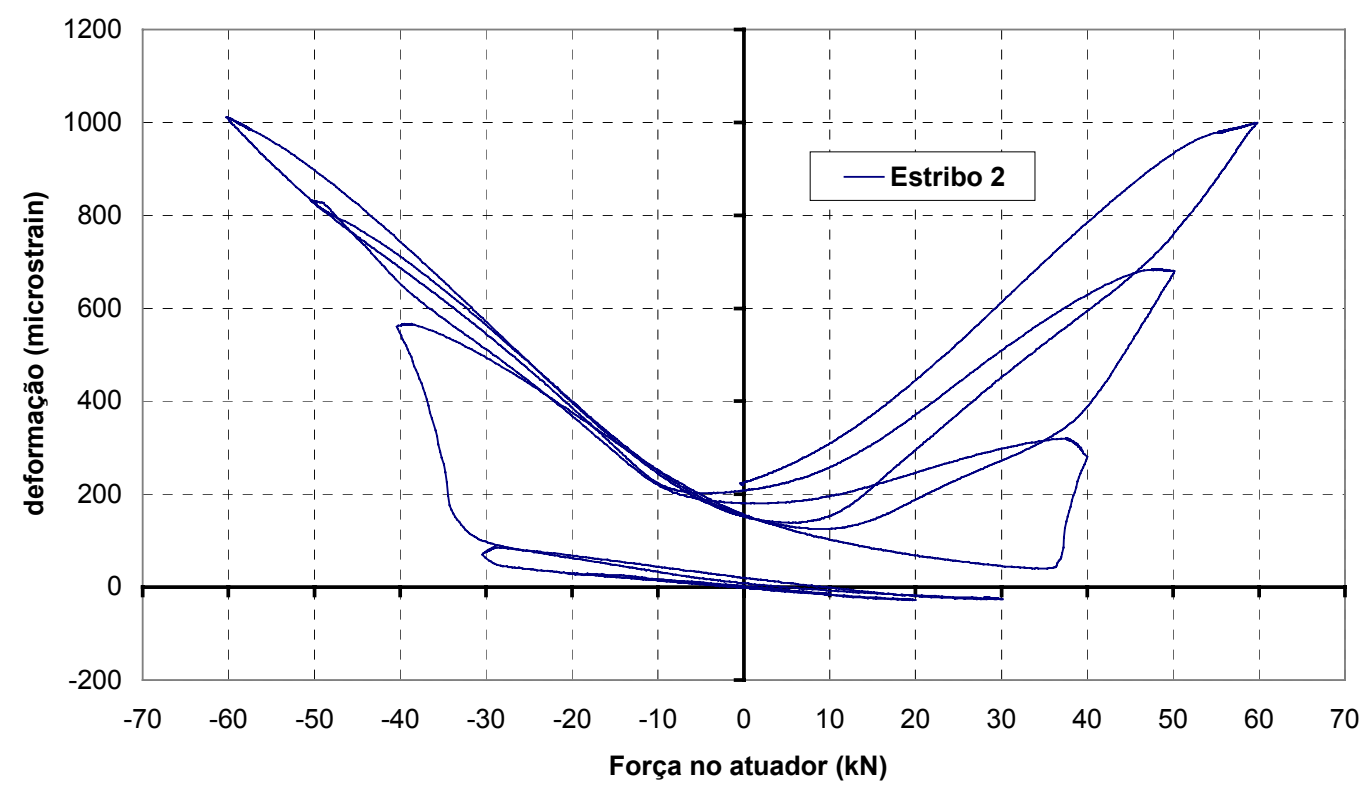

Figura 7.6: Deformações no estribo 2 da ligação LVP4: Etapa 1

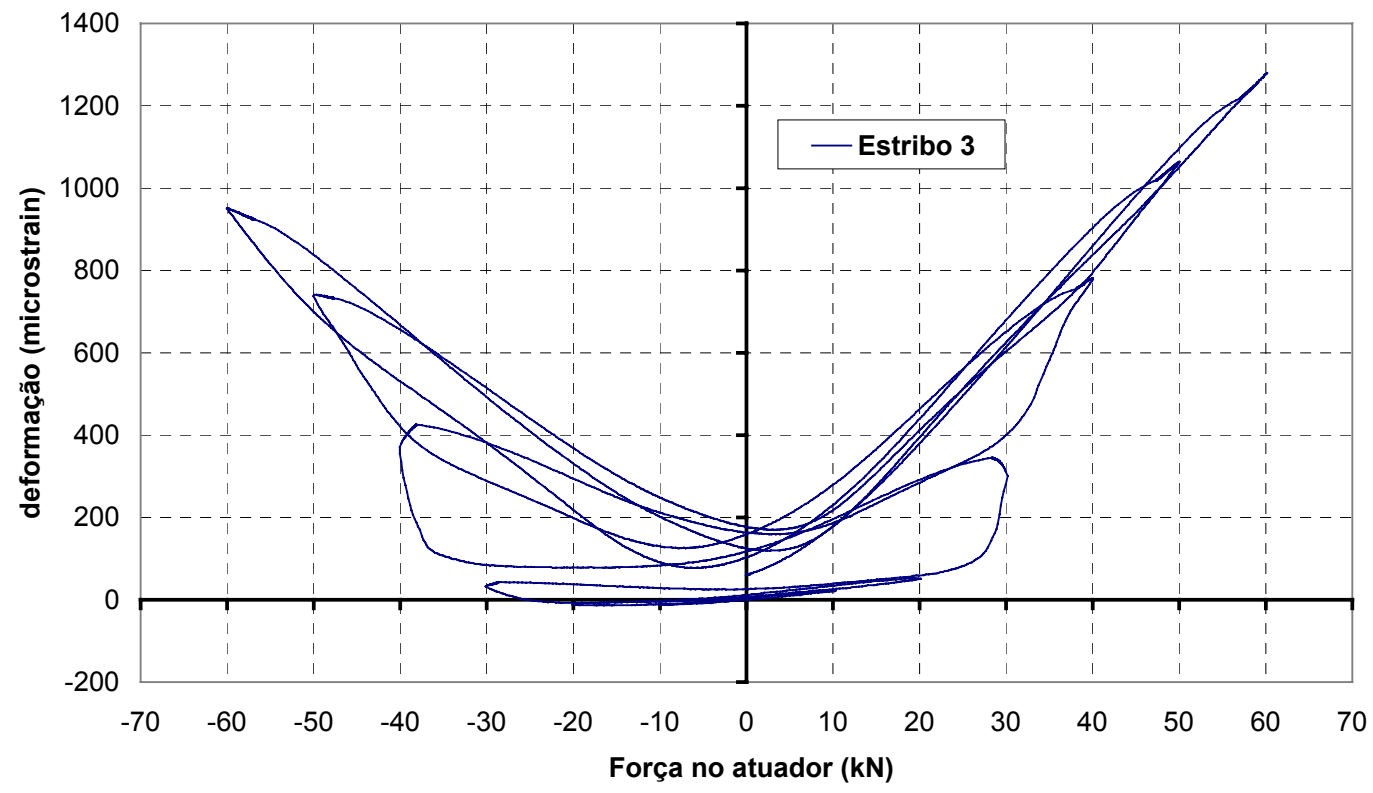

Figura 7.7: Deformações no estribo 3 da ligação LVP5: Etapa 1

A seguir apresenta-se um procedimento relativamente simples para a previsão da força de fissuração dos nós de pórtico. Trata-se de uma análise semelhante a que é feita usualmente para a determinação da força cortante nos nós de pórtico.

Considerando o painel nó de pórtico como um elemento submetido a um estado plano de tensões, conforme a figura 7.8 , a tensão principal de tração pode ser obtida por: 


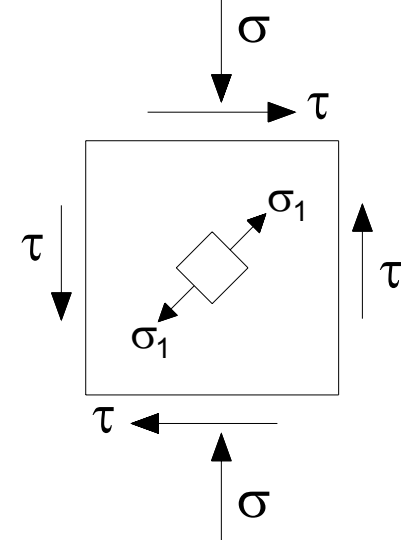

Figura 7.8: Tensões atuantes no nó de pórtico: estado plano de tensões

$\sigma_{1}=\frac{-\sigma}{2}+\sqrt{\frac{\sigma^{2}}{4}+\tau^{2}}$

ou, isolando a tensão de cisalhamento $\tau$,

$\tau=\sigma_{1} \sqrt{1+\frac{\sigma}{\sigma_{1}}}$

Quando a tensão principal $\sigma_{1}$ atinge a resistência à tração simples do concreto $f_{t}$, iniciase a fissuração do nó de pórtico. Assim,

$$
\tau=f_{t} \sqrt{1+\frac{\sigma}{f_{t}}}
$$

Entendendo que a tensão de cisalhamento $\tau$ seja dada pela razão entre a força cortante no nó e sua área efetiva e que a tensão normal de compressão $\sigma$ seja a razão entre a força normal no pilar $(N)$ pela área da seção bruta do mesmo $\left(A_{p}\right)$, a força cortante de fissuração do nó pode ser determinada por:

$$
V_{c r}=f_{t} \sqrt{1+\frac{N}{A_{p} f_{t}}}\left(b_{j} h_{j}\right)
$$

Entretanto, em conseqüência da simplificação adotada para o estado de solicitação do nó, a expressão (7.4) fornece valores um pouco acima dos valores reais para o início da fissuração do nó. Por esse motivo, a partir de correlações com resultados experimentais, JIURU et al. (1992) sugerem um ajuste na expressão de $V_{\text {cr }}$ :

$$
V_{c r}=0,9 f_{t} \sqrt{1+\frac{N}{4 A_{p} f_{t}}}\left(b_{j} h_{j}\right)
$$


A tabela 7.1 contém os valores das forças no atuador experimentais e os calculados, correspondentes ao início de fissuração do nó $\left(F_{c r}\right)$. Os valores de $F_{c r}$ calculados são obtidos a partir dos valores de $V_{c r}$, utilizando-se equações de equilíbrio e de compatibilidade na seção da viga, além do equilíbrio de forças e momentos na ligação como um todo.

Tabela 7.1: Início da fissuração do nó: valores experimentais e teóricos

\begin{tabular}{|c|c|c|c|}
\hline Ligação & $\begin{array}{c}\mathbf{F}_{\mathbf{c r}}(\mathbf{k N}) \\
\text { Experimental }\end{array}$ & $\begin{array}{c}\mathbf{F}_{\mathbf{c r}} \mathbf{( k N )} \\
\text { s/ correção }\end{array}$ & $\begin{array}{c}\mathbf{F}_{\mathbf{c r}}(\mathbf{k N}) \\
\text { Jiuru et al. (1992) }\end{array}$ \\
\hline LVP1 & 50 & 67,05 & 41,38 \\
\hline LVP2 & 52 & 73,41 & 46,32 \\
\hline LVP3 & 35 & 44,30 & 27,38 \\
\hline LVP4 & 35 & 46,22 & 28,88 \\
\hline LVP5 & 37 & 48,00 & 30,26 \\
\hline
\end{tabular}

A comparação dos resultados contidos na tabela 7.1 indica que os valores experimentais situam-se entre os fornecidos pela expressão (7.4) da teoria da elasticidade e os fornecidos com a correção proposta por JIURU et al. (1992) na expressão (7.5).

Com o intuito de obter um melhor ajuste dos resultados experimentais, utilizou-se a seguinte expressão modificada para a determinação da força cortante de fissuração do nó:

$\mathrm{V}_{\mathrm{cr}}=\beta \mathrm{f}_{\mathrm{t}} \sqrt{1+\frac{N}{\mathrm{~A}_{\mathrm{p}} \mathrm{f}_{\mathrm{t}}}}\left(\mathrm{b}_{\mathrm{j}} \mathrm{h}_{\mathrm{j}}\right)$

a qual deriva da expressão clássica (7.4) para o caso de estado duplo de tensões, introduzindo apenas um fator de correção $\beta$. O valor de $\beta$ que melhor se ajustou aos dados experimentais foi de 0,744 . (vide tabela 7.2).

Tabela 7.2: Força de fissuração do nó - valores experimentais e teóricos da expressão (7.6)

\begin{tabular}{|c|c|c|}
\hline Ligação & $\begin{array}{c}\mathbf{F}_{\mathrm{cr}}(\mathbf{k N}) \\
\text { Experimental }\end{array}$ & $\begin{array}{c}\mathbf{F}_{\mathbf{c r}}(\mathbf{k N}) \\
\text { Expressão (7.6) }\end{array}$ \\
\hline LVP1 & 50 & 49,87 \\
\hline LVP2 & 52 & 54,60 \\
\hline LVP3 & 35 & 32,95 \\
\hline LVP4 & 35 & 34,38 \\
\hline LVP5 & 37 & 35,70 \\
\hline \multicolumn{3}{|c|}{$\beta=0,744$} \\
\hline
\end{tabular}

\subsubsection{Comportamento mecânico dos nós frente as ações cíclicas}

A análise do comportamento mecânico do nó de pórtico foi realizada com o auxílio das curvas deformações nos estribos versus a força aplicada pelo atuador, uma vez que esta grandeza está diretamente relacionada com a força cortante solicitante no nó. 
Inicialmente são apresentados os gráficos deformação $x$ força da última etapa de carregamento das ligações LVP1, LVP3 e LVP4, as quais foram submetidas a ações cíclicas de intensidade elevada.

\section{LIGAÇÃO LVP1}

Na última etapa de carregamento (etapa 3), a ligação LVP1 foi submetida a ações cíclicas de modo a simular um sismo de intensidade moderada, conforme mencionado no item 6.7 .

Os gráficos das figuras 7.9 à 7.11 contêm as deformações dos estribos 1,3 e 4 da terceira etapa de carregamento. $\mathrm{O}$ estribo 2 foi perdido. Nesta terceira etapa de carregamento foram aplicados um total de oito ciclos, com controle de deslocamentos.

A tabela 7.3 contém os valores máximos das forças no atuador ao longo dos ciclos, com os respectivos deslocamentos reais nas vigas, medidos a partir do transdutor T1.

Tabela 7.3: Forças máximas nos ciclos - Etapa 3 da ligação LVP1

\begin{tabular}{|c|c|c|c|c|}
\hline Ciclo & $\begin{array}{c}\mathbf{F}(\mathbf{k N}): \\
\text { Sentido negativo }\end{array}$ & $\begin{array}{c}\text { Desl. Viga } \\
(\mathrm{mm})\end{array}$ & $\begin{array}{c}\mathbf{F}(\mathbf{k N}): \\
\text { Sentido positivo }\end{array}$ & $\begin{array}{c}\text { Desl. Viga } \\
(\mathrm{mm})\end{array}$ \\
\hline 1 & $-115,6$ & $-24,7$ & $+96,2$ & $+20,6$ \\
\hline 2 & $-108,3$ & $-24,2$ & $+92,3$ & $+20,7$ \\
\hline 3 & $-106,8$ & $-24,4$ & $+90,0$ & $+20,8$ \\
\hline 4 & $-136,6$ & $-36,3$ & $+113,2$ & $+32,7$ \\
\hline 5 & $-108,3$ & $-31,0$ & $+106,7$ & $+33,0$ \\
\hline 6 & $-105,1$ & $-31,4$ & $+99,9$ & $+33,3$ \\
\hline 7 & $-100,5$ & $-31,4$ & $+113,1$ & $+45,9$ \\
\hline 8 & $-57,1$ & $-20,9$ & $+101,1$ & $+47,6$ \\
\hline
\end{tabular}

Os deslocamentos na viga ditos reais referem-se as medidas do transdutor T1 descontadas dos deslocamentos ocasionados por pequenos giros do quadro horizontal, que surgiram em virtude das folgas dos parafusos e da própria deformação dos elementos que compõem o quadro. Para a ligação viga-pilar de concreto, o giro do quadro pode ser encarado como uma rotação de corpo rígido. Essa rotação foi avaliada a partir dos transdutores T12 e T13 posicionados no quadro metálico. 

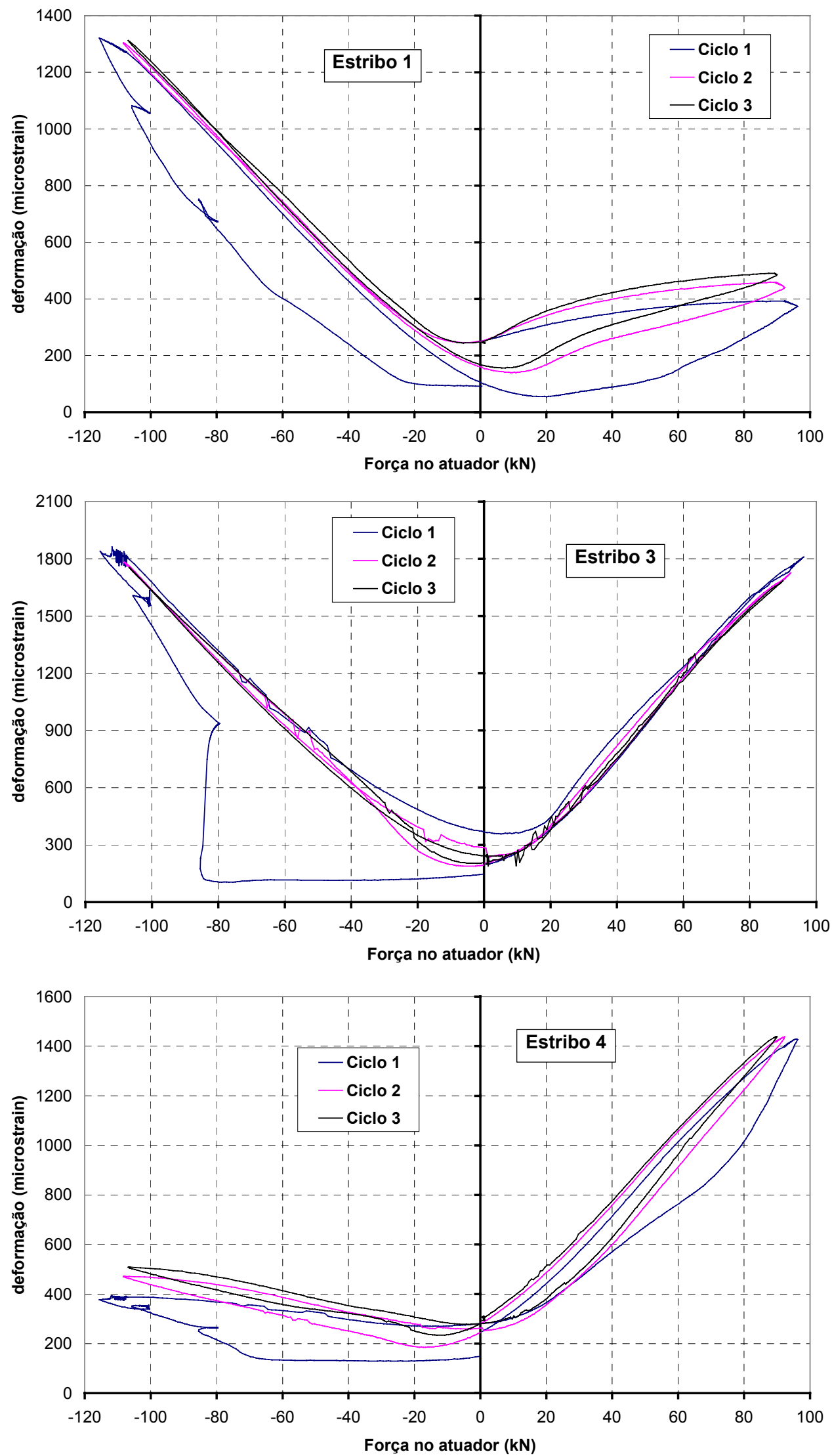

Figura 7.9: Deformação nos estribos do nó da ligação LVP1: Etapa 3 - ciclos 1 à 3 

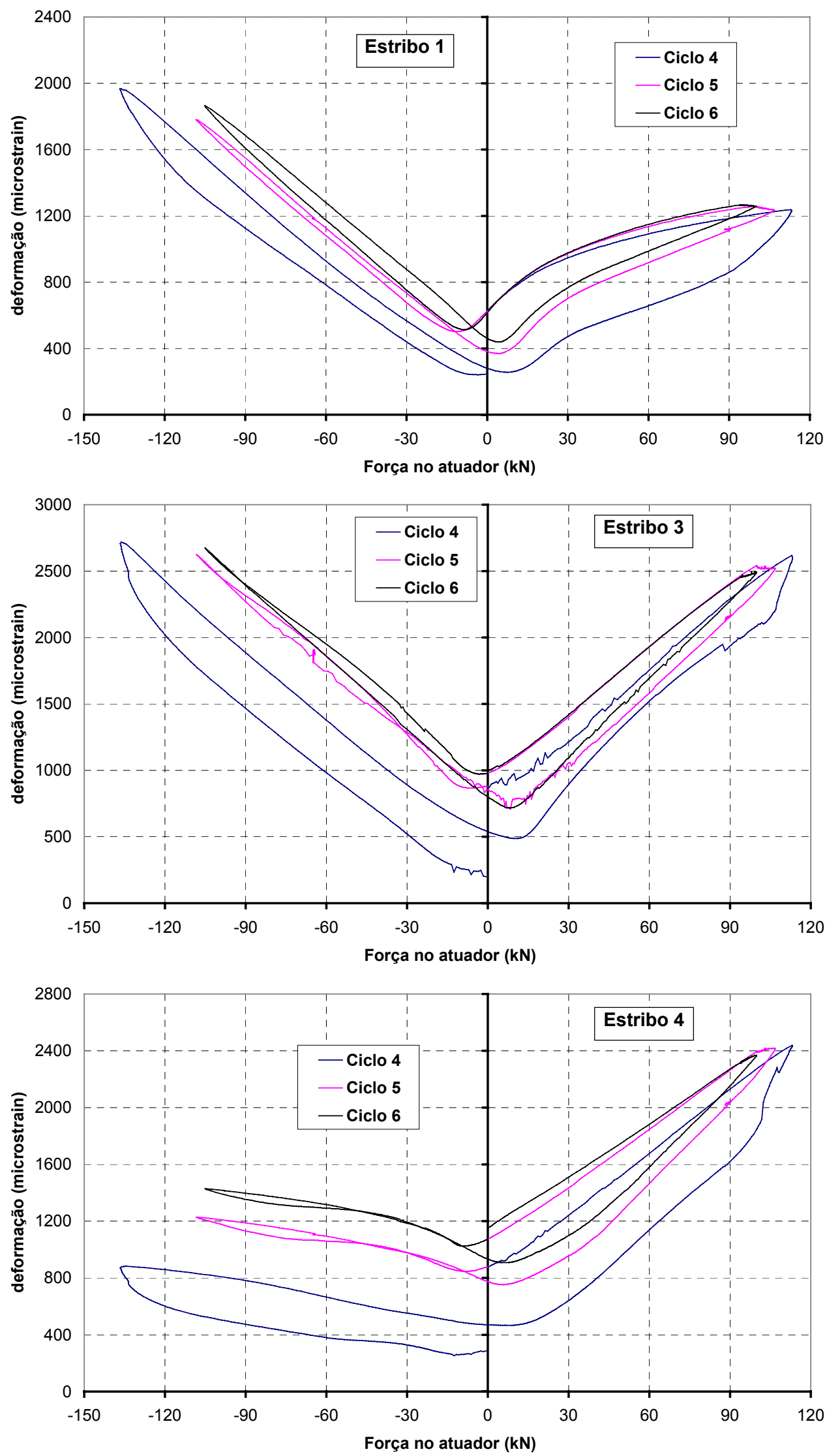

Figura 7.10: Deformação nos estribos do nó da ligação LVP1: Etapa 3 - ciclos 4 à 6 

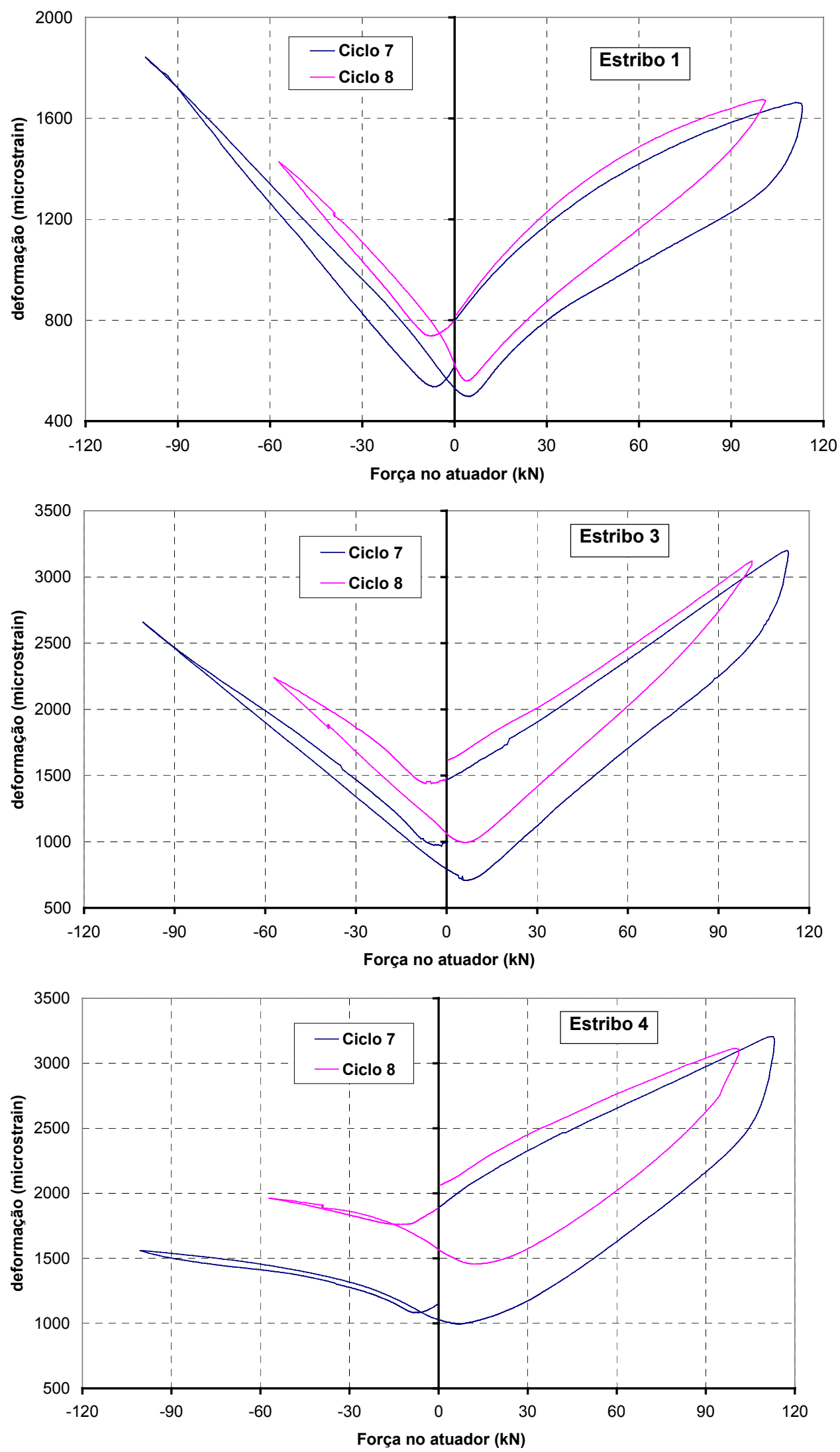

Figura 7.11: Deformação nos estribos do nó da ligação LVP1: Etapa 3 - ciclos 7 e 8 
Com base nas figuras 7.9 à 7.11 foram feitas as seguintes análises e observações:

1) Com o decorrer dos ciclos de carregamento, as diferenças de solicitações nos estribos $1,3 \mathrm{e}$ 4 diminuem, ou seja, a participação dos estribos na resistência do nó de pórtico tende a ser mais uniforme. Na realidade, o gradiente de deformações nos estribos ao longo da altura do nó diminui com a aplicação da ação cíclica.

2) Nos estribos mais afastados da região central, observa-se uma diferença significativa entre as deformações no sentido positivo e no sentido negativo das forças. De fato, para um determinado sentido de força, o estribo mais próximo da armadura de tração da viga é o mais solicitado.

3) Por outro lado, no estribo 3 (mais próximo da região central que os demais), as deformações nos dois sentidos de força são aproximadamente iguais, fato observado até o instante em que o nó atinge a sua máxima resistência.

4) Comparando-se os gráficos das figuras 7.9 à 7.11, nota-se uma perda de resistência da ligação nos dois sentidos de força, em especial para intensidades de solicitação maiores.

A fim de avaliar quantitativamente a perda de resistência da ligação com o carregamento cíclico, fixou-se uma deformação de referência alcançada pelo estribo 3, próxima à deformação máxima atingida nos ciclos com mesma amplitude de deslocamentos. Para esse valor de deformação, foram anotadas as forças atingidas nos ciclos (vide tabela 7.4).

Assim, por exemplo, no ciclo 1, quando a deformação no estribo 3 assumiu o valor de $1700 \mu \varepsilon$, a força no atuador atingiu o valor $-109,7 \mathrm{kN}$. No ciclo seguinte (ciclo 2), para esse mesmo valor de deformação, a força no atuador atingiu $-103,8 \mathrm{kN}$, indicando que houve uma perda de resistência em relação ao ciclo inicial. No ciclo 4, a amplitude de deslocamentos imposta à extremidade da viga foi maior que os três primeiros ciclos, o que resultou em maiores deformações nos estribos. Daí a razão de se estabelecer uma nova deformação de referência (neste caso de $2600 \mu \varepsilon$ ).

A tabela 7.4 apresenta uma comparação de dados referentes ao sentido negativo de forças, para avaliação da perda de resistência da ligação. As mesmas observações no sentido negativo foram notadas para o sentido positivo.

Tabela 7.4: Forças atingidas ao longo dos ciclos da etapa 3 para deformações de referência

\begin{tabular}{|c|c|c|}
\hline Ciclo & Deformação no estribo $\mathbf{3}=\mathbf{1 7 0 0} \mu \varepsilon$ & Perda de resistência (\%) \\
\hline 1 & $-109,7 \mathrm{kN}$ & 0 \\
\hline 2 & $-103,8 \mathrm{kN}$ & 5,4 \\
\hline 3 & $-103,8 \mathrm{kN}$ & 5,4 \\
\hline Ciclo & Deformação no estribo 3 = 2600 $\mu \varepsilon$ & Perda de resistência (\%) \\
\hline 4 & $-135,4 \mathrm{kN}$ & 0 \\
\hline 5 & $-107,1 \mathrm{kN}$ & 20,9 \\
\hline 6 & $-101,6 \mathrm{kN}$ & 25,0 \\
\hline 7 & $-97,6 \mathrm{kN}$ & 28,0 \\
\hline
\end{tabular}


A figura 7.12 contém o gráfico da perda de resistência da ligação com as deformações de referência no estribo 3 :

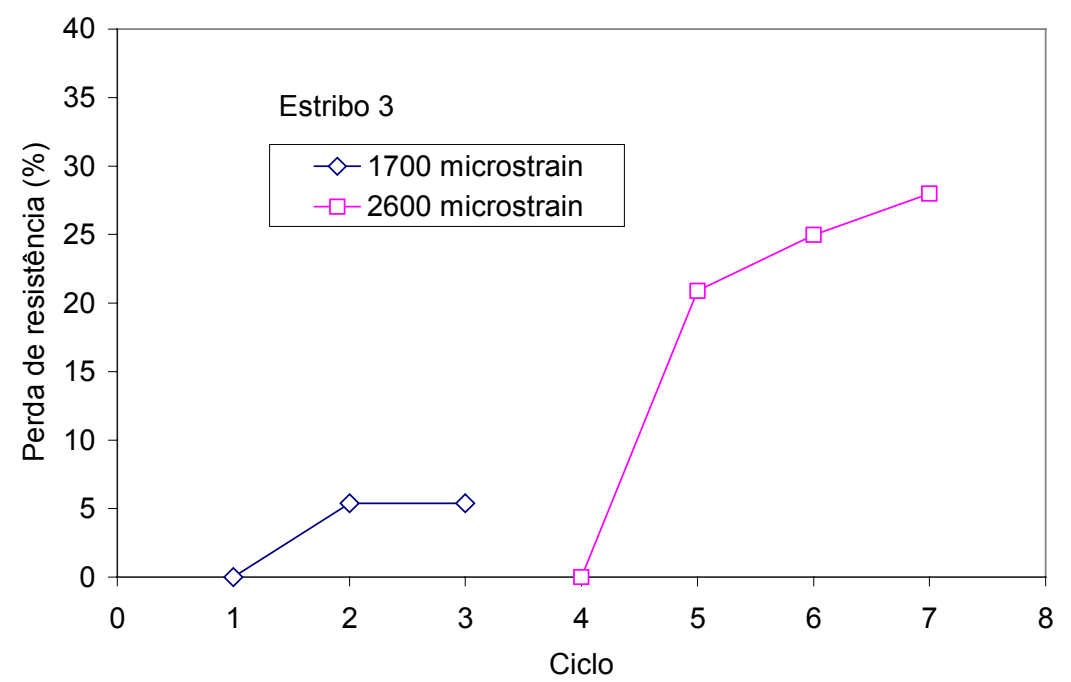

Figura 7.12: Perda de resistência da ligação LVP1: Etapa 3

Evidentemente, como conseqüência da maior intensidade de solicitações nos ciclos 4 à 7 , as perdas de resistências são maiores nesses ciclos quando comparadas aos três primeiros iniciais.

5) A queda brusca de resistência observada no ciclo 5 é conseqüência da intensa deterioração do concreto do nó de pórtico, impossibilitando os estribos de alcançarem maiores deformações. Tal deterioração significa que a biela diagonal não é mais capaz de resistir as forças impostas, limitando a força cortante horizontal desenvolvida no nó de pórtico.

6) A queda brusca na resistência da ligação, observada no ciclo 5, ocorreu no sentido negativo das forças. Tal fato pode estar relacionado com o sentido inicial de carregamento. Este comportamento foi observado nas três ligações submetidas a carregamentos cíclicos de elevada intensidade: LVP1, LVP3 e LVP4. Vale lembrar que a aplicação das forças em todas as ligações teve início no sentido negativo.

Observação com respeito ao salto de deformações do estribo 3: ciclo 1 da etapa 3:

Com base no registro de tempo dos dados coletados pelo sistema de aquisição, concluiu-se que o início do crescimento rápido das deformações no estribo 3 para o ciclo 1 coincidiu com o instante em que se verificou a formação de novas fissuras visíveis no nó de pórtico. Tal fato pode ser percebido pela comparação entre o panorama de fissuração no final da etapa 1 e no instante em que se percebeu a formação de novas fissuras para a força de $85 \mathrm{kN}$, no sentido negativo das forças da etapa 3 (figura 7.13). 


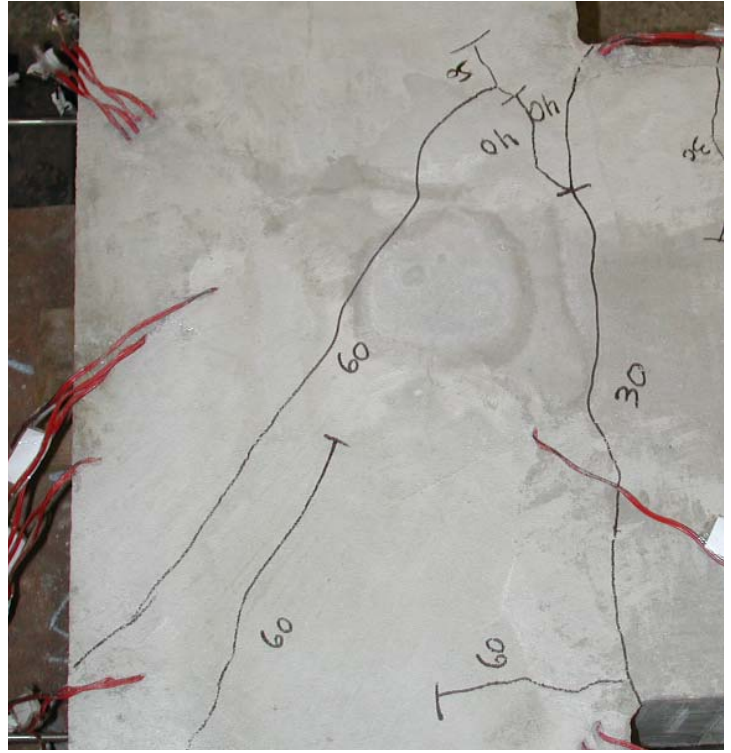

a) Final da etapa 1

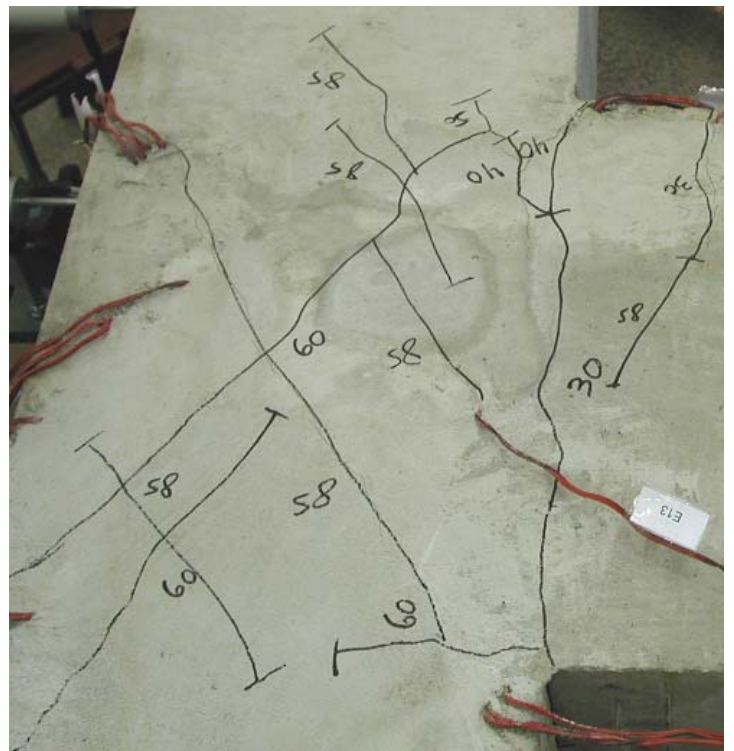

b) Ciclo 1 da etapa 3: $F=-85 \mathrm{kN}$

Figura 7.13: Comparação entre o panorama de fissuração: fim da etapa 1 e etapa 3/ciclo1

\section{LIGAÇÃO LVP3}

$\mathrm{Na}$ última etapa de carregamento, identificada como etapa 2, foram aplicados 12 ciclos de carregamento inversível com controle de forças.

A partir do ciclo 8 , resistência da ligação começou a diminuir rapidamente, conforme indicado na tabela 6.6. Nos ciclos 10 à 12, a resistência da ligação alcançou apenas uma resistência da ordem de $10 \%$ da resistência última, conseqüência do estado de deterioração avançado do nó de pórtico.

Os gráficos apresentados nas figuras 7.14 à 7.16 correspondem às curvas deformações nos estribos $x$ força no atuador dos ciclos 1 ao 9 . Conforme já mencionado no capítulo 6, planejou-se a aplicação do carregamento cíclico da seguinte forma: três ciclos com amplitude de força igual a $70 \mathrm{kN}$, seguido de mais três ciclos com amplitude de $80 \mathrm{kN}$, assim por diante, até que a ligação atingisse a sua resistência última. 

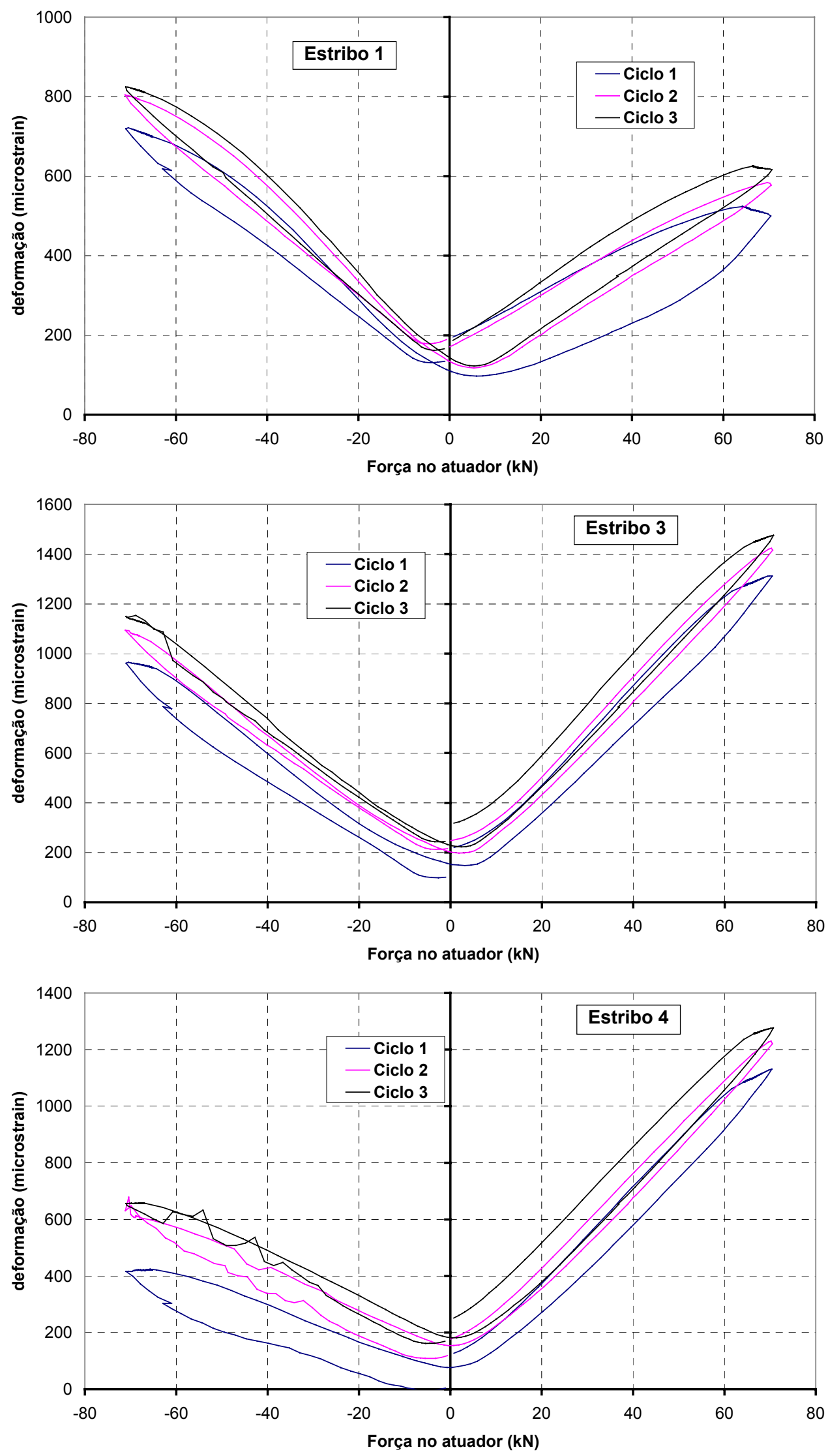

Figura 7.14: Deformação nos estribos do nó da ligação LVP3: Etapa 2 - ciclos 1 à 3 

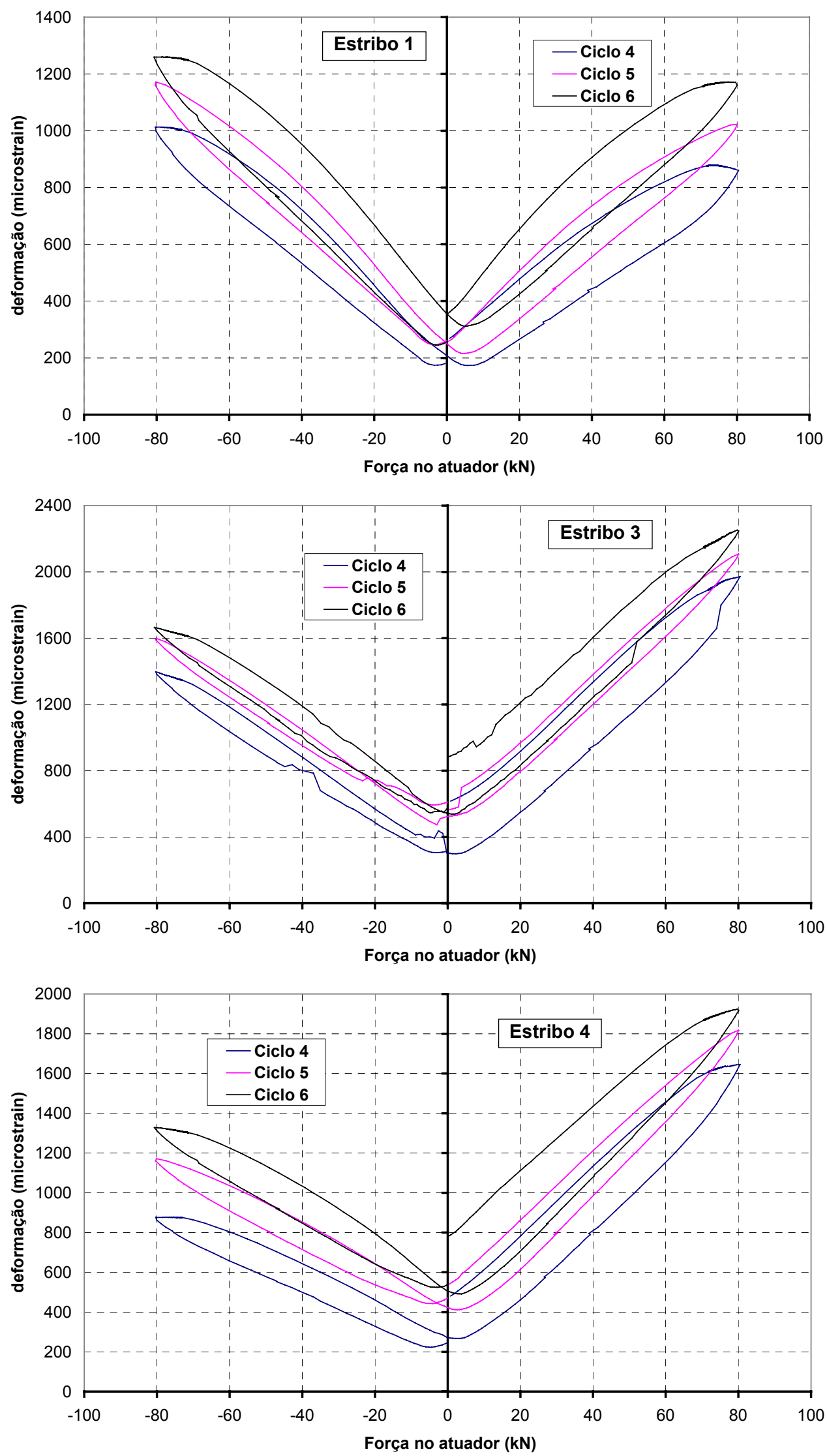

Figura 7.15: Deformação nos estribos do nó da ligação LVP3: Etapa 2 - ciclos 4 à 6 

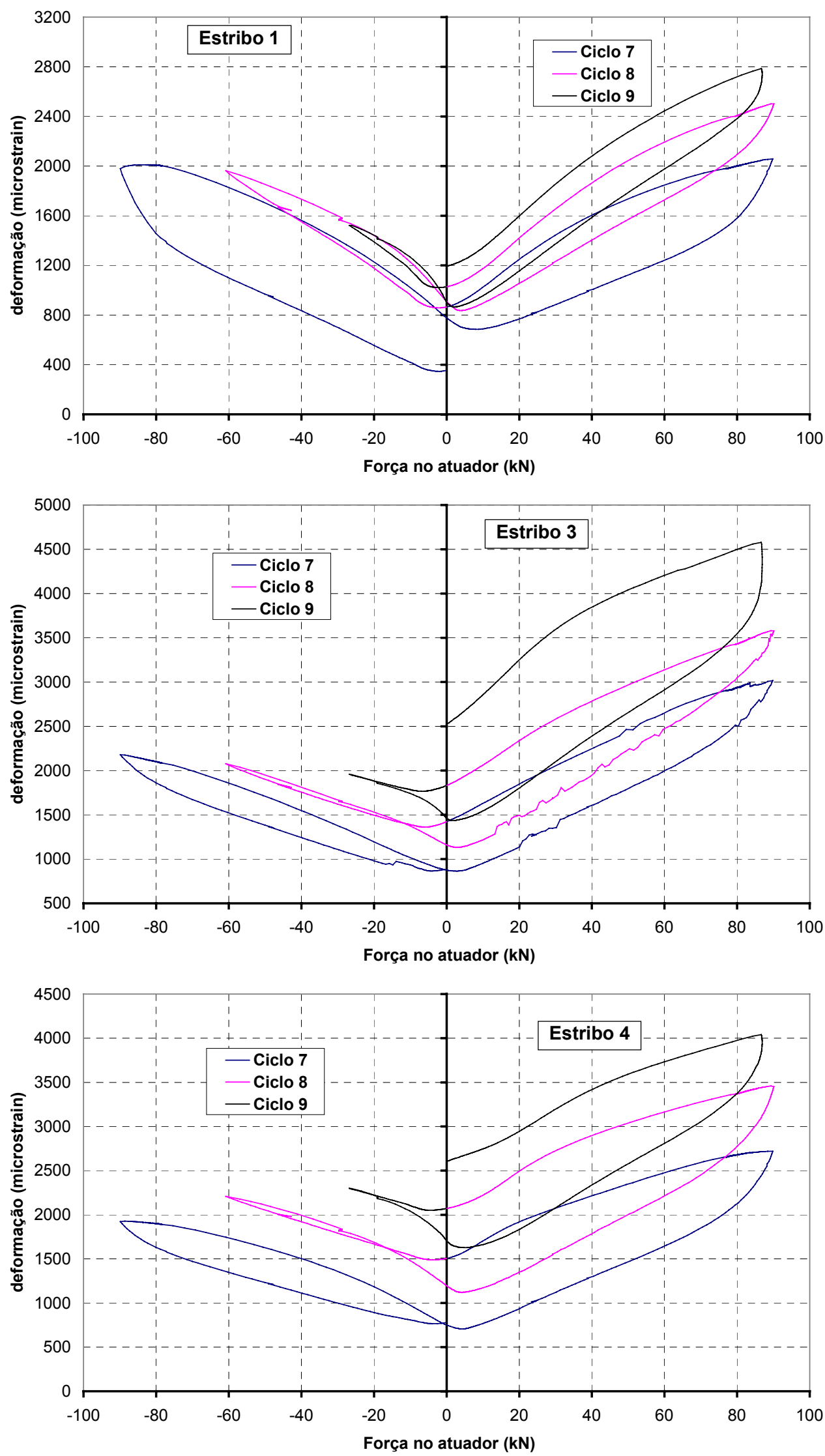

Figura 7.16: Deformação nos estribos do nó da ligação LVP3: Etapa 2 - ciclos 7 à 9 
Qualitativamente, as observações de 1) a 4) feitas para a ligação LVP1 aplicam-se à ligação LVP3. A perda de resistência em virtude da aplicação cíclica do carregamento também foi observada, o que já era, de fato, esperado.

Percebe-se também pelos gráficos que as deformações nos estribos crescem significativamente nos ciclos de mesma amplitude de forças. Ou seja, para uma mesma força cortante no nó de pórtico a ser atingida nos ciclos subseqüentes, a tendência das deformações nos estribos é aumentar, conforme pode ser identificado pela tabela 7.5.

Tabela 7.5: Valores das deformações nos estribos (em microstrain) da ligação LVP3: etapa 2

\begin{tabular}{|c|c|c|c|c|c|c|c|c|c|}
\hline $\begin{array}{c}\text { Ações } \\
\text { Negativas }\end{array}$ & $\begin{array}{c}\mathrm{F}=-70 \mathrm{kN} \\
\text { Ciclo 1 }\end{array}$ & $\begin{array}{c}\mathrm{F}=-70 \mathrm{kN} \\
\text { Ciclo 2 }\end{array}$ & $\begin{array}{c}\mathrm{F}=-70 \mathrm{kN} \\
\text { Ciclo 3 }\end{array}$ & $\begin{array}{c}\mathrm{F}=-80 \mathrm{kN} \\
\text { Ciclo 4 }\end{array}$ & $\begin{array}{c}\mathrm{F}=-80 \mathrm{kN} \\
\text { Ciclo 5 }\end{array}$ & $\begin{array}{c}\mathrm{F}=-80 \mathrm{kN} \\
\text { Ciclo 6 }\end{array}$ & $\begin{array}{c}\mathrm{F}=-90 \mathrm{kN} \\
\text { Ciclo 7 }\end{array}$ & $\begin{array}{c}\mathrm{F}=-61 \mathrm{kN} \\
\text { Ciclo 8 }\end{array}$ & $\begin{array}{c}\mathrm{F}=-27 \mathrm{kN} \\
\text { Ciclo 9 }\end{array}$ \\
\hline Estribo 1 & 705 & 785 & 805 & 995 & 1152 & 1238 & 1980 & 1963 & 1523 \\
\hline Estribo 3 & 940 & 1089 & 1150 & 1380 & 1583 & 1647 & 2180 & 2078 & 1956 \\
\hline Estribo 4 & 405 & 650 & 650 & 860 & 1154 & 1312 & 1922 & 2209 & 2298 \\
\hline $\begin{array}{c}\text { Ações } \\
\text { Positivas }\end{array}$ & $\begin{array}{c}\mathrm{F}=70 \mathrm{kN} \\
\text { Ciclo 1 }\end{array}$ & $\begin{array}{c}\mathrm{F}=70 \mathrm{kN} \\
\text { Ciclo 2 }\end{array}$ & $\begin{array}{c}\mathrm{F}=70 \mathrm{kN} \\
\text { Ciclo 3 }\end{array}$ & $\begin{array}{c}\mathrm{F}=80 \mathrm{kN} \\
\text { Ciclo 4 }\end{array}$ & $\begin{array}{c}\mathrm{F}=80 \mathrm{kN} \\
\text { Ciclo 5 }\end{array}$ & $\begin{array}{c}\mathrm{F}=80 \mathrm{kN} \\
\text { Ciclo 6 }\end{array}$ & $\begin{array}{c}\mathrm{F}=90 \mathrm{kN} \\
\text { Ciclo 7 }\end{array}$ & $\begin{array}{c}\mathrm{F}=90 \mathrm{kN} \\
\text { Ciclo 8 }\end{array}$ & $\begin{array}{c}\mathrm{F}=87 \mathrm{kN} \\
\text { Ciclo 9 }\end{array}$ \\
\hline Estribo 1 & 494 & 572 & 606 & 851 & 1020 & 1158 & 2060 & 2495 & 2752 \\
\hline Estribo 3 & 1302 & 1405 & 1454 & 1955 & 2103 & 2245 & 3017 & 3560 & 4411 \\
\hline Estribo 4 & 1122 & 1211 & 1256 & 1630 & 1813 & 1913 & 2719 & 3451 & 3970 \\
\hline
\end{tabular}

A tendência de aumento das deformações nos estribos para uma mesma amplitude de força é conseqüência da deterioração mecânica do concreto com o carregamento cíclico. Em outras palavras, a diminuição da resistência do concreto do nó significa também a diminuição da contribuição de resistência ao cisalhamento por parte da biela comprimida. Como a força cortante introduzida ao nó é a mesma (pelo fato de se manter a amplitude de força), cabe aos estribos aumentarem sua parcela de resistência ao cisalhamento, o que ocorre com o aumento das deformações nos mesmos.

Uma outra maneira de entender o aumento das deformações nos estribos do nó pode ser conseguida por meio da análise das expressões (5.54) e (5.55) e da figura 5.10 do capítulo 5, referentes as leis constitutivas empregadas pelo modelo de biela e tirante de HWANG \& LEE (1999). A crescente fissuração do concreto na região nodal frente as ações cíclicas significa maior queda das tensões de compressão alcançadas pelo concreto. Além disso, a evolução da fissuração significa também que as deformações principais de tração $\varepsilon_{r}$ crescem com os ciclos. Pela equação de compatibilidade em (5.61), se a deformação principal de tração $\varepsilon_{\mathrm{r}}$ aumenta, a deformação no estribo horizontal também apresenta aumento.

Nos últimos ciclos de carregamento - quando a deterioração do nó de pórtico esteve bem acentuada -as deformações residuais no concreto assumiram valores significativos, fato que pode ser percebido indiretamente pela análise de deformações alcançadas pelos estribos para forças do atuador nulas (gráficos das figuras 7.14 à 7.16). De fato, a ruína do nó de pórtico foi acompanhada de grandes deformações residuais no concreto.

Com base ainda na tabela 7.5, percebe-se que no ciclo 8 , no sentido positivo de forças, os estribos 3 e 4 ultrapassaram a deformação de escoamento, induzindo a maiores deformações residuais de tração no concreto para o ciclo posterior.

As tabelas 7.6 e 7.7 indicam quantitativamente os acréscimos de deformações nos estribos do nó da ligação LVP3 na etapa 2 de carregamento. Os acréscimos são em relação ao 
primeiro ciclo de mesma amplitude de força: os ciclos 2 e 3 em relação ao ciclo 1 ( $F= \pm 70 \mathrm{kN}$ ) e os ciclos 5 e 6 em relação ao ciclo $4(F= \pm 80 \mathrm{kN})$.

Tabela 7.6: Acréscimo de deformações nos estribos \%: Ligação LVP3/Etapa 2/Ações negativas

\begin{tabular}{|c|c|c|c|c|}
\hline Ciclo & Estribo 1 & Estribo 3 & Estribo 4 & Amplitude de Força \\
\hline 1 & - & - & - & \multirow{2}{*}{$\mathrm{F}=-70 \mathrm{kN}$} \\
\hline 2 & 11,3 & 15,9 & 60,5 & \\
\hline 3 & 14,2 & 22,3 & 60,5 & \multirow{2}{*}{$\mathrm{F}=-80 \mathrm{kN}$} \\
\hline 4 & - & - & - & \\
\hline 5 & 15,8 & 14,7 & 34,2 & \\
\hline 6 & 24,4 & 19,3 & 52,6 & \\
\hline
\end{tabular}

Tabela 7.7: Acréscimo de deformações nos estribos \%: Ligação LVP3/Etapa 2/Ações positivas

\begin{tabular}{|c|c|c|c|c|}
\hline Ciclo & Estribo 1 & Estribo 3 & Estribo 4 & Amplitude de Força \\
\hline 1 & - & - & - & \multirow{2}{*}{$\mathrm{F}=-70 \mathrm{kN}$} \\
\hline 2 & 15,8 & 7,9 & 8,0 & \\
\hline 3 & 22,7 & 11,7 & 11,9 & \\
\hline 4 & - & - & - & \multirow{2}{*}{$\mathrm{F}=-80 \mathrm{kN}$} \\
\hline 5 & 19,9 & 7,6 & 11,2 & \\
\hline 6 & 36,1 & 14,8 & 17,4 & \\
\hline
\end{tabular}

Constata-se pelas tabelas 7.6 e 7.7 que os estribos menos solicitados (estribo 4 no sentido negativo das forças e estribo 1 no sentido positivo) são os que sofreram os maiores acréscimos de deformações. Este fato está relacionado com a já mencionada uniformização das deformações dos estribos ao longo da altura do nó e compensa a gradual perda de resistência do concreto frente às forças cortantes.

\section{LIGAÇÃO LVP4}

Na ligação LVP4 foram dispostos apenas dois estribos na região do nó, diferentemente da ligação LVP3, com quatro estribos. O carregamento planejado para a ligação LVP4 foi idêntico ao da ligação LVP3.

A partir do ciclo 5, com o escoamento dos estribos, a ligação começou a perder resistência rapidamente. $O$ ensaio foi encerrado após a aplicação de 9 ciclos de carregamento, observando-se, ao final do ensaio, uma notável degradação do concreto na região do nó de pórtico. Conforme já mencionado, a deterioração do nó foi mais intensa na ligação LVP4 quando comparada à ligação LVP3. Vale lembrar que as duas ligações foram constituídas por concretos de praticamente mesma resistência à compressão (23,89 MPa para a ligação LVP3 e 24,62 MPa para a ligação LVP4).

Os gráficos das figuras 7.17 à 7.19 contêm as curvas deformação nos estribos versus força no atuador na segunda etapa de carregamento da ligação LVP4. 

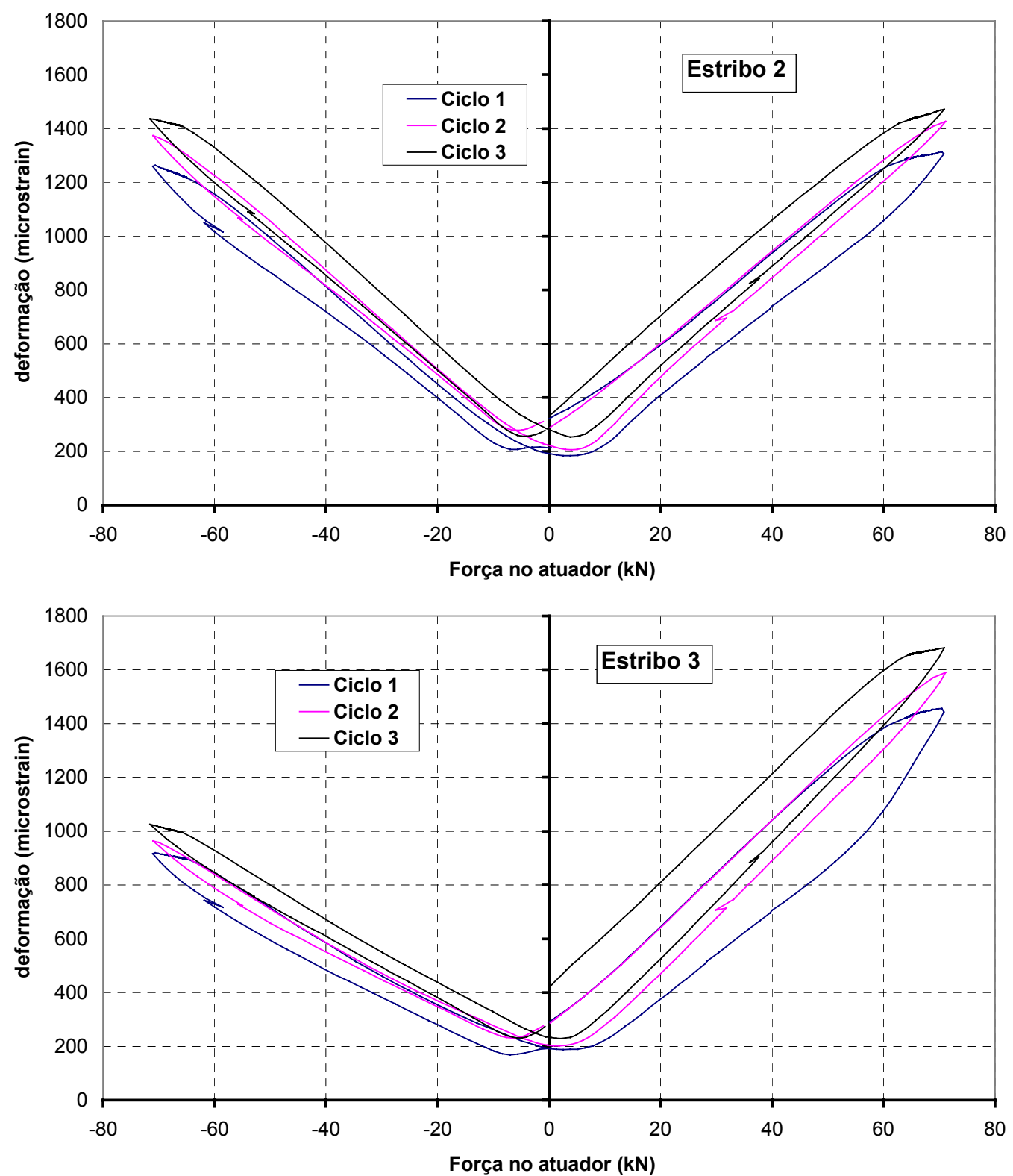

Figura 7.17: Deformação nos estribos do nó da ligação LVP4: Etapa 2 - ciclos 1 à 3 

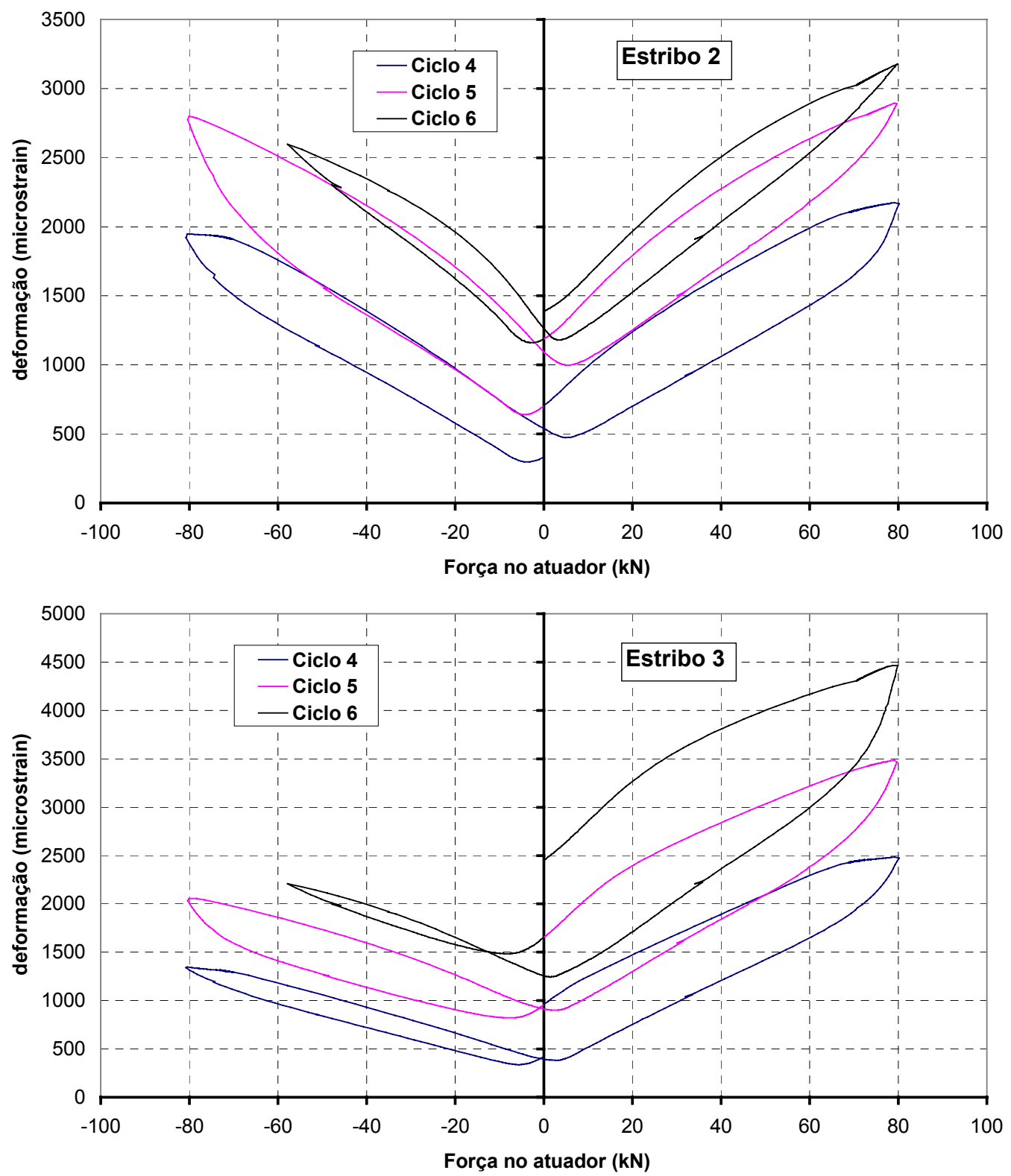

Figura 7.18: Deformação nos estribos do nó da ligação LVP4: Etapa 2 - ciclos 4 à 6 

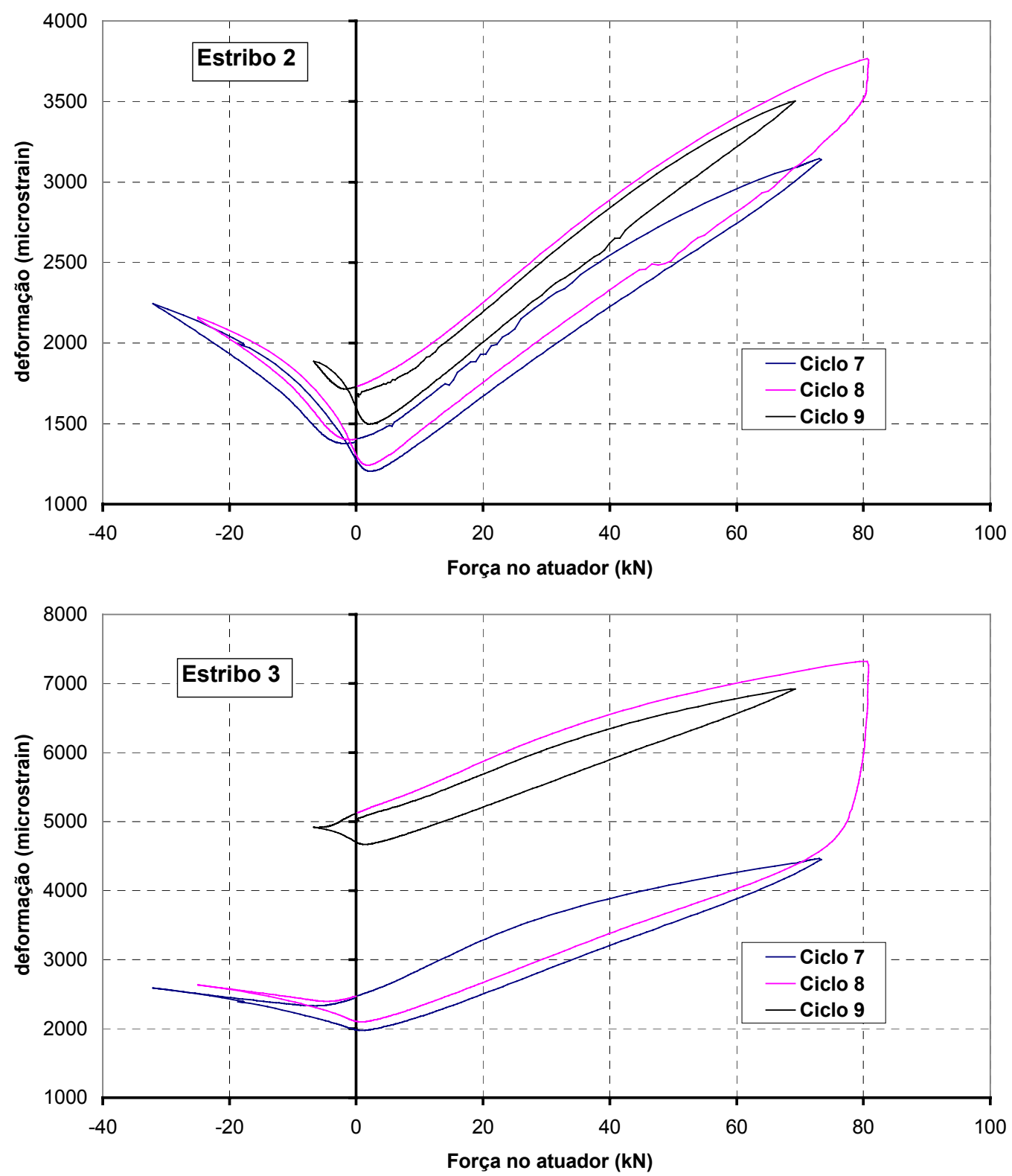

Figura 7.19: Deformação nos estribos do nó da ligação LVP4: Etapa 2 - ciclos 7 à 9

Pela análise dos gráficos das figuras 7.17 à 7.19, nota-se o acréscimo de deformações nos estribos do nó de pórtico para os ciclos de mesma amplitude de força, fato também observado e mencionado para a ligação LVP3.

A tabela 7.8 contém os valores das deformações atingidas pelos estribos da ligação LVP4 ao longo dos ciclos de carregamento (etapa 2). 
Tabela 7.8: Valores das deformações nos estribos (em microstrain) da ligação LVP4: etapa 2

\begin{tabular}{|c|c|c|c|c|c|c|c|c|c|}
\hline $\begin{array}{c}\text { Ações } \\
\text { Negativas }\end{array}$ & $\begin{array}{c}F=-70 \mathrm{kN} \\
\text { Ciclo } 1\end{array}$ & $\begin{array}{l}\mathrm{F}=-70 \mathrm{kN} \\
\text { Ciclo } 2\end{array}$ & $\begin{array}{l}\mathrm{F}=-70 \mathrm{kN} \\
\text { Ciclo } 3\end{array}$ & $\begin{array}{l}F=-80 \mathrm{kN} \\
\text { Ciclo } 4\end{array}$ & $\begin{array}{l}F=-80 \mathrm{kN} \\
\text { Ciclo } 5\end{array}$ & $\begin{array}{l}\mathrm{F}=-58 \mathrm{kN} \\
\text { Ciclo } 6\end{array}$ & $\begin{array}{l}F=-32 \mathrm{kN} \\
\text { Ciclo } 7\end{array}$ & $\begin{array}{c}F=-25 \mathrm{kN} \\
\text { Ciclo } 8\end{array}$ & $\begin{array}{r}F=-7 \mathrm{kN} \\
\text { Ciclo } 9\end{array}$ \\
\hline stribo 2 & 1232 & 1349 & 1399 & 1879 & 2744 & 2598 & 2244 & 2161 & 1888 \\
\hline Estribo 3 & 891 & 945 & 996 & 1318 & 2006 & 2207 & 2592 & 2634 & 4919 \\
\hline Ações & $F=70 \mathrm{kN}$ & $\mathrm{F}=70 \mathrm{kN}$ & $\mathrm{F}=70 \mathrm{kN}$ & $\mathrm{F}=80 \mathrm{kN}$ & $\mathrm{F}=80 \mathrm{kN}$ & $\mathrm{F}=80 \mathrm{kN}$ & $\mathrm{F}=73 \mathrm{kN}$ & $\mathrm{F}=81 \mathrm{kN}$ & $\mathrm{F}=69 \mathrm{kN}$ \\
\hline Positivas & Ciclo 1 & Ciclo 2 & Ciclo 3 & Ciclo 4 & Ciclo 5 & Ciclo 6 & Ciclo 7 & Ciclo 8 & Ciclo 9 \\
\hline stribo 2 & 1283 & 1400 & 1450 & 2153 & 2891 & 3178 & 3140 & 3749 & 3503 \\
\hline stribo 3 & 1410 & 1551 & 1650 & 2460 & 3467 & 4464 & 4453 & 7210 & 6923 \\
\hline
\end{tabular}

As tabelas 7.9 e 7.10 indicam quantitativamente o aumento das deformações nos estribos para os ciclos de mesma amplitude de força. A partir do ciclo 6, a ligação LVP4 não mais alcançou a força máxima prevista para o ciclo, por causa da ruína do nó. Por esse motivo, os dados de comparação nas tabelas 7.9 e 7.10 foram apresentados até o ciclo 5 .

Tabela 7.9: Acréscimo de deformações nos estribos\%: Ligação LVP4/Etapa 2/Ações negativas

\begin{tabular}{|c|c|c|c|}
\hline Ciclo & Estribo 2 & Estribo 3 & Amplitude de Força \\
\hline 1 & - & - & \multirow{2}{*}{$\mathrm{F}=-70 \mathrm{kN}$} \\
\hline 2 & 9,5 & 6,1 & \\
\hline 3 & 13,6 & 11,8 & \\
\hline 4 & - & - & \multirow{2}{*}{$\mathrm{F}=-80 \mathrm{kN}$} \\
\hline 5 & 46,0 & 52,0 & \\
\hline
\end{tabular}

Tabela 7.10: Acréscimo de deformações nos estribos\%: Ligação LVP4/Etapa 2/Ações positivas

\begin{tabular}{|c|c|c|c|}
\hline Ciclo & Estribo 2 & Estribo 3 & Amplitude de Força \\
\hline 1 & - & - & \multirow{2}{*}{$\mathrm{F}=-70 \mathrm{kN}$} \\
\hline 2 & 9,1 & 10,0 & \\
\hline 3 & 13,0 & 17,0 & \\
\hline 4 & - & - & \multirow{2}{*}{$\mathrm{F}=-80 \mathrm{kN}$} \\
\hline 5 & 34,3 & 40,9 & \multirow{2}{*}{} \\
\hline
\end{tabular}

Pelas tabelas 7.9 e 7.10, observa-se que os acréscimos de deformações nos estribos 2 e 3 foram razoavelmente iguais. Nota-se também que, próximo da ruína, ou quando a ligação alcança a máxima resistência, as deformações crescem significativamente, conforme mostram os valores referentes ao ciclo 5 .

Para fins de comparação das deformações entre as ligações LVP3 e LVP4, faz mais sentido analisar os dois estribos centrais do nó, ou seja, comparar as deformações dos estribos 2 e 3 das duas ligações. Entretanto, como as leituras das deformações dos extensômetros no estribo 2 da ligação LVP3 ficaram prejudicadas, tomou-se como base o estribo 3 para as análises seguintes.

Pelo fato de existirem apenas dois estribos no nó da ligação LVP4, seria sensato esperar deformações maiores nesta ligação comparadas às deformações da ligação LVP3, que possui quatro estribos na região nodal. No entanto, ao analisar os valores das tabelas $7.5 \mathrm{e}$ 7.8 , nota-se que as deformações no estribo 3 das duas ligações foram aproximadamente iguais até a ligação LVP3 se aproximar de sua resistência máxima, fato que ocorreu a partir do ciclo 4 , aos $80 \mathrm{kN}$ de força no atuador. Inclusive, na etapa anterior de carregamento (etapa 1), 
constatou-se que as deformações no estribo 3 das ligações LVP3 e LVP4 também assumiram valores aproximadamente iguais.

Na verdade, a diferença entre as deformações do estribo 3 das duas referidas ligações tornou-se mais evidente e acentuada próximo da ruína do nó de pórtico da ligação LVP4 (figuras 7.20 e 7.21 ).

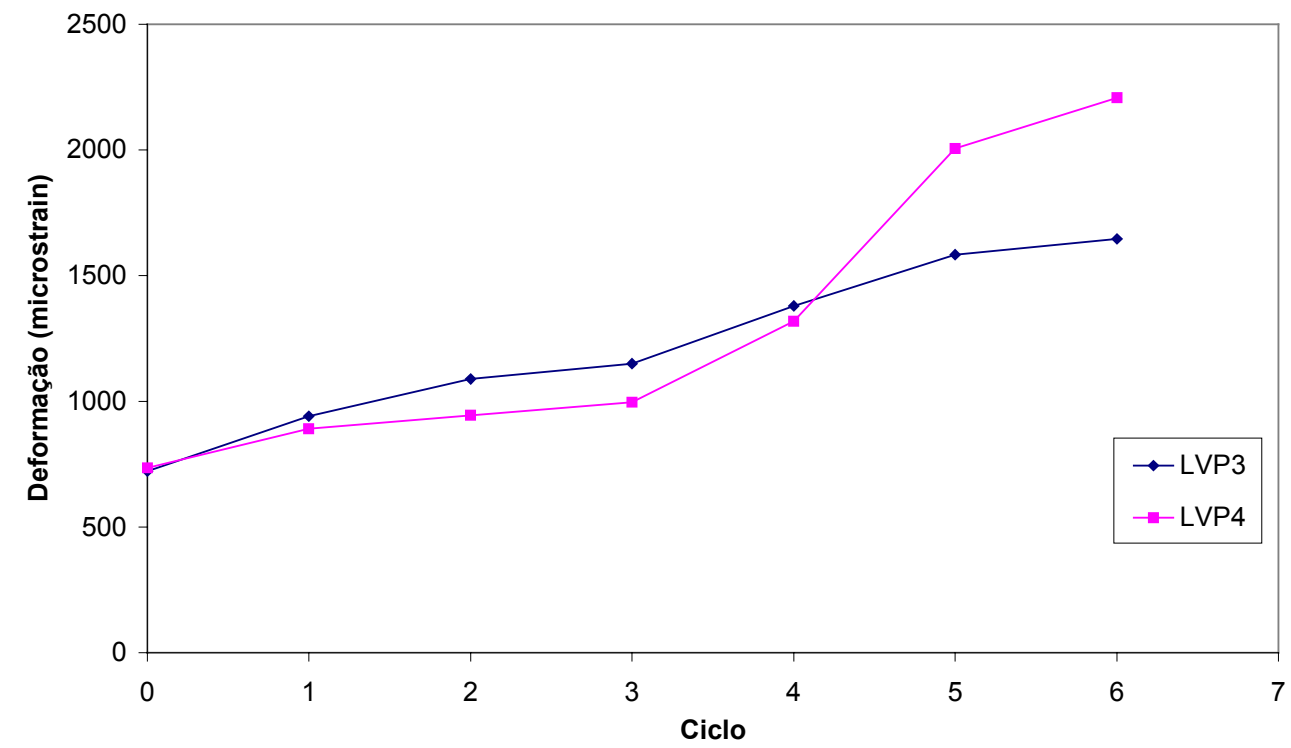

Figura 7.20: Deformações no estribo 3 das ligações LVP3 e LVP4: etapa 2 / sentido negativo

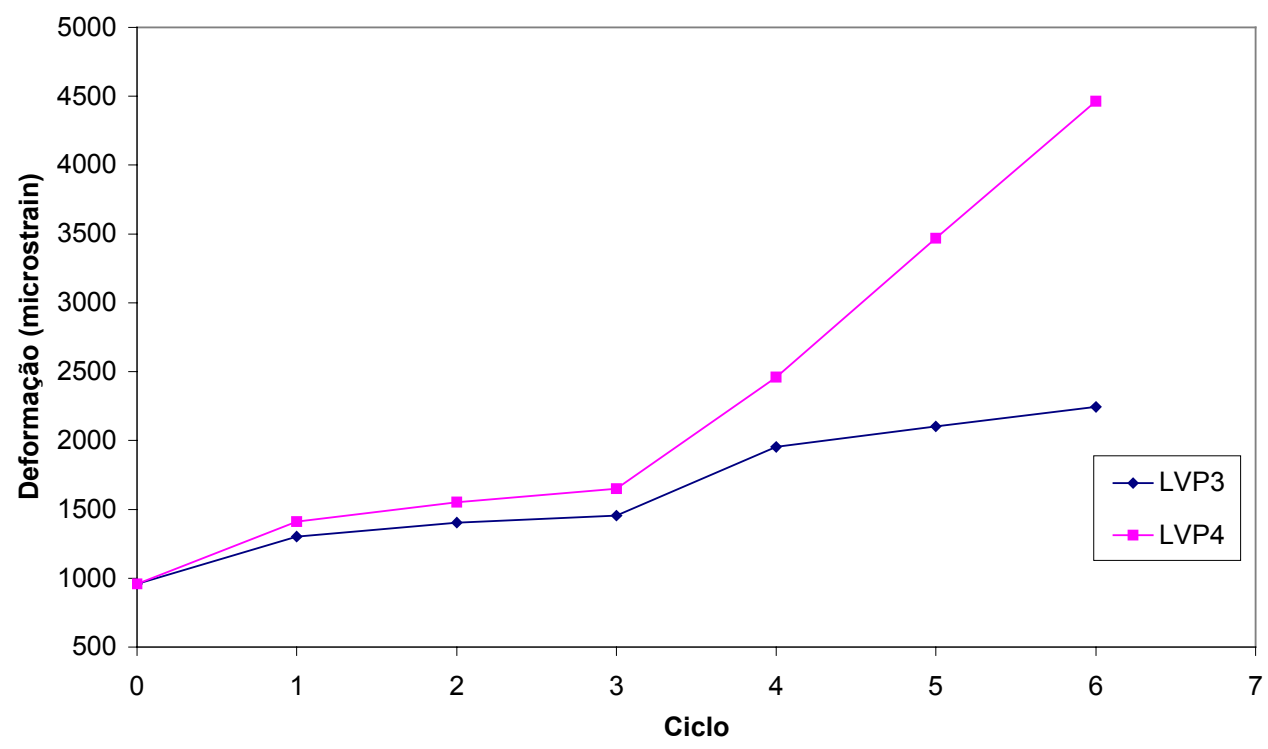

Figura 7.21: Deformações no estribo 3 das ligações LVP3 e LVP4: etapa 2 / sentido positivo 


\subsubsection{Resistência ao cisalhamento dos nós de pórtico}

Neste item, avalia-se a eficiência do modelo de biela e tirante proposto por HWANG \& LEE (1999) na previsão da resistência ao cisalhamento do nós de pórticos externos. Do ponto de vista mecânico, este modelo mostra ser mais completo que os modelos clássicos de biela e tirante, uma vez que considera a não-linearidade do concreto e do aço nas leis constitutivas dos materiais e faz uso da compatibilidade de deformações entre aço e concreto na região do nó. Daí a escolha desse modelo teórico para representar o comportamento dos nós e utilizá-lo nas comparações com os resultados experimentais.

O modelo de HWANG \& LEE (1999) fornece como resultado a força cortante resistente do nó de pórtico, bem como as parcelas de resistência em virtude das contribuições da biela diagonal e dos estribos horizontais e verticais. Além disso, o modelo se propõe a prever 0 modo de colapso do nó.

O valor da força cortante resistente calculado com o modelo de HWANG \& LEE (1999) é comparado com o valor máximo da força cortante no nó resistida pela ligação durante todo o ensaio, assim como recomendado pelos autores desse modelo.

Para a obtenção das forças cortantes experimentais atuantes nos nós de pórtico, aplicou-se a seguinte expressão, derivada do equilíbrio do painel mostrado na figura 7.22:

$\mathrm{V}_{\mathrm{jh}}=\mathrm{T}_{\mathrm{v}}-\mathrm{V}_{\mathrm{p}}$

onde $T_{v}$ é a força resultante da armadura tracionada da viga e $V_{p}$ é a força cortante no pilar.

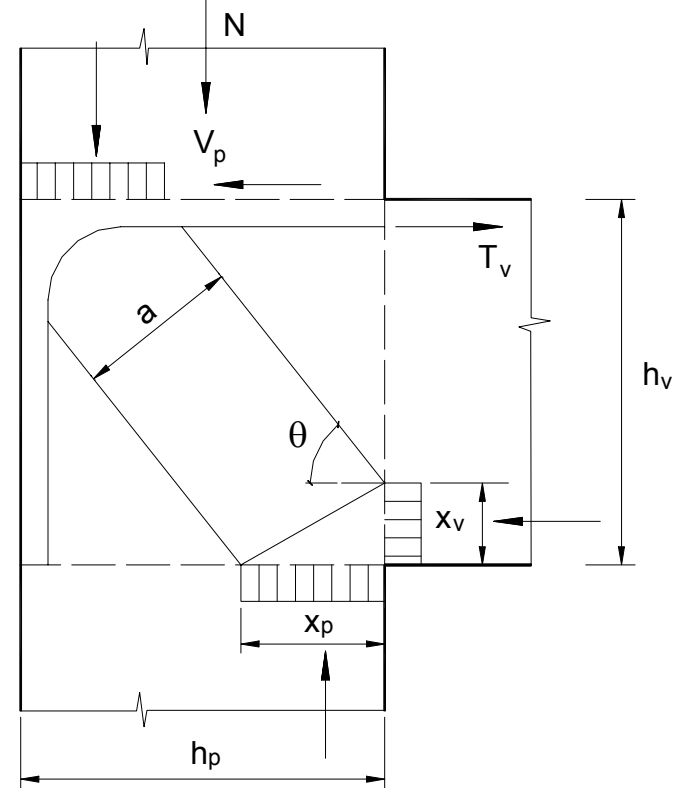

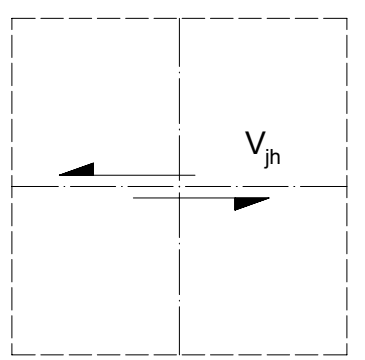

$$
\mathrm{V}_{\mathrm{jh}}=\mathrm{T}_{\mathrm{v}}-\mathrm{V}_{\mathrm{p}}
$$

Figura 7.22: Equilíbrio de forças para o cálculo da força cortante atuante no nó

A resultante de tração nas barras longitudinais da viga e a força cortante no pilar são, função da força atuante na extremidade da viga.

A tabela 7.11 contém os valores máximos das forças aplicadas na extremidade da viga durante os ensaios e as correspondentes forças cortantes atuantes nos nós. 
Tabela 7.11: Resistência ao cisalhamento horizontal das ligações: valores experimentais

\begin{tabular}{|c|c|c|c|}
\hline Modelo & $\mathbf{F ~ ( k N )}$ & $\mathbf{V}_{\mathbf{j h}}(\mathbf{k N})$ & Modo de ruína \\
\hline LVP1 & 136,6 & 539,5 & $(2)$ \\
\hline LVP2 & 131,1 & 514,1 & $(1)$ \\
\hline LVP3 & 90,0 & 364,4 & $(2)$ \\
\hline LVP4 & 80,7 & 327,2 & $(1)$ \\
\hline LVP5 & 93,9 & 380,4 & \\
\hline \multicolumn{4}{|l|}{} \\
$\begin{array}{l}\text { 1- esmagamento da biela com escoamento dos estribos (ciclo de maior solicitação do nó) } \\
\text { 2 - esmagamento da biela sem escoamento dos estribos (ciclo de maior solicitação do nó) }\end{array}$
\end{tabular}

Conforme já comentado, nos ensaios de todas as ligações, a ruína da ligação ocorreu por esmagamento da biela de compressão diagonal do nó de pórtico, sem que se tenha atingido a resistência máxima à flexão dos elementos viga e pilar.

As figuras de 7.23 à 7.27 contêm os gráficos de deformações nos estribos dos nós durante o ciclo em que se alcançou o maior valor da força cortante horizontal no ensaio. A tabela 7.12 contém os valores dessas deformações.

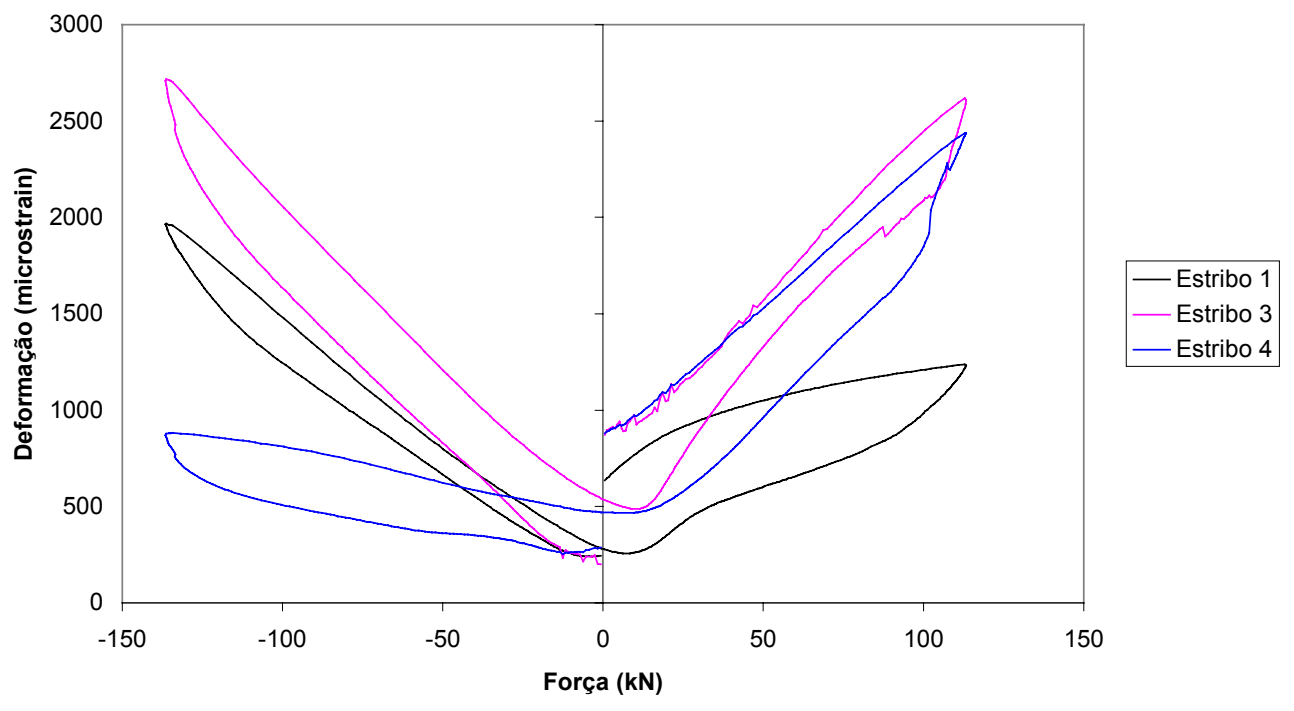

Figura 7.23: Deformação nos estribos do nó durante o ciclo de maior solicitação: Ligação LVP1 


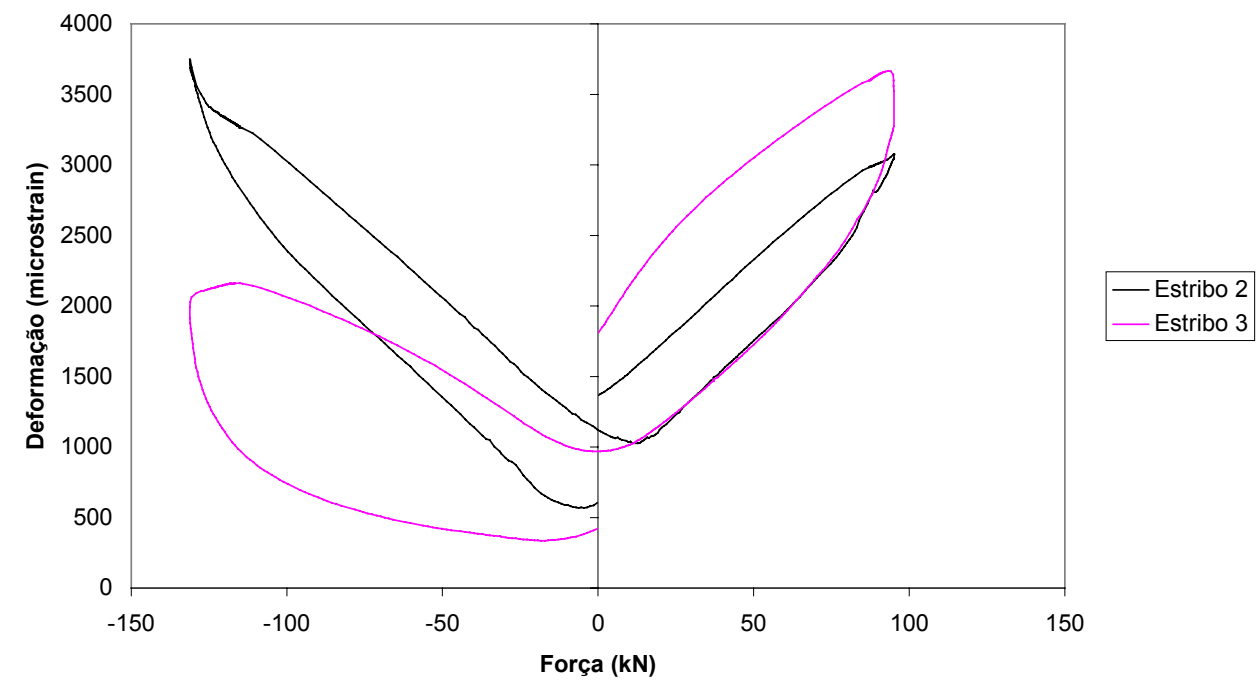

Figura 7.24: Deformação nos estribos do nó durante o ciclo de maior solicitação: Ligação LVP2

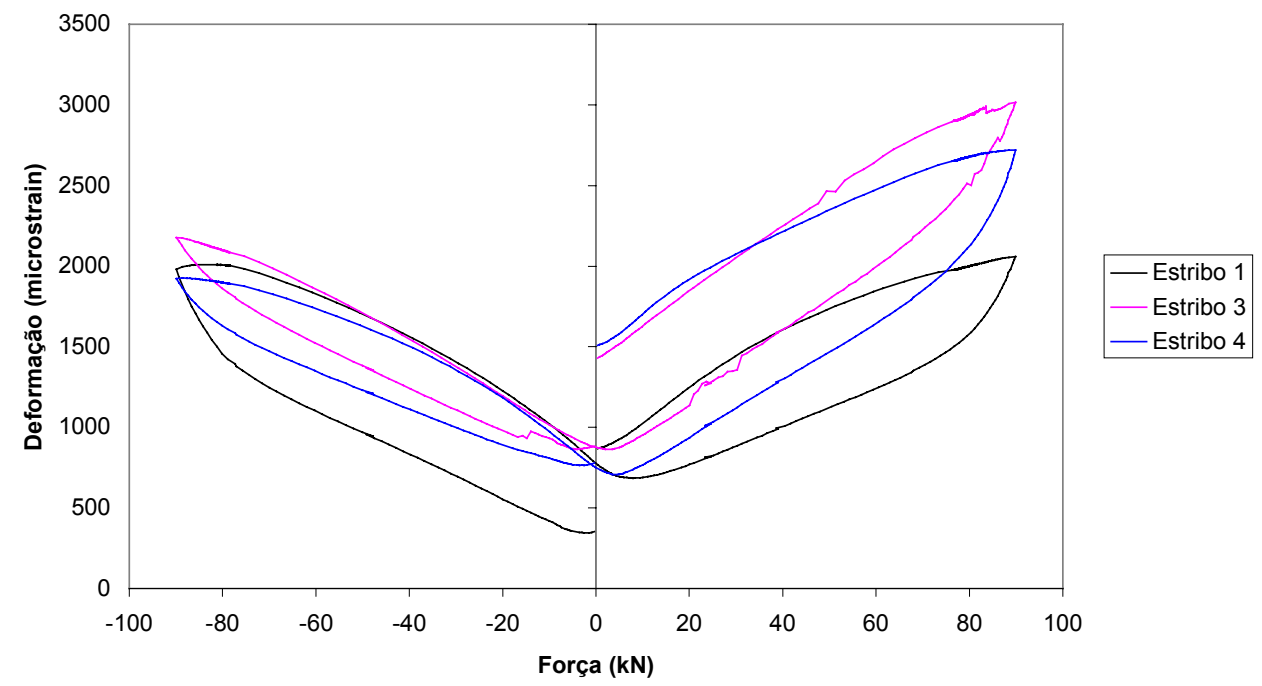

Figura 7.25: Deformação nos estribos do nó durante o ciclo de maior solicitação: Ligação LVP3

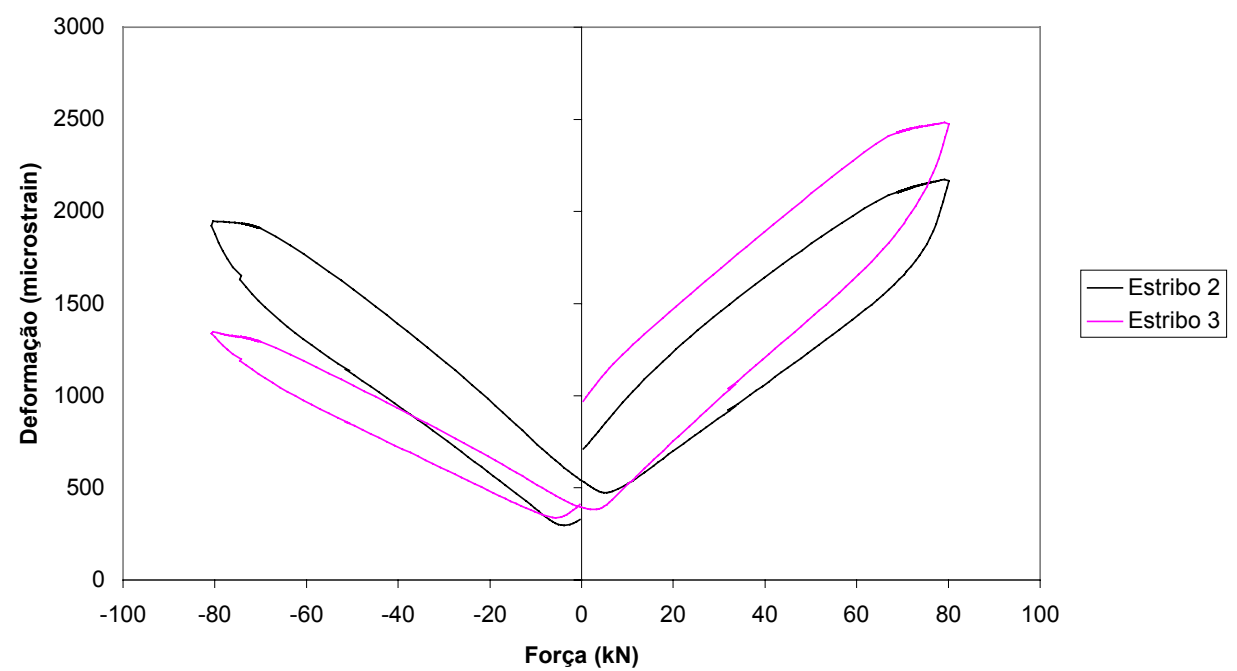

Figura 7.26: Deformação nos estribos do nó durante o ciclo de maior solicitação: Ligação LVP4 


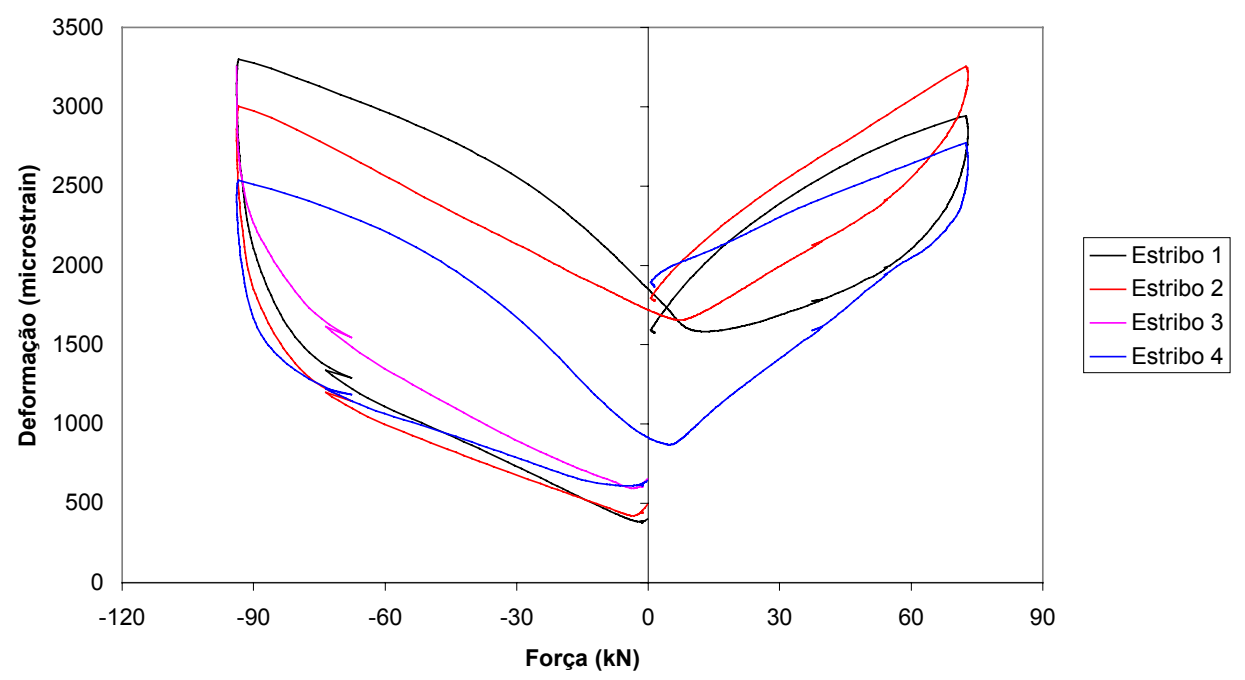

Figura 7.27: Deformação nos estribos do nó durante o ciclo de maior solicitação: Ligação LVP5

Tabela 7.12: Deformações nos estribos do nó ao longo da altura do mesmo

\begin{tabular}{|c|c|c|c|c|}
\hline Ligação & Estribo & $Y(\mathrm{~mm})$ & Deformação $(\mu \varepsilon)$ & $\varepsilon_{y}(\mu \varepsilon)$ \\
\hline \multirow[t]{4}{*}{ LVP1 } & 1 & +150 & 1965 & \multirow{4}{*}{2890} \\
\hline & 2 & +50 & perdido & \\
\hline & 3 & -50 & 2708 & \\
\hline & 4 & -150 & 870 & \\
\hline \multirow[t]{2}{*}{ LVP2 } & 2 & +75 & 3749 & \multirow[t]{2}{*}{2830} \\
\hline & 3 & -75 & 1922 & \\
\hline \multirow[t]{4}{*}{ LVP3 } & 1 & +120 & 1980 & \multirow{4}{*}{2830} \\
\hline & 2 & +40 & perdido & \\
\hline & 3 & -40 & 2180 & \\
\hline & 4 & -120 & 1922 & \\
\hline \multirow[t]{2}{*}{ LVP4 } & 2 & +75 & 1879 & \multirow[t]{2}{*}{2830} \\
\hline & 3 & -75 & 1318 & \\
\hline \multirow[t]{4}{*}{ LVP5 } & 1 & +120 & 3075 & \multirow[t]{4}{*}{2830} \\
\hline & 2 & +40 & 2784 & \\
\hline & 3 & -40 & 3253 & \\
\hline & 4 & -120 & 2399 & \\
\hline
\end{tabular}

Os valores das forças cortantes últimas dos nós de pórticos foram comparados com os valores das forças cortantes resistentes fornecidos pelo modelo de biela e tirante de HWANG \& LEE (1999), conforme a tabela 7.13. 
Tabela 7.13: Comparação entre resultados experimentais e os fornecidos pelo modelo de HWANG \& LEE (1999)

\begin{tabular}{|c|c|c|c|c|c|c|}
\hline \multirow{2}{*}{ Modelo } & \multicolumn{2}{|c|}{ Experimental } & \multicolumn{3}{c|}{ Hwang \& Lee (1999) } & \multirow{2}{*}{$\mathbf{V}_{\text {jh, Exp }} I$} \\
\cline { 2 - 5 } & $\mathrm{V}_{\mathrm{jh}}(\mathrm{kN})$ & Ruína & $\mathrm{V}_{\mathrm{jh}}(\mathrm{kN})_{(\mathrm{a})}$ & $\mathrm{V}_{\mathrm{jh}}(\mathrm{kN})_{(\mathrm{b})}$ & Caso & $\mathbf{V}_{\mathrm{jh}, \text { teórico (a) }}$ \\
\hline LVP1 & 539,5 & $(2)$ & 448,4 & 429,2 & $\mathrm{YH}$ & 1,20 \\
\hline LVP2 & 514,1 & $(1)$ & 441,8 & 431,2 & $\mathrm{YH}$ & 1,16 \\
\hline LVP3 & 364,4 & $(2)$ & 320,7 & 293,4 & $\mathrm{YH}$ & 1,14 \\
\hline LVP4 & 327,2 & $(2)$ & 302,2 & 278,6 & $\mathrm{YH}$ & 1,08 \\
\hline LVP5 & 380,4 & $(1)$ & 335,5 & 308,7 & $\mathrm{YH}$ & 1,13 \\
\hline $\begin{array}{l}\text { (a): Considerando a armadura intermediária do pilar } \\
\text { (b): Desconsiderando armadura intermediária do pilar }\end{array}$ & Média & $\mathbf{1 , 1 4}$ \\
\hline
\end{tabular}

Foram incluídas no cálculo da resistência ao cisalhamento as barras intermediárias do pilar, ou seja, as barras longitudinais mais próximas do centro da seção, tomando-se uma área efetiva de estribos verticais igual a 50 por cento da área das quatro barras intermediárias do pilar.

Do ponto de vista de previsão da força cortante resistente, a comparação indicada na tabela 7.13 mostra que o modelo de biela e tirante conduz a resultados satisfatórios, comprovando a existência de uma boa correlação entre valores teóricos e experimentais, em especial quando se espera que o nó de pórtico seja a região menos resistente da ligação.

Entretanto, o modelo de HWANG \& LEE não previu exatamente a forma de ruína do nó de pórtico, durante o ciclo em que os nós alcançaram a máxima resistência. Segundo o modelo de cálculo, em todas as cinco ligações a ruína do nó ocorreria com o escoamento dos estribos horizontais (caso YH), fato que, experimentalmente, somente foi observado nas ligações LVP2 e LVP5. Nos ensaios das demais ligações, os estribos não atingiram a plastificação.

Deve-se ressaltar que o escoamento dos estribos horizontais pode ocorrer após o ciclo de maior solicitação do nó, em decorrência da progressiva deterioração mecânica do concreto ocasionada pelo carregamento cíclico reversível. Este fato pôde ser observado na etapa final de carregamento das ligações LVP1, LVP3 e LVP4. Deve-se lembrar também que o modelo de biela e tirante em questão não considera o acúmulo da danificação do concreto em função dos ciclos de carregamento.

Os resultados experimentais também foram comparados com os fornecidos por normas que tratam do dimensionamento de nós de pórtico sob solicitações cíclicas de origem sísmica, a saber: a norma americana do ACI 318 (1995), a norma neozelandesa NZS-3101 (1995) e a norma japonesa AIJ (1991) (tabela 7.14). 
Tabela 7.14: Resistência ao cisalhamento: valores experimentais e fornecidos por normas de cálculo

\begin{tabular}{|c|c|c|c|c|c|}
\hline \multirow[t]{2}{*}{ Modelo } & Experimental & $\begin{array}{c}\text { Hwang\&Lee } \\
\text { (1999) }\end{array}$ & $\begin{array}{c}\mathrm{ACl}-318 \\
(1995)\end{array}$ & $\begin{array}{c}\text { NZS-3101 } \\
(1995)\end{array}$ & $\begin{array}{c}\text { AlJ } \\
(1991)\end{array}$ \\
\hline & $(\mathrm{kN})$ & $(\mathrm{kN})$ & $(\mathrm{kN})$ & $(\mathrm{kN})$ & $(\mathrm{kN})$ \\
\hline LVP1 & 539,5 & 448,4 & 380,0 & 485,16 & 436,6 \\
\hline LVP2 & 514,1 & 441,8 & 397,2 & 530,16 & 477,1 \\
\hline LVP3 & 364,4 & 320,7 & 292,1 & 286,68 & 258,0 \\
\hline LVP4 & 327,2 & 302,2 & 296,5 & 295,44 & 265,9 \\
\hline LVP5 & 380,4 & 335,5 & 304,2 & 310,92 & 279,8 \\
\hline \multicolumn{6}{|c|}{$\begin{array}{l}\text { ACI } 318 \text { (1995): } \quad V_{j}=0,083 \times \gamma \times \sqrt{f_{c}} \times A_{j} \quad \text { com } \gamma=12 \text { e } f_{c} \text { em MPa } \\
\text { NZS } 3101 \text { (1995) e AlJ (1991): } \quad V_{j}=k \times f_{c} \times A_{j} \quad \text { com } k=0,2(N Z S-3101) \text { e } k=0,18 \text { (AIJ) }\end{array}$} \\
\hline
\end{tabular}

De forma geral, os valores da força cortante resistente calculados com as expressões das normas foram da ordem de 15 à 25 por cento menores que os valores experimentais. $\mathrm{A}$ expressão fornecida pela norma americana conduziu a resultados mais conservadores para as duas ligações de maior resistência à compressão do concreto. Neste caso, as normas neozelandesa e a norma japonesa forneceram valores mais próximos dos experimentais. Tal diferença poderia ser identificada construindo-se o gráfico da tensão nominal resistente (força cortante $V_{j}$ dividida pela área efetiva $A_{j}$ ) em função da resistência à compressão do concreto, indicado na figura 7.28 .

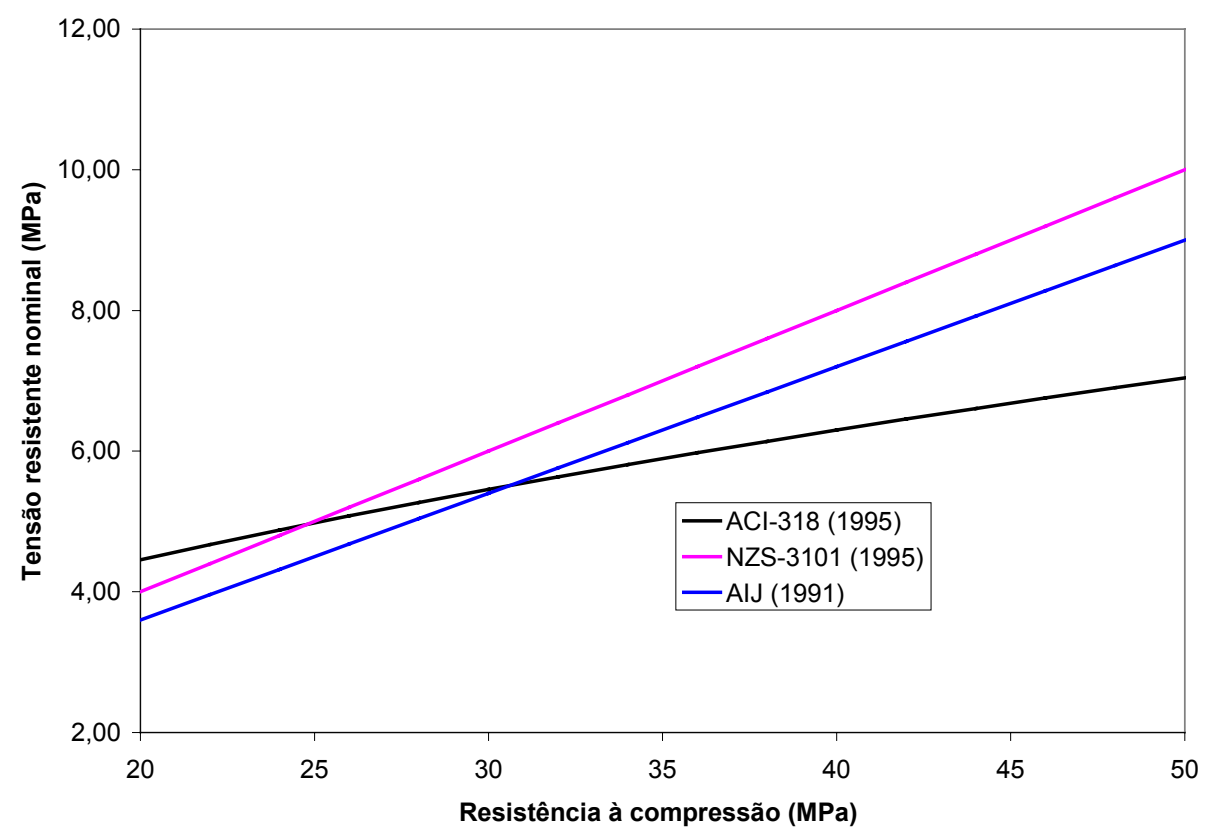

Figura 7.28: Resistência ao cisalhamento do nó segundo algumas normas de dimensionamento

Por sua vez, os valores fornecidos pelo modelo de biela e tirante de HWANG \& LEE (1999) foram ligeiramente melhores que os valores fornecidos pelas normas de cálculo. Entretanto, assim como observado na norma americana, aproximação com os resultados experimentais foi menor para as duas ligações (LVP1 e LVP2) de maior $f_{c}$. 
Com relação à solicitação dos estribos ao longo da altura do nó de pórtico, nota-se que os três estribos mais próximos da armadura tracionada da viga são os que mais participam da resistência à força cortante, tendo o estribo mais afastado uma participação menor. Este comportamento pode ser deduzido a partir da análise dos gráficos das figuras $7.23,7.25 \mathrm{e}$ 7.27, para as ligações que possuíram quatro estribos no nó (LVP1, LVP3 e LVP5). Vale frisar que, apesar disso, a tendência é de uniformização das deformações nos estribos ao longo da altura do nó, com o decorrer dos ciclos de carga.

A preocupação com a participação desigual dos estribos ao longo da altura do mesmo justifica-se pela necessidade de estipular uma área efetiva de estribos, informação que deve ser fornecida ao modelo de biela e tirante para a determinação da força cortante resistente. Assim, em virtude da participação desigual dos estribos frente ao cisalhamento, é usual assumir efetivas as áreas dos estribos mais próximos do centro do nó de pórtico e assumir como efetivas apenas 50 por cento das áreas dos estribos mais afastados do centro. Esse critério é sugerido pelos autores do modelo, sendo também adotado neste trabalho. Nas condições de projeto, acredita-se que tal critério seja coerente e razoável, podendo também ser adotado para o cálculo da área efetiva dos estribos verticais (barras intermediárias do pilar). Entretanto, com a maior uniformização das deformações ao longo dos ciclos, talvez a consideração de 60 à 70 por cento de área efetiva para os estribos mais afastados seja também razoável.

A participação dos estribos verticais conduziu a um acréscimo de cerca de $7 \%$ na resistência ao cisalhamento. No entanto, esta participação modesta se deve ao ângulo de inclinação da biela diagonal (em torno de 55 graus) das ligações ensaiadas no programa experimental. Em ligações com ângulos de biela menores, a participação dos estribos verticais é maior, fato que pode ser percebido pelo gráfico da figura 7.29 , construído a partir de equações contidas na formulação do modelo.

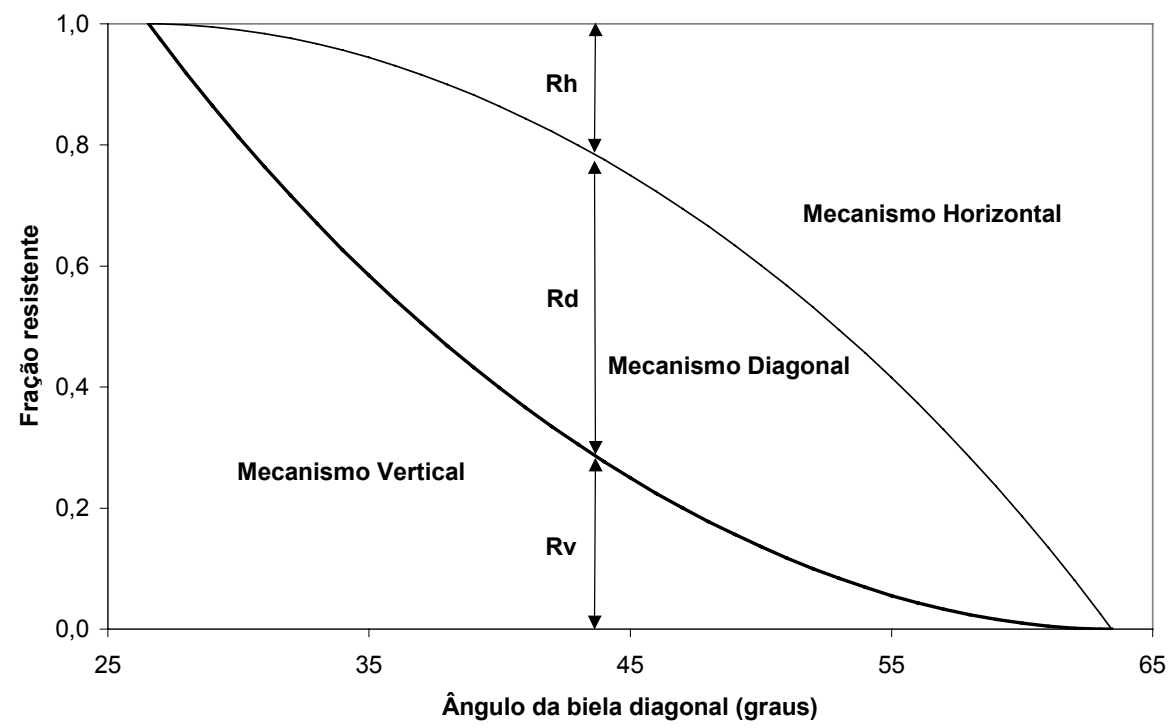

Figura 7.29: Distribuição da força cortante horizontal entre os três mecanismos 


\subsection{ANÁLISE GLOBAL}

\subsubsection{Emprego de modelos simplificados de dano e plasticidade}

Neste item, o comportamento experimental (global) da ligação viga-pilar é confrontado com os resultados fornecidos por modelos simplificados baseados na Mecânica do Dano e da Teoria da Plasticidade.

Propuseram-se algumas modificações na formulação original desses modelos, a fim de aprimorar a resposta numérica frente à resposta experimental.

A fim de levar as diferentes características estruturais entre viga e pilar, foi proposto a introdução de um novo parâmetro adimensional $\gamma$ na função que controla a evolução do dano. Com base em resultados do tipo força-deslocamento de ensaios encontrados na bibliografia especializada, conseguiu-se adquirir uma noção razoável dos valores possíveis para $\gamma$ da viga, conforme mostrado no capítulo 5. Para o pilar, ainda não se havia encontrado a ordem de grandeza desse parâmetro.

Por sua vez, a etapa experimental permitiu uma avaliação mais precisa do parâmetro $\gamma$, tanto para a viga quanto para o pilar.

Os parâmetros de entrada do modelo simplificado, determinados a partir dos resultados experimentais, estão indicados na tabela 7.15. Tais parâmetros são: momento de fissuração $M_{c r}$, momento de plastificação $M_{p}$, momento último $M_{u}$ e rotação plástica última $\phi_{p u}$, relativos aos elementos viga e pilar.

Tabela 7.15: Parâmetros de entrada do modelo simplificado de dano e plasticidade

\begin{tabular}{|c|c|c|c|c|c|c|c|c|}
\hline \multirow{2}{*}{ Ligação } & \multicolumn{4}{|c|}{ VIGA } & \multicolumn{4}{c|}{ PILAR } \\
\cline { 2 - 9 } & $\begin{array}{c}\mathbf{M}_{\mathbf{c r}} \\
(\mathrm{kN} . \mathrm{m})\end{array}$ & $\begin{array}{c}\mathbf{M}_{\mathbf{p}} \\
(\mathrm{kN} \cdot \mathrm{m})\end{array}$ & $\begin{array}{c}\mathbf{M}_{\mathbf{u}} \\
(\mathrm{kN} \cdot \mathrm{m})\end{array}$ & $\begin{array}{c}\phi_{\text {pu }} \\
(\mathrm{rad})\end{array}$ & $\begin{array}{c}\mathbf{M}_{\mathbf{c r}} \\
(\mathrm{kN} \cdot \mathrm{m})\end{array}$ & $\begin{array}{c}\mathbf{M}_{\mathbf{p}} \\
(\mathrm{kN} \cdot \mathrm{m})\end{array}$ & $\begin{array}{c}\mathbf{M}_{\mathbf{u}} \\
(\mathrm{kN} \cdot \mathrm{m})\end{array}$ & $\begin{array}{c}\phi_{\text {pu }} \\
(\mathrm{rad})\end{array}$ \\
\hline LVP1 & 20 & 169 & 212 & 0,012 & 29 & 155 & 164 & 0,003 \\
\hline LVP2 & 22 & 163 & 205 & 0,012 & 31 & 151 & 158 & 0,005 \\
\hline LVP3 & 13 & 155 & 186 & 0,011 & 19 & 131 & 145 & 0,004 \\
\hline LVP4 & 14 & 155 & 186 & 0,011 & 20 & 132 & 145 & 0,004 \\
\hline LVP5 & 15 & 155 & 186 & 0,011 & 20 & 132 & 145 & 0,004 \\
\hline
\end{tabular}

Os valores experimentais do dano nas extremidades da viga e do pilar foram obtidos a partir dos gráficos momento-rotação de cada elemento, por meio da relação entre a inclinação da curva no descarregamento e da inclinação da curva antes da fissuração (figura 7.30). 


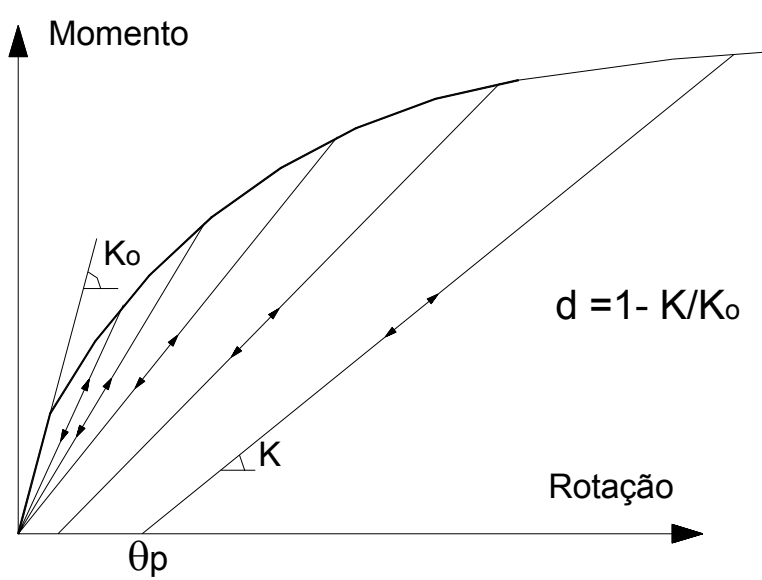

Figura 7.30: Determinação dos valores experimentais da variável de dano para viga e pilar

O valor de $\gamma$ que melhor se ajustou aos resultados experimentais, no que diz respeito à evolução do dano, foi determinado a partir das curvas momento termodinâmico versus dano, tanto para a viga quanto para o pilar, conforme as figuras 7.31 à 7.37 .

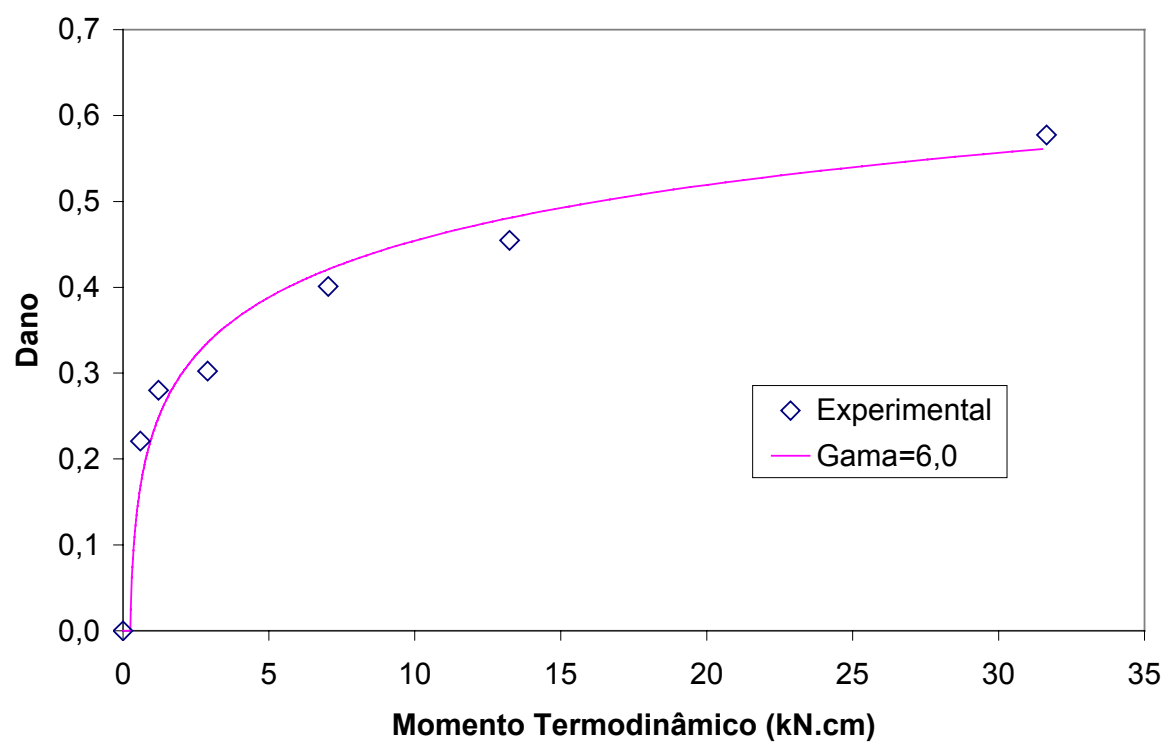

Figura 7.31: Evolução do dano na viga: Ligação LVP1 


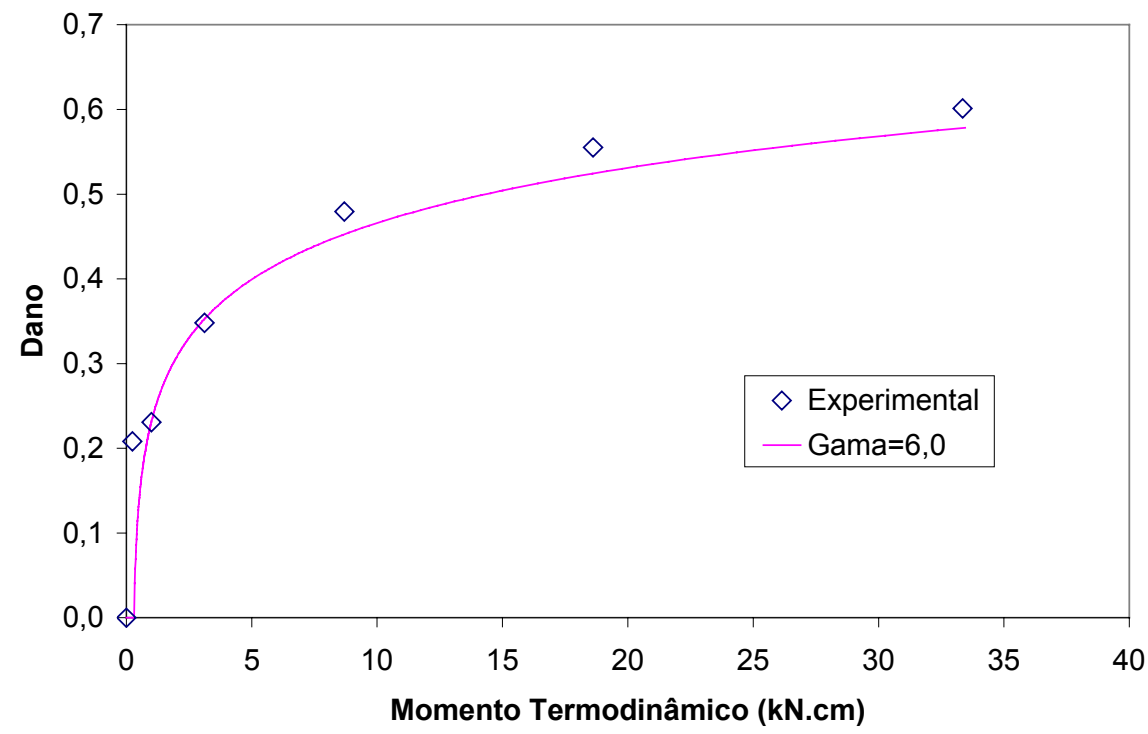

Figura 7.32: Evolução do dano na viga: Ligação LVP2

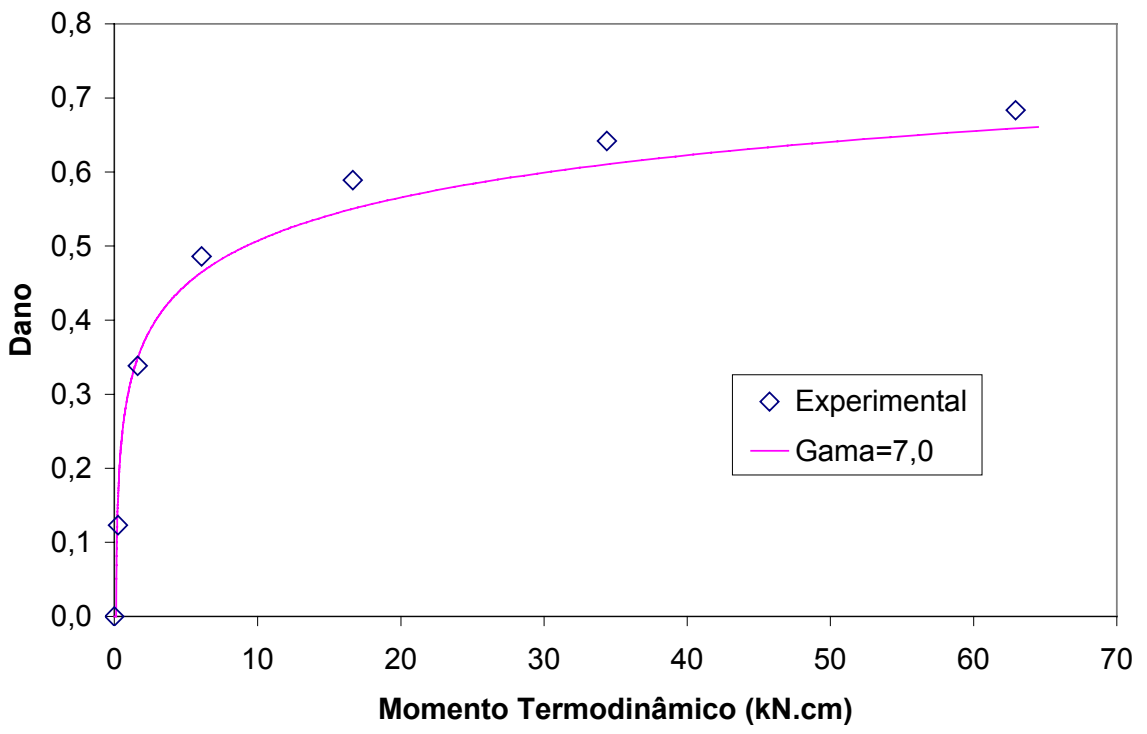

Figura 7.33: Evolução do dano na viga: Ligação LVP3 


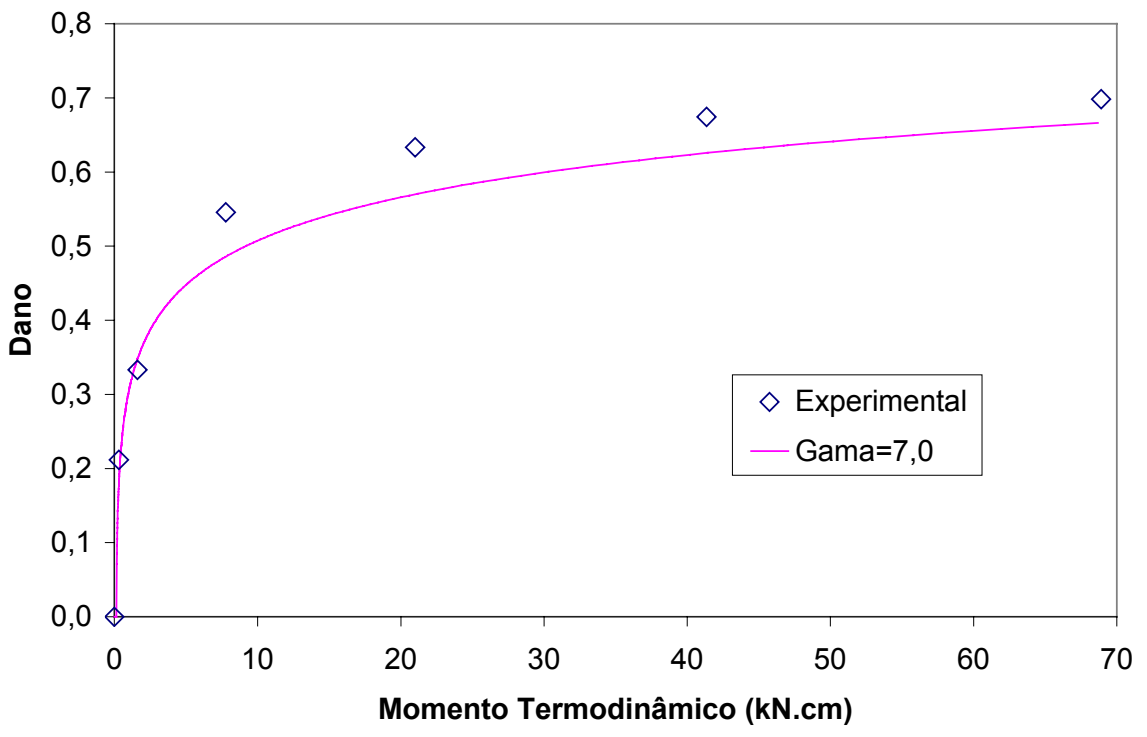

Figura 7.34: Evolução do dano na viga: Ligação LVP4

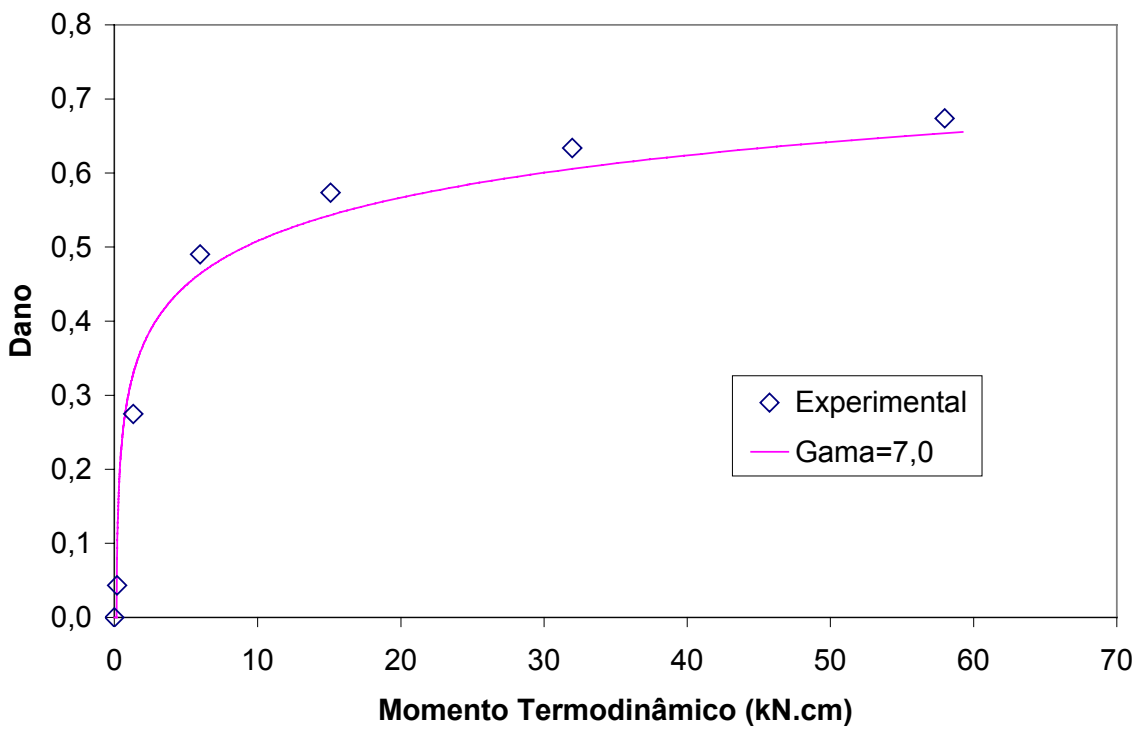

Figura 7.35: Evolução do dano na viga: Ligação LVP5 


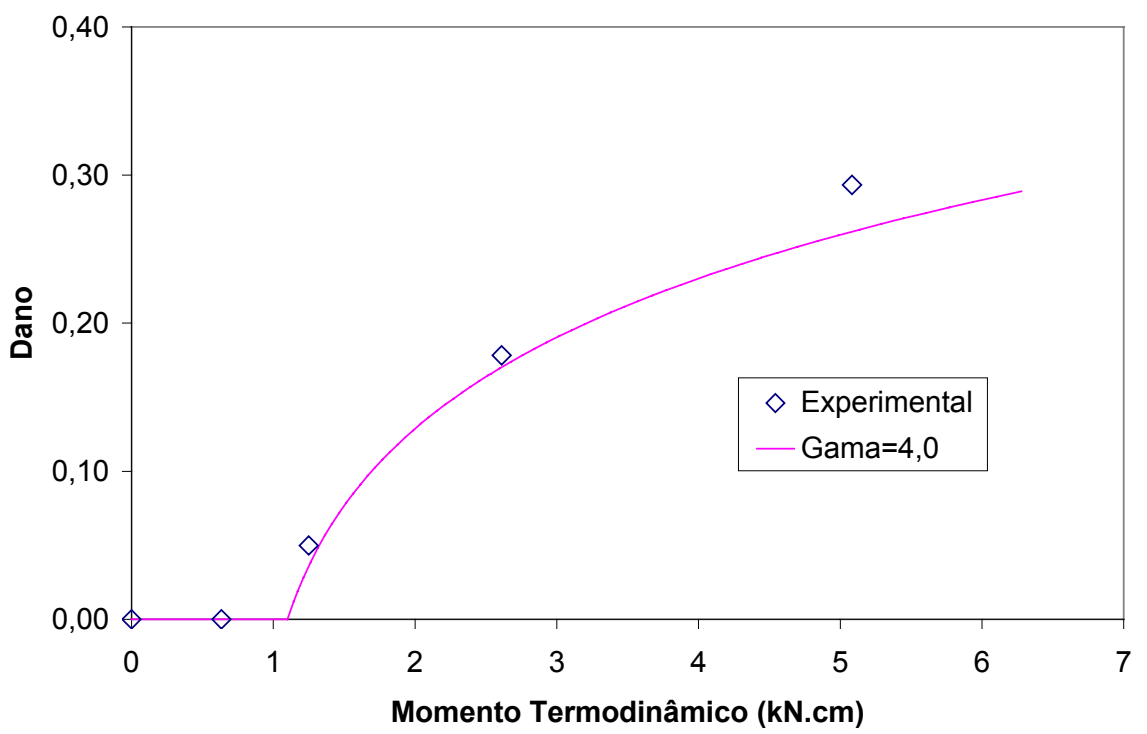

Figura 7.36: Evolução do dano no pilar: Ligação LVP2

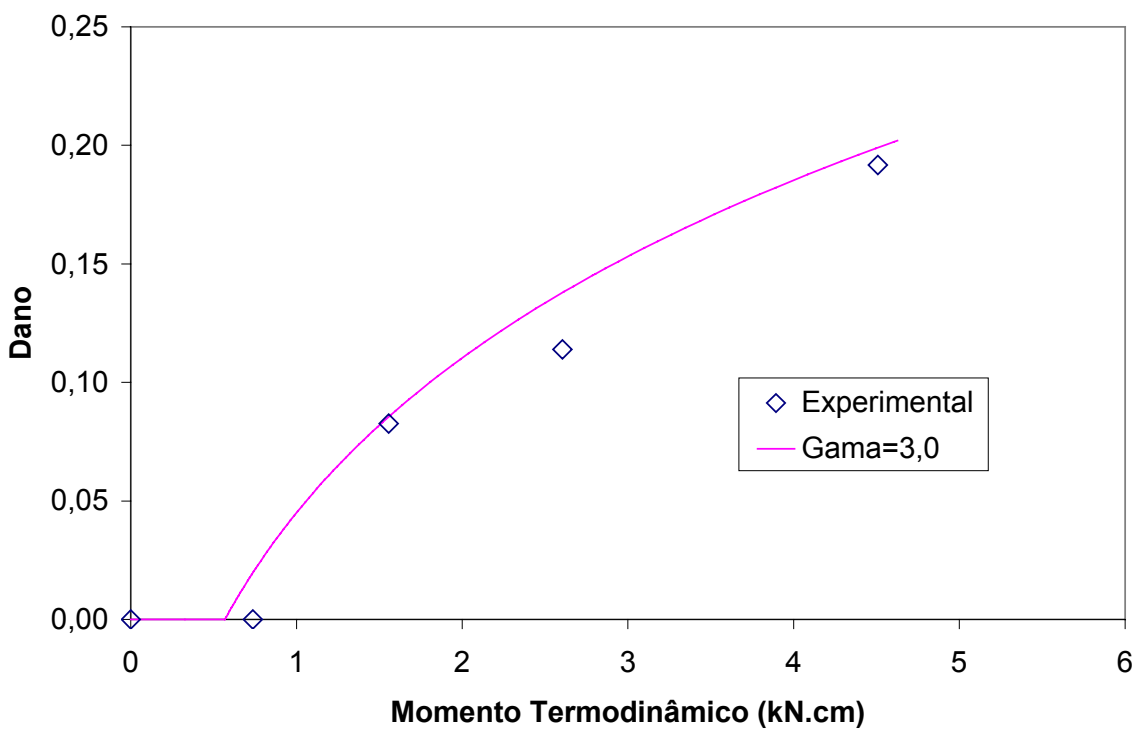

Figura 7.37: Evolução do dano no pilar: Ligação LVP5

Com base nos resultados indicados nas figuras 7.18 à 7.24 , os seguintes pontos podem ser destacados:

- Para as ligações LVP1 e LVP2, o parâmetro $\gamma$ das vigas assumiu um valor próximo de 6,0. Para as ligações LVP3 à LVP5, o parâmetro $\gamma$ das vigas assumiu um valor próximo de 7,0. Esta diferença pode indicar que a resistência à compressão do concreto influencia o valor de $\gamma$ das vigas, uma vez que as duas primeiras ligações apresentaram concretos cerca de $60 \%$ mais resistentes que as demais ligações.

- Nas ligações LVP1, LVP3 e LVP5, as quais continham quatro estribos no nó de pórtico, o parâmetro $\gamma$ dos pilares assumiu um valor próximo de 3,0. Para as ligações LVP2 e LVP4, com dois estribos no nó, o parâmetro $\gamma$ dos pilares assumiu valores próximos de 4,0. A maior deterioração mecânica da região nodal nas ligações com menos estribos 
no nó pode explicar os maiores valores de dano nas extremidades do pilar e, conseqüentemente, os maiores valores de $\gamma$.

Para o cálculo dos valores teóricos do dano com a introdução do parâmetro $\gamma$, utilizouse o modelo de dano proposto por FLORÉZ-LÓPEZ (1995), aplicável aos casos de carregamentos cíclicos sem levar em conta o efeito de fadiga de baixo ciclos. A não consideração na etapa 1 do acréscimo de dano por fadiga é justificável, uma vez que o carregamento aplicado nessa etapa consistiu na aplicação de cargas crescentes de um ciclo apenas.

\section{Etapa 1: Todas as ligações}

Conforme descrito no capítulo 6, todas as cinco ligações tiveram uma etapa em comum: a etapa inicial 1, na qual foram aplicados, na extremidade da viga, carregamentos alternados crescentes múltiplos de $10 \mathrm{kN}$, até se atingir a amplitude de $60 \mathrm{kN}$.

Nas figuras 7.38 à 7.47 são comparadas as curvas força-deslocamento experimentais com as teóricas fornecidas com o modelo de dano, no ponto de aplicação da carga na extremidade da viga.

A comparação de resultados indica que, de uma forma geral, o modelo simplificado de dano fornece resultados razoáveis e coerentes. A perda de rigidez é bem representada pelo modelo, fato que pode ser comprovado ao se analisar a tendência da curva forçadeslocamento durante o carregamento e a inclinação dessa curva durante o descarregamento. Entretanto, o modelo de dano somente captura as deformações residuais após o momento de plastificação. $\mathrm{Na}$ realidade, observa-se experimentalmente o surgimento de deformações (deslocamentos) residuais para intensidades de tensões relativamente baixas, muito antes da plastificação. 


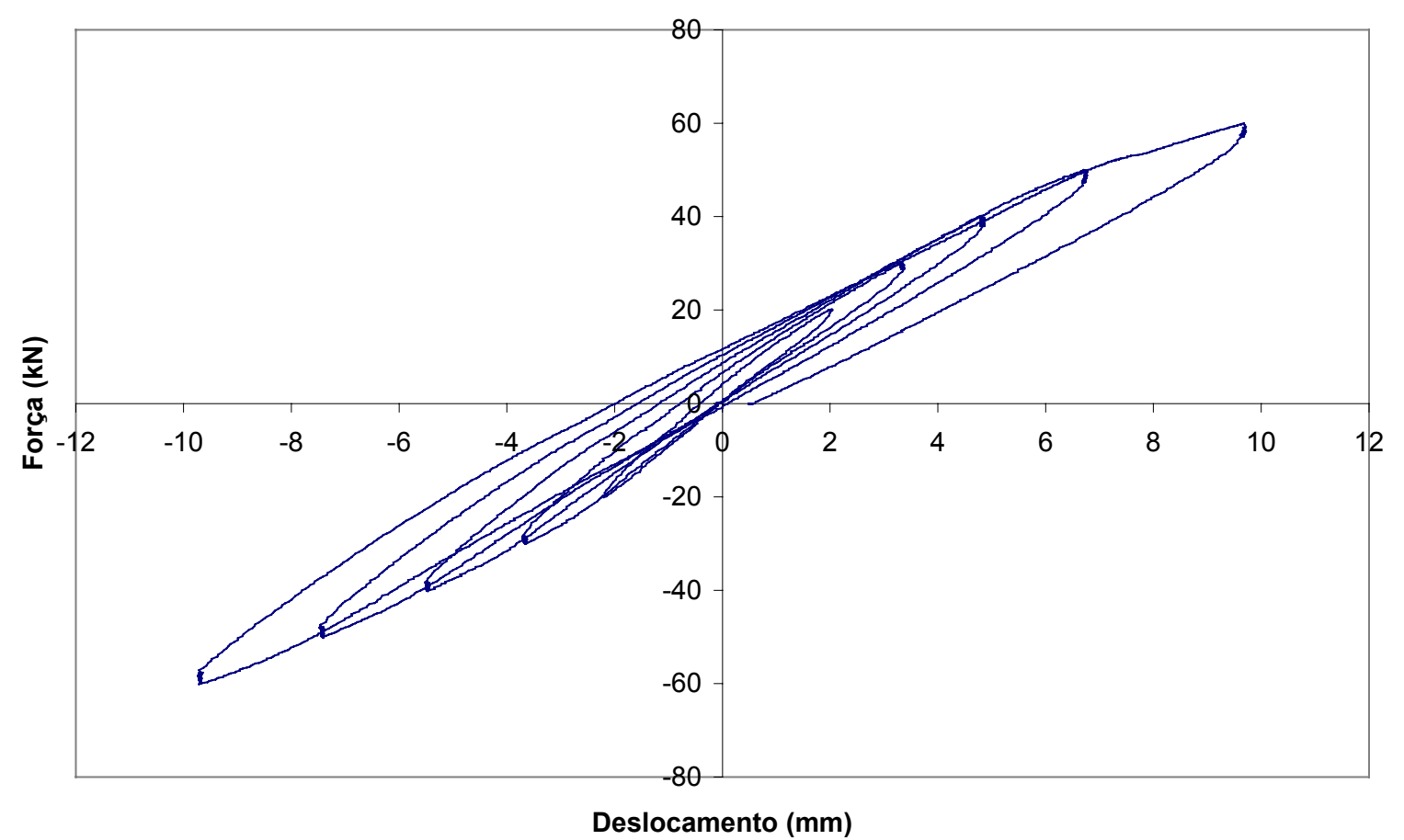

Figura 7.38: Curva força-deslocamento experimental na extremidade da viga: Ligação LVP1

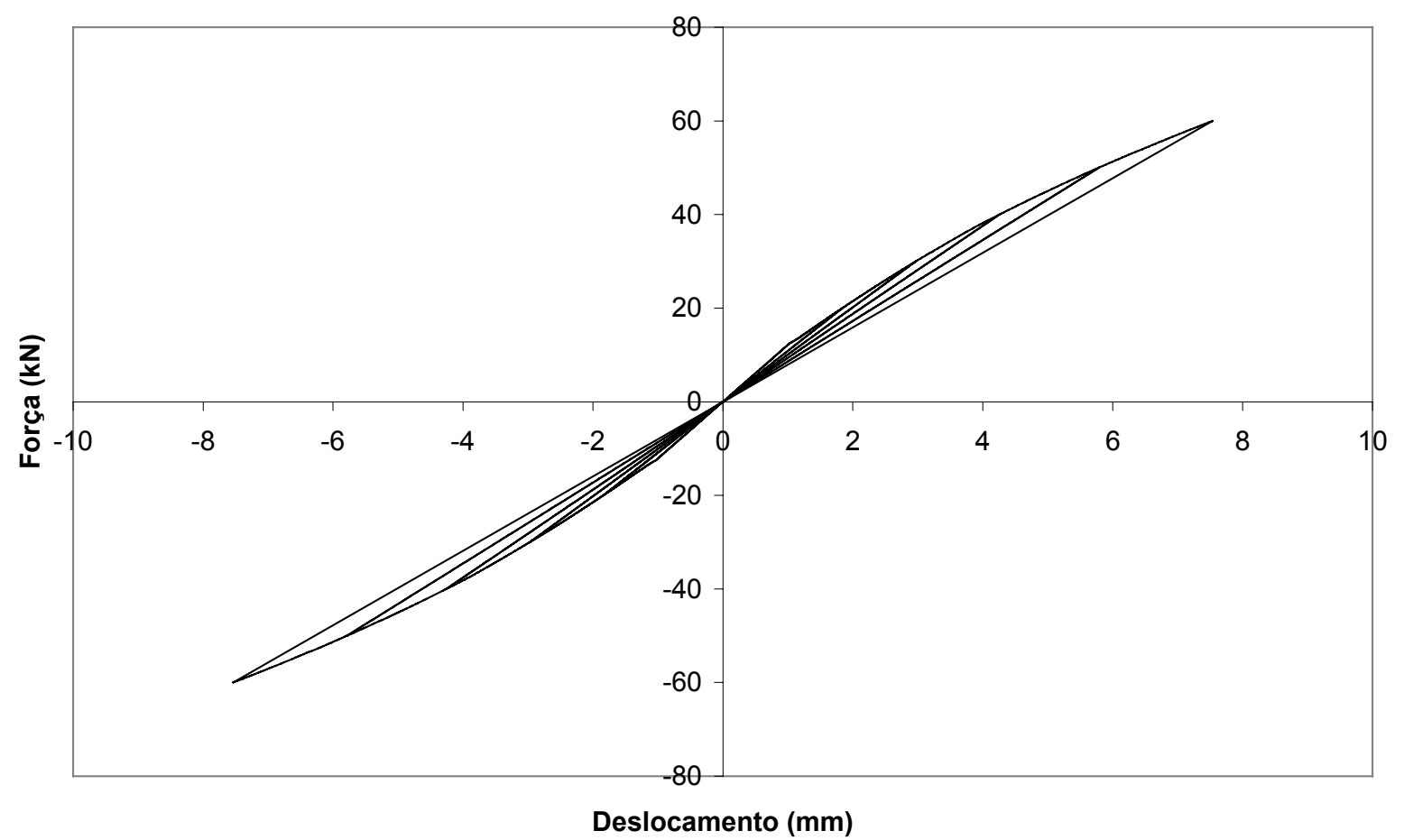

Figura 7.39: Curva força-deslocamento fornecida pelo modelo de dano: Ligação LVP1 


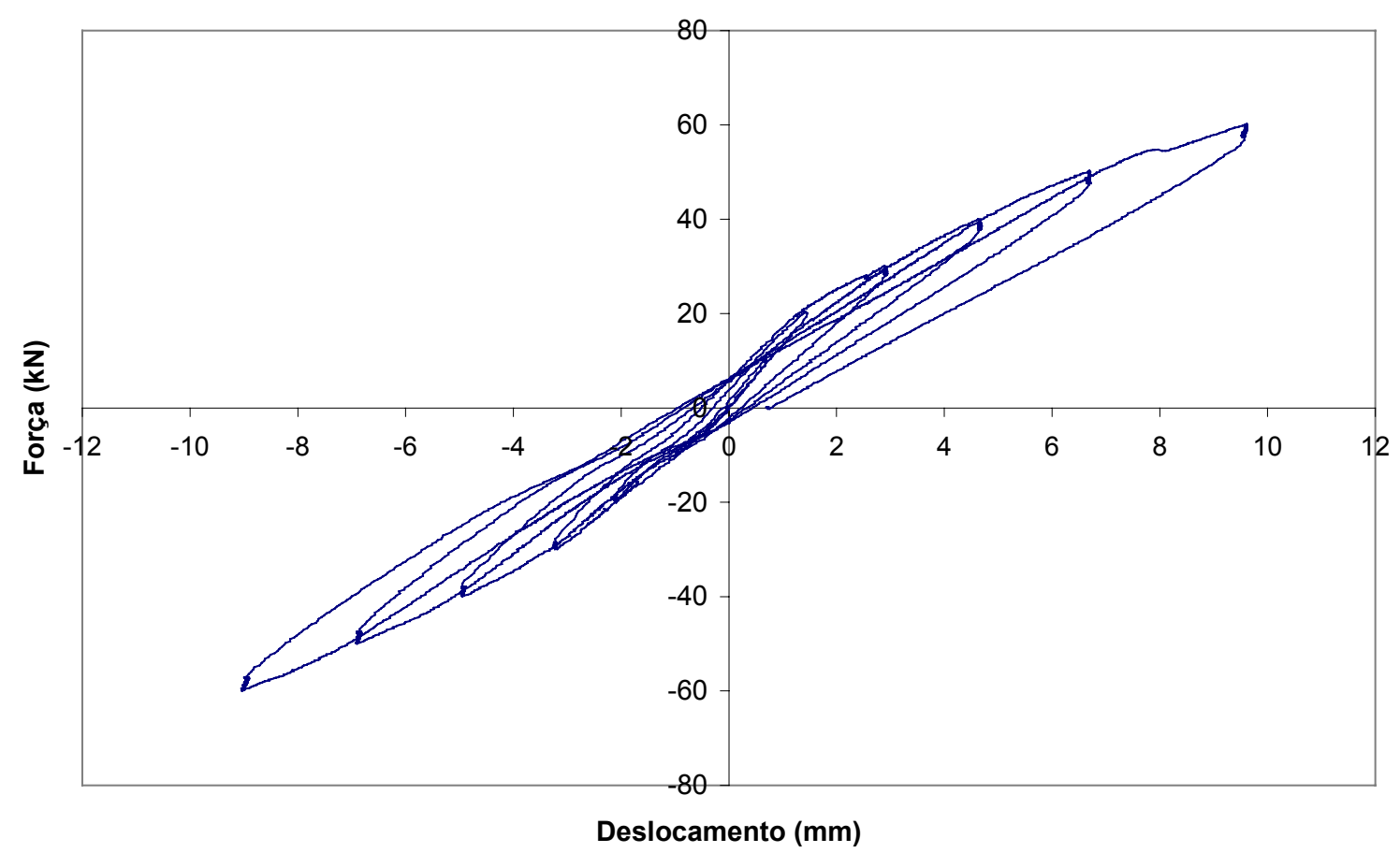

Figura 7.40: Curva força-deslocamento experimental na extremidade da viga: Ligação LVP2

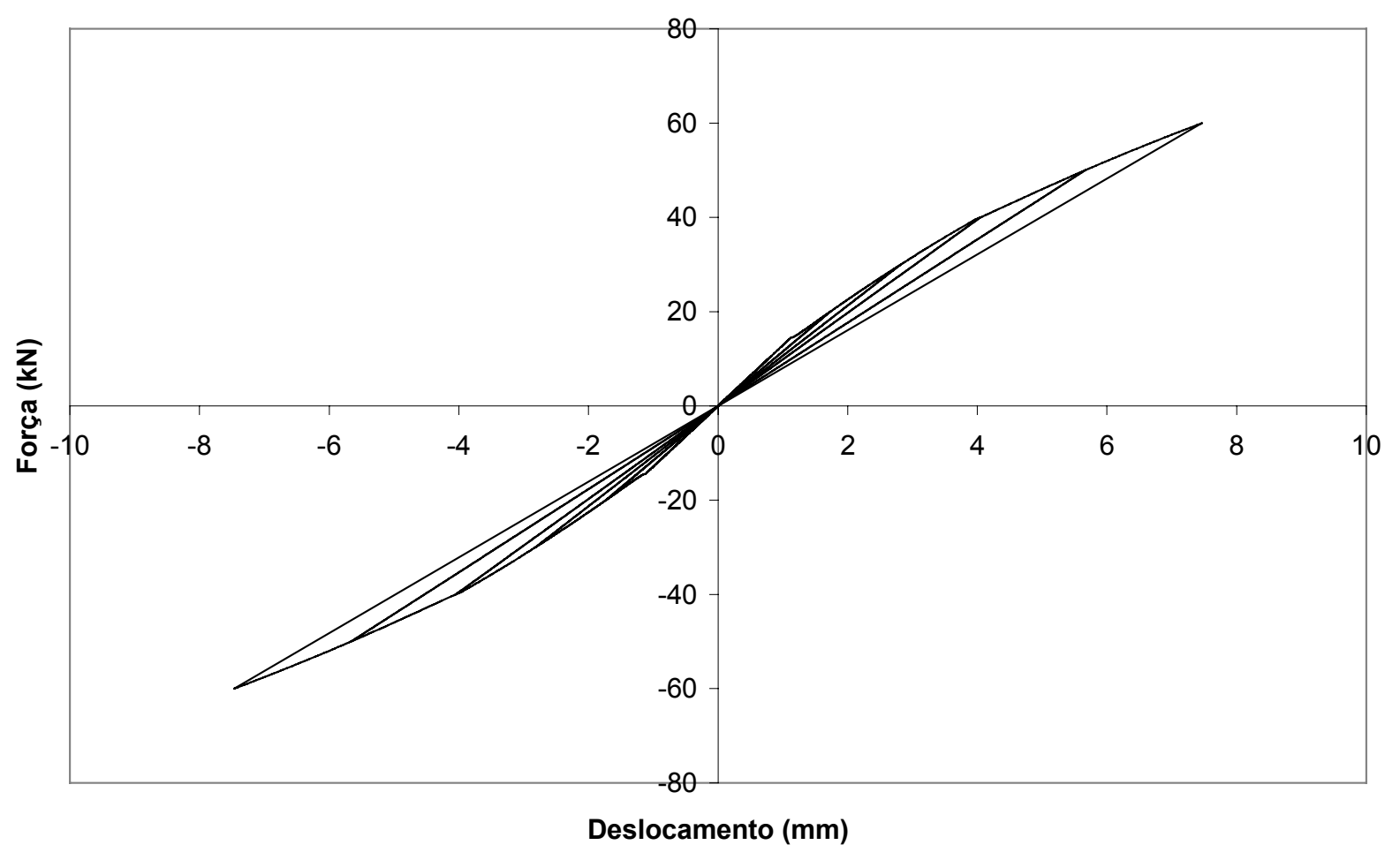

Figura 7.41: Curva força-deslocamento fornecida pelo modelo de dano: Ligação LVP2 


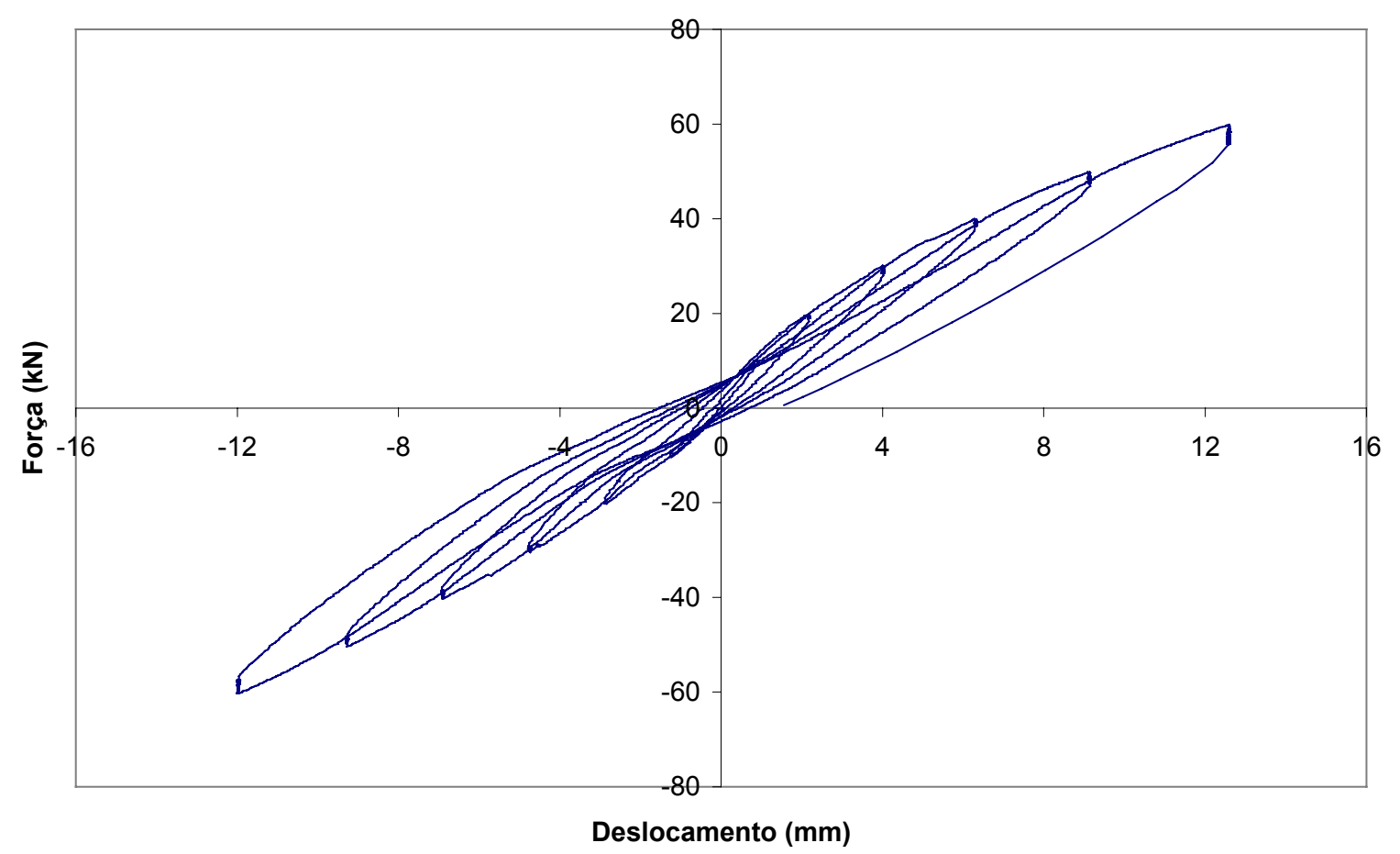

Figura 7.42: Curva força-deslocamento experimental na extremidade da viga: Ligação LVP3

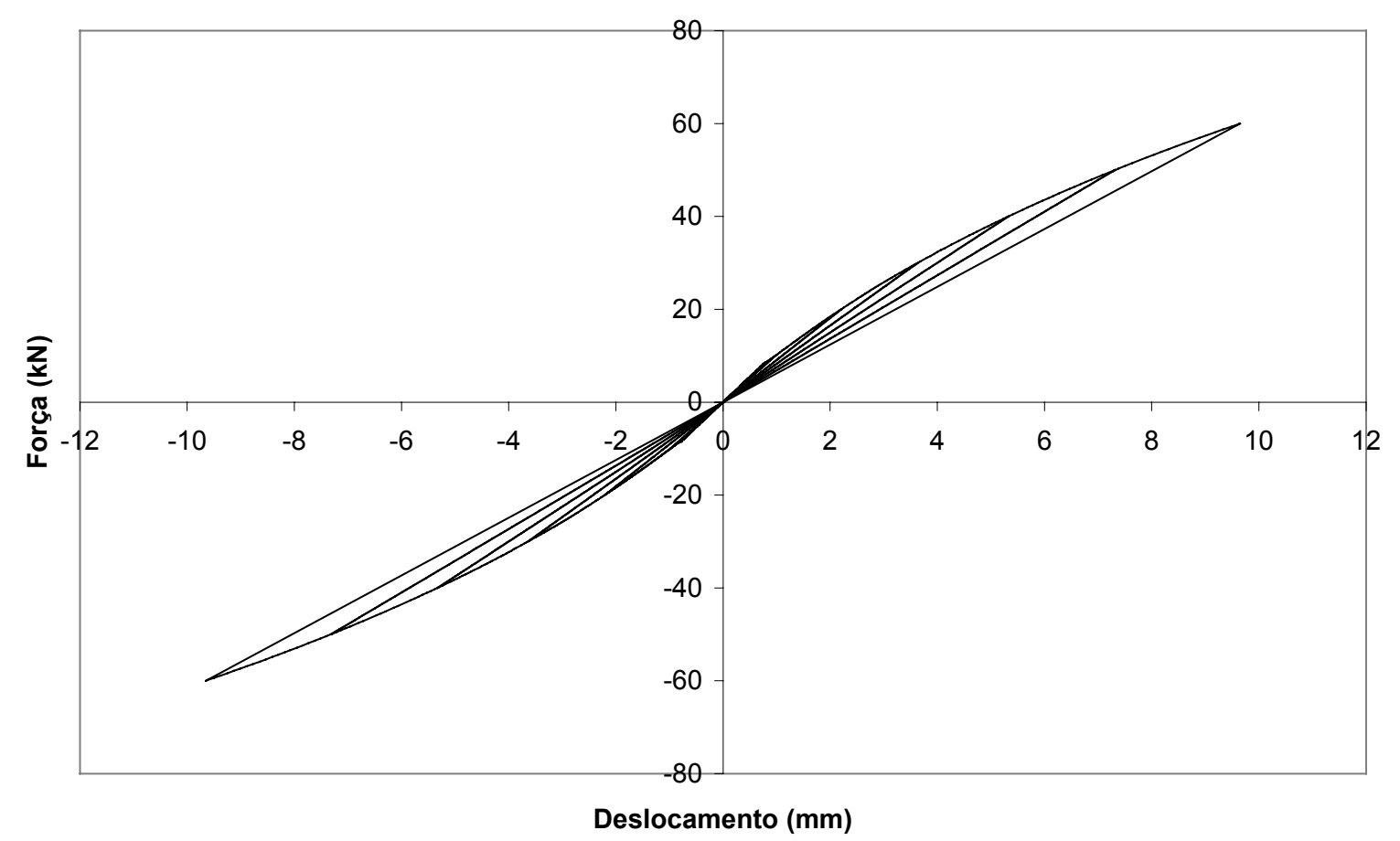

Figura 7.43: Curva força-deslocamento fornecida pelo modelo de dano: Ligação LVP3 


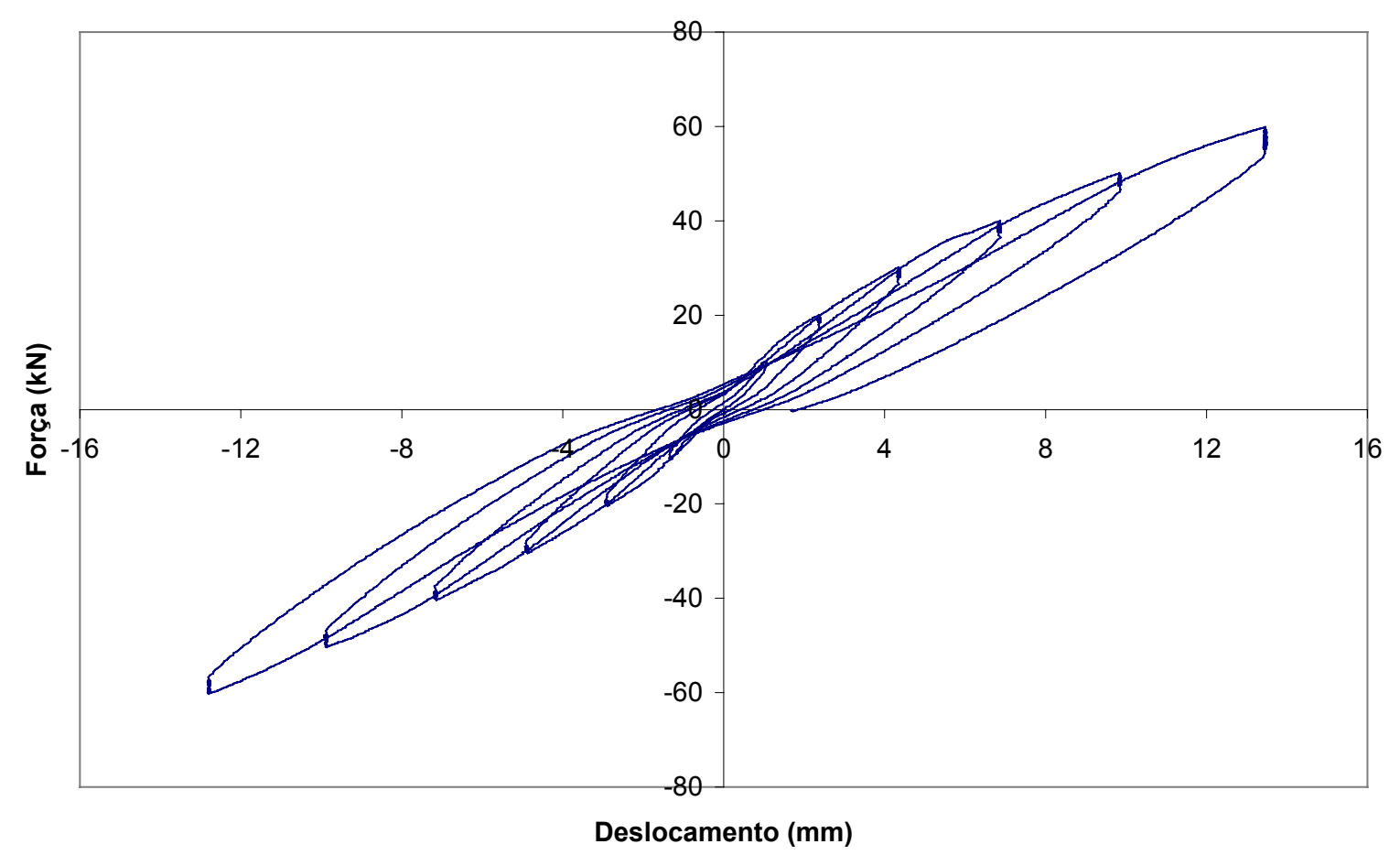

Figura 7.44: Curva força-deslocamento experimental na extremidade da viga: Ligação LVP4

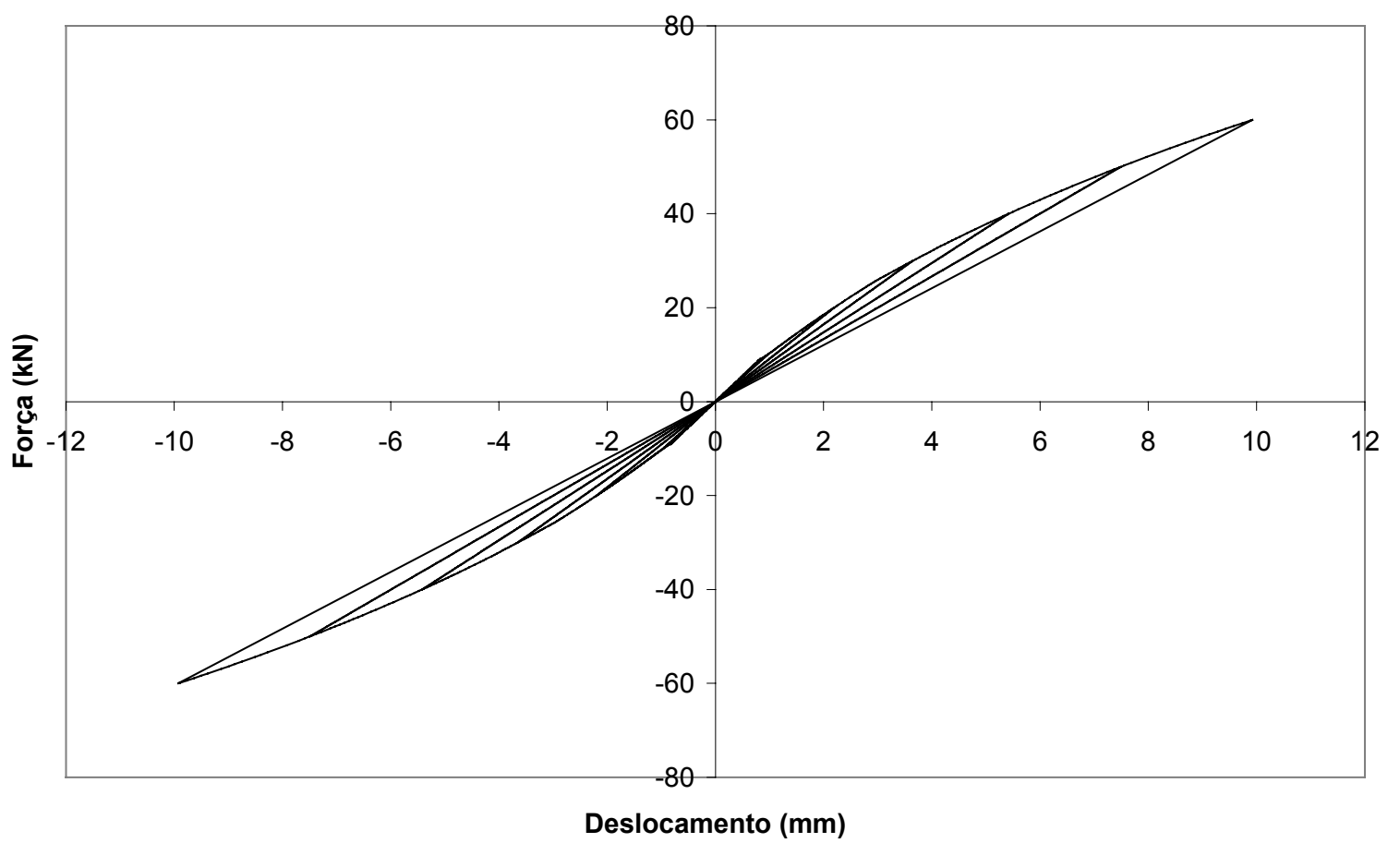

Figura 7.45: Curva força-deslocamento fornecida pelo modelo de dano: Ligação LVP4 


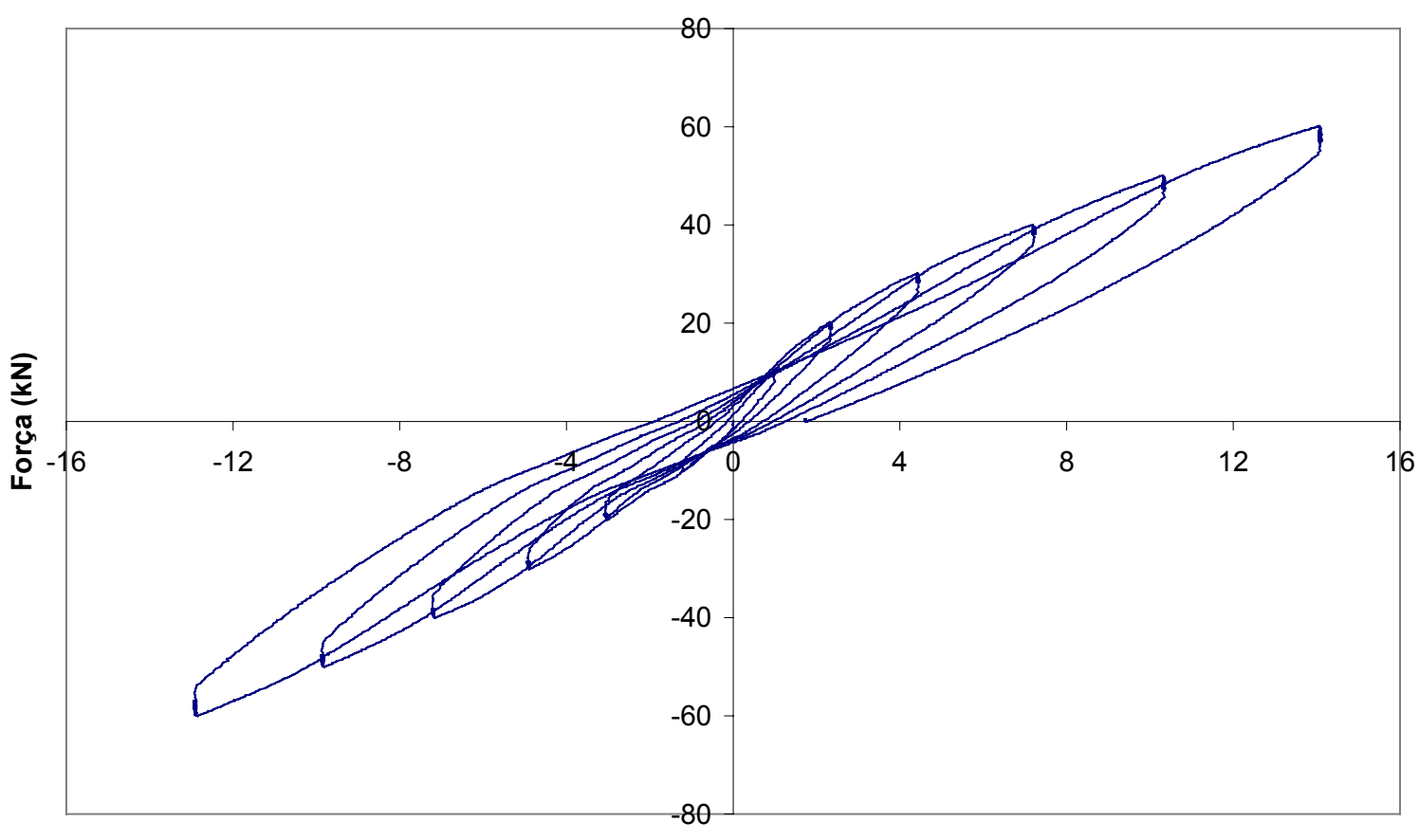

Deslocamento $(\mathrm{mm})$

Figura 7.46: Curva força-deslocamento experimental na extremidade da viga: Ligação LVP5

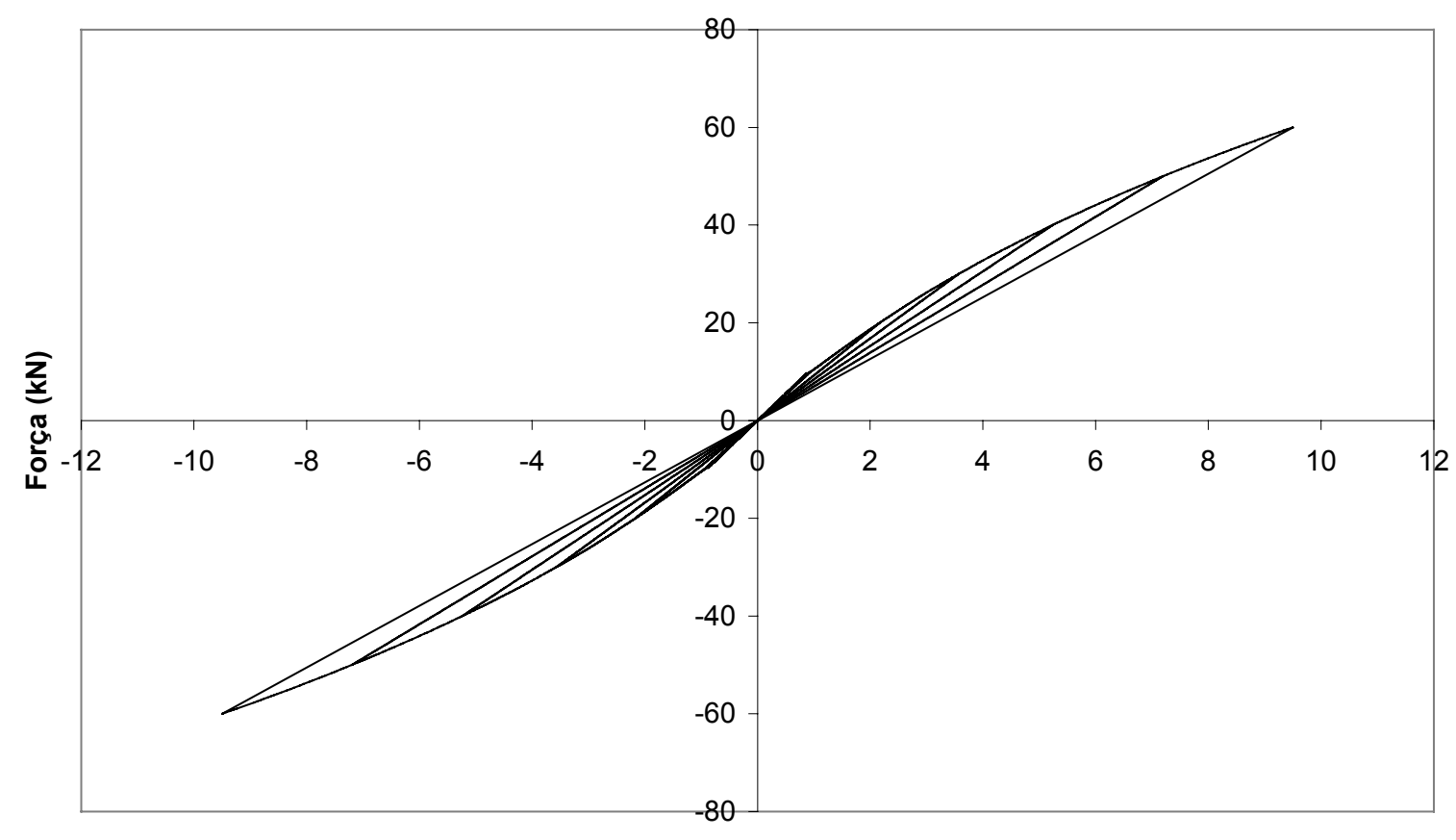

Deslocamento ( $\mathrm{mm}$ )

Figura 7.47: Curva força-deslocamento fornecida pelo modelo de dano: Ligação LVP5 


\section{LIGAÇÃO LVP1}

\section{Etapa 2:}

Na ligação LVP1, a etapa 2 consistiu na aplicação de 20 ciclos de carregamento alternado com amplitude de força constante e igual a $60 \mathrm{kN}$. As figuras 7.48 e 7.49 mostram a variação dos deslocamentos em função dos ciclos aplicados, tanto para o sentido negativo quanto para o sentido positivo das forças no atuador.

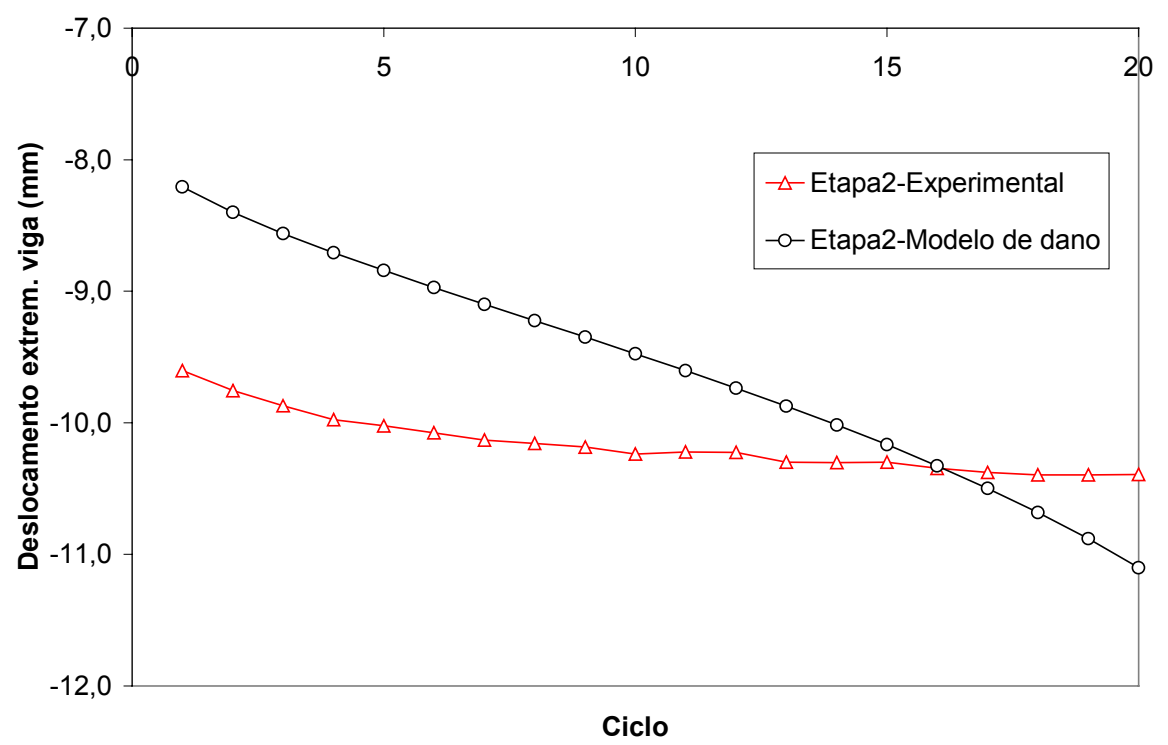

Figura 7.48: Deslocamentos na extremidade da viga em LVP1: Etapa2-Ações negativas

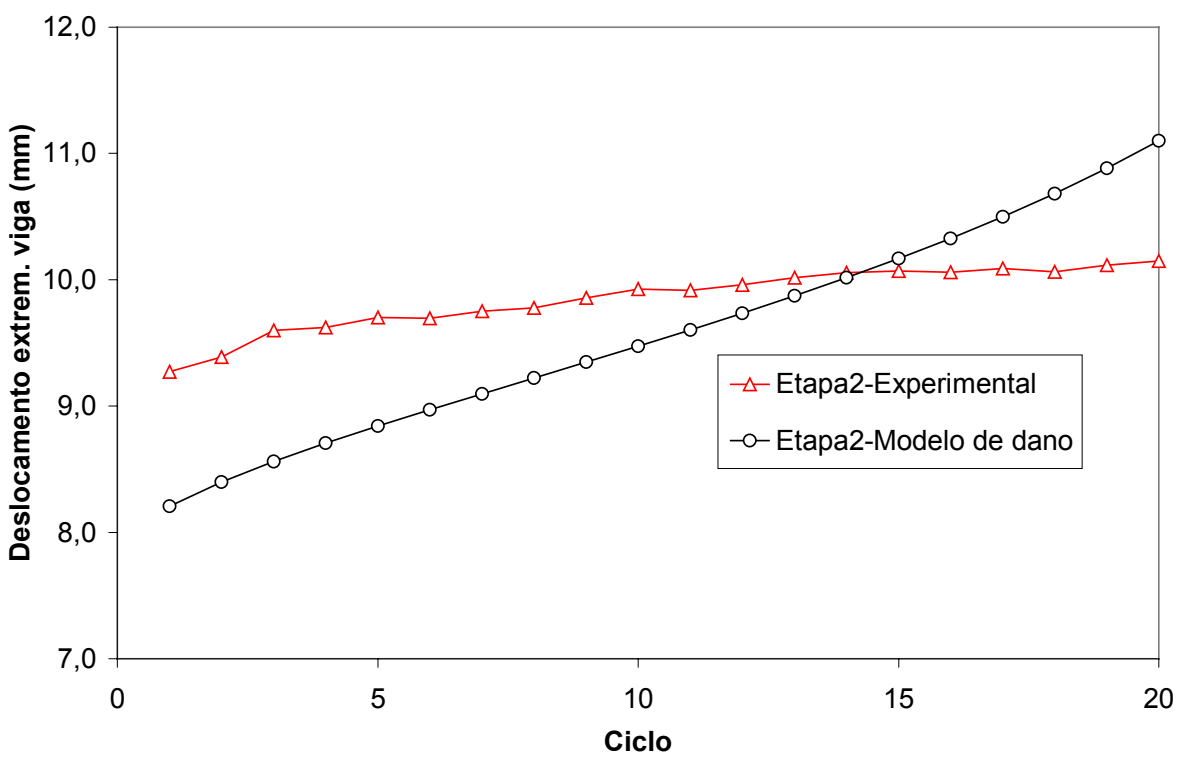

Figura 7.49: Deslocamentos na extremidade da viga em LVP1: Etapa2-Ações positivas

Os gráficos das figuras 7.48 e 7.49 indicam um aumento dos deslocamentos experimentais na viga em virtude dos ciclos de carregamentos impostos, sendo mais 
pronunciados nos ciclos iniciais e mais estabilizados nos finais. Conforme já comentado, o objetivo dessa etapa era familiarizar-se com a aplicação do carregamento cíclico e ter uma noção da velocidade de aplicação do mesmo, fornecendo dados que, posteriormente, possibilitaram a avaliação do número máximo de ciclos possíveis de serem aplicados em um dia de ensaio, caso fosse necessário o controle manual do carregamento.

De qualquer maneira, a fim de se ter uma idéia da resposta dos modelos numéricos, utilizou-se o modelo simplificado com a formulação modificada pelo parâmetro $\gamma$. Porém, em virtude da necessidade de se levar em conta o acréscimo de dano produzido pelo número de ciclos, incluiu-se na simulação o parâmetro z, o qual controla o incremento de dano por fadiga. Neste caso, utilizou-se a função polinomial do $2^{\circ}$ grau

$z=30(1-d)^{2}$

apresentada no capítulo 5 , que na verdade é uma expressão muito próxima da função original proposta por PICÓN \& FLÓREZ-LÓPEZ (2000).

Entretanto, como se percebe pela análise das figuras 7.48 e 7.49 , o modelo de dano fornece uma curva de deslocamento com uma tendência de aumento muito superior à curva experimental. Isso pode ser explicado pelo fato de a expressão do parâmetro $z$ ter sido originalmente estabelecida para a fadiga de baixos ciclos (low-cycle fatigue), onde os acréscimos de dano ao longo dos ciclos devem ser maiores, evidentemente. Acredita-se que um ajuste de z para intensidades de solicitações menores poderia melhorar a resposta numérica. Em termos quantitativos, uma alternativa seria reduzir o expoente do termo (1-d) para valores menores que 2. Essa idéia foi utilizada na etapa 2 da ligação LVP2.

\section{Etapa 3:}

A etapa 3 procurou simular um sismo de intensidade moderada, conforme descrito no item 6.7 do capítulo 6 .

Inicialmente simulou-se a resposta da ligação utilizando a função limite de dano modificada com o parâmetro $\gamma$, porém com o parâmetro $z$ expresso por um polinômio do $2^{\circ}$ grau, conforme proposto originalmente pelos autores. Entretanto, pelos resultados obtidos, os acréscimos de dano por fadiga foram muito elevados, sendo dessa forma, insatisfatórios. Entende-se que a expressão de z proposta por PICÓN \& FLÓREZ-LÓPEZ (2000) foi calibrada para a função limite original, ou seja, para valores de $\gamma$ igual a zero. Como neste caso os valores da variável de dano são maiores que os fornecidos pela função original, surge a necessidade de encontrar uma outra expressão para $z$ calibrada com a função limite de dano modificada.

Partindo dessa idéia, ajustou-se a expressão de z para a fadiga de baixos ciclos por meio da seguinte expressão:

$z=30(1-d)^{1,4}$

O ajuste no expoente melhorou a resposta numérica da curva força-deslocamento e dos valores da variável de dano da etapa 3 . As figuras 7.50 e 7.51 contêm as curvas força- 
deslocamento na extremidade da viga para os valores experimentais e para os valores teóricos obtidos com o modelo simplificado de dano e plasticidade.

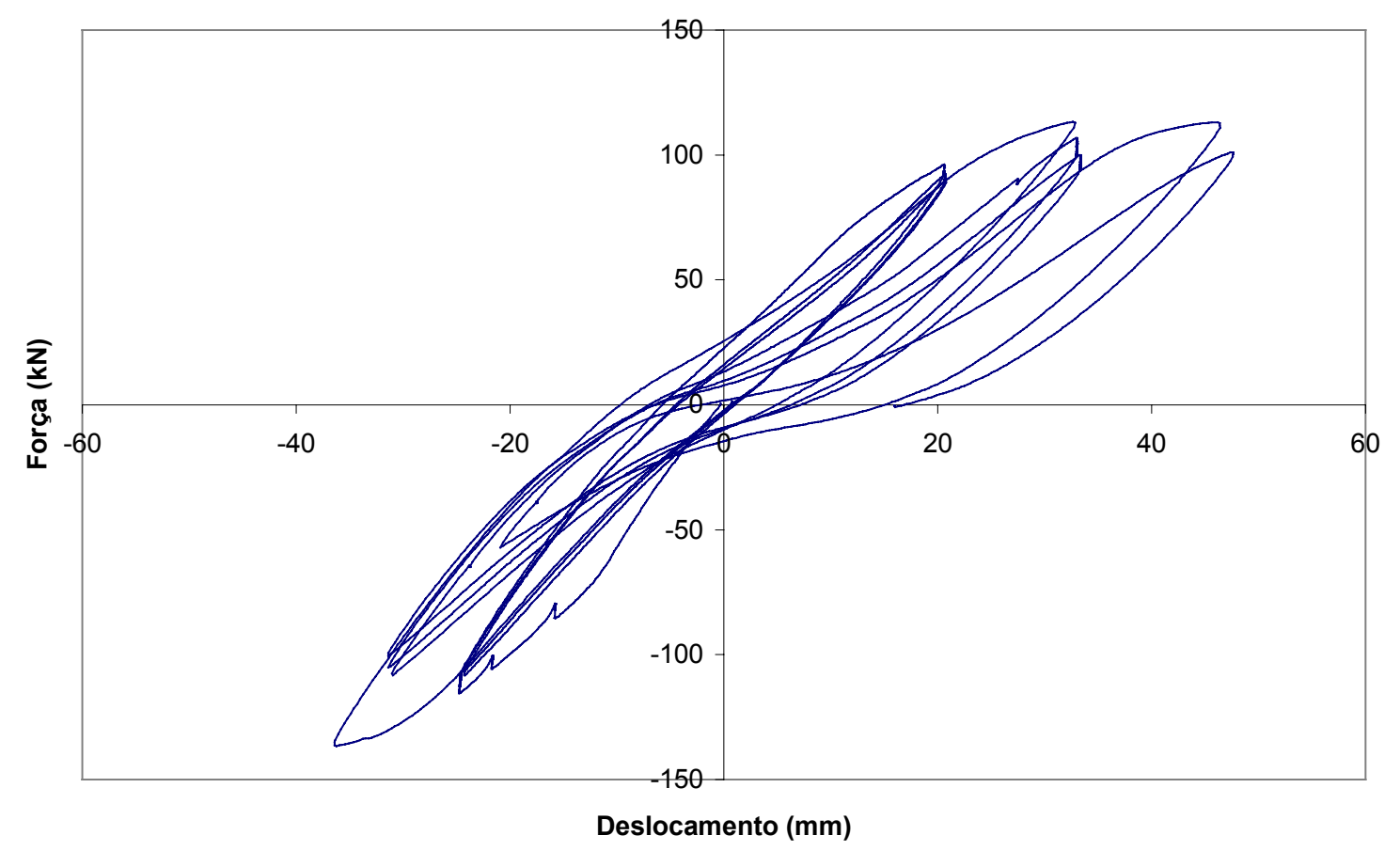

Figura 7.50: Curva força-deslocamento experimental em LVP1: Etapa 3

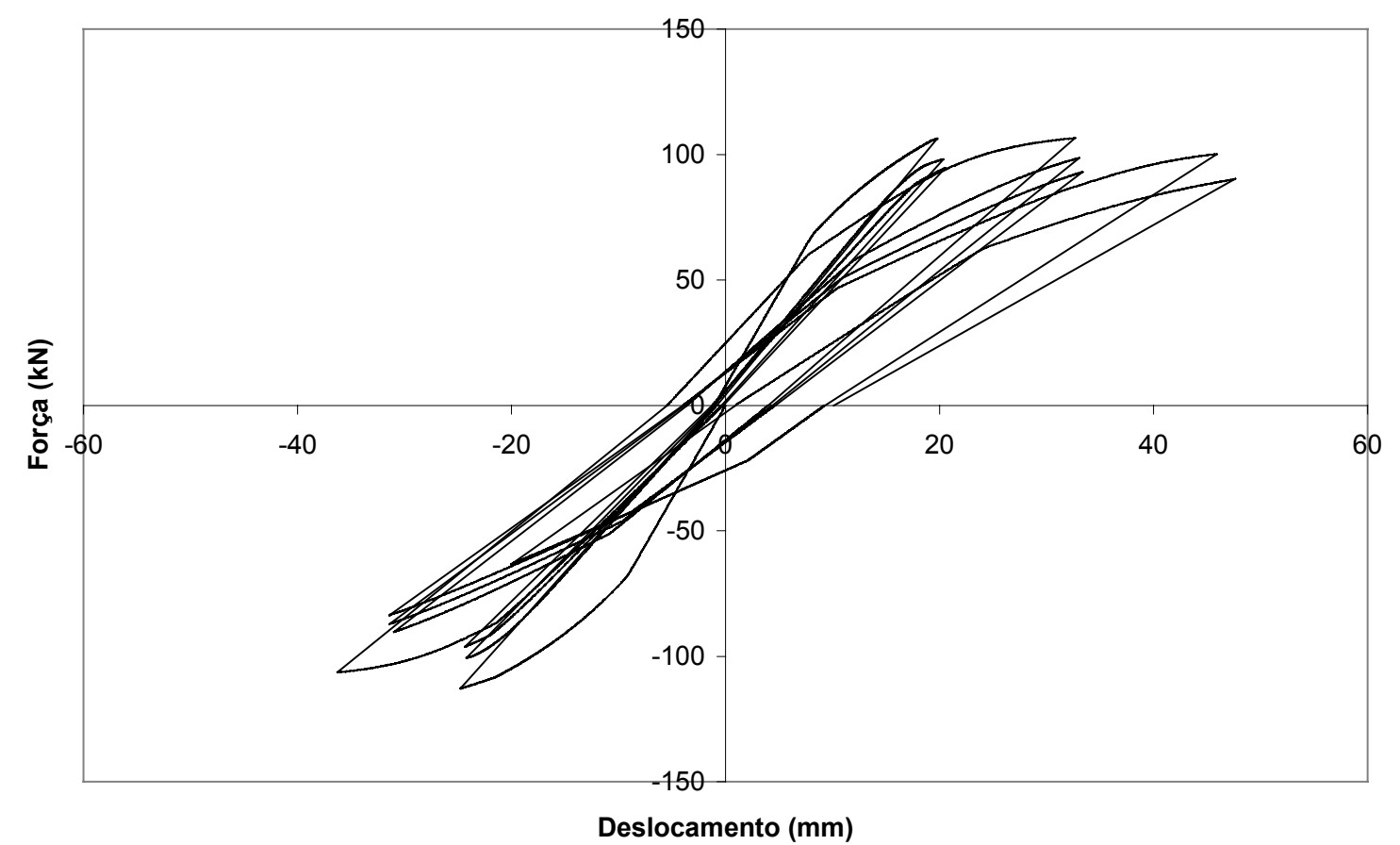

Figura 7.51: Curva força-deslocamento fornecida pelo modelo de dano para LVP1: Etapa 3

Os resultados mostram que o modelo simplificado simula de forma satisfatória a resposta global da ligação antes da ruína do nó de pórtico, simulando a perda de rigidez e de 
resistência razoavelmente. Os deslocamentos resultantes das deformações inelásticas na viga também foram bem representados antes da ruína do nó de pórtico.

No entanto, próximo da ruína do nó e também depois, os resultados do modelo simplificado se afastaram dos experimentais, especificamente com referência aos valores das forças máximas atingidas nos ciclos de carregamento. Na realidade, o modelo de dano não é capaz de prever a ruína da ligação pelo nó de pórtico - fato de certa forma óbvio, por se tratar de um modelo unidimensional.

A tabela 7.16 contém os dados experimentais e teóricos dos valores máximos de forças e deslocamentos atingidos nos ciclos da etapa 3 , referentes à ligação LVP1.

Tabela 7.16: Forças máximas atingidas na etapa 3 - Valores Experimentais e Teóricos

\begin{tabular}{|c|c|c|c|c|c|}
\hline \multicolumn{3}{|c|}{ Ações Negativas } & \multicolumn{3}{c|}{ Ações Positivas } \\
\hline Desl. (mm) & Exp.(kN) & Teórico $(\mathrm{kN})$ & Desl. $(\mathrm{mm})$ & Exp.(kN) & Teórico $(\mathrm{kN})$ \\
\hline$-24,7$ & $-115,57$ & $-112,89$ & 20,6 & 96,23 & 106,29 \\
\hline$-24,2$ & $-108,31$ & $-100,67$ & 20,7 & 92,33 & 98,13 \\
\hline$-24,4$ & $-106,81$ & $-96,25$ & 20,8 & 89,99 & 94,58 \\
\hline$-36,3$ & $-136,64$ & $-106,43$ & 32,7 & 113,22 & 106,53 \\
\hline$-31,0$ & $-108,31$ & $-90,33$ & 33,0 & 106,75 & 98,58 \\
\hline$-31,4$ & $-105,05$ & $-87,15$ & 33,3 & 99,87 & 93,03 \\
\hline$-31,4$ & $-100,52$ & $-83,67$ & 45,9 & 113,14 & 100,16 \\
\hline$-20,9$ & $-57,09$ & $-63,24$ & 47,6 & 101,13 & 90,21 \\
\hline
\end{tabular}




\section{LIGAÇÃO LVP2}

\section{Etapa 2:}

A etapa 2 do ensaio da ligação LVP2 foi constituída de 1000 ciclos de carregamento alternado com amplitude constante de forças igual a $60 \mathrm{kN}$, imaginando-se uma simulação de ações cíclicas em serviço.

Conforme mencionado nas análises da ligação LVP1, acredita-se que se possa ajustar o parâmetro z a fim de adaptá-lo para a situação de fadiga de ciclos elevados (high-cycle fatigue), situação a que corresponde a etapa 2 , em função da intensidade de tensões provocadas pelo carregamento. Assim, a seguinte função foi adotada para o parâmetro z:

$z=30(1-d)^{0,7}$

A tabela 7.17 contém os dados dos valores dos deslocamentos na extremidade da viga durante os ciclos da etapa 2, para o sentido negativo de forças. A figura 7.52 mostra graficamente a variação dos deslocamentos experimentais e dos teóricos (modelo simplificado de dano).

Tabela 7.17: Deslocamentos na extremidade da viga da ligação LVP2- Etapa 2

\begin{tabular}{|c|c|c|c|c|}
\hline Ciclo & $\begin{array}{c}\text { Experimental } \\
\mathbf{( m m})\end{array}$ & $\begin{array}{c}\text { Variação (\%) } \\
\text { Experimental }\end{array}$ & $\begin{array}{c}\text { Teórico } \\
\mathbf{( m m})\end{array}$ & $\begin{array}{c}\text { Variação (\%) } \\
\text { Teórico }\end{array}$ \\
\hline 50 & $-9,48$ & 4,87 & $-7,72$ & 1,31 \\
\hline 100 & $-9,87$ & 9,18 & $-8,30$ & 8,92 \\
\hline 150 & $-10,09$ & 11,62 & $-8,37$ & 9,84 \\
\hline 212 & $-10,14$ & 12,17 & $-8,44$ & 10,76 \\
\hline 411 & $-10,36$ & 14,60 & $-8,57$ & 12,47 \\
\hline 619 & $-10,55$ & 17,60 & $-8,65$ & 13,52 \\
\hline 1000 & $-10,71$ & 18,47 & $-8,76$ & 14,96 \\
\hline \multicolumn{5}{|l|}{ Ciclo inicial: Experimental: -9,04mm Teórico: -7,62mm } \\
\hline
\end{tabular}




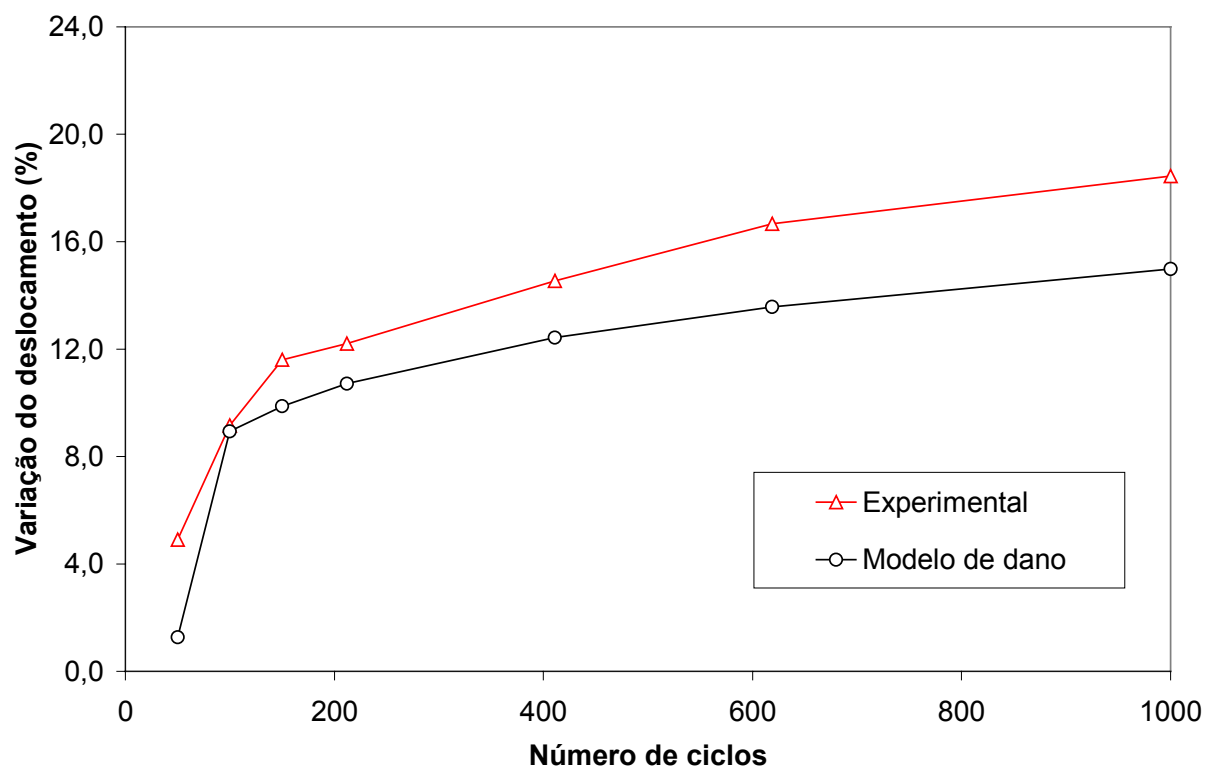

Figura 7.52: Variação dos deslocamentos na etapa 2 da ligação LVP2: ações negativas

Com base na tabela 7.17 e na figura 7.52, percebe-se que a tendência de aumento dos deslocamentos globais - fato decorrente da natureza cíclica das ações - é bem simulada pelo modelo de dano com o parâmetro $z$ ajustado de acordo com a expressão (7.10). A boa resposta do modelo numérico, neste caso, reforça a idéia da necessidade de se ajustar o parâmetro z em função da intensidade menor de solicitações.

A mesma tendência experimental do aumento dos deslocamentos na viga e a mesma eficiência do modelo simplificado de dano foram observadas no sentido positivo das forças no atuador.

\section{Etapa 3:}

$\mathrm{Na}$ etapa 3 foram aplicados carregamentos alternados crescentes até a ruína da ligação, que ocorreu por esmagamento da biela diagonal comprimida do nó de pórtico. $O$ carregamento aplicado na etapa 3 da ligação LVP2 é descrito no item 6.7 e ilustrado na figura 6.35 do capítulo 6 .

Para a simulação da resposta global da ligação, utilizou-se o mesmo parâmetro $z$ da etapa 2 (com expoente 0,7 ), pois do primeiro ao penúltimo ciclo dessa etapa (ciclo 1 ao 4 ), a força aplicada assumiu valores menores que a correspondente à plastificação da viga. No último ciclo (ciclo 5) ocorreu a plastificação das armaduras longitudinais da viga para o sentido de forças negativas. Entretanto, não foram aplicados ciclos adicionais após o a plastificação da viga, não havendo a necessidade de considerar o acréscimo de dano para a fadiga de baixos ciclos. Em outras palavras, admitiu-se que o carregamento tivesse sido aplicado monotonicamente, tendo o parâmetro $z$ pouca influência na variável de dano.

As figuras 7.53 e 7.54 mostram as curvas força-deslocamento experimentais e teóricas na extremidade da viga. A análise das referidas curvas indica que o modelo simplificado deixa de ser representativo próximo da ruína do nó de pórtico (ciclo 5). Nos ciclos anteriores à ruína do nó (ciclos 1 à 4), o modelo simplificado forneceu uma boa resposta global quando comparada à experimental. 


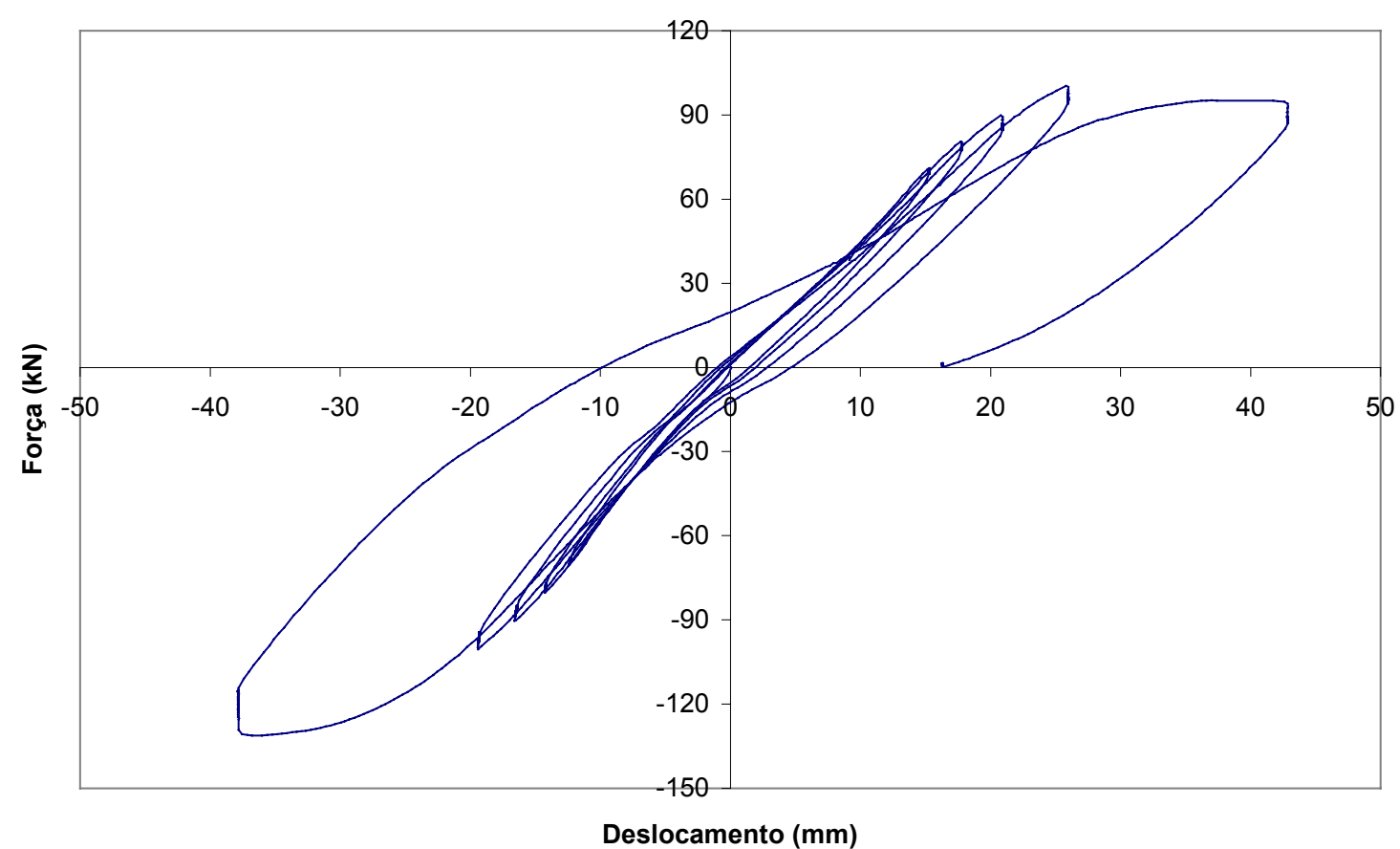

Figura 7.53: Curva força-deslocamento experimental em LVP2: Etapa 3

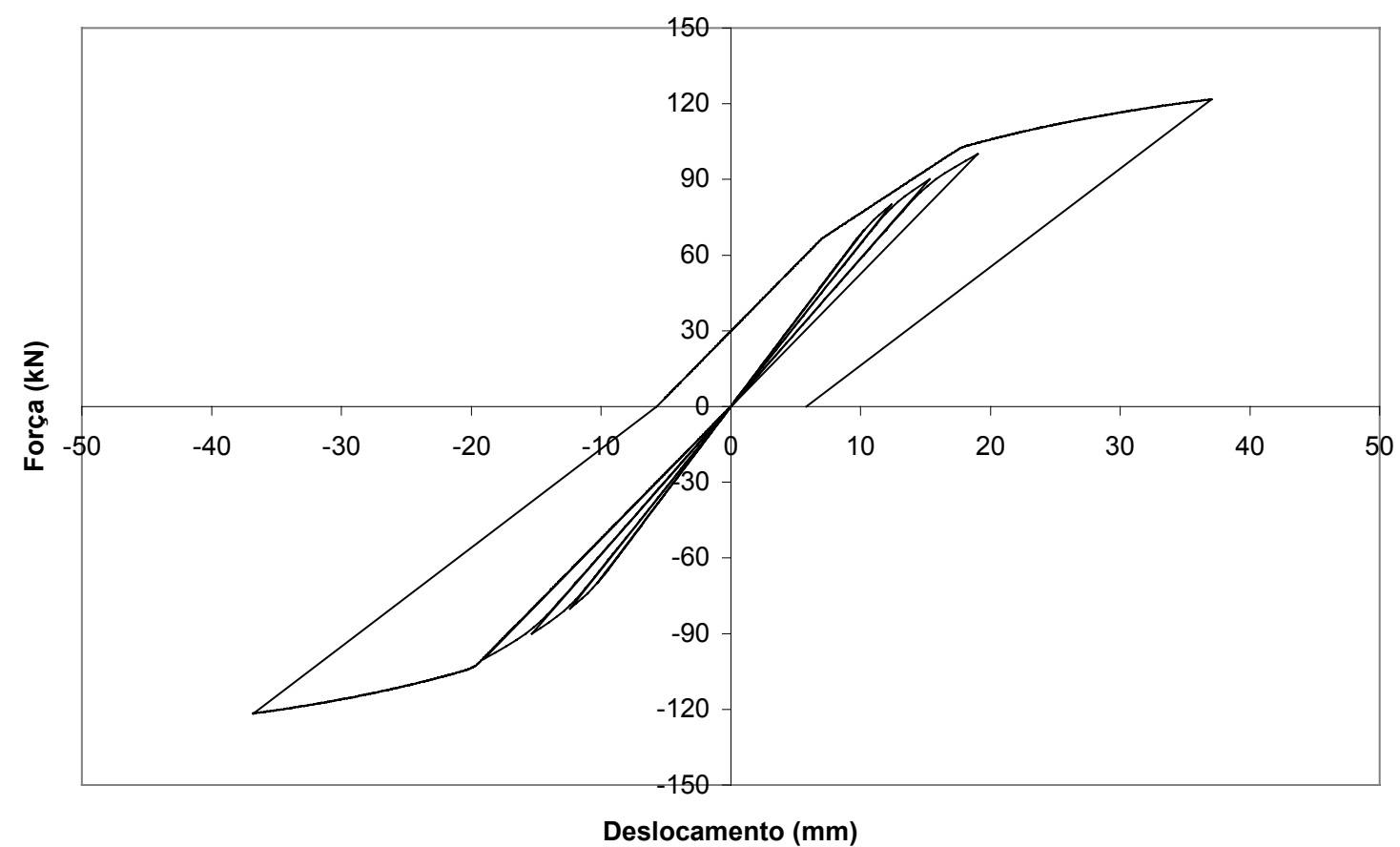

Figura 7.54: Curva força-deslocamento fornecida pelo modelo de dano para LVP2: Etapa 3 


\section{LIGAÇÃO LVP3}

\section{Etapa 2:}

$\mathrm{Na}$ etapa 2 foram aplicados carregamentos cíclicos alternados com amplitude de força crescente, até a evidência de perda de resistência da ligação antes de se atingir a força prevista no ciclo (ver figura 6.39 e tabela 6.6 do capítulo 6 ).

Nas simulações numéricas da etapa 2 com o modelo de dano, empregou-se a expressão (7.10) para determinar o valor de $z$, uma vez que as forças máximas dos ciclos desta etapa estiveram abaixo da força correspondente à plastificação (entre 60 à 80 por cento do momento de plastificação da viga).

As figuras 7.55 e 7.56 contêm as curvas força-deslocamento experimentais e as teóricas fornecidas pelo modelo de dano .

Pela análise dessas curvas, nota-se que o modelo de dano não consegue representar satisfatoriamente o comportamento global da ligação. Observa-se pela curva experimental da figura 7.55 que, à medida que a força no atuador se aproxima da força máxima resistente, ou quanto mais próximo da ruína do nó, maior o aumento dos deslocamentos nos ciclos de mesma amplitude de força. Além disso, os deslocamentos, em termos absolutos, assumiram valores elevados próximo e após a ruína do nó. Esse comportamento é mais visível no sentido positivo das forças.

De fato, a deterioração mecânica acentuada e precoce do nó de pórtico, antes mesmo da plastificação da viga, contribuiu para a grande diferença existente entre os resultados experimentais e os fornecidos pelo modelo de dano.

Em termos de detalhamento, a ligação LVP3 é idêntica à ligação LVP1, possuindo o mesmo número de estribos no nó $(4 \phi 8 \mathrm{~mm})$. A diferença de comportamento entre as duas ligações foi a resistência à compressão do concreto: 40,43 MPa em LVP1 e 24,62 MPa em LVP3. A maior resistência do concreto permitiu ao nó de pórtico da ligação LVP1 resistir a maiores tensões de cisalhamento, que se traduziram em forças aplicadas próximas ao momento último da viga, portanto ocorrendo a plastificação das armaduras. Em LVP3, a menor resistência à compressão do concreto não permitiu à ligação alcançar o momento de plastificação, ocorrendo a ruína do nó antes do escoamento das barras principais da viga. 


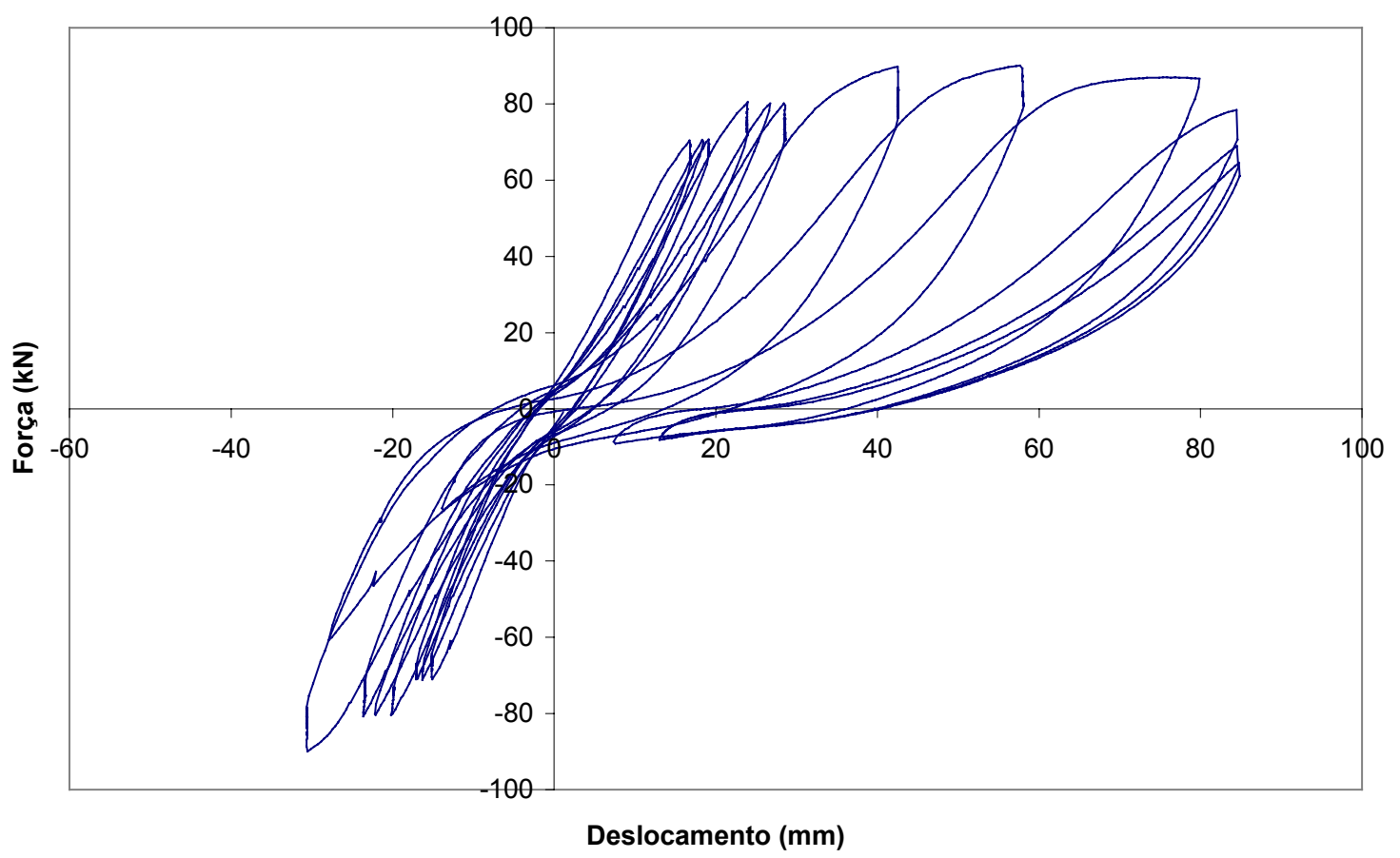

Figura 7.55: Curva força-deslocamento experimental em LVP3: Etapa 2

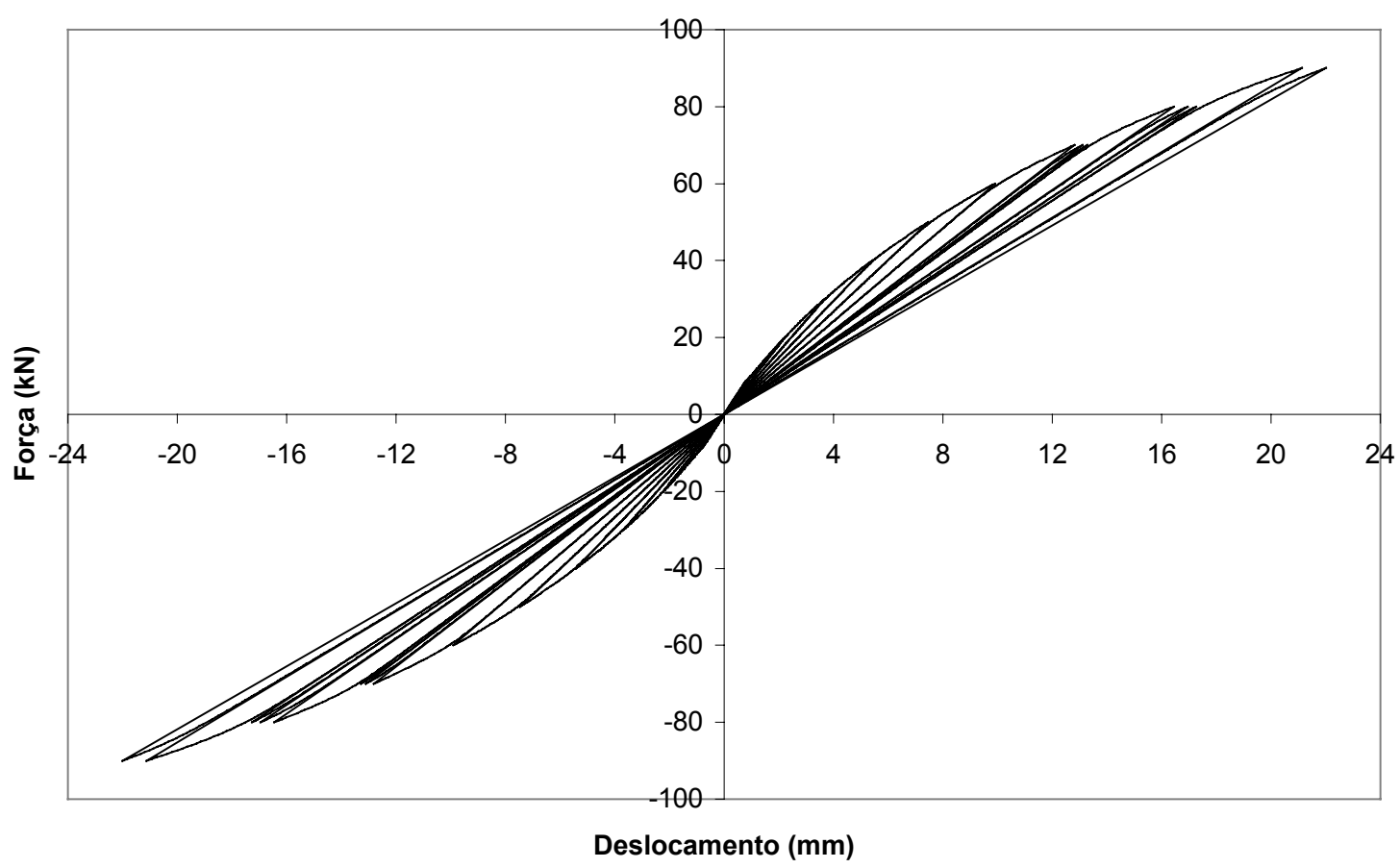

Figura 7.56: Curva força-deslocamento fornecida pelo modelo de dano para LVP3: Etapa 2 


\section{LIGAÇÃO LVP4}

\section{Etapa 2:}

O carregamento previsto para a etapa 2 da ligação LVP4 foi o mesmo do previsto para a ligação LVP3.

Com relação ao parâmetro z, empregou-se o mesmo da ligação LVP3 (expressão 7.10), em virtude da intensidade de solicitação nos dois modelos terem sido próximas.

As figuras 7.57 e 7.58 contém as curvas força-deslocamento experimentais e as teóricas fornecidas pelo modelo de dano .

A análise dessas curvas indica novamente acréscimos acentuados de deslocamentos próximos à ruína do nó de pórtico, nos dois sentidos de força, porém mais acentuados no sentido positivo. Com esse comportamento, coincidente com a degradação mecânica avançada do nó de pórtico, o modelo simplificado de dano não consegue simular de forma coerente o comportamento real da ligação.

Com base na figura 7.57, percebe-se um significativo aumento dos deslocamentos da viga no sentido positivo. Nos ensaios, observou-se a formação de fissuras bem visíveis na interface viga e pilar nos dois sentidos de forças, sendo a abertura de tais fissuras ligeiramente maiores no sentido positivo. O crescimento das aberturas dessas fissuras ao longo dos ciclos de carregamento também foi observado, sendo responsável pelo aumento das rotações relativas entre viga e pilar e, conseqüentemente, dos deslocamentos verticais na extremidade da viga. Na ligação LVP3, as fissuras de quina entre a face interna do pilar e a face da viga também foram maiores no sentido positivo de forças. 


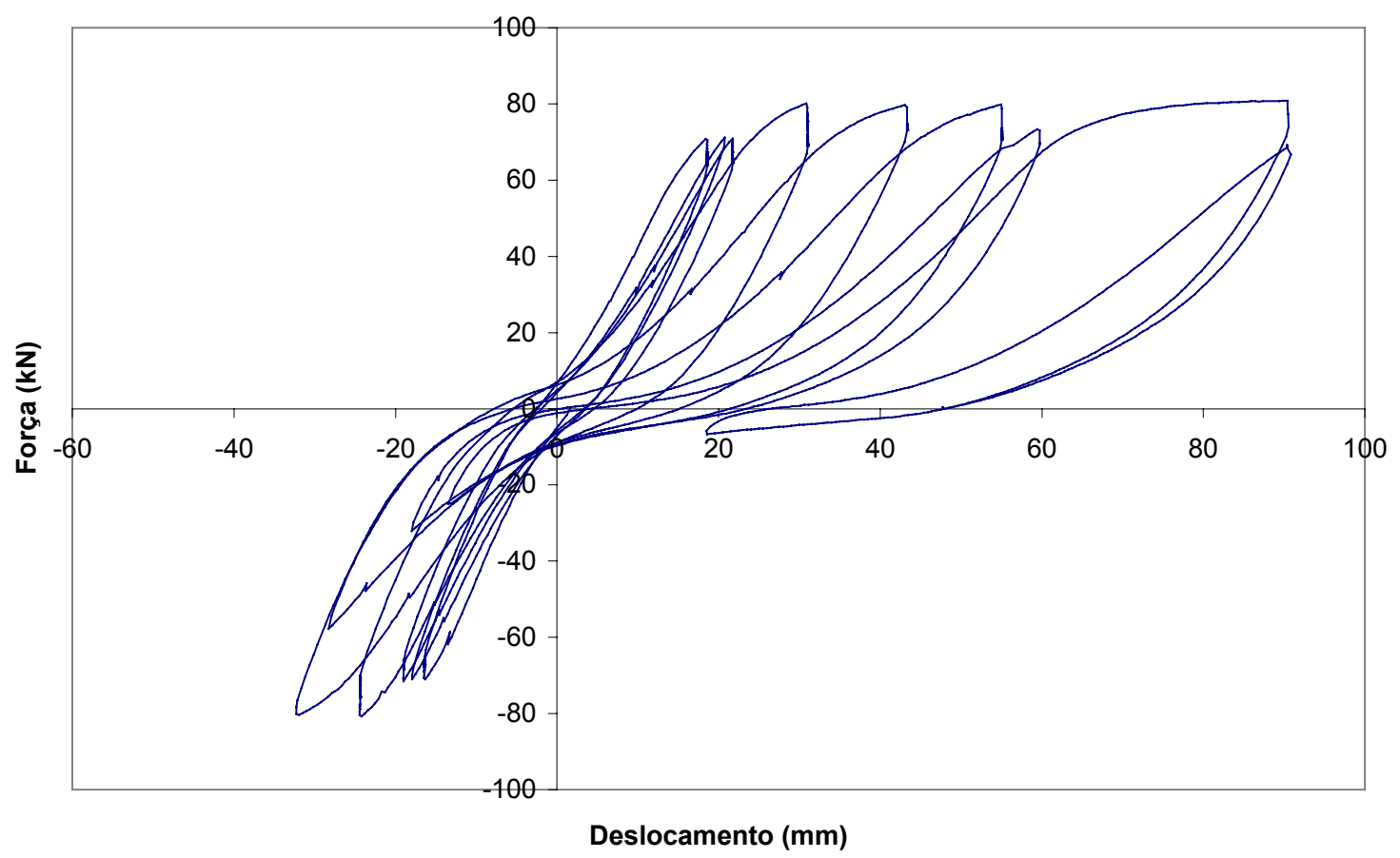

Figura 7.57: Curva força-deslocamento experimental em LVP4: Etapa 2

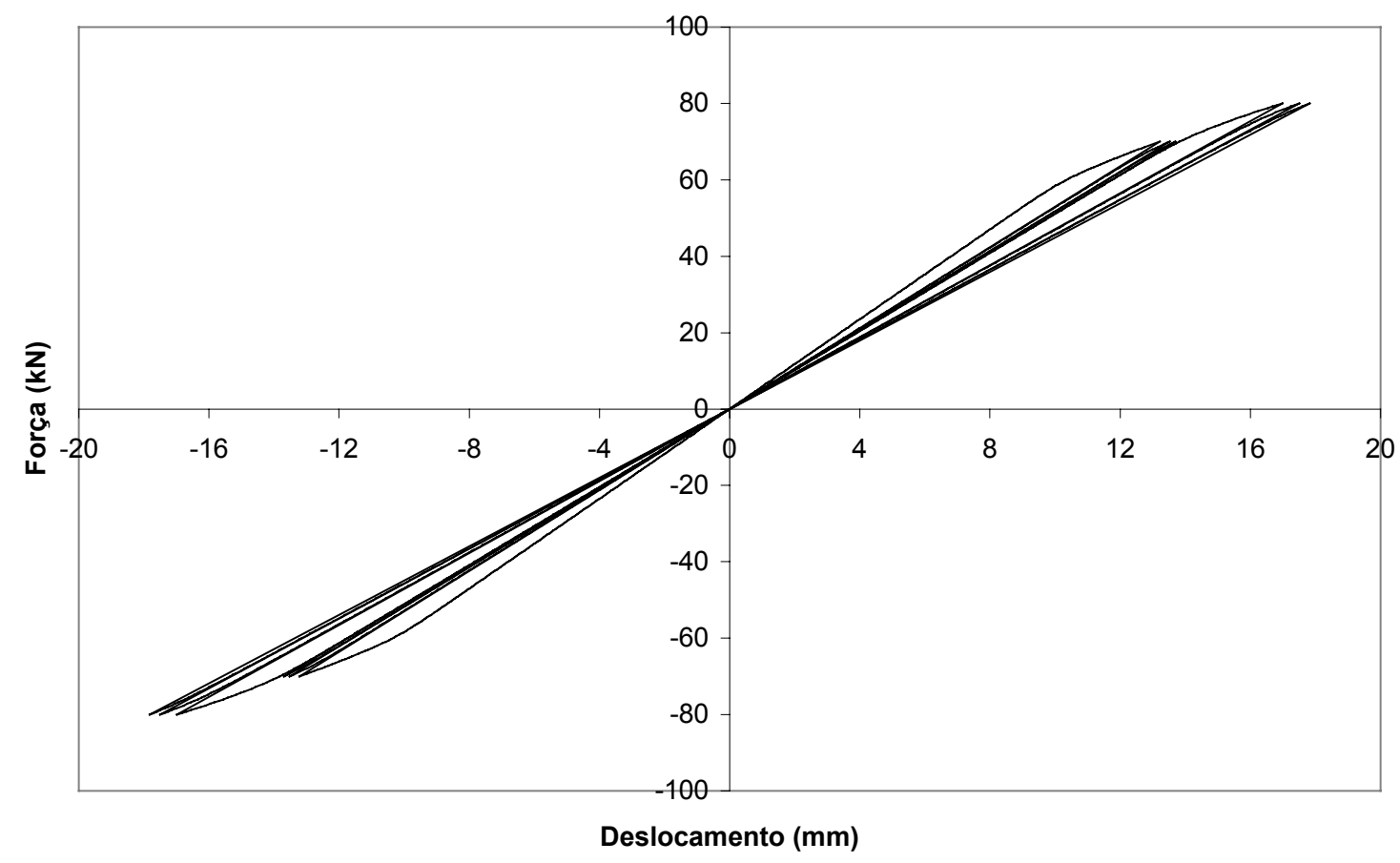

Figura 7.58: Curva força-deslocamento fornecida pelo modelo de dano para LVP4: Etapa 2 


\section{LIGAÇÃO LVP5}

\section{Etapa 2:}

O carregamento previsto para a etapa 2 foi o mesmo da ligação LVP2, ou seja, estavam previstos 1000 ciclos de carregamento cíclico alternado com amplitude de força constante e igual a $60 \mathrm{kN}$. Entretanto, em virtude da observação nos ensaios de uma deterioração relativamente avançada do concreto do nó antes dos 1000 ciclos, decidiu-se encerrar esta etapa no ciclo 437.

Para o parâmetro $z$ do modelo de dano, utilizou-se a mesma expressão empregada na ligação LVP2 (expressão 7.10).

A tabela 7.18 contém os dados experimentais e teóricos do modelo numérico em questão, referentes ao deslocamento na extremidade da viga em função do número de ciclos (ações negativas).

Tabela 7.18: Deslocamentos na extremidade da viga da ligação LVP5- Etapa 2

\begin{tabular}{|c|c|c|c|c|}
\hline Ciclo & $\begin{array}{c}\text { Experimental } \\
\mathbf{( m m})\end{array}$ & $\begin{array}{c}\text { Variação (\%) } \\
\text { Experimental }\end{array}$ & $\begin{array}{c}\text { Teórico } \\
\mathbf{( m m}\end{array}$ & $\begin{array}{c}\text { Variação (\%) } \\
\text { Teórico }\end{array}$ \\
\hline 50 & $-15,60$ & 21,40 & $-10,72$ & 10,00 \\
\hline 100 & $-20,69$ & 61,01 & $-10,94$ & 12,25 \\
\hline 250 & $-21,74$ & 69,18 & $-11,27$ & 15,66 \\
\hline 380 & $-22,06$ & 71,67 & $-11,44$ & 17,43 \\
\hline 437 & $-24,21$ & 88,40 & $-11,50$ & 18,06 \\
\hline \multicolumn{4}{|l|}{ Ciclo inicial: Experimental: -12,83mm Teórico: -9,74mm } \\
\hline
\end{tabular}

Pela tabela 7.18, percebe-se um aumento significativo dos deslocamentos experimentais na extremidade da viga. Neste caso, o modelo de dano não conseguiu similar tal aumento de deslocamentos, distanciando-se muito do comportamento real.

Quando comparada à ligação LVP2, tanto o aumento dos deslocamentos na viga quanto a própria deterioração do concreto da região nodal foi significativamente maior na ligação LVP5, embora esta última possuísse um número de estribos duas vezes maior que a ligação LVP2. A explicação pode estar na diferença entre as resistências do concreto à compressão.

Na ligação LVP2, o concreto apresentou uma resistência à compressão de 44,18 MPa. Na ligação LVP5, 25,91 MPa. Logo, o nó de pórtico da ligação LVP5 acabou sendo submetido a intensidades de tensões de cisalhamento, em relação à tensão resistente, maiores que a ligação LVP2. Esta maior solicitação relativa certamente contribuiu para a maior deterioração mecânica da ligação devido às ações cíclicas e, por conseqüência, para o crescimento mais pronunciado dos deslocamentos em LVP5.

Deve-se comentar também que, tendo o nó de pórtico das ligações LVP2 e LVP5 as mesmas dimensões, a resistência à compressão do concreto foi mais importante para a resistência ao cisalhamento do que a quantidade de estribos no nó. 


\section{Etapa 3:}

A etapa 3 foi constituída de apenas um ciclo, iniciando a aplicação do carregamento no sentido negativo até o instante em que a ligação atingisse a máxima resistência ou a máxima força no atuador. Após o alcance da capacidade máxima, observou-se a queda acentuada da força do atuador (queda de resistência da ligação). Neste instante, inverteu-se a força do atuador para o sentido oposto, até a máxima força no sentido positivo. Conforme já comentado, a ruína se deu por esmagamento da biela diagonal comprimida do nó.

A figura 7.59 contém a comparação entre a curva experimental e a teórica com a utilização do modelo de dano. Mais uma vez se confirma a limitação da eficiência do modelo numérico para ligações onde os nós de pórticos sofrem intensa danificação.

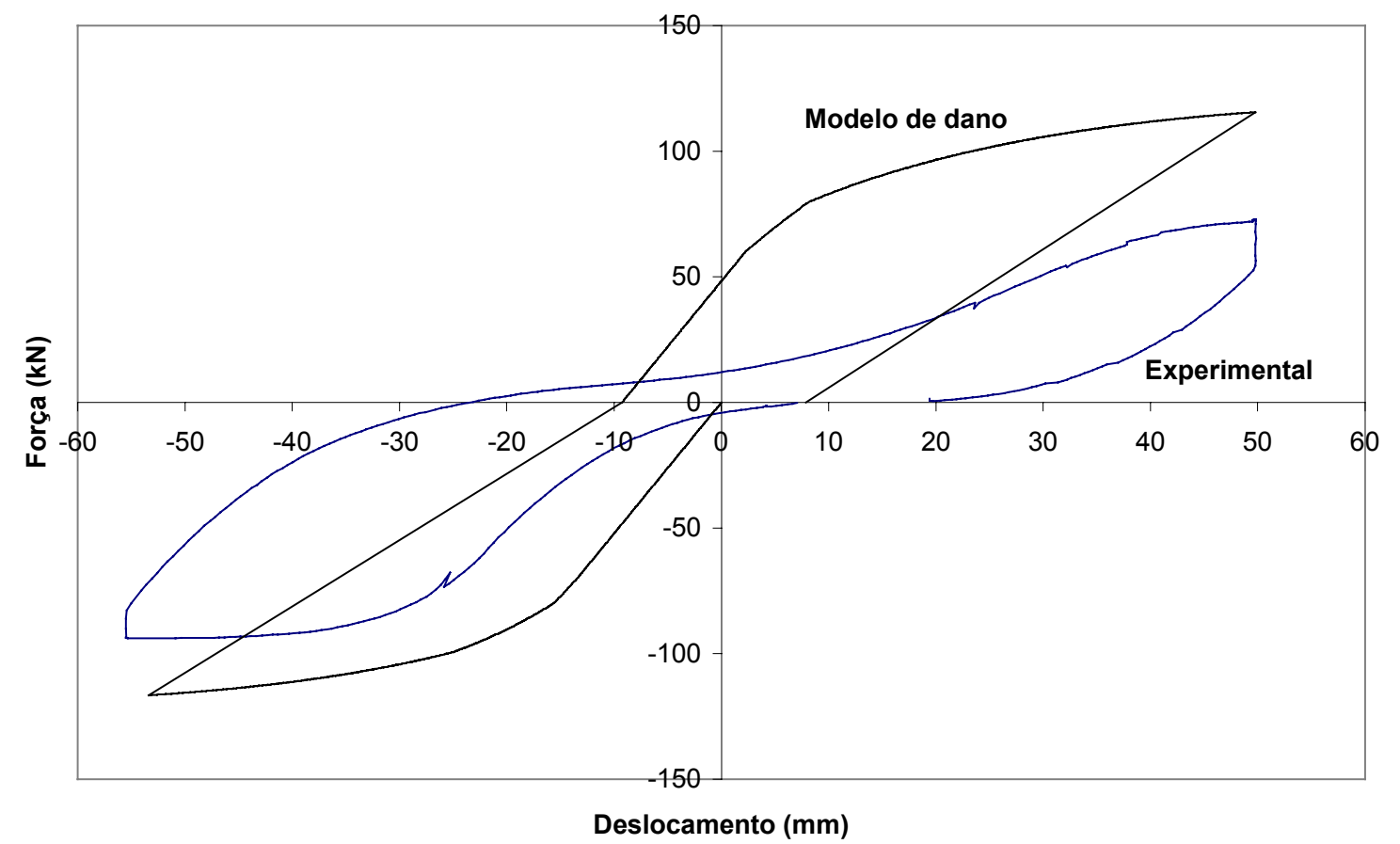

Figura 7.59: Comparação entre a curva experimental e teórica da ligação LVP5: etapa 3

\subsubsection{Comparações adicionais entre os modelos físicos ensaiados}

Neste item são feitas algumas comparações entre os modelos físicos das ligações, procurando-se inferir sobre a influência da taxa de estribos no comportamento global da ligação. As comparações foram feitas dentro de um mesmo tipo de carregamento aplicado.

A tabela 7.19 contém os valores dos deslocamentos máximos na extremidade da viga da etapa 1 de carregamento, comum a todas as cinco ligações. Na tabela, os valores referemse ao sentido negativo de forças. 
Tabela 7.19: Deslocamentos máximos na extremidade da viga: Etapa 1 - ações negativas

\begin{tabular}{|c|c|c|c|c|c|c|}
\hline Ciclo & $\begin{array}{c}\text { Força } \\
(\mathrm{kN})\end{array}$ & $\begin{array}{c}\text { LVP1 } \\
(\mathrm{mm})\end{array}$ & $\begin{array}{c}\text { LVP2 } \\
(\mathrm{mm})\end{array}$ & $\begin{array}{c}\text { LVP3 } \\
(\mathrm{mm})\end{array}$ & $\begin{array}{c}\text { LVP4 } \\
(\mathrm{mm})\end{array}$ & $\begin{array}{c}\text { LVP5 } \\
(\mathrm{mm})\end{array}$ \\
\hline 1 & 10 & $-1,07$ & $-0,99$ & $-1,20$ & $-1,25$ & $-1,17$ \\
\hline 2 & 20 & $-2,18$ & $-2,09$ & $-2,86$ & $-2,83$ & $-2,98$ \\
\hline 3 & 30 & $-3,63$ & $-3,23$ & $-4,72$ & $-4,77$ & $-4,85$ \\
\hline 4 & 40 & $-5,39$ & $-4,96$ & $-6,90$ & $-7,04$ & $-7,13$ \\
\hline 5 & 50 & $-7,29$ & $-6,93$ & $-9,30$ & $-9,76$ & $-9,80$ \\
\hline 6 & 60 & $-9,52$ & $-9,04$ & $-12,08$ & $-12,74$ & $-12,83$ \\
\hline
\end{tabular}

Com base na tabela 7.19, foram feitas comparações tomando-se ligações que apresentaram resistência à compressão do concreto próximas, a fim de avaliar a influência do número de estribos no nó sobre o comportamento global da ligação:

LVP1 e LVP2: A ligação LVP1 apresentou deslocamentos em média 6,7\% maiores que em LVP2, para uma resistência a compressão do concreto $8,5 \%$ menor. Por outro lado, o número de estribos do nó em LVP2 foi de $2 \phi 8 \mathrm{~mm}$, metade do disponível em LVP1.

LVP3 e LVP4: Houve uma pequena diferença (cerca de 3\%) entre os deslocamentos da ligação LVP3, com 4 $48 \mathrm{~mm}$ de estribos no nó, e os deslocamentos da ligação LVP4, com 2ф8mm de estribos. As resistências dos materiais foram praticamente as mesmas entre as duas ligações.

Essas observações indicam que parece haver pouca influência dos estribos sobre o comportamento global para solicitações em situações de serviço, em se tratando de ligações com concretos de mesma resistência à compressão.

Por fim, foram comparados os deslocamentos na extremidade da viga e as rotações relativas entre viga e pilar, para as ligações LVP3 e LVP4, referentes a etapa 2 de carregamento (tabela 7.20). Nesta etapa, as forças atingidas nos ciclos se aproximaram da força de ruína das ligações.

Tabela 7.20: Comportamento global na etapa 2 (ações negativas) - Ligações LVP3 e LVP4

\begin{tabular}{|c|c|c|c|c|c|}
\hline Ciclo & $\begin{array}{c}\text { Força } \\
(\mathrm{kN})\end{array}$ & $\begin{array}{c}\text { LVP3 } \\
\text { Deslocamento da } \\
\text { viga }(\mathrm{mm})\end{array}$ & $\begin{array}{c}\text { LVP4 } \\
\text { Deslocamento da } \\
\text { viga }(\mathrm{mm})\end{array}$ & $\begin{array}{c}\text { LVP3 } \\
\text { Rotação relativa } \\
\text { viga-pilar (rad) }\end{array}$ & $\begin{array}{c}\text { LVP4 } \\
\text { Rotação relativa } \\
\text { viga-pilar (rad) }\end{array}$ \\
\hline 1 & 70 & $-15,08$ & $-15,98$ & 0,0041 & 0,0046 \\
\hline 2 & 70 & $-16,34$ & $-17,61$ & 0,0045 & 0,0050 \\
\hline 3 & 70 & $-17,04$ & $-18,53$ & 0,0047 & 0,0052 \\
\hline 4 & 80 & $-20,64$ & $-23,79$ & 0,0057 & 0,0066 \\
\hline 5 & 80 & $-22,74$ & $-31,60$ & 0,0064 & 0,0083 \\
\hline
\end{tabular}

Os valores da tabela 7.20 mostram que, na ligação com menor número de estribos - a LVP4 - para os três ciclos de $70 \mathrm{kN}$, os deslocamentos na viga foram cerca de $7 \%$ maiores que em LVP3 e as rotações relativas entre viga e pilar cerca de $10 \%$ também maiores que em LVP3. Nos ciclos de $80 \mathrm{kN}$, a diferença de deslocamentos e rotações relativas aumentou entre as duas ligações em questão. No ciclo 5 , o deslocamento da viga na ligação LVP4 foi de cerca de $39 \%$ maior que em LVP3. Por sua vez, a rotação relativa na interface viga-pilar foi 
aproximadamente $30 \%$ maior em LVP4. Essa análise pode indicar que a influência dos estribos é importante para a resposta global da ligação a partir de solicitações maiores, tais como próximas da resistência da ligação.

Vale frisar que as ligações LVP3 e LVP4 possuíram as mesmas dimensões, o mesmo detalhamento das armaduras nos elementos viga e pilar (exceto no nó de pórtico), a mesma força normal aplicada no pilar, a mesma resistência ao escoamento do aço e praticamente a mesma resistência à compressão do concreto $(23,89 \mathrm{MPa}$ e $24,62 \mathrm{MPa})$. Dessa maneira, conseguiu-se isolar a variável taxa de estribos no nó de pórtico, possibilitando as conclusões mencionadas. 


\section{CONCLUSÕES

\subsection{CONCLUSÕES GERAIS}

Este trabalho destinou-se ao estudo do comportamento estrutural de nós de pórtico formados nas ligações entre viga e pilar - sob um tipo particular de carregamento: o cíclico. Este trabalho deu continuidade às pesquisas recentes desenvolvidas na Escola de Engenharia de São Carlos (EESC-USP) sobre a influência das solicitações cíclicas nas estruturas de concreto.

O trabalho foi desenvolvido em duas frentes: uma abordagem teórica, onde foram revistas as principais pesquisas desenvolvidas sobre o assunto e estudados os principais modelos teóricos que poderiam representar o comportamento dos nós de pórtico e das ligações viga-pilar que os definem. A outra frente consistiu de ensaios em laboratório de modelos físicos de ligações, fornecendo dados experimentais importantes para o entendimento dos fenômenos mecânicos envolvidos. Além disso, os resultados experimentais serviram como base para avaliar a eficiência dos modelos teóricos escolhidos neste trabalho para simular estruturalmente as ligações viga-pilar.

\section{Conclusões das análises sobre o emprego dos modelos teóricos}

\section{Modelos de análise local}

Com relação aos modelos utilizados neste trabalho para representar o nó de pórtico exclusivamente, as seguintes conclusões e observações podem ser destacadas:

> Tais modelos utilizam os conceitos dos conhecidos modelos de biela e tirante, assumindo que a resistência ao cisalhamento seja a soma da parcela resistente da biela diagonal comprimida e da parcela dos estribos colocados na região do nó. São bastante empregados para o dimensionamento e para a determinação da capacidade resistente dos nós.

Entre os modelos locais, foram destacados nesta pesquisa os modelos de PAULAY \& PRIESTLEY (1992) e o modelo de HWANG \& LEE (1999), este último aplicável aos nós externos. Embora tenham sido originalmente propostos para a situação de solicitações cíclicas, esses modelos podem ser adaptados ao caso de ações monotônicas.

O modelo de PAULAY \& PRIESTLEY (1992) contém hipóteses razoáveis no que diz respeito à transferência de esforços dos elementos viga e pilar para o nó de pórtico. $O$ 
modelo permite dimensionar a armadura transversal do nó de forma prática, em se tratando de ações cíclicas. Entretanto, não é aplicável na ausência de armadura longitudinal comprimida na viga.

Com base em dados experimentais da bibliografia especializada e com base nos resultados experimentais das cinco ligações ensaiadas, concluiu-se que o modelo de HWANG \& LEE (1999) fornece uma boa previsão da resistência ao cisalhamento de nós de pórtico externos frentes a ações cíclicas. O mesmo se aplica ao modelo de PAULAY \& PRIESTLEY (1992), diferenciando-se do modelo de HWANG \& LEE pela necessidade de se determinar as resultantes de compressão e de tração da seção da viga para o cálculo da força cortante resistente. Os valores de resistência à força cortante fornecidos por esses dois modelos estiveram entre 10 a $15 \%$ menores que os valores experimentais.

Acredita-se que o modelo de HWANG \& LEE (1999) possa ser aplicado na previsão da força cortante resistente do nó sob ação monotônica, devendo-se utilizar outro coeficiente de redução de resistência $\zeta$, em substituição ao apresentado na expressão (5.55), estabelecido para ações cíclicas. Em algumas simulações com nós externos, não apresentadas neste trabalho, a utilização da expressão da norma canadense CSA-A23.3 1994) para a determinação de $\zeta$

$$
\zeta=\frac{1}{0,8+170 \varepsilon_{\mathrm{r}}} \leq 0,85
$$

forneceu uma boa correlação com resultados experimentais.

$>$ Tanto no modelo de PAULAY \& PRIESTLEY (1992) quanto no modelo de HWANG \& LEE (2000), o acréscimo de força normal produz um aumento da resistência ao cisalhamento do nó, devido ao aumento da zona comprimida no pilar.

$>$ Com base na formulação dos modelos locais abordados neste trabalho ou mesmo por uma simples análise do critério de Mohr-Coulomb aplicável aos materiais frágeis com pequena resistência à tração, seria possível se chegar a conclusão de que a força normal no pilar de fato exerce uma influência benéfica sobre a resistência ao cisalhamento do nó de pórtico. Entretanto, não é isso o que mostra a grande dispersão dos resultados observada nos gráficos das figuras 4.6 e 4.7 do capítulo 4 , referente aos resultados experimentais coletados da bibliografia especializada, relacionando resistência do nó e força normal no pilar. Portanto, deve-se deixar claro que essa variável ainda necessita ser melhor estudada.

Vale ressaltar que normalmente se considera o nó de pórtico submetido apenas a tensões de cisalhamento ou ainda submetido a um estado plano de tensões (figura 8.2). Os resultados experimentais, tanto os da bibliografia especializada quanto os da etapa experimental desta pesquisa, indicam que essa simplificação de cálculo é razoável. Entretanto, deve-se reconhecer que o estado de solicitação real a que está sujeito o nó de pórtico é mais complexo do que o usualmente assumido (figura 8.1), podendo ser melhor explorado com a utilização dos modelos de biela e tirante. 

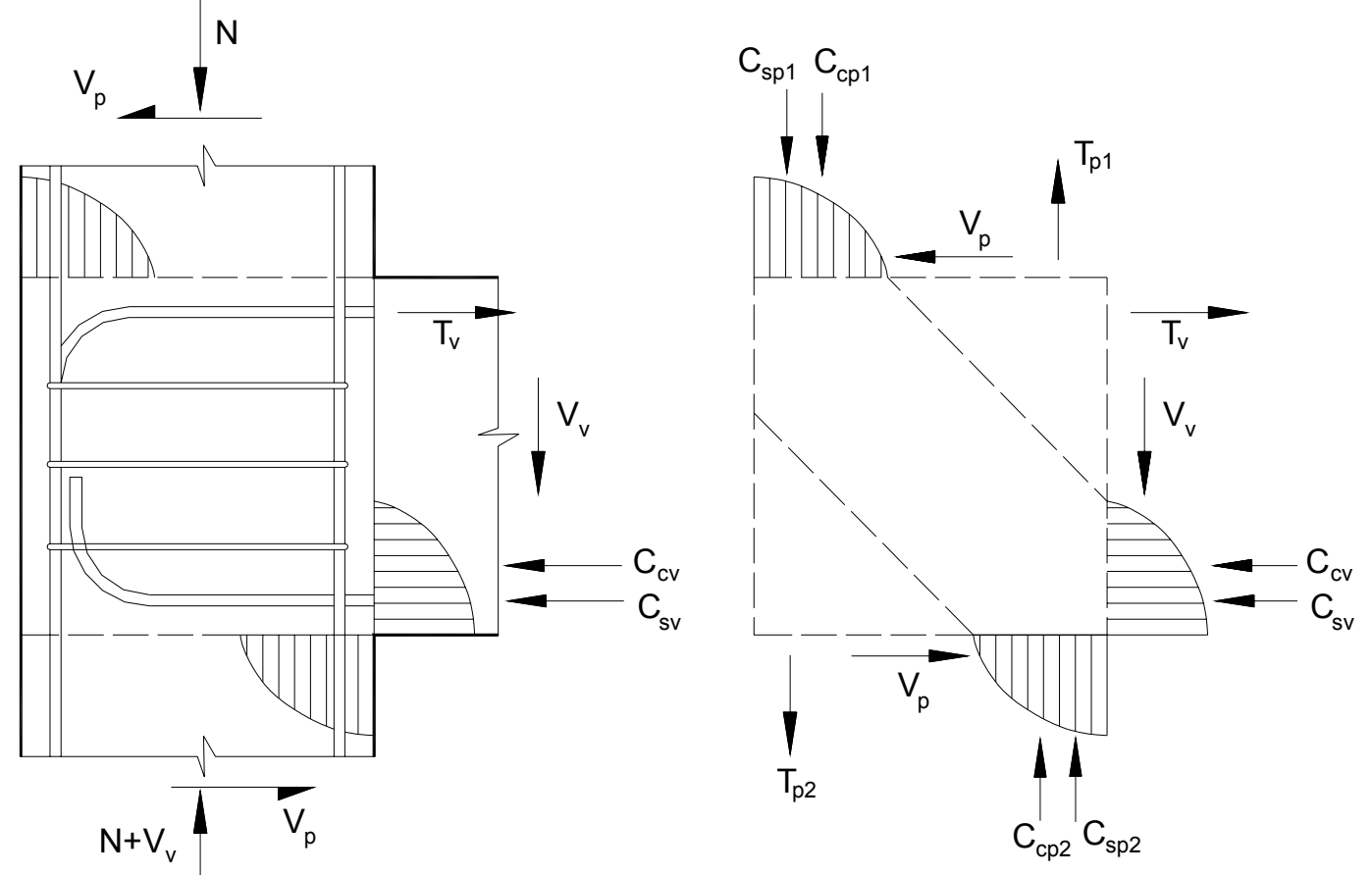

Figura 8.1: Estado de solicitação real em nós de pórticos externos

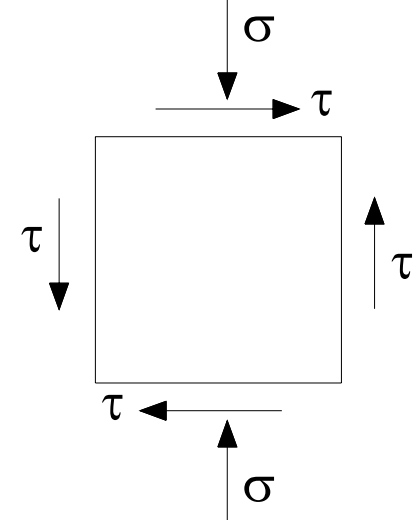

Figura 8.2: Estado simplificado de solicitação normalmente assumido para os nós externos

\section{Modelos de análise global}

Realizou-se um estudo sobre a simulação do comportamento global de ligações vigapilar de extremidade em concreto armado sob solicitações cíclicas e monotônicas, tendo como base os modelos simplificados de dano e de plasticidade propostos originalmente por CIPOLLINA \& FLÓREZ-LÓPEZ (1995), FLÓREZ-LÓPEZ (1995) e PICÓN \& FLÓREZ-LÓPEZ (2000). Sobre a utilização e aplicação desses modelos, são destacadas as seguintes conclusões e observações:

As primeiras simulações em ligações viga-pilar de extremidade empregando os modelos simplificados (item 5.3.4) mostraram um bom potencial desses modelos na representação 
da perda de rigidez/resistência dos elementos estruturais e na captura de deslocamentos permanentes mediante ações cíclicas de elevada intensidade.

Algumas modificações na formulação dos modelos originais foram sugeridas, a fim de aprimorar a resposta do modelo numérico quando confrontado com resultados experimentais de ligações encontrados na bibliografia especializada. Vale lembrar que as funções limites de controle da variável de dano foram originalmente identificadas com base em ensaios de ligações viga-pilar segundo o esquema estático ilustrado na figura 8.3a.

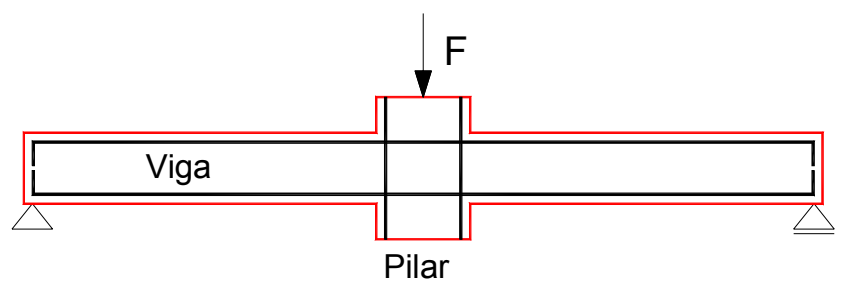

a)

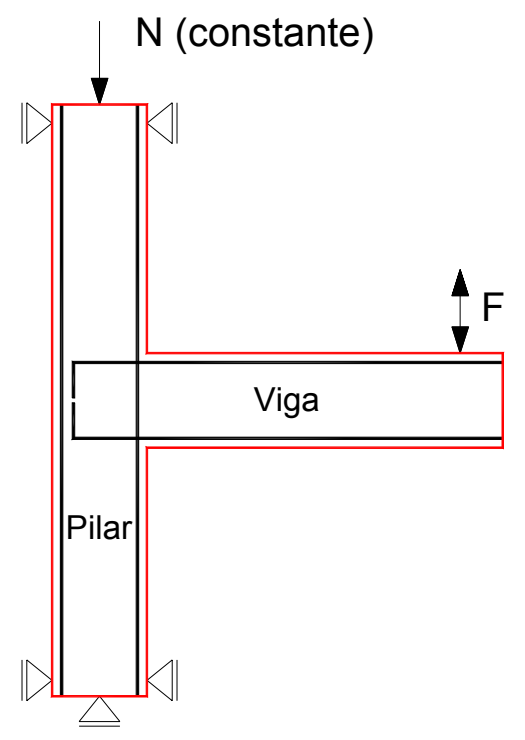

b)

Figura 8.3: Identificação das funções limites de dano: a) Ensaios utilizados por CIPOLLINA \& FLÓREZ-LÓPEZ (1995); b) Ensaios realizados na etapa experimental deste trabalho.

Neste trabalho foi proposta uma nova função que controla a evolução da danificação, com base em ensaios de ligações viga-pilar da figura $8.3 \mathrm{~b}$, formadas por elementos viga e pilar de características estruturais diferentes dos elementos das ligações ensaiadas para definir as funções de dano originais (figura 8.3a).

Nesta pesquisa, foi proposta uma nova função que controla a evolução da danificação, agora segundo as características estruturais do esquema estático da figura 8.2b.

Os resultados numéricos utilizando o modelo de dano modificado corresponderam às expectativas, mostrando um bom desempenho na representação da resposta global da ligação sob ações monotônicas e sob solicitações cíclicas de elevada intensidade, incluindo 
o efeito de fadiga de baixos ciclos. Essa boa resposta foi mais evidente em ligações bem armadas na região nodal.

Com a modificação na função limite de dano, introduziu-se um novo parâmetro ao modelo $(\gamma)$, o qual se supõe depender das características do elemento estrutural. As análises realizadas neste estudo indicaram que a eficiência do modelo de dano depende da forma de detalhamento da ligação, como por exemplo, o tipo de ancoragem das armaduras longitudinais das vigas. Entretanto, é possível que o valor de $\gamma$ que melhor represente o comportamento global da ligação dependa também do grau de confinamento dos elementos (viga, pilar, nó de pórtico) e do efeito pinching, este último referente às ações cíclicas reversíveis.

A modificação na função limite de dano e na função que determina o parâmetro controlador da fadiga foram sugeridas especificamente para as ligações viga-pilar de extremidade, buscando obter melhores resultados na simulação do comportamento global.

> Em princípio, o novo parâmetro $(\gamma)$ pode ser estendido a estruturas de pórtico inteiras, necessitando-se de investigações experimentais para determinar a ordem de grandeza desse parâmetro. Vale lembrar que, em estruturas hiperestáticas, existe redistribuição de esforços com a deterioração mecânica dos elementos. Portanto, espera-se que a evolução da danificação nessas estruturas seja menos acelerada; conseqüentemente os valores de $\gamma$ para viga e pilar (determinados neste trabalho para ligações isoladas isostáticas) seriam menores.

Com relação aos resultados fornecidos por esses modelos, quando comparados aos resultados experimentais, são feitas as seguintes considerações:

i) Na etapa 1 de todas as ligações, com o carregamento em nível de serviço, o modelo simplificado modificado com o parâmetro $\gamma$ forneceu bons resultados na simulação do comportamento global, independente da taxa de armadura transversal disposta na região nodal.

ii) Com base principalmente nos resultados obtidos na etapa 2 da ligação LVP2, parece ser possível calibrar o modelo de dano para a situação de carregamento cíclico com solicitações em nível de serviço, devendo-se ajustar o parâmetro z proposto originalmente por PICÓN \& FLÓREZ-LÓPEZ (2000) para controlar a fadiga.

iii) Na etapa 3 da ligação LVP1, submetida a ações cíclicas de elevada intensidade, a resposta do modelo simplificado foi satisfatória até a ocorrência da ruína do nó de pórtico. Alcançada a máxima resistência da ligação, governada na verdade pela resistência do nó, o modelo deixou de representar adequadamente o comportamento real da ligação.

iv) Em comparação com as ligações que foram também submetidas a ações cíclicas de maior intensidade (LVP3 e LVP4), a ligação LVP1 foi a que o modelo simplificado melhor representou, em virtude da maior resistência ao cisalhamento do nó dessa ligação em relação às outras duas citadas. 
v) As análises desenvolvidas nesta pesquisa indicam que os modelos simplificados de dano e plasticidade fornecem resultados mais insatisfatórios quanto maior for o nível esperado de deterioração mecânica do nó de pórtico.

vi) Na realidade, para que o modelo simplificado forneça uma resposta precisa exige-se uma boa calibração dos parâmetros que o definem. A boa resposta depende também do tipo de estrutura em questão e de variáveis associadas aos elementos de concreto armado, como taxas de armaduras e detalhamento empregado.

Por fim, destaca-se que os modelos simplificados, incluindo as modificações propostas nesta pesquisa para as ligações isoladas, podem ser eficientes na simulação da resposta global de uma estrutura em pórtico de concreto armado sob solicitações cíclicas, desde que se verifique que o nó de pórtico não seja a região mais limitante da ligação em termos de resistência. Essa verificação pode ser feita determinando-se a capacidade do nó frente ao cisalhamento, com a utilização dos modelos locais.

Em vista disso, recomenda-se a avaliação preliminar da capacidade dos nós de pórtico em relação às capacidades das vigas e dos pilares, de forma a obter um indicativo do quanto se pode esperar dos resultados fornecidos pelos modelos simplificados na representação global das estruturas de pórtico de concreto sob ações cíclicas.

\section{Conclusões referentes à etapa experimental}

> Os ensaios permitiram avaliar o comportamento mecânico do nó propriamente dito e correlacionar os fenômenos ocorridos no nó com a resposta global da ligação, frente a solicitações cíclicas.

$>$ Em todas as ligações ensaiadas, a ruína das ligações foi governada pela capacidade resistente do nó de pórtico. De fato, isso vem a reforçar a afirmação de que o nó de pórtico pode ser a região mais crítica da ligação, em especial frente a ações cíclicas.

De forma geral, notou-se que as ações cíclicas produziram os seguintes efeitos nas ligações de concreto armado ensaiadas: aumento dos deslocamentos globais; perda de rigidez dos elementos estruturais; propagação das fissuras formadas e aumento das aberturas das mesmas, aumento das deformações nas armaduras longitudinais das vigas; dos pilares e dos estribos do nó de pórtico, tendência de uniformização das deformações nos estribos do nó ao longo de sua altura.

> As ligações submetidas a ações cíclicas em nível de serviço (LVP2 e LVP5) de fato apresentaram uma degradação mecânica menor que as ligações submetidas a ações cíclicas próximas da capacidade prevista do nó (LVP1, LVP3 e LVP4).

$>$ Em todas as ligações, observou-se um típico panorama de fissuração (fissuras cruzadas) na região nodal, devido à inversão do carregamento. Próximo da ruína das ligações, foram observados o desprendimento do cobrimento do concreto na região do nó e a propagação das fissuras diagonais formadas nos nós até a face externa do pilar. 
> Pelos ensaios, verifica-se que o efeito cíclico das cargas de intensidade elevada contribui uma elevada degradação mecânica do nó de pórtico, sendo superior inclusive à deterioração dos elementos viga e pilar. Essa degradação está mais ligada à perda das propriedades resistentes do material concreto, sendo responsável pelo aumento gradual, no decorrer dos ciclos, das deformações nos estribos do nó, conforme mencionado na análise experimental. Nos ensaios, tal aumento de deformações tornou-se mais evidente próximo da ruína de nós com menores taxas de armadura transversal.

A degradação mecânica avançada no nó de pórtico também esteve acompanhada de grandes deslocamentos na extremidade da viga e maiores rotações relativas entre pilar e viga. Em resumo, isso mostra uma relação existente entre o comportamento do nó de pórtico e o comportamento da ligação como um todo, em termos de deslocamentos e rotações.

O comportamento do nó, em particular a sua resistência ao cisalhamento, sofre mais influencia da resistência à compressão do concreto do que da taxa de estribos do nó, em se tratando de ligações de mesmas dimensões para vigas e pilares. Essa conclusão baseia-se na comparação experimental entre as ligações LVP1 e LVP2, entre LVP2 e LVP5 e também nos resultados fornecidos pelo modelo de biela e tirante de HWANG \& LEE (1999).

Analisando-se todo o histórico de aplicação de forças nas ligações ensaiadas, entendeu-se que os estribos do nó assumiram um papel de maior importância nos estágios de carregamento mais próximos da resistência do nó de pórtico, influenciando, de fato, a resposta global da ligação. Isso foi mais evidente comparando-se as respostas das ligações LVP3 e LVP4 na etapa 3.

\section{Considerações finais a respeito do dimensionamento e detalhamento dos nós de pórtico}

Em termos de projeto e de desempenho estrutural, é desejável que o nó de pórtico apresente resistência suficiente de modo a não impedir o desenvolvimento total da capacidade das vigas e dos pilares. A grandeza que permite fazer essa avaliação é a resistência ao cisalhamento do nó, a qual pode ser calculada com segurança utilizando-se os modelos de biela e tirante abordados nesta pesquisa, ou ainda, pelas expressões recomendadas por normas que tratam do assunto.

Para nós externos, a forma mais eficiente de ancoragem das barras principais da viga, em termos de resistência e ductilidade, é a dobra a 90 graus para o interior do nó. Embora se recomende uma ponta vertical reta (após a dobra) entre $8 \phi$ e $12 \phi$ (onde $\phi$ é o diâmetro das barras da viga), o ideal é que essa ponta seja prolongada além das dimensões do nó, para o interior do pilar, a fim de aliviar as eventuais tensões de tração nessa região pelo efeito de emenda das barras da viga com as barras do pilar.

Em todas as cinco ligações ensaiadas, observou-se, nos dois sentidos de força aplicada, a propagação das fissuras diagonais formadas no nó para a face externa do pilar, com grande abertura próximo da ruína do nó de pórtico. Essa observação indica a necessidade 
de se dispor estribos adicionais acima e abaixo do nó (além dos estribos calculados para o restante do pilar), a fim de impedir o alargamento das fissuras que se propagam para fora do nó.

Conforme comentado na formulação dos modelos locais, as barras longitudinais intermediárias do pilar contribuem como estribos verticais na resistência aos esforços cortantes do nó. Nos ensaios das cinco ligações, as quatro barras intermediárias do pilar foram posicionadas próximas da primeira camada de armadura longitudinal. Entretanto, acredita-se que, por propiciar um melhor confinamento da região nodal, a distribuição uniforme das barras longitudinais do pilar ao longo do perímetro da seção seja mais benéfico para o nó de pórtico que a concentração dessas barras somente próximas das faces.

\subsection{SUGESTÕES PARA NOVAS PESQUISAS}

Tendo em vista o grande número de variáveis que exercem influência na resposta estrutural dos nós de pórticos, existe a evidente necessidade de futuras pesquisas, de modo a obter mais avanços no conhecimento do comportamento de ligações viga-pilar sujeitas a ações cíclicas. Dessa forma, são feitas algumas sugestões para pesquisas futuras:

Estudar a real influência da força normal no pilar sobre o nó de pórtico e sobre o comportamento global da ligação, tanto no caso de ações cíclicas quanto no caso de ações monotônicas. Este estudo possibilitaria identificar em quais regiões do sistema estrutural as condições seriam mais favoráveis e mais desfavoráveis, como por exemplo, num edifício de múltiplos pavimentos.

Avaliar, em termos qualitativos e quantitativos, o efeito da taxa de armadura longitudinal de flexão das vigas sobre o comportamento cíclico dos nós.

Obter um melhor ajuste do parâmetro z que controla o incremento de dano por fadiga para ações cíclicas em nível de serviço.

Acredita-se que o modelo de HWANG \& LEE (1999) possa ser ainda mais aprimorado com o emprego de leis constitutivas para os materiais aço e concreto que, de alguma forma, levem em conta a acumulação da perda das propriedades mecânicas resistentes, em função dos ciclos de carregamento.

Estudar o efeito das excentricidades dos eixos das vigas sobre o comportamento do nó de pórtico. Exemplo dessa ocorrência é o caso de duas vigas conectadas a um pilar interno, cujas resultantes de tração das armaduras principais apresentam uma excentricidade em relação ao centro de gravidade da seção do pilar.

Avaliar o efeito da adição de fibras de aço na região do nó sobre a resistência do mesmo e sobre a resposta global da ligação. 


\section{REFERÊNCIAS BIBLIOGRÁFICAS}

ACI-ASCE Committee 352 (1991). Recommendations for design of beam-column joints in monolithic reinforced concrete structures. American Concrete Institute, Detroit.

ALAMEDDINE, F.; EHSANI, M.R. (1991). High strength RC connections subjected to inelastic cyclic loading. Journal of Structural Engineering, v.117, n.3, p.829-50, Mar.

ÁLVARES, M.S. (1999). Contribuição ao estudo e emprego de modelos simplificados de dano e plasticidade para a análise de estruturas de barras em concreto armado. São Carlos. 113p. Tese (Doutorado) - Escola de Engenharia de São Carlos. Universidade de São Paulo.

AMERICAN CONCRETE INSTITUTE (1995). ACI 318R-95 - Building Code Requirements for Structural Concrete. Detroit.

ARCHITECTURAL INSTITUTE OF JAPAN (1991). AIJ - Structural Design Guidelines for Reinforced Concrete Buildings. Tokyo. (em japonês)

ASSOCIAÇÃO BRASILEIRA DE NORMAS TÉCNICAS (2003). NBR 6118. Projeto de estruturas de concreto - Procedimento. Rio de Janeiro, ABNT.

BAKIR \& BODUROGLU (2002). A new design equation for predicting the joint shear strength of monotonically loaded exterior beam-column joints. Engineering Structures, v.24, p.1105-17.

BALÁZS, G.L. (1991). Fatigue of bond. ACl Materials Journal, v.88, n.6, p.620-9, Nov-Dec.

BENDITO, A.; THOMSON, E.; FLÓREZ-LÓPEZ, J. (1997). Fatiga oligocíclica en elementos estructurales de concreto armado. In: XXVIII JORNADAS SUL-AMERICANAS DE ENGENHARIA ESTRUTURAL. Anais. São Carlos, Brasil, p.2079-87.

BERTERO, V.V.; POPOV, E.P. (1977). Seismic behavior of ductile moment-resisting reinforced concrete frames. Reinforced concrete structures in seismic zones, ACI Spec. Publ., SP-53, Detroit.

CANADIAN STANDARD ASSOCIATION (1994). CSA-A23.3-94 - Design of concrete structures. Toronto.

CASTRO, C.M. (2002). Concreto de Alto Desempenho: Estudo da aderência com a armadura sob ações repetidas. São Carlos. 194p. Dissertação (Mestrado) - Escola de Engenharia de São Carlos, Universidade de São Paulo.

CIPOLLINA, A.; FLÓREZ-LOPÉZ, J. (1995). Modelos simplificados de daño en pórticos de concreto armado. Revista Internacional de Métodos Numéricos para Cálculo y Diseño en Ingeniería, v.11, n.1, p.3-22.

COMITEE EURO-INTERNATIONAL DU BETON - CEB (1985). Model Code for seismic design of concrete structures. Bulletin d'Information, n.165.

COMITEE EURO-INTERNATIONAL DU BETON - CEB (1994). Behavior and analysis of reinforced concrete structures under alternate actions inducing inelastic response. Bulletin d'Information, n.220. 
DEGROOT, A.K.; KUSTERS, G.M.; MONNIER, T. (1981). Numerical modeling of bond-slip behavior. Concrete Mech., v.26, n.1b, p.90.

EHSANI, M.R.; WIGHT, J.K. (1985). Exterior reinforced concrete beam-to-column connections subjected to earthquake-type loading. ACl Journal, v.82, p.492-9, July-August.

ELIGEHAUSEN, R.; BERTERO, V.V.; POPOV, E.P. (1983). Local bond stress-slip relationships of deformed bars under generalized excitations. Berkeley, University of California, Earthquake Engineering Research Center. (Report no. UCB/EERC 83-23)

ELMORSI, M.; KIANOUSH, M.R.; TSO, W.K. (2000). Modeling bond-slip deformations in reinforced concrete beam-column joints. Canadian Journal of Civil Engineering, v.27, p.490-505.

FERNANDES, R.M. (2000). A influência das ações repetidas na aderência aço-concreto. São Carlos. 155p. Dissertação (Mestrado) - Escola de Engenharia de São Carlos. Universidade de São Paulo.

FILIPPOU, F.C.; POPOV, E.P.; BERTERO, V.V. (1983). Effects of bond deterioration on hysteretic behavior of reinforced concrete joints. Berkeley, University of California, Earthquake Engineering Research Center. (Report no. UCB/EERC 83-19)

FLEURY, F.; REYNOUARD, J.M.; MERABET, O. (2000). Multicomponent model of reinforced concrete joints for cyclic loading. Journal of Engineering Mechanics, v. 126, n.8, p.80411, August.

FLÓREZ-LÓPEZ, J. (1995). Simplified model of unilateral damage for RC frames. Journal of Structural Engineering, v.121, n.12, p.1765-72.

FUJII, S.; MORITA, S. (1991). Comparison between interior and exterior RC beam-column joint behavior. In: Design of beam-column joints for seismic resistance, ACI Special Publication SP-123, American Concrete Institute, Detroit, p.145-65.

FUSCO, P.B. (1994). Estruturas de concreto: solicitações tangenciais. São Paulo, EPUSP.

HANSON, N.W. (1971). Seismic resistance of concrete frames with grade 60 reinforcement. Journal of the Structural Division, v.97, n.6, p.1685-700.

HANSON, N.W.; CONNOR, H.W. (1967). Seismic resistance of reinforced concrete beamcolumn joints. Journal of the Structural Division, v.93, n.5, p.533-60, October.

HAWKINS, H.M. et al. (1982). Local bond strength of concrete for cyclic reversed loading. In: BARTOS, P., ed. Bond in concrete. London, Applied Science, p.151-61.

HWANG, S. J., AND LEE, H. J., (2000). Analytical Model for Predicting Shear Strengths of Interior Reinforced Concrete Beam-Column Joints for Seismic Resistance. ACI Structural Journal, v.97, n.1, p.35-44.

HWANG, S-J; LEE, H. J (1999). Analytical model for predicting shear strenghts of exterior reinforced concrete beam-column joints for seismic resistance. ACl Structural Journal, v.96, n.5, p.846-57.

JENNEWEIN, M., SCHÄFER, K. (1992). Standardisierte Nachweise von häufigen D-Bereichen, DAfStb. Helf, n.430, Beuth-Verlag, Berlim.

JIURU, T.; CHAOBIN, H.; KAIJIAN, Y.; YONGCHENG, Y. (1992). Seismic behavior and shear strength of framed joint using steel-fiber reinforced concrete. Journal of Structural Engineering, v.118, n.2, p.341-359, February.

KAKU, T.; ASAKUSA, H. (1991). Ductility estimation of exterior beam-column subassemblages in reinforced concrete frames. In: Design of beam-column joints for seismic resistance, $\mathrm{ACl}$ Special Publication SP-123, American Concrete Institute, Detroit, p.167-85. 
KEUSER, M.; MEHLHORN, G. (1987). Finite elements models for bond problems. Journal of Structural Engineering, v.113, n.10, p.2160-73.

KITAYAMA, K.; OTANI, S.; AOYAMA, H. (1991). Development of design criteria for RC interior beam-column joints. In: Design of beam-column joints for seismic resistance, ACI Special Publication SP-123, American Concrete Institute, Detroit, p.97-123.

KOCH, R.; BALÁZS, G.L. (1993). Slip increase under cyclic and long term loads. Otto Graf Journal, v.4, p.160-91.

KORDINA, K. (1984). Bewehrungsfuhrung in Ecken und Rahmenendknoten. Deutscher Auschuss fur Stahlbeton, part 354.

LA BORDERIE, C. (1991). Phenomenes unilateraux dans un materiau endommageable: modelisation et application a l'analyse de structures en beton. Paris, 1991. Thèse (Doctorat) - Université Paris 6.

LA BORDERIE, C.; PIJAUDIER-CABOT, G; MAZARS, J. (1991). Response of plain and reinforced concrete structures under cyclic loading. Cachan, France, Laboratoire de Mécanique et Technologie. (Rapport Interne, n.123).

LARANJEIRAS, A.C.R. (1976). Redução da aderência aço-concreto sob a ação de cargas repetidas. In: JORNADAS SUL-AMERICANAS DE ENGENHARIA ESTRUTURAL, 28., Salvador, 1976. Anais. Salvador, IBRACON, 1976, 25p.

LEE, L.N.; WIGHT, J.K.; HANSON, R.D. (1977). RC beam-column joints under large load reversals. Journal of the Structural Division, v.103, n.12, p.2337-50.

LEON, R.T. (1990). Shear strength and hysteretic behavior of interior beam-column joints. ACI Structural Journal, v.87, n.1, p.3-11, Jan-Feb.

LEONHARDT, F.; MÖNNIG, E. (1978). Construções de concreto: Princípios básicos sobre a armação de estruturas de concreto armado. 2ed. Rio de Janeiro, Interciência, v.3.

LUO, Y.H.; DURRANI, A.J.; BAI, S.; YUAN,J. (1994). Study of reinforcing detail of tension bars in frame corner connections. ACl Structural Journal, v.91, n.4, p.486-96.

MAYFIELD, B.; KONG, F.-K.; BENNISSON, A. (1971). Corner joint details in structural lightweight concrete. ACl Journal, v.68, n.5, p.366-72.

MEGGET, L.M. (1971). Anchorage of beam reinforcment in seismic resistant reinforced concrete frames. Christchurch. 85p. Master of engineering report - University of Canterbury.

MONTI, G.; FILIPPOU, F.C.; SPACONE, E. (1997b). Finite element for anchored bars under cyclic load reversals. Journal of Structural Engineering, v.123, n.5, p.614-23, May.

MURTHY, D.S.; GANDHI, P.; SREEDHAR, D.S.; VAIDYANATHAN, C.V.; MOHANTY, O.N.; JHA, R. (1998). Seismic resistance of concrete beam-column joints reinforced with TMT and CRS bars. In: INTERNATIONAL SYMPOSIUM ON INNOVATIVE WORLD OF CONCRETE, Calcutta, 1998. Proceedings. Indian Concrete Institute, v.2, p.739-746.

MURTY, D.; SASTRY, S.; LAKSHMI, P.; RAO, D. (1998). Adequacy of development lenghts of beam bars in end column-beam junctions. In: INTERNATIONAL SYMPOSIUM ON INNOVATIVE WORLD OF CONCRETE, Calcutta, 1998. Proceedings. Indian Concrete Institute, v.1, p.4.99-4.111.

NGO, D.; SCORDELIS, A.C. (1967). Finite element analysis of reinforced concrete beams. ACI Journal, v.64, n.3, p.152-63.

NILSON, A.H. (1971). Internal measurement of bond-slip. ACI Journal, v.69, n.7, p.439-41.

NILSSON, I.H.E. (1973). Reinforced concrete corners and joints subjected to bending moments. National Swedish Institute for Building Research, Stockholm, Sweden, Document D7. 
NILSSON, I.H.E.; LOSBERG, A. (1976). Reinforced concrete corners and joints subjected to bending moments. ASCE Journal of the Structural Division, v.102, n.6, p.1229-54.

NZS-3101 (1995). Concrete Structures Standard: Part1 - The design of concrete structures. Wellington.

ORTIZ, I.R. (1993). Strut-and-tie modeling of reinforced concrete short beams and beamcolumn joints. 208p. Tese (Doutorado) - University of Westminster.

ORTIZ, I.R. (1997). Estudo experimental de nós externos de pórticos: Modelagem em bielas e tirantes. In: XXVIII JORNADAS SUL-AMERICANAS DE ENGENHARIA ESTRUTURAL. Anais. São Carlos, Brasil, p.995-1003.

PANTAZOPOULOU, S.; BONACCI, J. (1994). On earthquake resistance reinforced concrete frame connections. Canadian Journal of Civil Engineering, v.21, n.2, p.307-28.

PARK, R. (1997). A static force-based procedure for the seismic assessment of existing reinforced concrete moment resisting frames. Bulletin of the New Zealand National Society for Earthquake Engineering, 30(3), 213-26.

PARK, R.; PAULAY, T. (1973). Behaviour of reinforced concrete external beam-column joints under cyclic loading. In: FIFTH WORLD CONFERENCE ON EARTHQUAKE ENGINEERING, Roma, 1973. Proceedings. v.1, paper 88.

PARK, R.; PAULAY, T. (1975). Reinforced concrete structures. 2ed. New York, John Wiley \& Sons, p.716-61.

PARK, Y.; ANG, A.H. (1985). Mechanistic seismic damage model for reinforced concrete. Journal of Structural Engineering, v.111, n.4, p.722-39.

PAULAY, T.; PRIESTLEY, M. (1992). Seismic design of reinforced concrete and mansory buildings. 2ed. New York, John Wiley \& Sons, p.1-303.

PAULTRE, P.; CASTELE, D.; RATTRAY, S.; MITCHELL, D. (1989). Seismic response of reinforced concrete frame subassemblages - a Canadian code perspective. Canadian Journal of Civil Engineering, v.16, p.627-49.

PERERA, R.; CARNICERO, A.; ALARCON, E.; GOMEZ, S. (2000). A fatigue damage model for seismic response of RC structures. Computers \& Structures, v.78, p.293-302.

PICON, R.A.; FLÓREZ-LÓPEZ, J. (2000). Evolucion de la degradacion de rigidez en porticos de concreto armado (CD-ROM). In: XXIX JORNADAS SUDAMERICANAS DE INGENIERIA ESTRUCTURAL. Punta del Leste, Uruguay.

POPOV, E.P. (1984). Bond and anchorage of reinforced bars under cyclic loading. Journal of American Concrete Institute, v.81, n.4, p.340-9, Jul-Aug.

RAFFAELLE, G.S.; WIGHT, J.K. (1995). Reinforced-concrete eccentric beam-column connections subjected to earthquake-type loading. ACl Structural Journal, v.92, n.1, p.45-55, Jan-Feb.

REAVELEY, L.D.; PANTELIDES, C.P.; CLYDE, C. (2000). Performance-based evaluation of RC beam-column joints. PEER Center News. http://www.peer.berkeley.edu/news/2000 winter.

RENTON, G. (1972). The behaviour of reinforced concrete beam-column joints under cyclic loading. Christchurch. 181p. Master of engineering thesis - University of Canterbury.

SCHLAICH, J. ; SCHAFER, K. (1989). Konstruieren in Stahlbetonbau. In: BETON-KALENDER, Teil 2. Berlin, Ernst \& Sohn.

SCOTT, R.H. (1996). Intrinsic mechanisms in reinforced concrete beam-column connection behaviour. ACl Structural Journal, v.93, n.3, p.336-46, May-Jun.

SCOTT, R.H., HAMIL, S.J. (1998). Connection zone strain in reinforced concrete beam-column connections. In: PROCEEDINGS OF THE $11^{\text {TH }}$ INTERNATIONAL CONFERENCE ON EXPERIMENTAL MECHANICS, Oxford, p.65-9. 
SCOTT, R.H.; HAMIL, S.J.; BAGLIN, P.S. (1999). Behaviour of high strength concrete beamcolumn connections. Paper. http://www.webgeordie.co.uk/stephenhami//brazil /brazil.htm.

SCRIBNER, C.F.; WIGHT, J.K. (1978). Delaying shear strength decay reinforced concrete flexural members large load reversals. Department of Civil Engineering, University of Michigan. (Report no. UMEE 78R2).

SILVA, R.C.; GIONGO, J.S. (2000). Modelos de bielas e tirantes aplicados a estruturas de concreto armado. São Carlos, EESC-USP, 189p.

SKETTRUP, E.; STRABO, J.; ANDERSEN, N.H., NIELSEN, T. (1984). Concrete frame corners. ACl Journal, v.81, n.6, p.587-93.

SMITH, B.J. (1972). Exterior reinforced concrete joints with low axial load under seismic loading. Christchurch. 103p. Master of engineering report - University of Canterbury.

TASSIOS, T.P. (1979). Properties of bond between concrete and steel under load cycles idealizing seismic actions. AICAP-CEB Symposium, Structural concrete under seismic actions, CEB, Bulletin d'Information, n.131, p.67-122.

TAYLOR, H.P.J. (1974). The behaviour of in-situ concrete beam-column joints. Cement and Concrete Association, Wexham Springs, technical Report 42.492.

THOMSON, E.; BENDITO, A.; FLÓREZ-LÓPEZ, J. (1998). Simplified model of low cycle fatigue for RC frames. Journal of Structural Engineering, v.124, n.9, p.1082-5.

VALLE, A. (1994). Estudo da aderência entre concreto e armadura sob carregamento cíclico. São Paulo. 171p. Dissertação (Mestrado) - Escola Politécnica, Universidade de São Paulo.

VASSILEV, T.V.; GOSPODINOV, G.K.; PETKOV, Z.B. (1994). Numerical modeling of hysteretic behaviour of R/C joints. Proceedings of the Second COST C1 Workshop on Semi-Rigid Behaviour, p.53-59.

VECCHIO, F.J.; EMARA, M.B. (1992). Shear deformations in reinforced concrete frames. ACI Structural Journal, v.89, n.1, p.46-56.

VOLUMN, R.L.; NEWMAN, J.B. (1999). Strut and tie models for analysis/design of external beamcolumn joints. Magazine of Concrete Research, v.51, n.6, p.415-25.

WILSON, I.D. (1998). SIFCON joints in pre-cast concrete structures. Proceedings of the VIII BCA Annual Conference on Higher Education and the Concrete Industry, Southampton, p.22739.

YANKELEVSKY, D.Z. (1985). New finite element for bond-slip analysis. Journal of Structural Engineering, v.111, n.7, p.1533-42.

ZAID, S.; SHIOHARA, H.; OTANI, S. (2000). Test of a new reinforcing detail for reinforced concrete interior beam-column joint. Journal of Structural Engineering, Architectural Institute of Japan, v.46b, p.561-9.

ZIYAEIFAR, M.; NOGUCHI, H. (2000). A refined model for beam elements and beam-column joints. Computers \& Structures, v.76, p.551-564. 


\section{BIBLIOGRAFIA COMPLEMENTAR}

ALVA, G.M.; EL DEBS, A.L. (2002). Análise numérica do comportamento de ligações viga-pilar de concreto armado submetidas a ações cíclicas (CD-ROM). In: XXX JORNADAS SULAMERICANAS DE ENGENHARIA ESTRUTURAL. Brasília, Brasil.

ALVA, G.M.S.; EL DEBS, A.L.H. (2003). Estudos sobre a aplicação de modelos de dano e plasticidade concentrados em ligações viga-pilar de concreto armado (CD-ROM). In: XXIV IBERIAN LATIN-AMERICAN CONGRESS ON COMPUTACIONAL METHODS IN ENGINEERING, Ouro Preto, Brasil.

BAKER, A.L.L. (1956). Ultimate load theory applied to the design of reinforced and prestressed concrete frames, Concrete Publications Ltd, London, 91p.

CIPPOLINA, A.; LÓPEZ-INOJOSA, A.; FLÓREZ-LÓPEZ, J. (1995). A simplified damaged mechanics approach to nonlinear analysis of frames. Computers \& Structures, v.54, n.6, p.1113-26.

COMITEE EURO-INTERNATIONAL DU BETON - CEB (1996). RC frames under earthquake loading: state-of-the-art report. Bulletin d'Information, n.231.

CORLEY, W.G. (1966). Rotation capacity of reinforced concrete beams. Journal of Structural Division, v.92, ST5, p.121-46.

MATTOCK, A.H. (1967). Discution of "Rotation capacity of reinforced concrete beams" by W.G.Corley. Journal of Structural Division, v.93, ST2, p.519-22.

PRIESTLEY, M.J.N.; SEIBLE, F.; CALVI, G.M. (1996). Seismic design and retrofit of bridges. John Wiley and Sons, Inc., New York, 686p.

SAWYER, H.A. (1964). Design of concrete frames for two failures states. Proceedings of the International Symposium on the Flexural Mechanics of Reinforced Concrete, ASCE-ACI, Miami, p. 405-31. 


\section{ANEXO A}

MODELO SIMPLIFICADO DE DANO E PLASTICIDADE PROPOSTO POR PICÓN \& FLÓREZ-LÓPEZ (2000) 


\section{INTRODUÇÃO}

Os modelos propostos por CIPOLLINA \& FLÓREZ-LÓPEZ (1995), FLÓREZ-LÓPEZ (1995), BENDITO et a. (1997) e THOMSON et al. (1998) e PICÓN \& FLÓREZ-LÓPEZ (2000) consistem em modelos simplificados de dano aplicáveis em estruturas de barras de concreto armado, baseados nos conceitos da mecânica do dano contínuo, empregando a noção de plasticidade concentrada. Nesses modelos assume-se, como simplificação, que todos os processos dissipativos do elemento ocorrem em rótulas dispostas em suas extremidades, mantendo o comportamento elástico no restante do elemento.
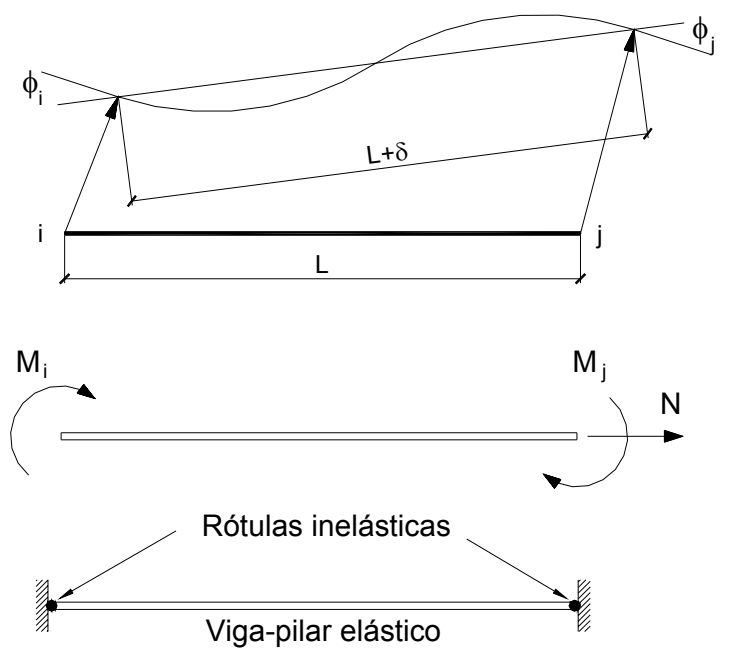

Figura A.1: Deformações e esforços generalizados do elemento finito utilizado nos modelos simplificados de dano e plasticidade

O modelo de PICÓN \& FLÓREZ-LÓPEZ (2000) utiliza parte da formulação empregada para o caso de carregamento monotônico, adaptando-a para o caso de ações cíclicas reversíveis, incluindo a consideração do fenômeno de perda de resistência (fadiga).

Quando se tem a inversão de sinal, torna-se necessário levar em conta a possibilidade de ter seções não-simétricas com respeito à armadura principal. Para isso, o modelo simplificado em questão define dois conjuntos de variáveis de dano independentes entre si: um conjunto para ações ditas positivas e outro para ações ditas negativas,

Ações positivas: $\left\{D^{+}\right\}=\left\{\begin{array}{l}d_{i}^{+} \\ d_{j}^{+}\end{array}\right\} \quad$ Ações negativas: $\left\{D^{-}\right\}=\left\{\begin{array}{l}d_{i}^{-} \\ d_{j}^{-}\end{array}\right\}$

segundo o sentido em que atua o momento, de acordo com a figura A.2. O valor de dano igual a 0 equivale a extremidades íntegras, sem degradação mecânica do material. $O$ valor de dano igual 1 significa a deterioração completa da extremidade, indicando um comportamento de articulação. 


$$
\begin{array}{lr}
M_{i}>0 & M j>0 \\
d_{i}^{-}=0 & d_{j}^{+}>0 \\
d_{i}^{+}>0 & d_{j}^{-}=0
\end{array}
$$

Figura A.2: Representação do estado de dano em um elemento de concreto armado

A utilização de duas variáveis diferentes de dano possibilita a descrição do comportamento unilateral, significando, por hipótese, que o dano originado pelas ações positivas não exercem influência no comportamento frente às ações negativas e vice-versa. Neste modelo assume-se, como idealização, que o fechamento das fissuras se dá

\begin{tabular}{|c|c|c|}
\hline & Extremidade $i$ & Extremidade $j$ \\
\hline$d \phi_{i}^{p}=0$ & se $\quad f_{i}<0 \quad$ ou $\quad \mathrm{df}_{\mathrm{i}}<0$ & se $\mathrm{f}_{\mathrm{j}}<0$ ou $\quad \mathrm{df}_{\mathrm{j}}<0$ \\
\hline $\begin{array}{l}\mathrm{d} \phi_{\mathrm{i}}^{\mathrm{p}} \neq 0 \quad \mathrm{~s} \\
\operatorname{com} \\
\mathrm{f}_{\mathrm{i}}=\operatorname{máx}\left(\mathrm{f}_{\mathrm{i}}^{+} ; \mathrm{f}_{\mathrm{i}}^{-}\right)\end{array}$ & se $\quad f_{i}=0 \quad$ e $\quad d f_{i}=0$ & $\begin{array}{l}d \phi_{j}^{p} \neq 0 \quad \text { se } f_{j}=0 \text { e } \quad d_{j}=0 \\
\text { com } \\
f_{j}=\operatorname{máx}\left(f_{j}^{+} ; f_{j}^{-}\right)\end{array}$ \\
\hline
\end{tabular}
imediatamente à mudança de sinal das ações.

\section{LEIS DE EVOLUÇÃO DA PLASTIFICAÇÃO}

As leis de evolução das deformações plásticas nas extremidades i e j do elemento são similares ao caso de carregamento monotônico, devendo-se considerar que a função limite $f$ apresenta agora duas expressões: uma para ações positivas e outra para ações negativas:

onde $\phi^{p}$ representa a rotação plástica na extremidade.

As funções limites são as mesmas do caso monotônico, porém adaptadas ao modelo histerético, propostas originalmente por FLÓREZ-LÓPEZ (1995):

\begin{tabular}{|c|c|}
\hline Extremidade $i$ & Extremidade $j$ \\
$\mathrm{f}_{\mathrm{i}}^{+}=\mathrm{M}_{\mathrm{i}}-\mathrm{X}_{\mathrm{i}}^{+}-\mathrm{R}_{\mathrm{i}}^{+}$ & $\mathrm{f}_{\mathrm{j}}^{+}=\mathrm{M}_{\mathrm{j}}-\mathrm{X}_{\mathrm{j}}^{+}-\mathrm{R}_{\mathrm{j}}^{+}$ \\
$\mathrm{f}_{\mathrm{i}}^{-}=-\mathrm{M}_{\mathrm{i}}+\mathrm{X}_{\mathrm{i}}^{-}-\mathrm{R}_{\mathrm{i}}^{-}$ & $\mathrm{f}_{\mathrm{j}}^{-}=-\mathrm{M}_{\mathrm{j}}+\mathrm{X}_{\mathrm{j}}^{-}-\mathrm{R}_{\mathrm{j}}^{-}$ \\
\hline
\end{tabular}

O termo $\mathrm{X}$ está associado ao endurecimento cinemático e o termo $\mathrm{R}$, associado ao endurecimento isótropo. Esses termos são determinados por:

$\mathrm{X}_{\mathrm{i}}^{+}=\alpha^{+} \frac{1-\mathrm{d}_{\mathrm{i}}^{+}}{4-\mathrm{d}_{\mathrm{i}}^{+}} \mathrm{c}^{+} \phi_{\mathrm{i}}^{\mathrm{p}} \quad \mathrm{X}_{\mathrm{i}}^{-}=\alpha^{-} \frac{1-\mathrm{d}_{\mathrm{i}}^{-}}{4-\mathrm{d}_{\mathrm{i}}^{-}} \mathrm{c}^{-} \phi_{\mathrm{i}}^{\mathrm{p}}$ 


$$
\begin{array}{ll}
\mathrm{X}_{\mathrm{j}}^{+}=\alpha^{+} \frac{1-\mathrm{d}_{\mathrm{j}}^{+}}{4-\mathrm{d}_{\mathrm{j}}^{+}} \mathrm{c}^{+} \phi_{\mathrm{j}}^{\mathrm{p}} \quad \mathrm{X}_{\mathrm{j}}^{-}=\alpha^{-} \frac{1-\mathrm{d}_{\mathrm{j}}^{-}}{4-\mathrm{d}_{\mathrm{j}}^{-}} \mathrm{c}^{-} \phi_{\mathrm{j}}^{\mathrm{p}} \\
\mathrm{R}_{\mathrm{i}}^{+}=\frac{1-\mathrm{d}_{\mathrm{i}}^{+}}{4-\mathrm{d}_{\mathrm{i}}^{+}}\left[\left(1-\alpha^{+}\right) \mathrm{c}^{+} \mathrm{p}_{\mathrm{i}}+4 \mathrm{M}_{\mathrm{y}}^{+}\right] & \mathrm{R}_{\mathrm{i}}^{-}=\frac{1-\mathrm{d}_{\mathrm{i}}^{-}}{4-\mathrm{d}_{\mathrm{i}}^{-}}\left[\left(1-\alpha^{-}\right) \mathrm{c}^{-} \mathrm{p}_{\mathrm{i}}+4 \mathrm{M}_{\mathrm{y}}^{-}\right] \\
\mathrm{R}_{\mathrm{j}}^{+}=\frac{1-\mathrm{d}_{\mathrm{j}}^{+}}{4-\mathrm{d}_{\mathrm{j}}^{+}}\left[\left(1-\alpha^{+}\right) \mathrm{c}^{+} \mathrm{p}_{\mathrm{j}}+4 \mathrm{M}_{\mathrm{y}}^{+}\right] & \mathrm{R}_{\mathrm{j}}^{-}=\frac{1-\mathrm{d}_{\mathrm{j}}^{-}}{4-\mathrm{d}_{\mathrm{j}}^{-}}\left[\left(1-\alpha^{-}\right) c^{-} \mathrm{p}_{\mathrm{j}}+4 \mathrm{M}_{\mathrm{y}}^{-}\right]
\end{array}
$$

A variável $p$ assume o valor, em módulo, da máxima deformação plástica atingida pela rótula genérica $\mathrm{i}$ ou $\mathrm{j}$ durante toda a história de deformações do elemento, sendo algebricamente representada por:

$$
\begin{array}{ll}
\mathrm{p}_{\mathrm{i}}(\mathrm{t})=\operatorname{máx}\left(\phi_{\mathrm{i}}^{\mathrm{p}}(\tau)\right) & \text { para }-\infty \leq \tau \leq \mathrm{t} \\
\left.\mathrm{p}_{\mathrm{j}}(\mathrm{t})=\operatorname{máx}\left(\phi_{\mathrm{j}}^{\mathrm{p}}(\tau)\right)\right) & \text { para }-\infty \leq \tau \leq \mathrm{t}
\end{array}
$$

Os parâmetros $\mathrm{C}^{+}, \mathrm{C}^{-}, \mathrm{M}_{\mathrm{y}}^{+}, \mathrm{M}_{\mathrm{y}}^{-}$são constantes que dependem do elemento e são introduzidas nas expressões que controlam a evolução da plastificação. Quando o elemento possui seção simétrica quanto à armadura principal, $\mathrm{c}^{+}=\mathrm{c}^{-}$e $\mathrm{M}_{\mathrm{y}}{ }^{+}=\mathrm{M}_{\mathrm{y}}{ }^{-}$.

As constantes $\alpha^{+}$e $\alpha^{-}$variam entre 0 e 1 e podem ser determinadas experimentalmente. Para elementos de concreto armado, PICÓN \& FLÓREZ-LÓPEZ (2000) recomendam o valor de 0,8 .

\section{LEIS DE EVOLUÇÃO DO DANO}

As leis de evolução do dano para ambas as extremidades do elemento são constituídas por funções limites independentes. Na realidade, o modelo proposto por PICÓN \& FLÓREZ-LÓPEZ (2000) é uma extensão do modelo histerético proposto anteriormente por FLÓREZ-LÓPEZ (1995), com algumas adaptações que visaram considerar o efeito da fadiga em pequeno número de ciclos (low cycle fatigue). Assim, as leis de evolução das variáveis de dano são expressas por: 


\begin{tabular}{|c|c|c|c|c|}
\hline \multicolumn{2}{|c|}{ Ações positivas } & \multicolumn{3}{|c|}{ Ações negativas } \\
\hline$\dot{\mathrm{d}}_{\mathrm{i}}^{+}=\frac{\left(\mathrm{G}_{\mathrm{i}}^{+}\right)^{z^{+}}}{\left(\mathrm{R}_{\mathrm{i}}^{+}\right)^{z^{+}} \frac{\partial \mathrm{R}_{\mathrm{i}}^{+}}{\partial \mathrm{d}_{\mathrm{i}}^{+}}}\left\langle\dot{\mathrm{G}}_{\mathrm{i}}^{+}\right\rangle$ & $\mathrm{G}_{\mathrm{i}}^{+} \geq \mathrm{G}_{\mathrm{cr}}$ & $\dot{\mathrm{d}}_{\mathrm{i}}^{-}=\frac{\left(\mathrm{G}_{\mathrm{i}}^{-}\right)^{z^{-}}}{\left(\mathrm{R}_{\mathrm{i}}^{-}\right)^{z^{-}} \frac{\partial \mathrm{R}_{\mathrm{i}}^{-}}{\partial \mathrm{d}_{\mathrm{i}}^{-}}}\left\langle\dot{\mathrm{G}}_{\mathrm{i}}^{-}\right\rangle$ & se & $\mathrm{G}_{\mathrm{i}}^{-} \geq \mathrm{G}_{\mathrm{cr}}$ \\
\hline $\begin{array}{l}\dot{\mathrm{d}}_{\mathrm{i}}^{+}=0 \text { se } \quad \mathrm{G}_{\mathrm{i}}^{+}<\mathrm{G}_{\mathrm{cr}} \\
\dot{\mathrm{d}}_{\mathrm{j}}^{+}=\frac{\left(\mathrm{G}_{\mathrm{j}}^{+}\right)^{z^{+}}}{\left(\mathrm{R}_{\mathrm{j}}^{+}\right)^{z^{+}} \frac{\partial \mathrm{R}_{\mathrm{j}}^{+}}{\partial \mathrm{d}_{\mathrm{j}}^{+}}}\left\langle\dot{\mathrm{G}}_{\mathrm{j}}^{+}\right\rangle\end{array}$ & $\mathrm{G}_{\mathrm{j}}^{+} \geq \mathrm{G}_{\mathrm{cr}}$ & $\begin{array}{l}\dot{\mathrm{d}}_{\mathrm{i}}^{-}=0 \text { se } \quad \mathrm{G}_{\mathrm{i}}^{-}<\mathrm{G}_{\mathrm{cl}} \\
\dot{\mathrm{d}}_{\mathrm{j}}^{-}=\frac{\left(\mathrm{G}_{\mathrm{j}}^{-}\right)^{z^{+}}}{\left(\mathrm{R}_{\mathrm{j}}^{-}\right)^{z^{-}} \frac{\partial \mathrm{R}_{\mathrm{j}}^{-}}{\partial \mathrm{d}_{\mathrm{j}}^{-}}}\left\langle\dot{\mathrm{G}}_{\mathrm{j}}^{-}\right\rangle\end{array}$ & se & $\mathrm{G}_{\mathrm{j}}^{-} \geq \mathrm{G}_{\mathrm{cr}}$ \\
\hline$\dot{\mathrm{d}}_{\mathrm{j}}^{+}=0 \quad$ se $\quad \mathrm{G}_{\mathrm{j}}^{+}<\mathrm{G}_{\mathrm{cr}}$ & & $\dot{\mathrm{d}}_{\mathrm{j}}^{-}=0 \quad$ se $\quad \mathrm{G}_{\mathrm{j}}^{-}<\mathrm{G}_{\mathrm{c}}$ & & \\
\hline
\end{tabular}

onde

$\mathrm{G}^{+}$e $\mathrm{G}^{-}$são as forças termodinâmicas associadas ao dano, para ações positivas e negativas, respectivamente, e calculadas mediante as seguintes expressões aplicáveis às extremidades $\mathrm{i}$ e j do elemento:

$$
\begin{array}{ll}
\mathrm{G}_{\mathrm{i}}^{+}=\frac{1}{2 S}\left(\frac{\mathrm{M}_{\mathrm{i}}^{+}}{1-\mathrm{d}_{\mathrm{i}}^{+}}\right)^{2} & \mathrm{G}_{\mathrm{i}}^{-}=\frac{1}{2 \mathrm{~S}}\left(\frac{\mathrm{M}_{\mathrm{i}}^{-}}{1-\mathrm{d}_{\mathrm{i}}^{-}}\right)^{2} \\
\mathrm{G}_{\mathrm{j}}^{+}=\frac{1}{2 \mathrm{~S}}\left(\frac{\mathrm{M}_{\mathrm{j}}^{+}}{1-\mathrm{d}_{\mathrm{j}}^{+}}\right)^{2} & \mathrm{G}_{\mathrm{j}}^{-}=\frac{1}{2 \mathrm{~S}}\left(\frac{\mathrm{M}_{\mathrm{j}}^{-}}{1-\mathrm{d}_{\mathrm{j}}^{-}}\right)^{2}
\end{array}
$$

sendo

$\mathrm{S}=\frac{4 \mathrm{EI}}{\mathrm{L}} ; \mathrm{L}$ é o comprimento do elemento; El é o módulo de rigidez do elemento;

$\mathrm{R}^{+} \mathrm{e} \mathrm{R}^{-}$são termos que representam a "resistência à fissuração", para ações positivas e negativas, respectivamente, sendo expressos por:

$$
\begin{array}{ll}
\mathrm{R}^{+}=\mathrm{G}_{\mathrm{cr}}+\mathrm{q}^{+} \frac{\ln \left(1-\mathrm{d}^{+}\right)}{1-\mathrm{d}^{+}} & \mathrm{R}^{-}=\mathrm{G}_{\mathrm{cr}}+\mathrm{q}^{-} \frac{\ln \left(1-\mathrm{d}^{-}\right)}{1-\mathrm{d}^{-}} \\
\frac{\partial \mathrm{R}^{+}}{\partial \mathrm{d}^{+}}=\mathrm{q}^{+}\left[\frac{\ln \left(1-\mathrm{d}^{+}\right)-1}{\left(1-\mathrm{d}^{+}\right)^{2}}\right] & \frac{\partial \mathrm{R}^{-}}{\partial \mathrm{d}^{-}}=\mathrm{q}^{-}\left[\frac{\ln \left(1-\mathrm{d}^{-}\right)-1}{\left(1-\mathrm{d}^{-}\right)^{2}}\right]
\end{array}
$$

$\mathrm{G}_{\mathrm{cr}}=\frac{1}{2 \mathrm{~S}} \mathrm{M}_{\mathrm{cr}}{ }^{2}$;

$M_{c r}$ é o momento de fissuração da seção;

$\mathrm{q}^{+}$e $\mathrm{q}^{-}$são constantes do elemento relacionadas ao endurecimento.

$\mathrm{z}^{+} \mathrm{e} \mathrm{z}^{+}$são parâmetros representativos da fadiga.

Inicialmente, BENDITO el al. (1997) e THOMSON et al. (1998) sugeriram que o parâmetro $z$ fosse constante durante toda a análise numérica. Entretanto, com base em investigações auxiliadas com simulações numéricas, PICÓN \& FLÓREZ-LÓPEZ (2000) 
propõem que o parâmetro $z$ varie em função do nível de dano da estrutura, segundo a seguinte expressão polinomial:

$\mathrm{z}=\mathrm{Ad} \mathrm{d}^{2}+\mathrm{Bd}+30$

onde

$A=\frac{2,5+30\left(d_{u}-1\right)}{d_{u}\left(d_{u}-1\right)} ; \quad B=-A-30$

$d_{u}$ é o dano correspondente ao momento último do elemento.

Deve-se notar que para valores de z próximos de 30 , os acréscimos de dano por fadiga são quase nulos. Para valores de $z$ próximos de 0 , os acréscimos de dano por fadiga são máximos. Quando o dano no elemento atinge o valor de $d_{u}, z$ assume o valor de 2,5.

\section{OBTENÇÃO DOS PARÂMETROS DO MODELO}

Os parâmetros $c, M_{y}, G_{c r}$ e q são obtidos, sem muitas dificuldades, por meio da resolução do seguinte sistema de equações não-lineares:

$$
\begin{aligned}
& M=M_{c r} \Rightarrow d=0 \quad \text { e } \quad g=0 \\
& M=M_{p} \Rightarrow \phi^{p}=0 ; \quad g=0 \quad \text { e } \quad f=0 \\
& M=M_{u} \Rightarrow d M=0 \quad \text { e } \quad g=0 \\
& M=M_{u} \Rightarrow \phi^{p}=\phi_{u}{ }^{p} ; \quad g=0 \quad \text { e } \quad f=0
\end{aligned}
$$

onde

$M_{c r}$ é o momento de fissuração;

$M_{p}$ é o momento correspondente ao início de plastificação;

$M_{u}$ é o momento último ;

$\phi_{\mathrm{u}}{ }^{\mathrm{p}}$ é a rotação plástica última;

$g=G-G_{c r}-q \frac{\ln (1-d)}{1-d}$

Os parâmetros $M_{c r}, M_{p}, M_{u}$ e $\phi_{u}{ }^{p}$ são os que devem ser introduzidos ao modelo simplificado, sendo as demais constantes determinadas pela resolução do sistema não-linear. Esses quatro parâmetros podem ser obtidos experimentalmente ou pelo cálculo usual de seções armadas sob carregamento monotônico.

É importante ressaltar que, quando a seção não é simétrica quanto à armadura, os parâmetros e constantes do modelo devem ser obtidos em relação às ações positivas e em relação às ações negativas. 


\begin{tabular}{|c|c|}
\hline Ações positivas & Ações negativas \\
\hline $\mathrm{M}_{\mathrm{cr}}$ & $\mathrm{M}_{\mathrm{cr}}$ \\
\hline $\mathrm{M}_{\mathrm{p}}{ }^{+}$ & $\mathrm{M}_{\mathrm{p}}{ }^{-}$ \\
\hline $\mathrm{M}_{\mathrm{u}}{ }^{+}$ & $\mathrm{M}_{\mathrm{u}}{ }^{-}$ \\
\hline$\phi_{\mathrm{pu}}{ }^{+}$ & $\phi_{\mathrm{pu}}{ }^{-}$ \\
\hline $\mathrm{q}^{+}$ & $\mathrm{q}^{-}$ \\
\hline $\mathrm{c}^{+}$ & $\mathrm{c}^{-}$ \\
\hline $\mathrm{M}_{\mathrm{y}}{ }^{+}$ & $\mathrm{M}_{\mathrm{y}}{ }^{-}$ \\
\hline $\mathrm{d}_{\mathrm{u}}^{+}$ & $\mathrm{d}_{\mathrm{u}}{ }^{-}$ \\
\hline$\alpha^{+}$ & $\alpha^{-}$ \\
\hline
\end{tabular}

